\title{
Droit international de l'environnement et mise en oeuvre du droit à l'eau potable en Afrique Centrale : le cas du Cameroun
}

Citation for published version (APA):

Atontsa, M. J. C. (2011). Droit international de l'environnement et mise en oeuvre du droit à l'eau potable en Afrique Centrale : le cas du Cameroun. [Doctoral Thesis, Maastricht University]. Datawyse / Universitaire Pers Maastricht. https://doi.org/10.26481/dis.20111109ca

Document status and date:

Published: 01/01/2011

DOI:

10.26481/dis.20111109ca

Document Version:

Publisher's PDF, also known as Version of record

Please check the document version of this publication:

- A submitted manuscript is the version of the article upon submission and before peer-review. There can be important differences between the submitted version and the official published version of record.

People interested in the research are advised to contact the author for the final version of the publication, or visit the DOI to the publisher's website.

- The final author version and the galley proof are versions of the publication after peer review.

- The final published version features the final layout of the paper including the volume, issue and page numbers.

Link to publication

\footnotetext{
General rights rights.

- You may freely distribute the URL identifying the publication in the public portal. please follow below link for the End User Agreement:

www.umlib.nl/taverne-license

Take down policy

If you believe that this document breaches copyright please contact us at:

repository@maastrichtuniversity.nl

providing details and we will investigate your claim.
}

Copyright and moral rights for the publications made accessible in the public portal are retained by the authors and/or other copyright owners and it is a condition of accessing publications that users recognise and abide by the legal requirements associated with these

- Users may download and print one copy of any publication from the public portal for the purpose of private study or research.

- You may not further distribute the material or use it for any profit-making activity or commercial gain

If the publication is distributed under the terms of Article $25 \mathrm{fa}$ of the Dutch Copyright Act, indicated by the "Taverne" license above, 


\section{DROIT INTERNATIONAL DE L'ENVIRONNEMENT ET MISE EN GEUVRE DU DROIT A L'EAU POTABLE EN AFRIQUE CENTRALE : LE CAS DU CAMEROUN}


(C) Marie Jeanne Carolle Atontsa, Maastricht 2011

ISBN 9789461590848

Production : Datawyse bv | Universitaire Pers Maastricht 


\title{
DROIT INTERNATIONAL DE L'ENVIRONNEMENT ET MISE EN GEUVRE DU DROIT A L'EAU POTABLE EN AFRIQUE CENTRALE : LE CAS DU CAMEROUN
}

\author{
DISSERTATION \\ To obtain the degree of Doctor at Maastricht University, \\ on the authority of the Rector Magnificus, Prof. dr. G.P.M.F. Mols \\ in accordance with the decision of the Board of Deans, to be defended in public \\ on Wednesday 09 November 2011, at 16.00 hours
}

By

Marie Jeanne Carolle ATONTSA Epouse NDEMEFO

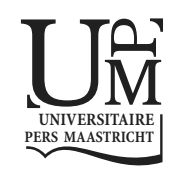




\section{Supervisors}

Prof. dr. Michael G. Faure

Prof. Jean-Louis Atangana Amougou, (University of Yaoundé II, Republic of Cameroon)

\section{Assessment Committee}

Prof. dr. C.A. Schwarz (chairman)

Prof. dr. G.E. van Maanen

Prof. dr. F.A.M. Stroink 


\section{Royaume des Pays-Bas}

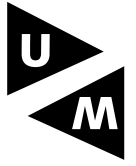

Université de Maastricht Faculté de Droit

\section{ANNEE UNIVERSITAIRE 2010-2011}

\section{THEME}

DROIT INTERNATIONAL DE L'ENVIRONNEMENT ET MISE EN CEUVRE DU DROIT A L'EAU POTABLE EN AFRIQUE CENTRALE : LE CAS DU CAMEROUN

\section{THESE DE DOCTORAT EN DROIT PUBLIC Option : Droit international de l'environnement}

Par Marie Jeanne Carolle ATONTSA Epouse NDEMEFO Master 2, Droit International et Comparé de l'Environnement

Directeur de thèse

Michael FAURE

Directeur METRO

Université de Maastricht

Maastricht / Pays Bas
Co-directeur de thèse

Jean-Louis ATANGANA

AMOUGOU

Directeur du CEDIC

Université de Yaoundé II Soa

Yaoundé / Cameroun 


\section{DEDICACES}

A

Mon tendre époux Prévitari Joseph NDEMEFO (et)

Mes enfants chéris : Princesse Divine NDEMEFO et son futur cadet pour avoir su me démontrer par leur patience qu'au bout de l'effort réside le succès.

Mes parents Rosalie METEKEU et Antoine TSAGUE pour leur apporter la preuve de l'aboutissement de leurs nombreux sacrifices. 


\section{REMERCIEMENTS}

Cette thèse est la somme d'un ensemble d'actions à la fois métaphysiques, individuelles et collectives auxquelles je voudrais rendre hommage. Au niveau métaphysique, qu'il me soit permis de louer l'Etre Suprême qui a su me combler de ses nombreuses grâces nécessaires pour mener à terme cette entreprise.

Au niveau individuel, elle est le fruit d'une volonté personnelle très forte qui a été rendue possible grâce à la disponibilité sans faille des Professeurs Michael FAURE et Jean Louis ATANGANA AMOUGOU, tous deux respectivement directeur et codirecteur de cette thèse. Il serait ingrat de ne pas réserver une ligne spéciale à l'Université de Maastricht qui a bien voulu rendre possible la soutenance de cette thèse, notamment en nous accordant (à mon codirecteur et à moi-même) les moyens de financer le voyage.

$\mathrm{Au}$ niveau collectif, elle est le résultat des encadrements et conseils de Madame Yleen SIMONIS, du Professeur Célestin KEUTCHA, de Docteur Yves Yao SOGLO, de Monsieur KAMDOUM Bernard, de Monsieur et Madame GUETSOP, ainsi que de la doctorante NKELLE MBELLE Adèle Nadège. Je voudrais par la même occasion remercier tous ceux que j'ai rencontrés ou interpellés et qui m'ont aidé lors de la collecte des données et informations nécessaires pour la rédaction. Il s'agit notamment du Professeur Sylvie PAQUEROT de l'Université d'Ottawa (au Canada), de Docteur FOTO et de Monsieur DJIAKAM Roger (du Ministère de l'eau et de l'Energie du Cameroun). Je pense aussi au Doyen Akuete SANTOS de l'Université de Lomé qui, lors de mon séjour au Togo, a bien voulu mettre à ma disposition la bibliothèque de l'université dont la riche documentation a guidé et séduit ma curiosité de chercheur. Je n'oublie pas l'Agence Universitaire de la Francophonie (AUF) dont l'allocation m'a permis d'obtenir mon diplôme de Master à l'Université de Limoges (France). Il me plait également de réserver une ligne entière à messieurs FOMEKONG, STOTSOP (Professeurs de français au lycée classique de Dschang) et Dr Yves Didier TIEBLEY qui ont bien voulu effectuer pour moi la tâche de relecture.

Je vois par ailleurs les sacrifices consentis par les membres de ma famille et de ma belle famille. Je n'oublie pas les personnes qui ont motivé et encouragé mes premiers pas dans la recherche. Il s'agit spécialement de ma grande sœur, Patricia KENGMO TAKAM (pour la discipline qu'elle m'a inculquée en toute chose) et mes autres frères et sœurs cadets (pour être restés soudés autour de l'aboutissement de ce travail).

Je dis enfin merci à tous les membres de jury de soutenance de la présente thèse ainsi que ceux qui m'ont aidé et dont j'ai involontairement omis de mentionner les noms. 


\section{SIGLES ET ABREVIATIONS}

A.A.A.S.

A.C.F.

A.F.D.

A.G.

Art.

A.I.E.A.

Al.

B.A.D.

B.E.I.

B.I.D.

B.M.

C.B.L.T.

C.D.H.

C.E.D.E.

C.E.E.

C.E.M.A.C.

C.O.H.R.E.

C.I.J.

C.I.R.D.I.

C.M.E.

D.D.C

D.E.D.

D.E.S.C.

D.I.C.E.

D.I.E.

D.I.E.P.A.

F.A.M.E.

F.A.O.

F.E.M.

F.M.I.

G.I.R.E.

G.P.O.B.A.

G.W.P.

$\mathrm{Kfw}$

M.I.N.A.D.E.R.

MIN.E.E.

MIN.E.F.

MIN.E.FI

MIN.M.E.E.

O.G.

O.I.

O.M.C.

O.M.D.
Association Américaine pour l'Avancement de la Science.

Action Contre la Faim.

Agence Française de Développement.

Assemblée Générale

Article.

Agence Internationale de L'Energie Atomique.

Alinéa.

Banque Africaine de Développement.

Banque Européenne d'Investissement.

Banque Islamique de Développement.

Banque Mondiale.

Commission du Bassin du Lac Tchad.

Conseil des Droits de l'Homme.

Conseil Européen du Droit de l'Environnement.

Communauté Economique Européenne.

Communauté Economique et Monétaire de l'Afrique Centrale.

Centre pour le droit au logement et contre les évictions.

Cour Internationale de Justice.

Centre International pour le Règlement des différents relatifs aux Investissements.

Conseil Mondial de l'Eau.

Direction Suisse pour le Développement et la Coopération.

Deutscher Entwicklungsdienst.

Droits Economiques, Sociaux et Culturels.

Droit Internationnal et Comparé de l'Environnement.

Droit International de l'Environnement.

Décennie Internationale de l'Eau Potable et l'Assainissement.

Forum Alternatif Mondial de l'Eau.

Fond Mondial pour l'Alimentation.

Fond pour l'Environnement Mondial.

Fond Mondial international.

Gestion Intégrée des Ressources en Eau.

Global Water Partnership on Output Based Aid.

Global Water Partnership.

Kreditanstalt für wiederaufbau.

Ministère de l'Agriculture et du Développement Rural.

Ministère de L'Eau et de l'Energie.

Ministère de l'Environnement et des Forêts.

Ministère de l'Economie et des Finances.

Ministère des Mines, de l'Eau et de l'Energie.

Observation Générale.

Organisation Internationale.

Organisation Mondiale du Commerce.

Objectif Millénaire du Développement. 
O.M.M. Organisation Météorologique Mondiale.

O.M.S. Organisation Mondiale de la Santé.

O.N.G. Organisation Non Gouvernementale.

O.N.U. Organisation des Nations Unies.

O.I.T. Organisation Internationale du Travail.

P.A.N. Plan d'Action National.

P.E.D. Pays en Développement.

P.I.D.E.S.C. Pacte International des Droits Economiques, Sociaux et Culturels.

P.I.D.C.P. Pacte International relatif aux droits Civiles et Politique.

P.N.U.E. Programme des Nations Unies pour l'Environnement.

P.N.U.D Programme des Nations Unies pour le Développement.

P.O.P. Polluant Organique Persistant.

P.P.P. Partenariat Public Privé.

R.W.S.S.I. Rural Water Supply and Sanitation Initiatives.

U.A Union Africaine.

U.I.C.N. Union Internationale pour la Conservation de la Nature.

U.N.E.S.C.O. Organisation des Nations Unies pour l'Education, la Science et la Culture.

UN- HABITAT Programme des Nations Unies pour les établissements humains.

U.N.I.C.E.F. Fonds des Nations Unies pour l'Enfance.

S.A.O. Substance Appauvrissant la couche d'Ozone. 


\section{LISTE DES TABLEAUX}

Tableau 1 : L'influence des entraves du droit à l'eau potable sur certains droits

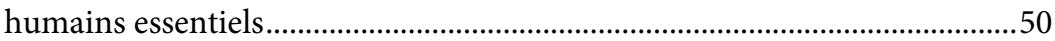

Tableau 2: Les esquisses de réponses aux malentendus autour du droit à l'eau potable.

Tableau 3 : Les étapes de réduction de la pauvreté en Afrique centrale ............................79

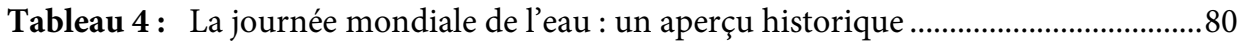

Tableau 5: La présentation du cadre juridique de l'eau au Cameroun ............................106

Tableau 6: Les critères d'accessibilité à l'eau potable (descripteurs du niveau de service par rapport à l'hygiène).

Tableau 7 : La prospective de la disponibilité des ressources en eau par région au Cameroun en 25 ans : 2025-2050.

\section{LISTE DES ENCADRES}

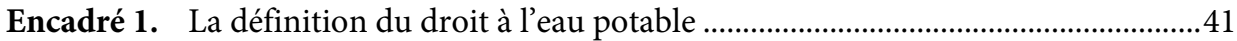

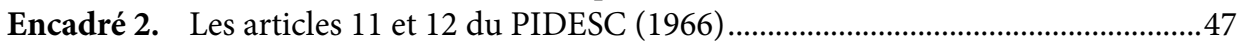

Encadré 3. Les trois obligations de l'Etat nées de l'Observation Générale $\mathrm{N}^{\circ} 15$............52

Encadré 4. Principes indispensables à la définition du droit à l'eau comme droit de l'homme.

Encadré 5. Les sources du droit à l'eau potable au niveau international universel.

Encadré 6. Le droit à l'eau potable dans les conventions internationales

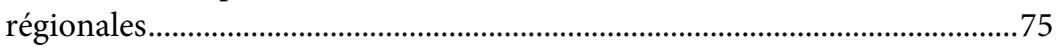

Encadré 7. Le droit à l'eau potable dans les conventions régionales africaines ..............77

Encadré 8. La liste des pays ayant constitutionalisé le droit à l'eau potable ...................102

Encadré 9. Les grandes innovations de la loi de 1998 portant régime de l'eau.............105

Encadré 10. Les obstacles à la mise en œuvre du droit à l'eau potable au Cameroun

Encadré 11. La place des différents acteurs dans la mise en œuvre du droit à l'eau potable.

Encadré 12. L'avis de l'OMC et de l'UNICEF sur les sources sûres d'eau potable ........129

Encadré 13. Que peut faire l'Etat pour garantir à sa population l'accès économique à l'eau potable?

Encadré 14. Les droits et obligations découlant du droit à l'eau potable

Encadré 15. Le plan d'action du GWP-CAFTAC pour la période 2005-2008 ................137

Encadré 16. Les groupes vulnérables et marginalisées ......................................................139

Encadré 17. Les critères essentiels à la bonne gouvernance de l'eau ................................145

Encadré 18. Les différents niveaux de participation ...........................................................147

Encadré 19. Que peut faire l'Etat pour renforcer l'accès à l'information et la participation de son public au processus décisionnel ? 


\section{RESUME}

"L'absence d'eau ou sa mauvaise répartition tue dix fois plus que toutes les guerres réunies». Conseil Mondial de l'Eau-2005.

Quel est le rôle du Droit international de l'environnement dans la mise en œuvre du droit à l'eau potable en Afrique centrale : le cas du Cameroun?

Le Droit international de l'environnement lato sensu joue un rôle essentiel dans la mise en œuvre du droit à l'eau potable en Afrique centrale et au Cameroun en particulier. Même si ce rôle n'est pas encore suffisant au regard de ses limites dans l'élaboration des mécanismes juridiques propices à la réalisation du droit à l'eau potable. La principale limite du droit international de l'environnement vient du fait que cette discipline est plus concentrée sur les questions du droit de l'eau (relevant de la souveraineté des Etats) que sur celle du droit à l'eau potable (concernant les individus ou groupes sociaux).

Lato sensu, les acteurs du droit international ont certes réussi à édicter des textes ${ }^{1}$ qui reconnaissent implicitement et quelquefois explicitement le droit à l'eau potable ; mais, ces textes, vu leurs généralités et quelquefois leurs spécificités, n’ont pas permis de façon définitive la réalisation du droit à l'eau en tant qu'un droit humain essentiel au plan international comme au plan interne.

Le PIDESC (Pacte International relatif aux Droits Economiques, Sociaux et Culturels) aurait peut-être pu constituer une arme non négligeable dans cette entreprise; mais, il ne fait malheureusement pas directement référence au droit en question. On le déduit simplement des autres Droits Economiques, Sociaux et Culturels tels que : le droit à la santé, le droit au logement suffisant, le droit à la nourriture, etc. Comme éclaireur, l'Observation Générale $\mathrm{N}^{\circ} 15$ vient en 2002 donner une plus value à ce droit notamment en lui accordant une définition plus précise. Cependant, comme son nom l'indique, cette observation demeure une simple observation sans aucune valeur juridique contraignante.

Cette thèse cherche donc autant que possible, à recenser au plan international les mécanismes juridiques de mise en œuvre du droit à l'eau potable afin de voir comment ces derniers pourraient être exploités au plan interne. Son objectif principal est de trouver une piste efficace de réalisation du droit à l'eau potable au Cameroun en particulier, en Afrique centrale et voir au plan universel.

\section{SUMMARY OF THE DISSERTATION}

(According to Article $23 \$ 3$ of the Regulation Governing the Attainment of Doctoral Degrees-Maastricht University 2003.)

What is the role of International Environmental Law (IEL) in implementing the right to drinking water in Central Africa : case of Cameroon ?

Lato sensu, the International Environmental Law plays a key role in implementing the right to drinking water in Central Africa, especially in Cameroon. Even if that role is not sufficient under the limitations in developing legal mechanism for the realization of the right to drinking water.

\footnotetext{
${ }^{1}$ Voir les notes de bas de page 7 et 8 .
} 
The essential limit of International Environmental Law is that, this discipline is more focused on right of water (under the sovereignty of states) than the right to drinking water (concerning individuals or social groups). Broadly defined, actors of international law have certainly managed to enact implicitly and sometimes explicitly text of official recognition of the right to drinking water. However, these texts seen their general nature and sometimes their specificities, failed to allow a final realization of the right to water as a basic human right internationally as well as domestically.

The ICESCR (International Covenant on Economic, Social and Cultural Rights) might be a significant weapon in this enterprise, but unfortunately it does not refer directly to the right. It is simply deduced from other ESCR such as : the right to health, the right to adequate housing, the right to food etc. As a scout, General Comment No. 15 edited in 2002 has given added value to this right, including giving a more precise definition, but as its name suggests, it remains a simple observation, with no binding legal force.

This $\mathrm{PhD}$ thesis aims as far as possible to identify at international universal plan, legal mechanisms to implement the right to drinking water, and to see how it could be used internally. Its main objective is to find an effective realization of the right to drinking water in Cameroon in particular, in Central Africa and at global level in general.

\section{NOTE EXPLICATIVE}

\section{Cette thèse a pour objectif :}

- de chercher une esquisse de définition claire au droit à l'eau potable et de lever les équivoques qui entourent la notion ;

- de voir comment du droit international largement défini, on pourrait extraire un droit à l'eau potable véritable et le mettre en œuvre au plan interne (l'étude est centrée sur l'Afrique centrale et sur le cas du Cameroun en particulier) ;

- de recenser les obstacles à la mise en œuvre du droit à l'eau potable en essayant d'y apporter des esquisses de solutions ;

- de voir quel avantage pourrait avoir une Convention-cadre dans ce domaine pour une mise en œuvre réussie du droit à l'eau potable.

\section{Cette thèse n'entend pas :}

- aboutir forcément à une solution miracle pour faire face à la crise globale de l'eau potable actuelle, mais elle cherche autant que faire se peut à limiter les atteintes portées à ce droit ;

- résoudre les problèmes géographiques liés à l'inaccessibilité à la ressource du point de vue globale, mais trouver des stratégies juridiques et quelque fois économiques de limitation du taux d'inaccessibilité.

Comme public cible, elle pourrait bien être bénéfique tout d'abord pour l'Afrique centrale et plus précisément pour le pays objet de l'étude (le Cameroun) où le droit à l'eau potable est encore en chantier. Elle pourrait servir de guide aux membres de la société civile, aux décideurs politiques et autres praticiens de droit ou chercheurs intéressés par la question de mise en œuvre du droit à l'eau potable. Ceux-ci pourraient s'en inspirer pour développer ou approfondir leurs connaissances dans le domaine. En définitive, cette thèse est donc rédigée pour être lue et appréciée pour une meilleure adaptation en fonction des contextes. 


\section{TABLE DES MATIERES}

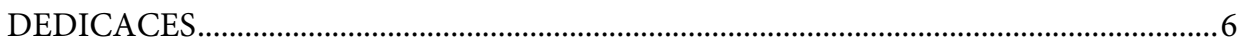

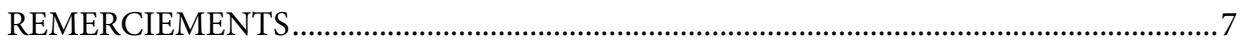

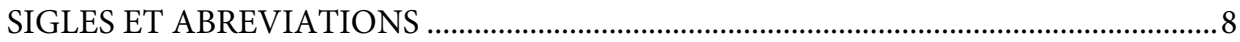

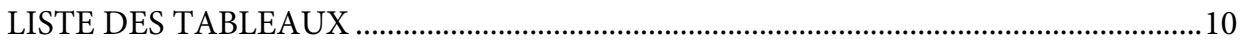

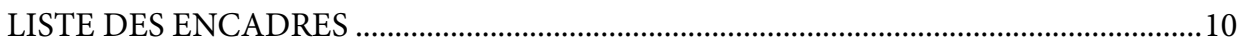

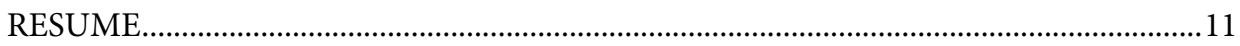

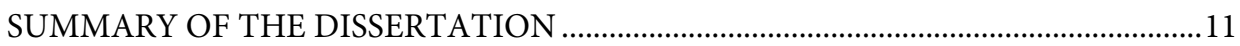

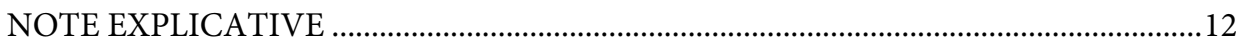

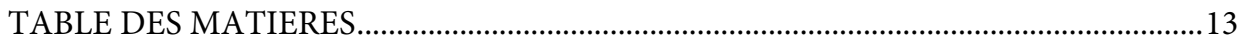

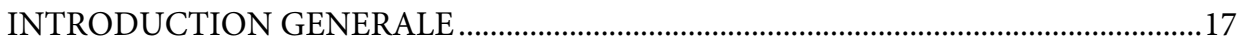

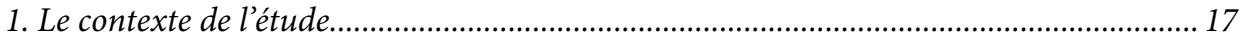

2. La justification et la délimitation du thème choisi........................................................... 18

3. La formulation des hypothèses et questions de recherche ................................................. 19

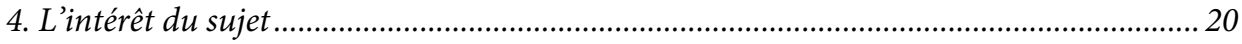

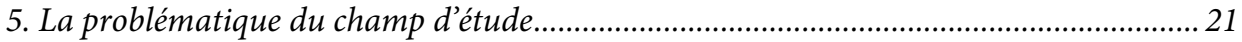

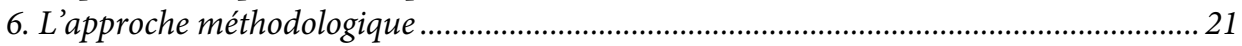

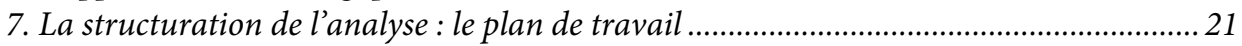

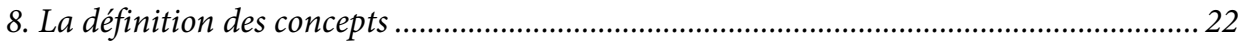

8.1. La fonction du Droit international de l'environnement........................................... 22

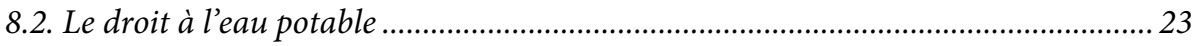

8.3. La mise en cuvre du droit à l'eau potable en Afrique centrale : le cas du Cameroun

\section{PREMIÈRE PARTIE}

\section{DE LA REVENDICATION, LA DIFFICILE CONSECRATION DU} DROIT A L'EAU POTABLE AU PLAN INTERNATIONAL ..................... 29

INTRODUCTION DE LA PREMIERE PARTIE.

CHAPITRE I

A NATURE JURIDIQUE CONTROVERSEE DU DROIT A L'EAU POTABLE ET SES IMPLICATIONS

SECTION I : La nature juridique et le contenu du droit à l'eau potable ...............................38

Paragraphe I : L'économie du principe du droit à l'eau potable............................................39

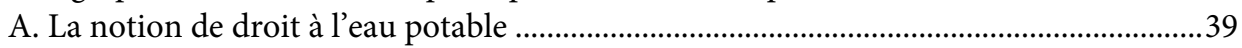

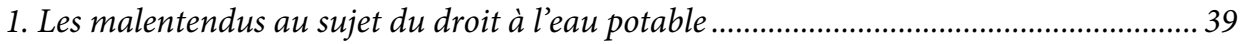

2. Le droit à l'eau potable, un droit fondamental de l'homme ............................................ 40

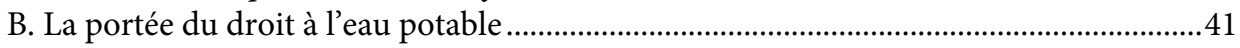

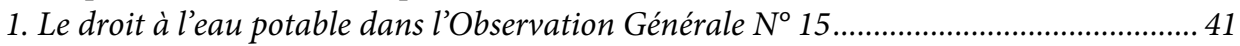

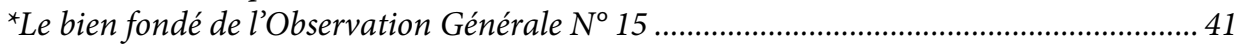

2. La problématique de l'exportation de l'eau potable .......................................................... 44 
Paragraphe II : Les rapports entre le droit à l'eau potable et le PIDESC . .44

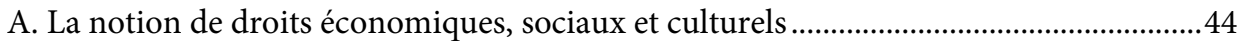

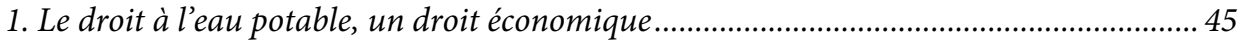

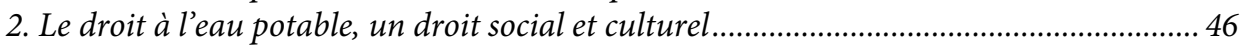

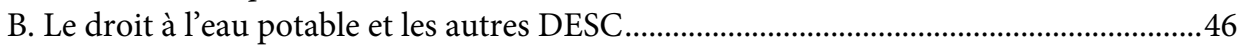

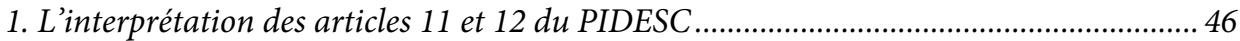

2. L'influence du droit à l'eau potable sur les autres DESC ................................................ 47

SECTION II : Les implications de la définition du droit à l'eau potable..............................50

Paragraphe I : Le comportement des Etats face au droit à l'eau potable .............................51

A. Le droit à l'eau potable, un gage contre la négligence de l'Etat.......................................51

B. L'évaluation des rapports produits par les Etats quant au droit à l'eau potable ............53

Paragraphe II : La mise en œuvre de la responsabilité de l'Etat ...........................................53

A. La responsabilité de l'Etat au plan international pour pollution des eaux.....................54

1. Les conflits interétatiques autour des questions d'eau dans le monde ..............................55

2. La nature de la responsabilité de l'Etat au plan international........................................57

3. Les modes de règlement des différends interétatiques ...................................................... 58

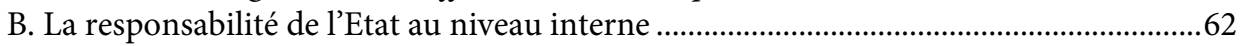

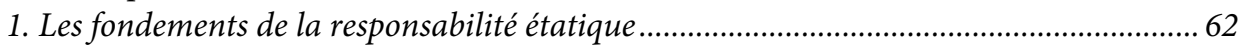

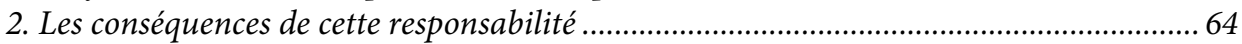

CHAPITRE II

LA DIFFICILE CONSECRATION DU DROIT A L'EAU POTABLE...............................69

SECTION I : De la lente reconnaissance ...........................................................................

Paragraphe I : Le droit à l'eau au plan international .............................................................70

A. Le droit à l'eau potable au plan international universel.................................................

B. Le droit à l'eau potable au plan international régional..................................................75

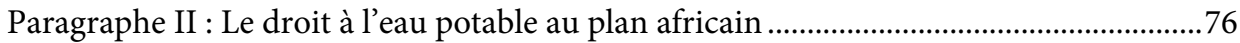

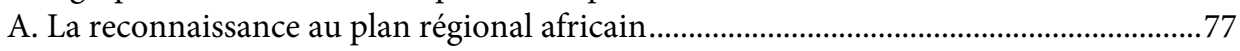

B. La reconnaissance au niveau de la sous région de l'Afrique centrale ...............................78

SECTION II :...A la forte promotion du droit à l'eau potable .............................................79

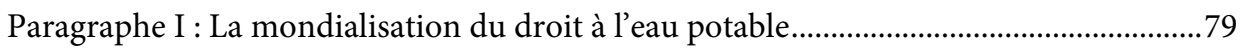

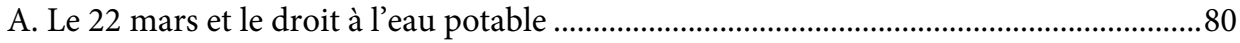

B. Les implications du 22 mars sur la vulgarisation du droit à l'eau potable.......................81

Paragraphe II : L'eau potable, un élément du patrimoine commun de l'humanité...........82

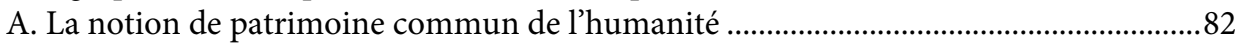

B. Ses implications en matière de droit à l'eau potable ...........................................................84

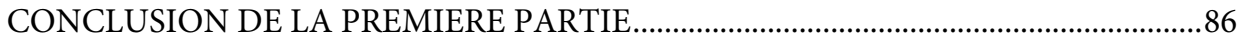


DEUXIEME PARTIE

\section{A LA FAIBLE EFFECTIVITE DU DROIT A L'EAU POTABLE AU PLAN

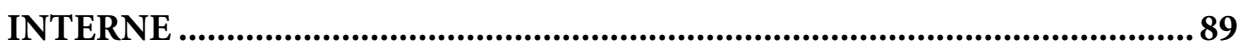

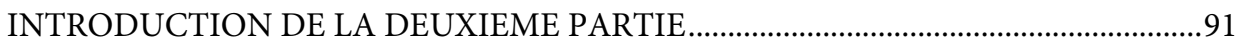

CHAPITRE III

DE L'HERITAGE A LA STRATEGIE CAMEROUNAISE DE MISE EN CEUVRE DE

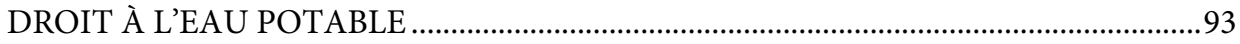

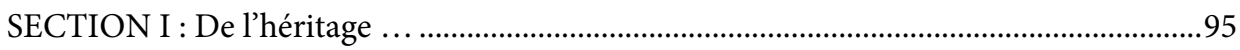

Paragraphe I : L'adhésion aux textes internationaux ..........................................................95

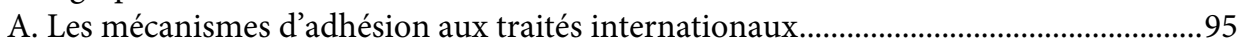

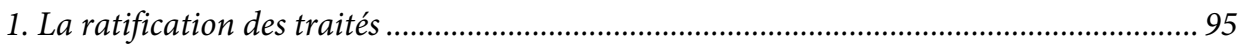

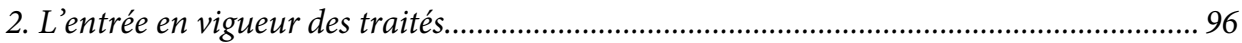

B. Le rythme de ratification des traités relatif à l'eau potable au Cameroun ......................97

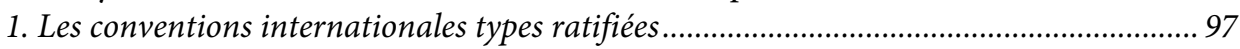

2. Les conventions africaines types ratifiées ........................................................................ 98

Paragraphe II : La politique camerounaise de mise en œuvre du droit à l'eau potable....99

A. Le droit à l'eau potable dans la loi fondamentale ...........................................................99

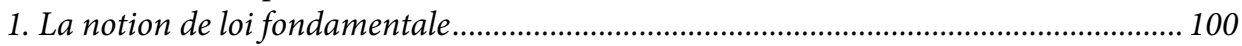

2. Le droit à l'eau potable, un droit transparent dans la loi fondamentale ....................... 101

B. Le droit à l'eau dans la législation camerounaise ...............................................................103

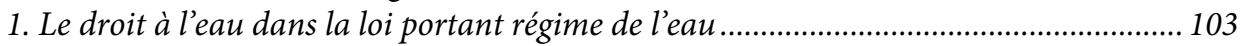

2. Les décrets d'application de la loi portant régime de l'eau.............................................. 105

SECTION II :...A la stratégie camerounaise de mise en œuvre du droit à l'eau potable109

Paragraphe I : Une protection formelle ..................................................................................109

A. La problématique de l'eau potable au Cameroun ............................................................109

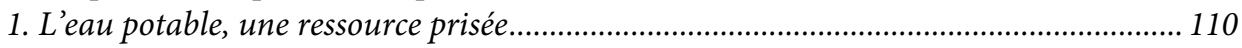

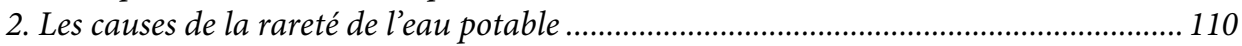

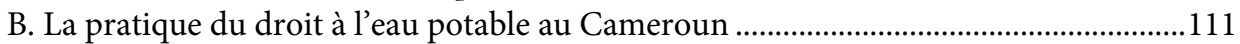

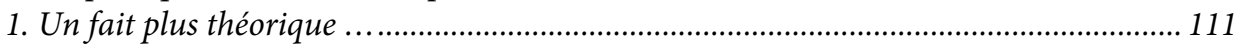

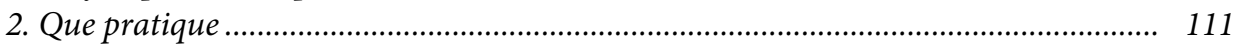

Paragraphe II : Le service de l'eau potable au Cameroun.....................................................113

A. La gestion et l'exploitation du service ................................................................................113

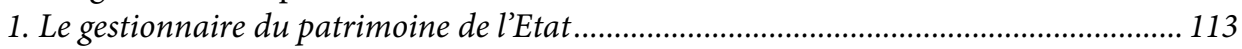

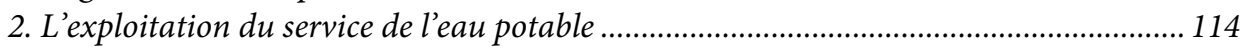

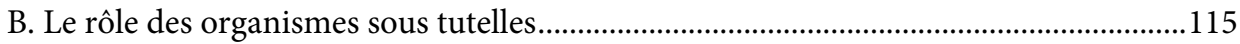

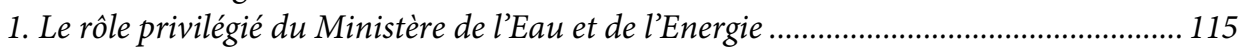

2. Le rôle des inspecteurs et inspecteurs adjoints de l'eau ...................................................... 116

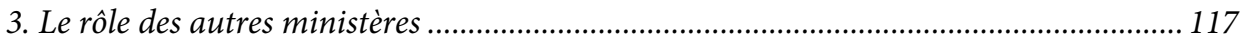

C. L'action des organismes d'appui technique et de conseils............................................118

1. Le rôle du Comité national de l'eau ............................................................................. 118

2. Le rôle du Comité national de l'environnement ............................................................. 119 
CHAPITRE IV

L'EFFECTIVITE DU DROIT A L'EAU POTABLE AU REGARD DU DROIT

CAMEROUNAIS

SECTION I : Le solutionnement des obstacles juridiques, institutionnels et pratiques 125

Paragraphe I : Le droit à l'eau potable, un droit accessible 128

A. Les critères d'accessibilité. 129

1. L'accès physique 130

2. L'accès économique... 131

B. La justiciabilité du droit à l'eau potable 132

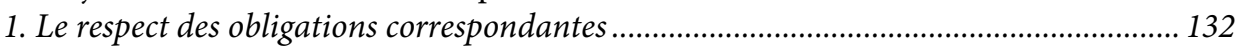

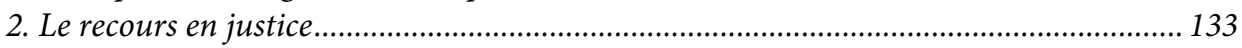

Paragraphe II : Le droit à l'eau potable, un droit assisté.......................................................134

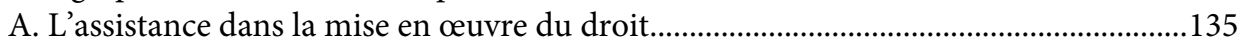

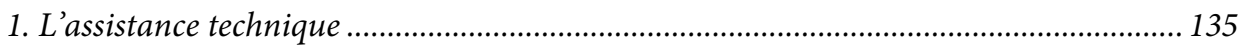

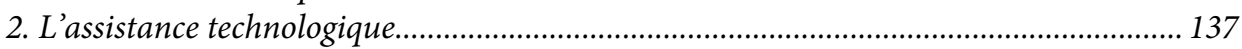

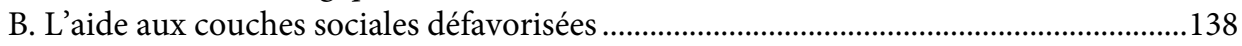

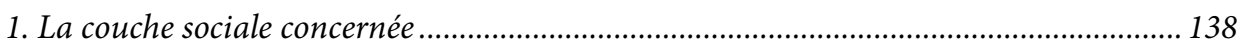

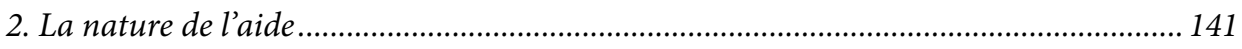

SECTION II : La démocratisation du droit à l'eau potable .................................................142

Paragraphe I : L'application de la méthode de gestion intégrée de l'eau potable.............143

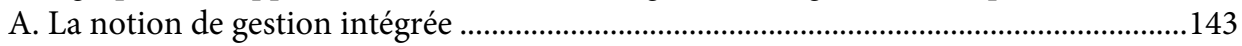

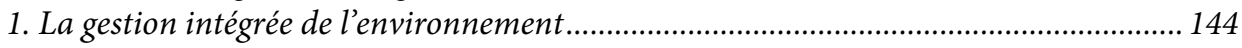

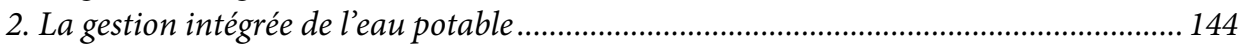

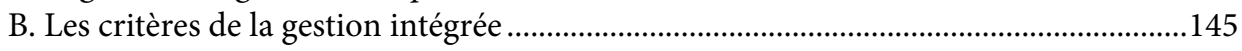

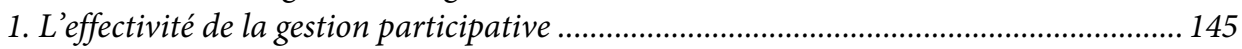

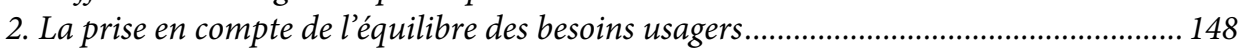

Paragraphe II : L'application des méthodes de gestion écologique et rationnelle ...........148

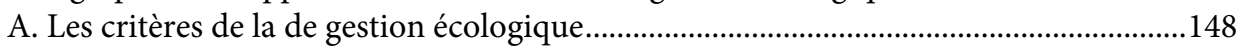

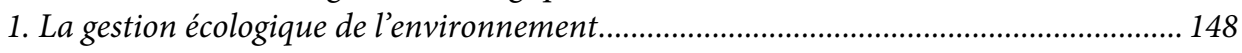

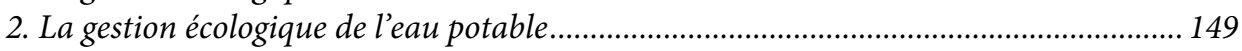

B. Les critères de la gestion rationnelle ....................................................................................149

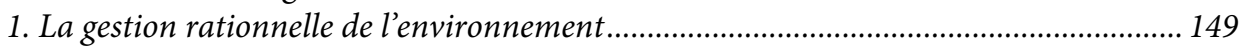

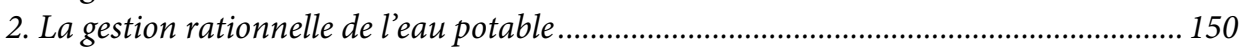

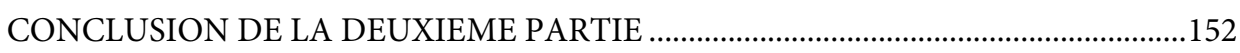

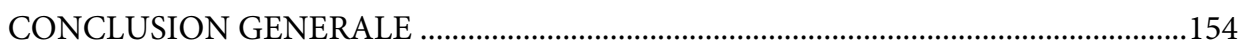

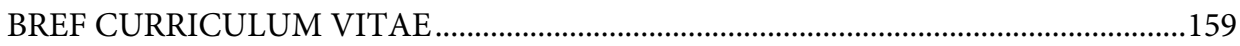

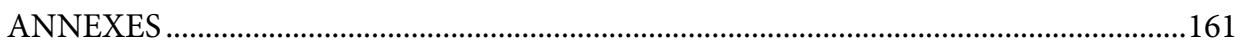

QUELQUES SOURCES IMPLICITES DU DROIT A L'EAU POTABLE A L'INTERNATIONAL. 


\section{INTRODUCTION GENERALE}

\section{Le contexte de l'étude}

L'eau est à l'environnement ce que le sang est à l'organisme humain". "L'eau est avec l'air, la seule ressource naturelle dont l'homme ne puisse se passer $»^{3}$.

$\mathrm{Au}$ cours de ces dernières années, de nombreuses recherches se sont intéressées à l'analyse, la compréhension et la protection des phénomènes environnementaux sans référence expresse au droit à l'eau potable. Celui-ci renvoie à une prérogative reconnue à un individu, lui permettant d'avoir effectivement accès à une eau de qualité sûre et suffisante ${ }^{4}$.

Depuis le sommet de Stockholm de 1972 jusqu'à celui de Johannesburg de 2002, plusieurs conférences ${ }^{5}$ internationales ont traité de l'eau, mais aucune convention spécifique n'est encore à ce jour réservée au droit à l'eau potable en tant que droit humain essentiel.

Seule l'Observation Générale $\mathrm{N}^{\circ} 15$ adoptée en 2002 donnait assez de précision à cette notion notamment en son article 2 qui la définit comme : "un approvisionnement suffisant, physiquement accessible et à un coût abordable, d'une eau salubre et de qualité acceptable pour les usages personnels et domestiques de chacun». Malgré sa pertinence, cette observation demeure un texte sans valeur juridique contraignante. Il a fallu attendre la nouvelle Résolution ${ }^{6}$ de l'Assemblée Générale des Nations Unies adoptée le 28 juillet 2010 pour voir le droit à l'eau potable être défini comme «un droit

\footnotetext{
${ }^{2}$ ECOVISME, Environnement Canada, Collection eau douce, "L'eau propre, la vie en dépend », 1992, p.1.

${ }^{3}$ SMETS (H), «Le droit à l'eau », consulté le 20 mars 2008 in www.academie-eau.org, p.1.

${ }^{4}$ Voir, www.who.int, « Qualité de l'eau de boisson », consulté le 15 avril 2008.

${ }^{5}$ Conférence des Nations Unies, Mar del Plata 1977; Consultation mondiale sur l'approvisionnement en eau et l'assainissement, New Delhi, PNUD «Un peu pour tous vaut mieux que beaucoup pour tout le monde. ", 1990; Conférence internationale sur l'eau et l'environnement (Dublin), 1992; Conférence des Nations Unies sur l'environnement et le développement, 1992; Conférence ministérielle sur l'eau potable et l'assainissement, 1994; Conférence internationale sur la population et le développement, 1994; Conférence des Nations Unies sur les établissements humains, 1996; $1^{\text {er }}$ Forum mondial de l'eau, Marrakech, 1997; $2^{\text {ème }}$ Forum mondial de l'eau, Haye, 2000; Conférence internationale de l'eau douce, Bonn, 2001; Sommet mondial sur le développement durable, Johannesburg, 2002; $3^{\text {ème }}$ Forum mondial de l'eau, Kyoto, 2003; $4^{\text {ème }}$ Forum mondial de l'eau, Mexico, 2006; $5^{\text {ème }}$ Forum mondial de l'eau, Istanbul, 2009 (la particularité de ce Forum est qu'il a donné naissance au Pacte d'Istanbul sur l'eau pour les autorités locales et régionales); Conférence internationale sur l'énergie et l'eau, Yaoundé, 2010; Décennie internationale d'action "l'eau source de vie» 2005-2015.

${ }^{6}$ La Résolution A/Res/64/292 (entérinée le 30 septembre 2010 par la Commission des droits de l'homme dans sa Résolution A/64/L.63/ Rev.1 en ces termes: "le droit à l'eau potable salubre et propre est un droit fondamental essentiel au plein exercice du droit à la vie et de tous les droits de l'homme. ") offre des moyens de mise en œuvre effective du droit à l'eau, notamment en interpellant les Etats et les Organisations internationales à «à fournir des ressources financières, à renforcer les capacités et à procéder à des transferts de technologie grâce à l'aide et la coopération internationale, en particulier en faveur des pays en développement "; voir www.un.org/apps/newsFr/storyF.asp?NewsID=22544, consulté le 8 novembre 2010. Cette résolution est adoptée avec 122 voix, 0 opposition et 41 abstentions (émanant des pays développés pour la plupart à l'exception de l'Allemagne et de l'Espagne). Pour justifier l'adoption ce texte, de nombreux Etats à l'instar du Nicaragua ont à juste titre rappelé « qu'environ 884 millions de personnes n'ont pas accès à l'eau potable salubre, que 443 millions de jours d'école sont perdus chaque année du fait de maladies hydriques et que plus de 2.6 milliards de personnes n'ont pas accès à un service d'assainissement adéquat ",voir www.camer.be/index1.php?art=11176\&rub=6:1, consulté le 5 novembre 2010.
} 
fondamental essentiel au plein exercice du droit à la vie et de tous les autres droits de l'homme ». Sans doute, cette nouvelle résolution vient apporter son coup de pouce dans la lourde tâche de faire de l'accès à l'eau potable et l'assainissement un droit humain universel. Il faut néanmoins préciser que cette résolution est loin d'être une panacée, car, malgré son vote, subsiste toujours le problème d'accès à l'eau potable et du garant de sa mise en œuvre aussi bien à l'international qu'au plan national.

L'eau est un gage pour la vie et la survie. Prenant conscience de ce fait, quelques textes récents de droit international ont tenté d'aborder indirectement ${ }^{7}$ et quelquefois directement $t^{8}$ la question du droit à l'eau potable, sans pour autant lui reconnaître le caractère fondamental. Ainsi, la nature juridique du droit à l'eau potable demeure spéculative. Bien qu'aucune Convention-cadre ne soit pas à ce jour explicitement consacrée au droit à l'eau potable, cela ne peut pas tout de suite amener à la conclusion que ce droit n'existe pas.

Lentement, progressivement, mais de façon significative, le droit international public lato sensu a édicté certains textes concourant à la reconnaissance et la protection du droit à l'eau potable. Toutefois, la mise en œuvre de ce droit dans les textes de droit international de l'environnement n'est pas évidente. D'une part, ils n'ont a priori pas été édictés pour régir le droit en question; et d'autre part, le droit international de l'environnement est une branche du droit international public et comme tel, freiné par la quasi-inexistence d'une force coercitive dans son application. Autrement dit, le défi actuel du droit international de l'environnement réside dans la conquête de la coercition, clé de voûte pour sa mise en œuvre véritable dans les territoires nationaux. Nous aurions pu consacrer notre thèse à une telle préoccupation. Malgré sa pertinence, il nous a semblé opportun et impératif d'aborder plutôt la question de "Droit international de l'environnement et mise en oeuvre du droit à l'eau potable en Afrique centrale : le cas du Cameroun » et ceci pour plusieurs raisons.

\section{La justification et la délimitation du thème choisi}

"S'il y a une région du monde où le rapport entre l'eau, la terre et le droit est déterminant, c'est certainement l'Afrique $»^{10}$. Les textes de droit international de l'environnement et

\footnotetext{
${ }^{7}$ La Déclaration universelle des droits de l'homme de 1948 (article 25), le Pacte International relatif aux Droits Economiques, Sociaux et Culturels de 1966 (article 11 al.1 et 12) et celui relatif aux Droits Civils et Politiques (article 6), la Déclaration de Stockholm de 1972 (principes 1 et 2), la Déclaration universelle pour l'élimination définitive de la faim et de la malnutrition de 1974 (article 1), la Déclaration de Rio sur l'environnement et le développement de 1992 (principe 1), la Convention sur la lutte contre la désertification de 1994 (article 2), le protocole de Kyoto de 1997 (relative à la Convention sur les changements climatiques de 1992 ) articles 2 et 3.

${ }^{8}$ Les deux Conventions de Genève de 1949 (Genève III et IV) relatives au traitement des prisonniers de guerre (article 20,26, 29, 46) et celle relative à la protection des personnes civiles en temps de guerre (article 85, 89, 127), voir aussi leurs Protocoles additionnel I sur les conflits internationaux (articles 54 et 55) et II sur les conflits non internationaux (articles 5 et 14); la Recommandation de l'OIT sur le logement des travailleurs de 1961 (para.7 (b et c), la Déclaration de la conférence des Nations Unies sur l'eau (Mar Del Plata de 1977, voir ses quatre principes), la Convention sur l'élimination de toutes formes de discrimination à l'égard des femmes de 1979 (article 14 al.2), et la Convention sur les droits de l'enfant de 1989 (article 24), l'Observation Générale $\mathrm{N}^{\circ} 15$ de 2002 (article 2), la Résolution A/Res/64/292 du 28 juillet 2010, (Disposition 1).

${ }^{9}$ Ces textes sont plus soucieux du droit de l'eau que du droit à l'eau potable.

${ }^{10}$ CONAC (G.) et (F.), Dir, La terre, l'eau et le droit en Afrique, à Madagascar et à L'̂̀le Maurice, Bruylant/AUPELF-UREF, Belgique, 1998, p.14.
} 
ceux relatifs à l'exercice du droit à l'eau potable ont été reçus en Afrique centrale de façon presque similaire (par ratification et insertion dans les textes internes). Bien que le Cameroun soit l'un des pays d'Afrique centrale les plus dotés en ressources en eau, ce pays comprend à quelques exceptions près (notamment les zones du Nord dont la disponibilité de l'eau varie suivant les saisons) d'abondantes ressources en eau mal entretenues, surexploitées, gaspillées et polluées.

Le droit à l'eau examiné dans la présente étude concerne l'eau de boisson utilisée pour la cuisine et l'hygiène corporelle. Le droit à l'eau potable ne signifie pas forcément la fourniture d'eau gratuite, mais l'accès effectif à l'eau potable et à l'assainissement pour tous. La mise en œuvre du droit à l'eau potable au Cameroun exige une double synergie : que d'une part les textes de droit international universel et régional traitant du droit à l'eau potable soient ratifiés par ce dernier, et que d'autre part, ces textes soient effectivement mis en œuvre dans la pratique. L'écart qui sépare les dispositions textuelles traitant de l'eau potable au Cameroun et la reconnaissance pratique de ce droit est un véritable fossé. Le défi de cette thèse consiste non seulement à apprécier mais aussi apporter les éléments nouveaux de rapprochement entre la théorie et la pratique du droit à l'eau potable au Cameroun pour une mise en œuvre réussie.

\section{La formulation des hypothèses et questions de recherche}

Au même titre que la liberté, la pratique du droit à l'eau potable de même que celle du droit à l'environnement est une conquête, une entreprise qui interpelle non seulement les chercheurs, mais l'ensemble de la communauté nationale et internationale. La controverse autour de la question a fait couler beaucoup d'encre et engendré une abondante critique doctrinale. Les réactions des auteurs sur la question de mise en œuvre du droit à l'eau en général sont de plus en plus vives ${ }^{11}$. Quasi inexistantes sont celles qui ont explicitement porté sur l'examen de la mise en œuvre de ce droit au Cameroun. La tendance des auteurs ayant abordé la question est de le faire soit de manière générale, soit de façon incomplète. Notre analyse cherche, dans la mesure du

\footnotetext{
${ }^{11}$ Communication de la Commission au Conseil et au Parlement Européen, «La gestion de l'eau dans les pays en développement: politiques et priorités de la coopération au développement de l'UE », Bruxelles, Com. (2002) 132 final, 28.p; GOURDREAU (F.) et RANCOURT (M.E.), "Le droit à l'eau face à la pratique des Etats », Université du Québec, Montréal, février 2004; SMETS (H.) : «Le droit à l'eau », Académie de l'eau, 2002, 166p., " Pour un droit effectif à l'eau potable », Académie de l'eau, avril 2005, 142p., «Le droit à l'eau dans les législations nationales ", Académie de l'eau, octobre 2005, 78p., "Une aide pour faciliter l'accès à l'eau des plus démunis en France », Académie de l'eau, août 2006, 18p., "Comment mettre en œuvre le droit à l'eau en France? ", Academie de l'eau, octobre 2006, 19p., "La reconnaissance officielle du droit à l'eau en France et à l'international», Académie de l'eau, décembre 2006, 114p., "L'accès à l'eau potable et le droit international ", Académie de l'eau, 2007, 50p., "Le droit d'accès à l'eau dans le contexte méditerranéen ", Académie de l'eau, mars 2007, 49p., "Le rôle des municipalités et des collectivités territoriales dans la mise en œuvre du droit à l'eau, ", Académie de l'eau, mars 2007, 20p., "Implementing the right to water in France ", French Water Academy, april 2007, 10p., "La prise en compte des dettes d'eau des usagers démunis en France », Académie de l'eau, avril 2008, 222p., " De l'eau à un prix abordable, la pratique des Etats ", Académie de l'eau, 2008, 254p., "Le droit à l'assainissement dans les législations nationales ", Académie de l'eau, 454p., «La mise en œuvre du droit à l'eau, les solutions à Paris », Académie de l'eau, août 2010, 140p., voir www.académie-eau.org, consulté le 21 novembre 2009 et le 06 septembre 2010.
} 
possible, à limiter les spéculations théoriques. Il est vrai que : « rares sont les discussions de problèmes concrets à la lumière du concept de développement durable $»^{12}$.

Mais, si le droit à l'eau potable hérité du droit international de l'environnement n'est pas d'application immédiate au Cameroun, cela est dû soit à l'écart entre la théorie de droit et la mise en ouvre du droit à l'eau potable, soit aux lacunes du droit international de l'environnement lui-même. Le défi de notre thèse consiste donc à voir si cette hypothèse est vérifiée. Ce qui nous amène en cas de réponse positive à envisager une synergie entre la théorie et la pratique du droit à l'eau potable. Le Cameroun comme échantillonnage choisi nous permet de vérifier cette hypothèse qui est susceptible d'être transposée en Afrique centrale en général. Il s'agit donc, dans les développements qui suivront, de répondre à cette préoccupation : le droit à l'eau potable existe-t-il au Came-roun ? Si oui, est-il effectivement mis en œuvre? Sinon, le droit international de l'environnement largement défini, dispose-t-il des moyens nécessaires pour asseoir ce droit au Cameroun ? Le Cameroun dispose-t-il à son niveau des instruments de facilitation de ce droit ?

\section{L'intérêt du sujet}

L'eau est incontestablement une question des plus stratégiques de notre temps ${ }^{13}$. A une époque où de très sérieux efforts sont déployés pour trouver de l'eau sur la planète mars, il est permis de s'interroger sur la question de savoir s'il ne serait pas bien plus utile de chercher à assurer de l'eau potable à tous les habitants de notre planète ${ }^{14}$. Selon les estimations de l'OMS (en 2004), une personne sur quatre (soit 1,4 milliards) n'a pas accès à l'eau potable; une personne sur trois (soit 2,4 milliards) n'a pas accès à l'assainissement et $80 \%$ de maladies proviennent de l'eau. La question du rôle du droit international de l'environnement dans la mise en œuvre du droit à l'eau potable en Afrique centrale et au Cameroun en particulier est une question d'actualité. L'indice de développement humain montre qu'en Afrique centrale, le Cameroun figure parmi les pays les plus exposés par la pénurie d'eau potable. Au regard de la croissance démographique, des activités humaines polluantes, de la montée rapide des maladies hydriques, des décès dus au manque d'eau potable, des lacunes du droit international de l'environnement en particulier, de vains efforts dans l'amélioration de la mauvaise répartition de la ressource, le problème de mise en œuvre du droit à l'eau potable demeure un fait quotidien.

Cette étude revêt aussi un intérêt académique indéniable, car, elle permet de voir dans quelle mesure du droit international, peut naître un droit à l'eau potable véritable. La présente étude cherche, entre autres, les mécanismes juridiques de mise en œuvre et de renforcement du droit à l'eau potable au Cameroun comme droit citoyen imposable à

\footnotetext{
${ }^{12}$ KRISTIN (B.), L'antagonisme " commerce et environnement» ou le principe de développement durable comme fil conducteur pour la réconciliation des intérêts commerciaux et environnementaux sous l'article XX du GATT, thèse de doctorat, Université de Laval, 2007, p.17.

${ }^{13}$ AUBRIOT (J.), «Le droit à l'eau : émergence, définition, situation actuelle et position des acteurs ", Service ACF-France, août, 2007, p.9.

${ }^{14}$ Message d'Alexandre Kiss, Ancien Président du Conseil européen du droit de l'environnement, fait en 2005 lors des assises sur le droit à l'eau ayant abouti au texte intitulé « Le droit à l'eau en Afrique et en Europe ».
} 
l'Etat. Il est enfin question d'examiner les conséquences pratiques pour les citoyens qui pourraient en théorie en bénéficier.

\section{La problématique du champ d'étude}

Le droit international de l'environnement comme les autres instruments de droit international a ceci de particulier que, son contenu n'est pas directement mis en ouvre dans les Etats. Quel est le rôle du droit international de l'environnement dans la mise en œuvre du droit à l'eau potable au Cameroun?

\section{L'approche méthodologique}

La méthodologie d'une telle étude consiste à l'exploitation d'une recherche documentaire. Laquelle nous induit à l'utilisation de deux méthodes : «la remontée des filières bibliographiques $»^{15}$ et "la méthode de la recherche systématique $»^{16}$. L'approche choisie est une approche doctrinale fondée sur l'analyse, la critique et la création. Après avoir recensé, exploité et analysé les écrits dans le domaine, nous les passerons au champ de la critique pour enfin apporter notre propre contribution. Autrement dit, une telle étude exige une analyse pragmatique et non évasive, l'approche se fonde sur une analyse à la fois juridique et quelques fois économique du droit international de l'environnement. L'approche empirique nous permettra sûrement de décrire avec concision et précision les problèmes d'eau potable auxquels fait face le Cameroun, en envi-sageant contre qui ce droit doit être garanti. L'analyse pragmatique permettra de répondre à la question principale et partant d'adopter un plan de travail spécifique.

\section{La structuration de l'analyse : le plan de travail}

Il est nécessaire de préciser que, tout au long des analyses, certains textes importants de droit international de l'environnement ne feront pas l'objet de discussion car, n'ayant pas considérablement influencé le développement du droit à l'eau potable. La vérification des hypothèses se fera en deux temps. Une première partie permettra d'apprécier l'intérêt de la mobilisation de la communauté internationale en général pour la mise en œuvre du droit à l'eau potable; elle traitera des implications de la nature juridique controversée du droit à l'eau potable sur l'avenir de ce droit (chapitre I). C'est également dans cette partie que seront analysées les implications de la difficile consécration du droit à l'eau potable (chapitre II). Poursuivant cette logique, et dans une deuxième partie, nous apprécierons la capacité du Cameroun de s'approprier les normes internatio-nales militant pour le droit à l'eau potable (chapitre III). C'est dans cette partie que seront proposés les mécanismes avancés et futuristes de mise en œuvre de droit à l'eau potable au Cameroun notamment à travers l'idée d'une Convention-cadre dans le domaine, c'est-à-dire l'analyse de la question de l'effectivité du droit à l'eau potable au regard du droit camerounais (chapitre IV). L'objectif visé dans la présente étude ne sera bien sûr atteint que si de prime abord les termes clés du sujet ont été bien cernés.

\footnotetext{
${ }^{15}$ Qui consiste à partir des ouvrages, articles ou études les plus récents touchant à notre recherche pour dégager les idées essentielles en vue d'une analyse minutieuse.

${ }^{16}$ Recherche par grand thème à partir des fichiers des bibliothèques et des centres de documentations.
} 


\section{La définition des concepts}

Aborder convenablement la problématique de la mise en œuvre du droit à l'eau potable au Cameroun c'est au préalable s'interroger sur la discipline de Droit international de l'environnement.

\subsection{La fonction du Droit international de l'environnement}

L'environnement simplement perçu comme l'ensemble des éléments naturels qui nous entourent existe depuis toujours mais, est apparu dans certaines langues il n'y a pas longtemps ${ }^{17}$. Magnifié et rejeté, vanté par les poètes pour sa beauté et exploité à fond par les hommes mercantiles pour sa valeur économique, l'environnement suscite décidément chez les hommes, des sentiments contradictoires ${ }^{18}$. La prise de conscience de la dégradation de l'environnement et la nécessité d'en assurer la protection est très récente.

Le droit international de l'environnement est cette discipline qui au plan international assure sa protection et sa sauvegarde. Il s'applique à chaque fois que se posent les problèmes de pollution, de changements climatiques, de désertification, de sauvegarde de la biodiversité, de gestion des déchets dangereux, de règlement des conflits pour dommage à l'environnement, de sous-développement et de raréfaction de l'eau. Cette nouvelle branche du droit international public trouve son fondement au

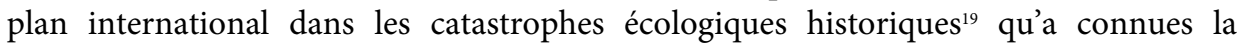
planète ainsi que la prise de conscience des philosophes, des scientifiques, des militants écologiques et des autorités étatiques ${ }^{20}$. Le Conseil de l'Europe à travers la Charte européenne de l'eau ${ }^{21}$ du 6 mai 1968 à facilité l'avènement de ce droit au plan international ${ }^{22}$ comme au plan régional. Toutefois, la reconnaissance et la mise en œuvre du droit à l'eau potable est plus l'œuvre des textes de droit de l'homme que ceux du droit international de l'environnement.

$\mathrm{Au}$ plan régional, la contribution manifeste du droit international de l'environnement dans la mise en œuvre du droit à l'eau potable est notoire aussi bien sur les autres continents ${ }^{23}$ qu'au plan régional africain ${ }^{24}$. Le droit international de l'environne-

\footnotetext{
17 Jadis assimilé à "Umwelt», "medio ambiente", "meio ambiente ", "al.biah" respectivement chez les allemands, néerlandais, espagnols, portugais et arabes; Ces expressions renvoient au terme milieu; Extrait de KISS (A.) et BEURIER (J.P.), Droit international de l'environnement, Pedone, $3^{\mathrm{e}}$ éd., Paris, 2004, p.11.

${ }^{18}$ LOWE NGINTEDEM (P.J.), Mémoire de Master 2 DICE, «Les ONG et la protection de l'environnement en Afrique centrale », juillet 2003, p.1, consulté en ligne sur www.mémoireonline.free.fr.

${ }^{19}$ Le Torrey Canyon de 1967, l'Amoco Cadiz de 1978, l'Exxon Valdez de 1989.

${ }^{20}$ LAVIEILLE (J.M.), Droit international de l'environnement, Ellipses, 2004, p.27.

${ }^{21}$ Premier texte à spécifier que l'eau et l'air ne connaissent pas de frontières.

${ }^{22}$ Voir note de bas de page 7 et 8 de cette thèse.

${ }^{23}$ La Charte européenne de l'eau de 1968 (para.1), la Convention de New York sur le droit relatif à l'utilisation des cours d'eaux à des fins autres que la navigations de 1997 (article 10), le Protocole de San Salvador de 1988 relatif à la Convention américaine sur les droits de l'Homme dans le domaine des Droits Economiques, Sociaux et Culturels (article 11 al.1.), le Protocole de Londres de 1999 (à la Convention sur la protection et l'utilisation transfrontalières des cours d'eau et lacs internationaux du 17 mars 1992, article 4 à 6), la Charte européenne des ressources en eau de 2001 (article 1).

${ }^{24}$ On a implicitement la Charte africaine des droits de l'homme et des peuples de 1981 (articles 16 et 24) et explicitement la Convention d'Alger de 1968 (article 5.al.1); la Charte africaine des droits et du bien être de l'enfant 1990 (article 14 (2)); la Charte des Eaux du Fleuve Sénégal de 2002 (article 4); la Convention de Maputo ou encore la Convention africaine pour la conservation de la nature et des ressources naturelles de
} 
ment tend donc à amorcer une panoplie de moyens pour affronter les drames environnementaux parmi lesquels la problématique de l'eau potable occupe une place préférentielle.

\subsection{Le droit à l'eau potable}

L'accès à l'eau potable est de plus en plus perçu comme un droit individuel et collectif auquel chacun peut légitimement prétendre. L'eau a de tout temps été d'un intérêt majeur pour la vie et le développement des êtres vivants. De sa formule chimique $\mathrm{H} 2 \mathrm{O}$, elle occupe près de $70 \%$ de l'espace du globe terrestre. Capable de revêtir plusieurs formes (solide, liquide, ou gazeuse), c'est aussi le constituant majoritaire des organismes vivants ${ }^{25}$. L'importance des activités qui se passent dans l'eau en général fait d'elle une ressource à enjeux divers ${ }^{26}$. Si l'eau est connue de tous comme un liquide capable de prendre plusieurs formes (solide, liquide et gazeuse), l'eau potable en particulier appelle à une vigilance particulière.

Selon la définition populaire, une eau potable est une eau incolore, inodore, sans saveur et agréable à boire. Cette définition, malgré sa pertinence, pose un problème : celui de l'appréciation de ces qualités. L'OMS affirme: "qu'une eau potable est une eau destinée à la consommation humaine qui peut être bue toute une vie sans danger pour la santé. ». Elle peut être une eau de robinet, de source contrôlée ou de forage. Les critères de potabilité sont au plan international fixés par les Recommandations de l'OMS de 1994, au plan régional par les directives sur l'eau et au plan national par l'Etat. Vu les coûts élevés d'approvisionnement en eau potable, il arrive très souvent que certains Etats ou régions méconnaissent les critères stricts de potabilité; ce qui par voie de conséquence engendre des effets nocifs sur la santé humaine. L'eau n'est donc pas seulement perçue comme une source de vie; de mauvaise qualité, elle peut devenir un véritable danger et générer de nombreux désastres.

Par droit à l'eau potable, il faut comprendre la possibilité offerte à tous les êtres humains sans distinctions de sexe, de race et de nationalité d'accéder durablement et

2003, (article 7 al.2), le Protocole à la Charte africaine des droits de l'homme et des peuples relatif aux droits des femmes de 2003 (article 15).

${ }^{25}$ Homme (corps $65 \%$, cerveau $22 \%$, os $83 \%$, rein $73 \%$, muscles $83 \%$ d'eau et de sang), plantes (laitues $96 \%$, tomates $95 \%$ ), animaux (poisson $80 \%$ ).

${ }^{26}$ Les enjeux de l'eau sont d'ordres sanitaires $(80 \%$ des maladies telles que le paludisme, le choléra, la dysenterie amibienne et la typhoïde proviennent de l'eau. 4 milliards de personnes dans le monde n'ont pas accès à la denrée.); sociaux (l'eau pose un problème de distribution : les populations localisées dans les zones rurales et périurbaines sont les plus touchées); économiques et financiers (l'approvisionnement en eau pour les activités agricoles industrielles et ménagères nécessitent des investissements très lourds); alimentaires (l'eau est un élément essentiel pour la nutrition des êtres vivants); politiques et géopolitiques (les grands bassins) versants sont partagés entre plusieurs pays et l'utilisation abusive peut être cause de dessèchement et de conflits ); environnementaux (Les rejets ménagers, les firmes industrielles, le déboisement constituent un danger réel pour l'eau. Plus elle est polluée, plus les coûts de traitements sont élevés et le nombre de personnes disposées à s'en procurer suffisamment diminue. Le traitement peut s'avérer insuffisant voire impossible : c'est le cas dans certains pays pauvres tels que le Cameroun). L'appréciation de la qualité de l'eau doit être soumise à deux types de contrôles majeurs. Le domaine de l'eau illustre bien les questions qui sont liées à la participation des populations, la bonne gouvernance, l'amélioration de la santé, l'impact du développement sur l'environnement, la prévention des conflits, le développement du secteur privé, le Partenariat Public Privé, le renforcement des capacités et la pauvreté; Étude diagnostique (domaine de l'eau), Stratégie du Ministère des Mines, de l'Eau et de l'Energie, République du Cameroun, Yaoundé, mars 2005. 
convenablement à une eau de qualité sûre. Ce droit est indissociable de l'accès à un assainissement adéquat, car, sans assainissement, la ressource est appelée à se dégrader. Le droit à l'eau est aussi le droit reconnu à toute personne quel que soit son niveau social de disposer "d'une quantité minimale d'eau ${ }^{27}$ de bonne qualité qui soit suffisante pour la vie et la santé $»^{28}$. Le droit à l'eau concerne tout le monde, plus particulièrement les personnes démunies (dans les pays développés) ${ }^{29}$ et les personnes non desservies dans les pays en développement (zones périurbaines et rurales) ${ }^{30}$. Il concerne aussi certains personnes morales telles que: les hôpitaux, les cliniques, les écoles, les maisons de retraite, les foyers de travailleurs, les pensionnats, les couvents, les mosquées ${ }^{31}$. De même que le droit à la santé, le droit à l'eau vise à protéger la santé des hommes bien plus que celle des animaux. Similaire au droit à la nourriture, il vise l'approvisionnement de tous les hommes avant toutes les autres espèces. La logique du droit à l'eau "est anthropocentrique et se situe dans une perspective de développement durable $»^{32}$. Le droit à l'eau potable ne signifie pas la gratuité du service de l'eau; il en est de même pour tous les autres droits économiques, sociaux et culturels. Le droit à l'eau potable prend pour acquis le respect du droit de l'environnement, il est conforme au droit à un environnement sain et équilibré, et bénéficie de la mise en œuvre de la gestion intégrée de la ressource ${ }^{33}$. C'est véritablement en 2002 que ce droit prend de l'ampleur avec l'adoption par le Conseil des Droits Economiques Sociaux et Culturels de l'Observation Générale $\mathrm{N}^{\circ} 15$. Celle-ci malgré son caractère non contraignant pose pour la première fois les jalons du droit à l'eau potable comme droit fondamental de l'homme ${ }^{34}$. Cette position a été tout récemment entérinée par l'Assemblée Générale des Nations Unies qui dans sa Résolution du 28 juillet 2010 a clairement reconnu le droit à l'eau et l'assainissement comme un droit humain fondamental. Ainsi, la question de droit à l'eau potable est de plus en plus présente dans l'arène des débats internationaux ${ }^{35}$. Les mouvements pro droit à l'eau potable, plus nombreux, visent la reconnaissance, l'application et la mise en œuvre du droit à l'eau potable au plan interne.

\subsection{La mise en ouvre du droit à l'eau potable en Afrique centrale : le cas du Cameroun}

L'Afrique centrale concernée par la présente étude est soumise à des dynamiques maritimes et littorales qui participent à sa configuration géopolitique et géostratégique. Située au centre du continent africain, cette partie de l'Afrique occupe une aire qui, d'Ouest en Est, part de $9^{\circ}$ à $31^{\circ}$ de longitude Est, et de quelques $14^{\circ}$ de latitude Sud, et

\footnotetext{
${ }^{27}$ Contenu dans l'article 10 de la Convention des Nations Unies sur l'utilisation des cours d'eaux à des fins autres que la navigation signée à New York en 1997.

${ }^{28}$ SMETS (H), «Le droit à l'eau », op.cit., p.1.

${ }^{29}$ Personnes dont le revenu après impôts et transferts sociaux est inférieur à $40 \%$ du revenu médian.

${ }^{30}$ Les chiffres sont d'environ 1,4 milliards pour les personnes non asservies en eau et de 2,3 milliards pour les personnes ne bénéficiant pas d'un assainissement élémentaire.

${ }^{31}$ Voir la loi anglaise, water industry Act 1999, et l'Ordonnance de la région bruxelloise du 8 septembre 1994 reglémentant la fourniture d'eau alimentaire.; Extrait de SMETS (H.), « Le droit à l'eau », op.cit., pp.3-4.

${ }^{32}$ SMETS (H.), Idem., p.11.

${ }^{33}$ SMETS (H.), Ibid., p.9.

${ }^{34}$ AUBRIOT (J.), «Le droit à l'eau : émergence, définition, situation actuelle et position des acteurs ", Service ACF-France, août, 2007, p.3.

${ }^{35}$ Voir note de bas de page 5.
} 
après de $24^{\circ}$ de latitude Nord. Il s'agit donc d'un espace chevauchant l'équateur et occupant l'espace centre occidental du continent africain (voir carte de l'Afrique).

L'Afrique centrale abrite le grand bassin forestier du Congo (vaste couvert végétal de 2,5 millions de $\mathrm{km}^{2}$ et seconde réserve mondiale des forêts denses et humides), qui représente $70 \%$ du type sylvestre en Afrique et correspond à $26 \%$ des forêts tropicales dans le monde ${ }^{36}$. La diversité biologique de l'Afrique centrale à elle seule joue un rôle crucial dans la lutte contre l'effet de serre. A ce titre, elle constitue la seconde réserve de la biosphère après la forêt amazonienne. Malheureusement, cette diversité ne fait pas que lui apporter du bonheur. Elle est dotée d'un domaine maritime, littoral, lacustre et fluvial dont la gestion pose un certain nombre de problèmes ${ }^{37}$ (politiques, économiques et sociaux). En dehors des zones sahéliennes, l'Afrique centrale est dotée d'abondantes ressources naturelles qui jouent un grand rôle dans le développement politique social, culturel et surtout économique de la région. On y trouve généralement un climat sec dans le Nord et humide dans le Sud. Au sens large, l'Afrique centrale encore appelée "zone CEMAC »8 $^{38}$ comprend à l'heure actuelle en plus des six pays initiaux ${ }^{39}$, le Burundi, l'Angola, la Zambie, Sao Tomé et le Rwanda. Dans le cadre de cette étude, l'Afrique centrale se limite au six pays susmentionnés à savoir le Cameroun, le Congo, le Gabon, la Guinée équatoriale, le Tchad et la république centrafricaine. Le problème d'accès à l'eau potable se pose dans ces zones de façon presque similaire. Nous avons dans la liste choisi d'examiner dans l'intérêt des autres pays de la région le cas du Cameroun qui, est généralement perçu de part sa riche diversité naturelle et culturelle comme "l'Afrique en miniature ".

Pour aborder convenablement les mécanismes de mise en œuvre du droit à l'eau potable au Cameroun, il faut partir de sa situation géographique. Le Cameroun s'étend ${ }^{40}$ entre le $2^{\text {ème }}$ degré et le $13^{\text {ème }}$ degré latitude Nord d'une part et entre le $9^{\text {ème }}$ degré et le $16^{\text {ème }}$ degré longitude Est d'autre part. Son hypoténuse s'étend sur $1500 \mathrm{~km}$ du lac Tchad au golfe de Guinée et sa base sur $800 \mathrm{~km}$ de l'océan atlantique à la frontière de République centrafricaine. Il est limité au Nord par le lac Tchad, au Nord-Est par la république Centrafricaine, au Sud par le Congo, le Gabon et la Guinée Equatoriale et à l'Ouest par la République Fédérale du Nigeria avec une superficie de $475000 \mathrm{~km}^{2_{41}}$.

On distingue deux grandes zones climatiques au Cameroun : la zone du sud dite équatoriale et celle du nord dite tropicale. Ces zones sont séparées par la région de l'Adamaoua appelée "château d'eau du Cameroun $»^{42}$. Du $2^{\text {ème }}$ degré latitude Nord, c'est la zone équatoriale. Elle se caractérise par des précipitations abondantes : $2000 \mathrm{~mm}$ de

\footnotetext{
${ }^{36}$ Voir www.fpae.org, Enjeux géopolitiques de l'Afrique centrale, bulletin trimestriel consulté le 09 juillet 2008.

${ }^{37}$ Avec l'avènement de la Commission du Bassin du Lac Tchad (C.B.L.T.), les conflits autour du contrôle des ressources du bassin trouvent un début de solution. Toutefois, à sa création, la C.B.L.T. accorde une mince disposition quant à la prévention et à la résolution de conflits en se remettant à l'Union Africaine (UA), à l'Organisation des Nations Unies (ONU) et à la Cour Internationale de Justice (CIJ). Néanmoins, la C.B.L.T. constitue à ce jour un forum de dialogues pour la prévention et la résolution des conflits dans le bassin.

${ }^{38}$ Communauté Economique et Monétaire d'Afrique Centrale.

${ }^{39}$ Que sont le Cameroun, le Congo, le Gabon, la Guinée équatoriale, le Tchad et la république centrafricaine.

${ }^{40}$ Cette présentation générale du Cameroun trouve sa source dans le Doc. Stratégie nationale de gestion des déchets, Draft II, Yaoundé, 2007, pp.10-18.

${ }^{41}$ D'après Morin in Atlas jeune Afrique, 1986, le Cameroun aurait plutôt une superficie de $465.000 \mathrm{~km}^{2}$.

${ }^{42} \mathrm{Du}$ fait de son altitude élevée et de la présence des sources de nombreux fleuves du pays.
} 
pluies en moyenne par an. La température moyenne se situe autour de $25^{\circ} \mathrm{C}$. Du $7^{\text {ème }}$ degré au $10^{\text {ème }}$ degré latitude Nord, s'étend la zone soudanaise. La saison sèche dure ici 5 à 6 mois. On y observe une température moyenne de $22^{\circ} \mathrm{C}$, et $1000 \mathrm{~mm}$ de pluies durant l'année. Au-delà du $2^{\text {ème }}$ degré de latitude Nord, la zone soudano sahé-lienne se signale par une saison sèche de 7 mois et des précipitations peu abondantes.

Le réseau hydrographique du Cameroun est constitué de sept complexes fluviaux ${ }^{43}$. Les ressources en eau renouvelables par habitant sont estimés à $18500 \mathrm{~m}^{3} /$ an qui place le pays largement au-dessus de la moyenne mondiale $\left(6400 \mathrm{~m}^{3} / \mathrm{an} \text {. }\right)^{44}$. Le taux d'accès de la population à l'eau potable demeure faible (les principales sources sont: les petits réseaux, les puits, les rivières, les fleuves, les eaux de pluies et les forages.). La quantité de précipitation varie suivant les régions $\mathrm{s}^{45}$ : le littoral est très arrosé d'où les récurrentes pluies. La pluviométrie reste abondante vers le rebord Est du plateau Sud. Il existe plusieurs régimes pluviométriques ${ }^{46}$ au Cameroun : le régime sahélien (dans l'extrême Nord) marqué par une grande saison sèche (9 mois); le régime tropical (latitude de Maroua $^{47}$-Kaélé comportant 750 à $800 \mathrm{~mm}$ de pluie/an); le régime de transition (du versant Nord du plateau de l'Adamaoua) avec une saison sèche variable de 4 à 6 mois et $1500 \mathrm{~mm}$ de pluie annuelle; le régime tropical de transition de l'Adamaoua (la saison sèche varie ici entre 3 et 4 mois).

$\mathrm{Du}$ point de vue démographique, le Cameroun regorge une population d'environ quinze millions d'habitants ${ }^{48}$ repartie dans l'ensemble du territoire.

Le pays est doté d'une économie dont les ressources essentielles proviennent du secteur primaire (agriculture, élevage et exploitation forestière.). Le taux d'alphabétisation s'élève à $63 \%{ }^{49}$. Le droit à l'eau potable au Cameroun se bute à l'accès limité des populations à la ressource combiné à l'insuffisance des mesures d'hygiène et d'assainissement. Le milieu rural et les zones sahéliennes sont à l'heure actuelle les plus touchés par la pénurie d'eau.

En dehors des régions du Nord et de l'extrême Nord, le Cameroun dispose d'abondantes ressources en eau. La partie Nord du pays se caractérise depuis une trentaine d'année par une diminution et une irrégularité de la pluviométrie; cette diminution est à l'origine de la fragilisation des écosystèmes et la réduction du potentiel des ressources naturelles comme la terre, la faune, la flore et les ressources en eau de surface et souterraines. L'essentiel voire la totalité des ressources en eau du Cameroun provient des pluies dont les eaux sont drainées par cinq bassins hydrographiques

43Que sont : la Sanaga $\left(132.990 \mathrm{~km}^{2}\right)$, le Congo $\left(94.860 \mathrm{~km}^{2}\right)$, la Bénoué $\left(90.675 \mathrm{~km}^{2}\right)$, les fleuves côtiers du Sud $\left(55.800 \mathrm{~km}^{2}\right)$, les fleuves côtiers de l'ouest $\left(44.640 \mathrm{~km}^{2}\right)$, le lac Tchad $\left(38.130 \mathrm{~km}^{2}\right)$, l'Ogoué $\left(7900 \mathrm{~km}^{2}\right)$.

${ }^{44}$ Doc. Stratégie Nationale de gestion des déchets, Draft II ? Yaoundé, 2007.

${ }^{45}$ On note une baisse des précipitations au Nord de l'Adamaoua (100 $\mathrm{mm}$ à Garoua, $800 \mathrm{~mm}$ à Maroua et 500 mm à Kousséri.

${ }^{46}$ D'après la classification faite par Suchel en 1987.

${ }^{47}$ A Maroua, les crues sont très violentes du fait du relief et de l'imperméabilité des sols.

${ }^{48}$ Estimation effectuée en 2001 par l'Institut National de la Statistique. Le nombre d'habitant au $\mathrm{km}^{2}$ est d'environ 31 personnes, le taux d'accroissement de la population s'élève à 2,5, et le taux d'urbanisme de $48 \%$ (www.diplomatie.gouv.fr/fr/pays-zones-geo_833/cameroun_361/presentation-du cameroun_946/geographie_8432.html).

${ }^{49}$ La parité filles /garçons est de 48,8\% dans les écoles maternelles, 45,20\% dans les écoles primaires, 54,19\% dans les écoles normales, 44,89\% dans les établissements secondaires et 39,12\% dans l'enseignement technique (information recueillie dans le document : Stratégie nationale de gestion des déchets, Draft II, Yaoundé, 2007). 
essentiels (le Lac Tchad, le Niger, le Congo, la Sanaga et les Fleuves côtiers). L'une des faiblesses du droit à l'eau potable dans sa mise en œuvre peut venir du fait que l'accès à l'eau potable n'est pas toujours antérieur au droit. La mise en œuvre du droit à l'eau potable au Cameroun signifie que l'Etat camerounais prenne des mesures nécessaires pour aider les consommateurs à bénéficier de ce droit (l'adoption et l'application effective des mesures législatives ${ }^{50}$ et conventionnelles relatives à l'eau potable). Elle renvoie non seulement à la protection des ressources en eau et l'application des méthodes propres à réduire la surexploitation et le gaspillage, mais également au recours à des techniques et technologies appropriées d'accès à l'eau potable. C'est-à-dire concrètement l'adoption et la mise en œuvre effective au plan national des stratégies et plans d'action efficaces d'accès à l'eau potable pour l'ensemble de la population camerounaise. Pour être efficace, l'accès doit être à la fois physique, économique et moral.

Parler de mise en œuvre du droit à l'eau potable au Cameroun dans le cadre de la présente étude amène à examiner comment du droit international largement défini on peut extraire un droit à l'eau potable et le mettre en œuvre au plan local.

\footnotetext{
${ }^{50}$ L'essentiel de ces mesures se trouvent dans la constitution camerounaise du 18 janvier 1996, la loi $\mathrm{N}^{\circ}$ 98/005 du 14 avril 1998 portant régime de l'eau et ses décrets d'application (Décret Nº 2001/161/PM du 08 mai 2001 fixant les attributions, l'organisation et le fonctionnement du Comité national de l'eau; Décret $\mathrm{N}^{\circ}$ 2001/162/PM du 08 mai 2001 fixant les modalités de désignation des agents assermentés pour la surveillance et le contrôle de la qualité de l'eau; Décret $\mathrm{N}^{\circ}$ 2001/163/PM du 08 mai 2001 réglementant les périmètres de protection autour des points de captage, de traitement et de stockage des eaux potabilisables; Décret $\mathrm{N}^{\circ}$ 2001/165/PM du 08 mai 2001 précisant les modalités de protection des eaux de surface et des eaux souterraines contre la pollution; Décret $\mathrm{N}^{\circ}$ 01/166/PM du 08 mai 2001 précisant les modalités et conditions de prélèvement des eaux de surfaces et des eaux souterraines à des fins industrielles ou commerciales; Décret $\mathrm{N}^{\circ}$ 2001/216 du 02 août 2001 portant création d'un compte d'affectation spéciale pour le financement des projets de développement durable en matière d'eau et d'assainissement; Décret $\mathrm{N}^{\circ}$ 2003/1397 du 10 juillet 2003 modifiant et complétant les articles $1^{\text {er }}$, 2 et 4 du Décret $N^{\circ} 2002 / 1721 / \mathrm{PM}$ du 08 octobre 2002 précisant les règles d'assiette, de contrôle et de recouvrement dans le cadre du programme de sécurisation des recettes des mines, de l'eau et de l'énergie; Décret $\mathrm{N}^{\circ}$ 2005/087 du 29 mars 2005 portant organisation du Ministère de l'Energie et de l' Eau, Décret $\mathrm{N}^{\circ}$ 2005/3089/PM du 29 août 2005 précisant les règles d'assiettes, de recouvrement et de contrôle de la taxe d'assainissement et de la redevance de prélèvement des eaux; Décret $\mathrm{N}^{\circ}$ 2005/493 du 31 décembre 2005 fixant les modalités de délégation des services publics de l'eau potable et de l'assainissement liquide en milieu urbain et périurbain.
} 

PREMIÈRE PARTIE

DE LA REVENDICATION, LA DIFFICILE

CONSECRATION DU DROIT A L'EAU POTABLE AU PLAN INTERNATIONAL ... 



\title{
INTRODUCTION DE LA PREMIERE PARTIE
}

\author{
"L'eau est le miroir de notre avenir », Gaston Bachelard.
}

Face aux problèmes écologiques de l'heure ${ }^{51}$ actuelle, le droit international de l'environnement n'est peut-être pas un remède miracle, mais pourrait-on imaginer aujourd'hui une protection de la biosphère sans ce droit?

Faire de l'environnement un élément juridique à protéger c'est lui reconnaître une place essentielle. En2 effet, la pression des menaces écologiques a conduit l'humanité à une prise de conscience générale. Cette prise de conscience est à l'origine de l'élaboration et de l'adoption de diverses déclarations, conventions, protocoles et directives environnementales. De nos jours, les traités internationaux font de plus en plus référence à la nécessité de préserver l'environnement en général et l'eau potable en particulier.

Dans cette logique, la Cour Internationale de Justice (C.I.J.) consacre en 1996 l'environnement comme "une valeur collective conditionnant la vie et la santé ». De façon progressive, le droit international de l'environnement tend à conquérir ses lettres de noblesse ${ }^{52}$. Des Etats aux citoyens, en passant par les ONG, les Organisations Internationales et les multinationales, le droit international de l'environnement s'apparente à une carte d'identification de ces acteurs sur la scène internationale. Cette discipline est incontournable pour penser et organiser la coopération.

Parmi les premiers textes internationaux protégeant l'environnement, on note un certain nombre de dispositions conventionnelles relatives à la protection des eaux frontalières contre la pollution ${ }^{53}$ (qui concerne le droit de l'eau non abordé par la présente étude). Le droit international de l'environnement perçoit de plus en plus l'eau comme une valeur essentielle à protéger et préserver. La Déclaration de Stockholm de 1972 dans son Principe 2 l'affirme solennellement en ces termes: "Les ressources naturelles du globe, y compris l'air, l'eau, la terre, la flore et la faune et particulièrement les échantillons représentatifs des écosystèmes naturels, doivent être préservés dans l'intérêt des générations présentes et à venir par une planification ou une gestion attentive selon que de besoin. ». L'eau est avec l'air deux ressources cruciales pour la survie des êtres vivants.

L'examen de « la fonction du droit international de l'environnement dans la mise en œuvre du droit à l'eau potable en Afrique centrale : le cas du Cameroun » revêt donc un intérêt particulier. A y voir de près, le droit international en général et le droit de l'environnement en particulier assurent une large vulgarisation du droit à l'eau potable. Les conférences tenues sur l'eau au plan international sont à l'origine des décisions non moins significatives dans la promotion de ce droit.

\footnotetext{
${ }^{51}$ Tels que la pollution, la désertification, les changements climatiques, la gestion des déchets dangereux, le règlement de conflits pour dommage à l'environnement, le sous-développement et la raréfaction de l'eau potable.

${ }_{52}$ Extrait de la préface de LAVIEILLE (J.M.), Le droit international de l'environnement op.cit.

${ }^{53}$ Le plus célèbre de ces traités est celui conclu entre les Etats-Unis et la Grande Bretagne concernant les eaux frontalières entre la Grande Bretagne et le Canada du 11 janvier 1909.
} 
Avec la conférence Mar del Plata de 1977, organisée sous l'égide des Nations Unies, l'eau est définie comme un droit faisant partie du patrimoine commun de l'humanité. C'est à compter de ce sommet qu'est mis sur pied un plan d'action d'évaluation systématique des ressources en eau. Bien avant cette date, le Sommet ${ }^{54}$ de Stockholm de 1972 posait déjà une petite fondation pour l'avènement du droit à l'eau potable en ces termes: "l'homme a un droit fondamental [...] à des conditions de vie dans un environnement dont la qualité lui permette de vivre dans la dignité et le bien-être. Il a le devoir solennel de protéger et d'améliorer l'environnement pour les générations présentes et futures $[\ldots] »^{55}$.

Depuis la Décennie Internationale de l'Eau Potable et de l'Assainissement $\left(D_{I E P A}{ }^{56}\right)$ : «tous les Peuples, quels que soient leur stade de développement et leur situation économique et sociale, ont le droit d'avoir accès à une eau potable dont la quantité et la qualité soient égales à leurs besoins essentiels. ", (1980-1990). A compter de cette période, l'ensemble de la communauté internationale commence à se mobiliser autour de la problématique centrale du droit à l'eau potable et de la gestion de l'eau. En 1990, le Sommet relatif à la consultation mondiale sur l'approvisionnement en eau et l'assainissement pour les années 1990 encore appelé conférence de New Delhi, (organisé par le PNUD et la DIEPA), lance un appel à toutes les nations sur la nécessité de définir une stratégie concertée et commune visant à intégrer au centre de la gestion des ressources en eau deux principes essentiels: l'approvisionnement en eau potable et l'assainissement de l'environnement. C'est de New Delhi que découle la formule « un peu pour tous vaut mieux que beaucoup pour peu de monde».

Les conférences de Dublin ${ }^{57}$ de 1992 et celle de Rio de Janeiro consacrent la valeur économique et sociale de l'eau ainsi que la notion de Partenariat Public Privé (P.P.P.) dans la gestion de l'eau. C'est à partir de là que naît la question de «bon gestionnaire : l'Etat ou le Privé ? ». Cette conférence donne naissance à la Déclaration de Dublin et ses quatre Principes.

La conférence ministérielle sur l'eau potable et l'assainissement de l'environnement (tenue à Noordlik en 1994), consacre pour sa part un programme d'action important: assigner une haute priorité aux programmes visant à fournir des systèmes de base d'assainissement et d'évacuation des excréments dans les zones urbaines et rurales.

La conférence des Nations Unies sur les établissements humains (habitat II, tenue à Istanbul en 1996) retient pour sa part que «les cadres de vie doivent être promus, grâce à l'approvisionnement en eau salubre et une gestion efficace des déchets". En vue de résoudre les problèmes mondiaux liés à l'eau, est créé en 1996 à l'initiative des Organisations Internationales et des spécialistes du secteur de l'eau le Conseil Mondial de l'Eau (CME) dont l'objectif est de préparer et organiser les Forums mondiaux ${ }^{58}$ sur l'eau tous les trois ans.

\footnotetext{
${ }^{54}$ Qui a connu la participation de plusieurs pays africains à l'instar du Cameroun.

${ }^{55}$ Principe 1.

${ }^{56}$ Instiguée et coordonnée par les Nations Unies; son prolongement est la conférence de New Delhi de septembre 1990, organisé par la DIEPA et le PNUD.

${ }^{57}$ Voir http://www.wmo.ch/web/homs/documents/français/icwedecf.html pour les détails.

${ }^{58}$ Le $1{ }^{\text {er }}$ Forum mondial de l'eau tenu à Marrakech en 1997 accorde quatre priorités à : l'approvisionnement en eau et l'assainissement; la gestion des eaux partagées; la conservation des écosystèmes; l'utilisation efficace de
} 
En 2000, l'Assemblée Générale des Nations Unies reconnaît que «l'accès à l'eau est un droit fondamental et non un besoin ». En septembre de la même année, lors de la conférence des chefs de gouvernement ayant abouti à la Déclaration du millénaire en faveur de la réduction de la pauvreté, l'objectif 7 de la cible 10 engage l'ensemble des signataires ${ }^{59}$ à $"$ réduire de moitié la proportion de personnes n'ayant pas accès de façon durable à l'eau potable d'ici $2015 »$. Prolongeant cet Objectif du Millénaire en matière de Développement durable, la conférence ministérielle de Bonn (de 2001) propose de réduire aussi le nombre de personnes n'ayant pas accès à l'assainissement. La conférence internationale sur l'eau douce tenue à Bonn (en 2001) retient que, pour accéder à l'eau potable, il est nécessaire d'assurer la sécurité de l'approvisionnement en eau, d'appliquer les règles de la décentralisation comme défi majeur dans le processus, d'encourager la recherche de nouveaux partenariats pour un meilleur approvisionnement en eau, de concilier à la fois les intérêts de l'humanité et de la nature, de renforcer et d'améliorer les modes de gouvernance (mobilisation des ressources financières, renforcement des capacités et mise en commun des connaissances).

En septembre 2002, lors du Sommet de Johannesburg (tenu du 28 août au 3 septembre), les Etats adoptent la Déclaration de Johannesburg sur le Développement durable qui contient l'engagement d'après lequel : «la fourniture d'eau potable salubre et de services adéquats d'assainissement sont nécessaires pour protéger la santé humaine et l'environnement». Relativement précis, ces objectifs n'ont pas une force juridique contraignante. Cette Déclaration prévoit de réduire d'ici 2010, de moitié le pourcentage

l'eau. Son aboutissement conduit à l'adoption du projet intitulé «Vision mondiale de l'eau » dont l'objectif est de Préparer à travers des réunions et colloques des perspectives durables sur l'eau, la vie et l'environnement Le $2^{\text {ème }}$ Forum mondial de l'eau, tenu à la Haye du 17 au 22 mars 2000 éxamine la question de la valeur économique et sociale de l'eau et de la place des partenaires privés dans la mise en œuvre de ce droit; c'est ici que la notion de "full cost recovery"( qui prône que "l'ensemble des coûts d'investissement soit recouverts par les usagers et que l'ensemble des prestations fournies répondent à un prix de marché " est utilisé). Les décisions issues de ce Forum encouragent : la participation de toutes les parties prenantes à la gestion intégrée des ressources en eau; la tarification de tous les services de l'eau en fonction de la totalité des coûts; l'augmentation des finances publiques (pour la recherche et innovation dans l'intérêt de la population) - Le $3^{\text {ème }}$ Forum mondial de l'eau tenu à Kyoto en 2003 sous le thème "Financer l'eau pour tous " accorde la priorité aux questions de : gouvernance (gestion intégrée des ressources en eau, genre; pauvreté, financements; coopération; efficacité dans l'utilisation de l'eau; prévention de la pollution des eaux; réduction des désastres et propose un plan de financement de la réalisation de l'objectif $7 \mathrm{du}$ cible 10 sur l'eau et l'assainissement. D'après le rapport issu de ce $3^{\text {ème }}$ Forum, les PPP «imposent de rendre l'eau plus attrayante aux yeux des investisseurs; ils nécessitent un cadre réglementaire et juridique adapté, des modalités contractuelles transparentes, des mécanismes de récupération des coûts fiables et l'acceptation par le grand public". Ce Rapport précise que "l'eau et l'assainissement doivent être accessibles à tous à un prix abordable" et que "l'accès à l'eau constitue un droit et un besoin fondamental». Au cours des discussions tenues lors du Forum, les ministres présents n'ont pas officiellement admis le droit à l'eau ainsi que l'OG. Estimant que ce droit existe déjà dans d'autres textes, même si c'est de manière implicite; c'est ce qui explique peut-être le fait que la Déclaration de Kyoto ne comporte rien sur le droit à l'eau - Le $4{ }^{\text {ème }}$ Forum mondial sur l'eau tenu à Mexico en 2006, a pour titre "Des actions locales pour un défi mondial. ", Les acteurs locaux sont placés au centre des débats; c'est le premier Forum mondial où la question de droit à l'eau est fortement débattue (le droit à l'eau y a fait l'objet de trois sessions: "securing the right to water, from the local to the global, civil societies perspectives" (FT3.35); "The right to water: what does it means and how to implement it" (F3.36); "Human rignt to water" (FT3.47); voir http://www.worldwatercouncil.org/ pour les détails.

${ }^{59}$ Elle a enregistré 189 signatures. 
de population n'ayant pas accès à l'eau potable et aux services d'assainissement ${ }^{60}$. Elle envisage également de : mettre en œuvre des systèmes efficaces d'assainissement dans les établissements publics, en particulier les écoles, d'encourager une action éducation et une sensibilisation à l'intention des enfants, d'encourager l'emploi des technologies de pratiques peu coûteuses socialement et culturellement acceptable, de développer des modes de financement et partenariats novateurs, d'intégrer les moyens d'assainissement dans la stratégie de gestion des ressources en eau. Ce deuxième Sommet de la Terre, encore appelé $($ Rio+10) reste le premier du genre à coupler officiellement l'accès à l'assainissement avec les OMD. La même année, le Comité des Droits Economiques, Sociaux et Culturels adopte l'Observation Générale $\mathrm{N}^{\circ} 15$ sur le droit à l'eau en explication des articles 11 et 12 du PIDESC. Malgré sa faible portée et sa force juridique non contraignante, c'est un important texte de reconnaissance du droit à l'eau comme droit de l'homme.

En 2003, «UN WATER» est créé avec pour objectif de suivre les évolutions de la Conférence des Nations Unies sur l'Environnement et le Développement (Rio+10) et d'instituer la journée mondiale de l'eau qui aura désormais lieu le 22 mars de chaque année à compter de 2005. Cette même année 2003 est déclarée «Année internationale de l'eau douce " par l'UNESCO. En 2005 comme prévu, lors de sa $58^{\text {ème }}$ Session, l'ONU déclare le 22 mars 2005 comme journée ${ }^{61}$ mondiale de l'eau et la décennie (2005-2015) comme la décennie internationale d'action "l'eau source de vie». Toujours au courant de la même année, (du 11 au 22 avril 2005 à New York), a lieu la Commission de Développement Durable avec pour objectif d'établir un document politique relatif à l'adoption d'une série de mesures concrètes pour affronter le manque d'avancées dans l'accès à l'eau potable et l'assainissement fixées par les rapports sur les OMD. Le droit à l'eau ne figure pas dans le texte final ${ }^{62}$.

En 2007 (du 23 au 24 mars à Marrakech), lors d'une importante conférence (réunissant les avocats, les ingénieurs, les architectes et autres praticiens en provenance du Maroc, de Tunisie, d'Algérie, d'Italie, d'Espagne et de France) est proposée l'élaboration d'une Convention méditerranéenne affirmant "le droit à l'eau pour tous " et la création d'un site consacré au droit à l'eau et au droit de l'eau. Finalement, cette

\footnotetext{
${ }^{60}$ "Aujourd'hui, près de la moitié de l'humanité n'a pas accès à l'eau potable et l'assainissement. Elle est ainsi victime de pathologies parfois mortelles, qui freinent le développement. La situation risque de s'aggraver. Les ressources en eau douce disponibles par habitant diminuent dramatiquement dans le monde, et, au rythme actuel, les 2/3 de l'humanité subiront dans quelques années une situation de pénurie. L'accès à l'eau potable et l'assainissement est au cour des problématiques de développement. C'est un enjeu écologique car la ressource est rare, c'est un enjeu de solidarité pour permettre l'accès des plus pauvres et des quarties défavorisés. C'est un enjeu de santé publique. C'est un enjeu social car, bien souvent, les femmes et les filles sont les premières victimes de l'insuffisance des infrastrutures. C'est un enjeu éducatif car, le temps qu'elles passent à aller puiser l'eau est pris sur le temps consacré aux études "; Propos tenus par Jacques Chirac au cours de ce Sommet; pour la source, voir GENE (C.), «Rapport sur la proposition de loi sur la coopération internationale des collectivités territoriales et des agences de l'eau dans les domaines de l'alimentation en eau et de l'assainissement ", Sénat, $\mathrm{n}^{\circ} 347,16$ juin $2004, \mathrm{p} .5$.

${ }^{61}$ Elle concerne l'ensemble de la société civile, les Organisations Internationales et les gouvernements.

${ }^{62} \mathrm{Du}$ fait des malentendus recueillis : les PED l'assimilent à la gratuité; certains Pays comme les Etats- Unis jugent ce droit trop contraignant ainsi que certains membres du G77; il n'y a que la société civile et certaines entreprises privées qui se sont explicitement exprimées en faveur de ce droit, AUBRIOT (J.), «Le droit à l'eau : émergence, définition, situation actuelle et position des acteurs ", Service ACF-France, août, 2007, p.20.
} 
entreprise ne sera pas vaine, le 28 juillet 2010, est adoptée par l'Assemblée Générale des Nations Unies (sur proposition de la Bolivie) une résolution sur le droit à l'eau et l'assainissement qui reconnaît ce droit comme un droit humain fondamental. Cette résolution constitue une étape charnière dans la définition du droit à l'eau potable et l'assainissement. Les conclusions retenues à l'issue de ces conférences sont suffisamment intéressantes pour favoriser la mise en œuvre du droit à l'eau potable au plan interne des Etats. Mais, la réalité demeure : les conclusions retenues lors d'une conférence quelles que soient leurs portées ne sauraient s'imposer aux participants. Bien plus, la pauvreté reste un véritable frein dans la mise en œuvre dudit droit.

L'examen de cette première partie respecte une double logique : le recadrage de la nature juridique du droit à l'eau potable (chapitre I) et l'analyse des implications de sa difficile consécration (chapitre II) pour une mise en œuvre réussie au plan interne. 

CHAPITRE I

LA NATURE JURIDIQUE CONTROVERSEE DU DROIT A L'EAU POTABLE ET SES IMPLICATIONS 
Définir le droit à l'eau, affirme Gérard $P A Y E N^{63}$, «c'est au préalable identifier l'autorité publique en charge de sa mise en cuvre avec ses obligations ${ }^{64}$ correspondantes. C'est-àdire établir clairement les droits et devoirs y relatifs et mentionner avec précision qui fait quoi. "Le moment est venu de considérer l'accès à l'eau potable et à l'assainissement comme un droit de l'homme, défini comme le droit à un approvisionnement suffisant, physiquement accessible et à un coût abordable en eau salubre de qualité acceptable, pour les usages personnels et domestiques (boisson, propreté, la-vage du linge, hygiène personnelle et domestique) et les nécessités de la vie et de la santé. Les Etats doivent donner la priorité aux utilisations personnelles et domestiques sur les autres utilisations et faire en sorte qu'un approvisionnement suffisant, de bonne qualité et d'un prix abordable pour tous soit fourni à distance raisonnable de leurs foyers ${ }^{65}$. Ainsi, définir le droit à l'eau potable, c'est mettre sur pied une autorité pu-blique responsable. C'est préciser les obligations de chacun, c'est aussi prévoir les moyens juridiques et financiers pour faciliter sa mise en œuvre.

La mise en œuvre du droit à l'eau potable concerne plus généralement les personnes défavorisées. Dans les pays développés, il s'agit des personnes démunies ou en situation de précarité (ceux que l'administration connaît mal ou pas du tout); dans les pays sous développés, il s'agit de la frange de la population vivant en milieu rural ou dans les zones périurbaines. Le droit à l'eau potable a longtemps revêtu un contenu et une nature juridique controversée (section I). Sa mise en œuvre au plan international et à fortiori interne n'est pas chose évidente malgré sa grande portée (section II). Le principal fondement du droit à l'eau potable au plan international est le Pacte International relatif aux Droits Economiques, Sociaux et Culturels (de 1966) dont l'interprétation a donné naissance à l'Observation Générale $\mathrm{N}^{\circ} 15$ (de 2002) et tout récemment à la Résolution de l'Assemblée Générale des Nation Unies du 28 juillet 2010 qui est à l'heure actuelle (malgré sa limite) ${ }^{66}$, le texte phare de définition du droit à l'eau et l'assainissement comme un droit fondamental de l'homme.

\section{SECTION I : La nature juridique et le contenu du droit à l'eau potable}

Le concept de droit «à l'eau pour tous » a été formalisé sous la dénomination de droit à l'eau lors de la conférence de Mar Del Plata ${ }^{67}$ de 1977. De plus en plus appréhendé comme un droit fondamental de l'homme indispensable à la réalisation des autres droits, bon nombres d'Etats pensent que l'adoption du droit à l'eau potable en tant que

\footnotetext{
${ }^{63}$ Membre du Conseil pour l'Eau et l'Assainissement, membre du panel international "pour financer l'eau pour tous ", Président du Comité international de l'ASTEE (l'Association des professionnels français de l'eau).

${ }^{64}$ PAYEN (G.), «Droit d'accès à l'eau potable, Aspects économiques, institutionnels et pratiques », lors du Congrès de Lausanne, 29 septembre 2005, p.2.

${ }^{65} \mathrm{CoDH}$, «Les droits de l'homme et l'accès à l'eau », R/2/104, 27 novembre 2006, para.66.

${ }^{66}$ Elle demeure comme son nom l'indique une simple résolution qui n'a pas été admise à l'unanimité; lors de son vote, on a enregistré 42 abstentions pour raisons diverses dont l'essentiel tenait à son caractère vague en matière de responsabilité de l'Etat relative au droit à l'eau potable.

${ }^{67}$ OUDEY (N.), «A propos de la justiciabilité du droit à l'eau en tant que droit économique, social et culturel », mars 2008, p.1.
} 
droit de l'homme ne concerne que les relations entre les citoyens et leurs Etats et pas les relations interétatiques ${ }^{68}$. Au contraire, d'autres Etats soutiennent que l'adoption du droit à l'eau potable comme droit fondamental de l'homme pourrait bien avoir des conséquences juridiques dans les relations étatiques au plan international. Dans tous les cas de figure, pour être un véritable droit revendicable devant les tribunaux, la définition $\mathrm{du}$ droit à l'eau potable (paragraphe I) doit entrainer des obligations aussi bien au niveau des rapports entre l'Etat et les individus qu'au niveau des rapports entre les individus eux-mêmes. A contrario, le droit à l'eau potable produit des effets sur les autres droits de l'homme reconnus dans le Pacte international relatif aux Droits Economiques, Sociaux et Culturels (paragraphe II).

\section{Paragraphe I : L'économie du principe du droit à l'eau potable}

La définition du droit à l'eau potable comme droit de l'homme (A) a une portée significative (B). Elle est essentielle au plein exercice de ce droit et pourrait même en être son essence. Le droit à l'eau connaît une meilleure définition avec l'avènement de l'Observation Générale $\mathrm{N}^{\circ} 15$ de 2002 prise en interprétation des articles 11 et $12 \mathrm{du}$ Pacte International relatif aux Droits Economiques, Sociaux et Culturels (PIDESC de 1996) et de la Résolution A/Res/64/292 de 2010 sur le droit à l'eau et l'assainissement. Dans ces textes, le droit à l'eau est désormais défini comme un droit fondamental de l'homme, indispensable à la jouissance de la vie et à la réalisation des autres droits de l'homme.

\section{A. La notion de droit à l'eau potable}

Le droit à l'eau est indissociable du droit à l'assainissement pour tous. Ce sont des droits fondamentaux aujourd'hui reconnus tant au plan international qu'au plan interne ${ }^{69}$. Malgré les équivoques autour de la notion (1), le droit à l'eau potable est un droit fondamental de l'homme (2).

\section{Les malentendus au sujet du droit à l'eau potable}

La nature juridique du droit à l'eau a pendant longtemps fait l'objet d'une grande controverse. Contrairement à une idée répandue, le droit à l'eau pour tous ne peut être identifié avec la gratuité de la fourniture d'une certaine quantité d'eau à chacun ${ }^{70}$. Le droit à l'eau "n'impose pas la gratuité, il doit plutôt en assurer l'accessibilité". Par exemple, le droit à l'eau potable interdit l'interruption arbitraire de l'approvisionnement en eau sans pour autant interdire l'interruption en cas de non paiement de facture

\footnotetext{
${ }^{68}$ Pour l'Autriche "Within the ambit of human rights concepts, any right to access to drinking water would exclusively concern the relationship between individual under the jurisdiction of particular State itself ", Les Etats-Unis ont la même opinion: The United States supported the progressive realization of the right to adequate food as component of the right to an adequate standard of living. The attainment of that right was a goal to be realized progressively - It did not give rise to international obligations or domestic legal entitlements (déclaration faite à la Commission des droits de l'homme le 16 avril 2004), Extrait de SMETS (H.), «L'accès à l'eau potable et le droit international », op.cit., pp.16-17.

${ }^{69}$ Voir le chapitre II de cette partie.

${ }^{70}$ SMETS (H.), « Le droit à l'eau », op.cit., p.5.
} 
d'eau $^{71}$. Le droit à l'eau offre certes des prérogatives, mais celles-ci sont souvent mal comprises ou mal interprétées.

Ainsi, consacrer le droit à l'eau potable n'entraîne pas forcément la gratuité de la ressource, mais renvoie à une facturation qui tienne compte de la situation des couches sociales défavorisées $^{72}$. Reconnaître le droit à l'eau potable n'implique pas forcément le branchement automatique aux réseaux de distribution, mais davantage la possibilité de se brancher aux réseaux existants. Ni encore la gestion absolue de l'eau par les pouvoirs publics, mais leur pouvoir de contrôle sur la ressource. Elle ne signifie pas non plus la perte de souveraineté sur la ressource, mais autorisation ou interdiction d'exploitation de celle-ci ${ }^{73}$. La définition du droit à l'eau comme un droit fondamental de l'homme ne fait plus l'objet de doute.

\section{Le droit à l'eau potable, un droit fondamental de l'homme}

Le droit à l'eau potable est «le droit pour toute personne quel que soit son niveau de vie de disposer d'une quantité minimale d'eau de bonne qualité qui soit suffisante pour la vie et la santé $\gg^{74}$. Le droit à l'eau potable se limite donc à l'eau destinée à la consommation et aux besoins humains essentiels tels que précisé dans le programme d'Action 21 : « dans la mise en valeur et l'utilisation des ressources en eau, il faut donner la priorité à la satisfaction des besoins fondamentaux et à la protection des écosystèmes ".

L'Observation Générale $\mathrm{N}^{\circ} 15$ donne une bonne lecture de ce droit. Elle le définit à son article 2 comme «le droit à un approvisionnement suffisant, physiquement accessible et à un coût abordable d'une eau salubre et de qualité acceptable pour les usages personnels et domestiques de chacun ". Le droit à l'eau concerne donc une frange d'eau très faible ${ }^{75}$.

Toutefois, au-delà de ces exigences, les utilisateurs doivent payer « un juste prix $»^{76}$. Cette définition du droit à l'eau comme droit fondamental vient d'être entérinée pour la première fois dans la Résolution de l'Assemblée Générale des Nations Unies (A/Res/64/292) qui reconnaît «le droit à l'eau et l'assainissement comme un droit fondamental, essentiel à la pleine jouissance de la vie à l'exercice des autres droits de l'homme $»^{77}$. Le droit à l'eau a donc désormais une portée significative.

\footnotetext{
${ }^{71}$ Rapport du sommaire du séminaire tenu le 29 et 30 mars 2007 op.cit., p.7.

${ }^{72}$ Elles concernent le cas de certaines personnes socialement marginalisées telles que les pauvres, les femmes et les enfants.

${ }^{73}$ Académie de l'eau, «Le droit à l'eau, un droit pour tous les citoyens », p.2, consulté dans www.academieeau.org, le 27 décembre 2008.

${ }^{74}$ Voir pour les détails, introduction générale, titre 8.2.

${ }^{75}$ Puisqu'au niveau mondial, 69\% de l'eau est utilisée pour l'agriculture, 23\% pour l'industrie et la production d'énergie et seulement $8 \%$ pour les usages domestiques; extrait de AUBRIOT (J.), «Le droit à l'eau : émergence, définition, situation actuelle et position des acteurs ", op.cit.,. p.24.

${ }^{76}$ Le juste prix ne s'applique qu'à l'eau utilisée pour des besoins autres que « fondamentaux », cela signifie que l'eau utilisée pour les besoins essentiels relève d'une logique différente, Agenda 21, para. 18.8.

${ }^{77}$ Voir la première disposition de cette Résolution.
} 
Encadré 1. La définition du droit à l'eau potable

\section{L'article 2 de l'Observation Générale $\mathrm{N}^{\circ} 15$ de 2002 :}

Il définit le droit à l'eau comme le droit à "un approvisionnement suffisant, physiquement accessible et à un coût abordable, d'une eau salubre et de qualité acceptable pour les usages personnels et domestiques de chacun ». On constate que celle-ci limite l'accès à la satisfaction des besoins humains essentiels.

La disposition 1 de la Résolution A/Res/64/292 des Nations Unies du 28 juillet 2010 : Le droit à l'eau est un «droit fondamental, essentiel à la pleine jouissance de la vie et à l'exercice des autres droits de l'homme". C'est la toute première résolution dans le monde à reconnaître par écrit le droit à l'eau potable et l'assainissement comme un droit humain fondamental. Elle marque un point historique dans la reconnaissance explicite du droit à l'eau potable.

B. La portée du droit à l'eau potable

La définition du droit à l'eau comme droit de l'homme produit une conséquence visible dans l'Observation Générale $\mathrm{N}^{\circ} 15$ (1) et pose le problème d'exportation de l'eau potable (2).

\section{Le droit à l'eau potable dans l'Observation Générale $N^{\circ} 15$}

Chacun des six organes de surveillance des traités relatifs aux droits humains de l'ONU (et plus précisément le Comité des Droits Economiques, Sociaux et Culturels), publie périodiquement des documents appelés observations générales ou recommandations générales. Celles-ci visent à aider les Etats parties à mieux comprendre certains aspects spécifiques du traité d'un comité en particulier celui relatif aux droits de l'homme. L'Observation Générale $N^{\circ} 15$ a été adoptée en novembre 2002 à Genève par le Comité des Droits Economiques, Sociaux et Culturels (CDESC) mis sur pied lui-même en 1985 par le Conseil économique et social de l'organisation des Nations Unies. Elle a pour objectif d'officialiser le droit à l'eau et de lever les équivoques autour de sa définition.

\section{${ }^{*}$ Le bien fondé de l'Observation Générale $N^{\circ} 15$}

L'Observation Générale de 2002 prend en compte trois critères essentiels: [ la disponibilité de l'eau (la quantité disponible doit être suffisante ${ }^{78}$ pour les usages personnels et domestiques); la qualité de l'eau (l'eau doit être salubre et acceptable, c'est-à-dire exempte de microbes et substances chimiques et par conséquent appropriée à la consommation humaine) ; l'accessibilité de l'eau (qui doit être à la fois physique ${ }^{79}$

\footnotetext{
${ }^{78}$ Elle se fonde sur les directives de l'OMS qui recommandent au moins 20 litres/personne/jour et une fourniture en permanence. Ces normes varient suivant les équipements sanitaires ainsi que les modes de distributions (bornes fontaines, puits ou desserte à domicile par exemple). Les normes SPHERES (Minimum Standards in Water, Sanitation and Hygiène Promotion, Chapter 2), in "The SPHERE projet ", Version révisée en 2004 fixe la quantité minimale à 15l/p/j. L'expert Peter GLEICK fixe la norme minimum à 501/p/j in: The right to water, water policy, 1999.

${ }^{79}$ L'Observation Générale $\mathrm{N}^{\circ} 15$ et les directives de la sous-commission soulignent à cet effet que : «la sécurité des personnes ne devraient pas être menacée lorsqu'elles ont physiquement accès à l'eau et à des équipements
} 
(disponible quantitativement et qualitativement), économique ${ }^{80}$ (offerte à un coût abordable), morale et équitable (son usage ne doit pas donner lieu à discrimination et la situation des groupes à risques doit être prise en compte) ]. L'Observation Générale $\mathrm{N}^{\circ} 15$ exige le respect des obligations telles que: la non discrimination, la quantité minimale, l'accès à des installations et service régulier d'eau salubre, la répartition équitable des systèmes d'alimentation en eau et des services d'eaux, l'adoption des stratégies nationales et plans d'action dans le domaine de l'eau, la surveillance, le programme d'approvisionnement en eau potable peu coûteux visant à protéger les groupes vulnérables et marginalisés, la prévention et le traitement fiable de l'eau.

La même observation générale énonce plusieurs conséquences possibles au plan international : « les Etats devraient s'engager à agir, individuellement et collectivement, en vue d'assurer le plein exercice du droit à l'eau (c'est le principe de coopération entre Etats si cher en droit international de l'environnement). Les Etats parties doivent respecter l'exercice du droit à l'eau dans les autres pays. La coopération internationale requiert des Etats parties qu'ils s'abstiennent de mener des actions qui entravent directement ou indirectement l'exercice du droit à l'eau dans d'autres pays. Les activités exercées dans la juridiction de l'Etat partie ne devraient pas empêcher un autre pays d'assurer l'exercice de ce droit aux personnes relevant de sa juridiction. Les Etats parties devraient s'abstenir dans tous les cas d'imposer (directement ou indirectement), à un autre pays des embargos et autres mesures similaires empêchant l'approvisionnement en eau et la fourniture de marchandises et de services qui sont essentiels pour assurer le droit à l'eau; Les Etats parties devraient prendre des mesures pour empêcher leurs propres ressortissants ou des compagnies qui relèvent de leur juridiction de violer le droit à l'eau de particuliers et de communautés dans d'autres pays $»^{81}$.

Pour ce qui est des accords internationaux, l'Observation générale stipule que : «Les Etats parties devraient veiller à ce que le droit à l'eau reçoive l'attention voulue dans les accords internationaux et, à cette fin, devraient envisager d'élaborer de nouveaux instruments juridiques $»^{82}$. Elle précise en outre qu' « en ce qui concerne la conclusion et la mise en œuvre d'autres accords internationaux et régionaux, les Etats parties devraient s'assurer que ces instruments n'ont pas d'incidence néfaste sur le droit à l'eau. Les accords de libéralisation du commerce ne devraient pas entraver ou amoindrir la capacité d'un pays d'assurer le plein exercice de ce droit». Par ailleurs, "Les Etats parties sont tenus de veiller à ce que les mesures qu'ils prennent en tant que membres d'organisations internationales tiennent dûment compte du droit à l'eau». En conséquence, les Etats parties qui sont membre d'institutions financières

\footnotetext{
et services d'assainissement, para. 37.

${ }^{80} \mathrm{Ce}$ critère est contenu dans le plan de mise en œuvre du Sommet mondial pour le développement durable de 2002 qui affirme que « les objectifs en matière de recouvrement des coûts ne devraient pas entraver l'accès des pauvres à l'eau potable» para. 26 (b), le programme d'Action 21 qui affirme que « au-delà des exigences concernant la satisfaction des besoins fondamentaux, les utilisateurs devraient payer un juste prix » chap.18, para. 8, la Recommandation (14) du Comité des ministres du Conseil de l'Europe aux pays membres de la Charte européenne des ressources en eau qui affirme que : "sans préjudice du droit à l'eau pour satisfaire aux besoins essentiels, la fourniture d'eau est soumise à paiement en vue de couvrir le coûts économiques liés à la production et à l'utilisation des ressources en eau " para. 19.

${ }^{81}$ SMETS (H.), «L'accès à l'eau potable et le droit international », op.cit., p.18.

${ }^{82}$ Telle qu'une Convention-cadre sur le droit à l'eau.
} 
internationales, notamment le Fond Monétaire International, la Banque mondiale et les Banques régionales de développement, devraient porter une plus grande attention à la protection du droit à l'eau dans les politiques de prêt, les accords de crédit et les autres initiatives internationales de ces institutions.

En bref, l'Observation Générale $\mathrm{N}^{\circ} 15$ définit le droit à l'eau comme un droit fondamental de l'homme reconnu dans le Pacte International relatif aux Droits Economiques, Sociaux et culturels (article 10). Elle prône la gestion rationnelle et durable de l'eau (article 11), recommande que l'accès soit physique, économique et morale (article 12) et interdit la discrimination dans la distribution de la ressource (article 13). L'OG reconnait aussi que le droit à l'eau et le droit à l'assainissement vont de pairs (article 15) et que le droit à l'eau entraîne chez l'Etat essentiellement trois obligations : l'obligation de respecter, de protéger et de mettre en œuvre (article 16). Cette même Observation Générale recommande d'assister les Etats (surtout ceux du Sud) dans la mise en œuvre du droit à l'eau (article 21). Comme tout texte juridique, elle regorge des insuffisances.

\section{* Les limites de l'Observation Générale $N^{\circ} 15$}

Malgré sa pertinence, l'Observation Générale $\mathrm{N}^{\circ} 15$ n'est pas juridiquement contraignante. C'est là sa principale faiblesse. Elle n'est "qu'une base internationale de choix pour clarifier et canaliser les mobilisations internationales sur ces questions et tendre à la réalisation du droit à l'eau $»^{83}$. L'Observation n'est donc pas un droit au sens juridique du terme. C'est peut être ce qui justifie le fait qu'elle "soit mal connue, très peu citée et exploitée $»^{84}$. Bien plus et comme l'affirme Henri SMETS : "Le caractère vague des engagements internationaux des Etats en matière d'aide aux pays en développement dans le secteur de l'eau ou de réalisations des objectifs du millénaire montre que certains Etats ne sont pas prêts à s'engager sur des objectifs précis et sont très satisfaits de l'adoption de textes sans portée concrète. Le droit de l'homme à l'eau, poursuit-il, doit d'abord être défini et mis en cuvre au plan interne avant de pouvoir évaluer les effets éventuels de ce droit au-delà des frontières. Il appartient aux Etats de fixer les conséquences internationales qu'ils veulent donner de l'adoption par eux du droit à l'eau en tant que droit de l'homme. En attendant, il est très prudent de ne pas laisser se créer des obligations internationales concernant un droit à peine mis en cuvre au plan interne ${ }^{85}$. L'Observation Générale $\mathrm{N}^{\circ} 15$ demeure tout de même l'une des rares expressions du droit à l'eau existant actuellement et faisant autorité. Elle a aussi le mérite de pouvoir inspirer les Etats dans la mise en œuvre de ce droit.

Cette Observation Générale vient d'être complétée par la Résolution des Nations Unies A/Res/64/292 du 28 juillet 2010 qui en plus de reconnaître l'accès à l'eau potable et à l'assainissement comme des droits humains fondamentaux, offre à l'Etat les moyens de les mettre en œuvre par la voie d'assistance technique et technologique (surtout des pays en développement) qu'elle prescrit. Toutefois, il faut préciser que cette résolution des Nations Unies est, elle aussi une simple mesure d'interpellation et n'entraîne pas

\footnotetext{
${ }^{83}$ AUBRIOT (J.), «Le droit à l'eau : emmergence, définition, situation actuelle et position des acteurs ", Service ACF-France, août, 2007, p.32.

${ }^{84}$ Idem.

${ }^{85}$ Dans son article « L'accès à l'eau potable et le droit international », publié par l'Académie de l'eau, pp.18-19.
} 
chez l'Etat une obligation de résultat, mais de moyen. La principale critique qui lui est formulée est celle de n'avoir pas fixé clairement le champ de responsabilité de l'Etat en la matière.

\section{La problématique de l'exportation de l'eau potable}

L'exportation est généralement une source de coopération mais parfois elle peut être une source de tension. Celle de l'eau potable en particulier soulève un certain nombre de questionnements au plan international. L'exportation de l'eau désigne tout transfert d'eau douce, brute ou potable, à travers les frontières à l'initiative de l'homme à quelques exceptions ${ }^{86}$ près. L'exportation de l'eau est soumise à une étude d'impact environnemental préalable ainsi qu'à un régime d'autorisation. Il convient de préciser à ce niveau que la reconnaissance du droit à l'eau n'oblige pas un Etat à fournir l'eau à un autre Etat ou à l'Etat voisin qui serait dans le besoin. Bien plus, en l'absence d'un traité ou d'une loi, il est dans la pratique difficile de procéder à l'exportation de l'eau. L'exportation de l'eau est une notion très sensible en droit international sauf aspects relevant de la gestion des fleuves internationaux. Dans ce dernier cas, Le Conseil européen de droit de l'environnement a adopté en 1999 le principe (qui s'applique aux nationaux et internationaux) d'après lequel les autorités étatiques, régionales et locales devraient privilégier la gestion par bassin. Les transferts d'eau inter-bassins doivent à la fois servir l'intérêt général et l'intérêt réciproque des usagers dûment informés et consultés en temps opportun en tenant compte de la nature des écosystèmes des bassins affectés. Les Etats devraient coopérer pour faciliter les transferts au plan international en vue de porter remède à des situations critiques.

En somme, s'il est vrai que les transferts d'eau peuvent à un moment donné devenir un remède miracle face à la crise de l'eau dans certaines régions du monde, il ne faut pas perdre de vue également que les transferts importants risquent considérablement de nuire dans l'avenir aux intérêts de l'Etat offrant. Aussi, avec les changements climatiques, l'Etat qui dispose "d'eau suffisante» aujourd'hui peut tomber dans la pénurie demain. Autrement dit, en matière d'exportation d'eau, il faut agir en toute prudence.

\section{Paragraphe II : Les rapports entre le droit à l'eau potable et le PIDESC}

Le droit à l'eau potable appartient à la catégorie des droits économiques et sociaux (A) et culturels indirectement tiré du Pacte International relatif aux Droits Economiques, Sociaux et Culturels (B).

A. La notion de droits économiques, sociaux et culturels

Les droits économiques, sociaux et culturels sont des droits fondamentaux indispensables à la pleine jouissance de la vie. Ils sont encore appelés des droits créances. Le droit à l'eau potable appartient à la catégorie des droits économiques (1), sociaux et

\footnotetext{
${ }^{86}$ Ces exceptions concernent l'eau contenue dans les produits alimentaires, l'eau potable en bouteille, l'eau de survie utilisée par les passagers lors d'un voyage; l'eau qui s'écoule naturellement d'un pays vers un autre etc., SMETS (H.), op.cit., p.21.
} 
culturels (2) indirectement prévu dans le Pacte international relatif aux droits économiques, sociaux et culturels de 1966 ratifié par environ 152 Etats $^{87}$. "L'eau fait partie intégrante de l'écosystème et constitue une ressource naturelle et un bien social et économique dont la quantité et la qualité déterminent l'affectation $»^{88}$. Les droits économiques et sociaux sont des droits faisant l'objet d'une réalisation progressive et n'entraînant pas encore à ce jour chez l'Etat une obligation immédiate mais une obligation de moyen. Les DESC ont été pour la première fois proclamés dans la Déclaration universelle des droits de l'homme de 1948 (dans les articles 22 à 27) et rendu obligatoires en 1966 dans le PIDESC. Encore appelés droits de la seconde génération par opposition au droits civils et politiques ${ }^{89}$, les DESC comprennent (d'après les articles 22 à 27 de la Déclaration universelle des droits de l'homme et 6 à 12 du PIDESC) : le droit au travail, le droit à la santé, le droit au logement décent, le droit à la sécurité sociale $[. .$.$] et par déduction le droit à l'eau potable.$

\section{Le droit à l'eau potable, un droit économique}

Moins qu'un bien ${ }^{90}$ économique, le droit à l'eau est davantage un droit économique, qui nécessite pour sa réalisation d'importants moyens financiers. L'eau a un prix que l'Etat et plus particulièrement les usagers doivent supporter. Ce prix n'est pas toujours abordable et créé parfois un déséquilibre au sein des populations. Les plus nanties ont plus la possibilité de s'en procurer que les personnes démunies. Ainsi, reconnaître le droit à l'eau potable ne signifie pas forcément que la ressource soit gratuite, mais davantage que le coût soit abordable pour tous et surtout pour les plus démunies. Le libre exercice du droit à l'eau potable se trouve freiné par la contingence économique qui pèse sur l'Etat. Pourtant, ce dernier devrait prendre des mesures fortes pour faciliter la mise en œuvre de ce droit notamment en :

- offrant aux usagers un service de l'eau peu coûteux (y compris des options technologiques bon marché accessibles aux personnes à bas revenus) ;

- promouvant les mesures d'hygiènes dans l'utilisation de l'eau et des services d'assainissements ;

- prenant en compte les besoins des femmes et des enfants lors des installations d'eau et d'assainissement ;

- $\quad$ veillant à ce que la politique de prix de l'eau et de l'assainissement soit appropriée ;

- fournissant des subventions pour les services d'eau et d'assainissement ;

- s'assurant que l'accès à l'eau n'est pas réduit (en cas de non-paiement) avant d'avoir vérifié la capacité de paiement de l’intéressé ${ }^{91}$.

\footnotetext{
${ }^{87}$ Extrait de l'Académie de l'eau, «Le droit à l'eau, un droit pour tous les citoyens », consulté dans www.academie-eau;org, le 10 mai 2009.

${ }^{88}$ Action 21, para. 18.8 .

${ }^{89} \mathrm{Ce}$ sont les droits de la première génération contenus aussi dans la Déclaration universelle des droits de l'homme mais rendus obligatoires dans un pacte différent : le PIDCP.

${ }^{90}$ "L'eau devrait être traité comme un bien social et culturel et non essentiellement comme un bien de nature économique ", Extrait dans www.un.org/french/events/water/4.pdf, in Année internationale de l'eau douce : «Le droit à l'eau », p.2.

${ }^{91}$ Conseil Economique et Social, Commission des Droits de l'Homme; Sous-commission de la promotion et de la protection des droits de l'homme, $57^{\text {ème }}$ session, Point 4 de l'ordre du jour, "Droits Economiques, sociaux et culturels, La réalisation du droit à l'eau potable et l'assainissement, p.8.
} 


\section{Le droit à l'eau potable, un droit social et culturel}

L'eau devrait être considérée à la fois comme un droit et un bien social auquel tout membre de la société peut légitimement prétendre. L'eau est un droit social et culturel indirectement contenu dans le Pacte international relatif aux droits économiques, sociaux et culturels de 1966 (ratifié par 157 Etats). L'accès à des quantités adéquates d'eau salubre à des fins personnelles ou domestiques est un droit fondamental de la personne ${ }^{92}$. Le droit social à une eau salubre renvoie à " un approvisionnement suffisant, physiquement accessible, et à un cô̂t abordable d'une eau salubre de qualité accep-table pour les usages personnels et domestiques de chacun $»^{93}$. Cette conception constitue une étape importante des droits de l'homme au niveau international en termes de protection juridique du droit à l'eau, bien que ce document ne soit pas juridiquement contraignant $t^{94}$. Bien plus, l'eau n'est pas encore pratiquement un bien social auquel tout le monde peut légitimement prétendre. Ipso facto, les responsables politiques, fournisseurs et gestionnaires de l'eau devraient mettre sur pied une politique de l'eau qui facilite la participation de tous en choisissant un mode de gestion qui soit le plus adapté aux possibilités techniques et économiques des usagers. "La connaissance des besoins, des souhaits et des possibilités de payer des usagers ainsi que les incitations à réduire les gaspillages, permettent de gérer l'eau en se fondant sur la demande plutôt que sur le développement de l'offre $»^{95}$.

Le droit à l'eau en tant que droit économique, social et culturel souffre des insuffisances à la fois juridiques et matérielles ${ }^{96}$. D'une part, ce droit est évoqué de manière implicite dans le PIDESC; d'autre part, la réalisation du droit à l'eau potable nécessite d'importants moyens économiques, financiers et sociaux qui font défaut à bon nombre d'Etats.

\section{B. Le droit à l'eau potable et les autres DESC}

Les articles 11 et 12 du PIDESC constituent les fondements juridiques (1) de la définition du droit à l'eau comme un droit économique, social et culturel. Ce qui produit des conséquences sur les autres droits économiques sociaux et culturels (2).

\section{L'interprétation des articles 11 et 12 du PIDESC}

Les articles 11 et 12 du PIDESC constituent les fondements juridiques de la définition du droit à l'eau potable comme un droit économique, social et culturel (voir Encadré 2).

\footnotetext{
${ }^{92}$ Voir Observation Générale $\mathrm{N}^{\circ} 15$ sur la mise en œuvre des articles 11 et 12 du Pacte international relatif aux droits économiques, sociaux et culturels et la Résolution A/Res/64/292 du 28 juillet 2010 sur le droit à l'eau et l'assainissement.

${ }^{93}$ Article 2, Observation Générale N ${ }^{\circ} 15$, Comité des droits économiques, sociaux et culturels de l'ONU 2002.

${ }^{94}$ Document du Conseil Mondial de l'Eau, $4^{\text {ème }}$ Forum Mondial de l'eau, «le droit à l'eau : du discours aux faits ».

95 SMETS (H.), «Le Droit à l'eau ", voir http://pmb.biblio.free.fr/opac_css/doc_num.php?explnum_id=192, p.3., consulté le 03 septembre 2009.

${ }_{96}$ OUDEY (N.), «A propos de la justiciabilité du droit à l'eau en tant que droit économique, social et culturel », op.cit., p.2.
} 
Encadré 2. Les articles 11 et 12 du PIDESC (1966)

\section{Article 11}

1. Les Etats parties au présent Pacte reconnaissent le droit de toute personne à un niveau de vie suffisant pour elle-même et sa famille, y compris une nourriture, un vêtement et un logement suffisants, ainsi qu'à une amélioration constante de ses conditions d'existence. Les Etats parties prendront des mesures appropriées pour assurer la réalisation de ce droit et ils reconnaissent en effet l'importance essentielle d'une coopération librement consentie [...]

\section{Article 12}

1. Les Etats parties au présent Pacte reconnaissent le droit qu'a toute personne de jouir $d u$ meilleur état de santé physique et mentale qu'elle soit capable d'atteindre.

2. Les mesures que les Etats Parties au présent Pacte prendront en vue d'assurer le plein exercice de ce droit devront comprendre les mesures nécessaires pour assurer:

a) La diminution de la mortinatalité et de la mortalité infantile ainsi que le développement sain de l'enfant;

b) L'amélioration de l'hygiène du milieu et de l'hygiène industrielle;

c) La prophylaxie et le traitement des maladies épidémiques, endémiques, professionnelles et autres ainsi que la lutte contre ces maladies [...].

Le droit à l'eau tire son origine de l'article 11 alinéa 1 du Pacte international relatif aux droits économiques, sociaux et culturels. Lequel reconnaît le droit à " un niveau de vie suffisant [...] y compris une nourriture, un vêtement et un logement suffisants, ainsi qu'à une amélioration constante de ses conditions d'existence ». L'emploi de l'expression "y compris » laisse entendre que la liste des droits énumérés n'est pas exhaustive. Le droit à l'eau est aussi lié au droit à la santé tel qu'il ressort de l'interprétation de l'article $12 \mathrm{du}$ même Pacte.

\section{L'influence du droit à l'eau potable sur les autres DESC}

Le droit a l'eau entretient des rapports couplés avec plusieurs autres droits économiques, sociaux et culturels contenus dans le PIDESC tels que : le droit des peuples à disposer de leurs ressources, le droit des conflits armés, le droit à la vie, le droit à la santé, le droit à la dignité, le droit à un niveau de vie suffisant.

\section{${ }^{*}$ Le droit à l'eau et le droit à un niveau de vie suffisant}

D'après l'article 11 al.1 du PIDESC: "Les Etats [...] reconnaissent le droit de toute personne à un niveau de vie suffisant pour elle-même et pour sa famille, y compris une nourriture, un vêtement et un logement suffisant ainsi qu'une amélioration constante de ses conditions d'existence ». L'emploi de l'expression "y compris » laisse entendre que la liste des droits cités n'est pas exhaustive. Pour la réalisation desdits droits, il faut un accès suffisant à l'eau potable, élément clé pour un niveau de vie suffisant. Cette exigence est également perceptible à l'article 25 de la Déclaration universelle des droits de l'homme ${ }^{97}$ et 27 de la Convention sur les droits de l'enfant ${ }^{98}$.

${ }^{97}$ "Toute personne a droit à un niveau de vie suffisant pour assurer sa santé, son bien être ". 


\section{${ }^{*}$ Le droit à l'eau et le droit à la santé}

L'être humain a besoin d'eau potable pour rester en santé. Le droit à l'eau potable, le droit à l'assainissement et le droit à la santé sont intimement liés. Chaque année, 1,8 millions de personnes parmi lesquelles $90 \%$ d'enfants de moins de cinq ans vivant pour la plupart dans les pays en développement meurent de suite de maladies hydriques ${ }^{99}$. D’après Kofi Annan ${ }^{100}$, "Nous ne battrons ni [...] la tuberculose, ni la malaria ou aucune autre maladie infectieuse qui frappent les pays en développement avant que l'on ait gagné la bataille de l'eau potable, de l'assainissement et de l'hygiène de base $»^{101}$.

Dans la plupart des pays en développement, près de $90 \%$ des eaux usées déversées sur les côtes sont des effluents bruts non traités. Pourtant, les eaux résiduelles constituent une menace ${ }^{102}$ réelle pour la santé des êtres humains et autres espèces vivantes. Dans le monde, $40 \%$ de la population ne dispose pas encore d'un service d'assainissement de base ${ }^{103}$. Le pourcentage est davantage accru en Afrique. Déversées parfois sans traitement, les eaux usées polluent les sources d'eaux potables, alourdissent les risques sanitaires surtout chez les populations marginalisées et partant menacent la nappe phréatique. Pourtant, plusieurs méthodes simples d'épuration peuvent être utilisées pour rendre l'eau potable à savoir : le dégrillage, la décantation, le tamisage, la filtration, la flottation et la coagulation. Le droit à l'eau et le droit à la santé ont des rapports très étroits. Dans l'Observation Générale $\mathrm{N}^{\circ} 15$, le Comité des droits économiques, sociaux et culturels se penche aussi sur ce droit : "le droit à la santé est un droit global, dans le champ duquel entrent non seulement la prestation de soins de santé appropriés en temps opportun, mais aussi les facteurs fondamentaux déterminants de la santé tels que l'accès à l'eau salubre et potable et à des moyens adéquats d'assainissement, l'accès à une quantité suffisante d'aliments sains (...) $»^{104}$.

\section{${ }^{*}$ Le droit à l'eau et le droit à la nourriture et au logement}

En 1992, le Comité des Nations Unies sur les droits économiques, sociaux et culturels adopte une Observation Générale sur le logement. Dans celle-ci, il réaffirme que «tous

\footnotetext{
${ }^{98}$ "Les Etats parties reconnaissent le droit de tout enfant à un niveau de vie suffisant pour permettre son développement physique, mental spirituel, moral et social ».

${ }^{99}$ Pour les détails, voir le rapport de l'OMS en 2004.

${ }^{100}$ Ancien Secrétaire Général des Nations Unies.

${ }^{101}$ Déclaration faite en 2001.

${ }^{102}$ Environ 4 milliards de cas de diarrhée sont à l'origine de 2,2 milliards de décès (les plus touchés sont les enfants de moins de 5 ans dans les pays en développement); près de $10 \%$ de la population des pays en développement est infectée par les parasites intestinaux (qui peuvent être réduits par un assainissement et un approvisionnement en eau adéquate); près de la moitié des populations en développement souffre de maladies d'origines hydriques qui pouvaient être évitées par un assainissement meilleur et un approvisionnement en eau de qualité; $C f$. OMS-UNICEF, «Evaluation mondiale 2000 de l'approvisionnement en eau et l'assainissement »; note 16, p.2.

${ }^{103}$ Extrait du deuxième rapport des Nations Unies sur la mise en valeur des ressources en eau. D'après les estimations de ce rapport, 8 millions de personnes meurent tous les ans du fait de l'absence des services d'assainissement dans certaines régions du monde.

${ }^{104}$ CESCR, "Le droit au meilleur état de santé susceptible d'être atteint », 2000, Observation Générale $N^{\circ} 14$, E/C.12/2000/4, par.11, Extrait de GOUDREAU (F.) et RANCOURT (M.), « Le droit à l'eau potable face à la pratique des Etats » op.cit., pp.8-9.
} 
les bénéficiaires $d u$ droit au logement doivent avoir accès à l'eau potable $»^{105}$. Outre le droit à un niveau de vie suffisant, l'article 11.1 du PIDESC traite aussi du droit à la nourriture et au logement suffisants ce qui n'exclut pas que le droit à l'eau « [...] tombe sous le sens que le droit à l'alimentation comprend non seulement le droit à la nourriture solide, mais aussi le droit à la nourriture liquide, à l'eau potable ${ }^{106}$. L'eau fait partie de la nourriture sous deux aspects : d'abord en tant que partie intégrante d'une alimentation saine et, ensuite comme composante essentielle de denrées alimentaires de base ${ }^{107}$. De même que l'accès à la nourriture et au logement implique l'accès à l'eau potable, la lutte contre la faim et la misère passe inéluctablement par un approvisionnement suffisant en une eau de bonne qualité.

\section{${ }^{*}$ Le droit à l'eau, le droit à la vie et la dignité}

Le droit à l'eau est un droit sous-jacent à certains droits de l'homme tel le droit à la vie, à la dignité, à la santé, à la nourriture, au logement, au bien-être et à l'éducation (comme l'illustre le Tableau ${ }^{1}$.

\footnotetext{
${ }^{105}$ L'Observation Générale $n^{\circ} 4$ du Comité des droits économiques, sociaux et culturels relatifs au droit à un logement suffisant (de 1991) précise que les bénéficiaires de ce droit doivent avoir un accès permanent à des ressources naturelles et communes telles que: l'eau potable, de l'énergie pour cuisiner, le chauffage et l'éclairage, des installations sanitaires et de lavage, des moyens de conservation des denrées alimentaires, un système d'évacuation des déchets, de drainage et des services d'urgence », art.11 al.1.

106 ZIEGLER M.J., (rapporteur spécial sur le droit à l'alimentation, lors de la Commission des droits de l'homme, économiques, sociaux et culturels), «Le droit à l'alimentation », 2001, E/CN.4/2001/5, par.39.

${ }^{107}$ Peter GLEICK, The world's water 2000-2001: The biennial Report on Freshwater Resources, 2000, Washington, Island Press, p.6.
} 
Tableau $1^{108}$ : L'influence des entraves du droit à l'eau potable sur certains droits humains essentiels

\begin{tabular}{|c|c|c|}
\hline Droit de l'homme & Entraves & Conséquences \\
\hline $\begin{array}{l}\text { Droit à la vie } \\
\left(\mathrm{PIDCP}^{109}\right)\end{array}$ & $\begin{array}{l}\text { - rareté de l'eau salubre } \\
\text { - eau infectée }\end{array}$ & $\begin{array}{l}\text { - stress hydrique, décès } \\
\text { - maladie, épidémie, décès }\end{array}$ \\
\hline $\begin{array}{l}\text { Droit à la dignité } \\
\text { (PIDCP) }\end{array}$ & $\begin{array}{l}\text { - inexistence de latrines } \\
\text { - excréments humains } \\
\text { disséminés }\end{array}$ & $\begin{array}{l}\text { - maladies urinaires dues au retard à se } \\
\text { soulager } \\
\text { - pollution des ressources en eau et insalubrité }\end{array}$ \\
\hline $\begin{array}{l}\text { Droit à la santé } \\
\left(\text { PIDESC }^{110}\right)\end{array}$ & $\begin{array}{l}\text { - eau souillée } \\
\text { - eaux croupies } \\
\text { - mauvaise hygiène }\end{array}$ & $\begin{array}{l}\text { - maladies hydriques } \\
\text { - fatigue due au transport de l'eau, mal de dos, } \\
\text { insectes et micro-organismes vecteurs de } \\
\text { maladie }\end{array}$ \\
\hline $\begin{array}{l}\text { Droit à la nourriture } \\
\text { (PIDESC) }\end{array}$ & $\begin{array}{l}\text { eau de qualité peu contrôlée } \\
\text { pour cuisson et vaisselle }\end{array}$ & $\begin{array}{l}\text { maladies hydriques (dysenterie amibienne, } \\
\text { typhoïde, diarrhée, choléra etc.) }\end{array}$ \\
\hline $\begin{array}{l}\text { Droit au logement } \\
\text { (PIDESC) }\end{array}$ & $\begin{array}{l}\text { transport d'eau sur de longues } \\
\text { distances }\end{array}$ & perte de temps, frein des activités \\
\hline $\begin{array}{l}\text { Droit au bien-être } \\
\text { (PIDESC) }\end{array}$ & raréfaction de l'eau & $\begin{array}{l}\text { hygiène limitée, cadre de vie déplaisant, peu } \\
\text { salubre }\end{array}$ \\
\hline $\begin{array}{l}\text { Droit à l'éducation } \\
\text { (PIDESC) }\end{array}$ & source d'eau potable éloignée & $\begin{array}{l}\text { - délaissement des couches sociales } \\
\text { défavorisées } \\
\text { - femmes et enfants analphabètes }\end{array}$ \\
\hline
\end{tabular}

Plusieurs autres instruments internationaux tels que la Convention sur les droits de l'enfant (article 6), la Déclaration universelle des droits de l'homme (article 3) et le Pacte sur les droits Civils et politiques (article 6) reconnaissent le droit à la vie et à la dignité. Ces derniers imposent aux Etats des obligations négatives (de ne pas enlever la vie) et positives (assurer la vie), lesquelles passent par l'accès des populations à une eau salubre.

\section{SECTION II : Les implications de la définition du droit à l'eau potable}

En vue de créer les conditions de stabilité et le bien-être nécessaires pour assurer entre les nations des relations pacifiques et amicales fondées sur le respect du principe de l'égalité des droits des peuples et de leur droit à disposer d'eux-mêmes, les Nations Unies favorisent ${ }^{111}$ le respect universel et effectif des droits de l'homme et des libertés fondamentales pour tous, sans distinction de race, de sexe de langue ou de religion. Ce qui signifie qu'un Etat qui viole ces recommandations pourrait engager sa responsabilité (paragraphe II). Tout dépend du comportement de l'Etat face au droit en question (paragraphe I). Le droit de l'homme visé dans le cas d'espèce concerne l'eau potable.

\footnotetext{
${ }^{108}$ Inspiré du Cadre 3, Académie de l'eau, article de SMETS (H.), «Le droit d'accès à l'eau potable dans le contexte Méditerranéen, www.academie-eau.org, consulté le 29 janvier 2008, p.14. Dans ce tableau, le mot " obstacle très proche du mot entrave » a été volontairement remplacé par le mot " conséquence ».

${ }^{109}$ Pacte international relatif aux droits civils et politiques (160 ratifications).

${ }^{110}$ Pacte international relatif aux droits économiques sociaux et culturels (157 ratifications).

${ }^{111}$ Article 55 (c) de la Charte des Nations Unies.
} 


\section{Paragraphe I : Le comportement des Etats face au droit à l'eau potable}

Pour évaluer l'application et le respect des règles établies dans les différentes conventions des Nations Unies, les Etats produisent des rapports (B) au comité onusien; mais avant d'en arriver là, chaque Etat doit s'assurer de la mise en œuvre effective de ces droits contenus dans les rapports au plan interne (A).

\section{A. Le droit à l'eau potable, un gage contre la négligence de l'Etat}

Le droit à l'eau potable, déclare l'Observation Générale $\mathrm{N}^{\circ} 15$, est un droit humain essentiel et, comme tel mérite une protection particulière. Il appartient à la catégorie des droits économiques, sociaux et culturels qui impliquent un engagement de l'Etat en fonction de ses moyens et une action progressive et non immédiate (comme dans le cadre des droits civils et politiques). Pour que le droit à l'eau devienne un droit effectif, il est important qu'il soit justiciable et exigible. Les citoyens du monde entier doivent être capables de revendiquer le respect de ce droit devant les juridictions nationales et régionales et internationales ${ }^{112}$.

Allant dans le même sens, les recours pour entrave à l'exercice du droit à l'eau potable ont déjà été reçus devant les organes de contrôle des conventions régionales pour les droits de l'homme: en Afrique, la RDC (ancien Zaïre) fut par exemple condamnée en $1996^{113}$ par la Commission africaine des droits de l'homme et des peuples pour violation de l'article 16 de la Charte ${ }^{14}$ africaine des droits de l'homme et des Peuples ${ }^{115}$ pour manquement par le gouvernement zaïrois de l'époque à l'obligation de fournir à sa population les services de bases tels que l'eau potable et l'électricité (Para.47). On note également le cas de l'Afrique du Sud qui (quoique n'ayant pas ratifié le PIDESC, a inscrit le droit à l'eau dans son dispositif constitutionnel de 1996). Elle a admis l'hypothèse de la justiciabilité du droit à l'eau dans l'affaire Grootboom ${ }^{116}$ (dans cette affaire, le juge constitutionnel avait donné gain de cause au requérant). En Europe, la Cour ${ }^{117}$ européenne des droits de l'homme assure la garantie de ce droit. Le droit à

\footnotetext{
112 «Le droit à l'eau, levier d'action contre les négligences étatiques », Wolf (M.), Dir; Terre des Hommes France, p.10.

${ }^{113}$ Opinion 4/4/96 et opinion 10/7/96, Communications 25/89, 47/90, 56/91 et 100/93.

${ }^{114}$ Depuis 2004, a côté de la Charte africaine, repose une Cour africaine des droits de l'homme qui à ce jour, a déjà connu plusieurs litiges relatifs aux droits fondamentaux.

${ }^{115}$ Adoptée en 1981 et entrée en vigueur en 1986.

${ }^{116}$ Grootboom and others v. Government of the republic of South Africa and others, Affaire $\mathrm{n}^{\circ}$ CCT11/00, decision du 4 octobre 2000. En l'espèce, une communauté de 900 squatters, évincés d'une propriété privée où ils avaient constitué une zone d'habitat informel, se sont installés sur un terrain de sports voisin. Parmi eux, vivaient Mme Irène Grootboom et de nombreux enfants. Ne disposant ni d'abri, ni d'accès à l'eau et à l'électricité, ni d'équipements sanitaires minimums, ils ont intenté une action en justice contre le gouvernement provincial et national. La Cour Sud-africaine a donné raison à leur requête et proclamé la justiciabilité des DESC. : "These rigths (DESC) are, at least to some extent, justiciable " et ajouté : "socioeconomic rights are expressly included in the Bill Rigths; they cannot be said to exist on paper only ". La Cour considérant que les DESC et donc le droit à l'eau sont justiciables, ces droits pourront donc directement être invoqués par des requérants devant les juridictions Sud-africaines; Extrait de OUDEY (N.), «A propos de la justiciabilité du droit à l'eau en tant que droit économique, social et culturel », op.cit. p.3.

${ }^{117}$ Celle-ci a déjà eu à condamner la perte d'usage d'un puit d'eau potable : dans l'affaire Zander c/ Suède, la Cour a eu à condamner la Suède pour pollution d'un puit d'eau potable devenu inutilisable; Information
} 
l'eau potable touche l'essentiel des droits fondamentaux, et à ce titre, il comporte une obligation à trois dimensions (l'obligation de respecter, de protéger et de mettre en œuvre).

Encadré 3. Les trois obligations de l'Etat nées de l'Observation Générale $\mathrm{N}^{\circ} 15$

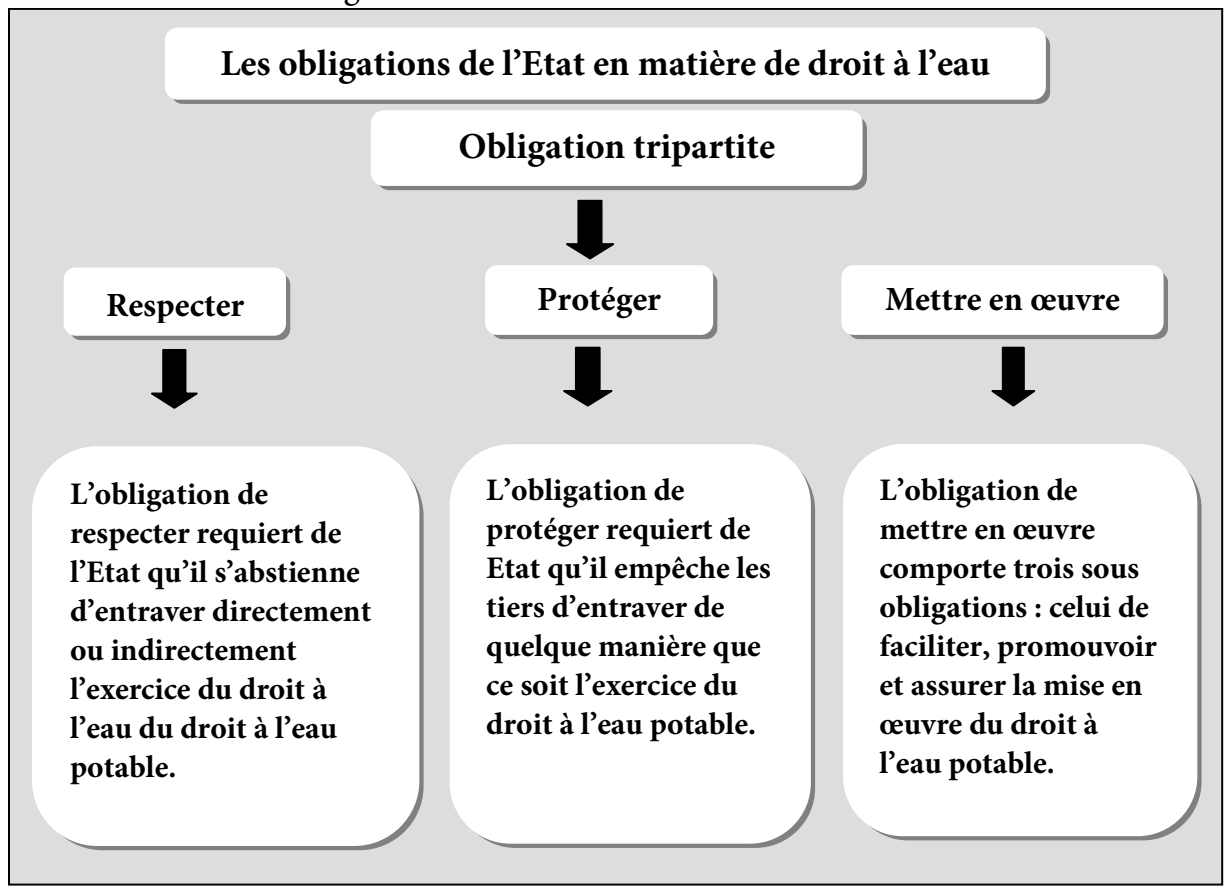

L'obligation de respecter empêche l'Etat d'exercer une activité qui ait pour conséquence d'entraver ou empêcher "l'accès impartial » à l'eau potable.

L'obligation de protéger oblige l'Etat à prendre des mesures législatives et réglementaires pour empêcher les tiers de refuser l'accès en toute égalité à une eau salubre.

L'obligation de mettre en œuvre comprend trois sous obligations : l'obligation de faciliter (qui recommande à l'Etat de prendre des mesures positives visant à aider les citoyens dans l'exercice libre de ce droit; l'obligation de promouvoir (recommande à l'Etat de diffuser les informations sur l'utilisation de l'eau de façon rationnelle et écologique ; l'obligation d'assurer oblige l'Etat à assurer effectivement la réalisation de ce droit (le rendre accessible et justiciable) ${ }^{118}$.

recueillie dans « Pour un droit effectif à l'eau potable», SMETS (H.), op.cit., p.24.

${ }^{118}$ Pour besoin d'approfondissement concernant ces obligations de l'Etat en matière de droit à l'eau, se référer au document du Comité des DESC, $29^{\text {ème }}$ session, "Questions de fonds concernant la mise en œuvre du Pacte International relatif aux Droits Economiques, Sociaux et Culturels ", Observation Générale $\mathrm{N}^{\circ} 15$ de 2002, le droit à l'eau (article 11 et 12 du Pacte international relatif aux droits économiques, sociaux et culturels), pp.914. 
Il n'existe pas à l'heure actuelle un moyen permettant de contraindre l'Etat à s'exécuter. L'obligation qui le lie continue d'être une simple obligation progressive suivant ses moyens. Cependant, l'obligation progressive ne signifie pas inertie de l'Etat. Au contraire, elle l'oblige d'abord à adopter des mesures législatives et un plan d'action national qui respectent les principes de non discriminations et de participation. Elle l'oblige ensuite à prendre en compte les besoins des populations les plus démunies et en choisissant des modèles de gestion adaptés. Elle l'oblige enfin à mettre en place des indicateurs clairs permettant de mesurer les avancées en matière de droit à l'eau et l'assainissement à travers la création ou l'incorporation d'organes législatifs, la promotion et la défense de ce droit ${ }^{119}$.

\section{B. L'évaluation des rapports produits par les Etats quant au droit à l'eau potable}

De plus en plus, le nombre considérable de communications reçues des gouvernements, des organisations intergouvernementales, des institutions nationales de protection des droits de l'homme et des associations civiles attestent non seulement de l'intérêt que soulève le droit à l'eau mais aussi de la nécessité évidente de l'aborder sous l'angle des droits de l'homme ${ }^{120}$. Pour évaluer l'application et le respect des règles établies par les différents pactes et conventions des Nations Unies, les Etats doivent émettre un rapport initial suivi de rapports périodiques pour chacun des instruments dont ils font parties. Ces rapports sont étudiés et assortis des observations du Comité onusien. En ce qui concerne l'évaluation du droit à l'eau potable, il faut noter que, seules les directives d'élaboration des rapports à soumettre au Comité sur les droits de l'enfant demandent aux Etats à l'heure actuelle de donner des informations concernant l'accessibilité à l'eau potable $^{121}$. Pour une meilleure évaluation, le Comité très souvent demande aux différentes parties prenantes à savoir les Etats, les organisations intergouvernementales, les associations, les experts ou les représentants du secteur privé de lui fournir des informations écrites au sujet de l'état du droit à l'eau potable dans leurs localités. Par la suite, les informations fournies peuvent faire l'objet d'une contre expertise ${ }^{122}$.

\section{Paragraphe II : La mise en ouvre de la responsabilité de l'Etat}

Parce ce que la problématique débattue relève du droit international de l'environnement, nous reviendrons brièvement sur la responsabilité de l'Etat au plan international pour pollution de l'environnement et plus précisément des eaux (A) avant d'envisager sa responsabilité au plan interne en matière de droit à l'eau potable (B).

\footnotetext{
${ }^{119}$ Voir pour les détails les articles 45 à 47 et 48, 53 et 54,55 à 59 de l'Observation Générale $\mathrm{N}^{\circ} 15$.

${ }^{120} \mathrm{CDH}$, « Rapport du haut commissariat des Nations Unies aux droits de l'homme sur la portée et la teneur des obligations pertinentes en rapport avec les droits de l'homme qui concernent l'accès équitable à l'eau potable et l'assainissement contractées au titre des instruments internationaux relatifs au droit de l'homme ", AG, 16 août 2007, p.27.

${ }^{121}$ Extrait de GOUDREAU (F.) et RANCOURT (M.), «Le droit à l'eau potable face à la pratique des Etats » op.cit.

${ }^{122} \mathrm{CDH}$, « Rapport du haut commissariat des Nations Unies aux droits de l'homme sur la portée et la teneur des obligations pertinentes en rapport avec les droits de l'homme qui concerne l'accès équitable à l'eau potable et l'assainissement contractées au titre des instruments internationaux relatifs au droit de l'homme ", op.cit., p.2.
} 
Si la violation d'une règle internationale protégeant l'environnement peut engager la responsabilité internationale de l'Etat à qui cette violation est imputable, encore faut-il qu'un sujet de droit international (un Etat ou une Organisation Internationale) puisse présenter la réclamation ${ }^{123}$. Autrement dit, l'individu pris isolement ne saurait engager avec succès la responsabilité d'un Etat pour non réalisation de son droit à l'eau. D'autant plus que ce dernier impose à l'Etat à ce jour une simple obligation progressive. La situation se complique davantage lorsque le dommage résulte de la pollution et intervient dans une zone qui échappe à toute compétence territoriale ${ }^{124}$. Dans ce cas, la Convention des Nations Unies sur le droit de la mer de 1982 (ou Convention de Montego Bay) a essayé d'y apporter une solution en énonçant que: "l'autorité a la charge d'assurer la protection du milieu marin en ce qui concerne les activités menées dans sa zone ». En poussant la réflexion, l'on peut d'emblée comprendre que cette autorité puisse du même coup engager la responsabilité des contrevenants avec succès. Ainsi, tous les Etats parties à une convention assument l'obligation réciproque de veiller au respect de ce traité. Cette théorie (de risque étatique) a pour but de protéger les Etats tiers et leurs ressortissants de l'exercice licite mais dommageable des compétences souveraines; l'objectif premier étant de réparer les dommages encourus et non forcément de prévenir l'activité dommageable ${ }^{125}$. La question reste celle de savoir si ces derniers peuvent aller jusqu'à en demander réparation en qualité de gardien de la convention en dépit du fait qu'ils n'aient pas directement subi le dommage ou si leur action doit se limiter à une simple opposition. Alexandre Kiss et Jean Pierre Beurrier ${ }^{126}$ pensent que: "qu'il s'agisse de dommage transfrontalier ou de tout autre dommage, un certain nombre d'obstacles doivent être surmontés pour que la réparation puisse être effective. De tels obstacles se retrouvent dans de nombreux cas lorsque l'environnement est détérioré et que des moyens juridiques internes ou internationaux doivent être mis en œuvre pour remédier au préjudice ».

La responsabilité internationale pour dommage causé à l'environnement et à l'eau potable en particulier soulève une préoccupation essentielle: qui sera responsable? Cette interrogation fait aussitôt penser aux caractères de la responsabilité internationale.

La victime ou l'auteur du dommage peut être soit une personne privée, ce qui mettra en cause la responsabilité internationale de la personne privée (ce cas de figure relève directement des règles de droit international privé), ou l'Etat, on est plus loin de la responsabilité de l'Etat au plan interne.

\section{A. La responsabilité de l'Etat au plan international pour pollution des eaux}

Parce que le domaine de l'eau relève de la souveraineté des Etats en général, la question de la mise en œuvre de la responsabilité de l'Etat au plan international concernée par la présente étude se réfère au cas de mise en œuvre de cette responsabilité pour pollution des ressources en eau. Très souvent, il arrive qu'un dommage aux eaux de surface

\footnotetext{
${ }^{123}$ Idem., p.428.

${ }^{124}$ Grand fonds marins, haute mer, espace aérien international, espace cosmique etc.

125 DUPUY (P.M.), La responsabilité internationale des Etats pour dommages d'origine technologique et industrielle, Paris, Pedone, 1976, p.15.

${ }^{126}$ Ouvrage op.cit., p.429.
} 
atteigne la nappe phréatique mettant ainsi en cause les ressources en eau potable. L'inquiétude ici se situe surtout au niveau de l'extension du dommage dans le temps et dans l'espace entraînant par exemple un dommage transfrontalier. Ce type de dommage est par définition international et ne se limite pas au voisinage immédiat. Il soulève à lui seul certaines préoccupations: qui sera responsable? De quoi sera t-il responsable? Comment parvenir à la réparation?

A la première préoccupation, il est évident que l'Etat sera la personne responsable. Soit parce qu'il est lui-même opérateur, soit parce qu'il exerce sa compétence territoriale sur la zone à partir de laquelle la pollution s'est produite.

De quoi sera t-il responsable ? Cette question soulève entre autres, la question de la réparation de dommage différé et complexe. Va-t-on dans ce cas imputer au responsable la réparation des dommages immédiats liés à l'origine par les causalités normatives simples ou bien va-t-on plus tard lui imputer la réparation des dommages constatés dans le temps?

Comment parvenir à la réparation ? La responsabilité de l'Etat sera-t-elle engagée devant ses propres tribunaux ou alors, en raison du caractère transfrontalier $\mathrm{du}$ dommage, faudrait-il intenter l'action en réparation devant une juridiction internationale? En existe-t-il une et est-elle compétente pour connaître ce type de question? Quels sont donc des modes alternatifs de règlements des différends environnementaux ? Ce sont là des questions originales autour de la réparation des dommages écologiques ${ }^{127}$ sur lesquelles nous ne nous attarderons pas trop parce qu'elles n'intéressent pas directement la présente étude.

Il sera dans cette partie d'abord question de recenser les différents conflits interétatiques autour de la question d'eau dans le monde (1) pour ensuite apprécier la nature de la responsabilité de l'Etat en la matière (2) et enfin voir les modes de règlement pacifiques de ces différents (3).

\section{Les conflits interétatiques autour des questions d'eau dans le monde}

Les conflits interétatiques autour des questions d'eau dans le monde vont grandissant. D'une part $40 \%$ de la population mondiale est installée sur 263 bassins fluviaux transfrontaliers et, d'autre part, certains Etats dépendent fortement pour leur approvisionnement en eau des ressources externe ${ }^{128}$.

La question d'accès à l'eau au Moyen Orient a par exemple engendré de sérieux conflits historiques. Le conflit de l'eau dans la localité de Beer-Sheba (en Israël) date de 4.000 ans environ. Jusqu'à nos jours, les problèmes d'eaux au Moyen Orient ne font que perdurer. Le fleuve Jourdain constitue encore une source de conflits entre les Arabes et les Israéliens (qui vivent sur un territoire où l'eau est rare).

\footnotetext{
${ }^{127}$ Voir pour les approfondissements, AUPEL-UREF, Le droit international de l'environnement, cours sur cassettes vidéo, Vidéo scope, Université de Nancy 2, 1998.

${ }^{128}$ Le taux de dépendance atteint $97 \%$ pour l'Egypte, 94\% pour la Hongrie, $80 \%$ pour la Syrie, $77 \%$ pour le Soudan, 55\% pour Israël, 53\% pour l'Irak [...] en Afrique, $80 \%$ des eaux de surface utilisées proviennent des ressources transfrontalières, information recueillie dans Annexe 14, Les guerres de l'eau: conflits interétatiques et infra étatiques, in Etudes et document du conseil d'Etat, TIBERGHIEN (F.) et suivant, «L'eau et son droit ", février 2010, p.357.
} 
La Turquie quant à elle s'adjuge le monopole de l'Euphrate et le Tigre (fleuves) en les détournant de leur lit. Cette action entraîne des conséquences en Irak et en Syrie qui dépendent directement de ces cours d'eau. Très souvent, la Turquie utilise cette position avantageuse qu'elle occupe pour faire pression lors de la résolution des conflits territoriaux et politiques.

Le fleuve Nil est également source de conflit en Ethiopie quand il s'agit de le partager avec l'Egypte.

En Extrême-Orient, plus précisément en Chine (qui contrôle en majorité le fleuve Tibet), les hostilités autour de l'eau émanent des populations avoisinantes qui contestent ce pouvoir de contrôle des Chinois.

En Amérique, les conflits (mineurs) opposent le Mexique aux Etats-Unis quant au fleuve Colorado qui alimente la métropole de Los Angeles diminuant ainsi son débit au détriment des Mexicains.

En Equateur, l'eau est rare et source de conflit; sa privation en Bolivie a été à l'origine de violentes réactions à telle enseigne qu'il a fallu engager des mercenaires pour défendre les intérêts privés des entreprises internationales et nationales ${ }^{129}$.

En Afrique du Nord et plus précisément en Algérie, le taux de remplissage des barrages est passé de $46 \%$ en juin 2001 à $38 \%$ en fin août de la même année. D’où la rationalisation en eau (par la solution 1 jour sur 3 par le biais d'un aménagement de plage horaire ce qui a provoqué le soulèvement de la localité d'Annaba en Algérie).

En Espagne, le 10 août 2001, une marche bleue fut organisée de Barcelone vers Bruxelles en contestation du plan national hydraulique ${ }^{130}$. Le 11 mars de la même année, plus de 120.000 personnes avaient manifesté à Madrid pour la même cause $»^{131}$. Les caractéristiques des situations conflictuelles autour des ressources en eau sont donc nombreuses et diversifiées. On peut les regrouper en six catégories selon Peter Gleick (du Pacific Institut) :

- le contrôle de la ressource (quand celle-ci est à la racine du conflit),

- $\quad$ son utilisation à des fins militaires (utilisation comme arme),

- son utilisation à des fins politiques,

- $\quad$ son utilisation à des fins de terrorisme,

- son utilisation comme cibles militaires,

- $\quad$ son utilisation pour des conflits de développements (lorsque celle-ci est source de tension majeure dans un contexte de développement économique et social) ${ }^{132}$.

L'eau est donc passée au premier plan des préoccupations internationales pour devenir une ressource stratégique d'enjeu géopolitique. Pour certains, d'ici 2015, si rien n'est fait, le conflit autour du pétrole va céder la place à celui autour de l'eau ; ce qui pourrait déclencher une autre guerre.

\footnotetext{
${ }^{129}$ Telle la loi de l'eau potable et des canalisations (Bolivie, 1999) qui avait privatisé les services de base sans tenir compte des coûts sociaux et environnementaux.

${ }^{130}$ Qui prévoyait la construction de 100 nouveaux barrages et le transfert de l'eau de l'Ebre vers l'Andalousie.

${ }^{131}$ Point de vue du Sud, "L'eau principe de vie et patrimoine collectif ", in L'eau, patrimoine commun de l'humanité, Harmattan, France, 2006, pp.14-16.

${ }^{132}$ PAQUEROT(S.), « Ressources en eau : les différentes facettes des conflits internationaux », lex electronica, Vol $12 \mathrm{n}^{\circ}$ 2, 2007, consulté dans le site www.lex-electronica.org/articles/v12-2/paquerot.pdf, consulté le 9 juillet 2008 .
} 


\section{La nature de la responsabilité de l'Etat au plan international}

La responsabilité de l'Etat en matière environnementale repose sur la base de la responsabilité objective. La responsabilité objective est d'actualité dans la majorité des textes internationaux de droit de l'environnement à quelques exceptions près ${ }^{133}$. La Convention de Lugano de 1993 sur la responsabilité civile pour dommage à l'environnement en est une illustration patente. La responsabilité objective repose sur des fondements de divers ordres.

Le point de vue juridique qui institue la responsabilité objective est le souci de dédommager la victime à tout prix, même en l'absence de toute faute. Le comportement subjectif de l'Etat à l'origine du dommage n'est pas pris en compte comme en matière de responsabilité pour fait illicite. La simple preuve de survenance du dommage suffit pour mettre en cause l'auteur du dommage. Dérogatoire au droit commun, ce type de responsabilité est une "objectivation de la responsabilité » qui fait fi du comportement de la victime pour imposer à l'Etat en cause une obligation de résultat. Aussi curieux que cela puisse sembler, la Convention de New York de 1997 n'a pas pris en considération ce type de responsabilité. En tout cas, cette omission n'est pas de nature à donner tort à la France d'avoir donné peu de crédit à ladite Convention et de s'être abstenue lors de son vote $^{134}$. Autrement dit, la preuve de l'absence de négligence ne suffit pas pour exonérer le mis en cause, qui est tenu de prendre toutes les mesures et les précautions de nature à éviter, voire prévenir le dommage.

Du point de vue économique, le fondement de la responsabilité objective est la prévention du dommage ; surtout en matière d'activités dangereuses pouvant entacher les ressources en eau douce. La responsabilité ne saurait se limiter à l'idée unique de reparation. D'autant plus que l'auteur du dommage n'est pas toujours solvable et les moyens pour l'y contraindre sont souvent bien limités. Prendre des précautions requises restent effectivement un moyen pour l'auteur du dommage, d'éviter sinon d'avoir à indemniser la victime ${ }^{135}$, du moins de réparer le préjudice subi par le mécanisme de la restitution «in integrum »; difficile dans l'exécution.

Du point de vue jurisprudentiel, la responsabilité objective trouve son fondement dans les affaires Gabcikovo/Nagymaros et Usines de pâte à papier sur le fleuve Uruguay ${ }^{136}$.

\footnotetext{
${ }^{133}$ Convention de New York de 1997 relative à l'utilisation des cours d'eaux à des fins autres que la navigation. ${ }^{134} \mathrm{La}$ France estimait que le texte avait été rédigé sous précipitation avec négligence d'où ses irrégularités de procédures. Dans cette Convention on note un déséquilibre entre le régime de la responsabilité (mal défini) et le régime de règlement des différends (bien établi). L'argument avancé par l'Ethiopie pour réfuter son adhésion tenait au fait que «ce texte n'était pas à mesure d'établir un équilibre certain entre les Etats quant à l'utilisation des cours d'eaux internationaux à des fins autres que la navigation ». Et que ce texte n'a rien prévu pour se conformer aux textes antérieurs relatifs au cours d'eaux. D'autres pays tels que l'Espagne, l'Israël ont suivi cette logique d'abstention. Ce dernier reproche au cadre 10 de la Convention de n'avoir pas suffisamment mis en exergue l'approvisionnement en eau potable, principe fondamental. La Turquie quant à elle a voté contre en regrettant que le texte n'ait fait aucune mention quant à la souveraineté des Etats sur les cours d'eaux situés sur leur territoire. Il n'y a que l'Egypte qui semble avoir accueilli à bras ouvert cette Convention dans l'espoir qu'elle permette une meilleure coopération entre les Pays des cours d'eaux partagés (d'amont en aval) bien que celle-ci ne soit finalement pas entrée en vigueur, Analyse effectuée à partir des extraits de POYDENOT (A.), op.cit., pp.25-26.

${ }^{135}$ FAURE (M.), L'analyse économique du droit de l'environnement, Bruxelles, éd. Bruylant, 2007, p.121.

${ }^{136}$ Uruguay/Argentine.
} 
Les cas de jurisprudences africaines dans le domaine sont rares. Cela est sans doute dû au fait que le droit de l'environnement en Afrique est un droit en chantier.

Toutefois, le dommage peut rester sans réparation en présence de certaines causes d'exonérations de la responsabilité comme celles applicables en droit commun telles que les causes étrangères à la victime et le comportement de la victime. Au rang des causes étrangères à la victime, figurent la force majeure, l'état de nécessité et la détresse ayant entraîné l'impossibilité d'agir dans le bon sens.

La force majeure en droit international est le fait pour un Etat bloqué par une situation d'événements imprévisibles et irrésistibles de manquer à ses obligations conventionnelles. Toutefois, sa preuve doit être apportée par l'Etat qui l'invoque. C'est pourquoi dans l'Affaire Detroit de Corfou, la Cour Internationale de justice, devant l'impossibilité de l'Albanie d'apporter la preuve de la force majeure, avait retenu purement et simplement la responsabilité internationale de ce dernier. Ces événements n'exonèrent en aucun cas l'Etat de son obligation d'informer et de notifier.

L'état de nécessité est une situation qui met l'Etat dans une position d'exécution impossible sous peine de nuire à ses propres intérêts. Ce principe pourrait bien s'arrimer avec la formule "nul ne peut transmettre plus de droit qu'il n'en a lui même" (nemo plus juris, en latin). Parmi les circonstances liées au comportement de la victime on a : le consentement, la légitime défense et autres mesures de réactions à l'attaque. La responsabilité internationale pour dommage à l'environnement "c'est la dernière chance qui reste lorsqu'on n'a pas su protéger l'écologie environnementale $»^{137}$. Ces règles doivent en principe être suffisamment claires et précises afin de contourner assez aisément les difficultés d'ordre politique (quand les Etats refusent d'engager leurs différentes responsabilités motif pris de ce que ce qu'ils reprochent à l'autre pourrait leur arriver demain); les difficultés d'ordre technique (la preuve de la responsabilité est parfois difficile à apporter surtout lorsque le dommage évolue dans le temps et dans l'espace), et enfin les difficultés d'ordre financier (qui concerne certains cas d'insolvabilité à la suite de la mise en œuvre de leur responsabilité avec succès).

Comme début de solution, la prévention s'impose, car, il vaut mieux prévenir que guérir. Comme le disait Antoine de Saint Exupery, "nous ne léguons pas la terre à nos enfants, nous la leur empruntons", or l'emprunt rime avec la restitution et le compte rendu. Lorsque que la responsabilité de l'Etat est mise en cause, il existe au plan international des mécanismes de mise en œuvre de cette responsabilité.

\section{Les modes de règlement des différends interétatiques}

Nous avons dans le cadre de cette étude privilégié les modes de règlements pacifiques au détriment des modes de règlements non pacifiques ${ }^{138}$.

$\mathrm{Au}$ rang des modes de règlements pacifiques, on trouve les procédures diplomatiques (la négociation, la médiation et les bons offices) les procédures instituées

\footnotetext{
${ }^{137}$ Voir AUPEL-UREF, Le droit international de l'environnement, cours sur cassettes vidéo, Vidéo scope, Université de Nancy 2, 1998 op.cit.

${ }^{138}$ Recours à la force, à la guerre. Cette voie de recours est dénoncée aujourd'hui dans la majorité des textes internationaux relatifs aux droits de l'homme. L'article 2 para. 3 de la Charte des Nations Unies recommande aux membres des organisations de "régler leurs différends internationaux par des moyens pacifiques, de telle manière que la paix et la sécurité internationale ainsi que la justice ne soient pas mis en danger ».
} 
(l'enquête, la conciliation et l'arbitrage) et la procédure de règlement par un organisme international (les organes des Nations Unies, et les juges internationaux). En adhérant à ce point de vue, l'article 33 paragraphe 1 de la Charte des Nations Unies dispose : "Les parties à tout différends dont la prolongation est susceptible de menacer le maintien de la paix et de la sécurité internationale doivent en chercher la solution avant tout dans les voies de négociation, d'enquête de médiation, de conciliation, d'arbitrage, de règlement judiciaire, de recours aux organismes ou aux accords internationaux ou encore à d'autres moyens pacifiques de leur choix».

Au rang des procédures diplomatiques, se trouvent la négociation, la médiation et les bons offices. Ces procédures sont très anciennes et s'appliquent dans le cadre d'un contentieux mineur ou trop important pour justifier l'intervention d'une organisation internationale.

La négociation est un processus informel et volontaire de règlement de différend. Lorsque les Etats en litige ont des rapports diplomatiques antérieurs, la négociation entre eux ne pose pas de problème particulier. Le souci survient lorsqu'il n'existe entre les Etats en litige aucun rapport ou alors des rapports rompus. Dans ce cas de figure, une mission spéciale serait utile dans la procédure de négociation. La négociation consiste en une communication directe ou indirecte entre deux ou plusieurs parties en vue de résoudre un litige les opposant. Très souvent, la négociation se déroule sous coulisse et fait intervenir des diplomates ou des hommes politiques. Le consensus peut aboutir à une déclaration commune, échange de notes ou traité. De même que dans les autres modes de règlement diplomatique des différends, la négociation n'offre pas de garantie, les parties sont libres de s'en conformer ou non.

Les bons offices ${ }^{139}$ sont le fait pour une personnalité politique et en raison de son influence et de ses rapports personnels avec les parties en litiges, d'intervenir entre les parties prenantes afin qu'une solution soit trouvée à leur différend. Cette procédure est dite politique pour deux raisons : la personne qui offre ses bons offices bénéficie a priori d'une présomption d'impartialité de façon à ne susciter aucune récusation des parties en cause. Les bons offices ne donnent pas lieu à un jugement. Ils se passent généralement en coulisse parfois à l'insu de la communauté internationale qui constate à un moment donné que le conflit est résolu.

La médiation diffère des bons offices par le fait que le conflit est soumis à un règlement par les soins d'une personnalité et d'une commission d'accord mutuel entre les parties. Ici, la commission est appelée commission de médiation alors que la personnalité est appelée médiateur. L'une des commissions ou médiateur propose aux parties une solution commune qui les arrange. Ce qui suppose que la médiation connaît dès le départ un débat de formalisme du fait de l'accord entre les parties (l'offre de médiation, le choix du médiateur, la solution proposée). Lorsque la médiation est plutôt offerte, c'est le médiateur lui-même qui propose ${ }^{140}$ cette médiation aux parties. Lorsque ce sont les parties qui s'entendent sur le choix du médiateur, on parle d'une médiation demandée. A l'issue de ces deux voies de recours, le succès de la méthode réside dans les

\footnotetext{
139 «Les bons offices et la médiation soit sur le recours des parties au conflit, soit sur l'initiative des puissances étrangères au conflit ont exclusivement le caractère de conseil et n'ont jamais force obligatoire ", article 6 de la Convention I de la Haye du 18 octobre 1907.

${ }^{140}$ Voir médiation offerte par le Pape en 1979 dans l'affaire du canal de BEAGLE entre l'Argentine et le Chili.
} 
talents des médiateurs mais davantage dans les pressions politiques de l'Etat représenté par ces derniers. Dans l'affaire Sandoz (en 1986) par exemple, le gouvernement suisse s'était proposé pour offrir ses bons offices dans les négociations réunissant des autorités infra étatiques. Aussi, c'est la Banque Internationale de Recherche et de Développement qui avait joué le rôle de médiateur dans le conflit indopakistanais relatif aux litiges qui concernaient les eaux de l'Indus; dans cette affaire, la médiation avait donné lieu au Traité du 19 septembre 1960 entre le Pakistan, l'Inde et la Banque.

Lorsque la résolution du conflit fait plutôt intervenir des institutions jugées impartiales, on parle de procédures instituées. Elle comprend : l'enquête, la conciliation et l'arbitrage.

L'enquête ${ }^{141}$ vise la facilitation d'un litige international qui n'a pas été résolu par voie diplomatique. Elle peut être prévue par des conventions ${ }^{142}$ bilatérales ou multilatérales ou sollicitée par les parties au litige. La commission d'enquête est librement constituée par les parties en cause. Elle est généralement composée des nationaux des parties en litige et de tiers indépendants choisi d'accord parties.

La conciliation ${ }^{143}$ est soumise à l'appréciation d'une commission préétablie qui essaie de le résoudre en sanctionnant son action par un rapport final. C'est une procédure mi-politique mi-juridique. Elle est mi-politique parce que la commission n'applique pas le droit, et mi-juridique parce que le rapport final est une conciliation et davantage parce qu'elle est généralement prévue dans un texte préexistant ou dans une décision ad hoc (décision de circonstance). Dans la commission de conciliation, les parties sont maîtresses de la décision. La commission est composée de 3 ou 5 membres et chaque partie choisit un ou deux membres. Le $3^{3^{\text {ème }}}$ ou le $5^{\text {ème }}$ membre est généralement neutre, ce qui rapproche considérablement la conciliation des procédures juridictionnelles.

Le règlement juridictionnel n'est généralement prévu qu'à titre exceptionnel, vu son caractère contraignant. Le règlement juridictionnel peut consister à saisir une "commission mixte de cours d'eau » soit des tribunaux de bassins fluviaux ou de région, d'une juridiction occasionnelle, d'une juridiction d'arbitrage ou enfin d'une juridiction permanente $^{144}$.

\footnotetext{
${ }^{141}$ D'après les faits, un Chalutier britannique fut arraisonné par un navire danois qui se serait livré à la pêche dans une zone interdite au large des îles Féroé; le Chalutier aurait pris la fuite, ce à quoi le navire danois répondra par des coups de canons. Le 15 novembre 1961, un accord fut signé par lequel une commission d'enquête dans l'affaire a été prévue. Composée d'un officier de marine hollandais et des professeurs Charles de Vischer (Belge) et A. Gros (Français), elle avait la tâche d'établir les faits de l'incidence en essayant de répondre à la question de savoir si le Chalutier était effectivement dans la zone interdite. En réponse à la question, la Commission n'a pu établir aucune preuve confirmant ou infirmant l'entré du Chalutier dans la zone interdite. Son rapport, adopté à la majorité de ses membres, sera limité à la constatation des faits, extrait de BENABDALLAH (J.), "Le règlement pacifique des différends internationaux ", Mémoire de DESA, MOHAMED Bedhri (Dir.), Université Mohamed $1^{\text {er }}$ Oudja, 2007, p.24.

${ }^{142}$ Comme exemple de convention du genre, on a : les articles 3 à 14 de la première Convention de la Haye du 29 juillet 1899, les articles 9 à 35 de la première Convention de la Haye du 18 octobre 1907, l'article 90 du premier Protocole aux Conventions de Genève (de 1949) du 10 juin 1977, BENABDALLAH (J.), «Le règlement pacifique des différents internationaux ", op.cit., p.24.

${ }^{143}$ La conciliation est très proche des bons offices et de la médiation; d'où la nécessité de les différencier.

${ }^{144}$ Extrait de l'article de POYDENOT op.cit., p.21.
} 
L'arbitrage est un mode de règlement des différends interétatiques par un juge choisi par les parties prenantes en charge d'appliquer la règle de droit. C'est un processus juridictionnel de règlement des différends par lequel un tiers appelé arbitre, entend d'abord les parties et rend ensuite une décision (appelée sentence) pour trancher le différend qui les oppose. L'arbitrage se rapproche de la procédure judiciaire; mais comporte des caractéristiques qui lui sont propres. L'arbitre peut être choisi à la suite d'un arrangement préalable (prévision conventionnelle par exemple). Il arrive parfois que celui-ci soit choisi par la voie d'une convention ad hoc: on parle dans ce cas de compromis d'arbitrage. L'arbitrage se singularise en ceci que les parties prenantes s'engagent à se soumettre à la sentence arbitrale. Le siège et l'instance sont choisis par les parties. Au plan international, les sentences arbitrales historiques se sont manifestées dans les affaires : des phoques à fourrure de la mer de Behring ${ }^{145}$, Fonderie du Trail ${ }^{146}$, Lac Lanoux $x^{147}$, Barrage de Gut ${ }^{148}$, Arbitrage Opar ${ }^{149}$ et Rhin de fer ${ }^{150}$. Cette succession d'affaires témoigne de la volonté de la société internationale de militer plus pour les procédures amiables plutôt que judiciaires. N'empêche que la sentence produise presque tous les effets d'une décision judiciaire et fasse parfois l'objet d'appel ou de recours en révision.

Parmi les règlements de conflits par une organisation internationale, se trouvent les organes des Nations Unies ${ }^{151}$ et les juges internationaux.

$\mathrm{Au}$ plan international, les juges commis et connus de principe en matière de différends interétatiques sont ceux de la C.I.J. (Cour Internationale de Justice). En principe tout Etat membre des Nations Unies est de droit membre de la C.I. ${ }^{152}$. La Cour Internationale de Justice a une compétence à la fois consultative et contentieuse (article $36 \mathrm{du}$ statut). Elle rend des décisions appelées arrêts; lesquels sont obligatoires, insusceptibles de recours ${ }^{153}$ et revêtus de la mention "non bis idem ». Les arrêts de la C.I.J. ont autorité de la chose jugée et force exécutoire laquelle peut aller jusqu'aux voies de recours non pacifiques ${ }^{154}$. Notons néanmoins qu'en matière environnementale, la

\footnotetext{
${ }^{145}$ Sentence arbitrale, Affaire des Otaries à fourure des îles Prolof, (Royaume Uni/Etats-Unis), 15 août 1983.

${ }^{146}$ Sentence arbitrale, Etats-Unis /Canada, 11 mars 1941.

${ }^{147}$ Sentence arbitrale, France/Espagne, 16 novembre 1957.

${ }^{148}$ Sentence arbitrale, Etats-Unis /Canada, 15 janvier, 12 février et 27 septembre 1968.

${ }^{149}$ Sentence arbitrale, Affaire usine Mox, relative à l'accès à l'information (art.9, Convention OSPAR, 2 juillet 2003.

${ }^{150}$ Sentence arbitrale, Belgique/Pays Bas, 24 mai 2005.

${ }^{151}$ L'organe principal des Nations Unies en matière de résolution des conflits internationaux est l'ONU. Ce dernier assume essentiellement trois missions : une mission préventive qui consiste à prévenir les différends internationaux avant qu'ils ne surgissent; une mission curative qui consiste à régler ou amener à régler pacifiquement ceux qui peuvent surgir et enfin une mission de contrôle qui consiste à prendre des mesures de police collectives pour empêcher ou faire cesser le recours à la force. Cet organe vu son étanchéité, ne fera pas l'objet de développement dans le cadre de cette étude, voir pour les approfondissements la Charte des Nations Unies du 26 juin 1945.

${ }^{152}$ En dépit de la condition de déclaration de compétence obligatoire par chaque Etat membre, art.36, para.2 du statut de la C.I.J.

${ }^{153}$ Art.60 du statut cité supra. Il faut quand même reconnaître que le texte prête un peu à confusion car l'art. $61 \mathrm{du}$ même statut accepte "lorsque cela est possible » le recours en révision et le recours en interprétation.

${ }^{154}$ Les voies de recours non pacifiques qui ne feront pas l'objet d'analyses vu leurs répercussions parfois désastreuses (sur les ressources hydriques et l'environnent en général en cas de conflits armés), sont de la compétence de l'Assemblée Générale des Nation Unies (article 9 et suivant de la Charte des Nations Unies) et du conseil de sécurité (article 23 et suivant, para.5 de la Charte).
} 
création de la chambre chargée des affaires environnementales auprès de la C.I.J. n'est pas très ancienne. Aussi, la création récente d'un tribunal international de l'eau basé à Amsterdam (au Pays Bas) chargé des préoccupations relatives au droit à l'eau est tout aussi appréciable. Même si ses décisions n'ont pas encore force exécutoire, il faut tout au moins espérer, que le futur lui accorde plus de crédit. Déjà que ce tribunal semble être l'instigateur de la Déclaration d'Amsterdam de 1991 sur la protection des intérêts de toute personne dépendant des ressources en eau. Dénuée de valeur juridique contraignante, cette Déclaration ${ }^{155}$, il faut l'espérer, inspirera les politiques juridiques africaines et pourquoi pas mondiales. Bien plus, la nouvelle Cour Pénale Internationale pourrait avoir à connaître pourquoi pas des crimes de guerres et autres infractions à dimension environnementale. Davantage nombreuses et diversifiées, les juridictions internationales croissent progressivement sur la scène internationale.

En somme, "Les Etats du monde actuel disposent à l'occasion de leurs relations internationales de tous les moyens nécessaires pour régler pacifiquement tous les différends qui pourraient en résulter. Ces moyens sont obligatoires quand à leur résultat et facultatifs quand au choix de ceux qui répondent le mieux à la nature du litige. L'essentiel c'est de préserver la paix et la sécurité internationale, le moyen pour y arriver importe peu ${ }^{156}$.

\section{B. La responsabilité de l'Etat au niveau interne}

Il est en principe de la responsabilité de chaque Etat de veiller à ce que : l'eau destinée à la consommation humaine dans son territoire soit potable, accessible et abordable pour tous les citoyens; les services en charge des questions d'eau fonctionnent de façon ininterrompue; la situation des couches sociales défavorisées soit abordée avec grand intérêt; l'assainissement soit collectif et l'approvisionnement régulier dans les zones rurales et urbaines. La mise en œuvre du droit à l'eau potable relève de la responsabilité des Etats dans l'exercice de leur droit souverain à exploiter leurs ressources hydriques et ce, en conformité avec leurs politiques nationales environnementales, de développement durable ${ }^{157}$. La mise en œuvre du droit à l'eau potable ressortit de la compétence de chaque Etat qui se doit de l'intégrer dans sa législation nationale et de veiller à son respect. Les mesures prises peuvent être d'ordre juridique, institutionnel ou financier.

Pour mieux aborder cette notion de responsabilité étatique, il faut partir de ses fondements (1) pour ensuite examiner ces conséquences (2).

\section{Les fondements de la responsabilité étatique}

Les bases de la responsabilité de l'Etat en matière de droit à l'eau potable au plan interne sont essentiellement la Convention ${ }^{158}$ sur l'élimination de toutes formes de discrimination à l'égard des femmes, la Déclaration de l'Assemblée Générale des Nations Unies sur le Développement de 1986, la Convention relative aux droits de l'enfant de

\footnotetext{
${ }^{155}$ Surtout sa disposition : "tous les membres des générations présentes et futures ont fondamentalement droit à une certaine qualité de vie incluant la faculté de disposer d'une quantité suffisante d'eau de bonne qualité ".

${ }^{156}$ BENABDALLAH (J.), "Le règlement pacifique des différents internationaux », op.cit., conclusion générale.

${ }^{157}$ C'est un développement qui répond aux besoins des générations présentes sans compromettre la capacité des générations futures de répondre aux leurs. Appliqué en matière de droit à l'eau, il voudrait que la ressource eau soit utilisée de manière écologique et rationnelle.

${ }^{158}$ Signée en 1979 avec 185 ratifications en mai 2008.
} 
1989, l'Observation Générale $\mathrm{N}^{\circ} 15$ de 2002, ainsi que la récente Résolution des Nations Unies du 28 juillet 2010.

D'après la Convention sur l'élimination de toutes formes de discriminations à l'égard des femmes de 1979, "les Etats leur assurent de bénéficier des conditions de vie convenables, notamment en ce qui concerne le logement, l'assainissement, l'approvisionnement en électricité et en eau». Le mot assainissement s'est greffé à l'eau potable depuis 1979 et, les deux notions sont depuis lors soudées. Cette convention comme les autres textes qui l'ont suivi ne fixe cependant pas le régime juridique de cette responsabilité étatique. A l'heure actuelle, elle continue d'être une simple obligation fondée sur les moyens et n'entraîne dans la pratique aucun effet contraignant.

La Déclaration de l'Assemblée Générale des Nations Unies sur le Développement de 1986 réaffirme les obligations nées de ce droit en ces termes : "les Etats doivent prendre au plan national, toutes les mesures nécessaires pour la réalisation du droit au développement et assurer l'égalité de chance de tous dans l'accès aux ressources de base, à l'éducation, aux services, à l'alimentation, au logement, à l'emploi et à une répartition équitable du revenu. ".

La Convention relative aux droits de l'enfant de 1989 précise pour sa part que les États prennent les mesures nécessaires pour lutter contre les maladies en fournissant de l'eau potable aux populations ${ }^{159}$. Son importance réside dans son contenu : elle oblige l'Etat à fournir de l'eau potable à sa population. Cette obligation est une simple obligation de moyen.

L'Observation Générale $\mathrm{N}^{\circ} 15$ définit au préalable trois obligations spécifiques qui incombent à l'Etat dans la mise en œuvre du droit à l'eau potable avant d'envisager d'autres parts neuf obligations ${ }^{160}$ de l'Etat en faveur de la mise en œuvre du droit à l'eau potable. Au rang de ces obligations spécifiques de l'Etat en matière de droit à l'eau potable on a : l'obligation de respecter, de protéger et mettre en œuvre ${ }^{161}$. Pour ce qui est des neuf obligations de l'Etat dans la mise en œuvre du droit à l'eau potable, on peut les regrouper au niveau national, communautaire et individuel.

Au niveau national, elles consistent à : adopter et mettre en œuvre une stratégie et un plan d'action visant l'ensemble de la population et intégrant cette dernière [1] ; contrôler dans quelle mesure le droit à l'eau potable est réalisé ou pas [2] ; adopter des programmes d'approvisionnement en eau potable relativement peu coûteux et donner la priorité aux groupes vulnérables et marginalisés [3].

Au niveau communautaire, elles consistent à : garantir le droit d'accès à l'eau, aux installations et aux services sans discrimination [4]; assurer l'accès physique à des installations et services qui fournissent régulièrement une eau salubre en quantité suffisante, qui comporte un nombre suffisant de points d'eau pour éviter les attentes excessives et qui soient à distance raisonnable du foyer [5] ; assurer une répartition équitable de tous les équipements et services disponibles [6].

$\mathrm{Au}$ niveau individuel, elles consistent à: assurer l'accès à la quantité d'eau essentielle, suffisante et salubre pour les usages personnels et domestiques afin de

\footnotetext{
${ }^{159}$ Article 24, para. 2.

${ }^{160}$ Voir, M. Woodhouse, «Realising the right to water », 2004.

${ }^{161} \mathrm{Cf}$. Encadré 3 de la présente thèse.
} 
prévenir les maladies [7] ; veiller à la sécurité des personnes ayant accès à l'eau [8] ; prendre des mesures pour prévenir, traiter et combattre les maladies hydriques en assurant notamment l'accès à un assainissement adéquat [9]. Ainsi, tout manquement des Etats à ces neuf obligations constitue une violation du droit à l'eau potable régie par la même Observation Générale à l'article 44.

\section{Les conséquences de cette responsabilité}

En principe, le manquement à une obligation entraine l'engagement de la responsabilité $\mathrm{du}$ mis en cause. Ce principe est actuellement difficile à apprécier en matière de droit à l'eau car, ce dernier implique chez l'Etat une simple obligation progressive. Parce que le droit à l'eau est un droit créance, sa réalisation nécessite d'énormes moyens finan-ciers qui font parfois défaut à certains Etat. Toutefois, cette difficulté dans la mise en œuvre du droit à l'eau ne doit pas justifier les atteintes portées à ce droit. Ces derniers doivent être sanctionnés ${ }^{162}$. L'observation ${ }^{163}$ Générale $\mathrm{N}^{\circ} 15$ a essayé de lister un certains nombre de violations en précisant que les manquements à l'obligation de respecter découlent des entraves de l'Etat partie au droit à l'eau. Il s'agit de : l'interruption ou du refus arbitraires ou injustifiés d'accès au service ou aux installations; des hausses disproportionnées ou discriminatoires du prix de l'eau; de la pollution et de l'appauvrissement des ressources en eau affectant la santé des personnes.

Les manquements à l'obligation de protéger découlent du fait que l'Etat n'a pas pris toutes les mesures voulues pour protéger les personnes relevant de sa juridiction contre des atteintes au droit à l'eau imputables aux tiers. Il s'agit entre autres du manquement aux obligations de: promulguer ou d'appliquer des lois visant à prévenir la contamination et le captage injuste de l'eau; de réguler et de contrôler efficacement les fournisseurs de services; de protéger les systèmes de distribution d'eau potable des entraves et des dommages.

Les manquements à l'obligation de mettre en œuvre viennent du fait que l'Etat partie n'a pas pris toutes les mesures voulues pour garantir l'exercice du droit à l'eau potable. Il s'agit : du manquement à l'obligation d'adopter ou de mettre en œuvre une politique nationale visant à garantir à chacun l'exercice de ce droit; de l'engagement des dépenses insuffisantes ou d'une mauvaise affectation de fonds publics empêchant les particuliers ou groupes (notamment les groupes vulnérables ou marginalisés) d'exercer leur droit à l'eau; du manquement à l'obligation de contrôler l'exercice de ce droit à l'échelle nationale; du manquement à l'obligation d'adopter des mécanismes d'aides d'urgence ; du manquement à l'obligation d'assurer à chacun l'exercice de l'essentiel de ce droit; du manquement à l'obligation de l'Etat de tenir compte de ses obligations juridiques internationales concernant le droit à l'eau lors de la conclusion d'accords avec d'autres Etats ou avec des organisations internationales.

Il importe de préciser que, malgré la prévision textuelle de ces cas importants de violation du droit à l'eau, les sanctions sont à ce jour illusoires car, l'observation générale comme son nom l'indique est un simple guide dont se servent les Etats pour

\footnotetext{
${ }^{162}$ L'Afrique du Sud est très avancée sur la position confère arrêt Grootboom développé dans le cadre de cette thèse, note de bas de page 116 .

${ }^{163}$ Voir le contenu de l'article 44, Observation Générale $\mathrm{N}^{\circ} 15$.
} 
asseoir leur droit à l'eau. Son utilisation comme arme de sanction est une véritable utopie. N'étant ni un traité ni un pacte, sa valeur juridique n'est pas contraignante.

De ce qui précède, l'on constate que la définition du droit à l'eau potable, si elle a fait l'objet d'inaction pendant une longue période, a connue une avancée significative avec l'avènement de l'Observation Générale $\mathrm{N}^{\circ} 15$ de 2002. A compter de cette date, il n'est plus seulement question de déduire indirectement le droit à l'eau potable de l'interprétation du Pacte International relatif aux Droits Sociaux, Economiques et Culturels (PIDESC) de 1966. Le droit à l'eau potable est désormais appréhendé comme faisant partie de la catégorie des droits économiques, sociaux et culturels. Il implique que, chaque personne, quel que soit son pouvoir économique, dispose d'une quantité d'eau suffisante pour satisfaire ses besoins humains essentiels. Une journée mondiale (le 22 mars) est chaque année consacrée à la question. Plus qu'un droit fondamental, la tendance actuelle est de considérer la ressource comme un élément du patrimoine commun de l'humanité. La Résolution A/Res/64/292 adoptée le 28 juillet 2010 reste à l'heure actuelle la toute première du genre à reconnaître explicitement le droit à l'eau potable et l'assainissement comme un droit fondamental indispensable à la pleine jouissance de la vie et à la réalisation des autres droits de l'homme.

Toutefois, cette affirmation pleine de contenu se limite-t-elle à une simple déclaration ou alors connait-elle une application pratique? Cette interrogation fera l'objet de réponse dans les chapitres à venir. Tout ceci concourt à dire qu'il existe bel et bien un droit à l'eau potable au plan international. Ce droit ne sera effectif que si l'on réussit à désigner avec précision le garant de sa mise en œuvre et à clarifier certaines zones d'ombres qui l'entourent (comme l'illustre le tableau 2 et l'Encadré 4). La reconnaissance effective du droit à l'eau «implique l'obligation de prendre des mesures pour améliorer progressivement les situations existantes et de faire en sorte que les plus déshérités aient progressivement accès à l'eau potable [...]. Il ne suffit pas de faire des gestes charitables à l'égard des exclus, il faut en outre reconnaitre aux personnes en situation de précarité la possibilité de faire valoir des droits sur un bien essentiel à leur vie. A cette fin, les Etats devraient prendre des mesures législatives et réglementaires pour préciser ce que implique effectivement le droit à l'eau, faire en sorte qu'il puisse être invoqué devant les tribunaux, et clarifier les obligations des pouvoirs publics en vue de respecter, protéger et assurer ce droit véritablement fondamental. ${ }^{164}$.

Tableau $2^{165}$ : Les esquisses de réponses aux malentendus autour du droit à l'eau potable

\begin{tabular}{|l|l|}
\hline \multicolumn{2}{|l|}{ Peut-on parler d'un droit de l'homme à l'eau potable ? Ce droit est-il réalisable ? } \\
\hline Oui & $\begin{array}{l}\text { Le droit de l'homme à l'eau a toujours existé mais il a effectivement pris corps en } 2002 \text { avec } \\
\text { l'adoption par le Comité des droits économiques, sociaux et culturels de l'Observation }\end{array}$ \\
& $\begin{array}{l}\text { Générale } N^{\circ} 15, \text { et tout récemment en } 2010 \text { avec l'adoption par l'Assemblée Générale des } \\
\text { Nations Unies de la résolution A/Res/64/292 qui considère désormais explicitement le droit à } \\
\text { l'eau comme un droit humain fondamental. Compte tenu du caractère non contraignant de } \\
\text { ces textes, il faut noter que le droit à l'eau potable n'a pas encore vraiment acquis ces lettres de }\end{array}$ \\
\hline
\end{tabular}

\footnotetext{
${ }^{164}$ SMETS (H.), « Le droit à l'eau », op.cit., p.139.

${ }^{165}$ Ce tableau cherche autant que faire ce peu à mettre à la disposition du lecteur un état sommaire du droit à l'eau à l'heure actuelle afin de lever certaines équivoques autour de la notion. Certains de ses éléments sont conçus à la lumière de l'exploitation du document de AUBRIOT (J.), « Le droit à l'eau : émergence, définition, situation actuelle et position des acteurs ", et d'autres à partir des analyses personnelles.
} 


\begin{tabular}{|c|c|}
\hline & $\begin{array}{l}\text { noblesse. Parce que le droit à l'eau est aussi un droit économique, social et culturel, sa } \\
\text { réalisation demeure progressive. }\end{array}$ \\
\hline \multicolumn{2}{|c|}{ Ce droit est-il officiellement et explicitement reconnu? } \\
\hline Oui & $\begin{array}{l}\text { Le droit à l'eau est officiellement et explicitement }{ }^{166} \text { reconnu dans plusieurs textes de portée } \\
\text { internationale. Toutefois, c'est la Résolution }{ }^{167} \text { des Nations Unies A/Res/64/292 du } 28 \text { juillet } \\
2010 \text { qui donne un véritable sens et une définition claire à ce droit, notamment en le } \\
\text { reconnaissant comme un droit fondamental nécessaire à la jouissance de la vie et à la } \\
\text { réalisation des autres droits de l'homme. }\end{array}$ \\
\hline \multicolumn{2}{|c|}{ Le droit à l'eau remet-il en cause la souveraineté étatique? } \\
\hline Non & $\begin{array}{l}\text { Reconnaître le droit à l'eau ne signifie pas pour l'Etat une perte de sa souveraineté sur ses } \\
\text { ressources en eau. Il signifie pour l'Etat qu'il prenne des mesures pour faciliter la mise en } \\
\text { œuvre de ce droit dans son territoire. Le principe } 21 \text { de la Déclaration de Stockholm de } 1972 \\
\text { donne une réponse claire à cette question : "Les Etats ont le droit souverain d'exploiter leurs } \\
\text { propres ressources selon leur politique d'environnement et de développement ». Le droit à l'eau } \\
\text { signifie que sous réserve de ses engagements internationaux, chaque Etat puisse auto-riser ou } \\
\text { non des exportations d'eaux potables et consentir ou non à des transferts d'eau potables pour } \\
\text { l'approvisionnement des populations voisines. }\end{array}$ \\
\hline \multicolumn{2}{|c|}{ L'Etat a-t-il des obligations en ce qui concerne le droit à l'eau potable? } \\
\hline Oui & $\begin{array}{l}\text { Les Etats sont les premiers acteurs garant du droit à l'eau au plan interne. Ils assurent la mise } \\
\text { en œuvre de ce droit au niveau national. Ils ont à leur charge trois obligations principales : } \\
\text { l'obligation de respecter, de protéger et de mettre en œuvre. }\end{array}$ \\
\hline \multicolumn{2}{|c|}{ La communauté internationale a-t-elle un rôle à jouer dans ce processus? } \\
\hline Oui & $\begin{array}{l}\text { C'est à elle qu'incombe la charge de nouveaux accords internationaux pour la promotion du } \\
\left.\text { droit à l'eau (voir article } 35 \text { de l'Observation Générale } \mathrm{N}^{\circ} 15\right) \text {. }\end{array}$ \\
\hline \multicolumn{2}{|c|}{ Existe-t'il des mécanismes de contrôle du droit à l'eau potable au plan international? } \\
\hline Oui & $\begin{array}{l}\text { Malgré la difficulté dans la mise en œuvre du droit à l'eau tant au plan international qu'au } \\
\text { plan interne, il existe divers mécanismes de contrôle de ce droit au rang desquels on trouve : } \\
\text { les organes }{ }^{168} \text { de suivi des instruments relatifs au droits de l'homme des Nations Unies, les } \\
\text { procédures spéciales }{ }^{169} \text { et le mécanisme d'examen périodique universel crée par le conseil des } \\
\text { droits de l'homme et les mécanismes régionaux }{ }^{170} \text { de défense des droits de l'homme. }\end{array}$ \\
\hline \multicolumn{2}{|c|}{ Le droit à l'eau englobe t-il le droit à l'assainissement? } \\
\hline
\end{tabular}

\footnotetext{
${ }^{166}$ Voir note de bas de page 8.

${ }^{167}$ Voir note bas de page 6.

${ }^{168}$ Le principal organe conventionnel qui contrôle l'application des droits économiques, sociaux et culturels est le Comité des droits économiques, sociaux et culturels. Les organes conventionnels jouent essentiellement quatre fonctions : l'examen périodique des rapports produits par les Etats sur l'application des instruments, l'exposition du contenu des droits et obligations découlant des instruments dans le cadre des observations générales ou des recommandations générales, l'examen des plaintes présentées en forme de communications ou requêtes émanant des particuliers ou groupes de particuliers, enquête pour vérification des violations graves des droits de l'homme, Information recueillie dans le document fiche d'information des droits de l'homme $\mathrm{N}^{\circ} 33$, "Questions fréquemment posées concernant les droits économiques, sociaux et culturels ", UN Genève, mars 2009, p.47.

${ }^{169}$ Les procédures spéciales du conseil des droits de l'homme font parties des mécanismes des Nations Unies s'occupant des droits de l'homme qui contrôlent le respect par les Etats parties de leurs obligations en matière de droit de l'homme. Le conseil des droits de l'homme nomme des experts indépendants chargés d'examiner la situation dans les pays. Ses experts sont appelés rapporteurs spéciaux, experts indépendants, représentants spéciaux, experts indépendants ou représentants spéciaux.

${ }^{170}$ Cette action est menée au plan africain par la cour et la Commission africaine des droits de l'homme et des peuples, au plan européen par le Comité européen des droits sociaux et en Amérique par la Cour et la Commission interaméricaine des droits de l'homme; propos recueillie dans le document fiche d'information des droits de l'homme $\mathrm{N}^{\circ} 33$ op.cit., p.51.
} 


\begin{tabular}{|c|c|}
\hline Absolument & $\begin{array}{l}\text { Le droit à l'assainissement fait partie intégrante du droit à l'eau spécifié dans l'Observation } \\
\text { Générale } \mathrm{N}^{\circ} 15 \text { en ces termes : "garantir l'accès à un assainissement adéquat est non seulement } \\
\text { fondamental pour le respect de la dignité humaine et la vie privée, mais constitue également un } \\
\text { des principaux moyens de protéger la qualité de l'approvisionnement et des ressources en eau } \\
\text { potable ». conformément au droit à la santé (voir Observation Générale } \mathrm{N}^{\circ} 4,1991 \text { ) et à un } \\
\text { logement suffisant (voir Observation Générale } \mathrm{N}^{\circ} 14,2000 \text { ), les Etats parties ont l'obligation } \\
\text { de fournir progressivement des services d'assainissement sûrs, en particulier dans les zones } \\
\text { rurales et les zones urbaines déshéritées, en tenant compte des besoins des femmes et des } \\
\text { enfants. }\end{array}$ \\
\hline \multicolumn{2}{|c|}{ Le droit à l'eau signifie t-il gratuité de l'eau? } \\
\hline Non & $\begin{array}{l}\text { Le droit à l'eau ne signifie pas gratuité de l'eau mais il consiste en un approvisionnement en } \\
\text { eau salubre, en quantité suffisante, accessible et à un coût abordable. L'eau a donc une valeur } \\
\text { économique, sociale et culturelle. Toutefois, le prix des services doit être établi sur la base du } \\
\text { principe d'équité pour ne pas marginaliser certaines couches sociales vulnérables. Moins } \\
\text { qu'un bien économique, ce n'est pas la ressource en soit qui a un coût, mais les services } \\
\text { permettant sa desserte. }\end{array}$ \\
\hline \multicolumn{2}{|c|}{ Le droit à l'eau concerne t-il uniquement les usages personnels et domestiques? } \\
\hline Oui & $\begin{array}{l}\text { Le droit à l'eau renvoie uniquement à l'eau nécessaire pour les besoins essentiels de l'homme; } \\
\text { il ne concerne pas les autres usages (tels qu'industriels ou agricoles) d'où la nécessité de lui } \\
\text { accorder une attention particulière. }\end{array}$ \\
\hline \multicolumn{2}{|c|}{ Les populations marginalisées sont-elles prioritaires dans l'accès? } \\
\hline Oui & $\begin{array}{l}\text { L’Observation Générale } \mathrm{N}^{\circ} 15 \text { stipule clairement notamment en ses articles } 15 \text { et } 16 \text { que la non } \\
\text { discrimination et l'égalité sont à garantir en terme d'accès à l'eau et qu'il est nécessaire de } \\
\text { porter une attention spéciale aux groupes sociales défavorisés. }\end{array}$ \\
\hline \multicolumn{2}{|c|}{ Le droit à l'eau signifie- t-il raccordement individuel pour chaque personne? } \\
\hline Non & $\begin{array}{l}\text { Le droit à l'eau ne signifie pas forcement que chaque ménage ou chaque habitation soit } \\
\text { raccordé individuellement. Il faut faire la différence selon que l'on se situe en milieu urbain ou } \\
\text { rural. En milieu urbain, le droit à l'eau concerne l'approvisionnement et l'assainissement des } \\
\text { eaux usées et donc le droit pour chaque personne d'être raccordé au réseau existant situé dans } \\
\text { son voisinage }{ }^{171} \text {. En milieu rural, il signifie que chaque personne dispose d'eau potable à } \\
\text { proximité de son domicile, ce qui signifie que chaque logement rural ne doit pas forcement } \\
\text { être raccordé à un réseau de distribution pour que l'on parle du droit à l'eau. }\end{array}$ \\
\hline \multicolumn{2}{|c|}{ Le droit à l'eau signifie t-il droit individuel et partant justiciabilité ? } \\
\hline Absolument & $\begin{array}{l}\text { Reconnaitre le droit à l'eau signifie rendre ce droit justiciable devant les tribunaux au même } \\
\text { titre que les autres droits de l'home tels que le droit à la vie. Reconnaître le droit à l'eau, c'est } \\
\text { appliquer les principes d'information et de participation des populations qui seront plus à } \\
\text { même de revendiquer leurs droits devant les tribunaux de l'ordre judiciaire. }\end{array}$ \\
\hline \multicolumn{2}{|c|}{$\begin{array}{l}\text { Peut-on renforcer et maintenir un droit subjectif à l'eau potable par exemple dans un Etat où l'eau } \\
\text { potable est rare? }\end{array}$} \\
\hline Oui & $\begin{array}{l}\text { Renforcer et maintenir le droit subjectif à l'eau } 8 \text { dans un Etat où l'eau potable est rare peut } \\
\text { constituer un début de solution au problème d'eau potable d'autant plus que la } \\
\text { reconnaissance et la mise en œuvre de ce droit peut en quelque sorte déjà constituer une } \\
\text { incitation juridique pour l'Etat garant. Dans cette logique cet Etat en vue de garantir l'accès de } \\
\text { sa population à la ressource peut aller jusqu'à exporter l'eau potable en attendant de trouver } \\
\text { les moyens de s'en en procurer. }\end{array}$ \\
\hline \multicolumn{2}{|c|}{ Le droit à l'eau est-il mieux garanti dans un texte constitutionnel ? } \\
\hline Oui & $\begin{array}{l}\text { La constitution peut mieux protéger et garantir le droit à l'eau. Etant le texte et la loi } \\
\text { fondamentale d'un pays, les droits qui y sont formulés sont considérés sans équivoque comme } \\
\text { des droits fondamentaux et partant mieux garantis. Conscient de cela, beaucoup de pays du }\end{array}$ \\
\hline
\end{tabular}

${ }^{171}$ SMETS (H.), Le droit à l'eau, op.cit., p.4. 


\begin{tabular}{|l|l|}
\hline & $\begin{array}{l}\text { monde et africains en particulier ont déjà à ce jour inséré le droit à l'eau dans le dispositif de } \\
\text { leur constitution afin de conférer à ce droit le caractère fondamental. Il faut néanmoins } \\
\text { relever que le Cameroun n'a pas encore explicitement inscrit ce droit dans sa constitution. On } \\
\text { continue néanmoins de le déduire des autres droits fondamentaux comme le droit à la vie qui } \\
\text { y est proclamé. }\end{array}$ \\
\hline Existe-t'il des normes de qualité, de quantité et de proximité ? \\
\hline Oui & $\begin{array}{l}\text { L'OMS a fixé les normes } \\
\text { ont aussi la possibilité d'adapter ses normes aux contextes locaux. Les normes SPHERES } \\
\text { constituent aussi une référence utilisée. }\end{array}$ \\
\hline
\end{tabular}

Encadré 4. Principes indispensables à la définition du droit à l'eau comme droit de l'homme

Pour que le droit à l'eau soit un véritable droit de l'homme, il doit comporter les principes ci-après :

Universalité et inaliénabilité : comme les autres droits de l'homme, le droit à l'eau doit être universel et inaliénable. Comme précisé à l'article 1 de la Déclaration universelle des droits de l'homme: " tous les êtres humains naissent libres et égaux, en dignité et en droit ».

Indivisibilité : les droits de l'homme sont indivisibles, le droit à l'eau doit l'être aussi. Ils font partie intégrante de la dignité humaine.

Interdépendance et corrélation : le droit à l'eau forme avec les autres droits de l'homme un tout. Pour qu'il soit réalisé, il faut que ceux-ci le soient aussi ( $C f$. inter connexité en droit à l'eau et les autres droits économiques, sociaux et culturels examinée supra).

Egalité et non discrimination : parce qu'ils naissent libres et égaux, tous les individus doivent pouvoir jouir librement de leurs droits sans aucune discrimination comme l'exige la plupart des textes de droit de l'homme.

Participation : chaque individu a le droit de participer aux activités ayant trait à la définition, la reconnaissance, la promotion ou la mise en œuvre de ses droits.

Obligation de rendre compte: les Etats et autres détenteurs de devoirs doivent répondre devant les instances agrées de la façon dont ils appliquent les droits de l'homme.

C'est de cette façon que l'on parviendra à reconnaître et à mettre en œuvre le droit à l'eau potable à tous les plans.

${ }^{172}$ Voir les détails à la note de bas de page 78. 
CHAPITRE II

LA DIFFICILE CONSECRATION DU DROIT A L'EAU POTABLE 
Le droit à l'eau potable et plus particulièrement sa reconnaissance est le fruit d'une longue spéculation. La reconnaissance est un acte juridique qui matérialise l'existence d'une entité ou d'une notion. C'est aussi un acte unilatéral et discrétionnaire par lequel un Etat prend position sur une situation ou un fait qui s'est produit en dehors de lui et dont il est disposé à tenir compte ${ }^{173}$.

Si le droit à l'eau potable en tant que droit humain essentiel n'a explicitement été mentionné dans aucun texte universel de l'environnement ou de droits fondamentaux (tel que la Déclaration universelle des droits de l'homme de 1948, et le Pacte international relatif aux droits économiques, sociaux et culturels et le Pacte international relatif aux droits civils et politiques du 16 décembre 1966), il s'est développé au plan international à travers d'importantes assises tenues sur l'eau (voir introduction de la première partie) ; lesquelles ont peu à peu donné naissance à certains textes juridiques œuvrant aujourd'hui pour la reconnaissance (section I) et la vulgarisation (section II) de ce droit.

\section{SECTION I : De la lente reconnaissance ...}

Nulle part dans les textes juridiques contraignants, les Etats n'ont cru bon d'introduire formellement le droit à l'eau potable pourtant débattu lors de plusieurs assises internationales (paragraphe I). Peut-être, comme l'affirmait l'ancien Vice Président de l'environnement de la Banque mondiale: "ce droit est tellement évident que même les rédacteurs de la Déclaration universelle des droits de l'homme n'ont pas cru bon de l'inscrire $»^{174}$. La reconnaissance du droit à l'eau potable a été plus rapide en Afrique qu'en Europe (paragraphe II).

\section{Paragraphe I : Le droit à l'eau au plan international}

L'eau insalubre est la première cause de mortalité dans le monde. Elle tue chaque année environ 8 millions d'êtres humains parmi lesquels 1,1 million sont des enfants. De nos jours, 1,2 milliards d'hommes, de femmes et d'enfants n'ont toujours pas toujours accès à l'eau potable. 2,6 milliards n'ont pas accès aux conditions élémentaires d'hygiène. Ce qui fait que 22.000 personnes meurent chaque jour des suites d'une maladie hydrique (choléra, typhoïde, diarrhée, etc.) soit 15 personnes par minute ${ }^{175}$. Fort de ce constat, un droit à l'eau potable émerge peu à peu au niveau international universel $(\mathrm{A})$ et régional (B).

\footnotetext{
${ }^{173}$ Définition recueillie dans le lexique des termes juridiques, p.440.

${ }^{174}$ Ismaël Serageldin, propos tenu lors d'une réunion avec les ONG au cours du $2^{\mathrm{e}}$ Forum mondial de l'eau, mars 2000, Extrait de l'article de PAQUEROT (S.), « Les droits d'accès à l'eau : aspects politiques et juridiques au plan international », 22 mai 2002, Créteil, p.3.

${ }^{175}$ Voir www.solidarités.org, Rapport sur l'eau insalubre, première cause de mortalité dans le monde, consulté le 03 mai 2008.
} 
A. Le droit à l'eau potable au plan international universel

Il importe de préciser de prime abord que, certains textes importants du droit international de l'environnement (mentionnés en Encadré 5) ne feront pas l'objet d'analyse approfondie dans les prochains développements ; car ils n'ont à proprement parler pas considérablement influencé le développement du droit à l'eau potable comme d'autres textes du droit de l'homme examinés.

Encadré 5. Les sources du droit à l'eau potable au niveau international universel

Les sources implicites :

la Déclaration universelle des droits de l'homme de 1948 (article 25);

le Pacte International relatif aux droits Economiques, sociaux et Culturels de 1966 (article 11al.1 et 12);

le Pacte International relatif aux Droits Civils et Politiques de 1966 (article 6 ${ }^{176}$ ) ;

la Déclaration de Stockholm sur l'environnement de 1972 ; principe 1 et 2 ;

la Déclaration universelle pour l'élimination définitive de la faim et de la malnutrition de 1974 (article $1^{177}$ );

la Déclaration de Rio sur l'environnement et le développement de 1992 ; principe 178 . la Convention ${ }^{179}$ sur la lutte contre la désertification de 1994 ; article 2.

le Protocole de Kyoto de 1997 relatif à la Convention-cadre des Nations Unies sur les changements climatiques de 1992 ; $\operatorname{articles}^{180} 2$ et 3.

Les sources explicites :

la Convention de Genève relative au traitement des prisonniers de guerre de 1949 articles $^{181} 20,26,29,46$;

la Convention de Genève relative à la protection des personnes civiles en tant de guerre de 1949, articles ${ }^{182} 85,89$ et 127.

la Recommandation ${ }^{183}$ de l'organisation internationale du travail sur le logement des travailleurs de 1961, (para. 7(b));

les deux Protocoles additionnels ${ }^{184}$ let 2 aux Conventions de Genève (1977);

la Convention sur l'élimination de toutes sortes de discriminations à l'égard des femmes de 1979, article 14 ;

la Convention sur le droit de l'enfant de 1989, article 24(al.2);

l'Agenda 21 issu de la conférence de Rio de 1992 sur l'environnement et le développement; chapitre 18 (para. 18.47);

la Déclaration de Dublin sur l'eau dans un objectif de développement de 1992 (voir ses 4 principes);

la Déclaration d'Amsterdam de 1992, article $1^{185}$;

l'Observation Générale $N^{\circ} 15$ du 26 novembre 2002 (article 2);

la Résolution A/Res/64/292 du 28 juillet 2010 (disposition 1).

\footnotetext{
176 "Le droit à la vie est inhérent à la personne humaine. Ce droit doit être protégé par la loi. Nul ne doit être arbitrairement privé de la vie». Par déduction à cet article, l'eau potable et la vie vont de pair. Priver une personne d'avoir accès à l'eau potable, c'est en principe le priver de vie.

177 "Chaque homme, femme et enfant a le droit inaliénable d'être libéré de la faim et de la malnutrition afin de se développer pleinement [...]».
} 
Même s'il n'y apparaît pas explicitement, le droit à l'eau potable semble avoir guidé les rédacteurs de la Déclaration universelle des droits de l'homme de 1948. L'article 25 y afférent nous le justifie : "toute personne a droit à un niveau de vie suffisant pour assurer sa santé et son bien-être et ceux de sa famille notamment l'alimentation, l'habillement, le logement, les soins médicaux ainsi que pour les services sociaux nécessaires ".

Le Pacte ${ }^{186}$ international relatif aux droits économiques, sociaux et culturels de1966 vient renforcer cette Déclaration notamment en ses articles 11 al.1 et 12. Le droit à l'eau ainsi que son rapport avec les autres droits économiques, sociaux et culturels est indirectement déduit de ces articles.

En 1977, lors de la conférence Mar Del Plata, il a été solennellement affirmé que «tous les peuples quels que soient leurs stade de développement et leur situation économique et sociale, ont le droit d'avoir accès à une eau potable dont la quantité et la qualité soient égales à leurs besoins essentiels».

Le droit à l'eau est également reconnu en droit humanitaire dans les Protocole I et II de 1977 (à la Déclaration de Genève de 1949). L'article 54 du Protocole I interdit d'attaquer, de détruire, d'enlever des biens indispensables à la survie de la population

\footnotetext{
${ }^{178}$ Les êtres humains sont au centre des préoccupations relatives au développement durable. Ils ont droit à une vie saine et productive, en harmonie avec la nature.

${ }^{179}$ Cette Convention a pour but de lutter contre la désertification et d'atténuer les effets de la sécheresse dans les pays gravement touchés par la sécheresse et /ou la désertification en particulier en Afrique grâce à des mesures efficaces à tous les niveaux [...] dans le cadre d'une approche intégrée compatible avec le programme d'Action 21 en vue de contribuer à l'instauration d'un développement durable dans les zones touchées; article 2. ${ }^{180}$ Qui dénonce l'émission dans la nature des gaz à effet de serre. Allant dans ce sens, PARIZEL (D.) dans son article: "Vingt litres d'eau potable par jour: un droit humain fondamental!" affirme que: "décidément, l'humanité n'apprend pas vite! Si ses trépidantes activités relâchent toujours plus de gaz à effet de serre dans l'atmosphère, elle continue aussi à polluer, sans relâche et de plus en plus massivement, les eaux de surface. Si l'industrie, et l'activité économique en général, portent évidemment une lourde responsabilité dans ce triste état de faits, l'agriculture intensive doit également être montrée du doigt: l'épandage massif des pesticides et des nitrates provenant des engrais et des lisiers pose plus que jamais, problème ».

${ }^{181}$ "[...] La puissance détentrice fournira aux prisonniers de guerre évacués de l'eau potable et de la nourriture en suffisance ainsi que les vêtements et les soins médicaux nécessaires [...]" article 20; " [... ] De l'eau potable en suffisance sera fournie au prisonniers de guerre [...]" article 26; "[...] La puissance détentrice sera tenue de prendre toutes les mesures d'hygiène nécessaires pour assurer la propreté et la salubrité des camps et pour prévenir les épidémies [...]" article 29; "[.. ] La puissance détentrice fournira aux prisonniers de guerre, pendant le transfert, de l'eau potable et de la nourriture en suffisance pour les maintenir en bonne santé [...] " article 46.

182 "[...] il leur sera fourni une quantité d'eau et de savon suffisante pour leurs soins quotidiens de propreté corporelle et le blanchissage de leur linge; les installations et les facilités nécessaires leur seront accordées à cet effet. Ils disposeront en outre d'installation de douche ou bains [... ]" article 85; "[... ] De l'eau potable en suffisance leur sera fourni [...]" article 89; "[...] La puissance détentrice fournira aux internés, pendant le transfert, de l'eau potable et de la nourriture en quantité, qualité et variété suffisante pour les maintenir en bonne santé, ainsi que les vêtements, les abris convenables et les soins médicaux nécessaires [ ... ] » article 127.

${ }^{183}$ "Les normes d'habitation prévues au paragraphe 19 des principes généraux devraient visées l'adduction d'eau salubre dans les logements des travailleurs en quantité suffisamment grande pour couvrir les besoins personnels et tous les besoins ménagers (b), l'évacuation adéquate des eaux usées et des ordures ménagères (c) [... ] ", point 7.

${ }^{184}$ Protocole additionnel 1 sur les conflits internationaux (article 54 et 55) et protocole additionnel 2 sur les conflits non internationaux (article 5 et 14). Pour les détails, voir les articles 20, 26, 29 et 46 de la Convention de Genève III et les articles 85, 89 et 127 de la Convention de Genève IV.

185 «Tous les membres des générations présentes et futures ont le droit fondamental à des moyens d'existence durables, y compris la disponibilité d'eau en quantité et qualité suffisantes ".

${ }^{186}$ Détaillé en début de chapitre I de la première partie.
} 
civile, tels que les installations et réserves d'eaux potables. Ces principes influencent considérablement le droit international coutumier. La limite du droit ici évoqué est qu'il concerne uniquement la période de guerre; "pourtant, ce qui est protégé en temps de guerre devrait aussi l'être en temps de paix $»^{187}$.

Le droit à l'eau est explicitement contenu dans la Convention sur l'élimination de toutes formes de discriminations à l'égard des femmes (signée en 1979 et ratifiée par 185 Etats) qui stipule en son article $14(2)(\mathrm{h})$ que : "Les Etats parties prennent toutes les mesures nécessaires pour éliminer la discrimination à l'égard des femmes [...] Ils leur assurent [...] de bénéficier de conditions de vie convenables, notamment en ce qui concerne le logement, l'assainissement, l'approvisionnement en électricité et en eau, les transports et les communications ». Cette Convention montre comment le droit à l'eau et le droit à l'assainissement sont intimement liés.

La Convention relative aux droits de l'enfant (signée en 1989 avec 193 ratifications) prescrit pour sa part que : "Les Etats prennent les mesures appropriées pour lutter contre la maladie [...] grâce à la fourniture [...] d'eau potable» (article 24 (2) (c). Toutefois, dans ces deux dernières conventions; si le droit à l'eau est conventionnellement reconnu en ce qui concerne les femmes et les enfants, on ne peut déduire la réalité juridique du caractère universel des droits humains. Puisque d'une part, s'agissant de la Convention sur l'élimination de toutes formes de discrimination à l'égard des femmes telles que libellée, il s'agit d'une obligation de non discrimination. Or, celle-ci ne s'applique pas exclusivement aux droits fondamentaux. D'autre part, en ce qui concerne les enfants, la protection qui leur est accordée est en partie spécifique à leur état et ne peut donc être d'emblée considérée comme une représentation exacte des droits humains essentiels universels ${ }^{188}$. Les conventions de Genève de 1949 n'en reste pas à la marge. Elle protège spécialement le droit à l'eau en tant de guerre. Que devient ce droit en temps de paix?

La Convention ${ }^{199}$ de Rio du 5 juin 1992 sur les changements climatiques et le Protocole de Kyoto du 11 décembre 1997 contribuent aussi au développement du droit à l'eau potable au plan international. Toutefois, il faut relever pour regretter l'opposition des États-Unis (grand pollueur) à la ratification de cet important instrument conventionnel.

La Déclaration de Dublin (malgré son caractère déclaratif) de 1992, constitue la première du genre à consacrer l'accès à l'eau potable «comme un droit fondamental $»^{190}$. Elle a contribué de façon non négligeable à l'éclosion du droit à l'eau potable au niveau mondial. Elle reconnaît que le droit à l'eau est un droit fondamental ${ }^{191}$. Elle comprend

\footnotetext{
${ }^{187}$ PAQUEROT (S.), «Les droits d'accès à l'eau : aspects politiques et juridiques au plan international », op.cit., p.6.

${ }^{188}$ Idem., pp.5-6.

${ }^{189}$ Les changements climatiques influencent considérablement l'accès des populations à l'eau potable. Appelés encore "mécanismes physiques de l'effet de serre", les changements climatiques émanent du réchauffement considérable de la planète. Chaque année, les effusions de gaz sont de 7,11 milliards de tonnes; 2 milliards sont absorbés par les surfaces marines, 1,8 milliards de tonnes par les surfaces terrestres, les 3,3 milliards de tonnes non recyclés restant modifient considérablement les climats (Extrait de LAVIEILLE (J.M.) op.cit.).

${ }^{190}$ SMETHS (H.), «Le droit à l'eau dans le contexte méditerranéen », op.cit., p.24.

${ }^{191}$ D'après elle : "il est primordial de reconnaître le droit fondamental de l'homme à une eau salubre et une hygiène adéquate pour un prix abordable".
} 
quatre principes au contenu significatif : l'eau douce, ressource fragile et non renouvelable est indispensable à la vie, au développement et à l'environnement (principe 1) ; la gestion et la mise en valeur des ressources en eau doivent associer les usagers, les planificateurs et les décideurs à tous les échelons (principe 2). Les femmes jouent un rôle essentiel dans l'approvisionnement, la gestion et la préservation de l'eau; l'eau utilisée à des multiples fins a une valeur économique et devrait donc être reconnue comme un bien économique (principe 4). Cette Déclaration est la première du genre à faire de l'accès à l'eau potable un droit fondamental et à donner la priorité au "prix abordable $»^{192}$. Elle affirme qu'il est primordial de reconnaitre le droit fondamental de l'homme à une eau salubre et une hygiène adéquate pour un prix abordable ${ }^{193}$.

En 1992, la Conférence des Nations Unies pour l'environnement et le développement donne naissance à la Déclaration de Rio de Janeiro d'après laquelle « Les êtres humains [...] ont droit à une vie saine et productive en harmonie avec la nature ». Le programme d'Agenda 21 issu de cette conférence, il faut le reconnaître, n'a juridiquement pas de force contraignante mais comporte des éléments significatifs ${ }^{194}$ dans la mise en œuvre du droit à l'eau potable. Son chapitre 18 est consacré à l'eau douce. Ce chapitre interpelle la communauté entière à la gestion globale de l'eau douce et à l'intégration des plans d'action et programmes sectoriels relatifs à l'eau dans les politiques et stratégies nationales.

L'Assemblée Générale des Nations Unies a reconnu le droit à l'eau potable comme un droit fondamental dans sa Résolution A/RES/ J41/175, objet de l'Observation Générale $\mathrm{N}^{\circ} 15$ sur le «droit à l'eau» adopté en 2002. Le sommet mondial de Johannesburg sur le développement durable l'a entériné au cours de la même année.

La Résolution A/Res/64/292 du 28 juillet 2010 a récemment marqué un point significatif dans la définition du droit à l'eau comme droit humain fondamental nécessaire à la jouissance de la vie et à la réalisation des autres droits de l'homme.

A côté de ces quelques conventions qui n'ont pas suffi à développer le droit à l'eau au plan interne des Etats (du fait de leur faible portée et des difficultés dans leurs mises en œuvre), subsistent de nombreuses autres Déclarations ${ }^{195}$ non juridiquement contraignantes mais pouvant guider les initiatives étatiques.

In fine, les accords internationaux sont guidés par l'idée de consentement et ne produisent pas d'effet à l'égard des tiers. Ce qui rend difficile la mise en œuvre de ces

\footnotetext{
${ }^{192}$ Prix qui tient compte des situations individuelles (riches, pauvres, personnes âgées, enfants).

193 Propos extrait du Rapport de la Conférence internationale sur l'eau et l'environnement à l'origine de la Déclaration de Dublin de 1992.

194 "Le principe de base, accepté d'un commun accord, est que tous les peuples, quels que soient leur stade de développement et leur situation économique et sociale, ont le droit d'avoir accès à une eau potable dont la quantité et la qualité soient égales à leurs besoins essentiels », para. 18.47.

${ }^{195}$ La Déclaration sur le développement (adoptée par l'Assemblée générale des Nations Unies en 1986) qui stipule que : "Les Etats doivent prendre sur le plan national, toutes les mesures pour la réalisation du droit au développement et ils assurent notamment l'égalité des chances de tous dans l'accès aux ressources de base, à l'éducation, aux services de santé, à l'alimentation, au logement, à l'emploi et à une répartition équitable du revenu »., article 8.1., La Déclaration de la conférence Habitat II tenue à Istanbul en 1996 dispose pour sa part que : "Nous, chefs d'Etats ou de gouvernement, souscrivons aux objectifs universels qui consistent à garantir à tous un logement convenable [...] Nous devons aussi promouvoir des cadres de vie sains, grâce en particulier à l'approvisionnement en eau salubre en quantité suffisante, et à une gestion efficace des déchets. ", para. 11.
} 
conventions au plan interne des Etats qui ont clairement manifesté leur consentement à ne pas être pas liés. Le même problème survient au niveau des conventions régionales.

B. Le droit à l'eau potable au plan international régional

Encadré 6. Le droit à l'eau potable dans les conventions internationales régionales

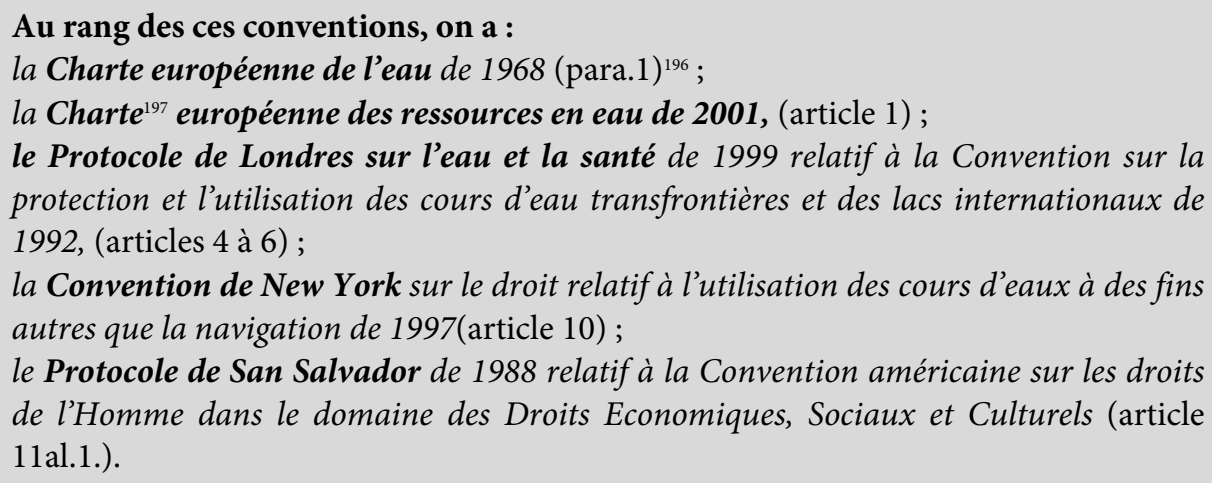

La consécration du droit à l'eau au plan régional a été plus rapide en Afrique qu'en Europe. Toutefois, le texte de référence dans le domaine est le protocole ${ }^{198}$ de Londres de 1999 sur l'eau et la santé199 à la Convention sur la protection et l'utilisation transfrontières des cours d'eau et lacs internationaux signée à Helsinki le 17 mars 1992. Le préambule à cette Convention exige "l'eau en quantité et en qualité suffisantes pour répondre aux besoins fondamentaux de l'homme et pour améliorer la santé ainsi que le développement durable». L'article 4 alinéa 2 est davantage plus intéressant. Il fait obligation aux Parties à la Convention de prendre les mesures nécessaires à l'approvisionnement adéquat en eau potable, exempte de micro-organismes, de parasites ou de substances à danger potentiel pour l'homme. L'article 5 poursuit: " les Parties sont guidées en particulier par les principes et orientations ci-après: un accès équitable à l'eau adéquat $d u$ point de vue aussi bien quantitatif que qualitatif [...] notamment aux personnes défavorisées ou socialement exclues». Cet article est particulièrement important, car il fait explicitement référence aux personnes défavorisées, rarement abordées en droit international ${ }^{200}$. L'article 6.1, ajoute que : «les Parties poursuivent les buts suivants : a) l'accès de tous à l'eau, b) l'assainissement pour tous... . Cet article a le mérite de considérer l'accès à l'eau potable et l'assainissement comme un droit pour tous.

\footnotetext{
196 "Il n' ya pas de vie sans eau, c'est un bien précieux, indispensable à toutes les activités humaines».

197 "Les ressources en eau douce doivent être utilisées conformément aux objectifs du développement durable, en tenant compte des générations présentes et futures ", article 1.

198 Il faut préciser que ce protocole étend son champ d'action aux eaux souterraines, aux estuaires, et eaux côtières utilisées à des fins récréatives ou pour l'aquaculture (art.3).

${ }^{199}$ Il n'aborde pas la question de droit à l'eau en tant que droit individuel mais, crée une simple obligation pour l'Etat.

${ }^{200}$ SMETS (H.), « L'accès à l'eau potable et le droit international » op.cit., p.6.
} 
Toutefois, il ne faut pas se leurrer, la gestion des eaux douces transfrontières ne sera effective que du moment où les pays accepteront de limiter leur souveraineté sur les ressources en eau. Parvenus à ce consensus, c'est alors qu'ils pourront et à juste titre, envisager la création d'une commission de gestion des bassins et partant d'un forum des commissions internationales garant du droit à l'eau potable. La Convention pour une utilisation transfrontière des cours d'eau et des lacs internationaux ${ }^{201}$, malgré son avancée, regorge des insuffisances qui peuvent être contournées par : la gestion avec une planification judicieuse afin d'équilibrer l'offre et la demande, la nécessité d'établir un réseau de métrologie précise et de promouvoir l'échange des données entre les Etats riverains, le renforcement des capacités des gouvernements afin de les aider à coopérer avec les partenaires internationaux, le secteur privé et les gouvernements locaux, la nécessité de fournir une eau à tous, plus particulièrement aux couches sociales défavorisées, la nécessité de mobiliser des fonds nécessaires à la mise en œuvre de ces principes au plan national.

La Convention des Nations Unies sur le droit relatif aux utilisations des cours d'eau internationaux à des fins autres que la navigation de 1997 considère qu'aucune utilisation d'un cours d'eau international n'a en principe priorité sur d'autres utilisations. Elle recommande qu'en cas de conflit d'usage, une attention particulière soit accordée à la «satisfaction des besoins essentiels» (article 10). Cette Convention comporte quelques lacunes : d'abord, l'article 3 a une portée relative (elle laisse aux Etats la liberté quant aux modalités d'application et d'adaptation de ses normes). Ensuite, elle se limite à donner des directives et des indications sans créer de vraies obligations. Ceci fait naître deux doutes : le premier est relatif à l'aptitude de la Convention à atteindre son objectif formel qui est celui de permettre une résolution pacifique des conflits en la matière, et le second à son aptitude à répondre aux problèmes de la redistribution ${ }^{202}$. Même si cette Convention n'est pas entrée en vigueur du fait de ces lacunes, elle a cependant inspiré plusieurs Etats dans la rédaction de leurs directives et lois.

En Amérique, le Protocole ${ }^{203}$ additionnel à la Convention américaine sur les droits de l'homme dans le domaine des droits économiques sociaux et culturels précise en son article 11.1 que : "Chacun a le droit de vivre dans un environnement sain et d'avoir accès aux services publics de base ». Ce principe pourrait bien inspirer les promoteurs du droit à l'eau potable au plan africain.

\section{Paragraphe II : Le droit à l'eau potable au plan africain}

Au niveau de l'Afrique en général (A) et de l'Afrique centrale (B) en particulier, la reconnaissance théorique du droit à l'eau est une entreprise bien avancée mais inachevée dans la pratique.

\footnotetext{
${ }^{201}$ Une ressource en eau est considérée comme internationale du fait de sa situation géographique : si elle traverse au moins deux pays ou si elle n'est pas intégralement soumise à une intégrité nationale.

${ }^{202}$ Les Notes d'analyses du CIHEAM, $\mathrm{N}^{\circ} 29$, «Le droit international de l'eau, état des lieux », février 2008, p.26.

${ }^{203}$ Protocole dit de San Salvador de 1988 en vigueur depuis novembre 1999, ratifié par 13 Etats d'Amérique Latine, Extrait de Académie de l'eau, «Le droit à l'eau dans les législations nationales », Nanterre, octobre 2005, p.12.
} 
A. La reconnaissance au plan régional africain

Encadré 7. Le droit à l'eau potable dans les conventions régionales africaines

Parmi les conventions africaines qui font référence au droit à l'eau potable, on a implicitement :

la Charte africaine des droits de l'homme et des peuples de 1981 (articles ${ }^{204} 16$ et 24). et explicitement :

la Convention d'Alger de 1968 (article 5.al.1);

la Charte africaine des droits et du bien être de l'enfant 1990 (article 14 (2)) ;

la Charte des Eaux du Fleuve Sénégal de 2002 (article 4);

la Convention de Maputo ou encore la Convention africaine pour la conservation de la nature et des ressources naturelles de 2003, (article 7 al.2).

le Protocole à la Charte africaine des droits de l'homme et des peuples relatif aux droits des femmes de 2003 (article 15).

Pour la première fois, le droit à l'eau potable ressort visiblement dans l'accord régional signé par les Etats africains en 1968 (Convention d'Alger) en ces termes : «Les Etats contractants s'efforcent de garantir aux populations un approvisionnement suffisant et continu en eaux appropriées $»^{205}$.

L'accord du 28 mai 1987 relatif au fleuve Zambèze est le plus grand du genre au plan africain : c'est le premier accord de bassin à se donner pour objectif spécifique la gestion rationnelle de l'environnement. "C'est l'exemple unique en Afrique d'une approche concertée, au niveau sous régional, des problèmes écologiques sous forme de plan d'action environnementale ${ }^{206}$. ». Malgré leur nombre réduit, ces conventions élaborées au plan africain contribuent à la limitation des atteintes portées au milieu marin et partant à une meilleure sauvegarde des ressources en eau d'Afrique.

La Charte ${ }^{207}$ africaine des droits et du bien-être de l'enfant signée à Addis-Abeba en Ethiopie dispose pour sa part que : «Les Etats parties à la présente Charte s'engagent à poursuivre le plein exercice de ce droit, notamment en prenant les mesures aux fins ciaprès : assurer la fourniture d'une alimentation adéquate et d'eau potable (article 14 (2) (c)). Il s'agit dans ce cas d'un droit individuel qui n'a pas encore son équivalent en Europe $^{208}$.

La Charte des eaux du fleuve Sénégal signée en mai 2002 (par le Mali, la Mauritanie, et le Sénégal) rappelle que: "Les principes directeurs de toute répartition des eaux du Fleuve visent à assurer aux populations des Etats riverains, la pleine jouissance de la

\footnotetext{
${ }^{204}$ Chaque personne " a le droit de jouir du meilleur état de santé physique et mentale qu'elle soit capable d'atteindre. " (article 16); "tous les peuples ont droit à un environnement satisfaisant et global, propice à leurs développements ", (article 24).

${ }^{205}$ Article 5 al.1. La même idée sera reprise à Maputo en 2003 (C'est la nouvelle Convention d'Alger au même intitulé) : "Les parties s'efforcent de garantir aux populations un approvisionnement suffisant et continu en eau appropriée ", article 7al.2. Contrairement à l'ancienne Convention d'Alger qui avait obtenu la signature de 30 Etats, la Convention de Maputo sera ratifiée par 33 Etats.

${ }^{206}$ Propos des KAMTO Maurice, recueillis dans son ouvrage op. cit., p. 255.

${ }^{207}$ De 1990, ratifiée par 37 Etats.

${ }^{208}$ SMETS (H), « Le droit à l'eau dans le contexte méditerranéen », op.cit., p.13.
} 
ressource, dans le respect de la sécurité des personnes et des ouvrages, ainsi que du droit fondamental de l'homme à une eau salubre, dans la perspective d'un développement durable» (article 4 al.3.).

Ce principe sera repris en mai 2003 à Maputo dans le Protocole à la Charte africaine des droits de l'homme et des peuples relatifs aux droits des femmes qui stipule que : "les Etats prennent les mesures nécessaires pour assurer aux femmes l'accès à l'eau potable » (article 15).

$\mathrm{Au}$ cours du Sommet du Mouvement des non-alignés à la Havane (crée le $1^{\text {er }}$ septembre 1961 à Belgrade en vue de défendre l'intérêt des pays qui ne sont ni avec ni contre ${ }^{209}$ tenu en 2004 puis en 2006, progressivement, un vaste mouvement d'initiatives en faveur du droit à l'eau potable en Afrique se fait sentir. Malgré la lourdeur et la lenteur dans le processus, quelques initiatives prises en Afrique au cours de cette période mentionnent déjà la nécessité de l'accès à l'eau potable. Par exemple, le but du RWSSI (Rural Water Supply and Sanitation Initiatives) est de "faciliter l'accès à l'eau et l'assainissement à 80\% de la population rurale en 2015 et $100 \%$ en 2025 ; avec pour finalité en cas de succès d'offrir l'eau potable à 277 millions d'individus et l'assainissement à 295 millions de personnes ${ }^{210}$.

Certes, les progrès sont lents et l'aide internationale peu importante ${ }^{211}$, mais ils existent, ce qui n'est pas rien.

\section{B. La reconnaissance au niveau de la sous région de l'Afrique centrale}

Les pays d'Afrique centrale ont ratifié d'importants instruments conventionnels adoptés au plan mondial (voir paragraphe I, A)) et africain (voir paragraphe II, A) concourant à la reconnaissance et à la promotion du droit à l'eau potable. Pour faire décoller l'économie de l'Afrique centrale, la population doit avoir un accès suffisant à l'eau potable. La réalisation d'un tel défi passe indéniablement par la résolution des problèmes conjoncturels que connaît la région. L'élaboration de nouvelles stratégies de lutte contre la pauvreté est un préliminaire pour l'accès à l'eau potable. Pour que l'objectif soit atteint, le Programme des Nations Unies pour le Développement (PNUD) doit honorer aux engagements pris lors du Sommet de Rio. Lesquels consistent à aider et améliorer au niveau national l'élaboration des politiques et la concentration d'énergie pour un système de gouvernance efficace.

Toutefois, les pays bénéficiaires devraient eux-mêmes évaluer et fixer leurs objectifs. L'assistance extérieure doit juste servir de mesure d'accompagnement du projet. Pour

\footnotetext{
${ }^{209}$ Il s'agit des pays neutres ou abstentionnistes. Parmi ces pays, les plus importants à l'échelle mondiale sont : l'Inde, l'Algérie, l'Egypte, l'Indonésie, le Pakistan, l'Afrique du Sud, ainsi que l'ex-Yougoslavie, consulté dans http://fr.wikipedia.org/wiki/Mouvement_des_non-align\%C3\%A9s, le 12 décembre 2009.

${ }^{210}$ SMETS (H.), « Le droit d'accès à l'eau potable dans le contexte Méditerranéen », Académie de l'eau, consulté dans le site www.academie-eau.org., le 29 juin 2008, p.20.

${ }^{211}$ Le 4 décembre 2006 dans sa Résolution A/C.2/61/L.16/Rev.1, l'Assemblée Générale des Nations Unies réaffirme "qu'il est nécessaire d'aider les pays en développement à assurer l'accès à l'eau potable et aux services d'assainissement de base, conformément à la Déclaration du Millénaire et au Plan de mise en ouvre de Johannesburg, afin notamment de réduire de moitié d'ici 2015, la proportion des personnes qui n'ont pas accès à l'eau potable à un prix abordable et qui n'ont pas accès aux services d'assainissement de base ». Extrait de SMETS (H.), «L'accès à l'eau potable et le droit international », op.cit., pp.5-6.
} 
accéder à l'eau potable, l'Afrique centrale doit également prendre en compte dans ses documents stratégiques la notion de pauvreté humaine (malnutrition, analphabétisme, mauvaises mentalités). Pour plus d'efficacité, les plans d'action de mise en œuvre du droit à l'eau potable doivent être définis par les pays concernés et non par les bailleurs de fonds. L'approche doit être multidimensionnelle (Cf. Tableau 3).

Tableau $^{212} 3$ : Les étapes de réduction de la pauvreté en Afrique centrale

\begin{tabular}{|c|c|c|c|}
\hline \multicolumn{4}{|c|}{ ETAPE STRATEGIQUE DE REDUCTION DE LA PAUVRETE EN AFRIQUE CENTRALE } \\
\hline ENTRANTS & RESULTATS INITIAUX & $\begin{array}{c}\text { RESULTATS } \\
\text { INTERMEDIARES }\end{array}$ & $\begin{array}{c}\text { RESULTATS A } \\
\text { LONGS TERMES }\end{array}$ \\
\hline $\begin{array}{l}\text { * Préparation du } \\
\text { DSRP }{ }^{213} \text { sous } \\
\text { l'impulsion de } \\
\text { l'Afrique } \\
\text { centrale } \\
\text { * Large8 } \\
\text { participation } \\
\text { * Planification } \\
\text { * Estimations des } \\
\text { coûts réalistes } \\
\text { * indicateurs du } \\
\text { processus }\end{array}$ & $\begin{array}{l}\text { * Stratégies à long terme } \\
\text { menées sous l'impulsion } \\
\text { de l'Afrique centrale } \\
\text { * Dispositifs institutionnels } \\
\text { et juridiques } \\
\text { * intégration des stratégies } \\
\text { dans le processus } \\
\text { budgétaire } \\
\text { * marge de contrôle réalisée } \\
\text { par les bailleurs de fonds }\end{array}$ & $\begin{array}{l}\text { * Ajustement des politiques } \\
\text { * Ajustement des dépenses } \\
\text { publiques/ priorités } \\
\text { * réalisations des objectifs du } \\
\text { DSRP intermédiaires } \\
\text { * suivi dans l'exécution }\end{array}$ & $\begin{array}{l}\text { * Utilisation efficace } \\
\text { des ressources } \\
\text { disponibles }\end{array}$ \\
\hline
\end{tabular}

\section{SECTION II :...A la forte promotion du droit à l'eau potable}

La promotion du droit à l'eau potable (paragraphe I) trouve son origine réelle dans les années 1980 et 1990 considérées comme la décennie internationale de l'eau potable. Ce droit est de plus en plus perçu comme un élément du patrimoine commun de l'humanité (paragraphe II).

\section{Paragraphe I : La mondialisation du droit à l'eau potable}

La mondialisation du droit à l'eau potable constitue un important instrument de sa promotion. L'attention nourrie qu'accorde la communauté internationale à la question de mise en œuvre du droit à l'eau potable au plan interne des Etats a entraîné au plan international la consécration du 22 mars de chaque année (A) comme la journée mondiale de l'eau. L'adoption d'une telle journée ne pouvait qu'avoir des implications dans la promotion dudit droit (B).

\footnotetext{
${ }^{212}$ Documentation recueillie auprès de la Banque Mondiale.

${ }^{213}$ Document stratégique de réduction de la pauvreté.
} 
A. Le 22 mars et le droit à l'eau potable

Dans sa Résolution A/RES/47/193, l'Assemblée Générale des Nations Unies déclare désormais le 22 mars de chaque année comme "journée mondiale de l'eau ». L'entrée en vigueur de cette décision a été fixée au 22 mars 1993 conformément aux exigences de la conférence des Nations Unies sur l'Environnement et le Développement de Rio de Janeiro $^{214}$. Cette Résolution invite les Etats à consacrer la date du 22 mars comme la journée mondiale de l'eau afin de concrétiser les actions telles que : la sensibilisation du public par des publications, des diffusions de documentaires, l'organisation de conférences, de tables rondes, de séminaires et des expositions liées à la conservation, au développement des ressources en eau et à la mise en œuvre des recommandations d'Action $21^{215}$. Le droit à l'eau potable connaît une promotion significative à compter de l'année 1993 au Cameroun comme dans le reste du monde. Toutefois, ce n'est qu'en 1994 que la journée mondiale s'inscrit dans une logique de thème international. Le tableau (Tableau 4) retrace de façon chronologique les thèmes débattus sur la question jusqu'à ce jour.

Tableau $^{216} 4$ : La journée mondiale de l'eau : un aperçu historique

\begin{tabular}{|c|c|c|}
\hline ANNEE & THEME & ORGANISATEUR \\
\hline $22 / 03 / 11$ & «L'eau pour les villes : répondre au défi urbain » & UN HABITAT / UN WATER \\
\hline $22 / 03 / 10$ & « De l'eau propre pour un monde sain » & ONU \\
\hline $22 / 03 / 09$ & « Eaux transfrontalières" & UNESCO \\
\hline 20/03/08 & «L'assainissement» & UNESCO \\
\hline 22/03/07 & «Faire Face à la pénurie de l'eau » & FAO \\
\hline 22/03/06 & « Eau et culture» & UNESCO \\
\hline 22/03/05 & «L'eau, source de vie» & ONU \\
\hline 22/03/04 & «L'eau et les catastrophes naturelles » & OMM \\
\hline 22/03/03 & «De l'eau pour le futur» & PNUE \\
\hline $22 / 03 / 02$ & «De l'eau pour le développement » & A.I.E.A. \\
\hline $22 / 03 / 01$ & « De l'eau pour la santé » & OMS \\
\hline $22 / 03 / 00$ & «L'eau pour le XXI ${ }^{\text {ème }}$ siècle » & UNESCO \\
\hline 22/03/99 & « La vie en aval des cours d'eau » & PNUE \\
\hline 22/03/98 & «L'eau souterraine, la ressource invisible» & UNICEF \\
\hline $22 / 03 / 97$ & « L'eau dans le monde : en existe-t'il assez! » & UNESCO \\
\hline 22/03/96 & «De l'eau pour les villes assoiffées » & OMM \\
\hline 22/03/95 & «Les femmes et l'eau» & Idem \\
\hline 22/03/94 & «La sauvegarde de nos ressources en eau est l'affaire de tous » & Idem \\
\hline
\end{tabular}

\footnotetext{
${ }^{214}$ Chapitre 18, Action 21, 1992.

${ }^{215}$ Information recueillie dans le site www.unesco.org/water/water_celebrations/index_fr.shtml, consulté le 18 juillet 2008 et le 22 mars 2010.

${ }^{216}$ Conception personnelle.
} 
Désormais, le 22 mars est consacré à la "vénération" de la ressource ainsi qu'à la "méditation sur le devenir de la ressource». Curieusement, un peu plus de quinze ans après l'institutionnalisation de la journée mondiale de l'eau, les problèmes liés à l'inaccessibilité des populations à la ressource continuent de se poser avec acuité au Cameroun comme dans le reste du monde. D'après certaines estimations faites par le PNUD, le monde risquera de se plonger d'ici 2015 dans un état de "Guerre générale de l'eau " si des mesures d'urgence ne sont pas prises. La mondialisation de la promotion du droit à l'eau potable, malgré ses sensibles implications, n'a pas encore réussi à faire face au "stress hydrique» qui sévit en Afrique centrale, surtout dans les zones sahéliennes.

B. Les implications du 22 mars sur la vulgarisation du droit à l'eau potable

L'internationalisation de la protection et de la promotion du droit à l'eau potable pourrait avoir des répercutions sensibles en Afrique centrale au fil du temps. Il faudrait pour ce faire, attirer l'attention de la société toute entière sur la nécessité de préserver cette ressource au profit des générations présentes et à venir. Le chemin parcouru n'est pas négligeable, mais le processus est à peine entamé.

Tout démarre en 1981 avec la consécration de la période 1981-1990 (par les Nations Unies) comme Décennie Internationale de l'Eau Potable et de l'Assainissement. L'objectif de cette décision est "d'assurer aux populations un approvisionnement en eau potable de qualité et en quantité suffisante ainsi que des installations sanitaires de base, d'ici 1990 ». Cette décision est accueillie favorablement dans la plupart des régions d'Afrique centrale. La D.I.E.P.A. a par exemple mobilisé le plus grand nombre de programmes d'aménagements hydrauliques au Cameroun ${ }^{217}$ tels que :

- le programme UNICEF (mené dans certains départements des provinces du centre et sud au Cameroun pour la construction et l'équipement d'une centaine de puits à grands diamètres);

- le programme d'adduction d'eau rurale, cofinancé par le Royaume du Danemark et l'Etat du Cameroun et baptisé projet "SCANWATER » qui porte sur 77 localités camerounaises pour 365 ouvrages réalisés ;

- les programmes des ressources hydriques des Monts Mandaras, financés conjointement par l'USAID et l'Etat du Cameroun qui concerne la réalisation de 35 petits barrages dans les Monts Mandaras;

- le projet BID de la Banque Islamique de Développement réalisé par les géologues du Ministère des Mines et Soreah entre 1989 et 1991 ; et la réalisation de 400 fo-rages dans les sept provinces par les géologues du Ministère des Mines, de l'Eau et de l'Energie ;

\footnotetext{
${ }^{217}$ En effet, dans le cadre de sa politique de développement visant à assurer le bien -être de sa population, le Cameroun avait accordé dans le $5^{\text {ème }}$ plan quinquennal (1980-1985) une place de choix aux problèmes d'approvisionnement en eau potable et d'assainissement aussi bien dans les zones urbaines que dans les zones rurales. Soixante six centres urbains sur les 98 équipés en réseaux d'approvisionnement en eau potable par la S.N.E.C. ont été réalisés entre 1980 et 1990; BOSCO (D.T.N) et suivant, L'eau au Cameroun, Tome I: approvisionnement en eau potable, PUY, septembre 2004, pp.32-33.
} 
- les programmes japonais (I et II) de réalisations de 300 à 400 forages avec le même ministère ;

- le programme de réalisation de 350 forages financé par les Pays Bas dans le Mbam ;

- les programmes de la Banque Mondiale ${ }^{218}$.

En 1991, l'Assemblée Générale des Nations Unies adopte le principe suivant lequel "les personnes âgées doivent avoir accès à l'eau potable et au logement en suf-fisance ».

En 2000, la Déclaration du millénaire des Nations Unies dont l'objectif est de réduire de moitié, d'ici 2015, la proportion des personnes n'ayant pas accès à l'eau potable ou n'ayant pas les moyens de s'en procurer voit le jour. Deux ans plus tard, l'année 2003 est consacrée " année internationale de l'eau ».

En 2005, la période 2005-2015 est proclamée par les Nations Unies comme la "Décennie internationale d'action l'eau source de vie " avec pour objectif la mise en œuvre des programmes et des projets ayant trait à l'eau, la participation et l'engagement des femmes dans les efforts de développement liés à l'eau, l'intensification de la coopération à tous les niveaux (prévention des catastrophes, des pollutions), la formation, le financement, l'évaluation et la gestion intégrée des ressources en eau. Dans cette décision, l'Afrique est définie comme région prioritaire. Ces multiples efforts n'ont certes pas suffi à rendre la mise en œuvre du droit à l'eau potable automatique en Afrique centrale; mais, ils ont réussi à poser un jalon favorable à la mise en œuvre de ce droit ainsi que de sa considération comme élément du patrimoine commun de l'humanité.

\section{Paragraphe II : L'eau potable, un élément du patrimoine commun de l'humanité}

Parmi les grands défis du millénaire, la problématique de l'eau potable occupe une place préférentielle. Classé comme catégorie de bien commun de l'humanité (A), l'eau potable est une ressource particulièrement rare et sa pénurie est source de conflits surtout lorsqu'il s'agit de la gérer en tant que ressource commune (B).

\section{A. La notion de patrimoine commun de l'humanité}

Par patrimoine en général, il faut entendre toute chose susceptible d'appropriation privée parce que capable de procurer à l'homme une certaine utilité. Le patrimoine peut aussi s'entendre comme l'ensemble des biens et obligations d'une personne envisagé comme une universalité de droit ${ }^{219}$. Ainsi, un patrimoine est un bien, mais tous les biens ne sont pas propres. Il existe des res communis (choses commune ou patrimoine commun qui ne sont pas susceptibles d'appropriation privée) et par conséquent ne sont pas des biens. C'est le cas des choses communes telles que l'air, la lumière et l'eau potable ${ }^{220}$. L'eau potable peut donc davantage être considérée comme une chose et non

\footnotetext{
${ }^{218}$ BOSCO (D.T.N.) et suivant, L'eau au Cameroun, op.cit., pp.33-34.

${ }^{219}$ C'est-à-dire une masse mouvante dont l'actif et le passif ne peuvent être dissociés, Code civil français, article 2092.

${ }^{220}$ Elle est comme l'air indispensable à l'homme, mais n'est pas susceptible d'appropriation privée mais collective, Voir à ce titre Launey (J.), « Moderniser la gestion de l'eau », Rapport d'information, AN, N 1170 , 03 novembre 2003, p.20.
} 
comme un bien; car, elle est affectée à l'usage de tous; ce qui rend aujourd'hui sa protection juridique des plus complexe $e^{221}$.

L'humanité quant à elle représente l'ensemble formé par les générations présentes et futures. "C'est probablement une solidarité intergénérationnelle qui caractériserait le mieux l'humanité avec bien sûr, le fait qu'il existe une unité autour de l'espèce humaine et une diversité très importante ${ }^{222} »$. La charte européenne de l'eau est l'un des tout premiers textes de droit international à affirmer que "l'eau n'a pas de frontière, les ressources en eau ne sont pas inépuisables, lorsque l'eau après utilisation est rendue dans un milieu naturel, elle ne doit pas compromettre les usages ultérieurs. La gestion des ressources en eau devrait s'inscrire dans le cadre des bassins naturels plutôt que dans celui des frontières administratives et politiques ». Cette gestion nécessite une coopération internationale.

D'après le principe 3 de la Déclaration de Rio, «le droit au développement doit être réalisé de façon à satisfaire équitablement les besoins relatifs au développement et à l'environnement des générations présentes et futures ». La notion de patrimoine commun a l'avantage de chercher à soustraire des espaces ou des biens à la souveraineté étatique et d'organiser la gestion de façon commune et durable. "Chaque génération humaine détient les ressources de la terre pour les générations futures et a la mission de faire en sorte que ce legs soit préservé et que, lorsqu'il en est fait usage, cet usage soit fait avec prudence $»^{223}$. Appliquée dans le domaine des ressources en eau, sa difficulté première vient du fait que la ressource en eau est supposée être la propriété de l'Etat dans lequel elle se trouve (sauf cas des ressources en eau partagées). L'article 136 de la Convention sur le droit de la mer de 1982, tente d'y apporter une précision en ces termes : «les fonds marins, la zone et ses ressources sont le patrimoine commun de l'humanité». Du préambule de la Charte mondiale de la nature de 1982, il ressort que «l'humanité fait partie de la nature et la vie dépend du fonctionnement ininterrompu des systèmes naturels qui sont la source d'énergie et de matières premières". L'article 3 al.1 de la Conventioncadre de lutte contre les changements climatiques poursuit: "il incombe aux parties de préserver le système climatique dans l'intérêt des générations présentes et futures, sur la base de l'équité et en fonction de leurs responsabilités communes, mais différenciés et de leurs capacités respectives». Allant dans le même sens, le préambule du Traité sur l'Antarctique du $1^{\text {er }}$ décembre 1959 reconnaît "qu'il est de l'intérêt de l'humanité tout entière que l'antarctique soit à jamais réservée aux seules activités pacifiques".

L'intérêt commun quant à lui exige que les êtres humains bénéficient des libertés, des égalités et des solidarités des trois générations de droit (droit des personnes, droit des peuples et droit de l'humanité). Cette dernière notion implique la responsabilité de ne pas causer de dommages écologiques aux Etats voisins et aux espaces internationaux. L'analyse de l'eau comme patrimoine commun de l'humanité est plus d'actualité dans les textes que dans les faits.

\footnotetext{
${ }^{221}$ AUBRIOT (J.), « Le droit à l'eau : émergence, définition, situation actuelle et position des acteurs », op.cit., p.42.

${ }^{222}$ LAVIEILLE (J.M.), op.cit., p.19.

${ }^{223}$ Convention de Bonn, Préambule, 1979.
} 
B. Ses implications en matière de droit à l'eau potable

Elément mythique, référence symbolique, objet de rites et expression de la culture, l'eau a joué et continue de jouer un grand rôle dans l'histoire des civilisations. Il suffit de lire l'histoire des grandes civilisations anciennes d'Egypte, de Mésopotamie ou de chine (fondée sur le bord des fleuves et dans les plaines d'alentour fertilisées par le limon) pour comprendre le rôle essentiel de l'eau dans l'histoire de l'humanité. C'est avec cette même eau que se fait la consécration des prêtres et l'octroi des sacrements. Elle serait une source de bénédiction et de purification. La ressource est aujourd'hui considérée comme un bien commun de l'humanité. Indispensable à la vie, l'eau est repartie de façon inégale sur le globe terrestre et interpelle à la fois la communauté internationale, régionale, et nationale; bref, tous les citoyens du monde entier.

Conscient de cette situation, un groupe d'auteurs originaires d'Afrique, d'Asie, d'Amérique et d'Europe, unis pour la même cause sont à l'origine d'une frémissante Déclaration: "Nous nous sommes rassemblés à trois reprises en 1998 sans autre légitimité et représentativité que celle d'être des citoyens concernés par le fait qu'un milliard et 400 millions de personnes sur 5,8 milliards d'habitants de la planète n'ont pas accès à l'eau potable, source primordiale de vie. Ce fait est inadmissible. Or, le risque est grand qu'en 2020, lorsque la population mondiale atteindra environ les 8 milliards d'êtres humains, les personnes n'ayant pas accès à l'eau potable s'élèvent à plus de 3 milliards. En tant que "source de vie", l'eau est un bien vital qui appartient aux habitants de la terre, en commun. Aucun d'entre eux individuellement ou en groupe, ne devrait avoir le droit d'en faire son appropriation privée. L'eau est un bien du patrimoine commun de l'humanité. La santé individuelle et collective en dépend. Il n'y a pas d'accès à la production de richesse sans accès à l'eau potable. L'eau, on le sait et tout le monde le dit, n'est pas une ressource comme les autres; elle n'est pas une marchandise échangeable, monnayable. Son caractère irremplaçable fait que toute communauté humaine et chacun de ses membres a le droit d'avoir accès à l'eau, en particulier à l'eau potable, en quantité et qualité nécessaires et indispensables à la vie et à l'activité économique. "224. L'idéal serait une mise en application conforme de ces recommandations. Mais, il ne faut pas se leurrer. Malgré la pertinence d'un tel point de vue, l'eau potable est loin d'être un acquis, l'accès à la ressource demeure bien évidemment une conquête. Au même titre que la liberté, le droit à l'eau potable doit s'arracher et même s'imposer de force.

Comme l'affirmait le socialiste Karl Marx: "Prolétaires du monde entier unissezvous, car vous n'avez que vos chaînes à perdre et tout un monde à gagner. ", les personnes impliquées dans la mise en œuvre du droit à l'eau potable doivent restés solidaires. Les conférences, les séminaires, et les tables rondes relatifs à la mise en œuvre du droit à l'eau potable doivent davantage se multiplier et l'idée d'une Convention-cadre dans le domaine projetée avec à l'esprit le défi de rendre l'eau potable accessible à tous.

Même si la reconnaissance officielle ainsi que la vulgarisation du droit à l'eau potable ne conduiront pas à elles seules à résoudre le problème de crise mondiale de l'eau, il faut tout de même reconnaître que celles-ci constituent déjà une fondation solide pour le devenir du droit en question. "L'accès à l'eau est un droit fondamental et

\footnotetext{
${ }^{224}$ Point de vue du Sud, «Le manifeste de l'eau : le droit de tous à la vie » in L'eau, patrimoine commun de l’humanité, op.cit., p. 287.
} 
universel dont les faits montrent qu'il s'avère inaccessible à un nombre croissant d'êtres humains. Le défi qui nous est lancé est celui de la vie, de la justice sociale, de la solidarité internationale et $d u$ devenir de notre planète ${ }^{225}$. Bien plus, la reconnaissance et la promotion du droit à l'eau potable «offrent plus de légitimité aux demandes de ceux qui manquent l'eau et les aident à exiger des comptes de leur gouvernement ».

${ }^{225}$ DELANOË (B.), Maire de Paris, juin 2007, Extrait de «La mise en œuvre du droit à l'eau, les solutions à Paris », SMETS (H.), août 2010, p.41. 


\section{CONCLUSION DE LA PREMIERE PARTIE}

Les multiples débats et conférences internationales organisés ces trente dernières années ont considérablement influencé le développement du droit à l'eau potable au plan international comme national.

Du point de vue international, la nature juridique du droit à l'eau potable est indirectement déduite des articles 11 al.1 et 12 du Pacte ${ }^{226}$ International relatif aux Droits Economiques, Sociaux et Culturels de 1966 qui reconnaît le droit à l'eau comme un droit économique, social et culturel. La nature juridique du droit à l'eau a précisément été formulée dans l'Observation ${ }^{227}$ Générale $\mathrm{N}^{\circ} 15$ de 2002 et la Résolution des Nations Unies A/Res/64/292 du 28 juillet 2010 dernier qui, malgré sa critique reste le premier texte du genre à reconnaître officiellement et explicitement le droit à l'eau potable et l'assainissement comme un droit humain fondamental indispensable à la vie et à la réalisation des autres droits de l'homme.

Quant à la consécration du droit à l'eau au plan international, elle s'est construite de façon certes lente, mais progressive. Cette entreprise a davantage été l'œuvre (indirecte ${ }^{228}$ et quelques fois directe ${ }^{229}$ ) de certains importants textes des droits de l'homme que du droit international de l'environnement lui même. il faut toutefois admettre que le droit international de l'environnement a influencé à sa manière le développement du droit à l'eau à travers notamment : le culte de l'environnement sain prôné dans la Déclaration de Stockholm de 1972 (sur l'environnement) et dans la Déclaration de Rio de Janeiro de 1992 (sur l'environnement et le développement); la lutte contre la raréfaction de l'eau contenue dans la Convention de lutte contre la désertification de 1994 ; la sauvegarde des écosystèmes et milieux fixée par la Convention-cadre de lutte contre les changements climatiques et son Protocole de Kyoto de 1997 et bien d'autres textes importants ${ }^{230}$. Nous avons explicitement déduit le droit à l'eau dans d'autres textes de droit international de l'environnement tels que la Convention d'Alger de 1968, l'Agenda 21 de 1992 (qui consacre son chapitre 18 à la question), la Déclaration de Dublin de 1992 (qui réserve ses quatre principes à la question), Le protocole de Londres sur l'eau et la santé de 1999, la Convention de New York de 1997 sur l'utilisation des cours d'eaux à des fins autres que la navigation (qui a connu une importante critique et, par conséquent n'est pas entrée en vigueur), La Convention d'Helsinki de 1992 sur la protection des cours d'eaux et des lacs internationaux (qui prône le renforcement des capacités et la coopération entre les Etats).

La reconnaissance et la mise en œuvre du droit d'accéder à l'eau potable et l'assainissement constituent une avancée juridique indispensable pour l'avenir des peuples, particulièrement ceux vulnérables ${ }^{231}$. Malgré la forte revendication et la reconnaissance explicite du droit à l'eau dans certains textes de droit international et

\footnotetext{
${ }^{226}$ Voir les détails au chapitre I de cette partie.

${ }^{227}$ Ibid.

${ }^{228}$ Voir note de bas de page 7.

${ }^{229}$ Voir note de bas de page 8.

${ }^{230}$ Pas suffisamment développés parce que relevant du droit de l'eau.

${ }^{231}$ AUBRIOT (J.), «Le droit à l'eau : émergence, définition, situation actuelle et position des acteurs ", op.cit., p.66.
} 
national, nous avons constaté que, "plus d'1,5 milliards de personnes n'ont toujours pas accès à l'eau potable et 2,4 milliards n'ont toujours pas accès à l'assainissement de base $e^{232} »$. Est-ce à dire que la reconnaissance du droit à l'eau potable est inutile dans l'accès des populations à la ressource ? La réponse est négative, car, le respect du droit à l'eau passe prioritairement par une reconnaissance officielle au plan international et national ; même si la garantie sûre de sa mise en œuvre dépend encore majoritairement de la volonté politique. Bien plus, la reconnaissance du droit ne résout pas tous les problèmes, mais elle permet la mise en place des bases juridiques mondiales et de pointer les responsabilités et obligations de chacun. "Affirmer le droit à l'eau, ce n'est pas l'inscrire sur un bout de papier pour l'ignorer le lendemain, Inscrire le droit à l'eau, cela veut dire prendre les mesures, mettre les budgets, mettre les priorités. $»^{233}$. C'est de cette façon que l'on parviendra à mettre effectivement en œuvre le droit à l'eau potable au plan interne.

\footnotetext{
${ }^{232}$ Voir rapport de l'OMS de 2004 sur la question.

${ }^{233}$ Déclaration de Jean Fabre, Directeur du Bureau PNUD, Genève, déclaration faite lors des Rencontres internationales pour le droit d'accès à l'eau, novembre 2006.
} 



\section{DEUXIEME PARTIE}

... A LA FAIBLE EFFECTIVITE DU DROIT A L'EAU POTABLE AU PLAN INTERNE 



\section{INTRODUCTION DE LA DEUXIEME PARTIE}

L'eau insalubre est la première cause de mortalité dans le monde. Elle tue chaque année 8 millions d'êtres humains parmi lesquels 1,1 million sont des enfants. De nos jours, 1,2 milliards d'hommes, de femmes et d'enfants n'ont toujours pas accès à l'eau potable. Environ 2,6 milliards n'ont pas accès aux conditions élémentaires d'hygiène. Du coup, 22.000 personnes meurent chaque jour de suite d'une maladie hydrique (telle que le choléra, la typhoïde ou la diarrhée) soit 15 personnes par minute ${ }^{234}$.

Si l'eau en général est abondante du point de vue disponibilité, elle reste rare du point de vue potabilité. Le déséquilibre au niveau de sa répartition continue de poser problème. Au niveau universel par exemple, neuf pays se partagent environ $60 \% \mathrm{du}$ débit annuel mondial. L'eau est en outre irrégulièrement repartie une année sur l'autre ou une saison sur l'autre suivie des multiples variations géographiques ${ }^{235}$; ce qui fait d'elle une ressource conflictuelle ${ }^{236}$. Fort de ce constat, il s'est tenu en 2009 à Istanbul, un Forum mondial de l'eau afin d'étudier les moyens de prévenir une crise de l'eau qui, selon l'ONU et le Conseil Mondial de l'Eau, affectera près de la moitié de la population d'ici 2030. La réalisation du droit à l'eau potable au plan interne signifie que ce dernier soit considéré comme un droit humain essentiel; ce qui engendre un certain nombre de questionnements : chaque individu a-t-il légitimement le droit d'exiger que l'eau reçue gratuitement ou non soit potable, accessible et fournie en permanence? Autrement dit, existe-t-il un droit individuel justiciable dans le domaine de l'eau potable? Si dans un pays, la réponse à cette question est affirmative, c'est que, dans ce pays, le droit à l'eau potable est bel et bien mis en œuvre au plan interne. Dans celui où la réponse est négative, c'est que le droit à l'eau potable n'est pas mis en œuvre au plan interne. Et enfin dans celui où la réponse est nuancée, c'est que le droit à l'eau connaît une mise en œuvre difficile au plan interne : c'est le cas du Cameroun.

L'intérêt de cette partie réside dans la recherche des mécanismes juridiques nécessaires à la mise en œuvre du droit à l'eau potable en Afrique centrale en général et au Cameroun en particulier (chapitre III). Ceci amènera à examiner l'effectivité du droit à l'eau potable au regard du droit camerounais (chapitre IV).

\footnotetext{
${ }^{234}$ Voir www.solidarités.org, Rapport sur l'eau insalubre, première cause de mortalité dans le monde, consulté le 03 mai 2008.

${ }^{235}$ Voir http://fr.wikipedia.org/wiki/G\%C3\%A9opolitique_de_1\%27eau\#R.C3.A9partition_g.C3.A9ographique, consulté le 12 septembre 2009.

${ }^{236}$ Voir les détails au chapitre I, section II, paragraphe II (A- 1) de cette thèse.
} 

CHAPITRE III

DE L'HERITAGE A LA STRATEGIE CAMEROUNAISE DE MISE EN GUVRE DE DROIT À L'EAU POTABLE 
La mise en œuvre du droit à l'eau potable au Cameroun est davantage l'œuvre du droit international lato sensu que l'œuvre du droit national camerounais lui-même. Pour que celle-ci soit effective, il faudrait que les différents acteurs ${ }^{237}$ y compris les individus soient intégrés dans le processus et que les instruments conventionnels ratifiés au plan international soient effectivement mis en œuvre dan la pratique. Le Cameroun dispose d'un important réseau hydrographique en Afrique centrale. Pourtant, la majorité de sa population n'a toujours pas un accès suffisant à l'eau potable. Cette denrée est rare dans la zone car, elle est inégalement répartie du Nord au Sud entre les milieux urbains et ruraux.

Le droit à l'eau potable au Cameroun se bute à l'accès limité des populations à la ressource combiné à l'insuffisance des mesures d'hygiène et d'assainissement adéquats. Le droit camerounais est lui-même très implicite sur la question du droit à l'eau potable en particulier ce qui justifie la quasi inexistence des cas de jurisprudences y relatives. Les obstacles à la mise en œuvre du droit à l'eau potable au Cameroun sont sommairement d'ordres juridique (un droit non constitutionalisé, qui fixe une disparité de compétences dans le domaine), pratique (on note une mauvaise répartition de la ressource ainsi que le non respect des méthodes d'assainissement adéquates; la ressource est abondante dans les régions du Sud et rare dans les régions du Nord) et institutionnelle (il ya une gouvernance insuffisante de l'eau du fait de la pauvreté qui limite encore l'accès de tous à la ressource).

Néanmoins, le pays essaie autant que possible de s'arrimer au processus international de mise en ouvre du droit à l'eau potable (section I) afin de dégager sa propre stratégie dans le domaine (section II). Le contexte actuel dans lequel évolue le droit à l'eau potable montre en général que «le droit n'est pas la garantie ultime permettant la réalisation $d u$ droit d'accès à l'eau potable pour tous; sinon, l'ensemble de ces pays dont la constitution comprend le droit à l'eau devrait se retrouver dans une bonne situation; ce qui n'est pas le cas ${ }^{238}$. ". Il est question dans cette partie de voir entre autres les causes de la rareté de l'eau potable dans un système en principe favorable à la mise en œuvre du droit à l'eau potable. Qu'est ce qui justifie la faible effectivité du droit à l'eau potable au Cameroun? Est-ce le droit national lui-même, la mauvaise volonté politique liée au problème de gouvernance ou alors un problème de ressource financière ${ }^{239}$ ? En d'autres termes quels sont les obstacles à la mise en œuvre du droit à l'eau potable au Cameroun? Est-ce le droit ou bien des facteurs externes au droit? Tant il est vrai que "définir un droit c'est identifier son titulaire, préciser son objet, identifier ceux auxquels il

\footnotetext{
${ }^{237}$ Tels que l'Etat, les prestataires de services d'eau, la société civile et les Organisations internationales.

${ }^{238}$ L'évaluation de l'atteinte de l'OMD $\mathrm{N}^{\circ} 7$ pour les pays qui ont reconnu le droit à l'eau dans leurs constitutions montre que la situation n'est pas sur la bonne voie en Ethiopie, en RDC, comme aux Philippines. Pour les pourcentages, voir AUBRIOT (J.), «Le droit à l'eau : émergence, définition, situation actuelle et position des acteurs ", op.cit. p.49.

${ }^{239}$ D'après le Professeur Abdoulaye Diarra, "L'effectivité du régime juridique d'un pays n'est pas sans rapport avec l'état de développement économique et le niveau d'information et d'éducation citoyens ". Ainsi, la mise en œuvre de l'ensemble des droits ne repose pas seulement sur l'appartenance à un régime démocra-tique; mais davantage sur une mobilisation financière importante pour créer les investissements de bases; voir AUBRIOT (J.), « Le droit à l'eau : émergence, définition, situation actuelle et position des acteurs », op.cit. p.50.
} 
est opposable et enfin prévoir une sanction pour garantir son res-pect $»^{240}$. C'est cette problématique qui fera l'objet de développements tout au long de ce chapitre.

\section{SECTION I : De l'héritage ...}

Comme la plupart des pays d'Afrique centrale (le Congo, le Gabon, le Tchad, la Centrafrique, la Guinée Equatoriale), le Cameroun dans l'optique de développer son propre droit à l'eau potable, s'est aligné dans la politique internationale de protection de l'environnement à travers l'adhésion aux textes internationaux facilitant la mise en œuvre du droit à l'eau potable (paragraphe I) en adoptant au fur et à mesure son propre droit relatif à l'eau potable (paragraphe II).

\section{Paragraphe I : L'adhésion aux textes internationaux}

Afin de rester dans la mouvance du développement du droit international de l'environnement et partant du droit à l'eau potable, le Cameroun, tout comme les autres pays d'Afrique centrale, a marqué son adhésion aux textes universels (B) et africains (C) à travers le mécanisme de la ratification et de l'insertion dans sa loi nationale (A).

\section{A. Les mécanismes d’adhésion aux traités internationaux}

On note sommairement au plan international sept étapes indispensables à l'élaboration d'un traité: la négociation (les Etats sont représentés dans ce processus par des plénipotentiaires ou individus investis du pouvoir de négocier tels que le Président de la Répu-blique, le ministre des affaires étrangères ou des relations extérieures), l'adoption du texte (les délégués des Etats votent le texte dans le respect des règles procédurales), l'authentification (les Etats présents lors de la négociation vérifie l'authenticité du texte et déclarent s'il faille oui ou non continuer la procédure), la signature (c'est la phase préparatoire pour la mise en vigueur du traité. A ce niveau, l'Etat n'est toujours pas engagé, sauf s'il s'agit d'un traité en forme simplifiée.), l'entrée en vigueur (elle doit être prévue dans les dispositions du traité conformément aux exigences de l'article 24 de la Convention de Vienne du 23 mai 1969 sur le droit des traités) et l'adhésion (elle concerne généralement les traités multilatéraux; les cas varient suivant que l'Etat était partie à la signature ou non. Si l'Etat était partie à la signature, il est déjà lié par le traité). Toutes ces étapes de la création du traité ne feront pas l'objet d'approfondissement, nous nous appesantirons sur l'entrée en vigueur (2) et la ratification des traités (1).

\section{La ratification des traités}

La manifestation de la volonté d'un Etat à être lié par un traité présente des formes variables caractérisées ou non par un certain formalisme ${ }^{241}$. "Dans les formes dites "solennelles", l'expression du consentement à être lié ne peut résulter que d'un acte

\footnotetext{
${ }^{240}$ Propos de Jean Rivero, (1910-2001), Ex-professeur à la faculté de droit de Paris.

${ }^{241}$ ADOUKI (D.E), Droit international public, Tome 1, Paris, Harmattan, 2002, p.89.
} 
postérieur et distinct de l'authentification $»^{242}$. D'après l'article 14 de la Convention de Vienne du 23 mai 1969, la volonté de l'Etat d'être définitivement lié par un traité s'exprime par voie de ratification, l'acceptation et de l'approbation. La ratification est la confirmation de la négociation conduite par un représentant de l'Etat (effectuée par le chef de l'Etat) tandis que l'acceptation et l'approbation relèvent de la compétence du Ministre des Affaires Etrangères ou d'autres autorités internes ${ }^{243}$. Toutefois, ces trois procédures produisent au plan international les mêmes effets: elles ne sont pas obligatoires et, il n'existe aucun délai prescrit. C'est l'acte de ratification qui rend définitivement le traité opposable à l'Etat.

Toutefois, la procédure de ratification varie suivant les ordres juridiques. Lorsqu'elle est l'œuvre exclusive de l'exécutif, on parle de régime d'Exception. Lorsqu'elle est l'œuvre du législatif, on parle du régime d'Assemblée. Elle peut aussi émaner d'une compétence partagée entre l'exécutif et le législatif; dans ce cas, le législatif accorde l'autorisation de ratifier au moyen d'une loi et l'exécutif ratifie au moyen d'un décret ${ }^{244}$. A l'heure actuelle, il n'existe pas en droit international, l'obligation d'un Etat à ratifier un traité auquel il a pris part. C'est la principale difficulté dans la mise en œuvre des traités au plan interne des Etats.

\section{L'entrée en vigueur des traités}

En principe, le traité entre en vigueur dès sa ratification; mais tout dépend, s'il est au départ bilatéral ou multilatéral. L'entrée en vigueur des traités bilatéraux se fait par l'échange des instruments de ratification. En cas de silence des parties sur les conditions d'entrée en vigueur, la date sera celle d'échange des instruments de ratification.

Quant aux traités multilatéraux, leur entrée en vigueur varie suivant les traités. L'unanimité est généralement requise pour les traités fermé ${ }^{245}$ et les traités élaborés dans le cadre d'une région déterminée ou les traités communautaires. Le traité instituant la C.E.M.A.C. du 16 mars 1994 par exemple prévoit en son article 6 que toute adhésion ne peut intervenir qu'après accord unanime des membres fondateurs (c'est-à-dire le Cameroun, la Centrafrique, le Congo, le Gabon, la Guinée Equatoriale et le Tchad) dont le consentement est exigé pour l'entrée en vigueur de la Convention. D’autres traités par contre exigent juste le consentement de certains Etats bien identifiés pour leur entrée en vigueur $^{246}$. Pour ce qui est des traités déjà en vigueur, c'est la date d'adhésion qui s'impose à l'Etat qui y adhère.

\footnotetext{
${ }^{242}$ Droit international public, In Ph, Manin, Paris, Masson, 1979, p.86.

${ }^{243}$ Idem.

${ }^{244}$ Ibid, p.91. Le droit congolais a prévu les cas de ratification par décret.

${ }^{245}$ Ibid, p.119.

${ }^{246}$ Le consentement des Etats-Unis, de l'URSS et du Royaume- Uni de la Grande Bretagne détermine l'entrée en vigueur du traité interdisant les essais d'armes nucléaires dans l'atmosphère, dans l'espace extra atmosphère et sous l'eau du 5 août 1963 et du traité de non prolifération des armes du $1^{\text {er }}$ juillet 1968.
} 
B. Le rythme de ratification des traités relatif à l'eau potable au Cameroun

Parmi les conventions internationales ratifiées par le Cameroun (1), rares sont celles qui au plan global font directement référence au droit à l'eau potable. Ce droit n'est réellement perceptible que dans les conventions régionales africaines (2).

\section{Les conventions internationales types ratifiées}

Comme la majorité des pays d'Afrique centrale, le Cameroun a tantôt ratifié, quelquefois adhere à une panoplie de textes internationaux de protection de l'environnement ${ }^{247}$ en général et de l'eau potable en particulier. Il est vrai, rares sont ceux qui font référence au droit à l'eau potable de façon explicite. Il a fallu attendre le vaste mouvement initié par la période 1981-1990 appelée "Décennie internationale de l'eau potable et de l'Assainissement » pour voir le droit à l'eau potable apparaître comme un droit humain essentiel. Comme conventions ratifiées au plan international par le Cameroun consacrant le droit à l'eau potable, on a : la Convention sur l'élimination de toute forme de discrimination à l'égard des femmes de 1979 qui dispose en son article 14 alinéa 2 que: "Les Etats prennent toutes les mesures appropriées pour éliminer la discrimination à l'égard des femmes dans les zones rurales afin d'assurer, sur la base de l'égalité de l'homme et de la femme; leur participation au développement rural et ses avantages. En particulier, ils leur assurent le droit de bénéficier des conditions de vie convenables, notamment en ce qui concerne le logement, l'assainissement, l'approvisionnement en eau et en électricité, les transports et les communications ".

La Convention relative aux droits de l'enfant de 1989 également ratifiée affirment pour sa part que : "les Etats parties reconnaissent le droit de l'enfant de jouir du meilleur état de santé possible et de bénéficier de services médicaux et de rééducation. Ils s'efforcent de garantir qu'aucun enfant ne soit privé du droit d'avoir accès à ces services [...] Les Etats parties s'efforcent d'assurer la réalisation intégrale du droit susmentionné et, en particulier, prennent des mesures appropriées pourlutter contre la maladie et la malnutrition, y compris dans le cadre des soins de santé primaires, grâce notamment à l'utilisation de techniques aisément disponibles et à la fourniture d'aliments nutritifs et d'eau potable, compte tenu des dangers et des risques de pollution du milieu naturel $[\ldots] »^{248}$.

Le Cameroun a ratifié, parfois adhéré à ces textes internationaux de façon lente et progressive. Cette lenteur dans la ratification et l'adhésion a d'ailleurs frappé la plupart des pays africains dans les années 1960-1972. Venant d'acquérir leur indépendance, ceux-ci craignaient que ce nouveau droit (droit international de l'environnement) soit une nouvelle forme de "joug » colonial. C'est depuis la conférence de Rio de Janeiro de 1992 que le Cameroun et tous les autres pays africains manifestent expressément leur désir de s'intéresser aux mouvements de protection et de promotion de l'environnement et partant de droit à l'eau potable. A la même période, le 22 mars est retenu lors de la

\footnotetext{
${ }^{247}$ Date de ratification de certaines Conventions internationales par le Cameroun: la Convention sur la diversité biologique et celle sur les changements climatiques de 1992 (ratifié le 19/10/1994); la Convention de lutte contre la désertification de 1994 (ratifiée le 29/05/1997); le Protocole de Kyoto de 1997 (ratifié le 22/07/2002).

${ }^{248}$ Art. 24 (1.c) de la Convention relative au droit de l'enfant de 1989.
} 
$47^{\text {ème }}$ session de l'Assemblée des Nations Unies comme «la journée mondiale de l'eau ». A voir de prêt, on note que l'adhésion du Cameroun aux textes internationaux de l'environnement relative à l'eau potable tend à devenir automatique au fil du temps. Même si la mise en œuvre de ces conventions n'est pas toujours évidente dans la pratique.

\section{Les conventions africaines types ratifiées}

Le Cameroun a ratifié un certain nombre de textes africains touchant directement au droit à l'eau potable. Le rythme de ratification est presque similaire à celui des autres pays d'Afrique centrale. Le Cameroun a valablement intégré les conventions et chartes africaines militant pour la mise en œuvre du droit à l'eau potable telles que: la Convention d'Alger de 1968 (sur la conservation de la nature et des ressources naturelles) devenue la Convention Maputo en 2003 qui dispose que: «les parties s'efforcent de garantir aux populations un approvisionnement suffisant et continu en eau appropriée ", la Charte africaine des droits de l'homme et des peuples de $1981^{249}$, la Charte africaine des Droits et du bien-être de l'enfant de 1990 qui fait obligation aux Etats de prendre des mesures nécessaires pour garantir la fourniture d'une eau de boisson saine et en quantité suffisante: "tout enfant a le droit de jouir du meilleur état de santé physique mental et spirituel possible » (art.14, al.1). Les Etats parties s'engagent à poursuivre le plein exercice de ce droit, notamment en prenant les mesures aux fins d'assurer la fourniture d'une alimentation adéquate et d'eau potable (art. 14 al.2). Le Protocole de Londres sur l'eau et la santé de 1999 dont les références relatives au droit à l'eau sont contenues dans les articles 4 à $6^{250}$.

Grosso modo, le rythme d'adhésion, mieux encore de ratification de textes relatifs à l'eau potable est presque similaire dans la majorité des pays d'Afrique centrale. Comme les autres Etats africains, le Cameroun prend très souvent part au processus d'adoption des accords régionaux africains et, par la suite approuve le traité par voie de signature (et/ou) ratification, ou encore par voie de consentement. Une fois le consentement accordé, l'Etat signataire peut insérer le traité dans sa loi nationale pour lui accorder plus de crédit. Il faut néanmoins reconnaître avec Willy Biro Sako ${ }^{251}$ que : «la force obligatoire des conventions n'est en réalité que théorique, car leur portée concrète est des plus aléatoires. Seul l'Etat peut agir quand il veut. La mise en application des obligations

\footnotetext{
${ }^{249}$ Elle reconnait implicitement le droit à l'eau notamment en son article 24 qui proclame que: «tous les peuples ont un droit à un environnement satisfaisant et global, propice à leur développement ». Cette Charte est à l'origine de la création en 2004 de la Cour africaine des droits de l'homme et des peuples, compétente pour connaître de tous les litiges ayant trait à la violation d'un droit de l'homme fondamental y compris ceux d'origines environnementaux. En plus d'être saisie par la Commission africaine des droits de l'homme, elle innove en ce sens qu'elle autorise sa saisine (en cas d'épuisement des voies de recours internes) par les ONG et les individus sous réserve du respect de l'article 34 (6) du Protocole à la Charte.

250 «Les parties prennent en particulier toutes les mesures appropriées pour assurer un approvisionnement adéquat en eau potable salubre [...] un assainissement adéquat [...]", art. 4 (al. 2 (a))", "Les parties sont guidées en particulier par les principes et orientations ci-après: un accès équitable à l'eau adéquat du point de vue aussi bien quantitatif que qualitatif devrait être assuré à tous les habitants, notamment aux personnes défavorisées ou socialement exclues ", art. 5 (al. 1), "Aux fins du présent Protocole, les parties poursuivent les buts suivants : l'accès de tous à l'eau potable (a), l'assainissement pour tous (b) », art. 6 (al. 1).

${ }^{251}$ Willy Biro Sako est ambassadeur, Haut représentant de la République centrafricaine en France.
} 
contractées par l'Etat demeure donc tributaire d'une réelle volonté politique qu'il ne faut cesser d'aiguillonner $»^{252}$.

\section{Paragraphe II : La politique camerounaise de mise en cuvre du droit à l'eau potable}

Le droit à l'eau potable affirme l'Observation Générale $\mathrm{N}^{\circ} 15$ est un droit humain essentiel. Quelle est la portée de cette affirmation dans un pays où ce droit est en construction comme le Cameroun?

Conférer au droit à l'eau le caractère fondamental peut être le début d'un processus de mise en œuvre de ce droit. Les Etats devraient, au-delà de la reconnaissance, définir l'entité publique responsable ainsi que ses champs de compétences. "Reconnaître un droit n'est pas une fin en soi mais apparaît être le début de la définition d'un objet qui, devra se concrétiser par la mise en place de politiques publiques, avec ou sans l'aide de partenaires techniques et financiers pour les Etats faibles, afin de garantir la mise en cuvre de ce droit ${ }^{253}$.

En droit interne, cette reconnaissance peut tirer sa source d'un droit fondamental constitutionnellement reconnu (A); ou tout simplement résulter d'une loi (B). Même s'il n'apparaît pas encore de façon explicite dans la loi fondamentale camerounaise, le droit à l'eau potable est notoire dans les autres lois ainsi que le droit coutumier. Après les deux décennies qui ont suivi l'indépendance du Cameroun, les textes abordant la question de droit à l'eau potable se préoccupent davantage des mesures d'installation des populations que des questions de droit à proprement parler.

Toutefois, les jalons de ce droit ont été posés par la loi 64/LF/23 du 13 novembre 1964 portant sur la protection de la santé publique et le Décret $\mathrm{N}^{\circ}$ 68/59/ du 30 avril 1968. Dans le premier texte, sont posées les bases des mesures de salubrité des centres urbains et des lieux habités. Dans le second, sont contenues les dispositions en matière d'évacuation des eaux usées et matières fécales ainsi que les ordures ménagères. La vétusté de ces textes a au fil du temps entrainé leurs abrogations.

\section{A. Le droit à l'eau potable dans la loi fondamentale}

La constitution est au plan national la norme suprême. Encore appelée loi fondamentale (1), c'est elle qui régit l'ensemble des institutions d'un Etat en les garantissant. Le droit à l'eau potable n'apparaît pas de façon explicite dans la constitution camerounaise (2). Ceci ne peut pas tout de suite aboutir à la conclusion hâtive de l'inexistence de ce droit.

Suivant cette logique, Henri Smets affirme que : «la constitution, la législation, plus généralement le droit doit exprimer un besoin, une demande. L'imposition d'une norme juridique n'est pas suffisante. La loi est et doit être l'expression d'une volonté politique pour avoir un impact réel. Si l'inverse se produit, le processus risque d'être nul en termes de résultats. En somme, le droit à l'eau ne révolutionnera rien, en revanche, le focus international actuel est une expression politique forte qui pourrait avoir un impact». Il ne faudrait pas croire un instant que la prise en compte du droit à l'eau comme droit

\footnotetext{
${ }^{252}$ Propos recueillis dans www.camer.be/indexl.php?art=11176\&rub=6:1, consulté le 5 novembre 2010.

${ }^{253}$ AUBRIOT (J.), «Le droit à l'eau : émergence, définition, situation actuelle et position des acteurs ", op.cit. p.50.
} 
fondamental résout totalement le problème de l'effectivité de ce droit. En tant que Droit Economique, Social et Culturel, le droit à l'eau n'est certes pas explicitement mentionné dans la loi constitutionnelle camerounaise, mais on peut le déduire des autres DESC qui y sont proclamés. La constitution camerounaise garantit les DESC dans son Préambule en en ces termes: "Le Peuple camerounais [...] affirme son attachement aux libertés fondamentales inscrites dans la Déclaration universelle des droits de l'homme, la Charte des Nations Unies, la Charte des droits de l'homme et des peuples et toutes les conventions internationales y relatives et dîment ratifiées".

On peut par déduction affirmer que la constitution reconnaît implicitement ce droit. La mention "toutes conventions y relatives dûment ratifiées" laisse entendre l'ensemble des traités ${ }^{254}$ ratifiés faisant explicitement ou implicitement référence au droit à l'eau potable.

Toutefois, cette forte proclamation signifie-t-elle forcément réalisation de ce droit ? Le Peuple camerounais a-t-il à ce jour effectivement accès à l'eau potable et à un assainissement de base?

La réponse négative est évidente, car ; une grande partie de la population camerounaise vit dans le manque d'eau potable et dans des conditions de vie déplorables. La situation est plus grave dans les zones rurales et les quartiers pauvres. Ceci amène à penser que la mise en œuvre effective des droits économiques, sociaux et culturels n'est pas encore une réalité au Cameroun. Si leur reconnaissance textuelle y est, l'absence de justiciabilité de ces droits, en revanche, continue de faire obstacle à leur mise en œuvre effective. L'obstacle principal à la mise en œuvre du droit à l'eau potable en tant que droit économique, social et culturel tient de la nature de ce droit. Il s'agit d'un droit créance dont le principal débiteur est l'Etat. Or ce dernier bénéficie souvent des "prérogatives exorbitantes de droit commun "255. Autrement dit, la justiciabilité des Droits Economiques, Sociaux et Culturels demeure à ce jour un véritable mythe au Cameroun; d'où la rareté des cas jurisprudentiels y relatifs.

\section{La notion de loi fondamentale}

Encore appelée loi fondamentale d'un pays, la constitution est au niveau de la hiérarchie des normes juridiques, la plus haute au plan national ${ }^{256}$. C'est un ensemble de textes juridiques qui définit les différentes institutions composant l'Etat et organise leurs relations. La forme usuelle est celle écrite. Au Cameroun, la constitution est formée d'un préambule $^{257}$ et d'un corps. C'est aussi l'endroit où peuvent être mieux proclamés et garantis les droits dits de la troisième génération (le droit à la vie, le droit à l'éducation,

\footnotetext{
254 Pacte International relatif au Droit Economique, Sociaux et Culturel de 1966; la Convention sur l'élimination de toutes les formes de discriminations à l'égard des femmes de 1979; la Convention sur le droit de l'enfant de 1989; la Charte africaine des droits et du bien-être de l'enfant de 1990.

${ }^{255}$ Qui lui permet de ne pas être traité comme un simple particulier. Ce qui lui donne la possibilité de modifier unilatéralement ses engagements envers ses contractants sans être poursuivie comme l'exige l'article $1134 \mathrm{du}$ code civil: "Les conventions légalement formées tiennent lieu de loi à ceux qui les ont faites "; pour les détails, voir cours de droit administratif général disponible sur http://www.oboulo.com/caractere-exorbitantpouvoirs-administration-contrats-administratifs-27498.html, consulté le 8 juillet 2010.

${ }^{256}$ Les normes internationales ont priorité sur les normes nationales.

${ }^{257}$ Le préambule de la constitution camerounaise a longtemps fait l'objet de débat tranché en 1996: le préambule fait partie intégrante de la constitution.
} 
le droit à un environnement sain, le droit à l'eau potable) et les libertés fondamentales (telles que la liberté de mouvement, la liberté de presse et la liberté d'opinion). La constitution joue un rôle significatif au sein de l'Etat. C'est elle qui garantit à chacun le respect de ses droits. Elle définit les différents organes de l'Etat suivant le principe de la séparation de pouvoir en leur donnant la possibilité de se contrôler mutuellement. Elle fixe l'ensemble des compétences sur le territoire en définissant l'organisation ${ }^{258}$ de l'Etat. D'après l'article 1 de la loi constitutionnelle camerounaise de 1996, "la Républi-que du Cameroun est un Etat unitaire décentralisé, elle est une et indivisible, laïque, démocratique et sociale». Du préambule aux 69 articles de la constitution camerounaise, il n'est nulle part mentionné explicitement le droit à l'eau potable comme droit citoyen. Pourtant, la constitution constitue une norme non moins sûre de protection ${ }^{259}$ et de promotion des droits fondamentaux.

\section{Le droit à l'eau potable, un droit transparent dans la loi fondamentale}

Le droit à l'eau potable est un droit fondamental. Bon nombre d'Etats semblent avoir marqué un pas en insérant ce droit dans leurs constitutions. Il s'agit notamment de certains pays d'Afrique ${ }^{260}$, d'Amérique ${ }^{261}$ et d'Europe ${ }^{262}$.

\footnotetext{
${ }^{258}$ Qui peut être unitaire centralisé, décentralisé, ou fédérale; information recueillie dans www.vie-publique.fr, le 27 décembre 2008.

${ }^{259}$ La constitution bénéficie d'une protection politique, des procédures de révision contraignantes et du contrôle de la constitutionnalité (vérification de la conformité d'une norme à la constitution ou vice versa).

${ }^{260}$ Congo : Constitution de 2005, article 48 qui garantit le droit à un logement décent, le droit à l'eau potable et l'énergie électrique; Ethiopie : constitution de 1998, article 90 (al. 1) : "dans la mesure où les ressources du pays le permettent, les politiques doivent viser à fournir à tous les éthiopiens un accès [...] à une eau propre "; Gambie : Constitution de 1996, article 216 (al. 4) : "l'Etat s'efforcera de faciliter l'accès à l'eau propre et saine"; Kenya, projet de constitution de 2005, article 65 et 66 : "toute personne a le droit d'avoir accès à une eau potable de qualité satisfaisante et en quantité suffisante » : " toute personne a droit à des installations sanitaires élémentaires "; Afrique du Sud : Constitution de 1996, section 27(1): "toute personne a le droit d'avoir des services de soins de santé, y compris en matière de santé génésique (b); à des aliments et de l'eau en quantité suffisante [...] »; Ouganda: Constitution de 1995, article 14: "l'Etat s'efforce de réaliser les droits fondamentaux de tous les ougandais [...] et à garantir notamment que tous les ougandais jouissent des droits d'opportunités ainsi que d'un accès à l'éducation, aux services de santé, à une eau propre et saine [...] "; Zambie : Constitution de 1996, article 112 : «l'Etat s'efforce à fournir une eau propre et saine ».

${ }^{261}$ Equateur: Constitution de 1998, article 23: "l'Etat reconnaîtra et garantira aux personnes les droits suivants : le droit à une qualité de vie qui assure la santé, l'alimentation et la nutrition, l'approvisionnement en eau potable, l'assainissement de l'environnement "; Uruguay: Constitution de 2004, article 47 : "el agua es recursa esencial para la vida.el acceso al agua potable y acceso al saneamiento, constituyen derechos humanos fundamentales »; Etats-Unis (Massachusetts et Pennsylvanie) : reconnaît le droit des peuples d'accéder à une eau salubre.

262 Belgique: Constitution de 2005: "l'accès à l'eau potable est un droit humain essentiel», Voir http://eaulozere.free.fr/pj/droit_eau.pdf, consulté le 27 décembre 2008.
} 
Encadré 8. La liste des pays ayant constitutionalisé le droit à l'eau potable

AFRIQUE
République démocratique du Congo : const.2005,
article 48.
Ethiopie : const. 1998, article 90 al. 1.
Gambie : const. 1996, article 216 (4).
Kenya : projet const. 2005, article 65.
Afrique du sud : const. 1966, section 27.
Ouganda : const. 1995, article 14.
Zambie : const. 1996, article 112.
AMERIQUE LATINE
Colombie : const. 1991, article 366.
Equateur : const. 1998, article 23.
Uruguay : const. 2004 , article 47.
ASIE

Malgré les efforts fournis au plan national pour asseoir le droit à l'eau potable en tant que droit citoyen, le Cameroun n'a pas à ce jour intégré de façon solennelle le droit à l'eau potable en tant que droit de l'homme fondamental. La constitution camerounaise s'est tout de même évertuée à reconnaître dans son préambule les autres droits économiques, sociaux et culturels. Au $21^{\mathrm{eme}}$ tiret de son préambule, elle dispose que : "toute personne a droit à un environnement sain. La protection de l'environnement est un devoir pour tous. L'Etat veille à la défense et à la promotion de l'environnement». Ce qui signifie en d'autres termes que c'est "le droit à un environnement qui garantit la santé de tous les êtres humains $»^{263}$ notamment par l'accès à l'eau potable. Même si le concept de droit à l'eau potable n'a pas la même portée dans un pays où il a été constitutionalisé que dans celui où il ne l'a pas été, la constitutionnalisation du droit à l'eau potable n'est pas forcément une garantie ultime de l'accès des populations à la ressource. Le droit ne garantit pas absolument le respect des services essentiel de l'eau potable. "Respecter, protéger et mettre en cuvre le droit à l'eau nécessite la mise en place de services publics adéquats permettant de satisfaire cet objectif [...] Le droit à l'eau n'est pas obligatoirement le vecteur d'amélioration des politiques publiques et gage de résultats, mais il témoigne néanmoins de la reconnaissance par l'Etat de la priorité de celui-ci ${ }^{264}$.

$\mathrm{Au}$-delà de la reconnaissance, il est nécessaire de définir avec précision l'entité publique responsable de donner avec précision les champs de compétences ainsi que les responsabilités, et enfin les moyens par les citoyens de faire valoir ce droit. La non

\footnotetext{
${ }^{263}$ ANDELA (J.J.), «Les implications juridiques du mouvement constitutionnel du 18 janvier 1996 en matière d'environnement au Cameroun ", in Revue juridique de l'environnement, décembre 2009, p.426.

${ }^{264}$ AUBRIOT (J.), " Le droit à l'eau : émergence, définition, situation actuelle et position des acteurs ", op.cit., p.49.
} 
constitutionnalisation du droit à l'eau potable au Cameroun n'implique pas forcément que ce dernier ne reconnaisse pas ce droit. Au contraire, il existe au Cameroun une grande législation de l'eau de laquelle on peut voir naître et "vivre » le droit à l'eau potable. Seulement, constitutionaliser le droit à l'eau pourrait davantage lui accorder de crédit.

Tout compte fait, l'essentiel ne réside pas uniquement dans la reconnaissance ou encore la constitutionnalisation du droit à l'eau potable ; le tout est dans les mentalités et la volonté politique. Cette dernière (la volonté politique) se doit d'adopter et asseoir un arsenal juridique et un dispositif qui permettent la participation de tous pour plus d'efficacité dans la gestion de cette ressource.

\section{B. Le droit à l'eau dans la législation camerounaise}

Même après les deux décennies qui ont suivi l'indépendance du Cameroun, les textes abordant la question de l'eau se préoccupent davantage de la sauvegarde de la ressource au sein de l'Etat (régie par le droit de l'eau) que des questions de droit à l'eau potable à proprement parler. Si le cadre juridique et institutionnel de l'eau est disparate et peu efficace au Cameroun, le droit à l'eau potable du moins théoriquement n'y est pas un véritable leurre. Il est présent dans la loi portant régime de l'eau (1) et ses décrets d'application (2).

\section{Le droit à l'eau dans la loi portant régime de l'eau}

Bien avant avril 1998, la législation s'intéressant à la question de droit à l'eau potable au Cameroun envisageait ce droit plus du côté utilisation et exploitation que sous l'angle de sa protection contre les abus. Afin de remédier à cette insuffisance, l'Etat du Cameroun (à travers l'ex-Ministère des Mines, de l'Eau et de l'Energie (devenue MINEE) et d'autres ministères impliqués dans la question d'eau potable, ont mis en place dès 1989 un comité Ad hoc chargé d'élaborer le projet de loi prenant en considération la gestion et l'utilisation de l'eau dans l'ensemble du territoire national. Ce projet de loi sera examiné et pris en compte par l'Assemblée nationale en mars 1998 puis, promulgué par le Président de la République le 14 avril 1998 sous la dénomination de la loi $\mathrm{N}^{\circ}$ 98/005 du 14 Avril 1998 portant régime de l'eau. Cette loi fixe «dans le respect des principes de gestion de l'environnement et de protection de la santé publique ", le cadre juridique général du régime de l'eau au Cameroun (article 1.). L'article 2 de la même loi poursuit : "l'eau est un bien du patrimoine national dont l'Etat assure la protection et la gestion et en facilite l'accès à tous". Il ressort de cette disposition que l'eau relève de la souveraineté des Etats. D'après les alinéas 2 et 3 de cette même loi, l'Etat peut transférer toute ou partie de ses prérogatives aux collectivités territoriales décentralisées par voie de concession ou d'affermage. Ces alinéas ont été édictés dans le but d'encourager la célérité dans le processus de mise en œuvre du droit à l'eau.

Malgré la richesse de cette loi, les dispositions 6 à 12 de ce texte nous semblent quelques peu contradictoires quant à la garantie du droit à l'eau potable. A l'article 6 par exemple, on lit: "toute personne physique ou morale, propriétaire d'installation susceptible d'entraîner la pollution des eaux doit prendre toutes les mesures nécessaires pour limiter ou supprimer les effets». Aucune autre précision n'y est apportée. On se demande sous quelle peine ses mesures doivent être prises. L'alinéa 2 du même article 
dispose: "toute personne qui produit ou détient les déchets doit en assurer elle-même l'élimination ou le recyclage ou les faire éliminer ou les faire recycler dans les installations agréées par l'Administration chargée des établissements après avis obligatoire de l'administration chargée de l'environnement. ». Les dispositions des articles 11 et 12 quant à elles n'offrent pas beaucoup de garantie au droit à l'eau lorsqu'elles affirment respectivement que : "les personnes qui offrent ou vendent l'eau de boisson doivent ellesmêmes s'assurer de la conformité de la qualité de cette eau aux normes en vigueur» et plus loin à l'article 12 que : "le contrôle de la qualité des eaux de boisson est assuré à tout moment par les personnels des administrations chargées de l'eau et de la santé publique assermentés et commissionnés à cet effet ». Doit-on comprendre par ces articles que le contrôle $a b$ initio est assuré par les consommateurs sous la vigilance des organismes de contrôle de la qualité ? Sûrement. Les chapitres 1 à 3 du Titre IV de la même loi traitent respectivement de la responsabilité pour atteinte au droit, des sanctions pénales et de la constatation des infractions. L'article 14 aborde le champ de la responsabilité civile et les articles 15 (et suivants) le champ de la responsabilité pénale.

D'après l'article 15 : "est punie d'un emprisonnement de deux à cinq ans et d'une amende de 5.000 .000 à 10.000.000 de F.CFA, ou de l'une de ces peines seulement, toute personne qui réalise un prélèvement des eaux souterraines en violation des dispositions de la présente loi ou de ses textes d'application (alinéa 1)». L'article 16 poursuit : " est punie d'un emprisonnement de 10 à 20 millions de F.CFA toute personne qui pollue et altère la qualité des eaux (alinéa1), en cas de récidive, le coupable encourt le double du maximum des peines prévues (alinéa 2)». Les sanctions prévues sont complétées par celles contenues dans le code pénal ainsi que dans la législation relative à l'environnement (article 17).

De l'analyse de cette loi, il en ressort que celle-ci ne donne pas une définition claire du droit à l'eau potable; même s'il faut reconnaitre qu'elle consacre juridiquement sa protection. Pourtant, une bonne loi sur l'eau doit : clarifier les droits et responsabilités des usagers et des fournisseurs d'eau ; clarifier le rôle de l'Etat vis-à-vis des autres parties prenantes; formaliser le processus de transfert des affectations de l'eau; donner un statut légal aux groupes d'usagers de l'eau et partant assurer la durabilité de la ressource ${ }^{265}$.

${ }^{265}$ GWP, « Partager la connaissance sur la Gestion Intégrée des Ressources en Eau », Toolbox, 2007, p.14. 
Encadré 9. Les grandes innovations de la loi de 1998 portant régime de l'eau

La loi de 1998 portant régime de l'eau au Cameroun est à l'origine de 6 grandes innovations ${ }^{266}$ dans le secteur de l'eau :

- une grande ouverture vers la délégation de la gestion,

- la rupture du monopole de l'unique concessionnaire,

- les systèmes alternatifs d'alimentation en eau potable (puits particuliers, citernes, sources et forages),

- une plus grande attention à la protection de l'environnement avec paiements des taxes et redevances liées à la détérioration de la qualité des eaux et de l'environnement,

- une gestion plus rigoureuse et efficace,

- des pistes pour une plus grande coordination nationale des activités du secteur de l'eau et de l'assainissement pour l'ensemble du territoire national.

\section{Les décrets d'application de la loi portant régime de l'eau}

L'article 2 de la loi $\mathrm{N}^{\circ}$ 2001/163/PM du 08 mai 2001 réglementant les périmètres de protection, autour des points de captage, de traitement et de stockage des eaux potabilisables ${ }^{267}$ apporte une définition à certains termes importants ${ }^{268}$ dans la mise en œuvre du droit à l'eau potable.

Les modalités et conditions de prélèvement des eaux de surface ou souterraines à des fins industrielles ou commerciales sont fixées par le Décret $\mathrm{N}^{\circ}$ 2001/164/PM du 08 mai 2001. L'article 2 de ce décret subordonne ces prélèvements à une autorisation préalable. L'article 3 quant à lui dispense les eaux affectées à des fins domestiques de toute autorisation préalable. Il précise que la fourniture de cette eau doit respecter les limites quantitatives et qualitatives nécessaires à l'alimentation humaine, aux besoins d'hygiène et aux productions végétales ou animales réservées à la consommation familiale. $A$ contrario, tout prélèvement des eaux de surface ou souterraines à des fins industrielles ou commerciales est assujetti au paiement d'une redevance dont le taux, l'assiette et le mode de recouvrement sont fixés par la loi de finance (article $4 \mathrm{du}$ même décret). De ce

\footnotetext{
${ }^{266}$ BOSCO (D.T.N.) et suivant, L'eau au Cameroun, op.cit., p.24.

267 "Toute eau de surface, souterraine ou de source qui, naturellement ou après un traitement approprié physico-chimique ou microbiologique, peut être consommée sans danger pour la santé ", article 2 du décret $\mathrm{N}^{\circ}$ 2001/PM du 08 mai 2001.

${ }^{268}$ Périmètre de protection : " aire de protection délimitée autour d'un point de captage, de traitement ou de stockage des eaux potabilisables destinées à l'alimentation "; périmètre de protection immédiat: "aire de prévention ou aire géographique dans laquelle les ouvrages de captage, de traitement et de stockage des eaux peuvent être atteints par tout polluant sans que celle-ci soit dégradée ou dissoute de façon suffisante, ou qu'il soit possible de la récupérer de manière efficace "; périmètre de protection rapprochée : " aire de surveillance ou aire géographique qui comprend tout ou partie du bassin hydrographique qui est susceptible d'alimenter un point de captage d'eau existant ou éventuel "; point de captage des eaux : "aire géographique où sont implantés les ouvrages de prélèvement des eaux potabilisables, à savoir notamment les puits, les forages, les drainages et autres ouvrages ayant pour objet d'opérer les prises d'eau potabilisables, y compris les captages de source à l'émergence "; point de traitement des eaux : " aire géographique où sont implantés les installations et autres équipements de traitement des eaux potabilisables "; point de stockage des eaux : " aire géographique où sont implantés les réservoirs et autres bassins de stockage des eaux potabilisables brutes ou traitées ", article 2 de la loi $\mathrm{N}^{\circ}$ 2001/163/PM du 08 mai 2001.
} 
qui précède, il ne faut pas vite déduire que la fourniture de l'eau destinée à la consommation humaine est gratuite au Cameroun. Celle-ci est conditionnée par l'acquisition d'un abonnement (privé ou collectif) assorti du paiement mensuel d'un taux fixé à l'heure actuelle à $450 \mathrm{~F} / \mathrm{m}^{3}$.

Le Décret $\mathrm{N}^{\circ}$ 2001/165/PM du 08 mai 2001 précisant les modalités de protection des eaux de surface et des eaux souterraines contre la pollution institue des mesures nécessaires à la mise en œuvre du droit à l'eau potable au Cameroun. Après avoir défini les différentes sources de pollutions des eaux (déchets, rejets d'eaux usées, eaux de ruissellements), ce dernier décrit les formes de rejets interdits. L'article 3 de la même loi interdit le déversement, les écoulements rejets, les infiltrations, les enfouissements épandages, les dépôts directs ou indirects dans les eaux de toute matière solide, liquide ou gazeuse susceptible : d'altérer la qualité des eaux de surface ou souterraines ou de la mer dans les limites territoriales, de porter atteinte à la santé publique, de mettre en cause le développement économique, de nuire à la qualité de la vie et au confort des riverains. L'article 8 autorise les déversements inoffensifs après approbation préalable du ministre chargé de l'eau ou autres administrations concernées. L'article 15 pour sa part assujettit les personnes physiques ou morales propriétaires d'installations raccordées aux réseaux d'égouts publics ou privées au paiement d'une taxe d'assainissement suivant les modalités fixées par la loi de finance. Cet article constitue un prolongement du principe pollueur payeur. Le contrôle des déversements est assuré sous l'autorité du ministre chargé de l'eau par des agents assermentés des administrations chargées de l'eau, de la santé publique, de l'environnement et le cas échéant par les agents assermentés de l'agriculture et de l'élevage (article 17 dudit Décret).

Tableau $^{269} 5$ : La présentation du cadre juridique de l'eau au Cameroun

\begin{tabular}{|c|c|c|c|}
\hline $\mathbf{N}^{\circ}$ & $\begin{array}{l}\text { CADRE LEGISLATIF ET } \\
\text { REGLEMENTAIRE }\end{array}$ & DOMAINE D'APPLICATION & DROITS \\
\hline 1 & $\begin{array}{l}\text { Loi } \mathrm{N}^{\circ} 98 / 005 \text { du } 14 \text { avril } \\
1998 \text { portant régime de l'eau }\end{array}$ & $\begin{array}{l}\text { - fixe le cadre juridique général de } \\
\text { gestion de l'eau } \\
\text { - } 7 \text { décrets pris en application de } \\
\text { certaines dispositions visées dans } \\
\text { cette loi ont déjà été signés et publiés }\end{array}$ & \\
\hline 1.1 & $\begin{array}{l}\text { Décret } \mathrm{N}^{\circ} 2001 / 161 / \mathrm{PM} \text { du } \\
08 \text { mai } 2001 \text { pris en } \\
\text { application de l'article } 19 \text { de } \\
\text { la loi portant régime de l'eau }\end{array}$ & $\begin{array}{l}\text { - fixe les attributions, l'organisation et } \\
\text { le fonctionnement du Comité } \\
\text { national de l'eau }\end{array}$ & \\
\hline 1.2 & $\begin{array}{l}\text { Décret } \mathrm{N}^{\circ} 2001 / 162 / \mathrm{PM} \text { du } \\
08 \text { mai } 2001 \text { pris en } \\
\text { application de l'article } 19 \text { de } \\
\text { la loi portant régime de l'eau }\end{array}$ & $\begin{array}{l}\text { - fixe les modalités de désignation des } \\
\text { agents assermentés pour la } \\
\text { surveillance et le contrôle de la } \\
\text { qualité des eaux }\end{array}$ & \\
\hline 1.3 & $\begin{array}{l}\text { Décret } \mathrm{N}^{\circ} 2001 / 163 / \mathrm{PM} \mathrm{du} \\
08 \text { mai } 2001 \text { pris en } \\
\text { application de l'article } 7 \\
\text { portant régime de l'eau }\end{array}$ & $\begin{array}{l}\text { - reglémente les périmètres de } \\
\text { protection autour des points de } \\
\text { captage, de traitement et de stockage } \\
\text { des eaux potabilisables }\end{array}$ & \\
\hline 1.4 & $\begin{array}{l}\text { Décret } \mathrm{N}^{\circ} 2001 / 164 / \mathrm{PM} \mathrm{du} \\
08 \text { mai } 2001 \text { pris en }\end{array}$ & $\begin{array}{l}\text { - précise les modalités et conditions de } \\
\text { prélèvement des eaux de surface ou }\end{array}$ & $\begin{array}{l}\text { - frais d'ouverture de dossier } \\
\text { et d'étude de la demande }\end{array}$ \\
\hline
\end{tabular}

${ }^{269}$ Conçu à partir de la documentation acquise auprès du Ministère de l'Eau et de l'Energie du Cameroun. 


\begin{tabular}{|c|c|c|c|}
\hline $\mathbf{N}^{\circ}$ & $\begin{array}{l}\text { CADRE LEGISLATIF ET } \\
\text { REGLEMENTAIRE }\end{array}$ & DOMAINE D'APPLICATION & DROITS \\
\hline & $\begin{array}{l}\text { application de l'article } 10 \text { de } \\
\text { la loi portant régime de l'eau }\end{array}$ & $\begin{array}{l}\text { des eaux souterraines à des fins } \\
\text { industrielles et commerciales. } \\
\text { - soumet à autorisation préalable les } \\
\text { prélèvements desdites eaux affectées } \\
\text { à ces fins et les assujettis au paiement } \\
\text { d'une redevance dont le taux, } \\
\text { l'assiette et le mode de recouvrement } \\
\text { sont fixés par la loi de finances. } \\
\text { - fixe la liste des pièces constitutives de } \\
\text { la demande d'autorisation de } \\
\text { prélèvement des eaux ainsi que les } \\
\text { frais d'ouverture et d'étude du } \\
\text { dossier y relatif. }\end{array}$ & $\begin{array}{l}\text { d'autorisation de } \\
\text { prélèvements } \\
\text { - } 50000 \mathrm{~F} . \mathrm{CFA} \text { : pour les } \\
\text { prélèvements inférieurs à : } \\
\text { - } 100 \mathrm{~m}^{3} / \text { jour ; } \\
\text { - } 200000 \mathrm{~F} . \mathrm{CFA} \text { : pour les } \\
\text { prélèvements compris entre } \\
200 \text { et } 500 \mathrm{~m}^{3} / \text { jour; } \\
\text { - } 300.000 \mathrm{~F} . \mathrm{CFA} \text { : pour les } \\
\text { prélèvements compris entre } \\
500 \text { et } 1000 \mathrm{~m}^{3} / \text { jour ; } \\
\text { - } 500.000 \mathrm{~F} . \mathrm{CFA} \text { : pour les } \\
\text { prélèvements supérieurs à } \\
1000 \mathrm{~m}^{3} / \text { jour. }\end{array}$ \\
\hline 1.5 & $\begin{array}{l}\text { Décret } \mathrm{N}^{\circ} 2001 / 165 / \mathrm{PM} \text { du } \\
08 \text { mai } 2001 \text { pris en } \\
\text { application des articles } 4 \text { et } \\
5 \text { de la loi portant régime de } \\
\text { l'eau }\end{array}$ & $\begin{array}{l}\text { - précise les modalités de protection } \\
\text { des eaux de surface et souterraines } \\
\text { contre la pollution. } \\
\text { - soumet à autorisation préalable tous } \\
\text { déversements, écoulements, rejets. } \\
\text { - Infiltration [...] susceptible de } \\
\text { polluer l'environnement et } \\
\text { l'assujettit au paiement d'une taxe } \\
\text { d'assainissement dont le montant est } \\
\text { - fixé par la loi de finance. } \\
\text { fixe la liste des pièces de la demande } \\
\text { d'autorisation de déversement des } \\
\text { eaux ainsi que les frais d'ouverture et } \\
\text { d'étude du dossier y relatif. }\end{array}$ & $\begin{array}{l}\text { - frais d'ouverture et d'étude } \\
\text { de dossier de la demande } \\
\text { d'autorisation de } \\
\text { déversement des eaux : } \\
\text { - taux unique de } 10.000 \\
\text { F.CFA }\end{array}$ \\
\hline 1.6 & $\begin{array}{l}\text { Décret } \mathrm{N}^{\circ} 2001 / 216 \text { du } 02 \\
\text { août } 2001 \text { pris en } \\
\text { application des articles } 25 \\
\text { de la loi portant régime de } \\
\text { l'eau. }\end{array}$ & $\begin{array}{l}\text { - crée un compte d'affectation spéciale } \\
\text { pour le financement des projets de } \\
\text { développement durable en matière } \\
\text { d'eau et d'assainissement, } \\
\text { - définit de manière exhaustive les } \\
\text { projets en question à savoir : } \\
\text { - le développement des ressources } \\
\text { en eau } \\
\text { - l'alimentation en eau des centres } \\
\text { urbains et des zones rurales, } \\
\text { - l'assainissement des zones } \\
\text { urbaines et rurales, } \\
\text { - l'hydraulique agro-pastorale } \\
\text { - précise en outre que les ressources } \\
\text { du Compte d'Affectation arrêté } \\
\text { annuellement par la loi de finances } \\
\text { proviennent du produit: } \\
\text { - de la taxe d'assainissement, } \\
\text { - de la redevance des prélèvements } \\
\text { des eaux, } \\
\text { - des amendes et transactions, } \\
\text { - des contributions de donateurs } \\
\text { internationaux, } \\
\text { - de toutes autres contributions } \\
\text { volontaires. }\end{array}$ & \\
\hline
\end{tabular}




\begin{tabular}{|c|c|c|c|}
\hline $\mathbf{N}^{\circ}$ & $\begin{array}{l}\text { CADRE LEGISLATIF ET } \\
\text { REGLEMENTAIRE }\end{array}$ & DOMAINE D'APPLICATION & DROITS \\
\hline 2. & $\begin{array}{l}\text { Article } 11^{\text {ème }} \text { de la loi } \mathrm{N}^{\circ} \\
2004 / 026 \text { du } 30 \text { décembre } \\
2004 \text { portant loi de finances } \\
\text { du Cameroun pour } \\
\text { l'exercice } 2005 \text { pris en } \\
\text { application des articles } 8 \text { et } \\
10 \text { de la loi portant régime } \\
\text { de l'eau }\end{array}$ & $\begin{array}{l}\text { - fixe les dispositions relatives au } \\
\text { secteur de l'eau, à savoir les taux de } \\
\text { la taxe d'assainissement sur le } \\
\text { déversement des eaux usées } \\
\text { industrielles et de la redevance de } \\
\text { prélèvements des eaux de surface ou } \\
\text { des eaux souterraines à des fins } \\
\text { industrielles ou commerciales }\end{array}$ & $\begin{array}{l}\text { - taux de la taxe } \\
\text { d'assainissement : } \\
\text { - } 2.000 \mathrm{~F} . \mathrm{CFA} / \text { unité de } \\
\text { charge polluante. } \\
\text { - taux de redevance de } \\
\text { prélèvement : } \\
\text { - } 100 \mathrm{~F} . \mathrm{CFA} / \mathrm{m}^{3} \text {, } \\
\text { - } 50 \mathrm{~F} . \mathrm{CFA} / \mathrm{m}^{3} \text { pour les } \\
\text { tranches d'eau } \\
\text { supérieures à } 1000 \mathrm{~m}^{3} \text {, } \\
\text { - } 25 \mathrm{~F} / \mathrm{m}^{3} \text { pour les } \\
\text { prélèvements des eaux } \\
\text { affectées à un usage } \\
\text { agricole, pastoral ou } \\
\text { piscicole dont les } \\
\text { quantités journalières } \\
\text { sont supérieures à } 5000 \\
\text { équivalents hommes. }\end{array}$ \\
\hline 2.1 & $\begin{array}{l}\text { Décret } \mathrm{N}^{\circ} 2005 / 3089 / \mathrm{PM} \text { du } \\
29 \text { août } 2005 \text { pris en } \\
\text { application de l'article } 11^{\text {ème }} \\
\text { de la loi } \mathrm{N}^{\circ} 2004 / 026 \text { du } 30 \\
\text { décembre } 2004\end{array}$ & $\begin{array}{l}\text { - précise l'assiette, le recouvrement et } \\
\text { le contrôle de la taxe } \\
\text { d'assainissement et de la redevance } \\
\text { de prélèvement des eaux, }\end{array}$ & $\begin{array}{l}\text { - accorde un abattement de } \\
75 \% \text { pour la détermination } \\
\text { de la base d'imposition à } \\
\text { soumettre à la taxe } \\
\text { d'assainissement et de la } \\
\text { redevance }\end{array}$ \\
\hline$-1 /-$ & & $\begin{array}{l}\text { - définit la formule de calcul du } \\
\text { nombre d'unités de charge polluante } \\
\text { contenue dans l'eau usée ainsi que } \\
\text { les paramètres utilisés, } \\
\text { - précise que le règlement de la } \\
\text { redevance de prélèvement des eaux } \\
\text { est mensuel et celui de la taxe } \\
\text { d'assainissement trimestriel. }\end{array}$ & \\
\hline 3. & $\begin{array}{l}\text { Articles } 15 \text { et } 16 \text { de la loi } \\
\text { portant régime de l'eau }\end{array}$ & $\begin{array}{l}\text { Fixent les sanctions pénales en cas de } \\
\text { violation des dispositions de la loi }\end{array}$ & $\begin{array}{l}\text { Article } 15 \text { : } \\
\text { - peine d'emprisonnement : } 2 \\
\text { à } 5 \text { ans, } \\
\text { - Amendes : } \\
5.000 .000 \text { F.CFA pour } \\
\text { prélèvement des eaux non- } \\
\text { conformes. } \\
\text { Article } 16: \\
\text { - peine d'emprisonnement de } \\
5 \text { à } 10 \text { ans, } \\
\text { - Amendes : } 10 \text { à } 20.000 \\
\text {.000F.CFA. }\end{array}$ \\
\hline
\end{tabular}

Ces barèmes ne semblent pas symboliques pour les couches sociales défavorisées ${ }^{270}$. Ce sont les personnes ne disposant pas de moyens nécessaires pour prendre elles-mêmes un abonnement ou s'approvisionnant (à prix double) chez les titulaires d'un abonnement

${ }^{270}$ Presque tout le temps frappées par les retards dans les paiements et les coupures pour non paiement. 
ou encore dans les puits ou rivières de sources douteuses. Pour cette couche de population, l'eau potable s'apparente encore à un luxe.

Pourtant, dans les coutumes ancestrales, le don de l'eau destinée à la consommation humaine était un devoir citoyen. Au Cameroun comme partout ailleurs en Afrique, il n'existe pas en droit coutumier une propriété privée exclusive sur l'eau. Les consommateurs ne bénéficient en fait que d'un simple droit d'usage. Le droit coutumier confère à la terre comme à l'eau un droit collectif sans aucun critère d'attribution ni de privation. Tout le monde y a droit sans discrimination. L'eau est assimilée à un "don de la nature $»^{271}$ et comme tel, mérite d'être gérée avec droiture et dans l'intérêt des créatures de Dieu. L'eau est donc, du point de vue du droit traditionnel, une ressource divine sacrée appartenant à tous. Sa gestion nécessite une certaine délicatesse. C'est « un patrimoine commun » de l'humanité. Le droit coutumier de l'eau repose sur: l'appartenance de l'eau à Dieu et aux divinités; le contrôle de la ressource par le maître de l'eau (chef de la localité) qui règle les conflits y relatifs ; l'utilisation du savoir local pour protéger les ressources en eau; l'octroi du simple droit d'usage aux utilisateurs ${ }^{272}$.

Le droit moderne de l'eau gouverné par le principe de la domanialité publique, cherche à bouleverser ce système traditionnel. Pour Maurice KAMTO et Célestin. M. BOMBA, «à travers la négation légale des eaux privées, les Etats veulent, surtout dans le contexte sahélien, affirmer l'idée que l'eau est le bien commun de toute la collectivité et qu'elle doit faire l'objet d'une protection et d'une répartition équitable entre tous les utilisateurs ${ }^{273}$. Cette approche fait aussi partie de la stratégie camerounaise de mise en œuvre du droit à l'eau.

\section{SECTION II : ...A la stratégie camerounaise de mise en œuvre du droit à l'eau potable}

Lorsqu'on mène une analyse de proximité, l'on se rend compte que, la protection du droit à l'eau potable au Cameroun est en fait davantage plus formelle (paragraphe I) qu'institutionnelle (paragraphe II).

\section{Paragraphe I : Une protection formelle}

Malgré la panoplie de textes juridiques traitant de la mise en œuvre du droit à l'eau potable au Cameroun, l'état des lieux (A) et la pratique du droit à l'eau (B) demeure encore un fait alarmant.

\section{A. La problématique de l'eau potable au Cameroun}

Le problème lié à l'accès insuffisant à l'eau potable (1) au Cameroun pourrait bien avoir une explication (2). La zone la plus touchée par la pénurie est la région du Grand Nord

\footnotetext{
${ }^{271}$ GERARD (S.), « La gestion démocratique de l'eau : un enjeu mondial d'intérêt général », p.15.

${ }^{272}$ ALISSOUTIN (R.L.), « La négation du savoir local dans les politiques de l'eau en Afrique », voir www.interreseaux.org/IMG/pdf/allissoutin_eau.pdf, consulté le 05 janvier 2009.

${ }^{273}$ ALISSOUTIN (R.L.), op.cit., p.3.
} 
Cameroun menacée par le désert. On y trouve un fort taux de maladies hydriques. La problématique du droit à l'eau potable est donc avant tout une problématique de droit d'accès.

\section{L'eau potable, une ressource prisée}

S'il est vrai que la ressource eau est abondante dans certains endroits du pays, du point de vue disponibilité, il n'en demeure pas moins vrai qu'elle demeure rare $^{274}$ du point de vue potabilité. D'après les estimations faites par l'O.M.S., moins de $30 \%$ de la population rurale contre $50 \%$ de la population urbaine est alimentée en eau potable. De façon globale, environ $42 \%$ de la population camerounaise n'a toujours pas accès à l'eau potable ${ }^{275}$. Ces chiffres témoignent de l'absence d'une volonté politique matérialisée par la relégation de l'approvisionnement en eau des populations au rang "d'axe mineur " dans la politique de développement du pays durant les trois dernières décennies. Ce qui justifie le fait qu'aujourd'hui, le pays ne dispose pas encore d'un cadre juridique unique d'orientation stratégique en matière de gestion de l'eau ${ }^{276}$.

\section{Les causes de la rareté de l'eau potable}

L'essentiel des ressources en eau du Cameroun se regroupe dans ses principaux bassins hydrographiques (Niger, Lac Tchad, Congo, Atlantique). Or, la gestion des ressources en eau devrait se faire à l'intérieur d'un même bassin ${ }^{277}$. La rareté de la ressource en eau potable se justifie par les comportements malsains de certains consommateurs (tels que la pollution tellurique des cours d'eaux; l'entretien des eaux stagnantes à proximité des domiciles; la construction des fosses sceptiques à proximité des points d'eaux; la mauvaise gestion de la ressource (les utilisations abusives); la gestion défectueuse des ins-tallations (parfois laissée à la charge du consommateur); et par certaines causes climatiques principalement dans la zone du Nord Cameroun (telles que l'irrégularité et la diminution de la pluviométrie). L'assainissement inadéquat est à l'origine des situations parfois calamiteuses comme les maladies ${ }^{278}$ épidémiques liées à la consommation d'eaux sales. Cette situation occasionne souvent la sécheresse et entraîne constamment la fragilisation des écosystèmes et la réduction du potentiel des ressources naturelles (telles que les terres, la faune, la flore et les ressources en eau ${ }^{279}$.

\footnotetext{
${ }^{274}$ L'affirmation de la rareté de l'eau douce est de plus en plus contestée par certains scientifiques qui considèrent qu'une confusion est entretenue à ce niveau entre limite et mauvaise gestion [...] L'eau ne serait à proprement parler pas "rare». Sa pollution produit cependant un effet de raréfaction. Extrait de l'introduction générale à la thèse de PAQUEROT (S.), « Le statut de l'eau douce en droit international : penser la res pu-blica universelle», (note de bas de page 9), p.2.

${ }^{275}$ Consulté dans http://www.latitudesciences.ird.fr/images/photos/JPE/jpe_depliant_web.pdf, le 08 janvier 2009.

${ }^{276}$ Voir http://fr.allafrica.com/stories/200804090928.html, consulté le 08 mai 2008.

${ }^{277}$ Idem.

${ }^{278}$ Voir le cas de l'épidémie de choléra qui se propage au Cameroun à l'heure actuelle (2011) surtout dans la zone du grand Nord.

${ }^{279}$ Documentation Global Water Partnership, central africa, «processus d'élaboration du PAGIRE du Cameroun : Document d'orientation », p.22, octobre 2005.
} 
B. La pratique du droit à l'eau potable au Cameroun

La pratique du droit à l'eau potable au Cameroun est un fait davantage plus théorique

(1) que pratique (2).

\section{Un fait plus théorique...}

L'analyse minutieuse du cadre juridique de l'eau au Cameroun montre que le droit à l'eau potable y est juridiquement consacré, mais ce droit reste théorique. En effet, malgré la multiplicité de textes législatifs relatifs à l'eau ${ }^{280}$, la mise en œuvre du droit à l'eau potable au Cameroun reste encore une quête permanente. Le développement du secteur de l'eau potable au Cameroun se heurte à de nombreux obstacles.

Encadré 10. Les obstacles à la mise en œuvre du droit à l'eau potable au Cameroun

Parmi les obstacles majeurs dans la mise en œuvre du droit à l'eau potable au Cameroun, on a :

- l'environnement institutionnel (problème de gouvernance et de pauvreté);

- le cadre législatif (absence de texte de définition et de mise en œuvre du droit à l'eau au Cameroun, inexistence d'une Convention-cadre sur le droit à l'eau à l'international);

- le cadre social (problème d'assainissement, mauvaise répartition de la ressource et la marginalisation de certaines couches sociales (les personnes habitant dans les zones rurales et les coins retirés ne sont pas à ce jour desservies par le service de distribution de l'eau potable).

\section{2...Que pratique}

Malgré la multiplicité des textes législatifs régissant le secteur de l'eau au Cameroun, le taux de couverture des populations en eau potable reste encore très faible (environ $60 \%$ en zone urbaine, $55 \%$ en zone périurbaine contre $30 \%$ en zone rurale). La situation en

\footnotetext{
280 Loi $\mathrm{N}^{\circ}$ 98/005 du 14 avril 1998; Décret $\mathrm{N}^{\circ}$ 2001/161/PM du 08 mai 2001 fixant les attributions, l'organisation et le fonctionnement du Comité national de l'eau; Décret N ${ }^{\circ}$ 2001/162/PM du 08 mai 2001 fixant les modalités de désignation des agents assermentés pour la surveillance et le contrôle de la qualité d'eaux; Décret $\mathrm{N}^{\circ}$ 2001/163/PM du 08 mai 2001 réglementant les périmètres de protection autour des points de captage, de traitement et de stockage des eaux potabilisables; Décret 2001/165/PM du 08 mai 2001 précisant les modalités de protection des eaux de surface et des eaux souterraines contre la pollution; Décret $\mathrm{N}^{\circ}$ 01/166/PM du 08 mai 2001 précisant les modalités et conditions de prélèvement des eaux de surfaces et des eaux souterraines à des fins industrielles ou commerciales; Décret $N^{\circ} 2001 / 216$ du 02 août 2001 portant création d'un compte d'affectation spéciale pour le financement des projets de développement durable en matière d'eau et d'assainissement; Décret 2003/1397 du 10 juillet 2003 modifiant et complétant les articles $1^{\mathrm{er}}$, 2 et 4 du Décret 2002/1721/PM du 08 octobre 2002 précisant les règles d'assiette, de contrôle et de recouvrement dans le cadre du programme de sécurisation des recettes des mines, de l'eau et de l'énergie; Décret 2005/087 du 29 mars 2005 portant organisation du Ministère de l'Energie et de l'Eau, Décret N ${ }^{\circ}$ 2005/3089/PM du 29 août 2005 précisant les règles d'assiettes, de recouvrement et de contrôle de la taxe d'assainissement et de la redevance de prélèvement des eaux; Décret $N^{\circ}$ 2005/493 du 31 décembre 2005 fixant les modalités de délégation des services publics de l'eau potable et de l'assainissement liquide en milieu urbain et périurbain; Décret 2005/494 du 31 décembre 2005 portant création de la Cameroon water corporation; Décret $N^{\circ}$ 2006/117 du 29 mars 2006 partant approbation des statuts de la Cameroon Water Utilities Corporation, etc.
} 
milieu rural est davantage plus critique: les installations sont certes payées par les finances publiques, mais sa gestion et son entretien sont encore laissés à la charge des bénéficiaires ${ }^{281}$.

La prise en compte de l'environnement urbain et rural par les pouvoirs publics reste encore très faible. La gestion de l'assainissement n'est pas séparée de celle du réseau d'adduction d'eau potable. Il existe très peu d'expériences réussies d'assainissement collectif au Cameroun. L'on dénombre une quinzaine de stations d'épuration à Douala et Yaoundé, presque toutes hors d'usage. Par conséquent, le volume des eaux usées est très élevé, oscillant entre 90 et $95 \%$ du volume d'eau consommée. La proportion de ménage camerounais disposant d'un système d'assainissement moderne est estimée à $7,3 \%{ }^{282}$. Les mécanismes de justiciabilité de ce droit sont encore très faibles au Cameroun voir quasi inexistants. Or, "l'existence d'un droit sans mécanisme de le défendre équivaut à une absence de droit [...] un droit n'est droit que quand il peut être défendu $»^{283}$. L'existence effective d'un droit dépend donc des mécanismes juridiques de sa défense, c'est-à-dire de sa justiciabilité.

Bien plus, la femme originaire de la sous région de l'Afrique centrale est victime des discriminations de toutes sortes. Elle est pressée par le poids de la coutume, affaiblie par son pouvoir d'achat parfois en dessous de la moyenne et souvent considérée comme le sexe faible. Tout ceci ajouté à une éducation reçue dans des conditions déplorables. Elle est presque toujours marginalisée lorsqu'il est question de prendre des décisions en matière de gestion ou de protection de l'environnement. Quatorze ans après la Déclaration de la plate-forme d'action de Beijing, la situation de la femme n'a presque pas du tout changé. Or, elle entretient d'intéressants rapports avec le milieu environnemental et celui de l'eau potable en particulier. Le désengagement de la femme dans le domaine de l'eau potable doit être considéré comme un échec si l'on veut parvenir à une gestion durable des écosystèmes. Car, il existe entre la femme et les ressources naturelles un rapport direct et essentiel. Ce rapport tire sa force de l'identité sexuelle et des rôles et responsabilités créés par la société qui continuent d'incomber aux femmes dans les ménages. La femme est plus avertie au sujet des menaces qui peuvent influencer l'environnement ${ }^{284}$. Il serait intéressant de s'interroger sur la pertinence de son rôle dans la gestion et la préservation de l'eau potable. L'analyse de la situation de la femme par rapport à l'environnement est une question préoccupante. Elle doit être prise très au sérieux si l'on veut atteindre l'objectif principal qu'est celui de développement durable $^{285}$. Les rapports que les femmes entretiennent avec l'environnement se manifestent de diverses façons. Elles sont souvent gardiennes des connaissances indigènes et initiatrices de nouvelles méthodes de gestion rationnelle de la biodiversité

\footnotetext{
${ }^{281}$ Consulté dans wwww.passerelle-ngam.org/presentation/situation-de-l-eau-au-cameroun.html; le 03 avril 2009.

282 «Le secteur de l'eau au Cameroun» op.cit., p.2.

${ }^{283}$ NZATI M. M. (D.M.), «Quel bilan dresser de l'effectivité et de la justiciabilité des droits économiques, sociaux et culturels en République démocratique du Congo au regard de la Déclaration universelle des droits de l'homme et de la Charte africaine des droits de l'homme et des peuples ", avril 2009, p.6.

${ }^{284}$ NGWAINMBI (F.G.), Mémoire de Master D.I.C.E., "Femme et environnement pour un développement durable dans la sous région de l'Afrique centrale au regard du droit international de l'environnement", Université de Limoges, août 2006, p.28.

${ }^{285}$ Idem, p. 12.
} 
et de l'environnement. En zone rurale, ce sont les femmes et les jeunes filles qui fournissent la quasi-totalité de l'eau servant à la famille. Cette eau est utilisée comme eau de boisson, dans la transformation et la préparation des aliments, pour le bain et la lessive. C'est elle qui fait la collecte, le stockage et contrôle l'utilisation des ressources. Les femmes font également de multiples usages de la ressource en eau qu'elles exploitent au maximum, et veillent à ce qu'elle ne soit pas polluée, étant donné la multiplicité de leurs besoins souvent concurrentiels ${ }^{286}$. Elles ne parviennent pas encore à éviter la contamination de l'eau disponible.

$\mathrm{Au}$ fur et à mesure que l'homme, les animaux et le ruissellement provenant des exploitations agricoles contaminent les sources d'eau potable, que s'accroît la sécheresse et que se dégradent les sources du fait d'une mauvaise gestion des bassins versants, les femmes et les jeunes sont obligés de parcourir de longues distances pour se procurer une eau parfois de qualité douteuse. Dans certaines régions telles que l'extrême Nord, les femmes doivent parcourir jusqu'à dix kilomètres à la recherche de cette eau ${ }^{287}$. Conscient de cette difficulté, l'Etat tente d'organiser de façon administrative ses services de l'eau.

\section{Paragraphe II : Le service de l'eau potable au Cameroun}

Le service de l'eau potable est exercé par le Ministère de l'Eau et de l'Energie et ses partenaires sous tutelles. Ce service connait une organisation administrative collégiale. L'Etat intervient pour répartir les compétences. C'est l'organe de tutelle (B). La tâche de l'eau lui incombe à titre principal. L'article 2 de loi N ${ }^{\circ}$ 98/005 du 14 avril 1998 portant régime de l'eau dispose : "l'eau est un bien du patrimoine national dont l'Etat assure la protection et la gestion en facilitant l'accès à tous ». Toutefois, l'Etat peut transférer toute ou partie de ses prérogatives aux organismes de gestion et d'exploitation du service de l'eau (A).

\section{A. La gestion et l'exploitation du service}

Avec la réorganisation de ce secteur en décembre 2005, deux nouvelles institutions ont été créées en vue de renforcer la distribution de l'eau. Il s'agit de la Cameroon Water Utilities Corporation (CAMWATER) qui gère le patrimoine de l'Etat (1) et de la société d'exploitation appelée la Camerounaise Des Eaux (CDE) qui assure la distribution de la ressource (2). Les activités de cette dernière ont débuté en juin 2008.

\section{Le gestionnaire du patrimoine de l'Etat}

La Camwater est une institution étatique régie par un contrat qui gère le patrimoine de l'Etat. Créée par Décret N²005/494 du 31 décembre 2005, la Camwater est placée sous la tutelle financière du ministre chargé des finances et sous la tutelle technique du ministre chargé de l'eau et de l'énergie. Elle assure la gestion pour le compte de l'Etat des biens et droits affectés au service public de l'eau potable en milieu urbain et périurbain. Ses missions essentielles sont: la planification, la réalisation d'études, la maîtrise d'ouvrage, la recherche et la gestion des financements pour l'ensemble des

\footnotetext{
${ }^{286} \mathrm{~A}$ la fois indispensable pour le bétail et la consommation humaine.

${ }^{287}$ NGWAINMBI (F.G.), Mémoire de Master D.I.C.E op.cit., p.31.
} 
infrastructures et ouvrages nécessaires au captage, à la production, au transport au stockage et à la distribution de l'eau potable; la construction, la maintenance et la gestion des infrastructures de production, de stockage et de transport de l'eau potable; le contrôle de la qualité de l'exploitation du service public de distribution de l'eau potable et des autres missions confiées aux sociétés chargées de l'exploitation du service public de distribution de l'eau potable en coopération avec les sociétés d'exploitation, l'information et la sensibilisation des usagers du service public de l'eau potable en milieu urbain et périurbain; et en général de toutes les opérations commerciales, industrielles, mobilières, immobilières et financières qui se rattachent directement aux objets définis ci-dessus ou de nature à favoriser leur développement ${ }^{288}$.

La Camwater est liée à l'Etat par un contrat « de concession de travaux publics et de gestion du patrimoine de l'hydraulique urbaine et périurbaine au profit de la Camwater ". Elle travaille en étroite collaboration avec le Ministère de l'Eau et de l'Energie et la société fermière (la Camerounaise Des Eaux). Les membres du personnel de la Camwater sont a priori choisis parmi les personnels de l'ex-Société Nationale des Eaux du Cameroun (SNEC).

\section{L'exploitation du service de l'eau potable}

La distribution de l'eau potable est aujourd'hui assurée au Cameroun par la Camerounaise Des Eaux. Avant juin 2008, cette gestion et exploitation des réseaux d'eau potable étaient dévolues à la Société Nationale des Eaux du Cameroun (créée le 22 mai 1967). Cette dernière avait pour mission d'effectuer pendant 40 ans toutes activités de production, de transport, de distribution et de commercialisation de l'eau potable en milieu urbain et périurbain. La SNEC ${ }^{289}$ a eu à gérer le service de l'eau potable auprès de $90 \%$ de la population urbaine du pays. Bien plus, elle disposait d'un système de production d'une capacité de $450.000 \mathrm{~m}^{3}$ /jour et d'un réseau de distribution de 4200 $\mathrm{km}^{290}$. Appuyé par les partenaires au développement, l'Etat du Cameroun engagera vers les années 1990 la privatisation de plusieurs sociétés parmi lesquelles la SNEC ${ }^{291}$. Le processus aboutira en 2005 à la création de la société concessionnaire. Désormais, les tâches dévolues à la SNEC ressortissent à la compétence de la société fermière appelée la Camerounaise Des Eaux (CDE).

Créée par décret $\mathrm{N}^{\circ} 2005 / 493$ du 31 Décembre 2005 fixant les modalités de délégation des services de l'eau potable et de l'assainissement liquide en milieux urbains et périurbains, la CDE est une société privée (d'origine marocaine) chargée de: la production et la distribution de l'eau potable en milieux urbain et périurbain ; l'entretien des infrastructures, du traitement de l'eau et des activités liées à la fonction commerciale ; du relevé, la facturation et l'encaissement des recettes. Le capital social de la société fermière est détenu à hauteur des deux tiers au moins par des actionnaires privés, dont $51 \%$ au moins par un actionnaire de référence et $24 \%$ au moins par les

\footnotetext{
${ }^{288}$ Article 2 du Décret N²005/494 du 31 décembre 2005.

${ }^{289}$ Elle compte plus de 225.000 abonnés pour 90 millions de $\mathrm{m}^{3}$ d'eau vendu /an.

${ }^{290}$ Documentation de la Camwater, "Investir dans le secteur de l'eau potable au Cameroun », juin 2000, p.2.

${ }^{291}$ La première tentative de privatisation de la SNEC initiée en 1999 en vue de la mise en concession de la fourniture de l'eau potable est déclarée infructueuse en 2003.
} 
actionnaires camerounais ${ }^{292}$. La mise en œuvre du droit à l'eau potable au Cameroun est une entreprise évolutive. Elle est passée tour à tour de l'héritage (voir la section I du présent chapitre) à la stratégie camerounaise de mise en œuvre dudit droit (voir la section II du même chapitre).

Néanmoins, il faut reconnaître que l'avancée de cette stratégie n'a pas suffi à desservir la totalité de la population en eau de qualité sûre. Ainsi, une grande majorité des populations urbaines, périurbaines et surtout rurales n'a toujours pas accès à l'eau potable en quantité et en qualité suffisantes. L'Etat du Cameroun à travers ses multiples ministères et prioritairement celui de l'Energie et de l'Eau cherche autant que possible à institutionnaliser un cadre juridique plus favorable à la mise en œuvre du droit à l'eau potable. La création de la Cameroon Water Utilities Corporation en 2005 et le démarrage des activités du nouvel opérateur (la Camerounaise Des Eaux) dans le domaine de l'eau potable au Cameroun en 2008 constituent une avancée louable mais insuffisante ${ }^{293}$. Même si le droit à l'eau potable ne s'apparente pas encore à un véritable droit subjectif dont peuvent directement se prévaloir les citoyens camerounais, les perspectives d'avenir sont heureuses au regard de la pratique internationale. Il est vrai, ce droit demeure encore au Cameroun non constitutionnalisé et peu codifié; mais les organismes d'appui extra étatiques tels que les $\mathrm{ONG}^{294}$ et les associations jouent un rôle significatif dans la mise en ouvre de ce droit.

$\mathrm{Au}$ Cameroun, cette entreprise est l'œuvre de diverses institutions de financement telles : la Banque Mondiale, la Global Water Partnerhip on Output Based Aid (GPOBA), la Exim Bank of China, l'Agence Française de Développement (AFD), la Banque Européenne d'Investissement (BEI), la Banque Islamique de développement (BID) et la Banque Africaine de Développement (BAD).

\section{B. Le rôle des organismes sous tutelles}

Ce rôle est dévolu au Ministère de l'Eau et de l'Energie (1), aux inspecteurs de l'eau (2) et a2ux autres ministères (3).

\section{Le rôle privilégié du Ministère de l'Eau et de l'Energie}

Ce département ministériel en charge des projets d'eau potable, d'assainissement et de lutte contre la pollution a connu une grande évolution aussi bien dans son organisation et ses attributions que dans sa dénomination. En 1977, le décret $N^{\circ} 77 / 371$ du 26 septembre confie au MINEE le rôle d'approvisionnement en eau potable et assainissement des agglomérations urbaines. A cette époque, les zones rurales relevaient

\footnotetext{
${ }^{292}$ Documentation Camwater op.cit., p.3.

${ }^{293}$ Les ménages camerounais continuent de souffrir du problème d'absence ou de coupure intempestive d'eau. $\mathrm{Au}$ point où les sapeurs pompiers initialement formés pour assurer le service des incendies sont passés au premier rang de distributeur permanent de la ressource dans certains quartiers, Observation faite de 2009 à 2011.

${ }^{294}$ Depuis les conférences internationales de Stockholm et de Rio de 1972 et 1992, les ONG jouent en matière environnementales un rôle d'alerte (dénonciation des risques environnementaux), de sensibilisation (information des citoyens), de gestion (de l'environnement à travers diverses formes d'interventions) et participation (au processus) décisionnel. Au Cameroun Provillage et la Global Water Partnership assurent assez efficacement ce rôle en matière de développement du droit à l'eau potable.
} 
de la compétence du ministère de l'agriculture. Restructuré en 1988, le ministère de l'eau se dénomme désormais : Ministère des Mines, de l'Eau et de l'Energie (MINMEE) et ses compétences s'étendent désormais aux zones rurales. Ce qui aboutit à la création de la Direction de l'Hydraulique Rurale (DHR) et la Direction de l'Eau et d'Assainissement dans les zones Urbaines (DEAU). La DEAU a également la charge d'établir les normes de qualité du milieu et de rejets des effluents liquides et gazeux.

Dans le Décret de 1977 précité, on note une sectorisation et une opposition zone rurale et urbaine. Le constat est que ce décret ne fait pas référence aux zones périurbaines (périphérique aux villes). Heureusement, le Décret 96/227 du $1^{\text {er }}$ octobre 1996 vient réorganiser ce département ministériel tout simplement en Direction de l'Eau qui comprend à cette période trois sous directions chargées distinctement de la gestion de l'eau, des adductions d'eau et de l'assainissement ${ }^{295}$. En même temps, c'est le MINMEE qui assure la tutelle de l'ex-Société Nationale des Eaux du Cameroun $(\mathrm{SNEC})^{296}$.

En 2005, le Décret No 2005/087 du 29 mars 2005 apporte de nouvelles innovations: le MINMEE devient le Ministère de l'Energie et de l'Eau (MINEE). Ce département ministériel a à compter de cette date trois fonctions essentielles: l'élaboration, la mise en œuvre et l'évaluation de la politique gouvernementale en matière de production, de transport et de distribution de l'énergie et de l'eau. A cet effet, il est chargé de: l'élaboration des plans et stratégies gouvernementales en matière d'alimentation en énergie et en eau; de la prospection, de la recherche et de l'exploitation des eaux dans les villes et les campagnes; de la promotion des énergies nouvelles en liaison avec le ministre chargé de la recherche scientifique ${ }^{297}$.

\section{Le rôle des inspecteurs et inspecteurs adjoints de l'eau}

Institués par le Décret $\mathrm{N}^{\circ}$ 2001/162/PM du 08 mai 2001(fixant les modalités de désignation des agents assermentés dans la surveillance et le contrôle de la qualité des eaux), les inspecteurs sont désignés parmi les fonctionnaires de la catégorie A et les contractuels d'administration de la $10^{\mathrm{e}}$ à la $12^{\mathrm{e}}$ catégorie spécialisés dans le domaine de l'eau, en service au ministère chargé de l'eau. Les inspecteurs adjoints sont désignés parmi les fonctionnaires de la catégorie $\mathrm{B}$ et les contractuels d'administration de la $7^{\mathrm{e}}$ à la $8^{\mathrm{e}}$ catégorie $^{298}$ (de la même spécialité que celle mentionnée à l'alinéa 1 ci-dessus). Peuvent également être désignés comme inspecteurs ou inspecteurs adjoints de l'eau : les agents publics d'autres administrations chargés de la santé publique et l'environnement sur proposition de leurs chefs de départements ministériels respectifs (article 8 du Décret). Préalablement à leurs nominations ${ }^{299}$, ils sont soumis à une formation théorique et pratique en matière de contrôle et de surveillance de la qualité de l'eau.

\footnotetext{
${ }^{295}$ Extrait de BOSCO (D.T.N) et suivant, L'eau au Cameroun, op.cit., pp.44-46.

${ }^{296}$ Depuis juin 2008, le nouveau gérant est appelé fermier.

${ }^{297}$ Article $1^{\text {er }}$, Decret $N^{\circ} 2005 / 087$ du 29 mars 2005 portant organisation du MINEE.

${ }^{298}$ Article 7 du même décret.

${ }^{299}$ Les inspecteurs sont nommés par arrêté du Ministre chargé de l'eau. Dans l'exercice de leur fonction, ils doivent se munir de leur carte professionnelle.
} 
Ils sont compétents pour: contrôler la qualité des eaux de consommation, les installations publiques ou privées de distribution d'eau, de prélèvement et de traitement des eaux de surface ou des eaux souterraines à des fins industrielles ou commerciales ; recueillir les données et autres informations nécessaires au calcul et au recouvrement de la taxe d'assainissement et de la redevance de prélèvement des eaux à des fins industrielles ou commerciales; initier toute sanction administrative à l'encontre de tout contrevenant aux dispositions de la législation de réglementation relative à l'eau (article 12 du Décret). En cas d'infraction, l'administration chargée de l'eau fait notifier le procès verbal de constatation d'infraction au contrevenant qui dispose d'un délai de 20 jours à compter de la notification pour contester le procès verbal. Passé ce délai, toute contestation est irrecevable (article 14 du même Décret).

\section{Le rôle des autres ministères}

Le Ministère de l'Eau et de l'Energie est assisté dans sa tâche par plusieurs autres ministères. Le Ministère de la ville qui est chargé de la définition des programmes d'alimentation en eau potable et d'assainissement dans les villes de son ressort. Il assure également la tutelle de la Société Immobilière du Cameroun (SIC) qui a la charge des réseaux secondaires d'alimentation en eau potable et d'assainissement dans les logements qu'elle gère.

Le Ministère de l'Agriculture (MINAGRI) qui comprend une Direction du Génie Rural et de l'Hydraulique Agricole (devenue Direction du Développement Communautaire du Génie Rural en 1986) est chargé entre autres des études de l'hydraulique villageoise et pastorale en liaison avec les autres ministères. Cette direction agit en "phase» avec la Direction de l'Hydraulique Rurale du MINNEE. Cette action conjointe et très peu spécifique est parfois à l'origine des échecs constatés lors de la mise en place des initiatives de récupération des coûts de l'eau dans les villages ${ }^{300}$.

Le Ministère de la santé publique est quant à lui chargé de l'étude et de la mise en œuvre de la politique gouvernementale en matière d'hygiène et de l'assainissement en milieu urbain et rural, de la surveillance sanitaire des collectivités et la promotion de la salubrité de l'environnement, de l'identification et la résolution de tous les problèmes sanitaires significatifs de la nation, du contrôle de la qualité des eaux de consommation $^{301}$.

Le Ministère du Développement industriel et commercial (MINDIC) assure pour sa part l'étude et l'application du plan directeur d'industrialisation, le contrôle de qualité, la fixation du coût de l'eau en relation avec les autres ministères impliqués ${ }^{302}$.

Le Ministère de l'environnement et des Forêts (créé par le Décret N 92/069 du 09 avril 1992) remplace l'ex-Comité National Permanent de l'Homme et de la Biosphère (M.B.A) dissout en 1989 et assure la gestion des écosystèmes environnementaux. Il est compétent pour élaborer le plan national de gestion de l'environnement, concevoir et établir un système de collecte, de traitement et de diffusion des informations relatives à l'environnement, concevoir un cadre de gestion de l'environnement publié sous forme

\footnotetext{
${ }^{300}$ BOSCO (D.T.N) et suivant, L'eau au Cameroun, op.cit., p.48.

${ }^{301}$ Idem, p.51.

${ }^{302}$ Ibid., p.52.
} 
de loi. De façon générale, ce ministère est chargé de proposer les mesures de gestion rationnelle et durable des ressources naturelles et d'élaborer les plans directeurs de protection de l'environnement. Il s'assure avec les autres ministères désignés de la gestion rationnelle et équitable des ressources en eau.

\section{L'action des organismes d'appui technique et de conseils}

Les organismes d'appui technique et de conseils regroupent les comités institués dans différents départements ministériels pour orienter et appuyer les actions gouvernementales en matière d'hygiène et salubrité de manière générale, ainsi que de l'eau et de l'assainissement en particulier. Parmi ces organismes, on a : la Commission Nationale d'Hygiène et Sécurité au Travail (sous la tutelle du Ministère de la Santé), le Conseil Supérieur de la Santé, de l'Hygiène et des Affaires Sociales (également au Ministère de la santé), le Comité National de l'Environnement du Secrétariat Permanent à l'environnement basé au (MINEF) et le Comité National de L'eau (placé sous la responsabilité du MINEE). Dans un souci de synthèse, seuls les deux derniers feront l'objet d'analyse.

\section{Le rôle du Comité national de l'eau}

Créé par décret $\mathrm{N}^{\circ} 85 / 758$ du 30 juin 1985 en application de la loi Nº4/013 du 05 décembre 1984 (portant régime de l'eau au Cameroun modifiée), cet organe est consultatif. Il est chargé d'assister le gouvernement dans l'élaboration de la politique de l'eau et de la recherche des moyens de sa mise en œuvre, de proposer les grandes orientations de la politique de l'eau, notamment le plan national d'utilisation des ressources en eau, de donner son avis sur les projets de textes de lois et règlements relatifs à la politique de l'eau.

Depuis l'avènement du Décret $\mathrm{N}^{\circ}$ 2001/161/PM du 08 mai 2001, la composition ainsi que les attributions du Comité ont évolué. Le Comité national de l'eau comprend à compter de cette date :

- un président : le ministre chargé de l'eau,

- un représentant du ministre chargé des finances,

- un représentant du ministre chargé de la santé publique,

- un représentant du ministre chargé de l'environnement,

- un représentant du ministre chargé de l'aménagement du territoire,

- un représentant du ministre chargé de l'urbanisme et de l'habitat,

- un représentant du ministre chargé de l'administration territoriale,

- un représentant du ministre chargé de la ville,

- un représentant du ministre chargé de l'agriculture,

- un représentant du ministre chargé de l'élevage, des pêches et des industries animales,

- un représentant du ministre chargé de la météorologie,

- un représentant du ministre chargé du développement industriel et commercial,

- le président de la chambre d'agriculture, d'élevage et de la pêche et des forêts ou son représentant,

- un représentant des associations des mairies, 
- un représentant des concessionnaires du service public de l'énergie (article $3 \mathrm{du}$ Décret $\mathrm{N}^{\circ}$ 2001/161/PM du 08 mai 2001).

Bref, le Comité national de l'eau réunit en son sein presque tous les acteurs du domaine de l'eau au plan national. Ses fonctions essentielles se résument en trois points : étudier et proposer au gouvernement toutes les mesures ou actions tendant à assurer la conservation, la protection et l'utilisation durable de l'eau, émettre des avis sur les questions ou problèmes relatifs à l'eau dont il est saisi par le gouvernement, faire au gouvernement toute proposition ou recommandation concourant à la gestion rationnelle de l'eau. En ce qui concerne notamment l'élaboration et la mise en œuvre des plans ou projets de développement durable en matière d'eau et d'assainissement (article 2 du même Décret).

\section{Le rôle du Comité national de l'environnement}

C'est l'organe en charge de la coordination des phénomènes environnementaux. Il est chargé de mener des réflexions sur la portée et l'impact des actions de développement sur l'exploitation et l'évolution des ressources naturelles, de rechercher les méthodes en vue d'une gestion saine de l'environnement par une sensibilisation de la population. Toutefois, il importe de préciser que, depuis la dissolution du MINPAT en 1996, les attributions de ce Comité ont été transférées au Ministère de l'Environnement et des forêts.

Au regard de l'analyse ci-dessus, l'on est en droit d'affirmer que le service de l'eau potable fait intervenir au Cameroun de nombreux acteurs certes importants dans la gestion écologique de l'eau en général, mais trop nombreux pour assurer un service efficace fondé sur la célérité.

La spécialisation des compétences en la matière pourrait bien constituer un début de solution dans la mise en œuvre effective de ce droit. Ainsi, on pourrait par exemple confier ce seul service au Ministère de l'Eau et de L'Energie qui bénéficiera des conseils des autres ministères. Loin d'être un gage certain de l'accès définitif des populations à l'eau potable, la mise en œuvre du droit à l'eau potable au plan interne permettrait de promouvoir une politique de l'eau potable plus soucieuse de l'équité, de renforcer les financements et de mettre un terme à l'ignorance, à la méconnaissance du droit. "Le droit à l'eau en tant que principe juridique est un moyen pour promouvoir une réduction des maladies hydriques $»^{303}$. Ce droit donne aux personnes bénéficiaires les moyens de défendre plus légitimement leurs intérêts. Sa mise en œuvre effective interpelle tous les acteurs et les sujets de droit international.

Encadré 11. La place des différents acteurs dans la mise en œuvre du droit à l'eau potable

- La communauté internationale

A travers les OI, les Nations Unies, la Banque mondiale, le FMI ; la communauté internationale intervient pour fournir une assistance financière ou technique aux

\footnotetext{
${ }^{303}$ AUBRIOT (J.), « Le droit à l'eau : émergence, définition, situation actuelle et position des acteurs ", op.cit., p.66.
} 
gouvernements, vérifier ou contrôler les politiques instituées dans le secteur de l'eau et coordonner l'ensemble des actions liées à l'eau entre les gouvernements.

\section{- L'Etat}

L'Etat est compétent pour : accorder la priorité au service de l'eau potable lors de l'élaboration des politiques sectorielles et budgétaires, décentraliser le service de l'eau afin d'éviter les encombrements dans le secteur, adopter des lois favorables à la mise en œuvre du droit à l'eau potable, établir et planifier des plans d'actions efficaces dans le domaine de l'eau potable, assurer la coordination entre les différents ministères en charge de la question et les services compétents, protéger et promouvoir le droit à l'eau potable à travers des actions concrètes, s'assurer de la disponibilité et de l'accessibilité des informations relatives au droit à l'eau au public, intégrer les mesures de bonne gouvernance dans la gestion des services de l'eau potable, veiller au respect des obligations contractuelles prises par le concessionnaire et fermier, étendre le service de l'eau potable dans les zones non desservies, encourager la notion de prix abordable pour tous et contrôler régulièrement la qualité de l'eau distribuée aux populations.

\section{- Le Concessionnaire ${ }^{304}$}

Doit respecter ses obligations contractuelles envers l'Etat.

\section{- Le Fermier ${ }^{305}$}

Doit respecter ses obligations contractuelles envers l'Etat et envers les individus

\section{- La société civile}

Est chargée de renforcer les capacités de la communauté, soutenir les actions gouvernementales, d'éduquer et sensibiliser les publics au sujet du droit à l'eau et dénoncer les abus dans le secteur.

\section{- Les individus}

Ils ont la charge :d'identifier les besoins suivant une politique d'actions communes et si possible les soumettre à L'Etat ou aux associations de défense des intérêts des consommateurs, de s'informer sur le droit à l'eau afin de pouvoir légitimement le revendiquer en temps opportun, de contribuer régulièrement à la gestion pérenne de l'eau potable, d'adopter un comportement sain et anti- pollution et de coopérer avec les autres acteurs suscités et avec les autres membres de la communautés locales.

\footnotetext{
${ }^{304} \mathrm{Au}$ cameroun, cette fonction est dévolue à la société étatique de patrimoine appelée la Camwater est qui liée à l'Etat par un contrat appelé "Contrat de concession de travaux publics et de gestion du patrimoine de l'hydraulique urbaine et périurbaine au profit de la Camwater".

${ }^{305}$ Il est appelé CDE (Camerounaise Des Eaux) et est lié à l'Etat par un contrat d'affermage qui définit clairement les droits et obligations du fermier. La Camerounaise Des Eaux à la charge de: produire, transporter et distribuer l'eau potable sur l'étendu du territoire affermé, d'exploiter le service confié suivant les règles de l'art et dans des conditions qui assurent à la fois la rentabilité optimale des matériels mis à sa disposition et aux meilleurs conditions de coûts pour les usagers. Elle assure cette tâche dans le respect permanent de la protection de l'environnement quant aux choix des matériaux acquis et utilisés ainsi que des technologies et modes d'exploitation adoptés (art. 7 al.1 du contrat d'affermage). Ce même fermier doit en permanence assurer au service public affermé, un fonctionnement permanent, et garantir la production, le transport et la distribution d'une eau de bonne qualité et à une bonne pression. L'essentiel des relations entre le fermier et l'usager est contenue dans le Règlement de service de distribution de l'eau potable dans les centres urbains et périurbains du Cameroun. Ce règlement de service détermine à son tour les conditions d'application du contrat d'affermage aux usagers.
} 
Pour parvenir à la mise en œuvre effective du droit à l'eau potable, l'implication de tous les acteurs est indispensable. Au Cameroun en particulier, la mise en œuvre du droit à l'eau potable se trouve freinée par les obstacles à la fois d'ordre juridique, institutionnel et pratique. 

CHAPITRE IV

L'EFFECTIVITE DU DROIT A L'EAU POTABLE AU REGARD DU DROIT CAMEROUNAIS 
La mise en œuvre du droit à l'eau potable ressortit à la compétence de chaque Etat qui se doit de l'intégrer dans sa législation nationale et de veiller à son respect. Ces mesures prises peuvent être à la fois d'ordres juridique, institutionnel et pratique. Chaque Etat définit la gestion, la responsabilité et veille à la couverture des services en la matière de façon progressive et suivant ses moyens. Autrement dit, la gouvernance de l'eau varie suivant les Etats. Elle doit tenir compte des plans d'action ainsi que des points de vue des bénéficiaires. Il relève de la compétence de chaque Etat de veiller ${ }^{306}$ à ce que : l'eau destinée à la consommation humaine sur son territoire soit potable, accessible et abordable pour tous les citoyens; les services en charge des questions d'eau fonctionnent de façon ininterrompue; la situation des couches sociales défavorisées soit abordée avec grand intérêt; l'assainissement soit collectif dans les zones urbaines et l'approvisionnement en eau régulier dans les zones rurales.

De la Déclaration ${ }^{307}$ universelle des droits de l'homme de 1948 en passant par le Pacte $^{308}$ international relatif aux droits économiques, sociaux et culturels de 1966 pour aboutir à la Déclaration ${ }^{309}$ de Stockholm de 1972 ratifiés par le Cameroun, aucun de ces textes fondamentaux n'a de façon explicite fait référence au droit à l'eau en tant que droit humain essentiel. A côté de cette difficulté, chaque Etat est au plan interne appelé à édicter sa propre législation de l'eau potable en s'inspirant des textes internationaux incitateurs comme l'Observation Générale $\mathrm{N}^{\circ} 15$ et la Résolution A/64/L.63/Rev.1 du 28 juillet 2010 (qui fait du droit à l'eau potable et l'assainissement, un droit fondamental indispensable dans la jouissance de la vie et dans la réalisation des autres droits de l'homme). Cela se justifie sans doute par le fait qu'il n'existe pas à ce jour une Convention-cadre d'harmonisation de ce droit.

En dépit de la rareté des accords internationaux directement consacrés au droit à l'eau potable, un nombre croissant d'Etats reconnaissent aujourd'hui qu'il s'agit bien d'un droit fondamental ${ }^{310}$. C'est ainsi qu'au Cameroun, il existe un arsenal juridique en bute cependant à des obstacles juridiques, institutionnels et pratiques (section I) duquel on peut voir naître un droit à l'eau potable; quoique la constitution camerounaise ne fasse pas directement référence à ce droit comme dans certains autres droits nationaux. Cela ne change pas grand chose à la mise en œuvre du droit en question. Car, le tout n'est pas de constitutionnaliser le droit à l'eau, mais de trouver des moyens pour faciliter sa mise en ouvre. Si la législation camerounaise comme beaucoup d'autres législations des pays d'Afrique centrale, ne met pas un accent sur le droit à l'eau considéré comme un droit fondamental, il existe tout de même des mécanismes juridiques de renforcement d'un tel droit (section II).

\footnotetext{
306 Voir à ce sujet: «le droit à l'eau, un droit pour tous les citoyens » op.cit., consulté dans http://www.astee.org/communication/cai/fichiers/34_1.pdf, p.3.

${ }^{307}$ "Toute personne a droit à un niveau de vie suffisant pour assurer sa santé, son bien-être et ceux de sa famille notamment pour l'alimentation, l'habillement et le logement, les soins médicaux ainsi que les services sociaux nécessaires ", art.25.

${ }^{308}$ Les Etats reconnaissent le droit de toute personne à un niveau de vie suffisant, pour elle et sa famille $\mathrm{y}$ compris une nourriture, un vêtement et un logement suffisants, art.11.1.

${ }^{309}$ L'homme a un droit fondamental à la liberté, à l'égalité et à des conditions de vie satisfaisantes dans un environnement donc la qualité lui permette de vivre dans la dignité et le bien-être, principe 1 .

310 SMETS (H.), «L'accès à l'eau potable et le droit international », voir http://www.academieeau.org/IMG/pdf/MURCA.pdf, p.2., consulté le 05 septembre 2009.
} 


\section{SECTION I : Le solutionnement des obstacles juridiques, institutionnels et pratiques}

La constitution camerounaise ne fait pas explicitement référence au droit à l'eau. L'essentiel de ce droit est contenu nous l'avons dit dans la loi $N^{\circ}$ 98/005 du 14 avril 1998 portant régime de l'eau (et ses décrets d'application). Ces textes ne traitent pas spécifiquement du droit à l'eau, mais du statut de l'eau en général. L'article 2 de cette loi fait de l'eau un bien économique dont la gestion incombe à l'Etat à titre principal et par délégation à la Camerounaise Des Eaux chargée de l'exploitation du service de la production et de la distribution d'eau potable en milieu urbain et périurbain et la société étatique de patrimoine et la Camwater chargée pour sa part de la gestion de l'ensemble du patrimoine de l'Etat en milieu urbain, et périurbain ainsi que du contrôle de la qualité de l'exploitation du service public de production, de transport et de distribution de l'eau potable (tel que précédemment illustré au chapitre 3 ).

Pour parvenir à un droit effectif à l'eau potable au Cameroun, il faut résoudre les difficultés d'ordre juridiques en mettant sur pied un arsenal juridique qui définisse clairement le droit à l'eau et ses implications pour les citoyens bénéficiaires et qui spécialise les compétences en la matière. Au lieu de laisser intervenir tous les ministères dans le domaine comme c'est le cas, on pourrait par exemple penser à conférer la seule compétence au Ministère de l'Eau et de l'Energie (sans désengager la responsabilité des autres ministères dans le processus de mise en œuvre dudit droit) ; ce qui aurait comme avantage de limiter les lenteurs et les lourdeurs dans le processus. La résolution des obstacles juridiques passe également par l'adhésion du pays à des actions en faveur d'une Convention-cadre dans le domaine de l'eau potable. Car, malgré la divergence des idées au sujet de la question s'il faille oui ${ }^{311}$ ou non $^{312}$ adopter une Convention-cadre dans le domaine de l'eau potable, la réponse affirmative est évidente. Une Convention du genre ne peut qu'être la bienvenue dans le contexte de crise globale de l'eau potable actuelle. Certes, une telle idée n'est pas nouvelle; "mais, nulle part dans les textes juridiques contraignants, les Etats n'ont cru bon d'introduire formellement le droit à l'eau qu'ils ont pourtant affirmé à plusieurs reprises $»^{313}$. Il existe plusieurs conventions faisant

\footnotetext{
${ }^{311}$ Plusieurs mouvements militent pour une Convention-cadre dans le domaine de l'eau potable. On a par exemple La Green cross international et l'alliance Maghreb-Machrek de l'eau qui ont initié un processus en faveur d'une gouvernance effective de l'eau au niveau international dont l'aboutissement est la mise à jour du document " Principes Fondamentaux pour une Convention-cadre sur le droit à l'eau "; L'académie de l'eau qui a mis sur pied une importante mobilisation littéraire pour asseoir le droit à l'eau comme droit humain, Henri Smets est l'un des «maestro » de cette action (pour les détails voir la documentation y relative dans www.academie-eau.org .

${ }^{312}$ Pour certains, une Convention-cadre dans le domaine de l'eau potable est sans importance: primo, revendiquer un nouvel outil conventionnel pour poursuivre la mise en œuvre du droit à l'eau vient à donner raison aux Etats qui pensent que ce droit n'existe pas. Secundo, les processus normatifs sont longs, pénibles et largement décevants à la fois du point de vue du contenu et du point de vue des modalités d'effectivité dans le système international. Tercio, il ya à l'heure actuellement une Convention pendante : celle de New York sur le droit relatif à l'utilisation des cours d'eaux à des fins autres que la navigation qui n'a pas encore reçu le nombre de ratification nécessaires pour son entrée en vigueur; cf. Document de Réflexion et plan d'action, "pour la mise en œuvre du droit à l'eau en tant que droit humain, une plate forme pour organiser la mobilisation ", Atelier $\mathrm{N}^{\circ} 1$ du FAME, Genève, 18 mars 2005, p.5.

${ }^{313}$ PAQUEROT (S.), «Le droit d'accès à l'eau : Aspects politiques et juridiques au plan international ", op.cit., p.9.
} 
référence au droit à l'eau potable, mais, aucune ${ }^{314}$ d'elle ne l'envisage comme un droit humain essentiel ni ne consacre tout son contenu à la question; même pas la Convention $^{315}$ de New York sur le droit relatif à l'utilisation des cours d'eaux internationaux à des fins autres que la navigation ou même celle d'Helsinki ${ }^{316}$ sur la protection et l'utilisation des cours d'eaux transfrontières et des lacs internationaux. Pour être une vrai solution, la Convention-cadre doit mentionner clairement les obligations de chacun (Qui fait quoi pour faciliter la réalisation de ce droit ?) et veiller à ce que dans ses dispositions figurent les mentions suivantes et ce en détails : " le droit à l'eau est un droit fondamental de l'homme et consiste en un approvisionnement suffisant en eau, physiquement accessible et à un coût abordable. Le droit à l'eau implique l'accès à un système d'approvisionnement qui permette à ses titulaires d'exercer leur droit d'accès et d'usage sans discrimination et en toute sécurité. Le droit à l'eau garantit un accès pérenne, sans entraves ni interruption arbitraire et, en cas de pénurie, les habitations précaires ne seront pas défavorisées dans l'accès. L'eau distribuée doit toujours être de qualité acceptable et surtout non contaminée. Les Etats sont les principaux garants de la mise en cuvre effective de ce droit. Ils ont la responsabilité d'assurer l'accès de tous à l'eau potable selon une politique qui tienne compte de la situation de tous et de toutes les zones (zones rurales et zones urbaines). Les Etats doivent instituer une politique de gestion de l'eau potable qui tienne compte des règles du développement durable (les règles de la gestion intégrée doivent par exemple être une priorité). Les lois et règlement au plan national doivent être pris en conformité à ces exigences".

Le droit à l'eau est un droit justiciable au même titre que les autres droits de l'homme. L'autre objectif phare de la Convention-cadre sera de renforcer les capacités et le pouvoir des décisions pris au niveau local, continental et international. L'efficacité de cette action passera par le culte de la coopération et de la participation. La Conventioncadre se doit d'exprimer clairement la nécessité de la participation de tous dans l'accès à l'eau potable. Les dispositions des articles de la Convention envisagée doivent clairement prendre en compte les données telles que : la participation du public ainsi que de la société civile. Cette action doit se développer autour des partenaires pluriels, reconnus et égaux; la participation doit s'étendre au niveau du processus décisionnel et de l'évaluation des projets liés à l'eau potable et l'assainissement. Les populations, les autochtones et les collectivités territoriales décentralisées locales ont un grand rôle à jouer dans le processus (ceux-ci connaissent mieux les cultures locales, les milieux, les pratiques traditionnelles ainsi que les technologies appropriées au milieu). Cette Convention devra clairement mentionner l'obligation d'informer et d'intégrer les citoyens dans le processus de mise en œuvre du droit à l'eau potable. Cette obligation

\footnotetext{
${ }^{314}$ Si ce n'est l'Observation Générale $N^{\circ} 15$ et la Résolution A/64/L.63/Rev.1 du 28 juillet 2010 qui, dans la pratique n'ont aucune valeur juridique contraignante.

${ }^{315}$ Signée le 21 mai 1997 et pas encore en vigueur jusqu'à nos jours du fait de ses nombreuses lacunes. Elle est faible du point de vue de son contenu et ne comporte aucun mécanisme obligatoire de règlement des différends. Bien plus, elle ne reconnaît pas le droit à l'eau comme droit humain; Cf. Document de Réflexion et plan d'action, "pour la mise en œuvre du droit à l'eau en tant que droit humain, une plate forme pour organiser la mobilisation », op.cit., p.5.

${ }^{316}$ Signée en 1992 entre les Etats de la CEE; également désignée sous le terme de Convention sur l'eau. Sa portée demeure limitée entre les pays signataires; elle entrera en vigueur en 1996. Elle fournit le cadre juridique de la coopération régionale sur les ressources en eau partagée (rivières, lacs et eaux souterraines).
} 
d'information doit être définie comme suit : chaque Etat partie à cette Convention doit mettre à la disposition du public dans le cadre de sa législation nationale, les informations sur le droit à l'eau sans que ce public n'ait à faire valoir un intérêt particulier sauf réserve ${ }^{317}$ à l'obligation d'information prévue à l'article 4 de la Convention sur l'accès à l'information, la participation du public au processus décisionnel et l'accès à la justice en matière d'environnement. Bien plus, les institutions législatives de chaque pays devraient pour accompagner cette Convention : "lutter pour mettre en place des procédures juridiques et judiciaires accordant la possibilité au peuple d'obliger les dirigeants (l'exécutif) au respect de leurs obligations constitutionnelles. Car, un Etat de droit est aussi celui qui sait assumer ses responsabilités face à son Peuple en même temps qu'il admet de répondre de ses actions ou inactions face à lui. $»^{318}$.

Ainsi, les individus parviendront à revendiquer avec succès ce droit devant les tribunaux ou devant les juridictions continentales ou internationales qui auront eux aussi acquis de part cette Convention le pouvoir de rendre des décisions obligatoires. L'idée d'une Convention-cadre dans le domaine de l'eau potable est d'une utilité certaine. Toutefois, l'inquiétude persiste: "Certes une Convention de l'ONU sur le droit à l'eau pourrait être un moteur d'accélération du processus mais, quels Etats vont porter ce processus et quels Etats vont faire blocage? Les USA qui refusent tout ce qui a trait au PIDESC vont-ils soutenir ce projet? Est-ce que les Pays en développement qui n'auraient pas encore saisi le contenu du droit à l'eau et l'assimilent parfois encore à tort à la gratuité vont soutenir le processus ${ }^{319}$ ?".

Il ne faut pas se leurrer, le parcours vers une Convention-cadre dans le domaine de l'eau potable est plein d'embûches. Mais, il est évident que rien de grandiose ne se réalise sans embûches. Certes, un instrument conventionnel international n'aura peut-être un impact positif significatif sur les populations qui souffrent déjà du manque d'accès à l'eau que si au niveau national, la volonté politique existe. Une Convention-cadre dans le domaine de l'eau potable ne viendra probablement pas résoudre tous les problèmes auxquels font face les individus dans la revendication et le respect de leur droit y relatif, mais, elle serait une arme suffisante contre les problèmes que pose par exemple H. Tazi Sadeq ${ }^{320}$ lorsqu'elle affirme que : «le droit à l'eau paraît être un droit individuel, mais, dans nos sociétés, il peut difficilement être revendiqué, et défendu de manière individuelle. La revendication et la défense doivent pouvoir être faites de manière collective. Mais nos

\footnotetext{
${ }^{317}$ Une demande d'information sur l'environnement peut être refusée si l'autorité publique à laquelle la demande est adressée n'est pas en possession de l'information demandée ou la demande est manifestement abusive ou formulée en termes trop généraux ou porte sur des documents en cours d'élaboration ou concerne des concertations internes des autorités publiques (à condition que cette exception soit prévue par le droit interne ou la coutume ) compte tenu de l'intérêt que la vulgarisation des informations demandées présenterait pour le public art. 4 al. 2; Pour les cas de rejet de la demande d'information, voir article 4 al. 4 de la même Convention.

${ }^{318}$ NZATI (D.M.), «Quel bilan dresser de l'effectivité et de la justiciabilité des droits économiques, sociaux et culturels en République démocratique du Congo au regard de la Déclaration universelle des droits de l'homme et de la Charte africaine des droits de l'homme et des peuples », op.cit., p.8.

${ }^{319}$ AUBRIOT (J.), «Le droit à l'eau : émergence, définition, situation actuelle et position des acteurs », op.cit., p.44.

${ }^{320}$ Houria Tazi SADEQ est présidente de l'Alliance Maghreb-Machrek pour l'eau (ALMAE) et gouverneur au Conseil Mondial de l'eau du Maroc.
} 
législations ne le permettent pas. L'action est toujours individuelle. Les ONG n'ont pas la capacité de faire ce qu'elles pourraient faire. Là aussi, c'est un chantier sur lequel il faut réfléchir. Moyens de recours, oui, mais accessibles à qui? Je n'imagine pas un simple citoyen d'un bidonville revendiquer son droit à l'eau sur la base d'une coûteuse procédure. Soyons concrets. Je pense que là aussi, il y a une réflexion à mener. Et je me dis: "qu'est-ce que le droit à l'eau aujourd'hui? Quelle serait la plus-value pour le quotidien des gens? $»^{321}$.

Ce sont là d'intéressantes pistes ouvertes pour interpeller et inciter la communauté internationale à adopter cette Convention dont l'utilité ne fait plus l'objet de doute.

On pourrait également résoudre les difficultés d'ordre institutionnel en appliquant les règles de bonne gouvernance dans le secteur (utilisation effective et efficiente des budgets alloués pour accélérer le processus de mise en œuvre de ce droit) en encourageant la volonté politique et surtout en luttant efficacement contre la pauvreté.

Pour ce qui est des difficultés d'ordre pratique, on pourrait enfin former et informer les citoyens sur le bien fondé de l'assainissement et de l'utilisation rationnelle des ressources naturelles en générales. Si ces recommandations sont prises en compte, le droit à l'eau potable deviendrait ainsi un droit accessible sinon à tous (paragraphe I), du moins au grand nombre. Pour y parvenir et dans l'optique de maintenir en veille tous les efforts entrepris, il serait louable d'assister le Cameroun dans ce processus (paragraphe II).

\section{Paragraphe I : Le droit à l'eau potable, un droit accessible}

Afin que la mise en œuvre du droit à l'eau potable devienne une réalité au Cameroun, il faudrait que les critères d'accessibilité $(\mathrm{A})$ soient respectés et que le problème des couches sociales défavorisées soit résolu (B). «Pour que les populations humaines et les écosystèmes puissent se développer, l'eau doit être propre, elle doit rester propre et surtout elle doit être accessible à tous $\aleph^{322}$. Pour que tout ceci soit réalisable, il faudrait que l'accès passe si possible avant le droit car, à quoi sert véritablement le droit à l'eau potable dans un pays où les populations n'ont pas accès à la ressource?

\footnotetext{
${ }^{321}$ Information recueillie dans « Le droit à l'eau en Afrique et en Europe », Académie de l'eau, 2005, p.26.

${ }^{322}$ Message de Mme BOKAVA Irina, Directrice générale de l'UNESCO à l'occasion de la journée mondiale de l'eau en 2010, « De l'eau pour un monde sain », 22 mars 2010.
} 
Tableau $6^{323}$ : Les critères d'accessibilité à l'eau potable (descripteurs du niveau de service par rapport à l'hygiène).

\begin{tabular}{|l|l|l|l|}
\hline Niveau de service & $\begin{array}{l}\text { Eloignement en termes } \\
\text { de distance parcourue } \\
\text { ou de temps dépensé } \\
\text { (évalué en mètres }(\mathbf{m}) \\
\text { et par minute }(\mathbf{m i n}))\end{array}$ & $\begin{array}{l}\text { Quantité collectée } \\
\text { par/litre/personnes/jour } \\
(\mathbf{a b r e ́ v . ~} \mathbf{1} / \mathbf{p} / \mathbf{j})\end{array}$ & $\begin{array}{l}\text { Niveau de } \\
\text { préoccupation pour la } \\
\text { santé }\end{array}$ \\
\hline Aucun accès & $\begin{array}{l}\text { + de } 1000 \mathrm{~m} \text { ou } 30 \mathrm{~min} \\
\text { parcourus pour la } \\
\text { recherche de l'eau }\end{array}$ & $\begin{array}{l}\text { Souvent moins de } 5 \mathrm{l} / \mathrm{p} / \mathrm{j} \text { (très } \\
\text { faible) }\end{array}$ & $\begin{array}{l}\text { Optimal (car la qualité } \\
\text { est difficilement } \\
\text { garantie) }\end{array}$ \\
\hline Accès de base & $\begin{array}{l}\leq \text { à } 100 \mathrm{~m} \text { (soit } 5 \text { à } 30 \\
\text { min de distance } \\
\text { parcourue }\end{array}$ & $\begin{array}{l}\text { Il est improbable que la quantité } \\
\text { dépasse } 201 / \mathrm{p} / \mathrm{j} \text { (faible) }\end{array}$ & $\begin{array}{l}\text { Moyen (car la qualité est } \\
\text { difficilement) garantie) }\end{array}$ \\
\hline Accès intermédiaire & $\begin{array}{l}\text { Sur le site (un seul } \\
\text { robinet / maison ou } \\
\text { terrain) }\end{array}$ & Peut atteindre $50 \mathrm{l} / \mathrm{p} / \mathrm{j}$ (moyen) $)$ & $\begin{array}{l}\text { Faible (car, la majorité } \\
\text { des besoins essentiels } \\
\text { peuvent être garantis) }\end{array}$ \\
\hline Accès optimal & $\begin{array}{l}\text { Servie à domicile par } \\
\text { plusieurs robinets }\end{array}$ & $\begin{array}{l}\text { Comprise entre } 100 \text { et } 300 \mathrm{l} / \mathrm{j} \\
\text { (variante) }\end{array}$ & $\begin{array}{l}\text { Très faible (car tous les } \\
\text { besoins peuvent être } \\
\text { remplis parce que la } \\
\text { quantité est } \\
\text { suffisamment bonne et } \\
\text { régulière. }\end{array}$ \\
\hline
\end{tabular}

\section{A. Les critères d'accessibilité}

Par critère d'accessibilité, il faut entendre la réalisation d'un certains nombre d'éléments matérialisant la mise en œuvre du droit à l'eau telle que l'accès moral, physique (1) et économique (2).

Encadré 12 ${ }^{324}$. L'avis de l'OMC et de l'UNICEF sur les sources sûres d'eau potable

\section{Les sources d'eau potable améliorées}

- Raccordement à domicile

- Borne fontaine publique

- Puits forés

- Puits creusés, protégés

- Source protégée

- Citerne d'eau de pluie

\section{Les sources d'eau potable non améliorées}

- Puits non protégés

\footnotetext{
${ }^{323}$ COHRE, AAAS, DDC et UN-HABITA, « Manuel de droit à l'eau et l'assainissement, un outil pour aider les décideurs et praticiens à développer des stratégies de mise en œuvre du droit de l'homme à l'eau et l'assainissement ", Genève, 2008, p.119.

${ }^{324}$ Conçu à la lumièe du document de COHRE, AAAS, DDC et UN-HABITA, Manuel de droit à l'eau et l'assainissement, un outil pour aider les décideurs et praticiens à developper des stratégies de mise en œuvre du droit de l'homme à l'eau et l'assainissement, op.cit., p.151 (l'intitulé de cet encadré a été modifié et reformulé dans le cadre de cette thèse).
} 
- Source non protégée

- Rivière ou étang

- Eau fournie par un vendeur

- Eau en bouteille ${ }^{325}$

- Eau provenant des camions citernes

\section{L'accès physique}

L'accès physique à l'eau potable signifie que l'eau ainsi que les installations d'assainissement de base soient disponibles et accessibles à tous. Il signifie aussi accès à une eau salubre, de qualité acceptable et en quantité suffisante au moins pour les besoins humains essentiels. Pour que ce critère soit respecté, il faut que l'eau soit disponible (voir Tableau 7). "Ne pas avoir accès à l'eau et aux dispositifs d'assainissement est un euphémisme courtois pour désigner une forme de privation qui menace des vies, détruit toute opportunité et porte atteinte à la dignité humaine. Pour les populations pauvres, ne pas avoir accès à l'eau signifie utiliser l'eau des fossés, des rivières et des lacs pollués par des matières fécales d'origine humaine et animale, ou encore employer la même eau que les animaux. Cela signifie également ne pas disposer d'assez d'eau pour satisfaire ne seraitce que les besoins humains les plus élémentaires $»^{326}$

Tableau $^{327} 7$ : La prospective de la disponibilité des ressources en eau par région au Cameroun en 25 ans : 2025-2050

\begin{tabular}{|l|c|c|c|c|c|c|}
\hline Province & \multicolumn{3}{|c|}{ SITUATION EN 2025 } & \multicolumn{3}{c|}{ SITUATION EN 2050 } \\
\hline & $\begin{array}{c}\text { Quantité } \\
\text { d'eau par } \\
\text { habitant, } \\
\mathbf{x 1 0}^{\mathbf{3} \mathbf{m}^{3}}\end{array}$ & $\begin{array}{c}\text { Etat de } \\
\text { disponibilité }\end{array}$ & Population & $\begin{array}{c}\text { Quantité } \\
\text { d'eau par } \\
\text { habitant, } \\
\mathbf{x 1 0}^{\mathbf{3}} \mathbf{m}^{3}\end{array}$ & $\begin{array}{c}\text { Etat de dispo- } \\
\text { nibilité }\end{array}$ & Population \\
\hline Sud & 38,6 & Satisfaisant & 866.993 & 23,1 & Satisfaisant & 1.445 .733 \\
\hline Est & 29,5 & Satisfaisant & 1.521 .495 & 14,2 & Satisfaisant & 3.153 .810 \\
\hline Adamoua & 17,8 & Satisfaisant & 1.419 .318 & 8,8 & Satisfaisant & 2.863 .766 \\
\hline Sud-Ouest & 16,9 & Satisfaisant & 2.416 .128 & 8,4 & Satisfaisant & 4.832 .241 \\
\hline Centre & 7,6 & Satisfaisant & 5.183 .926 & 3,5 & Satisfaisant & 11.520 .389 \\
\hline Nord & 5,9 & Satisfaisant & 3.162 .296 & 2,2 & Satisfaisant & 8.383 .901 \\
\hline Littoral & 4,2 & Satisfaisant & 5.064 .067 & 1,8 & Satisfaisant & 11.978 .616 \\
\hline Nord-Ouest & 5,2 & Satisfaisant & 3.322 .972 & 2,8 & Satisfaisant & 6.171 .677 \\
\hline Ouest & 2,4 & Satisfaisant & 3.661 .756 & 1,3 & Stress hydrique & 6.958 .955 \\
\hline Extrême Nord & 1,7 & Satisfaisant & 5.146 .462 & 0,9 & Pénurie & 10.011 .683 \\
\hline Cameroun & 8,1 & Satisfaisant & 31.765 .414 & 3,9 & Satisfaisant & 66.852 .771 \\
\hline
\end{tabular}

\footnotetext{
${ }^{325}$ L'eau en bouteille n'est pas considérée comme une eau améliorée en raison de la limitation de sa quantité. ${ }^{326}$ PNUD, Rapport mondial sur le développement humain 2006, Au-delà de la Pénurie : Pouvoir, pauvreté et crise mondiale de l'eau, p.5.

${ }^{327}$ Cameroon water development Report, M. FONTEH (2003).
} 
D'après le PNUD, une zone est considérée en pénurie d'eau lorsque la disponibilité en eau par habitant et par an est inférieure à $1000 \mathrm{~m}^{3}$. Lorsque cette quantité est inférieure à $1.700 \mathrm{~m}^{3}$ par habitant par an, on parle de stress hydrique. Ainsi, le Cameroun disposera d'une quantité d'eau appréciable à l'horizon 2025. A l'horizon 2050, la zone de l'extrême Nord sera menacée de pénurie tandis que l'ouest connaîtra une situation de stress hydrique lié à la forte agglomération des population ${ }^{328}$ si rien n'est fait. Pour que l'accès physique s'exerce en toute plénitude, il ne faudrait pas qu'il existe une discrimination quelconque fondée sur la couleur, le sexe, l'âge, la langue, la religion, l'opinion politique ou toute autre opinion. Cela implique en outre la vulgarisation des informations relatives à l'eau.

\section{L'accès économique}

L'accès économique ( «affordability» ou encore critère d'abordabilité) signifie que l'eau et les installations de base soient d'un coût abordable pour tous. Cela implique également que les coûts directs et indirects qu'entraîne l'approvisionnement en eau potable soient raisonnables. Ce critère est assez subjectif car, le budget de l'eau occupe une place peu importante dans les ménages et varie d'un pays à l'autre suivant les situations sociales ${ }^{329}$. Comme le recommande le Comité des droits économiques, sociaux et culturels, les coûts des soins de santé ainsi que les services relatifs aux facteurs fondamentaux déterminants de la santé doivent être établis sur la base du principe de l'équité. Pour faire en sorte que ces services, qu'ils soient fournis par des opérateurs publics ou privés, soient abordables pour tous, y compris pour les plus pauvres ${ }^{330}$. Ainsi, le coût abordable de l'eau concerne plus particulièrement les couches sociales défavorisées.

Encadré 13. Que peut faire l'Etat pour garantir à sa population l'accès économique à l'eau potable?

L'Etat doit :

- établir les normes pour la tarification de l'eau en prenant en compte la capacité à payer de chaque individu.

- effectuer constamment un contrôle de respect des normes instituées.

- accorder des subventions aux utilisateurs à bas revenus.

- mettre sur pied un mode de paiement souple.

- réviser régulièrement les lois susceptibles d'augmenter les coûts au-delà du coup abordable.

- limiter les suspensions et les coupures pour non paiements en cas d'extrême nécessité.

\footnotetext{
${ }^{328}$ Processus d'élaboration du plan d'action de Gestion Intégrée des Ressources en Eau au Cameroun, Document d'orientation, GWP op.cit., p.18.

${ }^{329}$ SMETHS (H.), op.cit.; « Le droit à l'eau », p.57.

${ }^{330}$ Idem.
} 
Quand bien même ces critères seraient réalisés, la mise en œuvre effective du droit à l'eau potable exige que ce droit devienne un droit individuel revendicable devant les tribunaux.

\section{B. La justiciabilité du droit à l'eau potable}

La justiciabilité du droit à l'eau implique que ce droit soit accepté comme un droit individuel (2) et que l'on puisse le revendiquer à titre individuel ou collectif devant les juridictions de l'ordre judiciaire. Ceci entraîne des obligations correspondantes spécifiques (1). Parce que l'eau potable est essentielle pour la vie et que son absence constitue une menace pour la survie, plusieurs Etats à ce jour reconnaissent déjà ce droit comme droit individuel. Toutefois, sa portée varie d'un pays à l'autre car, les obligations positives des pouvoirs publics dans ce domaine diffèrent d'un endroit à l'autre ${ }^{331}$.

\section{Le respect des obligations correspondantes}

La réalisation du droit à l'eau implique le respect de certains droits et obligations en matière d'approvisionnement en eau potable et l'assainissement à la charge de l'Etat en premier et au bénéfice des citoyens en particulier. Pour donner un sens plénier au droit à l'eau potable, les autorités publiques en charge des questions d'eau doivent : préciser à tous la portée de ce droit, définir sans ambiguïté le champ des responsabilités et prévoir les modes de financement du service de l'eau en faisant intervenir la solidarité collective.

\footnotetext{
${ }^{331}$ Dans les pays industrialisés (sur la base de l'Observation Générale $\mathrm{N}^{\circ} 15$ et la pratique des Etats), le respect de ce droit signifie: surveiller la qualité de l'eau potable, prévenir l'épuisement des ressources en eau et empêcher les pollutions des eaux destinées à la consommation humaine (a); veiller à ce que les équipements et services concernant l'eau potable soient répartis sur tout le territoire et disponibles sans discriminations pour tous (b); fournir l'eau potable dans des conditions d'urgence (c); interdire les mesures discriminatoires ou arbitraires de coupures ou de restriction d'eau (d); surveiller le prix de l'eau potable et éviter les abus de position dominantes (e); veiller à ce que les groupes vulnérables aient accès à des installations et services qui fournissent régulièrement une eau salubre en quantité suffisante, qui comportent un nombre suffisant de points d'eau pour éviter des attentes excessives, et qui soient à distance raisonnable du foyer (bornes fontaines en milieu rural et équipements des aires de repos des gens de voyage); adopter et mettre en ouvre des programmes d'approvisionnement en eau relativement peu coûteux visant à faciliter l'accès aux groupes vulnérables et marginalisés (f); prévoir une tarification sociale et/ ou une aide sociale ciblée pour que l'eau distribuée par réseau soit économiquement accessible aux plus démunis (g). Ces recommandations ne posent pas de problème majeur dans les pays industrialisés déjà bien avancés dans le processus; par contre, dans les pays en développement, ces derniers exigences (g) sont théoriques car, difficiles à mettre en œuvre dans un pays qui manque de politique efficace d'aide sociale en général; pour ce qui est de l'exigence (f) relatif à création suffisante des points d'eaux, il ne peut pas connaître un grand succès : car la création des points d'eau demande d'énormes investissements pas toujours à la disposition de l'Etat dans les pays sous développés; Informations fournies à la lumière de l'article de SMETS (H.), "Pour un droit effectif à l'eau ", op.cit., pp.2627.
} 
Encadré 14. Les droits et obligations découlant du droit à l'eau potable

Comme obligations des autorités publiques ${ }^{332}$, celles-ci doivent :

- garantir et veiller au respect des normes régissant le droit à l'eau potable au plan interne. Ils doivent protéger le droit des personnes qui ont «soif de l'eau et de la justice »;

- décentraliser au maximum le service de l'eau pour le rendre plus près des usagers ;

- harmoniser le prix de l'eau en prenant en compte la situation des personnes défavorisées ;

- adopter un plan national efficace de mise en œuvre du droit à l'eau et rechercher les financements pour en assurer le bon fonctionnement.

Comme obligations des usagers $^{333}$, ils doivent :

- contribuer aux coûts du service de l'eau conformément à la législation en vigueur,

- assurer l'entretien de leurs installations et signaler en toute solidarité les pannes ou la vétusté des points d'eau à proximité de leur domicile.

Comme droit pour les usagers ${ }^{334}$, les autorités publiques et les responsables du service de l'eau doivent mettre à leur disposition les informations dont ils ont besoin pour la réalisation de leur droit à l'eau. Le droit à l'eau potable doit être "un acte de responsabilité des autorités publiques et un acte de solidarité entre citoyens ${ }^{335}$ " pour une revendication réussie devant les tribunaux.

\section{Le recours en justice}

Le droit à l'eau malgré sa revendication n'est pas encore suffisamment pris en compte comme droit individuel au Cameroun. C'est d'ailleurs le cas dans la majorité des pays de l'Afrique centrale. Autrement dit, si un citoyen peut déjà saisir l'autorité compétente pour se plaindre en cas d'abus de pouvoir par une autorité du service de l'eau, il ne peut pas encore sur la base de son droit à l'eau saisir la justice pour revendiquer qu'on lui fournisse l'eau sans qu'il n'ait préalablement payé les frais peu importe le motif. C'est-àdire que les personnes non desservies et démunies n'ont à ce jour, aucun pouvoir ni force leur permettant de contraindre les autorités compétentes à s'exécuter. Tant il est vrai que le droit à l'eau entraîne de la part de l'Etat une simple obligation progressive, de moyen et non de résultat. Le droit à l'eau ne signifie pas gratuité. Ainsi, l'Etat continue d'agir selon ses possibilités. En somme, les cas de contentieux liés au droit à l'eau sont relativement rares dans la pratique. Exception faite de ceux liés à la pollution de la ressource en eau.

Comme début de solution au problème d'accès à l'eau potable, il ne serait pas illogique de penser à la création au Cameroun d'un compte social afin d'aider les personnes démunis comme déjà en vigueur dans certains pays développés tels que la France ${ }^{336}$.

\footnotetext{
${ }^{332}$ Académie de l'eau, «Le droit à l'eau, un droit pour tous les citoyens » op.cit., p.3.

${ }^{333}$ Idem.

${ }^{334} \underline{\text { Ibid. }}$. p.1.

${ }^{335}$ Ibid.

${ }^{336}$ Voir pour les détails : « La prise en compte des dettes d'eau des usagers démunis en France », op.cit., SMETS
} 
Aussi, rendre effectif le droit à l'eau potable signifie le rendre justiciable. Ce qui permettrait aux personnes victimes d'abus de voir leur plainte examinée. Dans ce sens, l'Afrique du Sud dans son arrêt Grootboom ${ }^{337}$ a adopté une position assez salutaire en admettant la justiciabilité du droit à l'eau potable. Dans la même logique, il s'est tout récemment tenue à Rotterdam une conférence internationale sur la justiciabilité des Droits Sociaux Economiques et Culturels. La Cour Internationale de Justice (C.I.J.) admet déjà la justiciabilité de certains droits sociaux économiques et culturels. N'est-ce pas là une façon d'admettre la justiciabilité du droit à l'eau potable? "The recognition of justiciability of economic, social and cultural rights is growing and becoming stronger by the day [...] Administrative tribunal and courts should recognise the justiciability of ESC rights and grant appropriate remedies in the event of violations of these rights by State or non State (Paragraph 37). All in all, the draft principles and guidelines make a very strong in favour of the justiciability of ESC $»^{338}$.

\section{Paragraphe II : Le droit à l'eau potable, un droit assisté}

Le droit à l'eau potable au Cameroun a besoin d'assistance non seulement dans sa mise en œuvre (A) mais également en ce qui concerne les couches sociales défavorisées (B). L'OMS $^{339}$ par exemple doit davantage intervenir pour fixer les normes de qualité de l'eau. Ces normes ne sont malheureusement pas très strictes, car c'est au plan interne que chaque Etat établit sa règle de potabilité en tenant compte de certains paramètres ${ }^{340}$.

Organe central de financement, de planification et de coordination des activités de développements, le Programme des Nations Unies pour le Développement (PNUD) est l'organisme principal d'aide et d'assistance au développement institué par les Nations Unies. Le P.N.U.D ${ }^{341}$ assiste techniquement et technologiquement dans les secteurs précis tels que: l'eau, l'agriculture, la santé, l'enseignement, la planification des économies, l'industrie et l'environnement en général.

(H.), 222p.

${ }^{337}$ Voir les faits de cette affaire dans la note de bas de page 116.

${ }^{338}$ HENRAD (C.), «Introduction : the justiciability of ESC rights and the interdependence of al fundamental rights", in http://www.erasmuslawreview.nl/, pp.377-378.

${ }^{339}$ Encore appelée World Heath Organisation (W.H.O.), cette institution est née le 7 avril 1948. Son siège se trouve à Genève. Elle est l'institution spéciale des Nations Unies pour la santé. Elle dépend directement du Conseil Economique et Social. D'après sa constitution, l'O.M.S. a pour objectif d'amener tous les peuples du monde à un niveau de santé le plus élevé possible. La santé étant définie dans ce même document comme un "état de complet bien-être physique, mental et social et ne consistant pas seulement en une absence de maladie ou d'infirmité».

340 Tels que la qualité organoleptique (couleur, turbidité, odeur, saveur); paramètres physico-chimiques naturels (température, chlorure, sulfate); substances indésirables (nitrate, nitrite, pesticides); substances toxiques (arsénic, cadmium, plomb, hydrocarbures); paramètres microbiologiques (microbes pathogènes); voir http://fr.wikipedia.org/wiki/Eau_potable, consulté le 21 août 2008.

${ }^{341}$ Représenté dans plusieurs pays, il comporte environ 112 bureaux de représentants résidants dans les pays en développement. Depuis la conférence de Rio de 1992, le P.N.U.D. a accompagné pas mal de projets concourant à la mise en œuvre du droit à l'eau potable. Il a notamment assisté le Cameroun comme la plupart des pays africains dans la planification et l'amélioration du cadre juridique et institutionnel en matière d'environnement. 


\section{A. L'assistance dans la mise en œuvre du droit}

L'assistance dans la mise en œuvre du droit à l'eau potable est désormais une condition indispensable à la l'existence et la survie de ce droit. La communauté internationale semble l'avoir une fois encore bien compris. L'Assemblée Générale des Nations Unies a le 28 juillet 2010 reconnu solennellement ce principe qu'on pourrait qualifier de "coopération" en ces termes: "l'Etat et les Organisations internationales doivent apporter des ressources financières, renforcer les capacités et procéder à des transferts technologiques grâce à l'aide et la coopération internationales en particulier en faveur des pays en développement, afin d'intensifier les efforts faits pour fournir une eau potable et des services d'assainissement qui soient accessibles et abordables à tous ${ }^{342}$.

Pour que le droit à l'eau soit effectif au Cameroun, il faut une assistance à la fois technique (1) et technologique (2). Ce rôle est dévolu à la société civile qui doit coopérer avec l'Etat et les sociétés privées en charge de la question pour une mise en œuvre efficace du droit à l'eau potable. Dans ce sens, le paragraphe 60 de l'OG N ${ }^{\circ} 15$ stipule que: "les Organisations des Nations Unies et notamment les autres organisations qui s'occupent de l'eau comme l'OMS, la FAO, l'UNICEF, le PNUE, l'ONU-HABITAT, le PNUD devraient coopérer efficacement avec les Etats parties en mettant à leur profit leurs compétences respectives pour faciliter la mise en œuvre $d u$ droit». L'aide provenant d'autres institutions non moins importantes telles que la BAD et la BM et le FMI est aussi importante. Bien plus, certaines autres organisations internationales telles que l'OMC, L'OIT et le CIRDI (Centre Internationale pour le Règlement des Différends relatifs aux Investissements) sont dotées d'organes de résolutions de différents composés d'experts indépendants dont les décisions peuvent influencer le développement du droit à l'eau. Pour que l'assistance dans la mise en œuvre du droit soit efficace, il faut au préalable qu'il y ait collaboration entre les OI entre elles et entre ces dernières et les gouvernements afin d'éviter les aides multiples sujettes à détournement. La création de L'UN-WATER est un moyen de contrôler ces actions. "L'assistance bilatérale et multilatérale dans le secteur de l'eau [...] devrait être orientée prioritairement vers les pays incapables de réaliser par eux-mêmes les aspects essentiels du droit à l'eau et à l'assainissement pour leur population; elle devrait être fournie d'une manière qui n'entrave pas la réalisation des droits de l'homme et se concentrer sur les projets qui apportent les bénéfices tangibles à ceux qui n'ont pas un accès de base à l'eau et à l'assainissement $»^{343}$.

\section{L'assistance technique}

La mise en œuvre du droit à l'eau potable au Cameroun passe indéniablement par une assistance internationale dans l'adoption des plans d'actions nationaux ainsi que des stratégies efficaces d'accès à l'eau potable. "Les pays développés devraient apporter en fonction des ressources dont ils disposent, une aide financière et technique suffisante pour compléter les ressources des pays en développement en vue d'assurer que chaque personne

\footnotetext{
${ }^{342}$ Voir la deuxième disposition de cette Résolution.

${ }^{343}$ Directive de la sous-commission, section 10.3, extrait du Document de COHRE, AAAS, DDC et UNHABITAT, «Manuel de droit à l'eau et l'assainissement, un outil pour aider les décideurs et praticiens à développer des stratégies de mise en œuvre du droit de l'homme à l'eau et l'assainissement », op.cit.
} 
ait accès aussi vite que possible à au moins des services de base d'eau et d'assainissement ${ }^{344}$. L'assistance peut par exemple être utile en matière d'organisation des séminaires de formation et des forums discussion sur l'eau. L'assistance ou la coopération peut aussi consister à transférer au Cameroun des moyens techniques nécessaires à la mise en œuvre du droit en question. Les actions du Global Water Partnership dans le domaine sont non moins négligeables.

Le Partenariat Mondial de l'eau (G.W.P) a été créé en 1996 dans le but d'appuyer les pays dans la gestion durable de leurs ressources en eau. Le Partenariat Mondial de l'Eau est un réseau indépendant, ouvert aux gouvernements, aux organismes de recherche et de formation, aux entreprises privées, aux organismes de coopération bilatérale et multilatérale, aux institutions de financement du développement et à toute organisation ou groupe d'acteurs impliqués dans la gestion des ressources en eau. Le Partenariat Mondial de l'Eau favorise les échanges des expertises, des expériences et des pratiques en matière de gestion intégrée. C'est une structure décentralisée à gestion autonome (organisée autour des partenariats et comités techniques régionaux, nationaux et locaux).

Le GWP-CAFTAC représente le Comité Technique du GWP pour l'Afrique centrale. Il a été créé le $1^{\mathrm{er}}$ avril 2004 et est composé de cinq membres $^{345}$. Sa mission principale est de développer des actions multiformes au niveau de la sous région dont le but est d'aider les autres acteurs du secteur de l'eau dans la mise en œuvre du droit à l'eau potable. Le GWP-CAFTAC (localisé au Cameroun) a pour objectif majeur de regrouper tous les acteurs dans le domaine de l'eau et de les impliquer dans le processus de mise en œuvre. Il agit à travers des forums de dialogues et d'échanges d'informations entre acteurs, des méthodes de facilitation et de planification de la GIRE, des méthodes de renforcement des capacités et de formation des acteurs du secteur de l'eau. Ses actions peuvent se résumer comme suit :

\footnotetext{
${ }^{344} \underline{\mathrm{Idem}}$.

${ }^{345}$ Deux personnalités sont désignées par le MINEE, ensuite viennent Monsieur Ossette Jean Michel, Chairman, J.P BIDJOCKA, membre du GWP-CAFTAC, et Mathias Fru (Extrait du Document d'orientation Global Water Partnership Central Africa, «Processus d'Elaboration du Plan d'Action de Gestion Intégrée des Ressources en Eau du Cameroun », version finale, octobre 2005, p.62.
} 
Encadré 15. Le plan d'action du GWP - CAFTAC pour la période 2005-2008

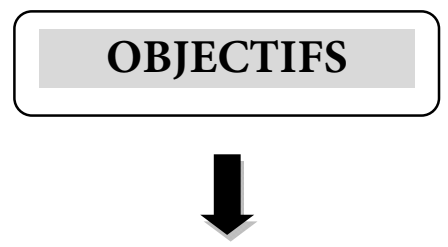

- Assurer une Gestion Intégrée des Ressources en Eau

- Impliquer les différents acteurs dans le processus

\section{RESULTATS ATTENDUS}

Etape 1 : Faciliter les initiatives gouvernementales en matière d'élaboration des Plans d'Actions Nationaux (PNA) d'accès à l'eau potable.

Etape 2 : Adopter les principes de Gestion Intégrée des Ressources en Eau.

Etape 3 : Renforcer la coopération entre différents acteurs.

Etape 4 : Créer des partenariats au niveau local.

Etape 5 : Rendre opérationnel le Réseau GWP-Cameroun.

Le GWP-Cameroun assiste le gouvernement dans le processus d'élaboration d'un plan de gestion intégrée des ressources en eau grâce au programme Néerlandais de développement des ressources en eau d'Afrique ${ }^{346}$. En plus de cette assistance technique, le Cameroun a besoin d'une assistance technologique pour réussir son opération de mise en œuvre du droit à l'eau potable.

\section{L'assistance technologique}

Pour que le droit à l'eau potable ne s'effrite pas au point de devenir « un catalogue de voux pieux", il est important, vu les moyens limités de l'Etat camerounais, que ce dernier soit assisté technologiquement dans ses initiatives et actions par d'autres acteurs. Tant il est vrai, les organes en charge du service de l'eau potable limitent à ce jour leur intervention dans les zones urbaines et périurbaines. L'assistance technologique apportée par exemple par PROVILLAGE dans la mise en œuvre du droit à l'eau potable au Cameroun est visible.

Présente au Cameroun depuis 1991, PROVILLAGE est une institution qui travaille en partenariat avec le MINEFI/ MINADER/ MINNEE/ Kfw/ $\mathrm{DED}^{347}$. Le programme

\footnotetext{
${ }^{346}$ Grâce à l'initiative néerlandaise de l'eau, le gouvernement de la République du Cameroun bénéficie d'un appui financier dans la préparation des P.A.N de G.I.R.E et la mise en œuvre d'une plateforme de concertation des acteurs du secteur de l'eau du Cameroun.

${ }^{347}$ Crée depuis 1963 en charge d'améliorer les conditions de vie des populations d'Afrique, d'Asie et
} 
PROVILLAGE vise l'amélioration de l'approvisionnement en eau potable des populations rurales de manière permanente et suffisante afin de réduire les maladies hydriques.

PROVILLAGE agit en construisant des puits, en aménageant des sources, en installant des systèmes de maintenance durables, en renforçant les actions des ONG locales, en impliquant les communes dans les programmes de sensibilisation contre la pénurie d'eau et la pandémie VIH/ SIDA. Au Cameroun, PROVILLAGE a à ce jour réalisé près de 100 puits et sources dans 6 départements. La ressource financière principale de PROVILLAGE est la Kfw. Lors de la réalisation des ouvrages, la population supporte $10 \%$ des coûts totaux du projet ${ }^{348}$. L'exécution du programme de PROVILLAGE est assurée par la D.E.D. Malgré quelques obstacles naturels (état du sol dans certaines localités) et humains (résistance de la population dans la contribution symbolique.), les actions de PROVILLAGE ont permis à un grand nombre de ménage camerounais d'avoir accès à l'eau potable quoique le projet demeure limité dans certaines zones rurales ciblées.

\section{B. L'aide aux couches sociales défavorisées}

Assurer l'accès à l'eau et à l'assainissement pour tous y compris les groupes les plus vulnérables et marginalisés et ce, sans discrimination, est un élément clé du cadre des droits de l'homme ${ }^{349}$. Prenant appui sur la célèbre phrase biblique : "Retirez vous de moi, maudits, allez dans le feu éternel qui a été préparé pour le diable et ses anges car, j'ai eu soif et vous ne m'avez pas donné à boire. $»^{350}$, les communautés religieuses œuvrent pour faciliter l'accès à l'eau potable aux populations; surtout celles pauvres ou marginalisées. Certains prennent des initiatives personnelles visant à créer des points d'eaux. Reconnaissant ce caractère sacré de l'eau, les églises et les organisations religieuses africaines réunies en conférence à Entebbe (Ouganda) du 21 au 25 mai 2007 déclaraient: "L'eau est l'origine et la source de vie. Elle exprime la grâce de Dieu, perpétuellement envers l'ensemble de la création. Nous sommes appelés à être les intendants responsables de ce don exceptionnel qui nous a été confié, à le préserver et à le partager pour le bien de l'humanité $»^{351}$. Pour aborder convenablement la question de la nature de l'aide (2), il importe de revenir sur le qualificatif couches sociales défavorisées (1).

\section{La couche sociale concernée}

Le droit à l'eau concerne particulièrement les personnes qui n'ont pas accès à l'eau potable. C'est-à-dire les couches sociales défavorisées qui peuvent être vulnérables ou marginalisées. Ces termes ne sont pas interchangeables. Les enfants par exemple sont naturellement vulnérables mais pas forcément marginalisés. Alors que les femmes, en

\footnotetext{
d'Amérique Latine.

${ }^{348}$ Dirk et Heiko W, brochure, ATS PROVILLAGE, octobre 2005.

349 « Manuel du droit à l'eau et l'assainissement, résume exécutif : un outil pour aider les décideurs et praticiens à développer les stratégies de mise en œuvre des stratégies du droit de l'homme à l'eau et l'assainissement ", p.xxx.

${ }^{350}$ Mathieu 25, 41-42.

${ }^{351}$ Déclaration de la conférence, « Les églises pour l'eau en Afrique », Entebbe, mai 2007.
} 
particulier celles vivant dans zones pauvres, sont souvent marginalisées mais rarement vulnérables. Ainsi, certaines personnes telles que celles appartenant à des groupes ethniques peuvent être marginalisées du fait de certains critères sociaux ou culturels tandis que d'autres groupes sociaux tels que les personnes en détention et les prisonniers sont à la fois vulnérables et marginalisées. La liste des personnes défavorisées comprend $^{352}$ les personnes vulnérables et marginalisées.

Encadré $^{353}$ 16. Les groupes vulnérables et marginalisées

\section{Les groupes vulnérables et marginalisés comprennent :}

- les femmes ;

- les enfants ;

- les habitants des zones rurales et périurbaines;

- les populations autochtones;

- les communautés nomades et voyageuses ;

- les réfugiés, les demandeurs d'asile, les personnes déplacées à l'intérieur de leur pays et celles retournant dans leur foyer ;

- les personnes âgées et les handicapés ;

- les personnes souffrant d'une maladie grave ou chronique ;

- les personnes victimes de catastrophes naturelles ou vivant dans les zones sujettes à catastrophe ;

- les personnes vivant dans les zones pauvres en eau (zone arides et semi arides);

- les détenus et les prisonniers.

Il convient de signaler que l'attention accordée aux groupes vulnérables et marginalisés n'est qu'un moyen de parvenir au slogan «droit d'accès à l'eau potable et assainissement pour tous". D'après l'OG $\mathrm{N}^{\circ} 15$ : "les Etats parties devraient prêter une attention particulière pour veiller à ce que [...] Les femmes ne soient pas exclues des processus de prise de décisions concernant les ressources en eau et les droits correspondants. Il faut alléger la charge excessive qui constitue pour elles l'obligation d'aller chercher l'eau $»^{354}$.

Pour être efficaces, les programmes de mise en œuvre du droit à l'eau doivent intégrer l'avis des enfants. Car, généralement dans les pays en voie de développement, les enfants et plus particulièrement les filles ont la charge de l'eau pour les besoins familiaux; ainsi, les plans de montage des robinets et des bornes fontaines doivent prendre en compte le facteur taille des enfants. Conformément aux exigences du paragraphe 16 (c) de L'OG $\mathrm{N}^{\circ} 15$ : «Les Etats parties doivent veiller à ce que les zones rurales et urbaines déshéritées disposent d'un système d'approvisionnement en eau convenable entretenu ».

$\mathrm{Au}$ Cameroun, cette exigence n'est pas encore une réalité certaine. Car, les services de distribution de l'eau potable limite encore leurs actions dans les zones urbaines et

\footnotetext{
${ }^{352}$ Manuel du droit à l'eau et l'assainissement, Résumé exécutif, op.cit., p.xxxi.

${ }^{353}$ Idem.

${ }_{354}$ Observation Générale $N^{\circ} 15$, para. 16, voir aussi la Convention sur l'élimination de toutes les formes de discriminations à l'égard des femmes.
} 
périurbaines (comme le précise l'intitulé du règlement de service affermé de distribution de l'eau potable sur le territoire camerounais). Les zones reculées du périmètre de distribution et les zones rurales continuent de s'approvisionner en eau parfois de qualité douteuse pour la consommation humaine. Parfois, elles doivent attendre de bénéficier d'un projet d'adduction d'eau financé par l'Etat lui-même ou par tout autre membre de la société civile. Il arrive de fois que l'attente se solde par une action concrète. Mais, très souvent, ces zones sont victimes de marginalisation de la part des pouvoirs publics; c'est ce qui justifie le fort taux de maladies hydriques qui s'y enregistre. Cependant, le droit des populations autochtones est de plus en plus renforcé au plan international ${ }^{355}$. D'après le paragraphe 16 (e) de L'OG $\mathrm{N}^{\circ} 15$ : « les Etats parties doivent veiller à ce que les [...] communautés nomades et les gens du voyage disposent d'un approvisionnement en eau adéquat dans leurs sites traditionnels ou les haltes désignés». Le problème des communautés nomades est souvent celui de pénurie et d'usurpation des sources d'eau appartenant aux communautés locales. Lorsque qu'on fait un tour auprès des agences de voyage, des zones d'arrêts momentanés au cours des voyages ou auprès des communautés nomades, on comprend tout de suite que cette recommandation reste comme son nom l'indique une simple déclaration au Cameroun. Dans ce secteur, il est question « $d u$ sauve qui peut». D'après le paragraphe 16 (f) de L'OG $\mathrm{N}^{\circ} 15$ : «les réfugiés, demandeurs d'asile, personnes déplacées à lintérieur de leur pays et celles retournant dans leur foyer doivent disposer d'un approvisionnement en eau adéquat indépendamment du fait qu'ils vivent dans des camps ou des zones urbaines. Les réfugiés et les demandeurs d'asile doivent avoir accès à l'eau au même titre et dans les mêmes conditions que les nationaux». Comment cette recommandation pourrait se vérifier dans la pratique camerounaise quand l'Etat n'arrive pas déjà à assurer la large distribution de l'eau potable pour ses propres nationaux?

D'après le paragraphe $16(\mathrm{~h})$ de L'OG $\mathrm{N}^{\circ} 15$, «les Etats parties doivent veiller à ce que les groupes [...] qui ont des difficultés à accéder physiquement à l'eau telles que les personnes âgées, les personnes handicapées ${ }^{356}$ disposent d'un approvisionnement en eau salubre en quantité suffisante ». "Les personnes âgées devraient avoir accès suffisant à la nourriture, à l'eau, un abri, des vêtements et des soins médicaux par le biais d'assistance en revenu, d'une aide de la famille et de la communauté et par leur propres moyens ${ }^{357}$. La Convention des Nations Unies relative au droit de personnes handicapées affirme pour sa part que les handicapés doivent bénéficier d'un égal accès aux services d'approvisionnement en eau propre et assainissement adéquat.

\footnotetext{
${ }^{355}$ Dans ce sens l'Assemblée Générale des Nations Unies a adopté une Déclaration relative au droit des populations autochtones, UN DOC, A/RES/61/295; disponible sur www.ohchr.org. L'OG N 15 para. 16 (d) poursuit: "L'accès des populations autochtones aux ressources en eau sur leurs terres ancestrales doit être protégé de la pollution et des utilisations illégales. Les Etats devraient fournir aux populations autochtones des ressources leur permettant de concevoir, d'assurer et de contrôler leur accès à l'eau ».

${ }^{356}$ Il existe aussi une Convention dite CDPH (Convention des Nations Unies relative aux droits des personnes Handicapés qui dispose que: "Les Etats parties reconnaissent le droit des personnes handicapées [...] qui garantit l'égalité d'accès des handicapés aux services d'approvisionnement en eau propre, et l'accès à des services appropriés et abordables, dispositif et autres formes d'assistance nécessaires aux besoins des personnes handicapées. ", article 28.2 (a), décembre 2006, pas encore en vigueur consultable sur www.ohchr.org.

${ }^{357}$ Pour la source, se référer à www.un.org.
} 
D'après le paragraphe $16(\mathrm{~h})$ de L'OG $\mathrm{N}^{\circ} 15$, «les Etats parties devraient veiller à ce que [...] les groupes qui ont des difficultés à accéder physiquement à l'eau tels que les personnes victimes de catastrophes naturelles ou vivant dans les zones sujettes à catastrophe [...] disposent d'un approvisionnement en eau salubre en quantité suffisante». "Les Etats parties devraient veiller à ce que [...] les groupes qui ont des difficultés à accéder physiquement à l'eau telles que les personnes qui vivent dans les zones arides et semi arides ou sur les petites îles disposent d'un approvisionnement en eau salubre en quantité suffisante $»^{358}$.

D'après le texte adopté par le Premier congrès des Nations Unies relatif à la prévention du crime et le traitement des délinquants (organisé à Genève en 1955, et approuvé par le Comité Economique et Social dans sa Résolution 663C (XXIV du 31 juillet 1957 et 2076 (LXII) du 13 mai 1977), de l'eau potable doit être à la disposition de chaque prisonnier dès lors qu'il en a besoin ${ }^{359}$. Il en est de même pour les personnes en déten-tion.

Aussi pertinente que peuvent sembler ces recommandations développées dans l'Observation Générale $\mathrm{N}^{\circ} 15$, elle demeure malheureusement un texte juridique sans valeur juridique contraignante, une simple observation pouvant orienter les Etats comme son nom l'indique. Chacun des groupes marginalisés suscités se bats à son niveau pour accéder à une eau parfois de qualité douteuse pour sa santé.

\section{La nature de l'aide}

De prime abord, il importe de préciser que l'aide allouée aux personnes défavorisées doit être juste et équitable. L'aide doit en outre respecter le principe de la non discrimination qui interdit «toute exclusion, restriction ou favoritisme quel que soit le critère sur lequel elles sont fondées $»^{360}$. Ce principe ne vise pas seulement l'élimination de la discrimination à l'endroit de certains groupes ou personnes, mais requiert de la part des pouvoirs publics et autres garants de droits de l'homme qu'ils prennent des mesures positives pour s'assurer que leurs programmes et stratégies d'accès à l'eau potable n'excluent pas certaines personnes surtout celles défavorisées ou démunies. Pour être efficace, l'aide doit comporter certains éléments : l'existence au plan national d'une loi anti-discrimination claire et une institution de veille de cette loi ; la prise en compte de la situation des groupes vulnérables dans les budgets publics consacrés à l'eau potable. L'aide peut aussi consister à créer un compte social pour secourir les personnes démunies ou incapables de régler leur facture. Plusieurs pays (occidentaux) pour la plupart ont déjà intégré dans leur règlement de service affermé de distribution de l'eau potable ce compte social pour aider les personnes démunies dans le règlement de leur facture. Ce qui n'est pas encore le cas dans le règlement camerounais de distribution de l'eau potable. Pourtant, le Cameroun gagnerait à copier ce mécanisme (utilisé par exemple en France) afin de limiter certains désastres que connaissent les personnes défavorisées dans l'accès à l'eau potable. L'aide peut aussi consister à accorder un

\footnotetext{
${ }^{358} \mathrm{OG}, \mathrm{N}^{\circ} 15$, para. $16(\mathrm{~h})$.

${ }^{359}$ Voir pour les détails www.ohchr.org.

${ }^{360}$ Race, sexe, couleur, langue, religion, opinion, politique, religion, opinion ou nationalité.
} 
moratoire dans le paiement des factures lorsque la demande est sollicitée par une personne jugée démunie ou défavorisée.

Pour être efficace, l'aide doit être à la fois préventive (basée sur une politique d'aide quantifiée avec détermination des modalités d'attribution. Dans l'optique de prévenir le développement des maladies hydriques ainsi que les coupures d'eau pour non paiement de factures) et curative ${ }^{361}$ (afin de résoudre le problème des dettes d'eau). L'efficacité dans l'action repose sur la solidarité entre les acteurs dans le domaine et entre les riches et les pauvres. On pourrait aussi penser à créer un compte spécial au près des services sociaux pour recevoir les aides volontaires et les destiner au profit des personnes démunies ou défavorisées.

Toutefois, la pratique du prix raisonnable et abordable reste l'un des moyens les plus sûrs dans la mise en œuvre du droit à l'eau potable au Cameroun.

\section{SECTION II : La démocratisation du droit à l'eau potable}

La crise de l'eau trouverait son origine dans la pauvreté, l'inégalité des rapports de forces ainsi que dans des politiques de gestion de l'eau inadaptées qui en aggravent la rareté ${ }^{362}$. "L'eau n'est pas seulement une manne inégalement repartie sur le globe terrestre, c'est aussi une ressource dont la gestion détermine les possibilités d'utilisation. $»^{363}$. La gestion de l'eau en général et celle de l'eau potable en particulier n'est pas évidente dans la pratique. Car elle nécessite une attention particulière. Il faut tantôt respecter les règles de partage pour ce qui est des eaux internationales, tantôt traiter les eaux usées avant de les rejeter dans la nature afin de limiter les contaminations de la nappe phréatique ainsi que des autres sources d'eau potable. Cette dernière mesure est davantage plus complexe surtout dans les pays du sud où la construction, le développement, et l'entretien des infrastructures indispensables au traitement de l'eau, sont encore en pleine construction. Cela rend problématique l'effectivité du droit à l'eau potable. Pourtant, «la protection de l'eau potable contre les pollutions et la préservation de sa qualité constituent des enjeux significatifs $»^{364}$ dans la mise en œuvre de ce droit. Ces enjeux nécessitent l'utilisation d'une méthode de gestion non seulement intégrée (paragraphe I) mais aussi écologique et rationnelle (paragraphe II) pour un développement durable.

\footnotetext{
${ }^{361}$ SMETS (H.), «La mise en œuvre du droit à l'eau, les solutions à Paris », Académie de l'eau, Paris, août 2010, p.71.

${ }^{362}$ PNUD, Rapport mondial sur le dévellopement humain 2006, op.cit., préface, p.v.

${ }^{363}$ Santini (A.), Proposition de loi sur la coopération internationale des collectivités territoriales et des agences de l'eau dans les domaines de l'alimentation en eau et de l'assainissement, AN, Rapport, $\mathrm{n}^{\circ} 2041,26$ janvier 2005, p.5; (extrait de GUERARD (S.), «La gestion démocratique de l'eau, un enjeux général d'intérêt mondial », p.6.).

${ }^{364}$ Décision $\mathrm{n}^{\circ}$ 2004-04 du 04 février 2004 de la Commission nationale du débat public relative au projet d'extension des capacités de Fos-conteneurs «FOS 2XL », JORF (Journal officiel de la République française), 18 février 2004, (texte consultable sur : www.legigrance.gouv.fr ); voir GUERARD (S.) op.cit., p.7.
} 


\section{Paragraphe I : L'application de la méthode de gestion intégrée de l'eau potable}

Il est internationalement admis que la crise de l'eau est une crise de gouvernance résultant essentiellement de nos modes de gestion inadaptées et ayant en premier lieu des retombées tragiques sur la vie quotidienne des populations pauvres ${ }^{365}$. "L'eau ne manque pas, elle est simplement mal gérée». Pour rendre effectif le droit à l'eau potable au Cameroun, la méthode de gestion intégrée de la ressource devient de plus en plus incontournable. La gestion intégrée est née officiellement à Dublin en 1992 et regorge quatre principes essentiels: l'eau douce est une ressource limitée et vulnérable essentielle pour préserver la vie, le développement et l'environnement; (parce que l'eau douce est indispensable à la vie, au développement et à l'environnement, sa mise en cuvre exige une bonne gestion et une bonne rationalisation de la ressource); l'exploitation et la gestion de l'eau doivent se fonder sur une approche participative impliquant les utilisateurs, les planificateurs et les décideurs à tous les niveaux [L'eau est l'affaire de tous. Les décisions doivent aussi parfois émaner de la racine (cela implique l'association des usagers dans le processus décisionnel)]; les femmes jouent un rôle crucial dans l'approvisionnement, la gestion et la préservation de l'eau. Elles doivent abandonner le statut d'observatrices marginalisées pour s'impliquer dans les prises de décisions. La mise en œuvre de ce principe signifie qu'on leur donne les moyens de leur politique. L'eau a une valeur économique dans toutes ses utilisations concurrentes et doit être perçue davantage comme un bien social. Ce principe met en exergue le droit fondamental de l'homme à une eau salubre qui soit suffisante et abordable pour tous. Considérer l'eau comme un bien économique et la gérer comme telle. C'est «ouvrir la voie à une utilisation efficace et équitable de cette ressource $»^{366}$.

Ainsi, la gestion intégrée est une méthode qui intègre à la fois le respect des règles de protection environnementale et de l'eau potable. Pour mieux appréhender cette partie, il est nécessaire d'aborder la question de gestion intégrée (A) avant d'examiner ses critères (B).

\section{A. La notion de gestion intégrée}

La Gestion Intégrée des Ressources en Eau (GIRE) est définie de diverses manières, mais ces définitions ${ }^{367}$ se rapprochent en bien de points : elles sont toutes fondées sur l'idée de

\footnotetext{
${ }^{365}$ I nforesources, « Gestion Intégrée des Ressources en Eau, la voie du développement durable », Focus N1/03, p.5.

366 MORIARTY(P.), et suivant., «La gestion intégrée des ressources en eau, le sous-secteur de l'approvisionnement en eau et l'assainissement domestiques ", extrait de cahier thématique 9-F, WHO collaborating centre since 1968, p.12.

${ }^{367}$ La GIRE est un processus qui encourage la valeur et la gestion coordonnée de l'eau, des terres et des ressources associées en vue de maximiser le bien-être économique et social qui en résulte d'une manière équitable, sans compromettre la durabilité d'écosystèmes vitaux (Partenariat Mondial de l'Eau, 2000). La GIRE est un processus d'attribution de fonctions et de systèmes d'eau, l'établissement des normes, la mise en vigueur (surveillance) et la gestion. Elle comprend la collecte des données, l'analyse de processus physiques et socioéconomiques, la considération des différents intérêts et la prise de décisions par rapport à la disponibilité, l'exploitation et l'usage des ressources en eau (HOFWEGEN et JASPERS, 1999). La GIRE est une question de planification et de gestion coordonnées des terres, de l'eau et d'autres ressources naturelles en vue de leur utilisation équitable, efficace et durable (Calder, 1999). La GIRE exprime l'idée que les ressources en eau
} 
coordination et de concertation dans la gestion. Par gestion intégrée, il faut comprendre une gestion qui intègre les règles démocratiques, c'est-à-dire qui offre la possibilité à tous les acteurs d'intervenir dans le secteur pour apporter leur savoir faire. Pour être efficace, dans le domaine de l'eau potable (2), elle doit comporter les mesures de gestion intégrée de l'environnement (1).

\section{La gestion intégrée de l'environnement}

Pour parvenir à une mise en œuvre effective du droit à l'eau potable au Cameroun, il faut mettre en pratique les règles de la gestion intégrée de l'environnement. La gestion intégrée de l'environnement a été évoquée à Stockholm en 1972 notamment en son principe $13:$ : les Etats devraient adopter une conception intégrée et coordonnée de leur planification et du développement, de façon que leur développement soit compatible avec la nécessité de protéger et d'améliorer l'environnement dans l'intérêt de leur population ».

Dans la même logique, la Déclaration de Rio de 1992 affirme pour sa part en son principe 4 que: "pour parvenir à un développement durable, la protection de l'environnement doit faire partie intégrante du processus de développement et ne peut être considérée isolement». Ainsi, la gestion intégrée de l'environnement est devenue une condition indispensable au développement durable ${ }^{368}$. L'agenda 21 voyant l'importance de la méthode de gestion intégrée, lui a consacré tout son chapitre 8 intitulé: «intégration du processus de décision sur l'environnement et le développement ». La méthode de gestion intégrée de l'environnement se retrouve aussi au niveau de la Déclaration sur les forêts ; même s'il faut reconnaître qu'elle a une valeur juridique non contraignante remarquable depuis son intitulés ${ }^{69}$.

\section{La gestion intégrée de l'eau potable}

Le concept et les principes de la Gestion Intégrée des Ressources en Eau (GIRE) ont été pour la première fois explicitement exprimés lors de la conférence internationale sur l'eau et l'environnement de 1992 à Dublin et dans le chapitre 18 de l'Agenda 21 établi à Rio au cours de la même année. La Gestion Intégrée des Ressources en Eau est une approche mise sur pied pour répondre aux demandes de plus en plus grandes et concurrentielles sur l'eau douce dont la quantité est de plus en plus limitée pour le grand nombre de la population. Cette approche cherche à garantir le développement coordonné de l'eau, des terres et des ressources connexes pour optimiser le bien-être économique et social sans compromettre la durabilité des systèmes environnementaux. Le succès de cette méthode repose aussi sur le respect des règles essentielles à la bonne gouvernance de l'eau (voir Encadré 17).

\footnotetext{
devraient être gérées de façon holistique, en coordonnant et en intégrant tous les aspects et les fonctions du prélèvement de l'eau, de surveillance et de l'eau et de la fourniture des services liés à l'eau, afin que ceux qui dépendent des ressources en profitent durablement et équitablement (CE, 1998). (toutes ces définitions sont extrait de MORIARTY (P.), et suivant., "La gestion intégrée des ressources en eau, le sous-secteur de l'approvisionnement en eau et l'assainissement domestiques", op.cit., p.13.).

368 CAUDAL (S.), «Les conditions juridiques de gestion intégrée de l'environnement », Université Jean Moulin 3, p.1.

${ }^{369}$ Déclaration de principes, non juridiquement contraignante, mais faisant autorité, pour un consensus mondial sur la gestion, la conservation et l'exploitation écologiquement viable de tous les types de forêts.
} 
La notion de gouvernance de l'eau renvoie aux systèmes politiques, administratifs, économiques et sociaux qui gèrent les services ou les ressources en eau ${ }^{370}$. Elle varie suivant les pays, car, elle tient compte des particularités sociales, économiques et culturelles. L'approche pour une bonne gouvernance et performance de l'eau implique la transparence, l'équité et la cohérence dans l'action. Bien plus, celle-ci se doit d'être responsable, efficace et réceptive. Une bonne gouvernance de l'eau potable implique en somme la participation de tous les usagers, de la société civile, de l'Etat ainsi que du secteur privé.

Encadré $^{371}$ 17. Les critères essentiels à la bonne gouvernance de l'eau

\section{PRINCIPES POUR UNE GOUVERNANCE EFFECTIVE DE L'EAU}

- Ouverte et transparente : les institutions doivent travailler de manière ouverte et transparente ;

- Fédératrice et communicative : une participation améliorée (qui dépend de tous les niveaux de l'Etat) peut susciter une plus grande confiance dans les résultats escomptés et dans les institutions qui élaborent les politiques ;

- Equitable et éthique : ouvert à tous sans discrimination ;

En termes de performances et d'exploitation, une bonne gouvernance de l'eau implique que les processus et l'exploitation soient :

- Responsabilisés: les responsabilités en termes de processus légaux et exécutifs doivent être clairement établies. Chaque institution doit expliquer et assumer la responsabilité pour ses actions;

- Efficaces: avec un bon rendement juridique, économique, social, politique et environnementale;

- Réactifs et durables: les objectifs doivent être clairs, l'impact environnemental évalué en tenant compte s'il y a lieu des expériences passées.

B. Les critères de la gestion intégrée

La gestion intégrée de l'eau potable obéit à deux critères essentiels: la gestion participative (1) et la prise en compte de l'équilibre des besoins usagers (2).

\section{L'effectivité de la gestion participative}

Pour être efficace, l'approche utilisée dans la gestion intégrée des ressources en eau potable doit être attentive à la demande. "La démarche attentive ${ }^{372}$ est participative et implique les bénéficiaires à tous les niveaux. "En démocratie, la décision politique passe d'abord par l'information et le débat citoyen. [...] Incontestablement, l'eau est un problème global qui concerne chaque citoyen $d u$ monde ${ }^{373}$. Les individus et les groupes

\footnotetext{
${ }^{370}$ GWP, « Partager la connaissance sur la Gestion Intégrée des Ressources en Eau », Toolbox, 2007, p.31.

371 Réalisé à la lumière du document de GWP, "Partager la connaissance sur la Gestion Intégrée des Ressources en Eau ", op.cit., p.8.

${ }^{372}$ Document de la Banque Africaine de Développement: "Politique de gestion intégrée des ressources en eau », avril 2000, p.52.

${ }^{373}$ Favier (C.), Préface, in Petrella (R.), L'eau. Res publica ou marchandise ?, Editions « La Dispute », 2003, pp.9-12.
} 
ont droit de participer au processus de prise de décisions qui peuvent agir sur l'exercice de leur droit à l'eau ${ }^{374}$. Le plan de Johannesburg s'allie à cette politique. Il affirme : les Etats s'engagent à faciliter l'accès à la participation et l'information du public, y compris des femmes, à tous les degrés d'intervention de politiques et prises de décisions relatives à la gestion des ressources en eau et la mise en œuvre des projets relatifs à l'eau ${ }^{375}$. Cette approche a l'avantage de tenir compte des préférences des usagers ainsi que de leurs capacités contributives. L'une des raisons qui explique l'échec de cette approche dans les pays en développement comme le Cameroun est le manque de concertation dans la prise des décisions et surtout la difficile implication des populations dans les projets concernés pas l'eau ainsi qu'une faible défense de l'intégrité environnementale.

Pourtant, la participation du public est une condition sine qua non de succès dans la mise en œuvre des méthodes de gestion intégrée de l'eau potable et partant du droit à l'eau potable au Cameroun. La participation du public à la gestion des ressources en eau sera davantage accrue si les pratiques de gouvernance communautaires traditionnelles sont reconnues et intégrées dans le processus de gestion ${ }^{376}$. Si les règles de gestion intègrent davantage l'intervention conjointe de l'Etat, la société civile et le secteur privé, les résultats de cette méthode seront plus perceptibles. Pour une plus value, le choix du mode de financement doit par exemple prendre en compte la capacité contributive des différents acteurs. La principale cause de l'échec des mesures instituées pour la GIRE vient du fait que les propositions pour améliorer l'utilisation de l'eau "partent d'idées généralement importées ». Les bailleurs de fonds très souvent imposent la mise en œuvre des mesures préalablement établies aux pays en développement comme condition pour être financés sans pour autant réfléchir sur son adaptation et, réciproquement, les Etats des pays en développement voient la GIRE uniquement comme une obligation imposée pour obtenir des financements et aucun effort n'est fait en faveur de sa mise en ouvre réelle sur le terrain, une fois ceux-ci obtenus ${ }^{377}$. Il existe plusieurs niveaux de participation (tels qu'illustrés dans l'Encadré.18).

\footnotetext{
${ }^{374}$ OG., para. 48.

${ }^{375}$ Plan de mise en œuvre de Johannesburg, para. 25 (b).

${ }^{376}$ Information Eau, N 592 : juillet, août, septembre 2009 : « La synthèse de l'OIE : la GIRE dans les pays en développement : quelles clés pour sa réussite? », Consultée dans www.oieau.org, le 04 mars 2010, p.2.

${ }^{377}$ Idem.
} 
Encadré $1 \mathbf{8}^{378}$. Les différents niveaux de participation

Participation passive : l'information est reçue, mais il n'existe pas de possibilité d'exprimer ses opinions.

Fourniture d'information: répondre aux questions posées par les intervenants extérieurs, mais pas de possibilité de décider sur des questions posées, ni d'influencer les décisions à venir parce que l'information recueillie n'est pas partagée.

Consultation : les points de vue sont pris en compte, mais les décisions sont prises par les autres.

Participation fonctionnelle : participation en groupe constituée par des intervenants extérieurs afin d'atteindre les objectifs fixés par les intervenants intérieurs.

Participation interactive : participation au processus de planification, d'analyse de besoins, de recueils d'informations et aux différentes phases de prises de décisions. Les intervenants extérieurs soutiennent ces prises de position.

Auto-mobilisation : les citoyens prennent l'initiative de planification, d'évaluation des besoins et de recueils d'informations, de définition des objectifs et de l'action collective. Les intervenants extérieurs fournissent un support technique et jouent un rôle de facilitateur ou catalyseur, plutôt que de diriger les activités ou les décisions prises.

Encadré 19 $^{379}$. Que peut faire l'Etat pour renforcer l'accès à l'information et la participation de son public au processus décisionnel ?

\section{L'Etat doit :}

1. Introduire les mécanismes pour faciliter au public l'accès à l'information relative aux politiques et processus de prise de décision dans le secteur de l'eau et de l'assainissement (par le recours aux médias de communication utilisés par les plus pauvres tels que la radio).

2. Assurer au public l'accès à une qualité d'eau satisfaisante et aux données de l'hygiène du milieu.

3. Organiser des processus participatifs de politiques en matière d'eau et d'assainissement et des programmes afin de garantir une véritable participation des représentants des groupes vulnérables et marginalisés.

4. Prévoir des budgets permettant aux communautés de développer et gérer les installations et services d'eau et d'assainissement à petite échelle dans les circonstances adaptées.

5. Assurer que les usagers sont à même de participer aux règlements et aux contrôles de fournisseurs de service.

\footnotetext{
${ }^{378}$ Conçu à la lumière du document de COHRE, AAAS, DDC et UN-HABITAT, « Manuel de droit à l'eau et l'assainissement, un outil pour aider les décideurs et praticiens à développer des stratégies de mise en œuvre du droit de l'homme à l'eau et l'assainissement », op.cit., p.106.

${ }^{379}$ Conçu à la lumière du document de COHRE, AAAS, DDC et UN-HABITA, « Manuel de droit à l'eau et l'assainissement, un outil pour aider les décideurs et praticiens à développer des stratégies de mise en œuvre du droit de l'homme à l'eau et l'assainissement », op.cit., p.101.
} 


\section{La prise en compte de l'équilibre des besoins usagers}

Chacun a droit sans discrimination, à l'accès à l'eau potable et à l'assainissement. Les autorités politiques responsables veillent à ce que les besoins élémentaires soient assurés et tiennent compte des contraintes liées à des circonstances de lieu et de temps lorsqu'elles fixent les conditions d'exercice de ce droit imprescriptible. Elles exercent leur responsabilité au plus près des usagers, dans la plus grande transparence possible, avec la préoccupation de mettre en œuvre les solutions les plus appropriées aux problèmes posés. La protection du droit d'accès à l'eau exige la mobilisation de tous les moyens disponibles afin de s'adapter à l'extrême diversité des situations. L'éventail des possibilités doit être d'autant plus large que ce droit est un droit fondamental de la personne ${ }^{380}$. La politique intégrée de gestion de l'eau potable a comme avantage de : "préconiser l'application de prix minimaux pour l'offre minimale de l'eau pour les besoins fondamentaux le cas échéant, afin de permettre aux pauvres des zones rurales et périurbaines d'avoir accès aux services de l'eau même lorsque des mesures de recouvrement de l'intégralité des coûts financiers seront mis en œuvre ${ }^{381}$.

La gestion intégrée de ressources en eau "n'est pas un produit, mais un processus qui offre un cadre souple à plusieurs portes d'entrée, tel un puzzle où chaque action ajoutée est un pas de plus vers la concrétisation d'une méthode de gestion durable». La GIRE est un processus qui permet de passer d'un "état présent à un état meilleur envisageable dans le futur, en appliquant des principes ou de bonnes pratiques de gestion de l'eau convenue en commun avec la participation de toutes les parties prenantes $»^{382}$.

\section{Paragraphe II : L’application des méthodes de gestion écologique et rationnelle}

Avec la détérioration globale de la biosphère, les ressources naturelles en général et l'eau potable en particulier s'est raréfiée. Fort de cela, le droit international de l'environnement a inventé une méthode importante de gestion de l'environnement pour s'adapter au changement : il s'agit de la gestion écologique (1) et rationnelle (2).

\section{A. Les critères de la de gestion écologique}

Pour parvenir à une bonne gestion écologique de l'environnement (1), il faut déjà développer les règles de la gestion écologique de l'eau potable (2).

\section{La gestion écologique de l'environnement}

Gérer l'environnement de manière écologique, c'est mettre en pratique des mécanismes de protection et de sauvegarde de l'écologie environnementale; de manière à limiter voir éradiquer la dégradation des ressources en eau du fait de diverses sortes de pollution (industrielles et non industrielles). Appliqué en matière de lutte contre les pollutions de l'eau, ce principe voudrait que les matières polluantes soient traitées ou

\footnotetext{
${ }^{380}$ www.academie-eau.org, CEDE, « Droit d'accès à l'eau potable et à l'assainissement », juin 2005.

${ }^{381}$ Document de la Banque Africaine de Développement: "Politique de gestion intégrée des ressources en eau » op.cit., p.23.

382 MORIARTY (P.), et suivant «La gestion intégrée des ressources en eau, le sous secteur de l'approvisionnement en eau et l'assainissement domestiques », op.cit., p.14.
} 
éliminées par les pays les plus technologiquement aptes à le faire (principe fondamental de droit international de l'environnement). De ce principe se dégagent d'autres sous principes: le traitement préférentiel des matières dégradantes ou susceptible de dégrader l'eau potable au lieu le plus proche possible du lieu de pollution; le principe de non discrimination dans le traitement des déchets pouvant altérer la qualité de l'eau. Le principe de gestion écologique de l'environnement s'applique à tous les niveaux y compris celui de l'eau potable.

\section{La gestion écologique de l'eau potable}

La gestion écologique de l'eau potable interpelle la société entière (comme en matière de la gestion intégrée suscitée). "S'il n'y a pas une volonté de la part des adultes de comprendre leur environnement direct, rien ne permettra alors de lutter contre la gabegie actuelle. Au-delà des manques évidents de moyens et d'infrastructures de certains pays, nous avons trop souvent constaté une ignorance, volontaire ou non, devant le danger de consommer une eau impropre ou de polluer son environnement. Au-delà des règles d'hygiène et de conservation de l'écosystème, il faut encourager le volontarisme et le principe d'action individuelle, fondement de nos sociétés humaines ${ }^{383}$.

L'information ainsi que la participation du public au processus décisionnel (dans le domaine du droit à l'eau potable) sont des conditions indispensables pour l'amélioration de la qualité des décisions ainsi que leur application. Elles doivent être complétées par la sensibilisation et la concertation dans la prise de décision des projets y relatifs. "Pour que les populations humaines et les écosystèmes se développent, l'eau doit être propre, elle doit rester propre et surtout elle doit être accessible à tous $»^{384}$.

B. Les critères de la gestion rationnelle

La gestion rationnelle de l'eau potable (1) est un démembrement de la gestion rationnelle de l'environnement (2).

\section{La gestion rationnelle de l'environnement}

La gestion rationnelle est une gestion conforme aux règles d'usage et d'éthique environnementale. C'est également une gestion qui interpelle tous les membres de la société (comme dans la gestion écologique). "Le propre de l'homme a toujours été de se développer, de transmettre la vie et de mourir en léguant aux générations qui lui succéderont un patrimoine qu'elles pourront à leur tour faire fructifier. Le développement durable n'est pas autre chose. Il est un devenir commun, une conscience forte d'appartenir à la fois à un passé, un présent et un avenir ${ }^{385}$. Dans un souci d'efficacité, tous les gouvernements en général et le Cameroun en particulier doit mettre sur pied des mécanismes financiers pérennes pour assurer l'assainissement des milieux de vie pour une mise en œuvre effective du droit à l'eau potable. Les usagers consommateurs doivent limiter les exploitations abusives des ressources en dénonçant notamment les

\footnotetext{
${ }^{383}$ La Tullaye (de) (L. et G.), Hydrotour. 6 milliards d'acteurs pour sauver l'eau, Editions Biglo, 2006, p.79.

${ }^{384}$ Extrait du message de Mme Irina Bokova (Directrice générale de l'UNESCO) à l'occasion de la journée mondiale de l'eau tenue le 22 mars 2010 sous le thème « De l'eau propre pour un monde sain ».

${ }^{385}$ La Tullaye (de) (L. et G.), op.cit., p.154.
} 
atteintes y relatives. Suivant cette logique, les partenaires au développement doivent orienter leur appui en tenant compte des préférences surtout des populations marginalisées.

\section{La gestion rationnelle de l'eau potable}

Parce que l'eau potable devient une ressource de plus en plus insuffisante pour satisfaire le besoin des populations, il devient nécessaire de la rationaliser. "La dégradation de l'environnement est un phénomène de civilisation qui compromet la viabilité du milieu légué aux générations futures. Le devoir de protection de l'environnement implique la promotion de nouvelles formes de développement et de croissance, la référence à de nouvelles solidarités planétaires, la mise en place de nouvelles institutions internationales de gestion environnementale. S'il n' ya pas de réponse mondialisée à cet enjeu vital, si la politique individualiste des Etats et les intérêts économiques des acteurs l'emportent sur la conscience mondiale écologique, le "nouvel » ordre mondial sera amputé d'un constituant essentiel ${ }^{386}$. La rationalité dans la gestion concerne toutes les couches sociales (les consommateurs et les distributeurs en premiers). Les installations doivent être accessibles, régulières et bien entretenues pour une utilisation rationnelle et éthique de l'eau.

Pour parvenir à une mise en œuvre effective du droit à l'eau potable au Cameroun et dans toute l'Afrique centrale en général, il faut résoudre nous l'avons dit essentiellement trois problèmes.

Le premier est d'ordre juridique, il faudrait mettre sur pied un arsenal juridique qui définisse clairement le droit à l'eau et ses implications pour les citoyens bénéficiaires et spécialise les compétences en la matière. Il faudrait spécialiser les acteurs dans le domaine notamment en accordant par exemple la seule compétence au Ministère de l'Eau et de l'Energie (sans désengager la responsabilité des autres ministères dans le processus de mise en œuvre du droit); ce qui aura comme avantage de limiter les lenteurs et les lourdeurs dans le processus. Il faudrait militer en faveur de l'adoption d'une Convention-cadre dans le domaine de l'eau potable; ce qui aurait comme avantage de fixer un cadre juridique clair de définition et de mise en œuvre du droit à l'eau.

Le second problème est d'ordre institutionnel et appelle l'application des règles de bonne gouvernance dans le secteur de l'eau (l'utilisation effective et efficiente des budgets alloués pour accélérer le processus de mise en œuvre de ce droit) et surtout la prise en compte de la "bonne volonté politique $»^{387}$ dans le processus de lutte contre la pauvreté.

Le troisième et dernier problème est d'ordre pratique, il faudrait encourager la formation et l'information des usagers sur le droit à l'eau potable et l'assainissement pour tous en leur inculquant une méthode de gestion fondée sur la rationalité et l'intégration. Il faudrait de façon générale prendre en compte les règles de la décentralisation des services de l'eau potable lors de la planification des mesures instituées. Ce n'est que de cette façon que l'on parviendra à développer un plan efficace

\footnotetext{
${ }^{386}$ Gounelle (M.), Relations internationales, Dalloz, Collection « Mémentos », 6 éd., 2004, p.57.

${ }^{387}$ Une volonté basée sur la recherche d'une meilleure gestion.
} 
de gestion intégrée des bassins versants en général et de l'eau potable au Cameroun en particulier.

S’il est vrai que les défis exposés dans le rapport (de l'OMD) prévu pour résoudre les questions d'accès à l'eau potable pour tous sont décourageants, la bataille n'est pas encore perdue d'avance. Le temps initialement fixé est court, il faut le reconnaître, 2015 est à l'horizon, l'objectif d'accès de tous à l'eau potable au Cameroun pourrait encore être atteint si le contexte économique et social de la région venait à être pris en compte lors de l'établissement des plans d'actions et stratégies d'accès à l'eau potable. La gouvernance de l'eau fait référence aux systèmes politiques, administratifs, économiques et sociaux gérant les services et les ressources en eau. Pour le faire, les gouvernements se doivent d'adopter des politiques de gestion conciliantes ${ }^{1388}$. La gestion démocratique de l'eau implique: l'évaluation de la valeur environnementale; l'implication de tous les acteurs étatiques et non étatiques dans le processus d'élaboration des politiques de décisions; l'évaluation de l'impact environnemental dans les projets d'eau potable; l'adoption des politiques de lutte contre la sécheresse et les inondations; le renforcement des capacités des collectivités locales; la multiplication des forums de sensibilisation et de formation sur l'eau potable.

L'institutionnalisation d'un programme assisté et intégré de mise en œuvre du droit à l'eau potable au Cameroun interpelle la communauté internationale à travers l'assistance de l'Etat (aussi bien techniquement que technologiquement) dans le processus notamment en lui accordant les moyens financiers et matériels de développer et maintenir en veille les stratégies et plans d'action mis sur pied. Cette assistance doit également offrir aux couches sociales défavorisées un cadre juridique favorable à la défense et la sauvegarde de leur droit.

Mettre en œuvre le droit à l'eau potable "pour tous " en Afrique centrale et au Cameroun en particulier c'est solutionner les obstacles recensés, c'est également spécialiser les organismes et les compétences en la matière et surtout trouver une solution pour remédier aux problèmes des couches sociales marginalisées et vulnérables.

${ }^{388}$ Qui prend en considération la participation des citoyens et leurs intérêts catégoriels. 


\section{CONCLUSION DE LA DEUXIEME PARTIE}

"Les pauvres et les indigènes cherchent l'eau, et il n'y en a point. Leur langue est desséchée par la soif. Moi, le Dieu d'Israël, je ne les abandonnerai pas. Je ferai jaillir des fleuves sur les collines, et des sources au milieu des vallées »; ESAÏE, 41, 17-18.

Nous pouvons affirmer au regard de tout ce qui précède que le droit à l'eau potable du moins théoriquement existe au Cameroun. C’est sa mise en œuvre pratique qui continue de poser problème. La ressource en elle-même est certes rare surtout dans la région du grand Nord, mais présente dans la région du Sud. La difficulté commence quant il s'agit de la destiner à la consommation humaine. Car, l'eau potable au Cameroun n'est pas encore la chose la mieux partagée. Les couches sociales défavorisées (telles que les personnes vivant des les zones non desservies, les habitants des zones rurales et périurbaines) sont les plus touchées par la pénurie. On pourrait comme nous l'avons recommandé dans les développements précédents leur apporter une assistance pour faciliter leur accès effectif à l'eau potable. Pour être efficace, cette assistance doit être à la fois préventive (afin de limiter les cas de coupure pour non paiement) et curative (afin d'aider les ménages où les compteurs ont été déposés pour non règlement de facture). L'efficacité dans l'action repose nous l'avons dit sur la solidarité entre les acteurs et entre les riches et les pauvres. On pourrait aussi penser à créer un fond spécial au près des services sociaux par exemple pour recevoir les aides volontaires et les destiner au profit des personnes démunies ou défavorisées. Cependant, le prix raisonnable reste le meilleur moyen pouvant garantir l'accès du grand nombre à la ressource.

Comme dans le reste des pays africains, le développement du droit à l'eau potable au Cameroun s'est construit à travers certains textes internationaux relatifs à la question $^{389}$ et l'adoption des stratégies nationales propre. La loi $\mathrm{N}^{\circ}$ 98/005 du 14 avril 1998 (et ses décrets d'applications) portant régime de l'eau au Cameroun et la loi constitutionnelle ${ }^{300}$ du 18 janvier 1996 malgré leurs lacunes (ne font pas explicitement référence à ce droit) sont une manifestation visible de l'existence de ce droit au Cameroun.

Cette partie a ceci comme intérêt qu'elle recense dans un premier temps de façon globale la majorité des obstacles ${ }^{311}$ entravant l'exercice libre du droit à l'eau potable au Cameroun pour enfin tenter d'y apporter remède (l'ensemble de ses solutions se résume au chapitre IV de la présente étude).

Pour parvenir à l'effectivité du droit à l'eau potable au Cameroun et dans le reste du monde en général, il faut résoudre comme nous l'avons dit, les obstacles d'ordres juridiques, politiques et pratiques ${ }^{32}$. Nous reviendrons sur la résolution des obstacles

\footnotetext{
${ }^{389}$ Voir pour les details, le chapitre II (section I-paragraphe II (B) de cette thèse.

${ }^{390}$ Modifiée en 2008, elle n'intègre pas le droit à l'eau potable dans son dispositif comme certains Etats suscités, elle reconnaît néanmoins les DESC contenus dans la Déclaration universelle des droits de l'homme de 1948 et le Pacte relatif au DESC de 1966 ratifiés par l'Etat.

${ }^{391}$ Ces obstacles nous l'avons dit, sont d'ordres juridique, pratique et institutionnel, voir les détails au chapitre III (section II, paragraphe I, B).

${ }^{392}$ Les détails de ces solutions sont réitérés en fin de chapitre IV.
} 
juridiques pour reparler de l'importance de la Convention-cadre relative au droit à l'eau potable.

L'institutionnalisation d'une telle Convention serait d'un grand intérêt pour le Cameroun. Premièrement, elle permettrait de clarifier davantage ce droit et imposerait à l'Etat un certain seuil nécessaire à la recevabilité de son document relatif au rapport annuel d'affirmation ou d'infirmation de la mise en œuvre du droit à l'eau potable dans son territoire. Sa portée est si grande qu'elle pourrait servir de table de référence à tous les pays qui n'ont pas encore suffisamment intégré la notion de droit à l'eau en tant que droit humain essentiel. Le Cameroun, s'il venait à ratifier cette Convention, pourrait s'en inspirer pour consolider la reconnaissance ainsi que la mise en œuvre du droit à l'eau potable dans son territoire. Celle-ci fournirait un corpus législatif commun, cohérent, et, clarifierait le rôle de l'Etat. Elle permettrait ainsi de sauvegarder tous les droits humains aujourd'hui acceptés ainsi que les conventions sur l'environnement ou celles en conflit avec d'autres du fait que l'eau ne soit pas considérée comme droit humain ${ }^{393}$. Une Convention-cadre dans le domaine de l'eau potable permettrait ainsi d'atteindre ou du moins tendre vers l'effectivité du droit à l'eau potable. Cet accord serait plus contraignant en ce sens qu'il serait l'essentiel d'une politique mondiale sur les droits de la personne humaine et des peuples. Il donnerait alors aux populations un moyen sûr de pression important sur les gouvernements ${ }^{394}$ comme prévu à l'article 35 de l'OG $\mathrm{N}^{\circ} 15$ : "les Etats devraient veiller à ce que le droit à l'eau reçoive l'attention voulu dans les accords internationaux et, à cette fin, devraient envisager d'élaborer le nouvel instrument juridique». A travers elle, la justiciabilité du droit à l'eau connaitra une grande avancée notamment par le canal des juridictions continentales, internationales qui auront eux aussi acquis de part cette Convention le pouvoir de rendre des décisions obligatoires. Certes, un instrument conventionnel international n'aura peut-être pas un impact positif significatif sur les populations qui souffrent déjà du manque d'accès à l'eau que si au niveau national, la volonté politique existe. Une Convention-cadre dans le domaine de l'eau potable ne viendra probablement pas résoudre tous les problèmes auxquels font face les individus dans la revendication et le respect de leur droit y relatif, mais, elle constituerait un grand pas dans l'avenir de ce droit.

\footnotetext{
${ }^{393}$ Propos tenus par Maude Barlow, Rencontres internationales du droit d'accès à l'eau, Marseille, novembre 2006. Elle est conjointement Présidente du groupe council of canadians et cofondatrice du projet planète bleue qui vise la limitation de la raréfaction de l'eau.

${ }^{394}$ Document de Réflexion et plan d'action, «Pour la mise en œuvre du droit à l'eau en tant que droit humain, une plate forme pour organiser la mobilisation », Atelier $\mathrm{N}^{\circ} 1$ du FAME, Génève, 18 mars 2005, p.5.
} 


\section{CONCLUSION GENERALE}

$\mathrm{Au}$ terme de cette étude, est-on véritablement en droit d'affirmer que le droit international de l'environnement concourt à mettre en œuvre le droit à l'eau potable en Afrique centrale et au Cameroun en particulier ? Peut-on en en déduire que le droit positif camerounais contribue à la sauvegarde de ce droit et partant garantit sa mise en œuvre?

Donner une réponse affirmative catégorique à cette préoccupation serait certes adopter une attitude mentale positive, mais l'approche resterait quelle que peu hâtive et illusoire. Au cours de nos développements, nous avons recensés les lacunes du droit international de l'environnement dans la mise en œuvre de ce droit (la principale étant qu'elle régit plus le droit de l'eau en général que le droit à l'eau potable en particulier).

$\mathrm{Au}$ plan international, cette thèse a reconnu la forte mobilisation des acteurs du droit international de l'environnement pour la mise en œuvre du droit à l'eau potable au Cameroun à travers l'esquisse de résolution du problème de sa nature juridique controversée ainsi que celui de sa difficile consécration. De fond en comble, cette entreprise a été davantage l'œuvre du droit de l'homme ${ }^{395}$ que du droit international de l'environnement.

Par déduction aux autres Droits Economiques Sociaux et Culturels (tel que le droit à la santé, le droit au logement, le droit à la nourriture, etc.) contenu dans le PIDESC de 1966, le droit à l'eau potable a été classé dans la catégorie des Droits Economiques, Sociaux et Culturels faisant l'objet d'une réalisation progressive. Comme nous l'avons précisé, avec l'avènement de l'Observation Générale $\mathrm{N}^{\circ} 15$ de 2002 (pris par le Comité des droits économiques, sociaux et culturels en interprétation des articles 10 et 11 du PIDESC de 1966) et de la Résolution A/Res/64/292 du 28 juillet 2010 dernier, le droit à l'eau connait, une avancée significative dans sa définition. Il est désormais officiellement défini comme un droit humain fondamental. Quoique ces textes n'aient en pratique aucune force juridique contraignante, ils restent tout de même les premiers textes du genre à consacrer le droit à l'eau potable comme un droit humain fondamental et à réactualiser le projet de subjectivation de ce droit.

Quant à la question de savoir si le droit à l'eau potable est oui ou non un droit subjectif revendicable devant les tribunaux, nous avons répondu avec optimisme et sans hésitation par l'affirmative en disant que : reconnaitre le droit à l'eau potable signifie le rendre justiciable devant les tribunaux au même titre que les autres droits de l'homme tels que le droit à la vie. Il est vrai que ce droit impose à l'heure actuelle chez l'Etat une simple obligation progressive en fonction de ses moyens, mais cela n'altère en rien sa protection devant les tribunaux. Présentement, au Cameroun comme dans la plupart des pays d'Afrique centrale, les hypothèses de contentieux juridictionnels pour entrave à l'exercice du droit à l'eau potable sont rares. Il y a tout de même le cas de l'Afrique du

\footnotetext{
${ }^{395}$ Il faut s'arrêter pour saluer la récente adoption de la Résolution A/Res/64/292 de l’Assemblée Générale des Nations Unies qui reconnaît explicitement le droit à l'eau et l'assainissement comme un droit humain fondamental essentiel à la jouissance de la vie et à la réalisation des autres droits de l'homme. Malgré sa limite (ne résout pas toujours le problème de justiciabilité dudit droit ni celui du garant de sa mise en œuvre), elle reste tout de même le premier instrument des Nations Unies à reconnaitre officiellement le droit à l'eau comme un droit humain fondamental.
} 
Sud qui, en plus de l'avoir constitutionnalisé, a reconnu sa justiciabilité dans l'affaire Grootboom $^{396}$.

Toujours au plan international, nous avons examiné les raisons de la difficile consécration du droit l'eau potable en notant que ce droit est passé tour à tour d'une lente reconnaissance à une forte promotion. Pour ce qui est de sa reconnaissance, elle a été plus rapide en Afrique ${ }^{397}$ que dans le reste du monde ${ }^{398}$. Quant à sa promotion, nous avons vu que la forte mobilisation en faveur de la revendication de ce droit a abouti à la consécration (par la résolution A/RES/47/193 de l'Assemblée Générale des Nations Unies) du 22 mars de chaque année comme journée mondiale de l'eau ${ }^{399}$ et la prise en compte de l'eau comme un élément du patrimoine commun de l'humanité.

Pour ce qui est de la mise en œuvre de ce droit au plan national, nous avons relevé sa faible effectivité au Cameroun en particulier. D’abord un droit hérité du droit international (par signature, ratification), le droit camerounais n'a pas encore réussi à mettre en œuvre toutes les conventions ratifiées. Bien plus, la mauvaise répartition de la ressource en eau (abondante dans les régions du Sud Cameroun et limitée dans les région du Nord) créée plus que jamais un déséquilibre dans la jouissance du droit au point où nous sommes venus à nous poser la question de savoir si la problématique du droit à l'eau potable se pose essentiellement en termes de droit d'accès, quel serait alors son avenir dans un pays qui n'as pas accès à la ressource ou qui l'a constitutionnalisée? Est-ce que le droit à l'eau potable y aura une influence significative?

Comme tentative de réponse, nous avons affirmé que: "renforcer et maintenir le droit subjectif à l'eau dans un Etat où l'eau potable est rare peut constituer un début de solution au problème d'eau potable d'autant plus que la reconnaissance et la mise en œuvre de ce droit peut en quelque sorte déjà constituer une incitation juridique pour l'Etat garant. Dans cette logique, cet Etat en vue de garantir l'accès de sa population à la ressource peut aller jusqu'à exporter l'eau potable en attendant de trouver les moyens de s'en procurer ${ }^{400}$. Nous ne nous y sommes pas trop attardée car, les débats y relatifs pourraient bien constituer une seconde thèse.

Pour ce qui est du droit positif camerounais proprement dit, nous avons trouvé plus particulièrement la loi $\mathrm{N}^{\circ}$ 98/005 du 14 avril 1998 portant régime de l'eau et ses décrets d'application riche en contenu mais un peu pauvre ${ }^{401}$ en leçon quant à la mise en ouvre du droit à l'eau potable. Ce texte ne donne pas une définition claire du droit à l'eau, or, il est unanimement admis que, "lorsqu'on ne sait pas ce que c'est qu'un droit, on ne peut qu'être insensible à sa violation". Nous avons également dénoncé les enchevêtrements de compétences en matière de droit à l'eau (où presque tous les ministères interviennent dans le service de l'eau potable) et recommandé une spécialisation des compétences pour une mise en œuvre plus efficiente. Toujours dans cette loi, nous avons apprécié la

\footnotetext{
${ }^{396}$ Voir les détails de cette affaire à la note de bas de page 116.

${ }^{397}$ Voir l'Encadré 7.

${ }^{398}$ Voir les Encadrés 5 et 6 ci-dessus.

${ }^{399}$ Elle a regorgé au fil du temps des thèmes très riches, Voir le tableau 4 pour les détails.

${ }^{400} \mathrm{La}$ source de cette information nous est personnelle; voir les détails dans le tableau contenu dans la conclusion énoncée au chapitre I.

${ }^{401}$ Cette loi, tout comme le droit international de l'environnement est plus préoccupée par le droit de l'eau que par le droit à l'eau potable.
} 
décentralisation et la délégation du service de l'eau potable au Partenariat Privé Public comme recommandé lors du $3^{\text {ème }}$ Forum Mondial de l'eau tenu à Tokyo en 2003. Le service de l'eau potable au Cameroun, nous l'avons dit, connait une organisation administrative collégiale: la Camerounaise Des Eaux qui assure le service de distribution, la Camwater (qui gère le patrimoine de l'Etat) et les Organismes soustutelles (qui assurent la tutelle et le contrôle de bonne gestion sur la Camerounaise Des Eaux et la Camwater).

Pour ce qui est du code de l'eau, le Cameroun n'en dispose pas encore à l'heure actuelle, il se sert dans la pratique de la loi $\mathrm{N}^{\circ}$ 98/005 portant régime de l'eau et de ses décrets d'application. Contrairement à certains Etats ${ }^{402}$ ayant constitutionnalisé le droit à l'eau potable, le Cameroun s'est limité dans sa loi constitutionnelle à affirmer son attachement aux conventions internationales phare (de reconnaissance du droit à l'eau potable) qu'il a ratifié à savoir la Déclaration universelle des droits de l'homme de 1948, le Pacte International relatif aux Droits Economiques, Sociaux et Culturels de 1966 ainsi que de la Charte africaine des droits de l'homme et des Peuples de 1981. Etait-ce là une façon pour le constituant de constitutionnaliser implicitement ce droit ?

A cette question, une réponse prudente s'impose car, constitutionaliser implicitement un droit déjà lui-même déduit implicitement dans la majorité des textes y relatifs n'avance pas à grand chose. La reconnaissance du droit à l'eau potable au plan interne peut également contribuer à consolider une politique juridique de l'eau plus soucieuse de l'équité, à renforcer les financements et bannir certaines discriminations dont sont victimes certaines couches sociales défavorisées. Ce qui aurait comme avantage de réduire sinon éradiquer le taux de maladies hydriques à travers la promotion de l'eau de qualité et des méthodes d'assainissement adéquates. Car, la problématique du droit à l'eau est avant tout une problématique de droit d'accès.

$\mathrm{Vu}$ les obstacles recensés tant an plan national qu'international, nous avons formulé certaines recommandations incontournables dans la mise en œuvre effective du droit à l'eau potable en Afrique centrale en particulier et dans le reste du monde en général. Lesquelles recommandations passent par la réduction voire l'éradication des obstacles d'ordre juridique, pratique et institutionnel recensés ainsi que la démocratisation dudit droit.

Pour le premier volet relatif aux obstacles juridiques, le droit à l'eau potable pour être effectif, doit être un droit accessible (physiquement, économiquement et moralement) et justiciable devant les tribunaux. Nous avons au cours de nos développements insisté sur le critère de justiciabilité qui constitue un élément clé de mise en œuvre du droit à l'eau potable. C'est d'ailleurs une condition sine qua non pour la réalisation de ce droit. Nous avons aussi recommandé d'assister les pays qui sont dans le besoin de mettre en œuvre leur droit à l'eau potable notamment en leur accordant des moyens financiers et matériels pour s'en procurer. Car, «à quoi servirait ce droit dans un pays qui n'a pratiquement pas d'eau? $»^{403}$. Cette assistance nous l'avons dit, doit être à

\footnotetext{
${ }^{402}$ Voir l'Encadré 8 traitant des pays ayant constitutionnalisé leur droit à l'eau.

${ }^{403} \mathrm{La}$ réponse à cette question est donnée dans le tableau 2 de cette thèse.
} 
la fois technique et technologique et surtout particulièrement destinée aux couches sociales défavorisées ${ }^{404}$.

Pour ce qui est du second volet, à savoir la nécessité de rendre démocratique le service de l'eau potable, cette recommandation a plusieurs avantages. Elle permettrait non seulement d'appliquer une méthode de gestion intégrée de l'eau potable qui prenne en compte la gestion participative et l'équilibre des besoins usagers, mais davantage une méthode de gestion écologique et rationnelle qui favorise la mise en pratique des mécanismes de protection et sauvegarde de l'écologie environnementale de façon à limiter voire éradiquer la dégradation des ressources en eau douce. D'autres parts, nous avons en l'absence d'une Convention-cadre réservée au droit à l'eau potable à l'heure actuelle, milité en faveur de son adoption. Cet important instrument conventionnel serait non seulement salutaire pour la consolidation du droit à l'eau potable autrefois controversée mais aussi complèterait les efforts de l'Observation Générale $\mathrm{N}^{\circ} 15$ et de la Résolution A/Res/64/292 du 28 juillet 2010 dans la recherche de mécanismes juridiques de mise en œuvre de ce droit. Cette Convention créerait ainsi de façon explicite un droit à l'eau potable et le renforcerait au plan interne des Etats qui l'auraient ratifié. Une telle convention si elle venait à exister, ne serait peut-être pas une panacée, mais constituerait un début de solution face à la crise globale de l'eau actuelle.

Pour ce qui est de la portée de cette thèse, sa rédaction a permis d'identifier un certains nombres de perspectives et de questionnements ${ }^{405}$ pouvant guider les recherches futures : le droit à l'eau est-il un droit subjectif? Peut-on de nos jours parler d'un véritable droit à l'eau sans mécanismes juridiques de revendication? Le droit à l'eau relève-t-il du droit international de l'environnement ou du droit de l'homme? Droit à l'eau ou droit de l'eau ? Que faut-il garantir en premier?

Comme le témoigne la problématique débattue, le droit à l'eau potable est avant tout une question de vie à enjeu transnational. Sa mise en œuvre effective ne dépend plus seulement du nombre de textes juridiques en la matière mais davantage de la volonté individuelle, collective et surtout politique en faveur d'actions concrètes.

En définitive, le droit à l'eau potable et surtout sa mise en œuvre effective n'est pas sans avenir au Cameroun. A condition de maintenir en veille l'ensemble de ces recommandations juridiques, économiques et sociales novateurs développées dans l'optique de faciliter sa mise en œuvre effective à savoir : donner une définition précise de ce droit et ses implications juridiques pour les citoyens qui doivent en bénéficier, spécialiser les compétences en la matière, établir de façon non équivoque la responsabilité de l'Etat en tant que garant «naturel» de ce droit, sensibiliser en particulier les pauvres et les personnes défavorisées sur son existence en leur accordant les moyens pour assurer sa mise en œuvre, encourager la solidarité de tous et plus particulièrement entre riches et pauvres, établir un calendrier d'évaluation annuel de la mise en œuvre du droit à l'eau au plan interne et, faire parvenir le rapport final à l'ONU pour évaluation et publication et enfin encourager les Etats à ratifier la Conventioncadre relative au droit à l'eau. Ces recommandations ne doivent pas être perçues comme

\footnotetext{
${ }^{404}$ Car, elles sont en premier concernées par ce droit.

${ }^{405}$ Dont la majorité des réponses figurent au tableau 2 du chapitre I de cette thèse.
} 
l'aboutissement de la bataille de mise en œuvre du droit à l'eau potable au plan interne, mais davantage comme un premier pas vers la réalisation de cet objectif.

Ainsi, l'Etat, la communauté internationale, la société civile et les individus, nous l'espérons fort bien, ne se perdront plus jamais de vue dans cette entreprise. Ils évolueront ensemble main dans la main vers la réalisation de cet objectif commun dont dépend l'avenir de l'humanité tout entière ${ }^{406}$. Dès lors, allons-nous continuer à "mettre en quarantaine » ces fortes recommandations développées et innovées dans le cadre de ce travail ou alors, ferons-nous désormais d'elles notre compagnon de tous les jours? Quelle sera notre choix et partant celui de nos dirigeants? A nous de voir, car tout dépend encore de nous.

\footnotetext{
${ }^{406}$ Comme l'affirmait son Excellence Nicolas Sarkozy le 17 janvier 2011 dernier lors de la préparation du $6^{\text {ème }}$ Forum mondial de l'eau (qui se tiendra à Marseille du 12 au 17 mars 2012), "The time for solution has come for water, as it has for sanitation. From now on, we have to apply concrete measures and make firm commitments. These commitments should be on voluntary basis by players of all categories-Governments, parliament, international organizations, businesses, local authorities, and non-governmental organization ».
} 


\section{BREF CURRICULUM VITAE}

(According to Article 25 of the Regulation Governing the Attainment of Doctoral Degrees-Maastricht University 2003)

\section{1- Données personnelles}

Naissance : $\quad 10$ septembre 1980, Mbouda, Cameroun

Nationalité : $\quad$ Camerounaise

Situation matrimoniale: Mariée, mère d'un enfant

\section{2- Formation académiques}

- Master 2 Droit international et comparé de l'environnement

Faculté de Droit et des Sciences économiques de l'Université de Limoges (France), 2006

- Maîtrise en Droit privé Faculté des Sciences juridiques et politiques de l'Université de Yaoundé II (Cameroun), 2004

- Licence en Droit et Science politique

Faculté des Sciences juridiques et politiques de l'Université de Dschang (Cameroun), 2003

- Diplôme d'études universitaires générales en Droit

Faculté des Sciences juridiques et politiques de l'Université de Dschang (Cameroun), 2001

- Baccalauréat (A4) langue et philosophique - option Espagnol

Lycée de Loum (Cameroun)

Diplôme obtenu en 1999

\section{2- Conférences et colloques internationaux}

- Participante à la visioconférence sur la gestion démocratique de l'eau organisée par la Banque Mondiale avec le concours de l'Agence universitaire de la Francophonie (avril 2007)

- Exposante au Premier Salon International de l'étudiant de Yaoundé pour le compte de l'Agence universitaire de la Francophonie (juillet 2007)

- Participation à la table ronde juridique : «L'entreprise et l'environnement ", Lomé (Togo) septembre 2008.

\section{3- Listes de publications, Honneurs et Mentions spéciales}

- «L'apport du droit international de l'environnement pour l'accès à l'eau potable en Afrique centrale ", Mémoire de fin de formation Master 2 Droit International et Comparé de L'Environnement, Université de Limoges (France), août 2007. 71p.

- «Une Vie Sans Eux », Roman, publié aux éditions l'Harmattan juin 2008, 86p. 
- «Le droit international au service de l'eau potable», article publié en ligne chez l'harmattan en 2008.

- Allocataire d'études de l'Agence universitaire de la Francophonie (2006-2007)

\section{4- Expériences professionnelles}

Période : De avril à septembre 2009

Poste: $\quad$ Ministère de l'Eau et de l'Energie du Cameroun, stagiaire à la cellule juridique

Fonctions : En charge des questions liées à l'eau potable

Réalisation: Membre du comité de relecture du règlement de service affermé, Participation au Projet d'organigramme Ministère de l'Eau et de l'Energie

Période: Depuis mai 2008

Poste: Projet Véolia environnement (France)/ village Bangoua (COMEGBA), Consultante (Volontaire)

Fonctions: En charge de la rédaction des stratégies relatives à l'accès des villageois à l'eau potable et de la proposition des méthodes de prévention des maladies hydriques

Réalisation : production d'un rapport traitant des méthodes de contrôle et de vérification de l'accessibilité de la communauté villageoise à l'eau potable 
ANNEXES $^{407}$

${ }^{407}$ Les commentaires faits au sujet des annexes ci-jointes sont propres à l'auteur de cette thèse. 


\section{REPERTOIRE $^{408}$ DES CONFERENCES INTERNATIONALES AUTOUR DE LA PROBLEMATIQUE DE L'EAU POTABLE}

\begin{tabular}{|c|c|c|}
\hline Lieu & Titre & Date \\
\hline Marseille (France) & $6^{\text {ème }}$ Forum mondial de l'eau & 12-17 mars 2012 \\
\hline Yaoundé (Cameroun) & $\begin{array}{l}\text { "Conférence internationale sur l'énergie } \\
\text { et l'eau » }\end{array}$ & 20-21 janvier 2010 \\
\hline Istanbul (Turquie) & $5^{\text {ème }}$ Forum mondial de l'eau & March, 16-22, 2009 \\
\hline sourakarta (Indonesia) & $\begin{array}{l}\text { Net work of Asian River Basin } \\
\text { Organizations-Third general meeting }\end{array}$ & February, 20-22, 2008 \\
\hline $\begin{array}{l}\text { Rome (Italie) } \\
\text { «EURO BIOB } 2007 »\end{array}$ & $\begin{array}{l}\text { Conférence internationale sur } \\
\text { l'application de la Directive cadre } \\
\text { européenne sur l'eau }\end{array}$ & $08-10$ novembre 2007 \\
\hline $\begin{array}{l}\text { Dongying (Chine) } \\
\text { «EURO BIOB 2007» }\end{array}$ & $\begin{array}{l}\text { Forum international de la rivière } \\
\text { « jaune " }\end{array}$ & 16-19 octobre 2007 \\
\hline Debrecen (Hongrie) & VIIe Assemblée Mondiale du RIOB & 07-09 juin 2007 \\
\hline Sorel- Tracy (Québec) & $\begin{array}{l}\text { Colloque international sur la gestion de } \\
\text { l'eau douce du Bassin St-Laurent et des } \\
\text { Grands lacs }\end{array}$ & 13-15 septembre 2007 \\
\hline Johannesburg (Afrique du Sud) & $\begin{array}{l}\text { Assemblée Générale des organismes } \\
\text { africains du Bassin et du Réseau des } \\
\text { Organismes du Bassin) }\end{array}$ & 04-07 mars 2007 \\
\hline Japon & $\begin{array}{l}9^{\text {ème }} \text { Séminaire Franco-japonais sur la } \\
\text { gestion de l'eau, des rivières et des zones } \\
\text { humides }\end{array}$ & 05-08 février 2007 \\
\hline $\begin{array}{l}\text { Megève (France) } \\
\text { «EURO BIOB 2006» }\end{array}$ & $\begin{array}{l}4^{\text {ème }} \text { conférence internationale pour } \\
\text { l'application de la Directive Cadre }\end{array}$ & 20-22 septembre 2006 \\
\hline Mexico & $4^{\text {ème }}$ Forum mondial de l'eau & $01 / 03 / 06$ \\
\hline Ouargla (Algérie) & $\begin{array}{l}\text { Colloque International sur les } \\
\text { Ressources en Eau souterraines dans le } \\
\text { Sahara }\end{array}$ & 12-13 décembre 2005 \\
\hline Chiang Rai (Thailand) & $\begin{array}{l}\text { Intergrated Water Ressource } \\
\text { Management of the Mikong River Basin }\end{array}$ & $28^{\text {th }}-29^{\text {th }}$ novembre 2005 \\
\hline $\begin{array}{l}\text { Namur (Wallonie)« EURO } \\
\text { BIOB 2005» }\end{array}$ & $\begin{array}{l}\text { Réunion internationale sur l'application } \\
\text { de la Directive cadre européenne sur } \\
\text { l'eau }\end{array}$ & $01 / 10 / 05$ \\
\hline $\begin{array}{l}\text { Dusanbe (Republic of } \\
\text { Tajikistan) }\end{array}$ & $\begin{array}{l}\text { International conference of régional } \\
\text { cooporation in Transboundary river } \\
\text { Basins } \\
\text { "Sustainable management of } \\
\text { Transboundary water": learning from } \\
\text { experience }\end{array}$ & $30^{\text {th }}$ May $-1^{\text {st }}$ June 2003 \\
\hline
\end{tabular}

\footnotetext{
408 Tableau conçu sur la base de certaines informations recueillies dans le site www.oieau.fr/fconfereces.htm, consulté le 20 juin 2008.
} 


\begin{tabular}{|c|c|c|}
\hline Lieu & Titre & Date \\
\hline Dakar (Sénégal) & $\begin{array}{l}\text { Conférence internationale : Réseau des } \\
\text { Commissions Internationales et des } \\
\text { Organismes de Bassin transfrontaliers et } \\
\text { réseaux africains des organismes de } \\
\text { Bassin }\end{array}$ & 03-06 novembre 2004 \\
\hline $\begin{array}{l}\text { Cracovie (Pologne) « EUROPE } \\
\text { INBO » }\end{array}$ & $\begin{array}{l}\text { Réunion internationale sur l'application } \\
\text { de la Directive cadre européenne su l'eau }\end{array}$ & 27-29 septembre 2004 \\
\hline $\begin{array}{l}\text { Paris (France) « AUTORITE } \\
\text { DU BASSIN DU NIGER » }\end{array}$ & $\begin{array}{l}\text { Partenariat international pour le Bassin } \\
\text { du Niger, vision partagée : de la stratégie } \\
\text { vers un plan d'action }\end{array}$ & $26-27$ avril 2004 \\
\hline $\begin{array}{l}\text { La Martinique (Antilles } \\
\text { Françaises) }\end{array}$ & Vie Assemblée Générale mondiale & 24-28 janvier 2004 \\
\hline Coglogin (France) & $\begin{array}{l}\text { Colloque international sur l'éthique de } \\
\text { l'eau et l'éducation de populations }\end{array}$ & 19 au 21 juin 2003 \\
\hline Limoges (France) & $\begin{array}{l}\text { Forum régional sur l'eau « Forum de } \\
\text { Limousin » }\end{array}$ & 01-02 décembre 2003 \\
\hline Evian(Génève) & Sommet du G8 à Evian & 01-03 juin 2003 \\
\hline Kyoto(Japon) & $3^{\text {ème }}$ Forum mondial de l'eau & Kyoto 2003 \\
\hline Japon & Forum mondial sur l'eau & 16-23 mars 2003 \\
\hline Thenon les Bains (France) & $\begin{array}{l}\text { Réseau international des organismes de } \\
\text { Bassin }\end{array}$ & $25-26$ novembre 2002 \\
\hline Delft (Pays Bas) & $\begin{array}{l}\text { Du conflit à la coopération : des } \\
\text { opportunités pour la gestion de l'eau }\end{array}$ & 20-22 novembre 2002 \\
\hline Madrid (Spain) & $\begin{array}{l}\text { International conference of basin } \\
\text { organisation }\end{array}$ & $04^{\text {th }}-6^{\text {th }}$ november 2002 \\
\hline Megève (France) & $\begin{array}{l}\text { Colloque international : l'eau en } \\
\text { montagne }\end{array}$ & 05-06 septembre 2002 \\
\hline Johannesburg (Afrique du Sud) & $\begin{array}{l}\text { Sommet mondial sur le développement } \\
\text { durable }\end{array}$ & 26 août -04 septembre 2002 \\
\hline Québec (Canada) & Assemblée Générale Riob & 28-30 mai 2002 \\
\hline Brasil & $\begin{array}{l}\text { IV Inter-American dialogue of water } \\
\text { management }\end{array}$ & $2^{\text {th }}-6^{\text {th }}$ september 2001 \\
\hline Bonn (Allemagne) & $\begin{array}{l}\text { Conférence internationale sur l'eau } \\
\text { douce }\end{array}$ & Bonn 2001 \\
\hline $\begin{array}{l}\text { Zakopane (Pologne), } \\
\text { San Salvador de bahia, } \\
\text { Valence (Espagne), } \\
\text { Morelia (Mexique). }\end{array}$ & $\begin{array}{l}\text { Assemblée Générale du RIO (Réseau } \\
\text { International des Organismes de Bassin) }\end{array}$ & $\begin{array}{l}\text { Zakopane } 2000 \\
\text { San Salvador de bahia } 1998 \\
\text { Valence } 1997 \\
\text { Morelia } 1996\end{array}$ \\
\hline La Haye (Pays Bas) & $2^{\text {ème }}$ Forum mondial de l'eau & $01 / 03 / 00$ \\
\hline Turin(Italie) & $\begin{array}{l}\text { Conférence ministérielle Euro- } \\
\text { méditerranéenne sur les gestions locales } \\
\text { de l'eau }\end{array}$ & $01 / 10 / 99$ \\
\hline Brésil & Colloque Franco-brésilien & 12 Aout 1999 \\
\hline Paris (France) & $\begin{array}{l}\text { Conférence internationale : « Eau et } \\
\text { Développement Durable» }\end{array}$ & 1998 \\
\hline Marrakech & $1^{\mathrm{er}}$ Forum mondial de l'eau & 1997 \\
\hline
\end{tabular}




\begin{tabular}{|c|c|c|}
\hline Lieu & Titre & Date \\
\hline $\begin{array}{l}\text { Marseille (France) } \\
\text { Istanbul (Turquie) }\end{array}$ & $\begin{array}{l}\text { Conférence Euro-méditerranéenne sur la } \\
\text { gestion locale de l'eau (EUROMED) } \\
\text { Conférence des Nations Unies sur les } \\
\text { établissements humains (habitat II) }\end{array}$ & 1996 \\
\hline $\begin{array}{l}\text { Noordwijk (Pays Bas) } \\
\text { Caire }\end{array}$ & 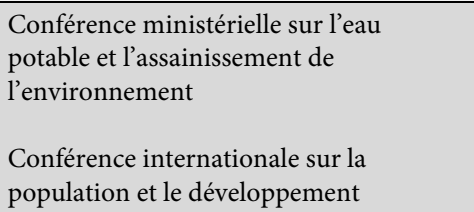 & 1994 \\
\hline $\begin{array}{l}\text { Rome (Italie) } \\
\text { Dublin (Irlande) }\end{array}$ & $\begin{array}{l}\text { Conférence méditerranéenne sur l'eau } \\
\text { Conférence Internationale sur l'eau et } \\
\text { l'environnement }\end{array}$ & 1992 \\
\hline Rio de janeiro (Brésil) & $\begin{array}{l}\text { Conférence Des Nations Unies sur } \\
\text { l'environnement et le développement }\end{array}$ & \\
\hline New Delhi (Inde) & $\begin{array}{l}\text { Consultation mondiale sur } \\
\text { l'approvisionnement en eau et } \\
\text { l'assainissement }\end{array}$ & 1990 \\
\hline Mar del Plata (Argentine) & Conférence des Nations Unies sur l'eau & 1977 \\
\hline
\end{tabular}

Les conférences tenues sur l'eau au plan international sont à l'origine des décisions non moins significatives dans la promotion du droit à l'eau potable en Afrique centrale. Depuis la conférence Mar del Plata, organisée sous l'égide des Nations Unies, l'eau est définie comme un bien commun de l'humanité. C'est à compter de ce Sommet qu'est mis sur pied un plan d'action d'évaluation systématique des ressources en eau. Bien avant 1977, le Sommet de Stockholm de 1972 tenu en Suède avait connu la participation de plusieurs pays africains à l'instar du Cameroun.

La conférence de 1990 relative à la consultation mondiale sur l'approvisionnement en eau et l'assainissement pour les années 1990 (New Delhi, organisé par le PNUD), lance un appel à toutes les Nations sur la nécessité de définir une stratégie concertée et commune visant à intégrer au centre de la gestion des ressources en eau deux principes essentiels : l'approvisionnement en eau potable et l'assainissement de l'environnement. C'est de New Delhi que découle la formule « un peu pour tous vaut mieux que beaucoup pour peu de monde ".

La conférence internationale sur l'eau et l'environnement organisée sous l'égide de l'O.M.M. en 1992 s'accroche sur quatre principes : l'eau douce est une ressource fragile et limitée, elle est indispensable à la vie, au développement et à l'environnement; la gestion et la mise en valeur des ressources en eau devraient reposer sur une approche participative et associée aux usagers; les femmes y jouent un rôle essentiel. L'eau, utilisée à des fins multiples a une valeur économique et devrait être considérée comme un bien économique.

La Conférence des Nations Unies sur l'environnement et le développement tenue à Rio la même année (dans son plan d'action 21, chapitre 18 consacré à l'eau) promeut : une gestion globale de l'eau douce, l'intégration des plans et des programmes sectoriels relatifs à l'eau dans le cadre des politiques économiques et sociales nationales. On note 
également la création de la commission sur le développement durable chargée d'évaluer le suivi de la conférence.

La conférence ministérielle sur l'eau potable et l'assainissement de l'environnement (tenue à Noordlik en 1994), consacre un programme d'action important : assigner une haute priorité aux programmes visant à fournir des systèmes de base d'assainissement et d'évacuation des excréments dans les zones urbaines et rurales.

La conférence internationale sur la population et le développement (tenue la même année au Caire) retient que «les facteurs liés à la population, à l'environnement et à l'éradication de la pauvreté doivent être intégrés dans les politiques de développement durable».

La conférence des Nations Unies sur les établissements humains (habitat II, tenue à Istanboul en 1996); retient que "les cadres de vie doivent être promus, grâce à l'approvisionnement en eau salubre et une gestion efficace des déchets".

Le $1^{\text {er }}$ Forum mondial de l'eau (tenu à Marrakech en 1997), accorde pour sa part quatre priorités à l'approvisionnement en eau et l'assainissement, la gestion des eaux partagées, la conservation des écosystèmes et à l'utilisation efficace de l'eau.

Le $2^{\text {ème }}$ Forum mondial de l'eau tenu à la Haye (aux Pays Bas) en 2000 exige pour sa part la participation de toutes les parties prenantes à la gestion intégrée des ressources en eau, la tarification de tous les services de l'eau en fonction de la totalité des coûts et l'augmentation des finances publiques (pour la recherche et innovation dans l'intérêt de la population).

La conférence internationale sur l'eau douce tenue à Bonn en 2001 retient que, pour accéder à l'eau potable, il est nécessaire d'assurer la sécurité de l'approvisionnement en eau pour lutter contre la pauvreté, d'appliquer les règles de la décentralisation comme défi majeur dans le processus, d'encourager la recherche de nouveaux partenariats pour un meilleur approvisionnement en eau, de concilier à la fois les intérêts de l'humanité et de la nature, de renforcement et d'améliorer les modes de gouvernance (mobilisation des ressources financières, de renforcer les capacités et enfin de mettre en commun les connaissances acquises dans le domaine.

La conférence de Johannesburg (tenue 10 ans après Rio) de 2002 prévoit dans sa cible 10 de réduire "d'ici 2010, de moitié, le pourcentage de population n'ayant pas accès à l'eau potable et aux services d'assainissement». Elle envisage des systèmes efficaces d'assainissement dans les établissements publics, en particulier les écoles, d'encourager une action éducation et une sensibilisation à l'intention des enfants, d'encourager l'emploi des technologies de pratiques peu coûteuses socialement et culturellement acceptables, de développer des modes de financement et partenariats novateurs et d'intégrer les moyens d'assainissement dans la stratégie de gestion des ressources en eau.

Le $3^{\text {ème }}$ Forum mondial de l'eau tenu à Kyoto en 2003 accorde la priorité aux questions de gouvernance, de gestion intégrée des ressources en eau, de genre, de pauvreté, de financements, de coopération, d'efficacité dans l'utilisation de l'eau, de prévention de la pollution des eaux et de réduction des désastres. A ce stade, on note déjà une nette évolution dans la mise en œuvre du droit à l'eau.

En 2006, le $4^{\text {ème }}$ Forum mondial sur l'eau tenu à Mexico, a pour titre «Des actions locales pour un défi mondial ». Les acteurs locaux sont placés au centre des débats.

Le $5^{\text {ème }}$ Forum mondial de l'eau (tenu à Istanbul en Turquie en 2009) avec pour thème: "Bridging divises for water » (établir des passerelles entre nos divergences dans 
le domaine de l'eau) a donné naissance à un Pacte dans le domaine de l'eau appelé «le Pacte d'Istanbul». Ce Pacte a pour objectif de trouver des moyens plus efficaces de gestion de l'eau qui soit adaptée au changement. Ses objectifs seront prochainement approfondis à Marseille en 2012 lors du $6^{\text {ème }}$ Forum mondial de l'eau encore appelé (Rio+ 20).

La conférence internationale de "l'énergie et l'eau au Cameroun» du 21 janvier 2010 cherche pour sa part à mettre sur pied une plate-forme destinée à toutes les parties prenantes dans le secteur, promouvoir l'investissement et évaluer les principaux défis et opportunités dans ce secteur.

Les conclusions retenues lors de la tenue de ces conférences sont suffisamment intéressantes pour faciliter la mise en œuvre du droit à l'eau potable au plan interne des Etats. Mais, la réalité demeure : les conclusions retenues lors d'une conférence quelles que soient leurs portées ne sauraient s'imposer de force aux participants. Bien plus, la pauvreté reste un véritable frein dans la mise en œuvre de ce droit en Afrique centrale. 
QUELQUES $^{409}$ ACCIDENTS PETROLIERS D'ENVERGURE INTERNATIONALE POUVANT ALTERER LA QUALITE DE L'EAU

\begin{tabular}{|c|c|c|c|}
\hline Catastrophe & Date & Lieu & Implications \\
\hline $\begin{array}{l}\text { Echouement du } \\
\text { Torrey Canyon }\end{array}$ & 18 mars 1967 & $\begin{array}{l}\text { Entre les îles Sorlingues et } \\
\text { la côte britannique }\end{array}$ & $\begin{array}{l}\text { Déversement en mer de } \\
120.000 \text { tonnes de pétrole brut }\end{array}$ \\
\hline $\begin{array}{l}\text { Echouement de } \\
\text { l'Amoco Cadiz }\end{array}$ & 16 mars 1978 & $\begin{array}{l}\text { Sur les côtes du Finistère } \\
\text { en Bretagne }\end{array}$ & $\begin{array}{l}\text { Déversement de } \\
220.000 \text { tonnes de pétrole brut } \\
\text { sur près de } 300 \mathrm{~km} \text { du littoral }\end{array}$ \\
\hline $\begin{array}{l}\text { Explosion de la plate } \\
\text { forme de forage Ixtoc } \\
1\end{array}$ & 3 juin 1979 & $\begin{array}{l}\text { Sur la Baie de Campêche, } \\
\text { golfe du Mexique }\end{array}$ & $\begin{array}{l}\text { Après } 295 \text { jours d'efforts, entre } \\
470.000 \text { tonnes et } 1500000 \\
\text { tonnes s'échappent, près d'un } \\
\text { tiers brûle et provoque une } \\
\text { forte pollution atmosphérique. } \\
\text { Le reste se répand sur le Golfe } \\
\text { du Mexique sous forme de } \\
\text { nappes dérivantes. }\end{array}$ \\
\hline $\begin{array}{l}\text { Collision entre } \\
\text { l'Atlantic Empress et } \\
\text { l'Agean Captain }\end{array}$ & 19 juillet 1979 & $\begin{array}{l}\text { Dans la mer des Caraïbes, } \\
\text { au large de l'île de Tobago }\end{array}$ & $\begin{array}{l}\text { Déversement de } 280.000 \\
\text { tonnes de pétrole en mer }\end{array}$ \\
\hline $\begin{array}{l}\text { Collision entre le } \\
\text { Burmah Agate et le } \\
\text { Minosa }\end{array}$ & $1^{\text {er }}$ novembre 1979 & $\begin{array}{l}\text { Au sud de Galveston, } \\
\text { Golfe du Mexique }\end{array}$ & $\begin{array}{l}\text { Déversement } 22.000 \text { tonnes de } \\
\text { brut en mer et flambage de } \\
65000 \text { tonnes à bord }\end{array}$ \\
\hline Naufrage du Tanio & 7 mars 1980 & $\begin{array}{l}\text { Nord de l'île de Batz, } \\
\text { Finistère }\end{array}$ & $\begin{array}{l}\text { Ecoulement de } 6.000 \text { tonnes de } \\
\text { fuel } \mathrm{N}^{\circ} 2 \text { avec la partie avant }\end{array}$ \\
\hline $\begin{array}{l}\text { Echouement du } \\
\text { cargo Cason }\end{array}$ & 5 décembre1987 & $\begin{array}{l}\text { Sur les côtes espagnoles } \\
\text { près du Cap Finistère }\end{array}$ & $\begin{array}{l}\text { Déversement et flambage en } \\
\text { mer de } 1.000 \text { tonnes de } \\
\text { produits chimiques toxiques et } \\
\text { corrosifs. }\end{array}$ \\
\hline $\begin{array}{l}\text { Echouement de } \\
\text { l'Exxon Valdez }\end{array}$ & 24 mars 1989 & $\begin{array}{l}\text { Sur la baie du prince } \\
\text { William, Alaska }\end{array}$ & $\begin{array}{l}\text { Déversement de } 42.000 \text { tonnes } \\
\text { de brut sur plus de } 2.000 \mathrm{~km} \\
\text { des côtes }\end{array}$ \\
\hline $\begin{array}{l}\text { Flambage du Mega } \\
\text { Borg }\end{array}$ & 8 juin 1990 & $\begin{array}{l}\text { Sur les côtes texanes, } \\
\text { Galveston }\end{array}$ & $\begin{array}{l}\text { Déversement en mer de } 42.000 \\
\text { tonnes }\end{array}$ \\
\hline $\begin{array}{l}\text { Ecoulement de la } \\
\text { barge Vistabella }\end{array}$ & 7 mars 1991 & $\begin{array}{l}\text { Au Sud-est de l'île de } \\
\text { Nevis }\end{array}$ & $\begin{array}{l}\text { Déversement de } 2.000 \text { tonnes } \\
\text { de fuel lourd sur l'archipel }\end{array}$ \\
\hline Guerre du Golfe & 26 janvier 1991 & Au Koweit & $\begin{array}{l}\text { Déversement en mer de } \\
700.000 \text { à } 900.000 \text { tonnes } \\
\text { d'hydrocarbures dû au } \\
\text { sabotage de l'armée irakienne } \\
\text { (c'est la plus meurtrière des } \\
\text { marées noire de l'époque) }\end{array}$ \\
\hline Explosion du Haven & 11 avril 1991 & $\begin{array}{l}\text { Sur la côte Ligure, côte } \\
\text { d'Azur française }\end{array}$ & $\begin{array}{l}\text { Perte de } 144.000 \text { tonnes de } \\
\text { brut }\end{array}$ \\
\hline $\begin{array}{l}\text { Echouement du } \\
\text { Braer }\end{array}$ & 5 janvier 1993 & $\begin{array}{l}\text { A la pointe Sud des îles } \\
\text { Shetland }\end{array}$ & $\begin{array}{l}\text { Déversement en mer de } 84.500 \\
\text { tonnes de brut }\end{array}$ \\
\hline $\begin{array}{l}\text { Echouement du Sea } \\
\text { Empress }\end{array}$ & 5 février 1996 & $\begin{array}{l}\text { Au port de Milford } \\
\text { Haven, Pays Galles }\end{array}$ & $\begin{array}{l}\text { Déversement sur une centaine } \\
\text { de km de la côte de } 73.000 \\
\text { tonnes de brut }\end{array}$ \\
\hline
\end{tabular}

\footnotetext{
${ }^{409}$ www.notreplanète.org.
} 


\begin{tabular}{|l|l|l|l|}
\hline \multicolumn{1}{|c|}{ Catastrophe } & \multicolumn{1}{|c|}{ Date } & \multicolumn{1}{c|}{ Lieu } & \multicolumn{1}{c|}{ Implications } \\
\hline Ecoulement d'Erika & 12 décembre 1999 & $\begin{array}{l}\text { Sur les larges côtes du } \\
\text { Finistère }\end{array}$ & $\begin{array}{l}\text { Déversement en mer et sur le } \\
\text { littoral de 30.000 tonnes de fuel } \\
\text { lourd de type 2 }\end{array}$ \\
\hline Sombrage du Prestige & 19 novembre 2002 & $\begin{array}{l}\text { Sur les larges côtes de } \\
\text { Galice, Espagne }\end{array}$ & $\begin{array}{l}\text { Déversement de } 70.000 \text { tonnes } \\
\text { de fuel sur les côtes espagnoles } \\
\text { et le littoral atlantique français }\end{array}$ \\
\hline Guerre au Liban & 14 juillet 2006 & Au Nord de Byblos, Liban & $\begin{array}{l}\text { Bombardement israélien } \\
\text { entraînant le déversement de } \\
10.000 \text { à 15.000 tonnes de fuel } \\
\text { dans la Méditerranée }\end{array}$ \\
\hline
\end{tabular}

Ce Tableau retrace de façon non exhaustive les catastrophes écologiques d'envergure internationale auquel a fait face la planète terre. Il faut s'arrêter pour regretter qu'après l'échouement de L'Exxon Valdez le 24 mars 1989 sur la Baie du Prince William, la prise de conscience amorcée n'ait pas réussie à mettre un terme aux catastrophes. Cela témoigne sinon de la légèreté des mécanismes de protection du moins de la réticence des exploitants marins plus intéressés par les gains économiques que procurent les produits pétroliers que par les désastres encourus. 
TYPOLOGIE ${ }^{410}$ DES DECHETS POUVANT ALTERER LA QUALITE DE L'EAU

\begin{tabular}{|c|c|c|}
\hline Catégories de déchets & Sous-catégories & Présentation \\
\hline \multirow[t]{4}{*}{ Déchet } & Déchets ménagers & Déchets produits par les ménages \\
\hline & Ordures ménagères & $\begin{array}{l}\text { Déchets liés à l'activité domestique des ménages } \\
\text { pris en compte par la collecte régulière }\end{array}$ \\
\hline & Encombrants des ménages & $\begin{array}{l}\text { Déchets liés à une activité occasionnelle qui, en } \\
\text { raison de leur volume et de leur poids, ne peuvent } \\
\text { être pris lors des collectes régulières }\end{array}$ \\
\hline & Déchets ménagers spéciaux & $\begin{array}{l}\text { Déchets présentant un ou plusieurs caractères } \\
\text { dommageables pour l'environnement et /ou qui } \\
\text { ne peuvent pas être éliminés par les mêmes voies } \\
\text { que les ordures ménagères sans créer de risque } \\
\text { lors de la collecte }\end{array}$ \\
\hline \multirow[t]{4}{*}{ Déchets de la collectivité } & Idem & Déchets produits par les services de la collectivité \\
\hline & Déchets du nettoiement & $\begin{array}{l}\text { Déchets liés au nettoyage des rues, des marchés, } \\
\text { des places publiques }\end{array}$ \\
\hline & Déchets des espaces verts & $\begin{array}{l}\text { Déchet liés à l'entretien des espaces verts : tontes } \\
\text { de gazons, tailles, élevages, feuilles mortes etc. }\end{array}$ \\
\hline & Déchets de l'assainissement & $\begin{array}{l}\text { Déchets résultant du fonctionnement des } \\
\text { dispositifs publics d'épuration et de l'entretien des } \\
\text { réseaux d'évacuation des eaux usées, pluviales ou } \\
\text { cours d'eau (boues, graisses déchets de } \\
\text { grillage,...) }\end{array}$ \\
\hline $\begin{array}{l}\text { Déchets des artisans et } \\
\text { commerçants, déchets } \\
\text { banals des activités } \\
\text { économiques et des } \\
\text { administrations }\end{array}$ & Idem & $\begin{array}{l}\text { Peuvent être confiés aux services communaux «à } \\
\text { condition de ne pas entraîner eu égard à leurs } \\
\text { caractéristiques, de sujétion techniques } \\
\text { particulières lors de leur élimination ». }\end{array}$ \\
\hline \multirow[t]{2}{*}{ Déchets industriels } & Déchets banals & $\begin{array}{l}\text { Déchets assimilables, à travers leur nature (ou } \\
\text { dangerosité), aux ordures ménagères. Dépassant } \\
\text { les volumes et quantités limites fixées par la } \\
\text { commune ou regroupement dans le contrat de } \\
\text { collecte, leur élimination est alors à la charge du } \\
\text { Producteur. }\end{array}$ \\
\hline & Déchets spéciaux & $\begin{array}{l}\text { Déchets dont la destination nécessite des } \\
\text { précautions particulières vis-à-vis de la } \\
\text { protection de l'environnement. }\end{array}$ \\
\hline
\end{tabular}

Comme l'illustre ce tableau, il existe plusieurs types de déchets dont la mauvaise gestion est susceptible de nuire à l'environnement et partant entraver l'exercice du droit à l'eau potable. Au plan international, les conventions types de gestion des déchets dangereux sont essentiellement les Conventions de Bâle ${ }^{411}$ de 1989, de Bamako ${ }^{412}$ de 1991, de

${ }^{410}$ NGNIKAM (E.) et (E.) TANAWA, Les villes d'Afrique face à leurs déchets, Utbm, décembre 2006, p.17.

${ }^{411}$ Elle vise trois formes d'interdictions : d'importer des déchets dangereux ou d'autres déchets; d'exporter les déchets dangereux ou d'autres déchets chez les Parties qui ont interdit l'importation des tels déchets; d'exporter les déchets dangereux et d'autres déchets si l'Etat d'importation ne donne pas par écrit son accord spécifique pour l'importation de ces déchets. Il lui a été fait le reproche d'avoir un tout petit peu ignoré le contexte africain. La Convention de Bamako est une réaction à cette Convention.

${ }^{412}$ Qui vise elle aussi trois interdictions : d'importer en Afrique des déchets dangereux de tout origine en 
Stockholm ${ }^{413}$ sur les Polluants Organiques Persistants du 23 mai 2001, la Conventioncadre $^{414}$ des Nations Unies sur les changements climatiques de 1992, le protocole ${ }^{415}$ de Kyoto de 1997, la Convention de Vienne ${ }^{416}$ pour la protection de la couche d'ozone de 1985, le Protocole ${ }^{417}$ de Montréal relatif à des substances appauvrissant la couche d'ozone de 1987, la Convention ${ }^{418}$ de Marpol de 1973/1978, la Convention d'Abidjan ${ }^{419}$ de 1981.

Dans l'ensemble, ces conventions cherchent autant que possible à limiter les atteintes portées à l'environnement en général et au droit à l'eau potable en particulier. En luttant contre les déchets dangereux, ces conventions de Droit international de l'environnement contribuent à l'assainissement des milieux, corollaire de l'accès à l'eau potable quoique la pratique montre les difficultés que connaissent ces conventions dans leur mise en œuvre. Plus de quarante ans après les indépendances africaines, «les villes, les institutions, et les Etats n'ont pas encore pu trouver les solutions appropriées pour collecter, traiter ou éliminer convenablement les déchets solides ménagers » ${ }^{420}$ malgré les filières ${ }^{421}$ de traitement de déchets répertoriés par Navarro en 1992.

provenance des parties non contractantes; de déverser des déchets dangereux dans la mer, les eaux intérieures et les voies d'eaux; de produire les déchets dangereux à l'intérieur de la zone compte tenu des considérations sociales, techniques et économiques.

${ }^{413}$ Elle vise la protection de la santé humaine et de l'environnement contre les POP (Polluants Organiques Persistants).

${ }^{414}$ Elle vise à stabiliser les concentrations de gaz à effet de serre dans l'atmosphère à un niveau qui empêche toute perturbation anthropique dangereuse du système climatique.

${ }^{415}$ Elle vise à réduire les émissions de gaz à effet de serre à l'origine des changements climatiques et des catastrophes écologiques (inondations, réchauffement de la planète).

${ }^{416}$ Elle vise la promotion des mesures adaptées à la protection de la santé humaine et l'environnement contre les effets néfastes résultants ou susceptibles de résulter des activités humaines qui modifient ou susceptibles de modifier la couche d'ozone.

${ }^{417}$ Elle cherche à réduire les SAO (Substances Appauvrissant la couche d'Ozone).

${ }^{418}$ Elle vise la prévention des pollutions par les hydrocarbures, les substances liquides transportées en vrac, les substances nuisibles transportées par mer en colis ou dans les conteneurs, les citernes ainsi que les eaux usées des navires. Cette Convention entrera en vigueur le 2 octobre 1983.

${ }^{419}$ Elle vise la coopération en matière de protection et de la mise en valeur du milieu marin et des zones côtières de la région de l'Afrique de l'Ouest et du Centre.

${ }^{420}$ NGNIKAM (E.) et (E.) TANAWA, op.cit., p.11.

${ }^{421}$ Ces filières sont au nombre de 20 . Les filières 1 à 16 ont pour objectifs d'exploiter le contenu (matière et /ou énergie du déchet). Les filières 16 à 20 visent l'élimination et la dépollution. 
QUELQUES SOURCES IMPLICITES DU DROIT A L'EAU POTABLE A L'INTERNATIONAL 

à 71 (1948).

\section{Préambule}

Considérant que la reconnaissance de la dignité inhérente à tous les membres de la famille humaine et de leurs droits égaux et inaliénables constitue le fondement de la liberté, de la justice et de la paix dans le monde,

Considérant que la méconnaissance et le mépris des droits de l'homme ont conduit à des actes de barbarie qui révoltent la conscience de l'humanité et que l'avènement d'un monde où les êtres humains seront libres de parler et de croire, libérés de la terreur et de la misère, a été proclamé comme la plus haute aspiration de l'homme,

Considérant qu'il est essentiel que les droits de l'homme soient protégés par un régime de droit pour que l'homme ne soit pas contraint, en suprême recours, à la révolte contre la tyrannie et l'oppression,

Considérant qu'il est essentiel d'encourager le développement de relations amicales entre nations,

Considérant que dans la Charte les peuples des Nations Unies ont proclamé à nouveau leur foi dans les droits fondamentaux de l'homme, dans la dignité et la valeur de la personne humaine, dans l'égalité des droits des hommes et des femmes, et qu'ils se sont déclarés résolus à favoriser le progrès social et à instaurer de meilleures conditions de vie dans une liberté plus grande,

Considérant que les Etats Membres se sont engagés à assurer, en coopération avec l'Organisation des Nations Unies, le respect universel et effectif des droits de l'homme et des libertés fondamentales,

Considérant qu'une conception commune de ces droits et libertés est de la plus haute importance pour remplir pleinement cet engagement,

\section{L'Assemblée générale}

Proclame la présente Déclaration universelle des droits de l'homme comme l'idéal commun à atteindre par tous les peuples et toutes les nations afin que tous les individus et tous les organes de la société, ayant cette Déclaration constamment à l'esprit, s'efforcent, par l'enseignement et l'éducation, de développer le respect de ces droits et libertés et d'en assurer, par des mesures progressives d'ordre national et international, la reconnaissance et l'application universelles et effectives, tant parmi les populations des Etats Membres eux-mêmes que parmi celles des territoires placés sous leur juridiction. 


\section{Article premier}

Tous les êtres humains naissent libres et égaux en dignité et en droits. Ils sont doués de raison et de conscience et doivent agir les uns envers les autres dans un esprit de fraternité.

\section{Article 2}

1. Chacun peut se prévaloir de tous les droits et de toutes les libertés proclamés dans la présente Déclaration, sans distinction aucune, notamment de race, de couleur, de sexe, de langue, de religion, d'opinion politique ou de toute autre opinion, d'origine nationale ou sociale, de fortune, de naissance ou de toute autre situation.

2. De plus, il ne sera fait aucune distinction fondée sur le statut politique, juridique ou international du pays ou du territoire dont une personne est ressortissante, que ce pays ou territoire soit indépendant, sous tutelle, non autonome ou soumis à une limitation quelconque de souveraineté.

\section{Article 3}

Tout individu a droit à la vie, à la liberté et à la sûreté de sa personne.

\section{Article 4}

Nul ne sera tenu en esclavage ni en servitude; l'esclavage et la traite des esclaves sont interdits sous toutes leurs formes.

\section{Article 5}

Nul ne sera soumis à la torture, ni à des peines ou traitements cruels, inhumains ou dégradants.

\section{Article 6}

Chacun a le droit à la reconnaissance en tous lieux de sa personnalité juridique.

\section{Article 7}

Tous sont égaux devant la loi et ont droit sans distinction à une égale protection de la loi. Tous ont droit à une protection égale contre toute discrimination qui violerait la présente Déclaration et contre toute provocation à une telle discrimination.

\section{Article 8}

Toute personne a droit à un recours effectif devant les juridictions nationales compétentes contre les actes violant les droits fondamentaux qui lui sont reconnus par la constitution ou par la loi.

\section{Article 9}

Nul ne peut être arbitrairement arrêté, détenu ni exilé.

\section{Article 10}

Toute personne a droit, en pleine égalité, à ce que sa cause soit entendue équitablement et publiquement par un tribunal indépendant et impartial, qui décidera, soit de ses droits et obligations, soit du bien-fondé de toute accusation en matière pénale dirigée contre elle. 


\section{Article 11}

1. Toute personne accusée d'un acte délictueux est présumée innocente jusqu'à ce que sa culpabilité ait été légalement établie au cours d'un procès public où toutes les garanties nécessaires à sa défense lui auront été assurées.

2. Nul ne sera condamné pour des actions ou omissions qui, au moment où elles ont été commises, ne constituaient pas un acte délictueux d'après le droit national ou international. De même, il ne sera infligé aucune peine plus forte que celle qui était applicable au moment où l'acte délictueux a été commis.

\section{Article 12}

Nul ne sera l'objet d'immixtions arbitraires dans sa vie privée, sa famille, son domicile ou sa correspondance, ni d'atteintes à son honneur et à sa réputation. Toute personne a droit à la protection de la loi contre de telles immixtions ou de telles atteintes.

\section{Article 13}

1. Toute personne a le droit de circuler librement et de choisir sa résidence à l'intérieur d'un Etat.

2. Toute personne a le droit de quitter tout pays, y compris le sien, et de revenir dans son pays.

\section{Article 14}

1. Devant la persécution, toute personne a le droit de chercher asile et de bénéficier de l'asile en d'autres pays.

2. Ce droit ne peut être invoqué dans le cas de poursuites réellement fondées sur un crime de droit commun ou sur des agissements contraires aux buts et aux principes des Nations Unies.

\section{Article 15}

1. Tout individu a droit à une nationalité.

2. Nul ne peut être arbitrairement privé de sa nationalité, ni du droit de changer de nationalité

\section{Article 16}

1. A partir de l'âge nubile, l'homme et la femme, sans aucune restriction quant à la race, la nationalité ou la religion, ont le droit de se marier et de fonder une famille. Ils ont des droits égaux au regard du mariage, durant le mariage et lors de sa dissolution.

2. Le mariage ne peut être conclu qu'avec le libre et plein consentement des futurs époux.

3. La famille est l'élément naturel et fondamental de la société et a droit à la protection de la société et de l'Etat.

\section{Article 17}

1. Toute personne, aussi bien seule qu'en collectivité, a droit à la propriété.

2. Nul ne peut être arbitrairement privé de sa propriété 


\section{Article 18}

Toute personne a droit à la liberté de pensée, de conscience et de religion; ce droit implique la liberté de changer de religion ou de conviction ainsi que la liberté de manifester sa religion ou sa conviction, seule ou en commun, tant en public qu'en privé, par l'enseignement, les pratiques, le culte et l'accomplissement des rites.

\section{Article 19}

Tout individu a droit à la liberté d'opinion et d'expression, ce qui implique le droit de ne pas être inquiété pour ses opinions et celui de chercher, de recevoir et de répandre, sans considérations de frontières, les informations et les idées par quelque moyen d'expression que ce soit.

\section{Article 20}

1. Toute personne a droit à la liberté de réunion et d'association pacifiques.

2. Nul ne peut être obligé de faire partie d'une association.

\section{Article 21}

1. Toute personne a le droit de prendre part à la direction des affaires publiques de son pays, soit directement, soit par l'intermédiaire de représentants librement choisis.

2. Toute personne a droit à accéder, dans des conditions d'égalité, aux fonctions publiques de son pays.

3. La volonté du peuple est le fondement de l'autorité des pouvoirs publics ; cette volonté doit s'exprimer par des élections honnêtes qui doivent avoir lieu périodiquement, au suffrage universel égal et au vote secret ou suivant une procédure équivalente assurant la liberté du vote.

\section{Article 22}

Toute personne, en tant que membre de la société, a droit à la sécurité sociale ; elle est fondée à obtenir la satisfaction des droits économiques, sociaux et culturels indispensables à sa dignité et au libre développement de sa personnalité, grâce à l'effort national et à la coopération internationale, compte tenu de l'organisation et des ressources de chaque pays.

\section{Article 23}

1. Toute personne a droit au travail, au libre choix de son travail, à des conditions équitables et satisfaisantes de travail et à la protection contre le chômage.

2. Tous on droit, sans aucune discrimination, à un salaire égal pour un travail égal

3. Quiconque travaille a droit à une rémunération équitable et satisfaisante lui assurant ainsi qu'à sa famille une existence conforme à la dignité humaine et complétée, s'il y a lieu, par tous autres moyens de protection sociale.

4. Toute personne a le droit de fonder avec d'autres des syndicats et de s'affilier à des syndicats pour la défense de ses intérêts.

\section{Article 24}

Toute personne a droit au repos et aux loisirs et notamment à une limitation raisonnable de la durée du travail et à des congés payés périodiques. 


\section{Article 25}

1. Toute personne a droit à un niveau de vie suffisant pour assurer sa santé, son bienêtre et ceux de sa famille, notamment pour l'alimentation, l'habillement, le logement, les soins médicaux ainsi que pour les services sociaux nécessaires; elle a droit à la sécurité en cas de chômage, de maladie, d'invalidité, de veuvage, de vieillesse ou dans les autres cas de perte de ses moyens de subsistance par suite de circonstances indépendantes de sa volonté.

2. La maternité et l'enfance ont droit à une aide et à une assistance spéciales. Tous les enfants, qu'ils soient nés dans le mariage ou hors mariage, jouissent de la même protection sociale.

\section{Article 26}

1. Toute personne a droit à l'éducation. L'éducation doit être gratuite, au moins en ce qui concerne l'enseignement élémentaire et fondamental. L'enseignement élémentaire est obligatoire. L'enseignement technique et professionnel doit être généralisé ; l'accès aux études supérieures doit être ouvert en pleine égalité à tous en fonction de leur mérite.

2. L'éducation doit viser au plein épanouissement de la personnalité humaine et au renforcement du respect des droits de l'homme et des libertés fondamentales. Elle doit favoriser la compréhension, la tolérance et l'amitié entre toutes les nations et tous les groupes raciaux ou religieux, ainsi que le développement des activités des Nations Unies pour le maintien de la paix.

3. Les parents ont, par priorité, le droit de choisir le genre d'éducation à donner à leurs enfants.

\section{Article 27}

1. Toute personne a le droit de prendre part librement à la vie culturelle de la communauté, de jouir des arts et de participer au progrès scientifique et aux bienfaits qui en résultent

2. Chacun a droit à la protection des intérêts moraux et matériels découlant de toute production scientifique, littéraire ou artistique dont il est l'auteur.

\section{Article 28}

Toute personne a droit à ce que règne, sur le plan social et sur le plan international, un ordre tel que les droits et libertés énoncés dans la présente Déclaration puissent y trouver plein effet.

\section{Article 29}

1. L'individu a des devoirs envers la communauté dans laquelle seul le libre et plein développement de sa personnalité est possible.

2. Dans l'exercice de ses droits et dans la jouissance de ses libertés, chacun n'est soumis qu'aux limitations établies par la loi exclusivement en vue d'assurer la reconnaissance et le respect des droits et libertés d'autrui et afin de satisfaire aux justes exigences de la morale, de l'ordre public et du bien-être général dans une société démocratique.

3. Ces droits et libertés ne pourront, en aucun cas, s'exercer contrairement aux buts et aux principes des Nations Unies. 
Article 30

Aucune disposition de la présente Déclaration ne peut être interprétée comme impliquant, pour un Etat, un groupement ou un individu, un droit quelconque de se livrer à une activité ou d'accomplir un acte visant à la destruction des droits et libertés qui y sont énoncés. 
Pacte international relatif aux droits économiques, sociaux et culturels, A.G. res. 2200A (XXI), 21 U.N. GAOR Supp. (No. 16) à 49, U.N. Doc. A/6316 (1966), 993 U.N.T.S. 3, entrée en vigueur le 3 janvier 1976.

\section{Préambule}

\section{Les Etats parties au présent Pacte,}

Considérant que, conformément aux principes énoncés dans la Charte des Nations Unies, la reconnaissance de la dignité inhérente à tous les membres de la famille humaine et de leurs droits égaux et inaliénables constitue le fondement de la liberté, de la justice et de la paix dans le monde,

Reconnaissant que ces droits découlent de la dignité inhérente à la personne humaine, Reconnaissant que, conformément à la Déclaration universelle des droits de l'homme, l'idéal de l'être humain libre, libéré de la crainte et de la misère, ne peut être réalisé que si des conditions permettant à chacun de jouir de ses droits économiques, sociaux et culturels, aussi bien que de ses droits civils et politiques, sont créées,

Considérant que la Charte des Nations Unies impose aux Etats l'obligation de promouvoir le respect universel et effectif des droits et des libertés de l'homme,

Prenant en considération le fait que l'individu a des devoirs envers autrui et envers la collectivité à laquelle il appartient et est tenu de s'efforcer de promouvoir et de respecter les droits reconnus dans le présent Pacte,

Sont convenus des articles suivants :

\section{Première partie}

\section{Article premier}

1. Tous les peuples ont le droit de disposer d'eux-mêmes. En vertu de ce droit, ils déterminent librement leur statut politique et assurent librement leur développement économique, social et culturel.

2. Pour atteindre leurs fins, tous les peuples peuvent disposer librement de leurs richesses et de leurs ressources naturelles, sans préjudice des obligations qui découlent de la coopération économique internationale, fondée sur le principe de l'intérêt mutuel, et du droit international. En aucun cas, un peuple ne pourra être privé de ses propres moyens de subsistance.

3. Les Etats parties au présent Pacte, y compris ceux qui ont la responsabilité d'administrer des territoires non autonomes et des territoires sous tutelle, sont tenus de faciliter la réalisation du droit des peuples à disposer d'eux-mêmes, et de respecter ce droit, conformément aux dispositions de la Charte des Nations Unies. 


\section{Deuxième partie}

\section{Article 2}

1. Chacun des Etats parties au présent Pacte s'engage à agir, tant par son effort propre que par l'assistance et la coopération internationales, notamment sur les plans économique et technique, au maximum de ses ressources disponibles, en vue d'assurer progressivement le plein exercice des droits reconnus dans le présent Pacte par tous les moyens appropriés, y compris en particulier l'adoption de mesures législatives.

2. Les Etats parties au présent Pacte s'engagent à garantir que les droits qui y sont énoncés seront exercés sans discrimination aucune fondée sur la race, la couleur, le sexe, la langue, la religion, l'opinion politique ou toute autre opinion, l'origine nationale ou sociale, la fortune, la naissance ou toute autre situation.

3. Les pays en voie de développement, compte dûment tenu des droits de l'homme et de leur économie nationale, peuvent déterminer dans quelle mesure ils garantiront les droits économiques reconnus dans le présent Pacte à des non-ressortissants.

\section{Article 3}

Les Etats parties au présent Pacte s'engagent à assurer le droit égal qu'ont l'homme et la femme au bénéfice de tous les droits économiques, sociaux et culturels qui sont énumérés dans le présent Pacte.

\section{Article 4}

Les Etats parties au présent Pacte reconnaissent que, dans la jouissance des droits assurés par l'Etat conformément au présent Pacte, l'Etat ne peut soumettre ces droits qu'aux limitations établies par la loi, dans la seule mesure compatible avec la nature de ces droits et exclusivement en vue de favoriser le bien-être général dans une société démocratique.

\section{Article 5}

1. Aucune disposition du présent Pacte ne peut être interprétée comme impliquant pour un Etat, un groupement ou un individu un droit quelconque de se livrer à une activité ou d'accomplir un acte visant à la destruction des droits ou libertés reconnus dans le présent Pacte ou à des limitations plus amples que celles prévues dans ledit Pacte.

2. Il ne peut être admis aucune restriction ou dérogation aux droits fondamentaux de l'homme reconnus ou en vigueur dans tout pays en vertu de lois, de conventions, de règlements ou de coutumes, sous prétexte que le présent Pacte ne les reconnaît pas ou les reconnaît à un moindre degré.

Troisième partie

\section{Article 6}

1. Les Etats parties au présent Pacte reconnaissent le droit au travail, qui comprend le droit qu'a toute personne d'obtenir la possibilité de gagner sa vie par un travail librement choisi ou accepté, et prendront des mesures appropriées pour sauvegarder ce droit.

2. Les mesures que chacun des Etats parties au présent Pacte prendra en vue d'assurer le plein exercice de ce droit doivent inclure l'orientation et la formation techniques et professionnelles, l'élaboration de programmes, de politiques et de techniques propres à 
assurer un développement économique, social et culturel constant et un plein emploi productif dans des conditions qui sauvegardent aux individus la jouissance des libertés politiques et économiques fondamentales.

\section{Article 7}

Les Etats parties au présent Pacte reconnaissent le droit qu'a toute personne de jouir de conditions de travail justes et favorables, qui assurent notamment :

a) La rémunération qui procure, au minimum, à tous les travailleurs :

i) Un salaire équitable et une rémunération égale pour un travail de valeur égale sans distinction aucune; en particulier, les femmes doivent avoir la garantie que les conditions de travail qui leur sont accordées ne sont pas inférieures à celles dont bénéficient les hommes et recevoir la même rémunération qu'eux pour un même travail ;

ii) Une existence décente pour eux et leur famille conformément aux dispositions du présent Pacte ;

b) La sécurité et l'hygiène du travail ;

c) La même possibilité pour tous d'être promus, dans leur travail, à la catégorie supérieure appropriée, sans autre considération que la durée des services accomplis et les aptitudes ;

d) Le repos, les loisirs, la limitation raisonnable de la durée du travail et les congés payés périodiques, ainsi que la rémunération des jours fériés.

\section{Article 8}

1. Les Etats parties au présent Pacte s'engagent à assurer :

a) Le droit qu'a toute personne de former avec d'autres des syndicats et de s'affilier au syndicat de son choix, sous la seule réserve des règles fixées par l'organisation intéressée, en vue de favoriser et de protéger ses intérêts économiques et sociaux. L'exercice de ce droit ne peut faire l'objet que des seules restrictions prévues par la loi et qui constituent des mesures nécessaires, dans une société démocratique, dans l'intérêt de la sécurité nationale ou de l'ordre public, ou pour protéger les droits et les libertés d'autrui.

b) Le droit qu'ont les syndicats de former des fédérations ou des confédérations nationales et le droit qu'ont celles-ci de former des organisations syndicales internationales ou de s'y affilier.

c) Le droit qu'ont les syndicats d'exercer librement leur activité, sans limitations autres que celles qui sont prévues par la loi et qui constituent des mesures nécessaires, dans une société démocratique, dans l'intérêt de la sécurité nationale ou de l'ordre public, ou pour protéger les droits et les libertés d'autrui.

d) Le droit de grève, exercé conformément aux lois de chaque pays.

2. Le présent article n'empêche pas de soumettre à des restrictions légales l'exercice de ces droits par les membres des forces armées, de la police ou de la fonction publique.

3. Aucune disposition du présent article ne permet aux Etats parties à la Convention de 1948 de l'Organisation internationale du Travail concernant la liberté syndicale et la protection du droit syndical de prendre des mesures législatives portant atteinte ou d'appliquer la loi de façon à porter atteinte aux garanties prévues dans ladite convention. 


\section{Article 9}

Les Etats parties au présent Pacte reconnaissent le droit de toute personne à la sécurité sociale, y compris les assurances sociales.

\section{Article 10}

Les Etats parties au présent Pacte reconnaissent que :

1. Une protection et une assistance aussi larges que possible doivent être accordées à la famille, qui est l'élément naturel et fondamental de la société, en particulier pour sa formation et aussi longtemps qu'elle a la responsabilité de l'entretien et de l'éducation d'enfants à charge. Le mariage doit être librement consenti par les futurs époux.

2. Une protection spéciale doit être accordée aux mères pendant une période de temps raisonnable avant et après la naissance des enfants. Les mères salariées doivent bénéficier, pendant cette même période, d'un congé payé ou d'un congé accompagné de prestations de sécurité sociale adéquates.

3. Des mesures spéciales de protection et d'assistance doivent être prises en faveur de tous les enfants et adolescents, sans discrimination aucune pour des raisons de filiation ou autres. Les enfants et adolescents doivent être protégés contre l'exploitation économique et sociale. Le fait de les employer à des travaux de nature à compromettre leur moralité ou leur santé, à mettre leur vie en danger ou à nuire à leur développement normal doit être sanctionné par la loi. Les Etats doivent aussi fixer des limites d'âge audessous desquelles l'emploi salarié de la main-d'œuvre enfantine sera interdit et sanctionné par la loi.

\section{Article 11}

1. Les Etats parties au présent Pacte reconnaissent le droit de toute personne à un niveau de vie suffisant pour elle-même et sa famille, y compris une nourriture, un vêtement et un logement suffisants, ainsi qu'à une amélioration constante de ses conditions d'existence. Les Etats parties prendront des mesures appropriées pour assurer la réalisation de ce droit et ils reconnaissent à cet effet l'importance essentielle d'une coopération internationale librement consentie.

2. Les Etats parties au présent Pacte, reconnaissant le droit fondamental qu'a toute personne d'être à l'abri de la faim, adopteront, individuellement et au moyen de la coopération internationale, les mesures nécessaires, y compris des programmes concrets :

a) Pour améliorer les méthodes de production, de conservation et de distribution des denrées alimentaires par la pleine utilisation des connaissances techniques et scientifiques, par la diffusion de principes d'éducation nutritionnelle et par le développement ou la réforme des régimes agraires, de manière à assurer au mieux la mise en valeur et l'utilisation des ressources naturelles ;

b) Pour assurer une répartition équitable des ressources alimentaires mondiales par rapport aux besoins, compte tenu des problèmes qui se posent tant aux pays importateurs qu'aux pays exportateurs de denrées alimentaires.

\section{Article 12}

1. Les Etats parties au présent Pacte reconnaissent le droit qu'a toute personne de jouir du meilleur état de santé physique et mentale qu'elle soit capable d'atteindre. 
2. Les mesures que les Etats parties au présent Pacte prendront en vue d'assurer le plein exercice de ce droit devront comprendre les mesures nécessaires pour assurer :

a) La diminution de la mortinatalité et de la mortalité infantile, ainsi que le développement sain de l'enfant ;

b) L'amélioration de tous les aspects de l'hygiène du milieu et de l'hygiène industrielle ;

c) La prophylaxie et le traitement des maladies épidémiques, endémiques, professionnelles et autres, ainsi que la lutte contre ces maladies ;

d) La création de conditions propres à assurer à tous des services médicaux et une aide médicale en cas de maladie.

\section{Article 13}

1. Les Etats parties au présent Pacte reconnaissent le droit de toute personne à l'éducation. Ils conviennent que l'éducation doit viser au plein épanouissement de la personnalité humaine et du sens de sa dignité et renforcer le respect des droits de l'homme et des libertés fondamentales. Ils conviennent en outre que l'éducation doit mettre toute personne en mesure de jouer un rôle utile dans une société libre, favoriser la compréhension, la tolérance et l'amitié entre toutes les nations et tous les groupes raciaux, ethniques ou religieux et encourager le développement des activités des Nations Unies pour le maintien de la paix.

2. Les Etats parties au présent Pacte reconnaissent qu'en vue d'assurer le plein exercice de ce droit :

a) L'enseignement primaire doit être obligatoire et accessible gratuitement à tous ;

b) L'enseignement secondaire, sous ses différentes formes, y compris l'enseignement secondaire technique et professionnel, doit être généralisé et rendu accessible à tous par tous les moyens appropriés et notamment par l'instauration progressive de la gratuité ;

c) L'enseignement supérieur doit être rendu accessible à tous en pleine égalité, en fonction des capacités de chacun, par tous les moyens appropriés et notamment par l'instauration progressive de la gratuité ;

d) L'éducation de base doit être encouragée ou intensifiée, dans toute la mesure possible, pour les personnes qui n'ont pas reçu d'instruction primaire ou qui ne l'ont pas reçue jusqu'à son terme ;

e) Il faut poursuivre activement le développement d'un réseau scolaire à tous les échelons, établir un système adéquat de bourses et améliorer de façon continue les conditions matérielles du personnel enseignant.

3. Les Etats parties au présent Pacte s'engagent à respecter la liberté des parents et, le cas échéant, des tuteurs légaux, de choisir pour leurs enfants des établissements autres que ceux des pouvoirs publics, mais conformes aux normes minimales qui peuvent être prescrites ou approuvées par l'Etat en matière d'éducation, et de faire assurer l'éducation religieuse et morale de leurs enfants, conformément à leurs propres convictions.

4. Aucune disposition du présent article ne doit être interprétée comme portant atteinte à la liberté des individus et des personnes morales de créer et de diriger des établissements d'enseignement, sous réserve que les principes énoncés au paragraphe 1 du présent article soient observés et que l'éducation donnée dans ces établissements soit conforme aux normes minimales qui peuvent être prescrites par l'Etat. 


\section{Article 14}

Tout Etat partie au présent Pacte qui, au moment où il devient partie, n'a pas encore pu assurer dans sa métropole ou dans les territoires placés sous sa juridiction le caractère obligatoire et la gratuité de l'enseignement primaire s'engage à établir et à adopter, dans un délai de deux ans, un plan détaillé des mesures nécessaires pour réaliser progressivement, dans un nombre raisonnable d'années fixé par ce plan, la pleine application du principe de l'enseignement primaire obligatoire et gratuit pour tous.

\section{Article 15}

1. Les Etats parties au présent Pacte reconnaissent à chacun le droit :

a) De participer à la vie culturelle ;

b) De bénéficier du progrès scientifique et de ses applications ;

c) De bénéficier de la protection des intérêts moraux et matériels découlant de toute production scientifique, littéraire ou artistique dont il est l'auteur.

2. Les mesures que les Etats parties au présent Pacte prendront en vue d'assurer le plein exercice de ce droit devront comprendre celles qui sont nécessaires pour assurer le maintien, le développement et la diffusion de la science et de la culture.

3. Les Etats parties au présent Pacte s'engagent à respecter la liberté indispensable à la recherche scientifique et aux activités créatrices.

4. Les Etats parties au présent Pacte reconnaissent les bienfaits qui doivent résulter de l'encouragement et du développement de la coopération et des contacts internationaux dans le domaine de la science et de la culture.

\section{Quatrième partie}

\section{Article 16}

1. Les Etats parties au présent Pacte s'engagent à présenter, conformément aux dispositions de la présente partie du Pacte, des rapports sur les mesures qu'ils auront adoptées et sur les progrès accomplis en vue d'assurer le respect des droits reconnus dans le Pacte.

2 .

a) Tous les rapports sont adressés au Secrétaire général de l'Organisation des Nations Unies, qui en transmet copie au Conseil économique et social, pour examen, conformément aux dispositions du présent Pacte ;

b) le Secrétaire général de l'Organisation des Nations Unies transmet également aux institutions spécialisées copie des rapports, ou de toutes parties pertinentes des rapports, envoyés par les Etats Parties au présent Pacte qui sont également membres desdites institutions spécialisées, pour autant que ces rapports, ou parties de rapports, ont trait à des questions relevant de la compétence desdites institutions aux termes de leurs actes constitutifs respectifs.

\section{Article 17}

1. Les Etats parties au présent Pacte présentent leurs rapports par étapes, selon un programme qu'établira le Conseil économique et social dans un délai d'un an à compter de la date d'entrée en vigueur du présent Pacte, après avoir consulté les Etats Parties et les institutions spécialisées intéressées. 
2. Les rapports peuvent faire connaître les facteurs et les difficultés empêchant ces Etats de s'acquitter pleinement des obligations prévues au présent Pacte.

3. Dans le cas où des renseignements à ce sujet ont déjà été adressés à l'Organisation des Nations Unies ou à une institution spécialisée par un Etat partie au Pacte, il ne sera pas nécessaire de reproduire lesdits renseignements et une référence précise à ces renseignements suffira.

\section{Article 18}

En vertu des responsabilités qui lui sont conférées par la Charte des Nations Unies dans le domaine des droits de l'homme et des libertés fondamentales, le Conseil économique et social pourra conclure des arrangements avec les institutions spécialisées, en vue de la présentation par celles-ci de rapports relatifs aux progrès accomplis quant à l'observation des dispositions du présent Pacte qui entrent dans le cadre de leurs activités. Ces rapports pourront comprendre des données sur les décisions et recommandations adoptées par les organes compétents des institutions spécialisées au sujet de cette mise en oeuvre.

\section{Article 19}

Le Conseil économique et social peut renvoyer à la Commission des droits de l'homme aux fins d'étude et de recommandations d'ordre général ou pour information, s'il y a lieu, les rapports concernant les droits de l'homme que communiquent les Etats conformément aux articles 16 et 17 et les rapports concernant les droits de l'homme que communiquent les institutions spécialisées conformément à l'article 18.

\section{Article 20}

Les Etats parties au présent Pacte et les institutions spécialisées intéressées peuvent présenter au Conseil économique et social des observations sur toute recommandation d'ordre général faite en vertu de l'article 19 ou sur toute mention d'une recommandation d'ordre général figurant dans un rapport de la Commission des droits de l'homme ou dans tout document mentionné dans ledit rapport.

\section{Article 21}

Le Conseil économique et social peut présenter de temps en temps à l'Assemblée générale des rapports contenant des recommandations de caractère général et un résumé des renseignements reçus des Etats parties au présent Pacte et des institutions spécialisées sur les mesures prises et les progrès accomplis en vue d'assurer le respect général des droits reconnus dans le prés8ent Pacte.

\section{Article 22}

Le Conseil économique et social peut porter à l'attention des autres organes de l'Organisation des Nations Unies, de leurs organes subsidiaires et des institutions spécialisées intéressées qui s'occupent de fournir une assistance technique toute question que soulèvent les rapports mentionnés dans la présente partie du présent Pacte et qui peut aider ces organismes à se prononcer, chacun dans sa propre sphère de compétence, sur l'opportunité de mesures internationales propres à contribuer à la mise en oeuvre effective et progressive du présent Pacte. 


\section{Article 23}

Les Etats parties au présent Pacte conviennent que les mesures d'ordre international destinées à assurer la réalisation des droits reconnus dans ledit Pacte comprennent notamment la conclusion de conventions, l'adoption de recommandations, la fourniture d'une assistance technique et l'organisation, en liaison avec les gouvernements intéressés, de réunions régionales et de réunions techniques aux fins de consultations et d'études.

\section{Article 24}

Aucune disposition du présent Pacte ne doit être interprétée comme portant atteinte aux dispositions de la Charte des Nations Unies et des constitutions des institutions spécialisées qui définissent les responsabilités respectives des divers organes de l'Organisation des Nations Unies et des institutions spécialisées en ce qui concerne les questions traitées dans le présent Pacte.

\section{Article 25}

Aucune disposition du présent Pacte ne sera interprétée comme portant atteinte au droit inhérent de tous les peuples à profiter et à user pleinement et librement de leurs richesses et ressources naturelles.

Cinquième partie

\section{Article 26}

1. Le présent Pacte est ouvert à la signature de tout Etat Membre de l'Organisation des Nations Unies ou membre de l'une quelconque de ses institutions spécialisées, de tout Etat partie au Statut de la Cour internationale de Justice, ainsi que tout autre Etat invité par l'Assemblée générale des Nations Unies à devenir partie au présent Pacte.

2. Le présent Pacte est sujet à ratification et les instruments de ratification seront déposés auprès du Secrétaire général de l'Organisation des Nations Unies.

3. Le présent Pacte sera ouvert à l'adhésion de tout Etat visé au paragraphe 1 du présent article.

4. L'adhésion se fera par le dépôt d'un instrument d'adhésion auprès du Secrétaire général de l'Organisation des Nations Unies.

5. Le Secrétaire général de l'Organisation des Nations Unies informe tous les Etats qui ont signéle présent Pacte ou qui y ont adhéré du dépôt de chaque instrument de ratification ou d'adhésion.

\section{Article 27}

1. Le présent Pacte entrera en vigueur trois mois après la date du dépôt auprès du Secrétaire général de l'Organisation des Nations Unies du trente-cinquième instrument de ratification ou d'adhésion.

2. Pour chacun des Etats qui ratifieront le présent Pacte ou y adhéreront après le dépôt du trente-cinquième instrument de ratification ou d'adhésion, ledit Pacte entrera en vigueur trois mois après la date du dépôt par cet Etat de son instrument de ratification ou d'adhésion. 


\section{Article 28}

Les dispositions du présent Pacte s'appliquent, sans limitation ni exception aucune, à toutes les unités constitutives des Etats fédératifs.

\section{Article 29}

1. Tout Etat partie au présent Pacte peut proposer un amendement et en déposer le texte auprès du Secrétaire général de l'Organisation des Nations Unies. Le Secrétaire général transmet alors tous projets d'amendements aux Etats Parties au présent Pacte en leur demandant de lui indiquer s'ils désirent voir convoquer une conférence d'Etats parties pour examiner ces projets et les mettre aux voix. Si un tiers au moins des Etats se déclarent en faveur de cette convocation, le Secrétaire général convoque la conférence sous les auspices de l'Organisation des Nations Unies. Tout amendement adopté par la majorité des Etats présents et votants à la conférence est soumis pour approbation à l'Assemblée générale des Nations Unies.

2. Ces amendements entrent en vigueur lorsqu'ils ont été approuvés par l'Assemblée générale des Nations Unies et acceptés, conformément à leurs règles constitutionnelles respectives, par une majorité des deux tiers des Etats parties au présent Pacte.

3. Lorsque ces amendements entrent en vigueur, ils sont obligatoires pour les Etats parties qui les ont acceptés, les autres Etats parties restant liés par les dispositions du présent Pacte et par tout amendement antérieur qu'ils ont accepté.

\section{Article 30}

Indépendamment des notifications prévues au paragraphe 5 de l'article 26, le Secrétaire général de l'Organisation des Nations Unies informera tous les Etats visés au paragraphe 1 dudit article :

a) Des signatures apposées au présent Pacte et des instruments de ratification et d'adhésion déposés conformément à l'article 26 ;

b) De la date à laquelle le présent Pacte entrera en vigueur conformément à l'article 27 et de la date à laquelle entreront en vigueur les amendements prévus à l'article 29.

Article 31

1. Le présent Pacte, dont les textes anglais, chinois, espagnol, français et russe font également foi, sera déposé aux archives de l'Organisation des Nations Unies.

2. Le Secrétaire général de l'Organisation des Nations Unies transmettra une copie certifiée conforme du présent Pacte à tous les Etats visés à l'article 26. 


\section{Conférence des Nations unies sur l'Environnement, Stockholm, 5 au 16 juin 1972. DECLARATION SUR L'ENVIRONNEMENT}

\section{Stockholm, 1972.}

La Conférence des Nations Unies sur l'environnement s'étant réunies à Stockholm du 5 au 16 juin 1972, et ayant examiné la nécessité d'adopter une conception commune et des principes communs qui inspireront et guideront les efforts des peuples du monde en vue de préserver et d'améliorer l'environnement,

Proclame ce qui suit :

\section{PREAMBULE}

1. L'homme est à la fois créature et créateur de son environnement, qui assure sa subsistance physique et lui offre la possibilité d'un développement intellectuel, moral, social et spirituel. Dans la longue et laborieuse évolution de la race humaine sur la terre, le moment est venu où, grâce aux progrès toujours plus rapides de la science et de la technique, l'homme a acquis le pouvoir de transformer son environnement d'innombrables manières et à une échelle sans précédent. Les deux éléments de son environnement, l'élément naturel et celui qu'il a lui-même créé, sont indispensables à son bien-être et à la pleine jouissance de ses droits fondamentaux, y compris le droit à la vie même.

2. La protection et l'amélioration de l'environnement est une question d'importance majeure qui affecte le bien-être des populations et le développement économique dans le monde entier; elle correspond au vœu ardent des peuples du monde entier, et constitue un devoir pour tous les gouvernements.

3. L'homme doit constamment faire le point de son expérience et continuer à découvrir, inventer, à créer et à avancer. Aujourd'hui, ce pouvoir qu'a l'homme de transformer le milieu dans lequel il vit, s'il est utilisé avec discernement, peut apporter à tous les peuples les bienfaits du développement et la possibilité d'améliorer la qualité de la vie. Utilisé abusivement ou inconsidérément, ce même pouvoir peut causer un mal incalculable aux êtres humains et à l'environnement. Les exemples de dommages, de destruction et de dévastation provoqués par l'homme se multiplient sous nos yeux en de nombreuses régions du globe. On constate des niveaux dangereux de pollution de l'eau, de l'air, de la terre et des êtres vivants; des perturbations profondes et regrettables de l'équilibre écologique de la biosphère; la destruction et l'épuisement des ressources irremplaçables; enfin de graves déficiences qui sont dangereuses pour la santé physique, mentale et sociale de l'homme, dans l'environnement qu'il crée, et en particulier dans son milieu de vie et de travail.

4. Dans les pays en voie de développement, la plupart des problèmes de l'environnement sont causés par le sous-développement. Des millions d'hommes continuent à vivre bien au-dessous des niveaux les plus bas compatibles avec une vie humaine décente, privés du nécessaire en ce qui concerne l'alimentation, le vêtement, le logement, l'éducation, la santé et l'hygiène. En conséquence, les pays en voie de développement doivent orienter leurs efforts vers le développement, en tenant compte de leurs priorités et de la nécessité 
de préserver et d'améliorer l'environnement. Dans les pays industrialisés, les problèmes de l'environnement sont généralement liés à l'industrialisation et au développement des techniques. Dans le même but, les pays industrialisés doivent s'efforcer de réduire l'écart entre eux et les pays en voie de développement.

5. L'augmentation naturelle de la population pose sans cesse de nouveaux problèmes pour la préservation de l'environnement et il faudrait adopter, selon que de besoin, des politiques et des mesures appropriées pour régler ces problèmes. Les hommes sont ce qu'il y a de plus précieux au monde. C'est le peuple qui anime le progrès social et crée la richesse de la société, qui développe la science et la technique et, par son dur travail, transforme sans cesse l'environnement. Avec le progrès social et l'évolution de la production, de la science et de la technique, le pouvoir de l'homme à améliorer son environnement se renforce chaque jour.

6. Nous sommes à un moment de l'histoire où nous devons orienter nos actions dans le monde entier en songeant davantage à leurs répercussions sur l'environnement. Nous pouvons, par ignorance ou par négligence, causer des dommages considérables et irréversibles à l'environnement terrestre dont dépendent notre vie et notre bien-être. En revanche, en approfondissant nos connaissances et en agissant plus sagement, nous pouvons assurer, à nous-mêmes et à notre postérité, des conditions de vie meilleures dans un environnement mieux adapté aux besoins et aux aspirations de l'humanité. Il existe de larges perspectives pour l'amélioration de la qualité de l'environnement et la création d'une vie heureuse. Il faut de l'enthousiasme, mais aussi du sang-froid; des efforts intenses, mais aussi une action ordonnée. Pour jouir librement des bienfaits de la nature, l'homme doit tirer parti de ses connaissances en vue de créer, en coopération avec elle, un environnement meilleur. Défendre et améliorer l'environnement pour les générations présentes et à venir est devenu pour l'humanité un objectif primordial, utile tâche dont il faudra coordonner et harmoniser la réalisation avec celle des objectifs fondamentaux déjà fixés de paix et de développement économique et social dans le monde entier.

7. Pour que ce but puisse être atteint, il faudra que tous, citoyens et collectivités, entreprises et institutions, à quelque niveau que ce soit, assument leurs responsabilités et se partagent équitablement les tâches. Les hommes de toutes conditions et les organisations les plus diverses peuvent, par les valeurs qu'ils admettent et par l'ensemble de leurs actes, déterminer l'environnement de demain. Les autorités locales et les gouvernements auront la responsabilité principale des politiques et de l'environnement dans les limites de leur juridiction. Une coopération internationale n'est pas moins nécessaire pour réunir les ressources nécessaires afin d'aider les pays en voie de développement à s'acquitter de leurs responsabilités dans ce domaine. Un nombre toujours plus élevé de problèmes d'environnement, de portée régionale ou mondiale ou touchant au domaine international commun, exigeront une coopération étendue entre les pays et une action de la part des organisations internationales dans l'intérêt de tous. La Conférence demande aux gouvernements et aux peuples d'unir leurs efforts pour préserver et améliorer l'environnement, dans l'intérêt des peuples et des générations futures. 


\section{PRINCIPES}

Exprime la conviction commune que :

\section{Principe 1}

L'homme a un droit fondamental à la liberté, à l'égalité et à des conditions de vie satisfaisantes, dans un environnement dont la qualité lui permette de vivre dans la dignité et le bien-être. Il a le devoir solennel de protéger et d'améliorer l'environnement pour les générations présentes et futures. A cet égard, les politiques qui encouragent ou qui perpétuent

l'apartheid, la ségrégation raciale, la discrimination, les formes, coloniales ou autres, d'oppression et de domination étrangères sont condamnées et doivent être éliminées.

\section{Principe 2}

Les ressources naturelles du globe, y compris l'air, l'eau, la terre, la flore et la faune, et particulièrement les échantillons représentatifs des écosystèmes naturels, doivent être préservés dans l'intérêt des générations présentes et à venir par une planification ou une gestion attentive selon que de besoin.

\section{Principe 3}

La capacité du globe de produire des ressources renouvelables essentielles doit être préservée et, partout où cela est possible, rétablie ou améliorée.

\section{Principe 4}

L'homme a une responsabilité particulière dans la sauvegarde et la sage gestion du patrimoine constitué par la flore et la faune sauvages et leur habitat, qui sont aujourd'hui gravement menacés par un concours de facteurs défavorables. La conservation de la nature, et notamment de la flore et de la faune sauvages, doit donc tenir une place importante dans la planification pour le développement économique.

\section{Principe 5}

Les ressources non renouvelables du globe doivent être exploitées de telle façon qu'elles ne risquent pas de s'épuiser et que les avantages retirés de leur utilisation soient partagés par toute l'humanité.

\section{Principe 6}

Les rejets de matières toxiques ou d'autres matières et les dégagements de chaleur en des quantités ou sous des concentrations telles que l'environnement ne puisse plus en neutraliser les effets doivent être interrompus de façon à éviter que les écosystèmes ne subissent des dommages graves ou irréversibles. La lutte légitime des peuples de tous les pays contre la pollution doit être encouragée.

\section{Principe 7}

Les Etats devront prendre toutes les mesures possibles pour empêcher la pollution des mers par des substances qui risquent de mettre en danger la santé de l'homme, de nuire aux ressources biologiques et à la vie des organismes marins, de porter atteinte aux agréments naturels ou de nuire à d'autres utilisations légitimes de la mer. 


\section{Principe 8}

Le développement économique et social est indispensable si l'on veut assurer un environnement propice à l'existence et au travail de l'homme et créer sur la terre des conditions nécessaires à l'amélioration de la qualité de la vie.

\section{Principe 9}

Les déficiences de l'environnement imputables à des conditions de sous-développement et à des catastrophes naturelles posent des problèmes graves, et le meilleur moyen d'y remédier est d'accélérer le développement par le transfert d'une aide financière et technique substantielle pour compléter l'effort national des pays en voie de développement et l'assistance fournie en tant que de besoin.

\section{Principe 10}

Pour les pays en voie de développement, la stabilité des prix et une rémunération adéquate pour les produits de base et les matières premières sont essentielles pour la gestion de l'environnement, les facteurs économiques devant être retenus au même titre que les processus écologiques.

\section{Principe 11}

Les politiques nationales d'environnement devraient renforcer le potentiel de progrès actuel et futur des pays en voie de développement, et non l'instauration de meilleures conditions de vie pour tous. Les Etats et les organisations internationales devraient prendre les mesures voulues pour s'entendre sur les moyens de parer aux conséquences économiques que peut avoir, au niveau national et international, l'application de mesures de protection de l'environnement.

\section{Principe 12}

Il faudrait dégager des ressources pour préserver et améliorer environnement, compte tenu de la situation et des besoins particuliers des pays en voie de développement et des dépenses que peut entraîner l'intégration de mesures de préservation de l'environnement dans la planification de leur développement, et aussi de la nécessité de mettre à leur disposition à cette fin, sur leur demande, une assistance internationale supplémentaire, aussi bien technique que financière.

\section{Principe 13}

Afin de rationaliser la gestion des ressources et ainsi d'environnement, les Etats devraient adopter une conception intégrée et coordonnée de leur planification du développement, de façon que leur développement soit compatible avec la nécessité de protéger et d' améliorer l'environnement dans l'intérêt de leur population.

\section{Principe 14}

Une planification rationnelle est un instrument essentiel si l'on veut concilier les impératifs du développement et la nécessité de préserver et d'améliorer l'environnement.

\section{Principe 15}

En planifiant les établissements humains et l'urbanisation, il faut veiller à éviter les atteintes à l'environnement et à obtenir le maximum d'avantages sociaux, économiques 
et écologiques pour tous. A cet égard, les projets conçus pour maintenir la domination du colonialisme et du racisme doivent être abandonnés.

\section{Principe 16}

Dans les régions où le taux d'accroissement de la population ou sa concentration excessive sont de nature à exercer une influence défavorable sur l'environnement ou le développement, et dans celles où la faible densité de population risque d'empêcher toute amélioration de l'environnement et de faire obstacle au développement, il faudrait mettre en oeuvre des politiques démographiques qui respectent les droits fondamentaux de l'homme et qui soient jugées adéquates par les gouvernements intéressé.

\section{Principe 17}

I1 convient que des institutions nationales appropriées soient chargées de planifier, de gérer ou de réglementer l'utilisation des ressources de l'environnement dont disposent les Etats, en vue d'améliorer la qualité de l'environnement.

\section{Principe 18}

Il convient de recourir à la science et à la technique, dans le cadre de leur contribution au développement économique et social, pour déceler, éviter ou limiter les dangers lui menacent l'environnement et résoudre les problèmes qu'il pose, et d'une manière générale pour le bien de l'humanité.

\section{Principe 19}

I1 est essentiel de dispenser un enseignement sur les questions d'environnement aux jeunes générations aussi bien qu'aux adultes, en tenant dûment compte des moins favorisés, afin de développer les bases nécessaires pour éclairer l'opinion publique et donner aux individus, aux entreprises et aux collectivités le sens de leurs responsabilités en ce qui concerne la protection et l'amélioration de l'environnement dans toute sa dimension humaine. Il est essentiel aussi que les moyens d'information de masse évitent de contribuer à la dégradation de l'environnement et, au contraire, diffusent des informations de caractère éducatif sur la nécessité de protéger et d'améliorer l'environnement afin de permettre à l'homme de se développer à tous les égards.

\section{Principe 20}

On devra encourager dans tous les pays, notamment dans les pays en voie de développement, la recherche scientifique et les activités de mise au point technique, dans le contexte des problèmes d'environnement, nationaux et multinationaux. A cet égard, on devra encourager et faciliter la libre circulation des informations les plus récentes et le transfert des données d'expérience, en vue d'aider à la solution des problèmes d'environnement; on devra mettre les techniques intéressant l'environnement à la disposition des pays en voie de développement, à des conditions qui en encouragent une large diffusion sans constituer pour eux une charge économique.

\section{Principe 21}

Conformément à la Charte des Nations Unies et aux principes du droit international, les Etats ont le droit souverain d'exploiter leurs propres ressources selon leur politique 
d'environnement et ils ont le devoir de faire en sorte que les activités exercées dans les limites de leur juridiction ou sous leur contrôle ne causent pas de dommages à d'autres Etats ou dans des régions ne relevant d'aucune juridiction nationale.

\section{Principe 22}

Les Etats doivent coopérer pour développer encore le droit international en ce qui concerne la responsabilité et l'indemnisation des victimes de la pollution et d'autres dommages écologiques que les activités menées dans les limites de la juridiction de ces Etats ou sous leur contrôle causent à des régions situées au-delà des limites de leur juridiction.

\section{Principe 23}

Sans préjudice des critères qui pourront être retenus par la communauté internationale, ni des normes qui devront être définies à l'échelon national, il faudra dans tous les cas tenir compte des échelles de valeurs prévalant dans chaque pays et de l'applicabilité de normes qui sont valables pour les pays les plus avancés mais qui peuvent ne pas être adaptées aux pays en voie de développement, et être pour ces pays d'un coût social injustifié.

\section{Principe 24}

Les questions internationales se rapportant à la protection et l'amélioration de l'environnement devraient être abordées dans un esprit de coopération par tous les pays, grands et petits sur un pied d'égalité. Une coopération par voie d'accords multilatéraux ou bilatéraux ou par d'autres moyens appropriés est indispensable pour limiter efficacement, prévenir, réduire et éliminer les atteintes à l'environnement résultant d'activités exercées dans tous les domaines, et ce dans le respect de la souveraineté et des intérêts de tous les Etats.

\section{Principe 25}

Les Etats doivent veiller à ce que les organisations internationales jouent un rôle coordonné, efficace et dynamique dans la préservation et l'amélioration de l'environnement.

\section{Principe 26}

I1 faut épargner à l'homme et à son environnement les effets des armes nucléaires et de tous autres moyens de destruction massive. Les Etats doivent s'efforcer, au sein des organes internationaux appropriés, d'arriver, dans les meilleurs délais, à un accord sur l'élimination et la destruction complète de telles armes.

\section{DÉCLARATION DE RIO}

\section{SUR L'ENVIRONNEMENT ET LE DÉVELOPPEMENT DE 1992}

\section{INTRODUCTION}

En 1972, la Conférence des Nations Unies sur l'environnement a adopté une série de principes pour une gestion écologiquement rationnelle de l'environnement. Cette 
«Déclaration de Stockholm» a placé les questions écologiques au rang des préoccupations internationales et a marqué le début d'un dialogue entre pays industrialisés et pays en développement concernant le lien qui existe entre la croissance économique, la pollution de l'indivis mondial (l'air, l'eau, les océans) et le bien-être des peuples dans le monde entier.

En juin 1992, à Rio de Janeiro (Brésil), la Conférence des Nations Unies sur l'environnement et le développement - connue sous le nom de Sommet "planète Terre» - a adopté une déclaration qui a fait progresser le concept des droits et des responsabilités des pays dans le domaine de l'environnement. La Déclaration de Rio sur l'environnement et le développement témoigne de deux grandes préoccupations apparues pendant l'intervalle de 20 années séparant ces deux conférences: la détérioration de l'environnement, notamment de sa capacité à entretenir la vie, et l'interdépendance de plus en plus manifeste entre le progrès économique à long terme et la nécessité d'une protection de l'environnement.

$\mathrm{Au}$ début du processus de négociation précédant le Sommet, M. Maurice Strong, Secrétaire général de la Conférence, a imaginé le concept de Charte de la Terre - énoncé des principes fondamentaux permettant un développement durable sur la Terre. La Déclaration de Rio qui a été adoptée par le Sommet était un compromis entre la position des pays industrialisés et celle des pays en développement. A l'origine, les premiers souhaitaient que soit adoptée une brève déclaration réaffirmant la Déclaration de Stockholm et soulignant la nécessité de protéger la planète. Quant aux pays en développement, ils désiraient que leurs sujets de préoccupation propres soient évoqués de manière plus détaillée, notamment qu'on souligne leur droit souverain au développement, qu'on reconnaisse que les pays industrialisés sont les principaux responsables des problèmes écologiques actuels et qu'on établisse que de nouvelles ressources et techniques sont nécessaires pour permettre aux pays en développement de ne pas appliquer des modes de développement aussi polluants que ceux des pays développés.

La Déclaration de Rio n'est pas juridiquement contraignante. Toutefois, il est vraisemblable que, comme dans le cas des déclarations des Nations Unies sur les droits de l'homme, les gouvernements se sentiront moralement obligés d'adhérer à ses principes.

\section{PRÉAMBULE}

La Conférence des Nations Unies sur l'environnement et le développement,

Réunie à Rio de Janeiro du 3 au 14 juin 1992,

Réaffirmant la Déclaration de la Conférence des Nations Unies sur l'environnement adoptée à Stockholm le 16 juin 1972, et cherchant à en assurer le prolongement,

Dans le but d'établir un partenariat mondial sur une base nouvelle et équitable en créant des niveaux de coopération nouveaux entre les Etats, les secteurs clefs de la société et les peuples, 
Euvrant en vue d'accords internationaux qui respectent les intérêts de tous et protègent l'intégrité du système mondial de l'environnement et du développement,

Reconnaissant que la Terre, foyer de l'humanité, constitue un tout marqué par l'interdépendance,

Proclame ce qui suit :

\section{PRINCIPE 1}

Les êtres humains sont au centre des préoccupations relatives au développement durable. Ils ont droit à une vie saine et productive en harmonie avec la nature.

\section{PRINCIPE 2}

Conformément à la Charte des Nations Unies et aux principes du droit international, les Etats ont le droit souverain d'exploiter leurs propres ressources selon leur politique d'environnement et de développement, et ils ont le devoir de faire en sorte que les activités exercées dans les limites de leur juridiction ou sous leur contrôle ne causent pas de dommages à l'environnement dans d'autres Etats ou dans des zones ne relevant d'aucune juridiction nationale.

\section{PRINCIPE 3}

Le droit au développement doit être réalisé de façon à satisfaire équitablement les besoins relatifs au développement et à l'environnement des générations présentes et futures.

\section{PRINCIPE 4}

Pour parvenir à un développement durable, la protection de l'environnement doit faire partie intégrante du processus de développement et ne peut être considérée isolément.

\section{PRINCIPE 5}

Tous les Etats et tous les peuples doivent coopérer à la tâche essentielle de l'élimination de la pauvreté, qui constitue une condition indispensable du développement durable, afin de réduire les différences de niveaux de vie et de mieux répondre aux besoins de la majorité des peuples du monde.

\section{PRINCIPE 6}

La situation et les besoins particuliers des pays en développement, en particulier des pays les moins avancés et des pays les plus vulnérables sur le plan de l'environnement, doivent se voir accorder une priorité spéciale. Les actions internationales entreprises en matière d'environnement et de développement devraient également prendre en considération les intérêts et les besoins de tous les pays.

\section{PRINCIPE 7}

Les Etats doivent coopérer dans un esprit de partenariat mondial en vue de conserver, de protéger et de rétablir la santé et l'intégrité de l'écosystème terrestre. Etant donné la diversité des rôles joués dans la dégradation de l'environnement mondial, les Etats ont des responsabilités communes mais différenciées. Les pays développés admettent la responsabilité qui leur incombe dans l'effort international en faveur du développement 
durable, compte tenu des pressions que leurs sociétés exercent sur l'environnement mondial et des techniques et des ressources financières dont ils disposent.

\section{PRINCIPE 8}

Afin de parvenir à un développement durable et à une meilleure qualité de vie pour tous les peuples, les Etats devraient réduire et éliminer les modes de production et de consommation non viables et promouvoir des politiques démographiques appropriées.

\section{PRINCIPE 9}

Les Etats devraient coopérer ou intensifier le renforcement des capacités endogènes en matière de développement durable en améliorant la compréhension scientifique par des échanges de connaissances scientifiques et techniques et en facilitant la mise au point, l'adaptation, la diffusion et le transfert de techniques, y compris de techniques nouvelles et novatrices.

\section{PRINCIPE 10}

La meilleure façon de traiter les questions d'environnement est d'assurer la participation de tous les citoyens concernés, au niveau qui convient. Au niveau national, chaque individu doit avoir dûment accès aux informations relatives à l'environnement que détiennent les autorités publiques, y compris aux informations relatives aux substances et activités dangereuses dans leurs collectivités, et avoir la possibilité de participer aux processus de prise de décision. Les Etats doivent faciliter et encourager la sensibilisation et la participation du public en mettant les informations à la disposition de celui-ci. Un accès effectif à des actions judiciaires et administratives, notamment des réparations et des recours, doit être assuré.

\section{PRINCIPE 11}

Les Etats doivent promulguer des mesures législatives efficaces en matière d'environnement. Les normes écologiques et les objectifs et priorités pour la gestion de l'environnement devraient être adaptés à la situation en matière d'environnement et de développement à laquelle ils s'appliquent. Les normes appliquées par certains pays peuvent ne pas convenir à d'autres pays, en particulier à des pays en développement, et leur imposer un coût économique et social injustifié.

\section{PRINCIPE 12}

Les Etats devraient coopérer pour promouvoir un système économique international ouvert et favorable, propre à engendrer une croissance économique et un développement durable dans tous les pays, qui permettrait de mieux lutter contre les problèmes de dégradation de l'environnement. Les mesures de politique commerciale motivées par des considérations relatives à l'environnement ne devraient pas constituer un moyen de discrimination arbitraire ou injustifiable, ni une restriction déguisée aux échanges internationaux. Toute action unilatérale visant à résoudre les grands problèmes écologiques au-delà de la juridiction du pays importateur devrait être évitée. Les mesures de lutte contre les problèmes écologiques transfrontières ou mondiaux devraient, autant que possible, être fondées sur un consensus international. 


\section{PRINCIPE 13}

Les Etats doivent élaborer une législation nationale concernant la responsabilité de la pollution et d'autres dommages à l'environnement et l'indemnisation de leurs victimes. Ils doivent aussi coopérer diligemment et plus résolument pour développer davantage le droit international concernant la responsabilité et l'indemnisation en cas d'effets néfastes de dommages causés à l'environnement dans des zones situées au-delà des limites de leur juridiction par des activités menées dans les limites de leur juridiction ou sous leur contrôle.

\section{PRINCIPE 14}

Les Etats devraient concerter efficacement leurs efforts pour décourager ou prévenir les déplacements et les transferts dans d'autres Etats de toutes activités et substances qui provoquent une grave détérioration de l'environnement ou dont on a constaté qu'elles étaient nocives pour la santé de l'homme.

\section{PRINCIPE 15}

Pour protéger l'environnement, des mesures de précaution doivent être largement appliquées par les Etats selon leurs capacités. En cas de risque de dommages graves ou irréversibles, l'absence de certitude scientifique absolue ne doit pas servir de prétexte pour remettre à plus tard l'adoption de mesures effectives visant à prévenir la dégradation de l'environnement.

\section{PRINCIPE 16}

Les autorités nationales devraient s'efforcer de promouvoir l'internalisation des coûts de protection de l'environnement et l'utilisation d'instruments économiques, en vertu du principe selon lequel c'est le pollueur qui doit, en principe, assumer le coût de la pollution, dans le souci de l'intérêt public et sans fausser le jeu du commerce international et de l'investissement.

\section{PRINCIPE 17}

Une étude d'impact sur l'environnement, en tant qu'instrument national, doit être entreprise dans le cas des activités envisagées qui risquent d'avoir des effets nocifs importants sur l'environnement et dépendent de la décision d'une autorité nationale compétente.

\section{PRINCIPE 18}

Les Etats doivent notifier immédiatement aux autres Etats toute catastrophe naturelle ou toute autre situation d'urgence qui risque d'avoir des effets néfastes soudains sur l'environnement de ces derniers. La communauté internationale doit faire tout son possible pour aider les Etats sinistrés.

\section{PRINCIPE 19}

Les Etats doivent prévenir suffisamment à l'avance les Etats susceptibles d'être affectés et leur communiquer toutes informations pertinentes sur les activités qui peuvent avoir des effets transfrontières sérieusement nocifs sur l'environnement et mener des consultations avec ces Etats rapidement et de bonne foi. 


\section{PRINCIPE 20}

Les femmes ont un rôle vital dans la gestion de l'environnement et le développement. Leur pleine participation est donc essentielle à la réalisation d'un développement durable.

\section{PRINCIPE 21}

Il faut mobiliser la créativité, les idéaux et le courage des jeunes du monde entier afin de forger un partenariat mondial, de manière à assurer un développement durable et à garantir à chacun un avenir meilleur.

\section{PRINCIPE 22}

Les populations et communautés autochtones et les autres collectivités locales ont un rôle vital à jouer dans la gestion de l'environnement et le développement du fait de leurs connaissances du milieu et de leurs pratiques traditionnelles. Les Etats devraient reconnaître leur identité, leur culture et leurs intérêts, leur accorder tout l'appui nécessaire et leur permettre de participer efficacement à la réalisation d'un développement durable.

\section{PRINCIPE 23}

L'environnement et les ressources naturelles des peuples soumis à oppression, domination et occupation doivent être protégés.

\section{PRINCIPE 24}

La guerre exerce une action intrinsèquement destructrice sur le développement durable. Les Etats doivent donc respecter le droit international relatif à la protection de l'environnement en temps de conflit armé et participer à son développement, selon que de besoin.

\section{PRINCIPE 25}

La paix, le développement et la protection de l'environnement sont interdépendants et indissociables.

\section{PRINCIPE 26}

Les Etats doivent résoudre pacifiquement tous leurs différends en matière d'environnement, en employant des moyens appropriés conformément à la Charte des Nations Unies.

\section{PRINCIPE 27}

Les Etats et les peuples doivent coopérer de bonne foi et dans un esprit de solidarité à l'application des principes consacrés dans la présente Déclaration et au développement du droit international dans le domaine du développement durable. 

QUELQUES SOURCES EXPLICITES DU DROIT A L'EAU POTABLE A L'INTERNATIONAL 
Convention sur l'élimination de toutes les formes de discrimination à l'égard des femmes, A.G. res. 34/180, 34 U.N.GAOR Supp. (No. 46) à 193, U.N. Doc. A/34/46, entrée en vigueur le 3 septembre, 1981.

\section{Les États parties à la présente Convention,}

Notant que la Charte des Nations Unies réaffirme la foi dans les droits fondamentaux de l'homme, dans la dignité et la valeur de la personne humaine et dans l'égalité des droits de l'homme et de la femme,

Notant que la Déclaration universelle des droits de l'homme affirme le principe de la non-discrimination et proclame que tous les êtres humains naissent libres et égaux en dignité et en droit, et que chacun peut se prévaloir de tous les droits et de toutes les libertés qui y sont énoncés, sans distinction aucune, notamment de sexe,

Notant que les États parties aux Pactes internationaux relatifs aux droits de l'homme ont l'obligation d'assurer l'égalité des droits de l'homme et de la femme dans l'exercice de tous les droits économiques, sociaux, culturels, civils et politiques,

Considérant les conventions internationales conclues sous l'égide de l'Organisation des Nations Unies et des institutions spécialisées en vue de promouvoir l'égalité des droits de l'homme et de la femme,

Notant également les résolutions, déclarations et recommandations adoptées par l'Organisation des Nations Unies et les institutions spécialisées en vue de promouvoir l'égalité des droits de l'homme et de la femme,

Préoccupés toutefois de constater qu'en dépit de ces divers instruments les femmes continuent de faire l'objet d'importantes discriminations,

Rappelant que la discrimination à l'encontre des femmes viole les principes de l'égalité des droits et du respect de la dignité humaine, qu'elle entrave la participation des femmes, dans les mêmes conditions que les hommes, à la vie politique, sociale, économique et culturelle de leur pays, qu'elle fait obstacle à l'accroissement du bien-être de la société et de la famille et qu'elle empêche les femmes de servir leur pays et l'humanité dans toute la mesure de leurs possibilités,

Préoccupés par le fait que, dans les situations de pauvreté, les femmes ont un minimum d'accès à l'alimentation, aux services médicaux, à l'éducation, à la formation, ainsi qu'aux possibilités d'emploi et à la satisfaction d'autres besoins,

Convaincus que l'instauration du nouvel ordre économique international fondé sur l'équité et la justice contribuera de façon significative à promouvoir l'égalité entre l'homme et la femme,

Soulignant que l'élimination de l'apartheid, de toutes les formes de racisme, de discrimination raciale, de colonialisme, de néocolonialisme, d'agression, d'occupation et 
domination étrangères et d'ingérence dans les affaires intérieures des États est indispensable à la pleine jouissance par l'homme et la femme de leurs droits,

Affirmant que le renforcement de la paix et de la sécurité internationales, le relâchement de la tension internationale, la coopération entre tous les États quels que soient leurs systèmes sociaux et économiques, le désarmement général et complet et, en particulier, le désarmement nucléaire sous contrôle international strict et efficace, l'affirmation des principes de la justice, de l'égalité et de l'avantage mutuel dans les relations entre pays et la réalisation du droit des peuples assujettis à une domination étrangère et coloniale et à une occupation étrangère à l'autodétermination et à l'indépendance, ainsi que le respect de la souveraineté nationale et de l'intégrité territoriale favoriseront le progrès social et le développement et contribueront par conséquent à la réalisation de la pleine égalité entre l'homme et la femme,

Convaincus que le développement complet d'un pays, le bien-être du monde et la cause de la paix demandent la participation maximale des femmes, à égalité avec les hommes, dans tous les domaines,

Ayant à l'esprit l'importance de la contribution des femmes au bien-être de la famille et au progrès de la société, qui jusqu'à présent n'a pas été pleinement reconnue, de l'importance sociale de la maternité et du rôle des parents dans la famille et dans l'éducation des enfants et conscients du fait que le rôle de la femme dans la procréation ne doit pas être une cause de discrimination et que l'éducation des enfants exige le partage des responsabilités entre les hommes, les femmes et la société dans son ensemble,

Conscients que le rôle traditionnel de l'homme dans la famille et dans la société doit évoluer autant que celui de la femme si on veut parvenir à une réelle égalité de l'homme et de la femme,

Résolus à mettre en oeuvre les principes énoncés dans la Déclaration sur l'élimination de la discrimination à l'égard des femmes et, pour ce faire, à adopter les mesures nécessaires à la suppression de cette discrimination sous toutes ses formes et dans toutes ses manifestations,

Sont convenus de ce qui suit :

\section{Première partie}

\section{Article premier}

Aux fins de la présente Convention, l'expression « discrimination à l'égard des femmes » vise toute distinction, exclusion ou restriction fondée sur le sexe qui a pour effet ou pour but de compromettre ou de détruire la reconnaissance, la jouissance ou l'exercice par les femmes, quel que soit leur état matrimonial, sur la base de l'égalité de l'homme et de la femme, des droits de l'homme et des libertés fondamentales dans les domaines politique, économique, social, culturel et civil ou dans tout autre domaine. 


\section{Article 2}

Les États parties condamnent la discrimination à l'égard des femmes sous toutes ses formes, conviennent de poursuivre par tous les moyens appropriés et sans retard une politique tendant à éliminer la discrimination à l'égard des femmes et, à cette fin, s'engagent à :

a) Inscrire dans leur constitution nationale ou toute autre disposition législative appropriée le principe de l'égalité des hommes et des femmes, si ce n'est déjà fait, et assurer par voie de législation ou par d'autres moyens appropriés l'application effective dudit principe ;

b) Adopter des mesures législatives et d'autres mesures appropriées assorties, y compris des sanctions en cas de besoin, interdisant toute discrimination à l'égard des femmes ;

c) Instaurer une protection juridictionnelle des droits des femmes sur un pied d'égalité avec les hommes et garantir, parle truchement des tribunaux nationaux compétents et d'autres institutions publiques, la protection effective des femmes contre tout acte discriminatoire ;

d) S'abstenir de tout acte ou pratique discriminatoire à l'égard des femmes et faire en sorte que les autorités publiques et les institutions publiques se conforment à cette obligation;

e) Prendre toutes mesures appropriées pour éliminer la discrimination pratiquée à l'égard des femmes par une personne, une organisation ou une entreprise quelconque ;

f) Prendre toutes les mesures appropriées, y compris des dispositions législatives, pour modifier ou abroger toute loi, disposition réglementaire, coutume ou pratique qui constitue une discrimination à l'égard des femmes ;

g) Abroger toutes les dispositions pénales qui constituent une discrimination à l'égard des femmes.

\section{Article 3}

Les États parties prennent dans tous les domaines, notamment dans les domaines politique, social, économique et culturel, toutes les mesures appropriées, y compris des dispositions législatives, pour assurer le plein développement et le progrès des femmes, en vue de leur garantir l'exercice et la jouissance des droits de l'homme et des libertés fondamentales sur la base de l'égalité avec les hommes.

\section{Article 4}

1. L'adoption par les États parties de mesures temporaires spéciales visant à accélérer l'instauration d'une égalité de fait entre les hommes et les femmes n'est pas considérée comme un acte de discrimination tel qu'il est défini dans la présente Convention, mais ne doit en aucune façon avoir pour conséquence le maintien de normes inégales ou distinctes ; ces mesures doivent être abrogées dès que les objectifs en matière d'égalité de chances et de traitement ont été atteints.

2. L'adoption par les États parties de mesures spéciales, y compris de mesures prévues dans la présente Convention, qui visent à protéger la maternité n'est pas considérée comme un acte discriminatoire. 


\section{Article 5}

Les États parties prennent toutes les mesures appropriées pour :

a) Modifier les schémas et modèles de comportement socio-culturel de l'homme et de la femme en vue de parvenir à l'élimination des préjugés et des pratiques coutumières, ou de tout autre type, qui sont fondés sur l'idée de l'infériorité ou de la supériorité de l'un ou l'autre sexe ou d'un rôle stéréotypé des hommes et des femmes ;

b) Faire en sorte que l'éducation familiale contribue à faire bien comprendre que la maternité est une fonction sociale et à faire reconnaître la responsabilité commune de l'homme et de la femme dans le soin d'élever leurs enfants et d'assurer leur développement, étant entendu que l'intérêt des enfants est la condition primordiale dans tous les cas.

\section{Article 6}

Les États parties prennent toutes les mesures appropriées, y compris des dispositions législatives, pour supprimer, sous toutes leurs formes, le trafic des femmes et l'exploitation de la prostitution des femmes.

\section{Deuxième partie}

\section{Article 7}

Les États parties prennent toutes les mesures appropriées pour éliminer la discrimination à l'égard des femmes dans la vie politique et publique du pays et, en particulier, leur assurent, dans des conditions d'égalité avec les hommes, le droit :

a) De voter à toutes les élections et dans tous les référendums publics et être éligibles à tous les organismes publiquement élus ;

b) De prendre part à l'élaboration de la politique de l'État et à son exécution, occuper des emplois publics et exercer toutes les fonctions publiques à tous les échelons du gouvernement ;

c) De participer aux organisations et associations non gouvernementales s'occupant de la vie publique et politique du pays.

\section{Article 8}

Les États parties prennent toutes les mesures appropriées pour que les femmes, dans des conditions d'égalité avec les hommes et sans aucune discrimination, aient la possibilité de représenter leur gouvernement à l'échelon international et de participer aux travaux des organisations internationales.

\section{Article 9}

1. Les États parties accordent aux femmes des droits égaux à ceux des hommes en ce qui concerne l'acquisition, le changement et la conservation de la nationalité. Ils garantissent en particulier que ni le mariage avec un étranger, ni le changement de nationalité du mari pendant le mariage ne change automatiquement la nationalité de la femme, ni ne la rend apatride, ni ne l'oblige à prendre la nationalité de son mari.

2. Les États parties accordent à la femme des droits égaux à ceux de l'homme en ce qui concerne la nationalité de leurs enfants. 


\section{Troisième partie}

\section{Article 10}

Les États parties prennent toutes les mesures appropriées pour éliminer la discrimination à l'égard des femmes afin de leur assurer des droits égaux à ceux des hommes en ce qui concerne l'éducation et, en particulier, pour assurer, sur la base de l'égalité de l'homme et de la femme :

a) Les mêmes conditions d'orientation professionnelle, d'accès aux études et d'obtention de diplômes dans les établissements d'enseignement de toutes catégories, dans les zones rurales comme dans les zones urbaines, cette égalité devant être assurée dans l'enseignement préscolaire, général, technique, professionnel et technique supérieur, ainsi que dans tout autre moyen de formation professionnelle ;

b) L'accès aux mêmes programmes, aux mêmes examens, à un personnel enseignant possédant les qualifications de même ordre, à des locaux scolaires et à un équipement de même qualité ;

c) L'élimination de toute conception stéréotypée des rôles de l'homme et de la femme à tous les niveaux et dans toutes les formes d'enseignement en encourageant l'éducation mixte et d'autres types d'éducation qui aideront à réaliser cet objectif et, en particulier, en révisant les livres et programmes scolaires et en adaptant les méthodes pédagogiques ;

d) Les mêmes possibilités en ce qui concerne l'octroi de bourses et autres subventions pour les études;

e) Les mêmes possibilités d'accès aux programmes d'éducation permanente, y compris aux programmes d'alphabétisation pour adultes et d'alphabétisation fonctionnelle, en vue notamment de réduire au plus tôt tout écart d'instruction existant entre les hommes et les femmes ;

f) La réduction des taux d'abandon féminin des études et l'organisation de programmes pour les filles et les femmes qui ont quitté l'école prématurément ;

g) Les mêmes possibilités de participer activement aux sports et à l'éducation physique ;

h) L'accès à des renseignements spécifiques d'ordre éducatif tendant à assurer la santé et le bien-être des familles, y compris l'information et des conseils relatifs à la planification de la famille.

\section{Article 11}

1. Les États parties s'engagent à prendre toutes le mesures appropriées pour éliminer la discrimination à l'égard des femmes dans le domaine de l'emploi, afin d'assurer, sur la base de l'égalité de l'homme et de la femme, les mêmes droits, et en particulier :

a) Le droit au travail en tant que droit inaliénable de tous les êtres humains ;

b) Le droit aux mêmes possibilités d'emploi, y compris l'application des mêmes critères de sélection en matière d'emploi ;

c) Le droit au libre choix de la profession et de l'emploi, le droit à la promotion, à la stabilité de l'emploi et à toutes les prestations et conditions de travail, le droit à la formation professionnelle et au recyclage, y compris l'apprentissage, le perfectionnement professionnel et la formation permanente ; 
d) Le droit à l'égalité de rémunération, y compris de prestation, à l'égalité de traitement pour un travail d'égale valeur aussi bien qu'à l'égalité de traitement en ce qui concerne l'évaluation de la qualité du travail ;

e) Le droit à la sécurité sociale, notamment aux prestations de retraite, de chômage, de maladie, d'invalidité et de vieillesse ou pour toute autre perte de capacité de travail, ainsi que le droit à des congés payés ;

f) Le droit à la protection de la santé et à la sécurité des conditions de travail, y compris la sauvegarde de la fonction de reproduction.

2. Afin de prévenir la discrimination à l'égard des femmes en raison de leur mariage ou de leur maternité et de garantir leur droit effectif au travail, les États parties s'engagent à prendre des mesures appropriées ayant pour objet :

a) D'interdire, sous peine de sanctions, le licenciement pour cause de grossesse ou de congé de maternité et la discrimination des les licenciements fondée sur le statut matrimonial ;

b) D'instituer l'octroi de congés de maternité payés ou ouvrant droit à des prestations sociales comparables, avec la garantie du maintien de l'emploi antérieur, des droits d'ancienneté et des avantages sociaux ;

c) D'encourager la fourniture des services sociaux d'appui nécessaires pour permettre aux parents de combiner les obligations familiales avec les responsabilités professionnelles et la participation à la vie publique, en particulier en favorisant l'établissement et le développement d'un réseau de garderies d'enfants ;

d) D'assurer une protection spéciale aux femmes enceintes dont il est prouvé que le travail est nocif.

3. Les lois visant à protéger les femmes dans les domaines visés par le présent article seront revues périodiquement en fonction des connaissances scientifiques et techniques et seront révisées, abrogées ou étendues, selon les besoins.

\section{Article 12}

1. Les États parties prennent toutes les mesures appropriées pour éliminer la discrimination à l'égard des femmes dans le domaine des soins de santé en vue de leur assurer, sur la base de l'égalité de l'homme et de la femme, les moyens d'accéder aux services médicaux, y compris ceux qui concernent la planification de la famille.

2. Nonobstant les dispositions du paragraphe 1 ci-dessus, les États parties fournissent aux femmes pendant la grossesse, pendant l'accouchement et après l'accouchement, des services appropriés et, au besoin, gratuits, ainsi qu'une nutrition adéquate pendant la grossesse et l'allaitement.

\section{Article 13}

Les États parties s'engagent à prendre toutes les mesures appropriées pour éliminer la discrimination à l'égard des femmes dans d'autres domaines de la vie économique et sociale, afin d'assurer, sur la base de l'égalité de l'homme et de la femme, les mêmes droits et, en particulier :

a) Le droit aux prestations familiales ;

b) Le droit aux prêts bancaires, prêts hypothécaires et autres formes de crédit financier ; 
c) Le droit de participer aux activités récréatives, aux sports et à tous les aspects de la vie culturelle.

\section{Article 14}

1. Les États parties tiennent compte des problèmes particuliers qui se posent aux femmes rurales et du rôle important que ces femmes jouent dans la survie économique de leurs familles, notamment par leur travail dans les secteurs non monétaires de l'économie, et prennent toutes les mesures appropriées pour assurer l'application des dispositions de la présente Convention aux femmes des zones rurales.

2. Les États parties prennent toutes les mesures appropriées pour éliminer la discrimination à l'égard des femmes dans les zones rurales afin d'assurer, sur la base de l'égalité de l'homme et de la femme, leur participation au développement rural et à ses avantages et, en particulier, ils leur assurent le droit :

a) De participer pleinement à l'élaboration et à l'exécution des plans de développement à tous les échelons ;

b) D'avoir accès aux services adéquats dans le domaine de la santé, y compris aux informations, conseils et services en matière de planification de la famille ;

c) De bénéficier directement des programmes de sécurité sociale ;

d) De recevoir tout type de formation et d'éducation, scolaires ou non, y compris en matière d'alphabétisation fonctionnelle, et de pouvoir bénéficier de tous les services communautaires et de vulgarisation, notamment pour accroître leurs compétences techniques ;

e) D'organiser des groupes d'entraide et des coopératives afin de permettre l'égalité de chances sur le plan économique, qu'il s'agisse de travail salarié ou de travail indépendant ;

f) De participer à toutes les activités de la communauté ;

g) D'avoir accès au crédit et aux prêts agricoles, ainsi qu'aux services de commercialisation et aux technologies appropriées, et de recevoir un traitement égal dans les réformes foncières et agraires et dans les projets d'aménagement rural ;

h) De bénéficier de conditions de vie convenables, notamment en ce qui concerne le logement, l'assainissement, l'approvisionnement en électricité et en eau, les transports et les communications.

\section{Quatrième partie}

\section{Article 15}

1. Les États parties reconnaissent à la femme l'égalité avec l'homme devant la loi.

2. Les États parties reconnaissent à la femme, en matière civile, une capacité juridique identique à celle de l'homme et les mêmes possibilités pour exercer cette capacité. Ils lui reconnaissent en particulier des droits égaux en ce qui concerne la conclusion de contrats et l'administration des biens et leur accordent le même traitement à tous les stades de la procédure judiciaire.

3. Les États parties conviennent que tout contrat et tout autre instrument privé, de quelque type que ce soit, ayant un effet juridique visant à limiter la capacité juridique de la femme doivent être considérés comme nuls. 
4. Les États parties reconnaissent à l'homme et à la femme les mêmes droits en ce qui concerne la législation relative au droit des personnes à circuler librement et à choisir leur résidence et leur domicile.

\section{Article 16}

1. Les États parties prennent toutes les mesures appropriées pour éliminer la discrimination à l'égard des femmes dans toutes les questions découlant du mariage et dans les rapports familiaux et, en particulier, assurent, sur la base de l'égalité de l'homme et de la femme :

a) Le même droit de contracter mariage ;

b) Le même droit de choisir librement son conjoint et de ne contracter mariage que de son libre et plein consentement ;

c) Les mêmes droits et les mêmes responsabilités au cours du mariage et lors de sa dissolution ;

d) Les mêmes droits et les mêmes responsabilités en tant que parents, quel que soit leur état matrimonial, pour les questions se rapportant à leurs enfants; dans tous les cas, l'intérêt des enfants est la considération primordiale ;

e) Les mêmes droits de décider librement et en toute connaissance de cause du nombre et de l'espacement des naissances et d'avoir accès aux informations, à l'éducation et aux moyens nécessaires pour leur permettre d'exercer ces droits ;

f) Les mêmes droits et responsabilités en matière de tutelle, de curatelle, de garde et d'adoption des enfants, ou d'institutions similaires, lorsque ces concepts existent dans la législation nationale; dans tous les cas, l'intérêt des enfants est la considération primordiale ;

g) Les mêmes droits personnels au mari et à la femme, y compris en ce qui concerne le choix du nom de famille, d'une profession et d'une occupation ;

h) Les mêmes droits à chacun des époux en matière de propriété, d'acquisition, de gestion, d'administration, de jouissance et de disposition des biens, tant à titre gratuit qu'à titre onéreux.

2. Les fiançailles et les mariages d'enfants n'ont pas d'effets juridiques et toutes les mesures nécessaires, y compris des dispositions législatives, sont prises afin de fixer un âge minimal pour le mariage et de rendre obligatoire l'inscription du mariage sur un registre officiel.

\section{Cinquième partie}

\section{Article 17}

1. Aux fins d'examiner les progrès réalisés dans l'application de la présente Convention, il est constitué un Comité pour l'élimination de la discrimination à l'égard des femmes (ci-après dénommé le Comité), qui se compose, au moment de l'entrée en vigueur de la Convention, de dix-huit, et après sa ratification ou l'adhésion du trente-cinquième État partie, de vingt-trois experts d'une haute autorité morale et éminemment compétents dans le domaine auquel s'applique la présente Convention. Ces experts sont élus par les États parties parmi les ressortissants et siègent à titre personnel, compte tenu du principe d'une répartition géographique équitable et de la représentation des différentes formes de civilisation ainsi que des principaux systèmes juridiques. 
2. Les membres du Comité sont élus au scrutin secret sur une liste de candidats désignés par les États parties. Chaque État partie peut désigner un candidat choisi parmi ses ressortissants.

3. La première élection a lieu six mois après la date d'entrée en vigueur de la présente Convention. Trois mois au moins avant la date de chaque élection, le Secrétaire général de l'Organisation des Nations Unies adresse une lettre aux États parties pour les inviter à soumettre leurs candidatures dans un délai de deux mois. Le Secrétaire général dresse une liste alphabétique de tous les candidats, en indiquant par quel État ils ont été désignés, liste qu'il communique aux États parties.

4. Les membres du Comité sont élus au cours d'une réunion des États parties convoquée par le Secrétaire général au Siège de l'Organisation des Nations Unies. A cette réunion, où le quorum est constitué par les deux tiers des États parties, sont élus membres du Comité les candidats ayant obtenu le plus grand nombre de voix et la majorité absolue des votes des représentants des États parties présents et votants.

5. Les membres du Comité sont élus pour quatre ans. Toutefois, le mandat de neuf des membres élus à la première élection prendra fin au bout de deux ans; le Président du Comité tirera au sort les noms de ces neuf membres immédiatement après la première élection.

6. L'élection des cinq membres additionnels du Comité se fera conformément aux dispositions des paragraphes 2,3 et 4 du présent article à la suite de la trente-cinquième ratification ou adhésion. Le mandat de deux des membres additionnels élus à cette occasion prendra fin au bout de deux ans; le nom de ces deux membres sera tiré au sort par le Président du Comité.

7. Pour remplir les vacances fortuites, l'État partie dont l'expert a cessé d'exercer ses fonctions de membre de Comité nommera un autre expert parmi ses ressortissants, sous réserve de l'approbation du Comité.

8. Les membres du Comité reçoivent, avec l'approbation de l'Assemblée générale, des émoluments prélevés sur les ressources de l'Organisation des Nations Unies dans les conditions fixées par l'Assemblée eu égard à l'importance des fonctions du Comité.

9. Le Secrétaire général de l'Organisation des Nations Unies met à la disposition du Comité le personnel et les moyens matériels qui lui sont nécessaires pour s'acquitter efficacement des fonctions qui lui sont confiées en vertu de la présente Convention.

\section{Article 18}

1. Les États parties s'engagent à présenter au Secrétaire général de l'Organisation des Nations Unies, pour examen parle Comité, un rapport sur les mesures d'ordre législatif, judiciaire, administratif ou autre qu'ils ont adoptées pour donner effet aux dispositions de la présente Convention et sur les progrès réalisés à cet égard :

a) Dans l'année suivant l'entrée en vigueur de la Convention dans l'État intéressé :

b) Puis tous les quatre ans, ainsi qu'à la demande du Comité.

2. Les rapports peuvent indiquer les facteurs et difficultés influant sur la mesure dans laquelle sont remplies les obligations prévues par la présente Convention.

\section{Article 19}

1. Le Comité adopte son propre règlement intérieur.

2. Le Comité élit son Bureau pour une période de deux ans. 


\section{Article 20}

1. Le Comité se réunit normalement pendant une période de deux semaines au plus chaque année pour examiner les rapports présentés conformément à l'article 18 de la présente Convention.

2. Les séances du Comité se tiennent normalement au Siège de l'Organisation des Nations Unies ou en tout autre lieu adéquat déterminé par le Comité.

\section{Article 21}

1. Le Comité rend compte chaque année à l'Assemblée générale de l'Organisation des Nations Unies, par l'intermédiaire du Conseil économique et social, de ses activités et peut formuler des suggestions et des recommandations générales fondées sur l'examen des rapports et des renseignements reçus des États parties. Ces suggestions et recommandations sont incluses dans le rapport du Comité, accompagnées, le cas échéant, des observations des États parties.

2. Le Secrétaire général de l'Organisation des Nations Unies transmet les rapports du Comité à la Commission de la condition de la femme, pour information.

\section{Article 22}

Les institutions spécialisées ont le droit d'être représentées lors de l'examen de la mise en œuvre de toute disposition de la présente Convention qui entre dans le cadre de leurs activités. Le Comité peut inviter les institutions spécialisées à soumettre des rapports sur l'application de la Convention dans les domaines qui entrent dans le cadre de leurs activités.

\section{Sixième partie}

\section{Article 23}

Aucune des dispositions de la présente Convention ne portera atteinte aux dispositions plus propices à la réalisation de l'égalité de l'homme et de la femme pouvant être contenues :

a) Dans la législation d'un État partie; ou

b) Dans toute autre convention, tout autre traité ou accord international en vigueur dans cet État.

\section{Article 24}

Les États parties s'engagent à adopter toutes les mesures nécessaires au niveau national pour assurer le plein exercice des droits reconnus par la présente Convention.

\section{Article 25}

1. La présente Convention est ouverte à la signature de tous les États.

2. Le Secrétaire général de l'Organisation des Nations Unies est désigné comme dépositaire de la présente Convention.

3. La présente Convention est sujette à ratification et les instruments de ratification seront déposés auprès du Secrétaire général de l'Organisation des Nations Unies.

4. La présente Convention sera ouverte à l'adhésion de tous les États. L'adhésion s'effectuera par le dépôt d'un instrument d'adhésion auprès du Secrétaire général de l'Organisation des Nations Unies. 


\section{Article 26}

1. Tout État partie peut demander à tout moment la révision de la présente Convention en adressant une communication écrite à cet effet au Secrétaire général de l'Organisation des Nations Unies.

2. L'Assemblée générale de l'Organisation des Nations Unies décide des mesures à prendre, le cas échéant, au sujet d'une demande de cette nature.

\section{Article 27}

1. La présente Convention entrera en vigueur le trentième jour qui suivra la date du dépôt auprès du Secrétaire général de l'Organisation des Nations Unies du vingtième instrument de ratification ou d'adhésion.

2. Pour chacun des États qui ratifieront la présente Convention ou y adhéreront après le dépôt du vingtième instrument de ratification ou d'adhésion, ladite Convention entrera en vigueur le trentième jour après la date du dépôt par cet État de son instrument de ramification ou d'adhésion.

\section{Article 28}

1. Le Secrétaire général de l'Organisation des Nations Unies recevra et communiquera à tous les États le texte des réserves qui auront été faites au moment de la ratification ou de l'adhésion.

2. Aucune réserve incompatible avec l'objet et le but de la présente Convention ne sera autorisée.

3. Les réserves peuvent être retirées à tout moment par voie de notification adressée au Secrétaire général de l'Organisation des Nations Unies, lequel informe tous les États parties à la Convention. La notification prendra effet à la date de réception.

\section{Article 29}

1. Tout différend entre deux ou plusieurs États parties concernant l'interprétation ou l'application de la présente Convention qui n'est pas réglé par voie de négociation est soumis à l'arbitrage, à la demande de l'un d'entre eux. Si, dans les six mois qui suivent la date de la demande d'arbitrage, les parties ne parviennent pas à se mettre d'accord sur l'organisation de l'arbitrage, l'une quelconque d'entre elles peut soumettre le différend à la Cour internationale de Justice, en déposant une requête conformément au Statut de la Cour.

2. Tout État partie pourra, au moment où il signera la présente Convention, la ratifiera ou y adhérera, déclarer qu'il ne se considère pas lié par les dispositions du paragraphe 1 du présent article. Les autres États parties ne seront pas liés par lesdites dispositions envers un État partie qui aura formulé une telle réserve.

3. Tout État partie qui aura formulé une réserve conformément aux dispositions du paragraphe $2 \mathrm{du}$ présent article pourra à tout moment lever cette réserve par une notification adressée au Secrétaire général de l'Organisation des Nations Unies.

\section{Article 30}

La présente Convention, dont les textes en anglais, arabe, chinois, espagnol, français et russe font également foi, sera déposée auprès du Secrétaire général de l'Organisation des Nations Unies. 


\section{Convention internationale des droits de l'enfant \\ Convention des Nations-Unies du 20 novembre 1989}

\section{Préambule}

Les Etats parties à la présente Convention,

Considérant que, conformément aux principes proclamés dans la Charte des Nations Unies, la reconnaissance de la dignité inhérente à tous les membres de la famille humaine ainsi que l'égalité et le caractère inaliénable de leurs droits sont le fondement de la liberté, de la justice et de la paix dans le monde,

Ayant à l'esprit le fait que les peuples des Nations Unies ont, dans la Charte, proclamé à nouveau leur foi dans les droits fondamentaux de l'homme et dans la dignité et la valeur de la personne humaine, et qu'ils ont résolu de favoriser le progrès social et d'instaurer de meilleures conditions de vie dans une liberté plus grande,

Reconnaissant que les Nations Unies, dans la Déclaration universelle des droits de l'homme et dans les pactes internationaux relatifs aux droits de l'homme, ont proclamé et sont convenues que chacun peut se prévaloir de tous les droits et de toutes les libertés qui y sont énoncés, sans distinction aucune, notamment de race, de couleur, de sexe, de langue, de religion, d'opinion politique ou de toute autre opinion, d'origine nationale ou sociale, de fortune, de naissance ou de toute autre situation,

Rappelant que, dans la Déclaration universelle des droits de l'homme, les Nations Unies ont proclamé que l'enfance a droit à une aide et à une assistance spéciale,

Convaincus que la famille, unité fondamentale de la société et milieu naturel pour la croissance et le bien-être de tous ses membres et en particulier des enfants, doit recevoir la protection et l'assistance dont elle a besoin pour pouvoir jouer pleinement son rôle dans la communauté,

Reconnaissant que l'enfant, pour l'épanouissement harmonieux de sa personnalité, doit grandir dans le milieu familial, dans un climat de bonheur, d'amour et de compréhension,

Considérant qu'il importe de préparer pleinement l'enfant à avoir une vie individuelle dans la société, et de l'élever dans l'esprit des idéaux proclamés dans la Charte des Nations Unies, et en particulier dans un esprit de paix, de dignité, de tolérance, de liberté, d'égalité et de solidarité,

Ayant à l'esprit que la nécessité d'accorder une protection spéciale à l'enfant a été énoncée dans la Déclaration de Genève de 1924 sur les droits de l'enfant et dans la Déclaration des droits de l'enfant adoptée par l'Assemblée générale le 20 novembre 1959, et qu'elle a été reconnue dans la Déclaration universelle des droits de l'homme, dans le Pacte international relatif aux droits civils et politiques (en particulier aux 
articles 23 et 24), dans le Pacte international relatif aux droits économiques, sociaux et culturels (en particulier à l'article 10) et dans les statuts et instruments pertinents des institutions spécialisées et des organisations internationales qui se préoccupent du bienêtre de l'enfant,

Ayant à l'esprit que, comme indiqué dans la Déclaration des droits de l'enfant, «l'enfant, en raison de son manque de maturité physique et intellectuelle, a besoin d'une protection spéciale et de soins spéciaux, notamment d'une protection juridique appropriée, avant comme après la naissance", Rappelant les dispositions de la Déclaration sur les principes sociaux et juridiques applicables à la protection et au bienêtre des enfants, envisagés surtout sous l'angle des pratiques en matière d'adoption et de placement familial sur les plans national et international, de l'Ensemble de règles minima des Nations Unies concernant l'administration de la justice pour mineurs (Règles de Beijing) et de la Déclaration sur la protection des femmes et des enfants en période d'urgence et de conflit armé,

Reconnaissant qu'il y a dans tous les pays du monde des enfants qui vivent dans des conditions particulièrement difficiles, et qu'il est nécessaire d'accorder à ces enfants une attention particulière,

Tenant dûment compte de l'importance des traditions et valeurs culturelles de chaque peuple dans la protection et le développement harmonieux de l'enfant,

Reconnaissant l'importance de la coopération internationale pour l'amélioration des conditions de vie des enfants dans tous les pays, en particulier dans les pays en développement,

Sont convenus de ce qui suit :

\section{Première partie}

\section{Article premier}

Au sens de la présente Convention, un enfant s'entend de tout être humain âgé de moins de dix-huit ans, sauf si la majorité est atteinte plus tôt en vertu de la législation qui lui est applicable.

\section{Article 2}

1. Les Etats parties s'engagent à respecter les droits qui sont énoncés dans la présente Convention et à les garantir à tout enfant relevant de leur juridiction, sans distinction aucune, indépendamment de toute considération de race, de couleur, de sexe, de langue, de religion, d'opinion politique ou autre de l'enfant ou de ses parents ou représentants légaux, de leur origine nationale, ethnique ou sociale, de leur situation de fortune, de leur incapacité, de leur naissance ou de toute autre situation.

2. Les Etats parties prennent toutes les mesures appropriées pour que l'enfant soit effectivement protégé contre toutes formes de discrimination ou de sanction motivées 
par la situation juridique, les activités, les opinions déclarées ou les convictions de ses parents, de ses représentants légaux ou des membres de sa famille.

\section{Article 3}

Dans toutes les décisions qui concernent les enfants, qu'elles soient le fait des institutions publiques ou privées de protection sociale, des tribunaux, des autorités administratives ou des organes législatifs, l'intérêt supérieur de l'enfant doit être une considération primordiale.

Les Etats parties s'engagent à assurer à l'enfant la protection et les soins nécessaires à son bien-être, compte tenu des droits et des devoirs de ses parents, de ses tuteurs ou des autres personnes légalement responsables de lui, et ils prennent à cette fin toutes les mesures législatives et administratives appropriées.

3. Les Etats parties veillent à ce que le fonctionnement des institutions, services et établissements qui ont la charge des enfants et assurent leur protection soit conforme aux normes fixées par les autorités compétentes, particulièrement dans le domaine de la sécurité et de la santé et en ce qui concerne le nombre et la compétence de leur personnel ainsi que l'existence d'un contrôle approprié.

\section{Article 4}

Les Etats parties s'engagent à prendre toutes les mesures législatives, administratives et autres qui sont nécessaires pour mettre en œuvre les droits reconnus dans la présente Convention. Dans le cas des droits économiques, sociaux et culturels, ils prennent ces mesures dans toutes les limites des ressources dont ils disposent et, s'il y a lieu, dans le cadre de la coopération internationale.

\section{Article 5}

Les Etats parties respectent la responsabilité, le droit et le devoir qu'ont les parents ou, le cas échéant, les membres de la famille élargie ou de la communauté, comme prévu par la coutume locale, les tuteurs ou autres personnes légalement responsables de l'enfant, de donner à celui-ci, d'une manière qui corresponde au développement de ses capacités, l'orientation et les conseils appropriés à l'exercice des droits que lui reconnaît la présente Convention.

\section{Article 6}

Les Etats parties reconnaissent que tout enfant a un droit inhérent à la vie.

Les Etats parties assurent dans toute la mesure possible la survie et le développement de l'enfant.

\section{Article 7}

1. L'enfant est enregistré aussitôt sa naissance et a dès celle-ci le droit à un nom, le droit d'acquérir une nationalité et, dans la mesure du possible, le droit de connaître ses parents et d'être élevé par eux. 
Les Etats parties veillent à mettre ces droits en œuvre conformément à leur législation nationale et aux obligations que leur imposent les instruments internationaux applicables en la matière, en particulier dans les cas où faute de cela l'enfant se trouverait apatride.

\section{Article 8}

Les Etats parties s'engagent à respecter le droit de l'enfant de préserver son identité, y compris sa nationalité, son nom et ses relations familiales, tels qu'ils sont reconnus par la loi, sans ingérence illégale.

Si un enfant est illégalement privé des éléments constitutifs de son identité ou de certains d'entre eux, les Etats parties doivent lui accorder une assistance et une protection appropriées, pour que son identité soit rétablie aussi rapidement que possible.

\section{Article 9}

1. Les Etats parties veillent à ce que l'enfant ne soit pas séparé de ses parents contre leur gré, à moins que les autorités compétentes ne décident, sous réserve de révision judiciaire et conformément aux lois et procédures applicables, que cette séparation est nécessaire dans l'intérêt supérieur de l'enfant. Une décision en ce sens peut être nécessaire dans certains cas particuliers, par exemple lorsque les parents maltraitent ou négligent l'enfant, ou lorsqu'ils vivent séparément et qu'une décision doit être prise au sujet du lieu de résidence de l'enfant.

2. Dans tous les cas prévus au paragraphe $1 \mathrm{du}$ présent article, toutes les parties intéressées doivent avoir la possibilité de participer aux délibérations et de faire connaître leurs vues.

Les Etats parties respectent le droit de l'enfant séparé de ses deux parents ou de l'un d'eux d'entretenir régulièrement des relations personnelles et des contacts directs avec ses deux parents, sauf si cela est contraire à l'intérêt supérieur de l'enfant.

Lorsque la séparation résulte de mesures prises par un Etat partie, telles que la détention, l'emprisonnement, l'exil, l'expulsion ou la mort (y compris la mort, quelle qu'en soit la cause, survenue en cours de détention) des deux parents ou de l'un d'eux, ou de l'enfant, l'Etat partie donne sur demande aux parents, à l'enfant ou, s'il y a lieu, à un autre membre de la famille les renseignements essentiels sur le lieu où se trouvent le membre ou les membres de la famille, à moins que la divulgation de ces renseignements ne soit préjudiciable au bien-être de l'enfant. Les Etats parties veillent en outre à ce que la présentation d'une telle demande n'entraîne pas en elle-même de conséquences fâcheuses pour la personne ou les personnes intéressées.

\section{Article 10}

1. Conformément à l'obligation incombant aux Etats parties en vertu du paragraphe 1 de l'article 9, toute demande faite par un enfant ou ses parents en vue d'entrer dans un Etat partie ou de le quitter aux fins de réunification familiale est considérée par les Etats parties dans un esprit positif, avec humanité et diligence. Les Etats parties veillent en 
outre à ce que la présentation d'une telle demande n'entraîne pas de conséquences fâcheuses pour les auteurs de la demande et les membres de leur famille.

2. Un enfant dont les parents résident dans des Etats différents a le droit d'entretenir, sauf circonstances exceptionnelles, des relations personnelles et des contacts directs réguliers avec ses deux parents. A cette fin, et conformément à l'obligation incombant aux Etats parties en vertu du paragraphe 1 de l'article 9, les Etats parties respectent le droit qu'ont l'enfant et ses parents de quitter tout pays, y compris le leur, et de revenir dans leur propre pays. Le droit de quitter tout pays ne peut faire l'objet que des restrictions prescrites par la loi qui sont nécessaires pour protéger la sécurité nationale, l'ordre public, la santé ou la moralité publiques, ou les droits et libertés d'autrui, et qui sont compatibles avec les autres droits reconnus dans la présente Convention.

\section{Article 11}

Les Etats parties prennent des mesures pour lutter contre les déplacements et les nonretours illicites d'enfants à l'étranger.

A cette fin, les Etats parties favorisent la conclusion d'accords bilatéraux ou multilatéraux ou l'adhésion aux accords existants.

\section{Article 12}

1. Les Etats parties garantissent à l'enfant qui est capable de discernement le droit d'exprimer librement son opinion sur toute question l'intéressant, les opinions de l'enfant étant dûment prises en considération eu égard à son âge et à son degré de maturité.

2. A cette fin, on donnera notamment à l'enfant la possibilité d'être entendu dans toute procédure judiciaire ou administrative l'intéressant, soit directement, soit par l'intermédiaire d'un représentant ou d'une organisation approprié, de façon compatible avec les règles de procédure de la législation nationale.

\section{Article 13}

1. L'enfant a droit à la liberté d'expression. Ce droit comprend la liberté de rechercher, de recevoir et de répandre des informations et des idées de toute espèce, sans considération de frontières, sous une forme orale, écrite, imprimée ou artistique, ou par tout autre moyen du choix de l'enfant.

2. L'exercice de ce droit ne peut faire l'objet que des seules restrictions qui sont prescrites par la loi et qui sont nécessaires :

- Au respect des droits ou de la réputation d'autrui ; ou

- A la sauvegarde de la sécurité nationale, de l'ordre public, de la santé ou de la moralité publiques.

\section{Article 14}

1. Les Etats parties respectent le droit de l'enfant à la liberté de pensée, de conscience et de religion.

2. Les Etats parties respectent le droit et le devoir des parents ou, le cas échéant, des représentants légaux de l'enfant, de guider celui-ci dans l'exercice du droit susmentionné d'une manière qui corresponde au développement de ses capacités. 
3. La liberté de manifester sa religion ou ses convictions ne peut être soumise qu'aux seules restrictions qui sont prescrites par la loi et qui sont nécessaires pour préserver la sûreté publique, l'ordre public, la santé et la moralité publiques, ou les libertés et droits fondamentaux d'autrui.

\section{Article 15}

1. Les Etats parties reconnaissent les droits de l'enfant à la liberté d'association et à la liberté de réunion pacifique.

2. L'exercice de ces droits ne peut faire l'objet que des seules restrictions qui sont prescrites par la loi et qui sont nécessaires dans une société démocratique, dans l'intérêt de la sécurité nationale, de la sûreté publique ou de l'ordre public, ou pour protéger la santé ou la moralité publiques, ou les droits et libertés d'autrui.

\section{Article 16}

1. Nul enfant ne fera l'objet d'immixtions arbitraires ou illégales dans sa vie privée, sa famille, son domicile ou sa correspondance, ni d'atteintes illégales à son honneur et à sa réputation.

2. L'enfant a droit à la protection de la loi contre de telles immixtions ou de telles atteintes.

\section{Article 17}

Les Etats parties reconnaissent l'importance de la fonction remplie par les médias et veillent à ce que l'enfant ait accès à une information et à des matériels provenant de sources nationales et internationales diverses, notamment ceux qui visent à promouvoir son bien-être social, spirituel et moral ainsi que sa santé physique et mentale. A cette fin, les Etats parties :

- Encouragent les médias à diffuser une information et des matériels qui présentent une utilité sociale et culturelle pour l'enfant et répondent à l'esprit de l'article 29 ;

- Encouragent la coopération internationale en vue de produire, d'échanger et de diffuser une information et des matériels de ce type provenant de différentes sources culturelles, nationales et internationales ;

- Encouragent la production et la diffusion de livres pour enfants ;

- Encouragent les médias à tenir particulièrement compte des besoins linguistiques des enfants autochtones ou appartenant à un groupe minoritaire ;

- Favorisent l'élaboration de principes directeurs appropriés destinés à protéger l'enfant contre l'information et les matériels qui nuisent à son bien-être, compte tenu des dispositions des articles 13 et 18.

\section{Article 18}

1. Les Etats parties s'emploient de leur mieux à assurer la reconnaissance du principe selon lequel les deux parents ont une responsabilité commune pour ce qui est d'élever l'enfant et d'assurer son développement. La responsabilité d'élever l'enfant et d'assurer son développement incombe au premier chef aux parents ou, le cas échéant, à ses représentants légaux. Ceux-ci doivent être guidés avant tout par l'intérêt supérieur de l'enfant. 
2. Pour garantir et promouvoir les droits énoncés dans la présente Convention, les Etats parties accordent l'aide appropriée aux parents et aux représentants légaux de l'enfant dans l'exercice de la responsabilité qui leur incombe d'élever l'enfant et assurent la mise en place d'institutions, d'établissements et de services chargés de veiller au bien-être des enfants.

3. Les Etats parties prennent toutes les mesures appropriées pour assurer aux enfants dont les parents travaillent le droit de bénéficier des services et établissements de garde d'enfants pour lesquels ils remplissent les conditions requises.

\section{Article 19}

Les Etats parties prennent toutes les mesures législatives, administratives, sociales et éducatives appropriées pour protéger l'enfant contre toute forme de violence, d'atteinte ou de brutalités physiques ou mentales, d'abandon ou de négligence, de mauvais traitements ou d'exploitation, y compris la violence sexuelle, pendant qu'il est sous la garde de ses parents ou de l'un d'eux, de son ou ses représentants légaux ou de toute autre personne à qui il est confié.

Ces mesures de protection doivent comprendre, selon qu'il conviendra, des procédures efficaces pour l'établissement de programmes sociaux visant à fournir l'appui nécessaire à l'enfant et à ceux à qui il est confié, ainsi que pour d'autres formes de prévention, et aux fins d'identification, de rapport, de renvoi, d'enquête, de traitement et de suivi pour les cas de mauvais traitements de l'enfant décrits ci-dessus, et comprendre également, selon qu'il conviendra, des procédures d'intervention judiciaire.

\section{Article 20}

1. Tout enfant qui est temporairement ou définitivement privé de son milieu familial, ou qui dans son propre intérêt ne peut être laissé dans ce milieu, a droit à une protection et une aide spéciales de l'Etat.

Les Etats parties prévoient pour cet enfant une protection de remplacement conforme à leur législation nationale.

Cette protection de remplacement peut notamment avoir la forme du placement dans une famille, de la «Kafalah » de droit islamique, de l'adoption ou, en cas de nécessité, du placement dans un établissement pour enfants approprié. Dans le choix entre ces solutions, il est dûment tenu compte de la nécessité d'une certaine continuité dans l'éducation de l'enfant, ainsi que de son origine ethnique, religieuse, culturelle et linguistique.

\section{Article 21}

Les Etats parties qui admettent et/ou autorisent l'adoption s'assurent que l'intérêt supérieur de l'enfant est la considération primordiale en la matière, et :

- Veillent à ce que l'adoption d'un enfant ne soit autorisée que par les autorités compétentes, qui vérifient, conformément à la loi et aux procédures applicables et sur la base de tous les renseignements fiables relatifs au cas considéré, que l'adoption peut avoir lieu eu égard à la situation de l'enfant par rapport à ses père et 
mère, parents et représentants légaux et que, le cas échéant, les personnes intéressées ont donné leur consentement à l'adoption en connaissance de cause, après s'être entourées des avis nécessaires ;

- Reconnaissent que l'adoption à l'étranger peut être envisagée comme un autre moyen d'assurer les soins nécessaires à l'enfant, si celui-ci ne peut, dans son pays d'origine, être placé dans une famille nourricière ou adoptive ou être convenablement élevé ;

- Veillent, en cas d'adoption à l'étranger, à ce que l'enfant ait le bénéfice de garanties et de normes équivalant à celles existant en cas d'adoption nationale ;

- Prennent toutes les mesures appropriées pour veiller à ce que, en cas d'adoption à l'étranger, le placement de l'enfant ne se traduise pas par un profit matériel indu pour les personnes qui en sont responsables;

- Poursuivent les objectifs du présent article en concluant des arrangements ou des accords bilatéraux ou multilatéraux, selon les cas, et s'efforcent dans ce cadre de veiller à ce que les placements d'enfants à l'étranger soient effectués par des autorités ou des organes compétents.

\section{Article 22}

1. Les Etats parties prennent les mesures appropriées pour qu'un enfant qui cherche à obtenir le statut de réfugié ou qui est considéré comme réfugié en vertu des règles et procédures du droit international ou national applicable, qu'il soit seul ou accompagné de ses père et mère ou de toute autre personne, bénéficie de la protection et de l'assistance humanitaire voulues pour lui permettre de jouir des droits que lui reconnaissent la présente Convention et les autres instruments internationaux relatifs aux droits de l'homme ou de caractère humanitaire auxquels lesdits Etats sont parties.

2. A cette fin, les Etats parties collaborent, selon qu'ils le jugent nécessaire, à tous les efforts faits par l'Organisation des Nations Unies et les autres organisations intergouvernementales ou non gouvernementales compétentes collaborant avec l'Organisation des Nations Unies pour protéger et aider les enfants qui se trouvent en pareille situation et pour rechercher les père et mère ou autres membres de la famille de tout enfant réfugié en vue d'obtenir les renseignements nécessaires pour le réunir à sa famille. Lorsque ni le père, ni la mère, ni aucun autre membre de la famille ne peut être retrouvé, l'enfant se voit accorder, selon les principes énoncés dans la présente Convention, la même protection que tout autre enfant définitivement ou temporairement privé de son milieu familial pour quelque raison que ce soit.

\section{Article 23}

1. Les Etats parties reconnaissent que les enfants mentalement ou physiquement handicapés doivent mener une vie pleine et décente, dans des conditions qui garantissent leur dignité, favorisent leur autonomie et facilitent leur participation active à la vie de la collectivité.

2. Les Etats parties reconnaissent le droit à des enfants handicapés de bénéficier de soins spéciaux et encouragent et assurent, dans la mesure des ressources disponibles, l'octroi, sur demande, aux enfants handicapés remplissant les conditions requises et à ceux qui 
en ont la charge, d'une aide adaptée à l'état de l'enfant et à la situation de ses parents ou de ceux à qui il est confié.

3. Eu égard aux besoins particuliers des enfants handicapés, l'aide fournie conformément au paragraphe 2 du présent article est gratuite chaque fois qu'il est possible, compte tenu des ressources financières de leurs parents ou de ceux à qui l'enfant est confié, et elle est conçue de telle sorte que les enfants handicapés aient effectivement accès à l'éducation, à la formation, aux soins de santé, à la rééducation, à la préparation à l'emploi et aux activités récréatives, et bénéficient de ces services de façon propre à assurer une intégration sociale aussi complète que possible et leur épanouissement personnel, y compris dans le domaine culturel et spirituel.

Dans un esprit de coopération internationale, les Etats parties favorisent l'échange d'informations pertinentes dans le domaine des soins de santé préventifs et du traitement médical, psychologique et fonctionnel des enfants handicapés, y compris par la diffusion d'informations concernant les méthodes de rééducation et les services de formation professionnelle, ainsi que l'accès à ces données, en vue de permettre aux Etats parties d'améliorer leurs capacités et leurs compétences et d'élargir leur expérience dans ces domaines. A cet égard, il est tenu particulièrement compte des besoins des pays en développement.

\section{Article 24}

Les Etats parties reconnaissent le droit de l'enfant de jouir du meilleur état de santé possible et de bénéficier de services médicaux et de rééducation. Ils s'efforcent de garantir qu'aucun enfant ne soit privé du droit d'avoir accès à ces services.

Les Etats parties s'efforcent d'assurer la réalisation intégrale du droit susmentionné et, en particulier, prennent les mesures appropriées pour :

- $\quad$ Réduire la mortalité parmi les nourrissons et les enfants ;

- Assurer à tous les enfants l'assistance médicale et les soins de santé nécessaires, l'accent étant mis sur le développement des soins de santé primaires ;

- $\quad$ Lutter contre la maladie et la malnutrition, y compris dans le cadre de soins de santé primaires, grâce notamment à l'utilisation de techniques aisément disponibles et à la fourniture d'aliments nutritifs et d'eau potable, compte tenu des dangers et des risques de pollution du milieu naturel ;

- Assurer aux mères des soins prénatals et postnatals appropriés ;

- Faire en sorte que tous les groupes de la société, en particulier les parents et les enfants, reçoivent une information sur la santé et la nutrition de l'enfant, les avantages de l'allaitement au sein, l'hygiène et la salubrité de l'environnement et la prévention des accidents, et bénéficient d'une aide leur permettant de mettre à profit cette information ;

- Développer les soins de santé préventifs, les conseils aux parents et l'éducation et les services en matière de planification familiale.

Les Etats parties prennent toutes les mesures efficaces appropriées en vue d'abolir les pratiques traditionnelles préjudiciables à la santé des enfants. 
Les Etats parties s'engagent à favoriser et à encourager la coopération internationale en vue d'assurer progressivement la pleine réalisation du droit reconnu dans le présent article.

A cet égard, il est tenu particulièrement compte des besoins des pays en développement.

\section{Article 25}

Les Etats parties reconnaissent à l'enfant qui a été placé par les autorités compétentes pour recevoir des soins, une protection ou un traitement physique ou mental, le droit à un examen périodique dudit traitement et de toute autre circonstance relative à son placement.

\section{Article 26}

Les Etats parties reconnaissent à tout enfant le droit de bénéficier de la sécurité sociale, y compris les assurances sociales, et prennent les mesures nécessaires pour assurer la pleine réalisation de ce droit en conformité avec leur législation nationale.

Les prestations doivent, lorsqu'il y a lieu, être accordées compte tenu des ressources et de la situation de l'enfant et des personnes responsables de son entretien, ainsi que de toute autre considération applicable à la demande de prestation faite par l'enfant ou en son nom.

\section{Article 27}

Les Etats parties reconnaissent le droit de tout enfant à un niveau de vie suffisant pour permettre son développement physique, mental, spirituel, moral et social.

C'est aux parents ou autres personnes ayant la charge de l'enfant qu'incombe au premier chef la responsabilité d'assurer, dans les limites de leurs possibilités et de leurs moyens financiers, les conditions de vie nécessaires au développement de l'enfant.

Les Etats parties adoptent les mesures appropriées, compte tenu des conditions nationales et dans la mesure de leurs moyens, pour aider les parents et autres personnes ayant la charge de l'enfant à mettre en œuvre ce droit et offrent, en cas de besoin, une assistance matérielle et des programmes d'appui, notamment en ce qui concerne l'alimentation, le vêtement et le logement.

4. Les Etats parties prennent toutes les mesures appropriées en vue d'assurer le recouvrement de la pension alimentaire de l'enfant auprès de ses parents ou des autres personnes ayant une responsabilité financière à son égard, que ce soit sur leur territoire ou à l'étranger. En particulier, pour tenir compte des cas où la personne qui a une responsabilité financière à l'égard de l'enfant vit dans un Etat autre que celui de l'enfant, les Etats parties favorisent l'adhésion à des accords internationaux ou la conclusion de tels accords ainsi que l'adoption de tous autres arrangements appropriés.

\section{Article 28}

1. Les Etats parties reconnaissent le droit de l'enfant à l'éducation, et en particulier, en vue d'assurer l'exercice de ce droit progressivement et sur la base de l'égalité des chances : 
Ils rendent l'enseignement primaire obligatoire et gratuit pour tous ;

Ils encouragent l'organisation de différentes formes d'enseignement secondaire, tant général que professionnel, les rendent ouvertes et accessibles à tout enfant, et prennent des mesures appropriées, telles que l'instauration de la gratuité de l'enseignement et l'offre d'une aide financière en cas de besoin ;

- Ils assurent à tous l'accès à l'enseignement supérieur, en fonction des capacités de chacun, par tous les moyens appropriés ;

- Ils rendent ouvertes et accessibles à tout enfant l'information et l'orientation scolaires et professionnelles ;

- Ils prennent des mesures pour encourager la régularité de la fréquentation scolaire et la réduction des taux d'abandon scolaire.

2. Les Etats parties prennent toutes les mesures appropriées pour veiller à ce que la discipline scolaire soit appliquée d'une manière compatible avec la dignité de l'enfant en tant qu'être humain et conformément à la présente Convention.

3. Les Etats parties favorisent et encouragent la coopération internationale dans le domaine de l'éducation, en vue notamment de contribuer à éliminer l'ignorance et l'analphabétisme dans le monde et de faciliter l'accès aux connaissances scientifiques et techniques et aux méthodes d'enseignement modernes. A cet égard, il est tenu particulièrement compte des besoins des pays en développement.

\section{Article 29}

1. Les Etats parties conviennent que l'éducation de l'enfant doit viser à :

- Favoriser l'épanouissement de la personnalité de l'enfant et le développement de ses dons et de ses aptitudes mentales et physiques, dans toute la mesure de leurs potentialités ;

- Inculquer à l'enfant le respect des droits de l'homme et des libertés fondamentales, et des principes consacrés dans la Charte des Nations Unies;

- Inculquer à l'enfant le respect de ses parents, de son identité, de sa langue et de ses valeurs culturelles, ainsi que le respect des valeurs nationales du pays dans lequel il vit, du pays duquel il peut être originaire et des civilisations différentes de la sienne ;

- Préparer l'enfant à assumer les responsabilités de la vie dans une société libre, dans un esprit de compréhension, de paix, de tolérance, d'égalité entre les sexes et d'amitié entre tous les peuples et groupes ethniques, nationaux et religieux, et avec les personnes d'origine autochtone ;

- Inculquer à l'enfant le respect du milieu naturel.

2. Aucune disposition du présent article ou de l'article 28 ne sera interprétée d'une manière qui porte atteinte à la liberté des personnes physiques ou morales de créer et de diriger des établissements d'enseignement, à condition que les principes énoncés au paragraphe 1 du présent article soient respectés et que l'éducation dispensée dans ces établissements soit conforme aux normes minimales que l'Etat aura prescrites. 


\section{Article 30}

Dans les Etats où il existe des minorités ethniques, religieuses ou linguistiques ou des personnes d'origine autochtone, un enfant autochtone ou appartenant à une de ces minorités ne peut être privé du droit d'avoir sa propre vie culturelle, de professer et de pratiquer sa propre religion ou d'employer sa propre langue en commun avec les autres membres de son groupe.

\section{Article 31}

1. Les Etats parties reconnaissent à l'enfant le droit au repos et aux loisirs, de se livrer au jeu et à des activités récréatives propres à son âge et de participer librement à la vie culturelle et artistique.

2. Les Etats parties respectent et favorisent le droit de l'enfant de participer pleinement à la vie culturelle et artistique et encouragent l'organisation à son intention de moyens appropriés de loisirs et d'activités récréatives, artistiques et culturelles, dans des conditions d'égalité.

\section{Article 32}

1. Les Etats parties reconnaissent le droit de l'enfant d'être protégé contre l'exploitation économique et de n'être astreint à aucun travail comportant des risques ou susceptible de compromettre son éducation ou de nuire à sa santé ou à son développement physique, mental, spirituel, moral ou social.

2. Les Etats parties prennent des mesures législatives, administratives, sociales et éducatives pour assurer l'application du présent article. A cette fin, et compte tenu des dispositions pertinentes des autres instruments internationaux, les Etats parties, en particulier :

- $\quad$ Fixent un âge minimum ou des âges minimums d'admission à l'emploi ;

- Prévoient une réglementation appropriée des horaires de travail et des conditions d'emploi ;

- Prévoient des peines ou autres sanctions appropriées pour assurer l'application effective du présent article.

\section{Article 33}

Les Etats parties prennent toutes les mesures appropriées, y compris des mesures législatives, administratives, sociales et éducatives, pour protéger les enfants contre l'usage illicite de stupéfiants et de substances psychotropes, tels que les définissent les conventions internationales pertinentes, et pour empêcher que des enfants ne soient utilisés pour la production et le trafic illicites de ces substances.

\section{Article 34}

Les Etats parties s'engagent à protéger l'enfant contre toutes les formes d'exploitation sexuelle et de violence sexuelle. A cette fin, les Etats prennent en particulier toutes les mesures appropriées sur les plans national, bilatéral et multilatéral pour empêcher :

- Que des enfants ne soient incités ou contraints à se livrer à une activité sexuelle illégale ;

- Que des enfants ne soient exploités à des fins de prostitution ou autres pratiques sexuelles illégales; 
- Que des enfants ne soient exploités aux fins de la production de spectacles ou de matériel de caractère pornographique.

\section{Article 35}

Les Etats parties prennent toutes les mesures appropriées sur les plans national, bilatéral et multilatéral pour empêcher l'enlèvement, la vente ou la traite d'enfants à quelque fin que ce soit et sous quelque forme que ce soit.

\section{Article 36}

Les Etats parties protègent l'enfant contre toutes autres formes d'exploitation préjudiciables à tout aspect de son bien- être.

\section{Article 37}

Les Etats parties veillent à ce que :

- Nul enfant ne soit soumis à la torture ni à des peines ou traitements cruels, inhumains ou dégradants. Ni la peine capitale ni l'emprisonnement à vie sans possibilité de libération ne doivent être prononcés pour les infractions commises par des personnes âgées de moins de dix-huit ans ;

- Nul enfant ne soit privé de liberté de façon illégale ou arbitraire. L'arrestation, la détention ou l'emprisonnement d'un enfant doit être en conformité avec la loi, n'être qu'une mesure de dernier ressort, et être d'une durée aussi brève que possible ;

- Tout enfant privé de liberté soit traité avec humanité et avec le respect dû à la dignité de la personne humaine, et d'une manière tenant compte des besoins des personnes de son âge. En particulier, tout enfant privé de liberté sera séparé des adultes, à moins que l'on estime préférable de ne pas le faire dans l'intérêt supérieur de l'enfant, et il a le droit de rester en contact avec sa famille par la correspondance et par les visites, sauf circonstances exceptionnelles ;

- Les enfants privés de liberté aient le droit d'avoir rapidement accès à l'assistance juridique ou à toute autre assistance appropriée, ainsi que le droit de contester la légalité de leur privation de liberté devant un tribunal ou une autre autorité compétente, indépendante et impartiale, et à ce qu'une décision rapide soit prise en la matière.

\section{Article 38}

1. Les Etats parties s'engagent à respecter et à faire respecter les règles du droit humanitaire international qui leur sont applicables en cas de conflit armé et dont la protection s'étend aux enfants.

Les Etats parties prennent toutes les mesures possibles dans la pratique pour veiller à ce que les personnes n'ayant pas atteint l'âge de quinze ans ne participent pas directement aux hostilités.

Les Etats parties s'abstiennent d'enrôler dans leurs forces armées toute personne n'ayant pas atteint l'âge de quinze ans. Lorsqu'ils incorporent des personnes de plus de quinze 
ans mais de moins de dix-huit ans, les Etats parties s'efforcent d'enrôler en priorité les plus âgées.

Conformément à l'obligation qui leur incombe en vertu du droit humanitaire international de protéger la population civile en cas de conflit armé, les Etats parties prennent toutes les mesures possibles dans la pratique pour que les enfants qui sont touchés par un conflit armé bénéficient d'une protection et de soins.

\section{Article 39}

Les Etats parties prennent toutes les mesures appropriées pour faciliter la réadaptation physique et psychologique et la réinsertion sociale de tout enfant victime de toute forme de négligence, d'exploitation ou de sévices, de torture ou de toute autre forme de peines ou traitements cruels, inhumains ou dégradants, ou de conflit armé. Cette réadaptation et cette réinsertion se déroulent dans des conditions qui favorisent la santé, le respect de soi et la dignité de l'enfant.

\section{Article 40}

1. Les Etats parties reconnaissent à tout enfant suspecté, accusé ou convaincu d'infraction à la loi pénale le droit à un traitement qui soit de nature à favoriser son sens de la dignité et de la valeur personnelle, qui renforce son respect pour les droits de l'homme et les libertés fondamentales d'autrui, et qui tienne compte de son âge ainsi que de la nécessité de faciliter sa réintégration dans la société et de lui faire assumer un rôle constructif au sein de celle-ci.

2. A cette fin, et compte tenu des dispositions pertinentes des instruments internationaux, les Etats parties veillent en particulier :

- A ce qu'aucun enfant ne soit suspecté, accusé ou convaincu d'infraction à la loi pénale en raison d'actions ou d'omissions qui n'étaient pas interdites par le droit national ou international au moment où elles ont été commises ;

- A ce que tout enfant suspecté ou accusé d'infraction à la loi pénale ait au moins le droit aux garanties suivantes :

- Etre présumé innocent jusqu'à ce que sa culpabilité ait été légalement établie ;

- Etre informé dans le plus court délai et directement des accusations portées contre lui, ou, le cas échéant, par l'intermédiaire de ses parents ou représentants légaux, et bénéficier d'une assistance juridique ou de toute autre assistance appropriée pour la préparation et la présentation de sa défense ;

- Que sa cause soit entendue sans retard par une autorité ou une instance judiciaire compétentes, indépendantes et impartiales, selon une procédure équitable aux termes de la loi, en présence de son conseil juridique ou autre et, à moins que cela ne soit jugé contraire à l'intérêt supérieur de l'enfant en raison notamment de son âge ou de sa situation, en présence de ses parents ou représentants légaux ;

- Ne pas être contraint de témoigner ou de s'avouer coupable; interroger ou faire interroger les témoins à charge, et obtenir la comparution et l'interrogatoire des témoins à décharge dans des conditions d'égalité ; 
- S'il est reconnu avoir enfreint la loi pénale, faire appel de cette décision et de toute mesure arrêtée en conséquence devant une autorité ou une instance judiciaire supérieure compétentes, indépendantes et impartiales, conformément à la loi ;

- Se faire assister gratuitement d'un interprète s'il ne comprend ou ne parle pas la langue utilisée ;

- Que sa vie privée soit pleinement respectée à tous les stades de la procédure.

3. Les Etats parties s'efforcent de promouvoir l'adoption de lois, de procédures, la mise en place d'autorités et d'institutions spécialement conçues pour les enfants suspectés, accusés ou convaincus d'infraction à la loi pénale, et en particulier :

- D'établir un âge minimum au-dessous duquel les enfants seront présumés n'avoir pas la capacité d'enfreindre la loi pénale ;

- De prendre des mesures, chaque fois que cela est possible et souhaitable, pour traiter ces enfants sans recourir à la procédure judiciaire, étant cependant entendu que les droits de l'homme et les garanties légales doivent être pleinement respectés.

4. Toute une gamme de dispositions, relatives notamment aux soins, à l'orientation et à la supervision, aux conseils, à la probation, au placement familial, aux programmes d'éducation générale et professionnelle et aux solutions autres qu'institutionnelles seront prévues en vue d'assurer aux enfants un traitement conforme à leur bien-être et proportionné à leur situation et à l'infraction.

\section{Article 41}

Aucune des dispositions de la présente Convention ne porte atteinte aux dispositions plus propices à la réalisation des droits de l'enfant qui peuvent figurer :

- Dans la législation d'un Etat partie; ou

- Dans le droit international en vigueur pour cet Etat.

\section{Deuxième partie}

\section{Article 42}

Les Etats parties s'engagent à faire largement connaître les principes et les dispositions de la présente Convention, par des moyens actifs et appropriés, aux adultes comme aux enfants.

\section{Article 43}

Aux fins d'examiner les progrès accomplis par les Etats parties dans l'exécution des obligations contractées par eux en vertu de la présente Convention, il est institué un Comité des droits de l'enfant qui s'acquitte des fonctions définies ci-après.

Le Comité se compose de dix experts de haute moralité et possédant une compétence reconnue dans le domaine visé par la présente Convention. Ses membres sont élus par les Etats parties parmi leurs ressortissants et siègent à titre personnel, compte tenu de la nécessité d'assurer une répartition géographique équitable et eu égard aux principaux systèmes juridiques. 
Les membres du Comité sont élus au scrutin secret sur une liste de personnes désignées par les Etats parties. Chaque Etat partie peut désigner un candidat parmi ses ressortissants.

La première élection aura lieu dans les six mois suivant la date d'entrée en vigueur de la présente Convention. Les élections auront lieu ensuite tous les deux ans. Quatre mois au moins avant la date de chaque élection, le Secrétaire général de l'Organisation des Nations Unies invitera par écrit les Etats parties à proposer leurs candidats dans un délai de deux mois. Le Secrétaire général dressera ensuite la liste alphabétique des candidats ainsi désignés, en indiquant les Etats parties qui les ont désignés, et la communiquera aux Etats parties à la présente Convention.

Les élections ont lieu lors des réunions des Etats parties, convoquées par le Secrétaire général au Siège de l'Organisation des Nations Unies. A ces réunions, pour lesquelles le quorum est constitué par les deux tiers des Etats parties, les candidats élus au Comité sont ceux qui obtiennent le plus grand nombre de voix et la majorité absolue des voix des représentants des Etats parties présents et votants.

Les membres du Comité sont élus pour quatre ans. Ils sont rééligibles si leur candidature est présentée à nouveau. Le mandat de cinq des membres élus lors de la première élection prend fin au bout de deux ans. Les noms de ces cinq membres seront tirés au sort par le président de la réunion immédiatement après la première élection.

En cas de décès ou de démission d'un membre du Comité, ou si, pour toute autre raison, un membre déclare ne plus pouvoir exercer ses fonctions au sein du Comité, l'Etat partie qui avait présenté sa candidature nomme un autre expert parmi ses ressortissants pour pourvoir le poste ainsi vacant jusqu'à l'expiration du mandat correspondant, sous réserve de l'approbation du Comité.

Le Comité adopte son règlement intérieur.

Le Comité élit son bureau pour une période de deux ans.

Les réunions du Comité se tiennent normalement au Siège de l'Organisation des Nations Unies, ou en tout autre lieu approprié déterminé par le Comité. Le Comité se réunit normalement chaque année. La durée de ses sessions est déterminée et modifiée, si nécessaire, par une réunion des Etats parties à la présente Convention, sous réserve de l'approbation de l'Assemblée générale.

Le Secrétaire général de l'Organisation des Nations Unies met à la disposition du Comité le personnel et les installations qui lui sont nécessaires pour s'acquitter efficacement des fonctions qui lui sont confiées en vertu de la présente Convention.

Les membres du Comité institué en vertu de la présente Convention reçoivent, avec l'approbation de l'Assemblée générale, des émoluments prélevés sur les ressources de 
l'Organisation des Nations Unies dans les conditions et selon les modalités fixées par l'Assemblée générale.

\section{Article 44}

1. Les Etats parties s'engagent à soumettre au Comité, par l'entremise du Secrétaire général de l'Organisation des Nations Unies, des rapports sur les mesures qu'ils auront adoptées pour donner effet aux droits reconnus dans la présente Convention et sur les progrès réalisés dans la jouissance de ces droits :

- Dans les deux ans à compter de la date de l'entrée en vigueur de la présente Convention pour les Etats parties intéressés ;

- Par la suite, tous les cinq ans.

2. Les rapports établis en application du présent article doivent, le cas échéant, indiquer les facteurs et les difficultés empêchant les Etats parties de s'acquitter pleinement des obligations prévues dans la présente Convention. Ils doivent également contenir des renseignements suffisants pour donner au Comité une idée précise de l'application de la Convention dans le pays considéré.

3. Les Etats parties ayant présenté au Comité un rapport initial complet n'ont pas, dans les rapports qu'ils lui présentent ensuite conformément à l'alinéa b du paragraphe $1 \mathrm{du}$ présent article, à répéter les renseignements de base antérieurement communiqués.

4. Le Comité peut demander aux Etats parties tous renseignements complémentaires relatifs à l'application de la Convention.

Le Comité soumet tous les deux ans à l'Assemblée générale, par l'entremise du Conseil économique et social, un rapport sur ses activités.

Les Etats parties assurent à leurs rapports une large diffusion dans leur propre pays.

\section{Article 45}

Pour promouvoir l'application effective de la Convention et encourager la coopération internationale dans le domaine visé par la Convention :

- Les institutions spécialisées, le Fonds des Nations Unies pour l'enfance et d'autres organes des Nations Unies ont le droit de se faire représenter lors de l'examen de l'application des dispositions de la présente Convention qui relèvent de leur mandat. Le Comité peut inviter les institutions spécialisées, le Fonds des Nations Unies pour l'enfance et tous autres organismes qu'il jugera appropriés à donner des avis spécialisés sur l'application de la Convention dans les domaines qui relèvent de leurs mandats respectifs. Il peut inviter les institutions spécialisées, le Fonds des Nations Unies pour l'enfance et d'autres organes des Nations Unies à lui présenter des rapports sur l'application de la Convention dans les secteurs qui relèvent de leur domaine d'activité ;

- Le Comité transmet, s'il le juge nécessaire, aux institutions spécialisées, au Fonds des Nations Unies pour l'enfance et aux autres organismes compétents tout rapport des Etats parties contenant une demande ou indiquant un besoin de conseils ou 
d'assistance techniques, accompagné, le cas échéant, des observations et suggestions du Comité touchant ladite demande ou indication ;

- Le Comité peut recommander à l'Assemblée générale de prier le Secrétaire général de procéder pour le Comité à des études sur des questions spécifiques touchant les droits de l'enfant ;

- Le Comité peut faire des suggestions et des recommandations d'ordre général fondées sur les renseignements reçus en application des articles 44 et 45 de la présente Convention. Ces suggestions et recommandations d'ordre général sont transmises à tout Etat partie intéressé et portées à l'attention de l'As semblée générale, accompagnées, le cas échéant, des observations des Etats parties.

\section{Troisième partie}

\section{Article 46}

La présente Convention est ouverte à la signature de tous les Etats.

\section{Article 47}

La présente Convention est sujette à ratification. Les instruments de ratification seront déposés auprès du Secrétaire général de l'Organisation des Nations Unies.

\section{Article 48}

La présente Convention restera ouverte à l'adhésion de tout Etat. Les instruments d'adhésion seront déposés auprès du Secrétaire général de l'Organisation des Nations Unies.

\section{Article 49}

La présente Convention entrera en vigueur le trentième jour qui suivra la date du dépôt auprès du Secrétaire général de l'Organisation des Nations Unies du vingtième instrument de ratification ou d'adhésion.

Pour chacun des Etats qui ratifieront la présente Convention ou y adhéreront après le dépôt du vingtième instrument de ratification ou d'adhésion, la Convention entrera en vigueur le trentième jour qui suivra le dépôt par cet Etat de son instrument de ratification ou d'adhésion.

\section{Article 50}

1. Tout Etat partie peut proposer un amendement et en déposer le texte auprès du Secrétaire général de l'Organisation des Nations Unies. Le Secrétaire général communique alors la proposition d'amendement aux Etats parties, en leur demandant de lui faire savoir s'ils sont favorables à la convocation d'une conférence des Etats parties en vue de l'examen de la proposition et de sa mise aux voix. Si, dans les quatre mois qui suivent la date de cette communication, un tiers au moins des Etats parties se prononcent en faveur de la convocation d'une telle conférence, le Secrétaire général convoque la conférence sous les auspices de l'Organisation des Nations Unies. Tout amendement adopté par la majorité des Etats parties présents et votants à la conférence est soumis pour approbation à l'Assemblée générale de l'Organisation des Nations Unies. 
2. Tout amendement adopté conformément aux dispositions du paragraphe $1 \mathrm{du}$ présent article entre en vigueur lorsqu'il a été approuvé par l'Assemblée générale des Nations Unies et accepté par une majorité des deux tiers des Etats parties.

3. Lorsqu'un amendement entre en vigueur, il a force obligatoire pour les Etats parties qui l'ont accepté, les autres Etats parties demeurant liés par les dispositions de la présente Convention et par tous amendements antérieurs acceptés par eux.

\section{Article 51}

Le Secrétaire général de l'Organisation des Nations Unies recevra et communiquera à tous les Etats le texte des réserves qui auront été faites par les Etats au moment de la ratification ou de l'adhésion.

Aucune réserve incompatible avec l'objet et le but de la présente Convention n'est autorisée.

Les réserves peuvent être retirées à tout moment par notification adressée au Secrétaire général de l'Organisation des Nations Unies, lequel en informe tous les Etats parties à la Convention. La notification prend effet à la date à laquelle elle est reçue par le Secrétaire général.

\section{Article 52}

Tout Etat partie peut dénoncer la présente Convention par notification écrite adressée au Secrétaire général de l'Organisation des Nations Unies. La dénonciation prend effet un an après la date à laquelle la notification a été reçue par le Secrétaire général.

\section{Article 53}

Le Secrétaire général de l'Organisation des Nations Unies est désigné comme dépositaire de la présente Convention.

\section{Article 54}

L'original de la présente Convention, dont les textes anglais, arabe, chinois, espagnol, français et russe font également foi, sera déposé auprès du Secrétaire général de l'Organisation des Nations Unies.

En foi de quoi les plénipotentiaires soussignés. dûment habilités par leurs gouvernements respectifs, ont signé la présente Convention. 


\section{DECLARATION ET RESERVES DE LA REPUBLIQUE FRANCAISE}

1 - Le Gouvernement de la République déclare que la présente Convention, notamment l'article 6, ne saurait être interprété comme faisant obstacle à l'application des dispositions de la législation française relative à l'interruption volontaire de grossesse.

2 - Le Gouvernement de la République déclare compte tenu de l'article 2 de la Constitution de la République française, que l'article 30 n'a pas lieu de s'appliquer en ce qui concerne la République

3 - Le Gouvernement de la République Française interprété l'article 40. paragraphe 2,b,v, comme posant un principe général auquel la loi peut apporter des exceptions limitées, Il en est ainsi, notamment. Pour, certaines infractions relevant en premier et dernier ressort du tribunal de police ainsi que pour les infractions de nature criminelle. $\mathrm{Au}$ demeurant les décisions rendues en dernier ressort peuvent faire l'objet d'un recours devant la Cour de Cassation qui statue sur la légalité de la décision intervenue. 


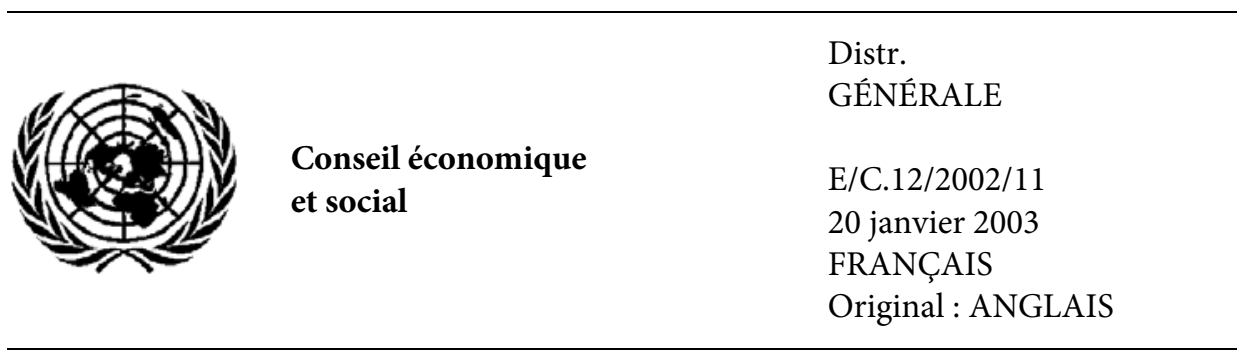

COMITÉ DES DROITS ÉCONOMIQUES,

SOCIAUX ET CULTURELS

Vingt-neuvième session

Genève, 11-29 novembre 2002

Point 3 de l'ordre du jour

QUESTIONS DE FOND CONCERNANT LA MISE EN GEURE DU PACTE INTERNATIONAL RELATIF AUX DROITS ÉCONOMIQUES, SOCIAUX ET CULTURELS

Observation générale $\mathrm{n}^{\circ} 15$ (2002)

Le droit à l'eau (art. 11 et 12 du Pacte international relatif

aux droits économiques, sociaux et culturels)

\section{INTRODUCTION}

1. L'eau est une ressource naturelle limitée et un bien public; elle est essentielle à la vie et à la santé. Le droit à l'eau est indispensable pour mener une vie digne. Il est une condition préalable à la réalisation des autres droits de l'homme. Le Comité ne cesse de constater que l'exercice du droit à l'eau est largement dénié tant dans les pays en développement que dans les pays développés. Plus d'un milliard de personnes ne bénéficient pas d'un approvisionnement élémentaire en eau, et plusieurs milliards de personnes n'ont pas accès à un assainissement adéquat, ce qui est la première cause de pollution de l'eau et de transmission de maladies d'origine hydrique ${ }^{422}$. La tendance persistante à la contamination de l'eau, à l'épuisement des ressources en eau et à leur répartition inégale exacerbe la pauvreté. Les États parties doivent adopter des mesures

\footnotetext{
${ }^{422}$ En 2000, l'Organisation mondiale de la santé a estimé que 1,1 milliard de personnes (dont $80 \%$ vivaient dans des zones rurales) n'avaient pas accès à un système d'approvisionnement amélioré capable de fournir au moins 20 litres d'eau salubre par personne et par jour et que 2,4 milliards de personnes n'avaient accès à aucun assainissement. (Voir OMS, Évaluation mondiale 2000 de l'approvisionnement en eau et de l'assainissement, Genève, 2000, p. 1.) En outre, 2,3 milliards de personnes contractent chaque année des maladies d'origine hydrique : voir Nations Unies, Commission du développement durable, Inventaire exhaustif des ressources mondiales en eau douce, rapport du Secrétaire général, New York, 1997, p. 46.
} 
effectives pour garantir l'exercice du droit à l'eau sans discrimination, conformément aux dispositions de la présente Observation générale.

\section{Fondements juridiques du droit à l'eau}

2. Le droit à l'eau consiste en un approvisionnement suffisant, physiquement accessible et à un coût abordable, d'une eau salubre et de qualité acceptable pour les usages personnels et domestiques de chacun. Une quantité adéquate d'eau salubre est nécessaire pour prévenir la mortalité due à la déshydratation et pour réduire le risque de transmission de maladies d'origine hydrique ainsi que pour la consommation, la cuisine et l'hygiène personnelle et domestique.

3. L'article 11, paragraphe 1, du Pacte énonce un certain nombre de droits qui découlent du droit à un niveau de vie suffisant - «y compris une nourriture, un vêtement et un logement suffisants »- et qui sont indispensables à sa réalisation. L'emploi de l'expression "ycompris» indique que ce catalogue de droits n'entendait pas être exhaustif. Le droit à l'eau fait clairement partie des garanties fondamentales pour assurer un niveau de vie suffisant, d'autant que l'eau est l'un des éléments les plus essentiels à la survie. En outre, le Comité a déjà reconnu que l'eau est un droit fondamental visé par le paragraphe 1 de l'article 11 [voir l'Observation générale $n^{0} 6$ (1995)] ${ }^{423}$. Le droit à l'eau est aussi inextricablement lié au droit au meilleur état de santé susceptible d'être atteint (art. 12, par. 1) $)^{424}$ et aux droits à une nourriture et à un logement suffisants (art. 11, par. 1) ${ }^{425}$. Il devrait également être considéré conjointement avec les autres droits consacrés dans la Charte internationale des droits de l'homme, et d'abord le droit à la vie et à la dignité.

4. Le droit à l'eau a été reconnu dans de nombreux documents internationaux, y compris des traités, déclarations et autres textes normatifs ${ }^{426}$. Par exemple, l'article 14,

\footnotetext{
${ }^{423}$ Voir les paragraphes 5 et 32 de l'Observation générale $n^{\circ} 6$ (1995) sur les droits économiques, sociaux et culturels des personnes âgées.

${ }^{424}$ Voir l'Observation générale $\mathrm{n}^{\circ} 14$ (2000) sur le droit au meilleur état de santé susceptible d'être atteint (par. $11,12$ a), b) et d), $15,34,36,40,43$ et 51$)$.

${ }^{425}$ Voir le paragraphe 8 b) de l'Observation générale $n^{\circ} 4$ (1991). Voir aussi le rapport présenté par M. Miloon Khotari, Rapporteur spécial sur le droit à un logement convenable en tant qu'élément du droit à un niveau de vie suffisant (E/CN.4/2002/59), conformément à la résolution 2001/28, en date du 20 avril 2001, de la Commission des droits de l'homme. Concernant le droit à une nourriture suffisante, voir le rapport présenté par M. Jean Ziegler, Rapporteur spécial sur le droit à l'alimentation (E/CN.4/2002/58), conformément à la résolution 2001/25, en date du 20 avril 2001, de la Commission des droits de l'homme.

${ }^{426}$ Voir l'article 14, paragraphe $2 \mathrm{~h}$ ), de la Convention sur l'élimination de toutes les formes de discrimination à l'égard des femmes; l'article 24, paragraphe $2 \mathrm{c}$ ), de la Convention relative aux droits de l'enfant; les articles 20, 26, 29 et 46 de la Convention de Genève relative au traitement des prisonniers de guerre (1949); les articles 85, 89 et 127 de la Convention de Genève relative à la protection des personnes civiles en temps de guerre; les articles 54 et 55 du Protocole additionnel I aux Conventions de Genève (1977); les articles 5 et 14 du Protocole additionnel II aux Conventions de Genève (1977); le préambule de la Déclaration de Mar Del Plata de la Conférence des Nations Unies sur l'eau; le paragraphe 18.47 d'Action 21, Rapport de la Conférence des Nations Unies sur l'environnement et le développement, Rio de Janeiro, 3-14 juin 1992 (A/CONF.151/26/Rev.1) (Vol. I et Vol. I/Corr.1, Vol. II, Vol. III et Vol. III/Corr.1) (publication des Nations Unies, numéro de vente : F.93.I.8), Vol. I : Résolutions adoptées par la Conférence, résolution 1, annexe II; le principe $\mathrm{n}^{\circ} 3$ de la Déclaration de Dublin sur l'eau dans la perspective d'un développement durable, Conférence internationale sur l'eau et l'environnement (A/CONF.151/PC/112); le principe $\mathrm{n}^{\circ} 2 \mathrm{du}$ Programme d'action, Rapport de la Conférence internationale sur la population et le développement, Le Caire, 5-13 septembre 1994 (publication des Nations Unies, numéro de vente : F.95.XIII.18), chap. I, résolution 1,
} 
paragraphe 2, de la Convention sur l'élimination de toutes les formes de discrimination à l'égard des femmes dispose que les États parties doivent assurer aux femmes le droit de «bénéficier de conditions de vie convenables, notamment en ce qui concerne [...] l'approvisionnement [...] en eau ». L'article 24, paragraphe 2, de la Convention relative aux droits de l'enfant fait obligation aux États parties de lutter contre la maladie et la malnutrition grâce «à la fourniture d'aliments nutritifs et d'eau potable ».

5. Le Comité aborde systématiquement la question du droit à l'eau lorsqu'il examine les rapports des États parties au regard de ses directives générales révisées concernant la forme et le contenu des rapports que les États parties doivent présenter conformément aux articles 16 et 17 du Pacte international relatif aux droits économiques, sociaux et culturels, ainsi que ses observations générales.

6. L'eau est nécessaire à des fins diverses, outre les usages personnels et domestiques, pour la réalisation de nombreux droits énoncés dans le Pacte, par exemple, pour la production alimentaire (droit à une nourriture suffisante) et pour l'hygiène du milieu (droit à la santé). Elle est essentielle pour obtenir des moyens de subsistance (droit de gagner sa vie par le travail) et pour exercer certaines pratiques culturelles (droit de participer à la vie culturelle). Néanmoins, les ressources en eau doivent être affectées en priorité aux usages personnels et domestiques. La priorité devrait aussi être donnée à la prévention de la faim et des maladies, ainsi qu'au respect des obligations fondamentales découlant de chacun des droits inscrits dans le Pacte ${ }^{427}$.

\section{L'eau et les droits énoncés dans le Pacte}

7. Le Comité note qu'il importe d'assurer un accès durable aux ressources en eau pour l'agriculture afin de réaliser le droit à une nourriture suffisante [voir l'Observation générale $\mathrm{n}^{\circ} 12$ (1999)] ${ }^{428}$. Il faut veiller à ce que les agriculteurs défavorisés et marginalisés, y compris les femmes, aient accès, dans des conditions équitables, à l'eau et aux systèmes de gestion de l'eau, notamment aux techniques durables de récupération des eaux de pluie et d'irrigation. Compte tenu de l'obligation faite à l'article premier, paragraphe 2, du Pacte, qui dispose qu'en aucun cas, un peuple ne pourra « être privé de ses propres moyens de subsistance", les États parties devraient garantir un approvisionnement en eau adéquat pour l'agriculture de subsistance et pour la sauvegarde des moyens de subsistance des peuples autochtones ${ }^{429}$.

annexe; les paragraphes 5 et 19 de la Recommandation 14 (2001) du Comité des ministres aux États membres de la Charte européenne des ressources en eau; la résolution 2002/6 de la Sous-Commission de la promotion et de la protection des droits de l'homme de l'ONU sur la réalisation du droit à l'eau potable. Voir aussi le rapport présenté par M. El Hadji Guissé, Rapporteur spécial de la Sous-Commission sur la promotion de la réalisation du droit à l'eau potable et à l'assainissement, concernant le rapport entre la jouissance des droits économiques, sociaux et culturels et la promotion de la réalisation du droit à l'eau potable et à l'assainissement (E/CN.4/Sub.2/2002/10).

${ }^{427}$ Voir aussi le Sommet mondial pour le développement durable, Plan d'application 2002, par. 25 c).

${ }^{428}$ Il s'agit à la fois de la disponibilité de nourriture et de l'accessibilité à une nourriture suffisante (voir l'Observation générale no 12 (1999), par. 12 et 13).

${ }^{429}$ Voir aussi la Déclaration d'accord accompagnant la Convention des Nations Unies sur le droit relatif aux utilisations des cours d'eau internationaux à des fins autres que la navigation (A/51/869 du 11 avril 1997), où il est dit que pour apprécier les besoins humains essentiels en cas de conflits concernant l'utilisation des cours d'eau, « il faut s'intéresser en particulier à la fourniture d'eau en quantité suffisante pour la vie humaine, qu'il s'agisse de l'eau potable ou de l'eau à réserver aux productions vivrières destinées à empêcher la famine ». 
8. L'hygiène du milieu, en tant qu'élément du droit à la santé consacré à l'alinéa $b$ du paragraphe 2 de l'article $12 \mathrm{du}$ Pacte, implique qu'il soit pris des mesures, sans discrimination, afin de prévenir les risques pour la santé dus à une eau insalubre et toxique $^{430}$. Par exemple, les États parties devraient veiller à ce que les ressources naturelles en eau soient protégées d'une contamination par des substances nocives et des microbes pathogènes. De même, les États parties devraient surveiller les cas où des écosystèmes aquatiques infestés de vecteurs de maladies constituent un risque pour l'habitat humain et prendre des mesures pour y remédier ${ }^{431}$.

9. Afin d'aider les États parties à mettre en œuvre le Pacte et à s'acquitter de leurs obligations en matière d'établissement de rapports, la présente Observation générale porte sur le contenu normatif du droit à l'eau en vertu des articles 11, paragraphe 1, et 12 (sect. II), sur les obligations des États parties (sect. III), sur les manquements à ces obligations (sect. IV), sur la mise en œuvre à l'échelon national (sect. V) et sur les obligations des acteurs autres que les États parties (sect. VI).

\section{CONTENU NORMATIF DU DROIT}

10. Le droit à l'eau consiste en des libertés et des droits. Parmi les premières figurent le droit d'accès ininterrompu à l'approvisionnement en eau nécessaire pour exercer le droit à l'eau, et le droit de ne pas subir d'entraves, notamment une interruption arbitraire de l'approvisionnement et d'avoir accès à une eau non contaminée. Par contre, les seconds correspondent au droit d'avoir accès à un système d'approvisionnement et de gestion qui donne à chacun la possibilité d'exercer, dans des conditions d'égalité, le droit à l'eau.

11. Les éléments constitutifs du droit à l'eau doivent être adéquats au regard de la dignité humaine, de la vie et de la santé, conformément aux articles 11, paragraphe 1, et $12 \mathrm{du}$ Pacte. La notion d'approvisionnement en eau adéquat doit être interprétée d'une manière compatible avec la dignité humaine, et non au sens étroit, en faisant simplement référence à des critères de volume et à des aspects techniques. L'eau devrait être considérée comme un bien social et culturel et non essentiellement comme un bien économique. Le droit à l'eau doit aussi être exercé dans des conditions de durabilité, afin que les générations actuelles et futures puissent en bénéficier ${ }^{432}$.

12. Si la notion d'approvisionnement en eau adéquat varie en fonction des situations, les facteurs ci-après sont pertinents quelles que soient les circonstances :

a) Disponibilité. L'eau disponible pour chaque personne doit être suffisante et constante ${ }^{433}$ pour les usages personnels et domestiques, qui sont normalement la

\footnotetext{
${ }^{430}$ Voir aussi le paragraphe 15 de l'Observation générale $\mathrm{n}^{\circ} 14$.

${ }^{431}$ Selon une définition de l'OMS, les maladies véhiculées par des vecteurs sont celles transmises par des insectes (paludisme, filariose, dengue, encéphalite japonaise et fièvre jaune), par des mollusques aquatiques qui servent d'hôtes intermédiaires (schistosomiase) et par des vertébrés qui tiennent lieu de réservoirs (zoonoses).

${ }^{432}$ Pour une définition de la durabilité, voir le Rapport de la Conférence Nations Unies sur l'environnement et le développement, Rio de Janeiro, 3-14 juin 1992, Déclaration sur l'environnement et le développement, principes 1, 8, 9, 10, 12 et 15; et Action 21, en particulier les principes 5.3, 7.27, 7.28, 7.35, 7.39, 7.41, 18.3, 18.8, $18.35,18.40,18.48,18.50,18.59$ et 18.68 .

${ }^{433}$ Le terme «constante " implique que l'approvisionnement en eau doit être suffisamment régulier pour les usages personnels et domestiques.
} 
consommation, l'assainissement individuel, le lavage du linge, la préparation des aliments ainsi que l'hygiène personnelle et domestique ${ }^{434}$. La quantité d'eau disponible pour chacun devrait correspondre aux directives de l'Organisation mondiale de la santé $(\mathrm{OMS})^{435}$. Il existe des groupes ou des particuliers qui ont besoin d'eau en quantité plus importante pour des raisons liées à la santé, au climat ou au travail.

b) Qualité. L'eau nécessaire pour chaque usage personnel et domestique doit être salubre et donc exempte de microbes, de substances chimiques et de risques radiologiques qui constituent une menace pour la santé ${ }^{436}$. En outre, l'eau doit avoir une couleur, une odeur et un goût acceptables pour chaque usage personnel ou domestique.

c) Accessibilité. L'eau, les installations et les services doivent être accessibles, sans discrimination, à toute personne relevant de la juridiction de l'État partie. L'accessibilité comporte quatre dimensions qui se recoupent :

i) Accessibilité physique: l'eau ainsi que les installations et services adéquats doivent être physiquement accessibles sans danger pour toutes les couches de la population. Chacun doit avoir accès à une eau salubre, de qualité acceptable et en quantité suffisante au foyer, dans les établissements d'enseignement et sur le lieu de travail, ou à proximité immédiate ${ }^{437}$. Tous les équipements et services doivent être de qualité suffisante, culturellement adaptés et respectueux de la parité entre les sexes, du cycle de vie et de la vie privée. La sécurité physique des personnes qui ont accès à ces installations et services ne doit pas être menacée ;

ii) Accessibilité économique : l'eau, les installations et les services doivent être d'un coût abordable pour tous. Les coûts directs et indirects qu'implique l'approvisionnement en eau doivent être raisonnables, et ils ne doivent pas compromettre ou menacer la réalisation des autres droits consacrés dans le Pacte ; iii) Non-discrimination: l'eau, les installations et les services doivent être accessibles à tous, en particulier aux couches de la population les plus vulnérables ou marginalisées, en droit et en fait, sans discrimination fondée sur l'un quelconque des motifs proscrits ;

\footnotetext{
${ }^{434}$ Dans ce contexte, par "consommation ", on entend la consommation d'eau contenue dans les boissons et dans les denrées alimentaires. Par « assainissement individuel », on entend l'évacuation des excreta humains, l'eau étant nécessaire dans certains systèmes. Par « préparation des aliments ", on entend l'hygiène alimentaire et la préparation des denrées alimentaires, que l'eau soit incorporée dans les aliments ou entre en contact avec ceux-ci. Par «hygiène personnelle et domestique », on entend la propreté corporelle et l'hygiène du foyer.

${ }^{435}$ Voir J. Bartram et G. Howard, « Domestic water quantity, service level and health : what should be the goal for water and health sectors ", OMS, 2002. Voir aussi P.H. Gleik, (1996) « Basic water requirements for human activities : meeting basic needs ", Water International, 21, p. 83 à 92.

${ }^{436}$ Le Comité renvoie les États parties au document de l'OMS intitulé Directives de qualité pour l'eau de boisson, $2^{\mathrm{e}}$ éd., vol. 1 à 3 (OMS, Genève, 1993), directives «destinées à servir de principes de base pour l'élaboration de normes nationales qui, si elles sont correctement appliquées, assureront la salubrité de l'eau de boisson grâce à l'élimination des constituants connus pour leur nocivité ou à la réduction de leur concentration jusqu'à une valeur minime».

437 Voir l'Observation générale $\mathrm{n}^{\circ} 4$ (1991), par. 8 b), l'Observation générale $\mathrm{n}^{\circ} 13$ (1999), par. 6 a), et l'Observation générale $\mathrm{n}^{\circ} 14$ (2000), par. 8 a) et b). On entend par foyer un logement permanent ou semi-permanent, ou une halte temporaire.
} 
iv) Accessibilité de l'information : l'accessibilité correspond au droit de rechercher, de recevoir et de répandre des informations concernant les questions relatives à l'eau ${ }^{438}$.

\section{Thèmes spéciaux de portée générale}

\section{Non-discrimination et égalité}

13. L'obligation qui incombe aux États parties de garantir que le droit à l'eau est exercé sans discrimination (art. 2, par. 2) et dans des conditions d'égalité entre les hommes et les femmes (art. 3) est contenue dans toutes les obligations découlant du Pacte. Celui-ci interdit toute discrimination fondée sur la race, la couleur, le sexe, l'âge, la langue, la religion, l'opinion politique ou toute autre opinion, l'origine nationale ou sociale, la fortune, la naissance, un handicap physique ou mental, l'état de santé (y compris l'infection par le VIH/sida), l'orientation sexuelle et la situation civile, politique, sociale ou autre, dont l'intention ou l'effet est d'infirmer le droit à l'eau ou d'en entraver l'exercice sur un pied d'égalité. Le Comité rappelle le paragraphe 12 de l'Observation générale $n^{\circ} 3$ (1990) disposant que même en temps de grave pénurie de ressources, les éléments vulnérables de la société doivent être protégés grâce à la mise en œuvre de programmes spécifiques relativement peu coûteux.

14. Les États parties devraient agir pour éliminer toute discrimination de fait fondée sur des motifs interdits, qui prive des particuliers et des groupes des moyens ou des droits nécessaires pour exercer leur droit à l'eau. Ils devraient veiller à ce que l'allocation des ressources en eau et les investissements correspondants facilitent l'accès à l'eau de tous les membres de la société. Une mauvaise affectation des ressources peut aboutir à une discrimination qui n'est pas toujours manifeste. Par exemple, les investissements ne devraient pas privilégier de manière disproportionnée des services et équipements d'approvisionnement coûteux, qui souvent ne sont accessibles qu'à une frange fortunée de la population, plutôt que des services et des installations susceptibles de bénéficier à une proportion bien plus forte de la population.

15. S'agissant du droit à l'eau, les États parties ont en particulier l'obligation de fournir l'eau et les installations nécessaires à ceux qui ne disposent pas de moyens suffisants, et de prévenir toute discrimination fondée sur des motifs interdits par les instruments internationaux concernant la fourniture d'eau et des services correspondants.

16. Même si chacun a droit à l'eau, les États parties devraient prêter une attention spéciale aux particuliers et aux groupes qui ont traditionnellement des difficultés à exercer ce droit, notamment les femmes, les enfants, les groupes minoritaires, les peuples autochtones, les réfugiés, les demandeurs d'asile, les personnes déplacées dans leur propre pays, les travailleurs migrants ainsi que les prisonniers et les détenus. En particulier, les États parties devraient prendre des mesures pour garantir ce qui suit :

a) Les femmes ne doivent pas être exclues des processus de prise de décisions concernant les ressources en eau et les droits correspondants. Il faut alléger la charge excessive que représente pour elles l'obligation d'aller chercher de l'eau ;

b) Les enfants ne doivent pas être privés de l'exercice de leurs droits fondamentaux à cause du manque d'eau potable en quantité suffisante à l'école et dans la famille ou

${ }^{438}$ Voir le paragraphe 48 de la présente Observation générale. 
de l'obligation d'aller chercher de l'eau. L'approvisionnement en eau adéquat des écoles qui ne disposent pas actuellement d'une eau potable en quantité suffisante devrait être assuré en priorité ;

c) Les zones rurales et les zones urbaines déshéritées doivent disposer d'un système d'approvisionnement en eau convenablement entretenu. L'accès aux sources d'eau traditionnelles devrait être protégé des utilisations illégales et de la pollution. Les zones urbaines déshéritées, y compris les établissements humains non structurés, et les personnes sans abri devraient disposer d'un système d'approvisionnement en eau convenablement entretenu. Le droit à l'eau ne doit être dénié à aucun ménage en raison de sa situation en matière de logement ou du point de vue foncier;

d) L'accès des peuples autochtones aux ressources en eau sur leurs terres ancestrales doit être protégé de la pollution et des utilisations illégales. Les États devraient fournir aux peuples autochtones des ressources leur permettant de concevoir, d'assurer et de contrôler leur accès à l'eau ;

e) Les communautés nomades et les gens du voyage doivent disposer d'un approvisionnement en eau adéquat dans leurs sites traditionnels ou à des haltes désignées ;

f) Les réfugiés, les demandeurs d'asile, les personnes déplacées dans leur propre pays et celles qui retournent dans leur foyer doivent disposer d'un approvisionnement en eau adéquat, indépendamment du fait qu'ils vivent dans des camps ou dans des zones urbaines. Les réfugiés et les demandeurs d'asile doivent avoir accès à l'eau au même titre et dans les mêmes conditions que les nationaux;

g) Les prisonniers et les détenus doivent avoir accès à une eau salubre en quantité suffisante pour leurs besoins personnels quotidiens, compte tenu des dispositions $\mathrm{du}$ droit international humanitaire et de l'Ensemble de règles minima des Nations Unies pour le traitement des détenus ${ }^{439}$;

h) Les groupes qui ont des difficultés à accéder physiquement à l'eau telles que les personnes âgées, les personnes handicapées, les victimes de catastrophes naturelles et les personnes qui vivent dans des zones sujettes à des catastrophes naturelles, dans des zones arides et semi-arides ou sur de petites îles doivent disposer d'un approvisionnement en eau salubre en quantité suffisante.

\section{OBLIGATIONS DES ÉTATS PARTIES}

\section{Obligations juridiques générales}

17. Certes, le Pacte prévoit la réalisation progressive des droits qui y sont énoncés et prend en considération les contraintes dues à la limitation des ressources disponibles, mais il n'en impose pas moins aux États parties diverses obligations avec effet immédiat. Les États parties ont des obligations immédiates au regard du droit à l'eau : par exemple, celle de garantir son exercice sans discrimination (art. 2, par. 2) et celle d'agir (art. 2, par. 1 ) en vue d'assurer l'application pleine et entière des articles 11, paragraphe 1, et 12. Les

\footnotetext{
439 Voir les articles 20, 26, 2946 de la troisième Convention de Genève du 12 août 1949; les articles 85, 89 et 127 de la quatrième Convention de Genève du 12 août 1949; et les articles 15 et 20, par. 2, de l'Ensemble de règles minima des Nations Unies pour le traitement des détenus, dans Droits de l'homme: Recueil d'instruments internationaux (publication des Nations Unies, numéro de vente : F.88.XIV.1).
} 
mesures à prendre à cet effet doivent avoir un caractère délibéré et concret et viser au plein exercice du droit à l'eau.

18. Les États parties ont l'obligation constante et permanente d'avancer aussi rapidement et aussi efficacement que possible vers le plein exercice du droit à l'eau. L'exercice de ce droit, comme de tous les autres droits énoncés dans le Pacte, doit être possible et réalisable, puisque tous les États parties contrôlent un large éventail de ressources, y compris l'eau, la technologie, les ressources financières et l'aide internationale.

19. Tout laisse supposer que le Pacte interdit toute mesure rétrograde s'agissant du droit à l'eau ${ }^{440}$. S'il prend une mesure délibérément rétrograde, l'État partie doit apporter la preuve qu'il l'a fait après avoir mûrement pesé toutes les autres solutions possibles et que cette mesure est pleinement justifiée eu égard à l'ensemble des droits visés dans le Pacte, et ce en utilisant au maximum les ressources disponibles.

Obligations juridiques spécifiques

20. Le droit à l'eau, comme tout droit fondamental, impose trois types d'obligations aux États parties : les obligations de respecter, de protéger et de mettre en œuvre.

\section{a) Obligations de respecter}

21. L'obligation de respecter requiert des États parties qu'ils s'abstiennent d'entraver directement ou indirectement l'exercice du droit à l'eau. L'État partie est notamment tenu de s'abstenir d'exercer une quelconque pratique ou activité qui consiste à refuser ou à restreindre l'accès en toute égalité à un approvisionnement en eau adéquat; de s'immiscer arbitrairement dans les arrangements coutumiers ou traditionnels de partage de l'eau; de limiter la quantité d'eau ou de polluer l'eau de façon illicite, du fait par exemple des déchets émis par des installations appartenant à des entreprises publiques ou de l'emploi et de l'essai d'armes; et de restreindre l'accès aux services et infrastructures ou de les détruire, à titre punitif, par exemple en temps de conflit armé en violation du droit international humanitaire.

22. Le Comité note que pendant les conflits armés, les situations d'urgence et les catastrophes naturelles, le droit à l'eau englobe les obligations qui incombent aux États parties en vertu du droit international humanitaire ${ }^{441}$, notamment concernant la protection des biens indispensables à la survie de la population civile tels que les installations et réserves d'eau potable et les ouvrages d'irrigation, la protection du milieu naturel contre des dommages étendus, durables et graves, et la garantie que les civils, détenus et prisonniers disposent d'un approvisionnement en eau adéquat ${ }^{442}$.

\footnotetext{
${ }^{440}$ Voir l'Observation générale $\mathrm{n}^{\circ} 3$ (1990), par. 9.

${ }^{441}$ Concernant le lien entre le droit des droits de l'homme et le droit humanitaire, le Comité prend note des conclusions de la Cour internationale de Justice dans Licéité de la menace de l'emploi d'armes nucléaires (avis consultatif demandé par l'Assemblée générale), Rapports de la CIJ (1996), p. 226, par. 25.

${ }^{442}$ Voir les articles 54 et $55 \mathrm{du}$ Protocole additionnel I aux Conventions de Genève (1977), l'article 14 du Protocole additionnel II (1977), les articles 20 et 46 de la troisième Convention de Genève du 12 août 1949 et l'article 3 commun aux Conventions de Genève du 12 août 1949.
} 


\section{b) Obligations de protéger}

23. L'obligation de protéger requiert des États parties qu'ils empêchent des tiers d'entraver de quelque manière que ce soit l'exercice du droit à l'eau. Il peut s'agir de particuliers, d'entreprises ou d'autres entités, ainsi que d'agents agissant sous leur autorité. Les États parties sont notamment tenus de prendre les mesures législatives et autres nécessaires et effectives pour empêcher, par exemple, des tiers de refuser l'accès en toute égalité à un approvisionnement en eau adéquat, et de polluer ou de capter de manière injuste les ressources en eau, y compris les sources naturelles, les puits et les systèmes de distribution d'eau.

24. Les États parties doivent veiller à ce que les tiers qui gèrent ou contrôlent les services (réseaux d'adduction d'eau, navires-citernes, accès à des cours d'eau et à des puits, etc.) ne compromettent pas l'accès physique, à un coût abordable et sans discrimination, à une eau salubre et de qualité acceptable, en quantité suffisante. Pour prévenir ce type de violation, il faut mettre en place un système réglementaire efficace qui soit conforme au Pacte et à la présente Observation générale et qui assure un contrôle indépendant, une participation véritable de la population et l'imposition de sanctions en cas d'infraction.

\section{c) Obligations de mettre en ouvre}

25. L'obligation de mettre en ouvre se décompose en obligations de faciliter, de promouvoir et d'assurer. L'obligation de faciliter requiert de l'État qu'il prenne des mesures positives pour aider les particuliers et les communautés à exercer le droit à l'eau. L'obligation de promouvoir requiert de l'État partie qu'il mène des actions pour assurer la diffusion d'informations appropriées sur l'utilisation hygiénique de l'eau, la protection des sources d'eau et les méthodes propres à réduire le gaspillage. Les États parties sont également tenus de mettre en œuvre (assurer la réalisation de) ce droit lorsque des particuliers ou des groupes sont incapables, pour des raisons échappant à leur contrôle, de l'exercer eux-mêmes avec leurs propres moyens.

26. L'obligation de mettre en œuvre requiert des États parties qu'ils adoptent les mesures nécessaires au plein exercice du droit à l'eau. Les États parties sont notamment tenus de faire une place suffisante à ce droit dans le système politique et juridique national, de préférence par l'adoption de mesures législatives; de se doter d'une stratégie et d'un plan d'action pour l'eau au niveau national afin de donner effet à ce droit; de veiller à ce que l'eau soit accessible à chacun à un coût abordable ; et de faciliter un accès amélioré et durable à l'eau, en particulier dans les zones rurales et les zones urbaines déshéritées.

27. Pour s'assurer que le coût de l'eau est abordable, les États parties doivent adopter les mesures nécessaires, notamment : a) avoir recours à diverses techniques et technologies appropriées d'un coût raisonnable; b) pratiquer des politiques de prix appropriées prévoyant par exemple un approvisionnement en eau gratuit ou à moindre coût; et c) verser des compléments de revenu. Le prix des services doit être établi sur la base du principe de l'équité, pour faire en sorte que ces services, qu'ils soient fournis par des opérateurs publics ou privés, soient abordables pour tous, y compris pour les groupes socialement défavorisés. L'équité exige que l'eau ne représente pas une part excessive des dépenses des ménages les plus pauvres par rapport aux ménages plus aisés. 
28. Les États parties devraient adopter des stratégies et programmes complets et intégrés en vue d'assurer aux générations actuelles et futures un approvisionnement suffisant en eau salubre ${ }^{433}$. Ces stratégies et programmes peuvent notamment avoir pour objectifs de : a) lutter contre l'appauvrissement des ressources en eau dû à des captages, à des détournements et à l'établissement de barrages sans souci de durabilité ; b) réduire et éliminer la contamination des bassins hydrographiques et des écosystèmes aquatiques par des substances telles que des éléments radioactifs, des produits chimiques nocifs et des excréta humains; c) surveiller les réserves d'eau; d) veiller à ce que les aménagements envisagés n'entravent pas un approvisionnement en eau adéquat; e) évaluer l'impact des actions qui sont susceptibles d'affecter la disponibilité de l'eau et les bassins hydrographiques des écosystèmes naturels, tels que les changements climatiques, la désertification et la salinité accrue du sol, la déforestation et la perte de biodiversité ${ }^{44}$; f) développer l'utilisation rationnelle de l'eau par les consommateurs finals; g) réduire le gaspillage durant la distribution de l'eau; h) prévoir des mécanismes pour faire face aux situations d'urgence; et i) mettre en place des institutions compétentes et des mécanismes institutionnels appropriés pour exécuter ces stratégies et programmes.

29. Garantir l'accès à un assainissement adéquat est non seulement fondamental pour le respect de la dignité humaine et de la vie privée, mais constitue aussi un des principaux moyens de protéger la qualité de l'approvisionnement et des ressources en eau potable ${ }^{445}$. Conformément aux droits à la santé et à un logement suffisant (voir les Observations générales $\mathrm{n}^{\text {os }} 4$ (1991) et 14 (2000)), les États parties ont l'obligation de fournir progressivement des services d'assainissement sûrs, en particulier dans les zones rurales et les zones urbaines déshéritées, en tenant compte des besoins des femmes et des enfants.

\section{Obligations internationales}

30. Conformément à l'article 2, paragraphe 1, à l'article 11, paragraphe 1, et à l'article 23 du Pacte, les États parties reconnaissent le rôle essentiel de l'assistance et de la coopération internationales et s'engagent à agir, individuellement et collectivement, en vue d'assurer le plein exercice du droit à l'eau.

31. Pour s'acquitter de leurs obligations internationales, les États parties doivent respecter l'exercice du droit à l'eau dans les autres pays. La coopération internationale requiert des États parties qu'ils s'abstiennent de mener des actions qui entravent, directement ou indirectement, l'exercice du droit à l'eau dans d'autres pays. Les activités

\footnotetext{
${ }^{443}$ Voir la note de bas de page 5 ci-dessus, Action 21, chap. 5, 7 et 18; Sommet mondial pour le développement durable, Plan d'application (2002), par. 6 a), l) et m), 7, 36 et 38 .

${ }^{444}$ Voir la Convention sur la diversité biologique, la Convention sur la lutte contre la désertification, la Convention-cadre sur les changements climatiques et les protocoles ultérieurs.

${ }^{445}$ Voir l'article 14, par. 2, de la Convention sur l'élimination de toutes les formes de discrimination à l'égard des femmes, qui dispose que les États parties assurent aux femmes le droit de «bénéficier de conditions de vie convenables, notamment en ce qui concerne [...] l'assainissement ". L'article 24, par. 2, de la Convention relative aux droits de l'enfant dispose que les États parties doivent « faire en sorte que tous les groupes de la société $[\ldots]$ reçoivent une information sur [...] les avantages de [...] l'hygiène et la salubrité de l'environnement ».
} 
exercées dans la juridiction de l'État partie ne devraient pas empêcher un autre pays d'assurer l'exercice de ce droit aux personnes relevant de sa juridiction ${ }^{446}$.

32. Les États parties devraient s'abstenir dans tous les cas d'imposer, directement ou indirectement, à un autre pays des embargos et autres mesures similaires empêchant l'approvisionnement en eau et la fourniture de marchandises et de services qui sont essentiels pour assurer le droit à l'eau ${ }^{447}$. L'eau ne devrait jamais être utilisée comme instrument de pression politique ou économique. À ce propos, le Comité rappelle sa position, décrite dans l'Observation générale $\mathrm{n}^{\circ} 8$ (1997), sur la relation entre les sanctions économiques et le respect des droits économiques, sociaux et culturels.

33. Les États parties devraient prendre des mesures pour empêcher leurs propres ressortissants ou des compagnies qui relèvent de leur juridiction, de violer le droit à l'eau de particuliers et de communautés dans d'autres pays. Les États parties doivent agir de manière compatible avec la Charte des Nations Unies et le droit international applicable lorsqu'ils sont à même d'inciter des tiers à respecter ce droit en usant de moyens juridiques ou politiques.

34. En fonction des ressources dont ils disposent, les États devraient faciliter l'exercice du droit à l'eau dans les autres pays, par exemple en fournissant des ressources en eau et une aide financière et technique, et apporter l'assistance nécessaire. En ce qui concerne l'aide en cas de catastrophe et les secours d'urgence, la priorité devrait être donnée aux droits consacrés dans le Pacte, notamment à un approvisionnement en eau adéquat. L'aide internationale devrait être fournie d'une manière qui soit non seulement compatible avec le Pacte et les autres instruments relatifs aux droits de l'homme, mais aussi viable et acceptable du point de vue culturel. Il est, en particulier, de la responsabilité et de l'intérêt des États parties économiquement développés d'aider à cet égard les États en développement plus démunis.

35. Les États parties devraient veiller à ce que le droit à l'eau reçoive l'attention voulue dans les accords internationaux et, à cette fin, devraient envisager d'élaborer de nouveaux instruments juridiques. En ce qui concerne la conclusion et la mise en œuvre d'autres accords internationaux et régionaux, les États parties devraient s'assurer que ces instruments n'ont pas d'incidence néfaste sur le droit à l'eau. Les accords de libéralisation du commerce ne devraient pas entraver ou amoindrir la capacité d'un pays d'assurer le plein exercice de ce droit.

36. Les États parties sont tenus de veiller à ce que les mesures qu'ils prennent en tant que membres d'organisations internationales tiennent dûment compte du droit à l'eau. En conséquence, les États parties qui sont membres d'institutions financières internationales, notamment le Fonds monétaire international, la Banque mondiale et les banques régionales de développement, devraient porter une plus grande attention à la

\footnotetext{
${ }^{446}$ Le Comité note qu’aux termes de la Convention des Nations Unies sur le droit relatif aux utilisations des cours d'eau internationaux à des fins autres que la navigation, les besoins sociaux et humains doivent être pris en considération lorsqu'il s'agit de déterminer l'utilisation équitable des cours d'eau, les États parties doivent prendre des mesures pour ne pas causer de dommages significatifs et, en cas de conflit, une attention spéciale doit être accordée à la satisfaction des besoins humains essentiels : voir les articles 5, 7 et 10 .

${ }^{447}$ Le Comité rappelle l'Observation générale $\mathrm{n}^{\circ} 8$, dans laquelle il a fait valoir que les sanctions perturbaient la distribution d'articles d'hygiène et compromettaient l'approvisionnement en eau potable, et que dans le cadre d'un régime de sanctions, il convenait de prévoir la réparation des infrastructures indispensables pour fournir de l'eau propre.
} 
protection du droit à l'eau dans les politiques de prêt, les accords de crédit et les autres initiatives internationales de ces institutions.

\section{Obligations fondamentales}

37. Dans l'Observation générale $\mathrm{n}^{0} 3$, le Comité confirme que les États parties ont l'obligation fondamentale minimum d'assurer, au moins, la satisfaction de l'essentiel de chacun des droits énoncés dans le Pacte. De l'avis du Comité, les obligations fondamentales se rapportant au droit à l'eau et ayant un effet immédiat sont au minimum :

a) D'assurer l'accès à la quantité d'eau essentielle, suffisante et salubre pour les usages personnels et domestiques, afin de prévenir les maladies ;

b) De garantir le droit d'accès à l'eau, aux installations et aux services sans discrimination, notamment pour les groupes vulnérables ou marginalisés ;

c) D'assurer l'accès physique à des installations et services qui fournissent régulièrement une eau salubre en quantité suffisante; qui comportent un nombre suffisant de points d'eau pour éviter des attentes excessives; et qui soient à distance raisonnable du foyer ;

d) De veiller à ce que la sécurité des personnes qui ont physiquement accès à l'eau ne soit pas menacée ;

e) D’assurer une répartition équitable de tous les équipements et services disponibles ;

f) D'adopter et de mettre en œuvre, au niveau national, une stratégie et un plan d'action visant l'ensemble de la population; cette stratégie et ce plan d'action devraient être élaborés et périodiquement examinés dans le cadre d'un processus participatif et transparent; ils devraient prévoir des méthodes, telles que des indicateurs et des critères sur le droit à l'eau, permettant de surveiller de près les progrès accomplis; une attention particulière devrait être accordée à tous les groupes vulnérables ou marginalisés lors de l'élaboration de la stratégie et du plan d'action, de même que dans leur contenu ;

g) De contrôler dans quelle mesure le droit à l'eau est réalisé ou ne l'est pas ;

h) D'adopter des programmes d'approvisionnement en eau relativement peu coûteux visant à protéger les groupes vulnérables et marginalisés ;

i) De prendre des mesures pour prévenir, traiter et combattre les maladies d'origine hydrique, en particulier en assurant l'accès à un assainissement adéquat.

38. Pour qu'il n'y ait aucun doute à ce sujet, le Comité tient à souligner qu'il incombe tout particulièrement aux États parties et aux autres intervenants en mesure d'apporter leur concours de fournir l'assistance et la coopération internationales - notamment sur les plans économique et technique - nécessaires pour permettre aux pays en développement d'honorer les obligations fondamentales mentionnées au paragraphe 37 ci-dessus.

\section{MANQUEMENTS AUX OBLIGATIONS}

39. Quand le contenu normatif du droit à l'eau (voir sect. II) est appliqué aux obligations des États parties (sect. III), le processus dynamique qui s'engage permet de mettre plus facilement en évidence les atteintes au droit à l'eau. On trouvera ci-après des exemples d'infractions. 
40. Pour démontrer qu'ils s'acquittent de leurs obligations générales et spécifiques, les États parties doivent établir qu'ils ont pris les mesures nécessaires et réalisables en vue d'assurer l'exercice du droit à l'eau. Conformément au droit international, le défaut d'exécution de bonne foi équivaut à une violation du droit. Il convient toutefois de souligner qu'un État partie ne peut justifier l'inexécution des obligations fondamentales énoncées au paragraphe 37 ci-dessus, auxquelles il est impossible de déroger.

41. Pour déterminer quelles actions ou omissions constituent une atteinte au droit à l'eau, il importe d'établir une distinction entre l'incapacité et le manque de volonté de l'État partie de s'acquitter de ses obligations. Ce constat découle des articles 11, paragraphe 1, et 12 du Pacte, qui parlent du droit à un niveau de vie suffisant et du droit à la santé, ainsi que de l'article 2, paragraphe 1 , du Pacte, lequel fait obligation à chaque État partie de prendre les mesures nécessaires au maximum de ses ressources disponibles. Un État dépourvu de la volonté d'utiliser au maximum les ressources à sa disposition pour donner effet au droit à l'eau manque par conséquent aux obligations lui incombant en vertu du Pacte. Si c'est la pénurie de ressources qui met un État dans l'impossibilité de se conformer aux obligations découlant du Pacte, l'État a alors la charge de démontrer qu'il n'a négligé aucun effort pour exploiter toutes les ressources à sa disposition en vue de s'acquitter à titre prioritaire des obligations indiquées cidessus.

42. Les atteintes au droit à l'eau peuvent être le fait d'une action directe - commission d'actes - soit de l'État soit de diverses entités insuffisamment contrôlées par l'État. Il peut s'agir de l'adoption de mesures rétrogrades incompatibles avec les obligations fondamentales (indiquées au paragraphe 37 ci-dessus), de l'abrogation ou de la suspension officielles de la législation qui est nécessaire pour continuer d'exercer le droit à l'eau, ou de l'adoption de lois ou de politiques manifestement incompatibles avec des obligations juridiques préexistantes de caractère interne ou international ayant trait au droit à l'eau.

43. Parmi les atteintes par omission figurent le fait pour un État de ne pas prendre les mesures voulues pour assurer le plein exercice du droit de chacun à l'eau, le fait de ne pas adopter de politique nationale sur l'eau, et le fait de ne pas assurer l'application des lois pertinentes.

44. Bien qu'il ne soit pas possible d'arrêter d'avance la liste complète des violations, les travaux du Comité permettent de dégager certains exemples typiques concernant les différents niveaux d'obligations :

a) Les manquements à l'obligation de respecter découlent des entraves de l'État partie au droit à l'eau. Il s'agit notamment : i) de l'interruption ou du refus arbitraires ou injustifiés d'accès aux services ou installations; ii) des hausses disproportionnées ou discriminatoires du prix de l'eau; iii) de la pollution et de l'appauvrissement des ressources en eau qui affectent la santé des personnes ;

b) Les manquements à l'obligation de protéger découlent du fait que l'État n'a pas pris toutes les mesures voulues pour protéger les personnes relevant de sa juridiction contre des atteintes au droit à l'eau imputables à des tiers ${ }^{48}$. Il s'agit notamment des manquements aux obligations : i) de promulguer ou d'appliquer des lois visant à

${ }^{448}$ Voir le paragraphe 23 pour une définition des « tiers ». 
prévenir la contamination et le captage injuste de l'eau ; ii) de réguler et de contrôler efficacement les fournisseurs de services; iii) de protéger les systèmes de distribution d'eau (réseaux d'adduction, puits, etc.) des entraves, dommages et déprédations ;

c) Les manquements à l'obligation de mettre en œuvre découlent du fait que l'État partie n'a pas pris toutes les mesures voulues pour garantir l'exercice du droit à l'eau. Il s'agit notamment : i) du manquement à l'obligation d'adopter ou de mettre en œuvre une politique nationale visant à garantir à chacun l'exercice de ce droit ; ii) de l'engagement de dépenses insuffisantes ou d'une mauvaise affectation des fonds publics empêchant des particuliers ou des groupes, notamment les groupes vulnérables ou marginalisés, d'exercer leur droit à l'eau; iii) du manquement à l'obligation de contrôler l'exercice de ce droit à l'échelle nationale, par exemple en définissant des indicateurs et des critères; iv) du manquement à l'obligation de prendre les mesures voulues pour remédier à la répartition injuste des équipements et des services; v) du manquement à l'obligation d'adopter des mécanismes d'aide d'urgence; vi) du manquement à l'obligation d'assurer à chacun l'exercice de l'essentiel de ce droit ; vii) du manquement à l'obligation de l'État de tenir compte de ses obligations juridiques internationales concernant le droit à l'eau lors de la conclusion d'accords avec d'autres États ou avec des organisations internationales.

\section{MISE EN GEUVRE À L'ÉCHELON NATIONAL}

45. L'article 2, paragraphe 1, du Pacte impose aux États parties l'obligation d'utiliser "tous les moyens appropriés, y compris en particulier l'adoption de mesures législatives» en vue de s'acquitter de leurs obligations en vertu du Pacte. Chaque État jouit d'une marge d'appréciation discrétionnaire quand il décide quelles mesures sont effectivement les mieux adaptées à sa situation particulière. Mais le Pacte impose clairement à chaque État de prendre toutes les dispositions nécessaires pour assurer à chacun l'exercice du droit à l'eau dès que possible. Les mesures mises en œuvre à l'échelon national pour réaliser le droit à l'eau ne devraient pas entraver l'exercice des autres droits fondamentaux.

\section{Législation, stratégies et politiques}

46. La législation, les stratégies et les politiques existantes devraient être réexaminées pour s'assurer qu'elles sont compatibles avec les obligations découlant du droit à l'eau, en vue de les abroger, amender ou modifier en cas d'incompatibilité avec les prescriptions du Pacte.

47. L'obligation de prendre les mesures voulues impose aux États parties d'adopter une stratégie ou un plan d'action au niveau national en vue d'assurer l'exercice du droit à l'eau. Il faut que cette stratégie : a) soit fondée sur le droit et les principes des droits de l'homme ; b) couvre tous les éléments du droit à l'eau et les obligations correspondantes des États parties; c) définisse des objectifs clairs; d) fixe les buts ou les résultats à atteindre et le calendrier correspondant; e) formule des politiques adéquates ainsi que les critères et indicateurs correspondants. Cette stratégie devrait aussi établir la responsabilité institutionnelle du processus; indiquer les ressources disponibles pour atteindre les objectifs, buts et résultats; allouer comme il convient les ressources en fonction de la responsabilité institutionnelle; et créer des mécanismes de responsabilité 
pour s'assurer de la mise en œuvre de la stratégie. Lorsqu'ils élaborent et appliquent leur stratégie, les États parties devraient mettre à profit l'assistance technique et la coopération des institutions spécialisées des Nations Unies (voir la section VI ci-après).

48. L'élaboration et la mise en œuvre d'une stratégie et d'un plan d'action à l'échelle nationale devraient notamment respecter les principes de non-discrimination et de participation de la population. Le droit des particuliers et des groupes de participer au processus de prise de décisions qui peuvent influer sur l'exercice de leur droit à l'eau doit faire partie intégrante de toute politique, de tout programme ou de toute stratégie concernant l'eau. Les particuliers et les groupes devraient avoir pleinement accès, en toute égalité, aux informations dont les autorités publiques ou les tiers disposent concernant l'eau, les services d'approvisionnement en eau et l'environnement.

49. La stratégie et le plan d'action nationaux sur l'eau devraient en outre reposer sur les principes de responsabilité, de transparence et d'indépendance de la magistrature, une bonne gouvernance étant indispensable à la mise en œuvre effective de l'ensemble des droits de l'homme, dont le droit à l'eau. Pour instaurer des conditions favorables à l'exercice de ce droit, les États parties devraient adopter des mesures appropriées afin que le secteur des entreprises privées tout comme la société civile prennent conscience et tiennent compte de l'importance à accorder au droit à l'eau dans l'exercice de leurs activités.

50. Les États parties peuvent avoir intérêt à adopter une législation-cadre pour donner effet à leur stratégie concernant le droit à l'eau. Cette législation devrait prévoir : a) les buts ou résultats à atteindre et le calendrier correspondant; b) les moyens de parvenir à l'objectif fixé ; c) la collaboration envisagée avec la société civile, le secteur privé et les organisations internationales; d) la responsabilité institutionnelle du processus; e) les mécanismes nationaux de contrôle; f) les procédures de recours.

51. Des mesures devraient être prises pour garantir une coordination suffisante entre les ministères nationaux, les autorités régionales et les autorités locales afin que les politiques relatives à l'eau soient cohérentes. Lorsque la mise en œuvre du droit à l'eau a été déléguée à des autorités régionales ou locales, l'État partie doit néanmoins s'acquitter des obligations qui lui incombent en vertu du Pacte et doit donc s'assurer que ces autorités disposent des ressources suffisantes pour entretenir et fournir les services et équipements nécessaires. Les États parties doivent aussi veiller à ce que les autorités en question ne refusent pas l'accès à ces services pour des motifs discriminatoires.

52. Les États parties sont tenus de contrôler effectivement l'exercice du droit à l'eau. Lorsqu'ils évaluent les progrès réalisés dans ce domaine, les États parties devraient cerner les facteurs et les difficultés qui les empêchent de s'acquitter de leurs obligations.

\section{Indicateurs et critères}

53. Pour faciliter ce contrôle, il faudrait prévoir des indicateurs et des critères dans les stratégies ou plans d'action nationaux sur l'eau. Ces indicateurs et critères devraient être conçus pour permettre de suivre à l'échelle nationale comme à l'échelle internationale comment l'État s'acquitte des obligations lui incombant au titre des articles 11, paragraphe 1, et 12 du Pacte. Ils devraient porter sur les différents éléments du droit à un approvisionnement en eau adéquat (quantité suffisante, salubrité, qualité acceptable, coût abordable et accessibilité physique), être ventilés en fonction des motifs de discrimination qui sont proscrits et couvrir toutes les personnes résidant sur le 
territoire de l'État partie ou placées sous son contrôle. Pour établir les indicateurs appropriés, les États parties pourraient s'inspirer des travaux actuels de l'OMS, de l'Organisation des Nations Unies pour l'alimentation et l'agriculture (FAO), du Centre des Nations Unies pour les établissements humains (Habitat), de l'Organisation internationale du Travail (OIT), du Fonds des Nations Unies pour l'enfance (UNICEF), du Programme des Nations Unies pour l'environnement (PNUE), du Programme des Nations Unies pour le développement (PNUD) et de la Commission des droits de l'homme de l'ONU.

54. Une fois qu'ils auront arrêté des indicateurs adaptés au droit à l'eau, les États parties sont invités à définir à l'échelle nationale des critères pour chaque indicateur ${ }^{449}$. Pendant l'examen du rapport périodique, le Comité procédera à une sorte d'étude de portée avec l'État partie. C'est-à-dire que le Comité et l'État partie examineront ensemble les indicateurs et les critères nationaux qui permettront de fixer les objectifs à atteindre au cours de la période couverte par le rapport suivant. Et pendant les cinq années qui suivront, l'État partie se servira de ces critères nationaux pour mieux contrôler l'exercice du droit à l'eau. Puis, lors de l'examen du rapport ultérieur, l'État partie et le Comité examineront si ces critères ont été ou non respectés et pour quelles raisons des difficultés ont peut-être surgi (voir l'Observation générale $n^{\circ} 14$, par. 58). En outre, quand ils définissent leurs critères et établissent leurs rapports, les États parties devraient exploiter le grand nombre d'informations et de services consultatifs fournis par les institutions spécialisées aux fins de la collecte et de la ventilation des données.

\section{Recours et responsabilité}

55. Tout particulier ou tout groupe dont le droit à l'eau a été enfreint doit avoir accès à des recours effectifs, judiciaires ou autres, à l'échelle nationale et internationale (voir l'Observation générale $\mathrm{n}^{\circ} 9$, par. 4, et le Principe 10 de la Déclaration de Rio sur l'environnement et le développement ${ }^{450}$ ). Le Comité note que le droit à l'eau a été consacré dans la constitution d'un certain nombre d'États et qu'il a fait l'objet de recours devant des tribunaux nationaux. Toutes les personnes dont le droit à l'eau a été enfreint sont fondées à recevoir une réparation adéquate, sous forme de restitution, indemnisation, satisfaction ou garantie de non répétition. Sur le plan national, ce sont les médiateurs, les commissions des droits de l'homme et autres mécanismes de cette nature qui peuvent être saisis en cas d'atteintes au droit à l'eau.

56. Avant que l'État partie, ou tout autre tiers, prenne une mesure qui entrave le droit d'un particulier à l'eau, les autorités compétentes doivent s'assurer qu'il agit d'une

\footnotetext{
${ }^{449}$ Voir E. Riedel, «New bearings to the State reporting procedure : practical ways to operationalize economic, social and cultural rights - The example of the right to health", in S. von Schorlemer (dir. publ.), Praxishandbuch UNO, 2002, p. 345 à 358. Le Comité note, par exemple, l'engagement pris dans le Plan d'application du Sommet mondial pour le développement durable (2002) de réduire, d'ici à 2015, la proportion de personnes qui n'ont pas les moyens matériels ou financiers d'accéder à une eau de boisson salubre (conformément à la Déclaration du Millénaire) et de personnes qui n'ont pas accès à un assainissement de base.

${ }^{450}$ Le Principe 10 de la Déclaration de Rio sur l'environnement et le développement de la Conférence des Nations Unies sur l'environnement et le développement de 1992 dispose qu'en ce qui concerne les questions d'environnement, « un accès effectif à des actions judiciaires et administratives, notamment des réparations et des recours, doit être assuré ».
} 
mesure conforme à la loi, compatible avec le Pacte et prévoyant : a) une possibilité de consultation véritable des intéressés; b) la communication en temps voulu d'informations complètes sur les mesures envisagées; c) une notification raisonnable des mesures envisagées; d) des voies de recours pour les intéressés; et e) une aide juridique pour pouvoir se prévaloir de recours en justice [voir aussi les Observations générales $n^{\circ} 4$ (1991) et $n^{\circ} 7$ (1997)]. En cas de non-paiement de la facture d'eau, la question de la capacité de paiement de l'intéressé doit être prise en compte. Nul ne doit en aucune circonstance être privé de la quantité d'eau essentielle.

57. L'incorporation à l'ordre juridique interne d'instruments internationaux consacrant le droit à l'eau peut élargir sensiblement le champ d'application des mesures de réparation et renforcer leur efficacité, et doit donc être encouragée dans tous les cas. Elle donne aux tribunaux la compétence voulue pour se prononcer sur les atteintes au droit à l'eau, ou tout au moins sur les obligations fondamentales qui en découlent, en invoquant directement le Pacte.

58. Les États parties devraient encourager les juges, magistrats et autres professionnels de la justice à s'intéresser davantage, dans l'exercice de leurs fonctions, aux atteintes au droit à l'eau.

59. Les États parties devraient respecter, protéger, faciliter et promouvoir l'action des défenseurs des droits de l'homme et des autres membres de la société civile afin d'aider les groupes vulnérables ou marginalisés à exercer leur droit à l'eau.

\section{OBLIGATIONS DES ACTEURS AUTRES QUE LES ÉTATS PARTIES}

60. Les organismes des Nations Unies et les autres organisations internationales qui s'occupent de l'eau, comme l'OMS, la FAO, l'UNICEF, le PNUE, ONU-Habitat, l'OIT, le PNUD et le Fonds international de développement agricole (FIDA), ou du commerce telles que l'Organisation mondiale du commerce (OMC), devraient coopérer efficacement avec les États parties, en mettant à profit leurs compétences respectives, pour faciliter la mise en œuvre du droit à l'eau à l'échelle nationale. Les institutions financières internationales, notamment le Fonds monétaire international (FMI) et la Banque mondiale, devraient prendre en compte le droit à l'eau dans le cadre de leurs politiques de prêt, de leurs accords de crédit, de leurs programmes d'ajustement structurel et de leurs autres projets de développement [voir l'Observation générale $\mathrm{n}^{\mathrm{o}} 2$ (1990)], afin de promouvoir l'exercice du droit à l'eau. Quand il examinera le rapport des États parties et vérifiera si ces pays sont en mesure de s'acquitter des obligations de mettre en œuvre le droit à l'eau, le Comité recensera les effets de l'assistance apportée par tous les autres acteurs. L'incorporation du droit et des principes des droits de l'homme dans les programmes et les politiques des organisations internationales facilitera beaucoup la réalisation du droit à l'eau. Le rôle de la Fédération internationale des sociétés de la Croix-Rouge et du Croissant-Rouge, du Comité international de la Croix-Rouge, du Haut-commissariat des Nations Unies pour les réfugiés (HCR), de l'OMS et de l'UNICEF, ainsi que des organisations non gouvernementales et d'autres associations, revêt une importance particulière quand il s'agit de fournir des secours en cas de catastrophe et d'apporter une assistance humanitaire dans les situations d'urgence. En matière d'aide, de distribution et de gestion de l'eau et des installations connexes, il convient d'accorder la priorité aux groupes les plus vulnérables ou marginalisés de la population. 


$\begin{array}{ll}\text { Assemblée générale } & \text { Distr. Générale } \\ 3 \text { août } 2010\end{array}$

Soixante-quatrième session

Point 48 de l'ordre du jour

\author{
Résolution adoptée par l'Assemblée générale \\ [sans renvoi à une grande commission (A/64/L.63/Rev.1 et Add.1)] \\ 64/292. Le droit fondamental à l'eau et à l'assainissement
}

\title{
L'Assemblée générale,
}

Rappelant ses résolutions 54/175 du 17 décembre 1999 sur le droit au développement, 55/196 du 20 décembre 2000, par laquelle elle a proclamé l'année 2003 Année internationale de l'eau douce, 58/217 du 23 décembre 2003, par laquelle elle a proclamé la période 2005-2015 Décennie internationale d'action, "L'eau, Source de vie ", 59/228 du 22 décembre 2004, 61/192 du 20 décembre 2006, par laquelle elle a proclamé 2008 Année internationale de l'assainissement, et 64/198 du 21 décembre 2009 relative à l'examen approfondi à mi-parcours de la mise en œuvre de la Décennie internationale d'action sur le thème "L'eau, source de vie »; Action 21 de juin 1992 ${ }^{451}$; le Programme pour l'habitat de $1996^{452}$; le Plan d'action de Mar del Plata de 1977, adopté par la Conférence des Nations Unies sur l'eau ${ }^{453}$; et la Déclaration de Rio sur l'environnement et le développement de juin $1992^{454}$,

Rappelant également la Déclaration universelle des droits de l'homme ${ }^{455}$, le Pacte international relatif aux droits économiques, sociaux et culturels, le Pacte international relatif aux droits civils et politiques ${ }^{456}$, la Convention internationale sur l'élimination de

\footnotetext{
${ }^{451}$ Rapport de la Conférence des Nations Unies sur l'environnement et le développement, Rio de Janeiro, 3-14 juin 1992, vol. I, Résolutions adoptées par la Conférence (publication des Nations Unies, numéro de vente: F.93.I.8 et rectificatif), résolution 1, annexe II.

${ }^{452}$ Rapport de la Conférence des Nations Unies sur les établissements humains (Habitat III), Istanbul, 3-14 juin 1996 (publication des Nations Unies, numéro de vente : F.97.IV.6), chap. I, résolution 1, annexe II.

${ }^{453}$ Rapport de la Conférence des Nations Unies sur l'eau, Mar del Plata, 14-25 mars 1977 (publication des Nations Unies, numéro de vente : F.77.II.A.12), chap. I.

${ }^{454}$ Rapport de la Conférence des Nations Unies sur l'environnement et le développement, Rio de Janeiro, 3-14 juin 1992, vol. I, Résolutions adoptées par la Conférence (publication des Nations Unies, numéro de vente: F.93.I.8 et rectificatif), résolution 1 , annexe I.

${ }^{455}$ Résolution 217 A (III).

${ }^{456}$ Voir résolution $2200 \mathrm{~A}(\mathrm{XXI})$, annexe.
} 
toutes les formes de discrimination raciale ${ }^{457}$, la Convention sur l'élimination de toutes les formes de discrimination à l'égard des femmes ${ }^{458}$, la Convention relative aux droits de l'enfant ${ }^{459}$, la Convention relative aux droits des personnes handicapées ${ }^{460}$ et la Convention de Genève relative à la protection des personnes civiles en temps de guerre, du 12 août $1949^{461}$,

Rappelant en outre toutes les résolutions du Conseil des droits de l'homme sur les droits de l'homme et l'accès à l'eau potable et à l'assainissement, notamment ses résolutions $7 / 22$ du 28 mars $2008^{462}$ et $12 / 8$ du $1^{\text {er }}$ octobre $2009^{463}$, relatives au droit à l'eau potable et à l'assainissement, l'observation générale $\mathrm{n}^{\mathrm{o}} 15$ (2002) du Comité des droits économiques, sociaux et culturels sur le droit à l'eau (articles 11 et 12 du Pacte international relatif aux droits économiques, sociaux et culturels) ${ }^{464}$ et le rapport de la Haut-commissaire des Nations Unies aux droits de l'homme sur la portée et la teneur des obligations pertinentes en rapport avec les droits de l'homme qui concernent l'accès équitable à l'eau potable et à l'assainissement, contractées au titre des instruments internationaux relatifs aux droits de l'homme ${ }^{465}$, ainsi que le rapport de l'experte indépendante chargée d'examiner la question des obligations en rapport avec les droits de l'homme qui concernent l'accès à l'eau potable et à l'assainissement ${ }^{466}$,

Notant avec une vive préoccupation qu'environ 884 millions de personnes n'ont pas accès à l'eau potable et que plus de 2,6 milliards de personnes n'ont pas accès à des services d'assainissement de base, et relevant avec inquiétude que près de 1,5 million d'enfants âgés de moins de 5 ans meurent et 443 millions de jours d'école sont perdus chaque année du fait de maladies d'origine hydrique ou liées à l'absence de services d'assainissement,

Constatant l'importance que revêt l'accès équitable à l'eau potable et l'assainissement, qui fait partie intégrante de la réalisation de tous les droits de l'homme,

Réaffirmant qu'il incombe aux États de promouvoir et de protéger tous les droits de l'homme, qui sont universels, indivisibles, interdépendants et intimement liés et doivent être traités globalement, de manière juste et équitable, sur un pied d'égalité et avec la même priorité,

Ayant à l'esprit l'engagement pris par la communauté internationale de réaliser tous les objectifs du Millénaire pour le développement et soulignant, à cet égard, la ferme volonté des chefs d'État et de gouvernement, telle qu'exprimée dans la Déclaration du

\footnotetext{
${ }^{457}$ Nations Unies, Recueil des Traités, vol. 660, n 9464.

${ }^{458}$ Ibid., vol. 1249, nº 20378.

${ }^{459}$ Ibid., vol. 1577, n 27531.

${ }^{460}$ Résolution 61/106, annexe I.

${ }^{461}$ Nations Unies, Recueil des Traités, vol. 75, no 973.

${ }^{462}$ Voir Documents officiels de l'Assemblée générale, soixante-troisième session, Supplément $n^{\circ} 53(\mathrm{~A} / 63 / 53)$, chap. II.

${ }^{463}$ Voir A/HRC/12/50, première partie, chap. I.

${ }^{464}$ Voir Documents officiels du Conseil économique et social, 2003, Supplément no 2 (E/2003/22), annexe IV.

${ }^{465} \mathrm{~A} / \mathrm{HRC} / 6 / 3$.

${ }^{466} \mathrm{~A} / \mathrm{HRC} / 12 / 24$.
} 
Millénaire ${ }^{467}$, de réduire de moitié, d'ici à 2015, la proportion des personnes qui n'ont pas accès à l'eau potable ou n'ont pas les moyens de s'en procurer et, comme convenu dans le Plan de mise en œuvre du Sommet mondial.

pour le développement durable («Plan de mise en œuvre de Johannesburg ») ${ }^{468}$, de celles qui n'ont pas accès à des services d'assainissement de base,

1. Reconnaît que le droit à l'eau potable et à l'assainissement est un droit fondamental, essentiel à la pleine jouissance de la vie et à l'exercice de tous les droits de l'homme ;

2. Demande aux États et aux organisations internationales d'apporter des ressources financières, de renforcer les capacités et de procéder à des transferts de technologies, grâce à l'aide et à la coopération internationales, en particulier en faveur des pays en développement, afin d'intensifier les efforts faits pour fournir une eau potable et des services d'assainissement qui soient accessibles et abordables pour tous ;

3. Salue la décision qu'a prise le Conseil des droits de l'homme de prier l'experte indépendante chargée d'examiner la question des obligations en rapport avec les droits de l'homme qui concernent l'accès à l'eau potable et à l'assainissement de présenter un rapport annuel à l'Assemblée ${ }^{13}$ et encourage celle-ci à continuer de s'acquitter de tous les aspects de son mandat et, agissant en consultation avec tous les organismes, fonds et programmes compétents des Nations Unies, à aborder dans le rapport qu'elle lui soumettra à sa soixante-sixième session les principaux problèmes liés à la réalisation du droit à l'eau potable et à l'assainissement et leurs incidences sur la réalisation des objectifs du Millénaire pour le développement.

${ }^{\mathrm{e}}$ séance plénière

juillet 2010

\footnotetext{
${ }^{467}$ Voir résolution 55/2.

$468{ }^{18}$ Voir Rapport du Sommet mondial pour le développement durable, Johannesburg (Afrique du Sud), 26 août- 4 septembre 2002 (publication des Nations Unies, numéro de vente : F.03.II.A.1), chap. I, résolution 2, annexe.
} 
QUELQUES SOURCES DU DROIT A L'EAU POTABLE AU PLAN INTERNE 
ASSEMBLEE NATIONALE

$6^{\text {ème }}$ Législature

Année législative 1997/1998

$3^{\text {ème }}$ Session Ordinaire

(Mars 1998)
REPUBLIQUE DU CAMEROUN

Paix - Travail - Patrie

LOI N ${ }^{\circ}$ 98-005 du 14 Avril 1998

PORTANT REGIME DE L'EAU

L'Assemblée Nationale a délibéré et adopté, en sa séance plénière du 31 mars 1998, le projet de loi $\mathrm{N}^{\circ} 634 / \mathrm{PJL} / \mathrm{AN}$ dont la teneur suit :

\section{TITRE I}

\section{DES DISPOSITIONS GENERALES}

ARTICLE ${ }^{\text {er }}$.- La présente loi fixe, dans le respect des principes de gestion de l'environnement et de protection de la santé publique, le cadre juridique général du régime de l'eau

ARTICLE 2.- (1) L'eau est un bien du patrimoine commun de la Nation dont l'Etat assure la protection et la gestion et en facilite l'accès à tous.

(2) Toutefois, l'Etat peut transférer tout ou partie de ses prérogatives aux collectivités territoriales décentralisées.

(3) La gestion de l'eau peut, en outre, faire l'objet de concession ou d'affermage, suivant des modalités fixées par un décret d'application de la présente loi.

ARTICLE 3.- Aux termes de la présente loi et de ses textes d'application, il faut entendre par:

- eaux de surface : les eaux de ruissellement, les cours d'eau et les eaux stagnantes;

- eaux souterraines : les eaux d'infiltration et les nappes ;

- eaux de source : les eaux proposées dans le commerce pour qu'il soit fait état de leurs qualités thérapeutique ;

- eaux minérales : les eaux souterraines contenant des substances minérales dissoutes ayant une action thérapeutique.

ARTICLE 4.- (1) Sont interdits les déversements, écoulements, jets, infiltrations, enfouissements, épandages, dépôts, directs ou indirects, dans les eaux de toute matière solide, liquide ou gazeuse et, en particulier, les déchets industriels, agricoles et atomiques susceptibles :

- d'altérer la qualité des eaux de surface ou souterraines ou des eaux de la mer, dans les limites territoriales;

- de porter atteinte à la santé publique ainsi qu'à la faune et la flore aquatiques ou sous-marines ;

- de mettre en cause le développement économique et touristique des régions. 
(2) Toutefois, le Ministre chargé de l'Eau, peut, après enquête et avis des autres Administrations concernées, autoriser et réglementer les déversements visés ci-dessus, dans le cas où ceux-ci garantissent l'innocuité et l'absence de nuisances, compte tenu des caractéristiques de l'effluent et du milieu récepteur.

(3) L'autorisation accordée peut être modifiée ou retirée soit à la demande du titulaire ou des tiers intéressés, soit à l'initiative de l'Administration, soit de plein droit, dans le cas prévu par l'acte d'autorisation.

ARTICLE 5.- (1) Un décret d'application de la présente loi fixe, sur rapport conjoint des Administrations compétentes, la liste des substances nocives ou dangereuses dont le rejet, le déversement, le dépôt, l'immersion ou l'introduction de manière directe ou indirecte dans les eaux sont, soit interdits, soit soumis à autorisation préalable desdites Administrations.

(2) Les déversements d'eaux résiduaires dans le réseau d'assainissement public ne doit nuire, ni à la conservation des ouvrages, ni à la gestion des eaux.

(3) Les installations de déversement établies antérieurement à la date de promulgation de la présente loi doivent se conformer à la réglementation, dans un délai fixé par un décret d'application de ladite loi.

(4) Les installations établies postérieurement à la date de promulgation de la présente loi doivent, dès leur mise en fonctionnement, être conformes aux normes de rejet fixées par la réglementation en vigueur.

ARTICLE 6.- (1) Toute personne physique ou morale, propriétaire d'installations susceptibles d'entraîner la pollution des eaux, doit prendre toutes les mesures nécessaires pour limiter ou en supprimer les effets.

(2) Toute personne qui produit ou détient des déchets doit en assurer elle-même l'élimination ou le recyclage, ou les faire éliminer ou les faire recycler dans des installations agréées par l'Administration chargée des établissements classés, après avis obligatoire de l'Administration chargée de l'environnement.

Elle est, en outre, sous réserve des règles liées à la confidentialité, tenue d'informer le public sur les effets de la production, la détention, l'élimination ou le recyclage des déchets sur l'eau, l'environnement et la santé publique, ainsi que sur les mesures destinées à en prévenir ou à en compenser les effets préjudiciables.

(3) Sont, en outre, interdits, le nettoyage et l'entretien des véhicules à moteur, des machines à combustion interne et d'autres engins similaires à proximité des eaux.

ARTICLE 7.- (1) En vue de protéger la qualité de l'eau destinée à l'alimentation, il est institué un périmètre de protection autour des points de captage, de traitement et de stockage des eaux. 
(2) Les terrains compris dans les périmètres de protection sont déclarés d'utilité publique.

ARTICLE 8.- (1) Une taxe d'assainissement est perçue par l'Etat sur les personnes physiques ou morales propriétaires d'installations raccordées aux réseaux d'égouts publics ou privés de collecte et de traitement des eaux usées.

(2) Le taux et les modalités de recouvrement de la taxe prévue à l'alinéa (1) sont fixés par la loi des finances.

ARTICLE 12.- Le contrôle de la qualité des eaux de consommation est assuré, à tout moment, par les personnels des Administrations chargées respectivement de l'eau et de la santé publique, assermentés et commissionnés à cet effet.

CHAPITRE II

DE L'EXPLOITATION DES EAUX DE SOURCE ET

DES EAUX MINERALES

ARTICLE 13.- L'exploitation des eaux de source et des eaux minérales est régie par une loi particulière.

\section{TITRE IV}

\section{DE LA RESPONSABILITE ET DES SANCTIONS}

\section{CHAPITRE I}

\section{DE LA RESPONSABILITE}

ARTICLE 14.- Sans préjudice des peines applicables sur le plan de la responsabilité pénale et nonobstant les vérifications effectuées par les Administrations chargées du contrôle, est responsable civilement, sans qu'il soit besoin de prouver une faute, toute personne qui a causé un dommage corporel ou matériel résultant de la mauvaise qualité des eaux d'alimentation qu'elle distribue.

\section{CHAPITRE II}

\section{DES SANTIONS PENALES}

ARTICLE 15.- (1) Est punie d'un emprisonnement de deux (2) ans à cinq (5) ans et d'une amende de cinq millions (5.000.000) à dix millions (10.000.000) de FCFA ou de l'une de ces deux peines seulement, toute personne qui :

- réalise un prélèvement des eaux de surface ou des eaux souterraines en violation des dispositions de la présente loi et/ou de ses textes d'application;

- réalise un prélèvement des eaux de surface ou des eaux souterraines non conforme aux critères, normes et mesures énoncés par l'étude d'impact ;

- empêche l'accomplissement des contrôles, surveillance et analyses prévus par la présente loi et/ou par ses textes d'application;

- fait fonctionner une installation de captage, de traitement et de stockage des eaux en violation des dispositions de la présente loi et/ou de ses textes d'application ;

- $\quad$ offre de l'eau de boisson au public sans se conformer aux normes de qualité en vigueur ; 
- viole un périmètre de protection autour des points de captage, de traitement et de stockage des eaux.

(2) En cas de récidive, le coupable encourt le double du maximum des peines prévues à l'alinéa (1) ci-dessus.

ARTICLE 16.- (1) Est punie d'un emprisonnement de cinq (5) ans à quinze (15) ans et d'une amende de dix millions (10.000.000) à vingt millions (20.000.000) de FCFA, toute personne qui pollue et altère la qualité des eaux.

(2) En cas de récidive, le coupable encourt le double du maximum des peines prévues à l'alinéa (1) ci-dessus.

ARTICLE 17.- Les sanctions prévues par la présente loi sont complétées par celles contenues dans le Code Pénal ainsi que dans la législation relative à la protection de l'environnement.

ARTICLE 18.- Les dispositions des articles 54 et 90 du Code Pénal relatives au sursis et aux circonstances atténuantes ne sont pas applicables aux sanctions prévues par la présente loi.

\section{CHAPITRE III}

\section{DE LA CONSTATATION DES INFRACTIONS}

ARTICLE 19.- (1) Sans préjudice des prérogatives reconnues au ministère public, aux officiers de police judiciaire à compétence générale, les agents assermentés de l'Administration chargée de l'eau ou des autres Administrations concernées, notamment de la santé et de l'environnement, sont chargés de la recherche, de la constatation et des poursuites en répression des infractions aux dispositions de la présente loi et de ses textes d'application.

(2) Les agents mentionnés à l'alinéa (1) ci-dessus prêtent serment devant le tribunal compétent, à la requête de l'Administration intéressée, suivant des modalités fixées par un décret d'application de la présente loi.

(3) Dans l'exercice de leurs fonctions, les agents assermentés sont tenus de se munir de leur carte professionnelle.

ARTICLE 20.- (1) Toute infraction constatée fait l'objet d'un procès-verbal régulier.

La recherche et la constatation des infractions sont effectuées par deux

(2) agents qui co-signent le procès-verbal. Ce procès-verbal fait foi jusqu'à l'inscription en faux.

ARTICLE 21.- (1) Tout procès-verbal de constatation d'infraction doit être transmis immédiatement à l'Administration chargée de l'eau qui fait notifier au contrevenant. 
Celui-ci dispose d'un délai de vingt (20) jours à compter de cette notification pour contester le procès-verbal. Passé ce délai, toute contestation devient irrecevable.

(2) En cas de contestation dans les délais prévus à l'alinéa (1) du présent article, la réclamation est examinée par l'Administration chargée de l'eau.

Si la contestation est fondée, le procès-verbal est classé sans suite.

Dans le cas contraire, et à défaut de transaction ou d'arbitrage définitif, l'Administration chargée de l'eau procède à des poursuites judiciaires conformément à la législation en vigueur.

\section{CHAPITRE IV}

\section{DE LA TRANSACTION ET DE L'ARBITRAGE}

ARTICLE 22.- (1) L'Administration chargée de l'eau a pleins pouvoirs pour transiger. Elle doit, pour ce faire, être dûment saisie par l'auteur de l'infraction.

Le montant de la transaction est fixé en concertation avec l'Administration chargée des finances. Ce montant ne peut être inférieur au minimum de l'amende pénale correspondante.

La procédure de transaction doit être antérieure à toute procédure judiciaire éventuelle, sous peine de nullité.

Le produit de la transaction est intégralement versé au Fonds prévu par la présente loi.

ARTICLE 23.- Les parties à un différend relatif à la gestion de l'eau peuvent le régler d'un commun accord par voie d'arbitrage.

ARTICLE 24.- (1) Les autorités traditionnelles ont compétence pour régler des litiges liés à l'utilisation des ressources en eau sur la base des us et coutumes locaux, sans préjudice du droit des parties au litige d'en saisir les tribunaux compétents.

(2) Il est dressé procès-verbal du règlement du litige. Une copie de ce procès-verbal, dûment signé par l'autorité administrative du ressort territorial de la communauté villageoise où a lieu le litige.

\section{TITRE V}

\section{DES DISPOSITIONS DIVERSES ET FINALES}

ARTICLE 25.- (1) En vue de garantir le financement des projets de développement durable en matière d'eau et d'assainissement, la loi de finances fixe annuellement les ressources particulières devant alimenter un compte d'affectation spéciale créé à cet effet par décret présidentiel, conformément aux dispositions des articles 39 et 41 de l'ordonnance $\mathrm{n}^{\circ}$ 62/OF/4 du 7 février 1962 relative au régime financier de l'Etat.

Ce décret détermine notamment les modalités de gestion du compte susvisé. 
(2) Le compte d'affectation spéciale prévu à l'alinéa (1) ci-dessus peut également recevoir, le cas échéant : des contributions des donateurs internationaux; toutes autres contributions volontaires; des dons et legs.

(3) Les ressources particulières prévues aux alinéas (1) et (2) ci-dessus ne peuvent être affectées à d'autres fins.

ARTICLE 26.- (1) Sans préjudice des dispositions de la législation relative à la gestion de l'environnement, il est institué, par la présente loi, un Comité National de l'Eau.

(2) Les attributions, l'organisation et le fonctionnement du Comité National de l'Eau sont fixés par un décret d'application de la présente loi.

ARTICLE 27.- Les spécifications relatives à la construction, à l'exploitation et à l'entretien des réseaux et installations publics ou privés d'alimentation en eau et d'assainissement sont fixées par un décret d'application de la présente loi.

ARTICLE 28.- L'utilisation de l'eau comme moyen de transport est régie par le cade de la marine marchande.

ARTICLE 29.- Des décrets d'application de la présente loi en précisent, en tant que de besoin, les modalités.

ARTICLE 30.- Sont abrogées toutes les dispositions antérieures de la loi ${ }^{\circ} 84 / 013$ du 05 décembre 1984 portant régime de l'eau.

ARTICLE 31.- La présent loi sera enregistrée, publiée suivant la procédure d'urgence, puis insérée au Journal Officiel en français et en anglais./- 
République du Cameroun

Paix - Travail - Patrie

LOI $N^{\circ}$ 96/12 DU 5 AOUT 1996

PORTANT LOI-CADRE RELATIVE A LA GESTION DE L'ENVIRONNEMENT

L'ASSEMBLEE NATIONALE A DELIBERE ET ADOPTE

LE PRESIDENT DE LA REPUBLIQUE PROMULGUE LA LOI DONT LA TENEUR SUIT :

\section{TITRE I}

DES DISPOSITIONS GENERALES

ARTICLE 1er.- La présente loi fixe le cadre juridique général de la gestion de l'environnement au Cameroun.

ARTICLE 2.- (1) L'environnement constitue en République du Cameroun un patrimoine commun de la nation. Il est une partie intégrante du patrimoine universel.

(2) Sa protection et la gestion rationnelle des ressources qu'il offre à la vie humaine sont d'intérêt général. Celles-ci visent en particulier la géosphère, l'hydrosphère, l'atmosphère, leur contenu matériel et immatériel, ainsi que les aspects sociaux et culturels qu'ils comprennent.

ARTICLE 3.- Le Président de la République définit la politique nationale de l'environnement. Sa mise en œuvre incombe au Gouvernement qui l'applique, de concert avec les collectivités territoriales décentralisées, les communautés de base et les associations de défense de l'environnement.

A cet effet, le Gouvernement élabore des stratégies, plans ou programmes nationaux tendant à assurer la conservation et l'utilisation durables des ressources de l'environnement.

\section{CHAPITRE I DES DEFINITIONS}

ARTICLE 4.- Au sens de la présente et de ses textes d'application, on entend par :

(a) «air» : l'ensemble des éléments constituant le fluide atmosphérique et dont la modification physique, chimique ou autre peut porter atteinte aux êtres vivants, aux écosystèmes et à l'environnement en général ;

(b) «audit environnemental»: l'évaluation systématique, documentée et objective de l'état de gestion de l'environnement et de ses ressources;

(c) «déchet»: tout résidu d'un processus de production, de transformation ou d'utilisation, toute substance ou tout matériau produit ou, plus généralement, tout bien meuble ou immeuble abandonné ou destiné à l'abandon ; 
(d) «développement durable»: le mode de développement qui vise à satisfaire les besoins de développement des générations présentes sans compromettre les capacités des générations futures à répondre aux leurs ;

(e) « eaux continentales » : l'ensemble hydrographique des eaux de surface et des eaux souterraines ;

(f) « eaux maritimes »: les eaux saumâtres et toutes les eaux de mer sous juridiction nationale camerounaise ;

(g) « écologie » : l'étude des relations qui existent entre les différents organismes vivants et le milieu ambiant ;

(h) «écosystème»: le complexe dynamique formé de communautés de plantes, d'animaux, de micro-organismes et de leur environnement vivant qui, par leur interaction, forment une unité fonctionnelle ;

(i) «effluent»: tout rejet liquide et gazeux d'origine domestique, agricole ou industrielle, traité ou non traité et déversé directement ou indirectement dans l'environnement ;

(j) «élimination des déchets»: l'ensemble des opérations comprenant la collecte, le transport, le stockage et le traitement nécessaires à la récupération des matériaux utiles ou de l'énergie, à leur recyclage, ou tout dépôt ou rejet sur les endroits appropriés de tout autre produit dans des conditions à éviter les nuisances et la dégradation de l'environnement.

(k) « environnement» : l'ensemble des éléments naturels ou artificiels et des équilibres bio-géochimiques auxquels ils participent, ainsi que des facteurs économiques, sociaux et culturels qui favorisent l'existence, la transformation et le développement du milieu, des organismes vivants et des activités humaines ;

(l) « équilibre écologique » : le rapport relativement stable créé progressivement au cours des temps entre l'homme, la faune et la flore, ainsi que leur interaction avec les conditions du milieu naturel dans lequel il vivent ;

(m) «établissement classés » : les établissements qui présentent des causes de danger ou des inconvénients, soit pour la sécurité, la salubrité ou la commodité du voisinage, soit pour la santé publique, ou pour l'agriculture, ainsi que pour la pêche ;

(n) « établissements humains » : l'ensemble des agglomérations urbaines et rurales, quels que soient leur type et leur taille, et l'ensemble des infrastructures dont elles doivent disposer pour assurer à leurs habitants une existence saine et décente ;

(o) « étude d'impact environnemental » : l'examen systématique en vue de déterminer si un projet a ou n'a pas un effet défavorable sur l'environnement ; 
(p) «gestion écologiquement rationnelle des déchets»: toutes mesures pratiques permettant d'assurer que les déchets sont gérés d'une manière qui garantisse la protection de la santé humaine et de l'environnement, contre les effets nuisibles que peuvent avoir ces déchets ;

(q) "gestion des déchets » : la collecte, le transport, le recyclage et l'élimination des déchets, y compris la surveillance des sites d'élimination ;

(r) «installation»: tout dispositif ou toute unité fixe ou mobile susceptible d'être générateur d'atteinte à l'environnement, quel que soit son propriétaire ou son affectation ;

(s) «nuisance»: l'ensemble des facteurs d'origine technique ou sociale qui compromettent l'environnement et rendent la vie malsaine ou pénible ;

(t) «polluant» : toute substance ou tout rejet solide, liquide ou gazeux, tout déchet, odeur, chaleur, son, vibration, rayonnement ou combinaison de ceux-ci, susceptibles de provoquer une pollution ;

(u) " pollueur» : toute personne physique ou morale émettant un polluant qui entraîne un déséquilibre dans le milieu naturel ;

(v) "pollution»: toute contamination ou modification directe ou indirecte de l'environnement provoquée par tout acte susceptible :

d'affecter défavorablement une utilisation du milieu favorable de l'homme ;

de provoquer ou qui risque de provoquer une situation préjudiciable pour la santé, la sécurité, le bien-être de l'homme, la flore et la faune, l'air, l'atmosphère, les eaux, les sols et le biens collectifs et individuels;

(w) «ressource génétique»: le matériel animal ou végétal d'une valeur réelle ou potentielle.

\section{CHAPITRE II}

\section{DES OBLIGATIONS GENERALES}

ARTICLE 5.- Les lois et règlements doivent garantir le droit de chacun à un environnement sain et assurer un équilibre harmonieux au sein des écosystèmes et entre les zones urbaines et les zones rurales.

ARTICLE 6.- (1) Toutes les institutions publiques et privées sont tenues, dans le cadre de leur compétence, de sensibiliser l'ensemble des populations aux problèmes de l'environnement.

(2) Elles doivent par conséquent intégrer dans leurs activités des programmes permettant d'assurer une meilleure connaissance de l'environnement. 
ARTICLE 7.- (1) Toute personne a le droit d'être informé sur les effets préjudiciables pour la santé, l'homme et l'environnement des activités nocives, ainsi que sur les mesures prises pour prévenir ou compenser ces effets.

(2) Un décret définit la consistance et les conditions d'exercice de ce droit.

ARTICLE 8.- (1) Les associations régulièrement déclarées ou reconnues d'utilité publique et exerçant leurs activités statutaires dans le domaine de la protection de l'environnement ne peuvent contribuer aux actions des organismes publics et parapublics en la matière que si elles sont agréées suivant des modalités fixées par des textes particuliers.

(2) Les communautés de base et les associations agréées contribuant à tout action des organismes publics et para-publics ayant pour objet la protection de l'environnement, peuvent exercer les droits reconnus à la partie civile en ce qui concerne les faits constituants une infraction aux dispositions de la présente loi et de ses textes d'application, et causant un préjudice direct ou indirect aux intérêts collectifs qu'elles ont pour objet de défendre.

\section{CHAPITRE III}

\section{DES PRINCIPES FONDAMENTAUX}

ARTICLE 9.- La gestion de l'environnement et des ressources naturelles s'inspire, dans le cadre des lois et règlements en vigueur, des principes suivants :

a) le principe de précaution, selon lequel l'absence de certitudes, compte tenu des connaissances scientifiques et techniques du moment, ne doit pas retarder l'adoption des mesures effectives et proportionnées visant à prévenir un risque de dommages graves et irréversibles à l'environnement à un coût économiquement acceptable ;

b) le principe d'action préventive et de correction, par priorité à la source, des atteintes à l'environnement, en utilisant les meilleures techniques disponibles à un coût économiquement acceptable ;

c) le principe pollueur-payeur, selon lequel les frais résultant des mesures de prévention, de réduction de la pollution et de la lutte contre celle-ci et de la remise en l'état des sites pollués doivent être supportés par le pollueur ;

d) le principe de responsabilité, selon lequel toute personne qui, par son action, crée des conditions de nature à porter atteinte à la santé de l'homme et à l'environnement, est tenue d'en assurer ou d'en faire assurer l'élimination dans des conditions propres à éviter lesdits effets ;

e) le principe de participation selon lequel

- chaque citoyen doit avoir accès aux informations relatives à l'environnement, y compris celles relatives aux substances et activités dangereuses; 
- chaque citoyen a le devoir de veiller à la sauvegarde de l'environnement et de contribuer à la protection de celui-ci ;

- les personnes publiques et privées doivent, dans toutes leurs activités, se conformer aux mêmes exigences ;

- les décisions concernant l'environnement doivent être prises après concertation avec les secteurs d'activité ou les groupes concernés, ou après débat public lorsqu'elles ont une portée générale ;

f) le principe de subsidiarité selon lequel, en l'absence d'une règle de droit écrit, générale ou spéciale en matière de protection de l'environnement, la norme coutumière identifiée d'un terroir donné et avérée plus efficace pour la protection de l'environnement s'applique.

\section{TITIRE II}

\section{DE L'ELABORATION DE LA COORDINATION ET}

DU FINANCEMENT DES POLITIQUES DE L'ENVIRONNEMENT

ARTICLE 10.- (1) Le Gouvernement élabore les politiques de l'environnement et en coordonne la mise en œuvre.

A cette fin, notamment, il :

- $\quad$ établit les normes de qualité pour l'air, l'eau, le sol et toutes normes nécessaires à la sauvegarde de la santé humaine et de l'environnement ;

- $\quad$ établit des rapports sur la pollution, l'état de conservation de la diversité biologique et sur l'état de l'environnement en général ;

- initie des recherches sur la qualité de l'environnement et les matières connexes ; prépare une révision du Plan National de Gestion de l'Environnement, selon la périodicité prévue à l'article 14 de la présente loi, en vue de l'adapter aux exigences nouvelles dans ce domaine ;

- initie et coordonne les actions qu'exige une situation critique, un état d'urgence environnemental ou toutes autres situations pouvant constituer une menace grave pour l'environnement ;

- publie et diffuse les informations relatives à la protection et à la gestion de l'environnement ;

- $\quad$ prend toutes autres mesures nécessaires à la mise en œuvre de la présente loi.

(2) Il est assisté dans ses missions d'élaboration de coordination,

d'exécution et de contrôle des politiques de l'environnement et une Commission Nationale Consultative de l'Environnement et du Développement Durable dont les attributions, l'organisation et le fonctionnement sont fixés par des décrets d'application de la présente loi.

ARTICLE 11.- (1) Il est institué un compte spécial d'affectation du Trésor, dénommé «Fonds National de l'Environnement et du Développement Durable » et ci-après désigné le « Fonds », qui a pour objet : 
- de contribuer au financement de l'audit environnemental; d'appuyer les projets de développement durable ; d'appuyer la recherche et l'éducation environnementales ;

- d'appuyer les programmes de promotion des technologies propres;

- d'encourager les initiatives locales en matière de protection de l'environnement, et de développement durable ;

- d'appuyer les associations agréées engagées dans la protection de l'environnement qui mènent des actions significatives dans ce domaine;

- d'appuyer les actions des départements ministériels dans le domaine de la gestion de l'environnement.

(2) L'organisation et le fonctionnement du Fonds sont fixés par un décret du Président de la République.

ARTICLE 12.- (1) Les ressources du Fonds proviennent:

- des dotations de l'Etat;

- des contributions des donateurs internationaux des contributions volontaires;

- du produit des amendes de transaction telle que prévue par la présente loi ;

- des dons et legs;

- des sommes recouvrées aux fins de remise en l'état des sites;

- de toute autre recette affectée ou autorisée par la loi.

(2) Elles ne peuvent être affectées à d'autres fins que celles ne correspondant qu'à l'objet du Fonds.

\section{TITRE III}

\section{DE LA GESTION DE L'ENVIRONNEMENT}

\section{CHAPITRE I}

DU PLAN NATIONAL DE GESTION DE L'ENVIRONNEMENT

ARTICLE 13.- Le Gouvernement est tenu d'élaborer un Plan National de Gestion de l'Environnement. Ce plan est révisé tout les cinq (5) ans.

ARITCLE 14.- (1) L'Administration chargée de l'environnement veille à l'intégration des considérations environnementales dans tous les plans et programmes économiques, énergétiques, fonciers et autres.

(2) Elle s'assure, en outre, que les engagements internationaux du Cameroun en matière environnementale sont introduits dans la législation, la réglementation et la politique nationale en la matière.

ARTICLE 15.- L'Administration chargée de l'environnement est tenue de réaliser la planification et de veiller à la gestion rationnelle de l'environnement, de mettre en place un système d'information environnementale comportant une base de données sur différents aspects de l'environnement, au niveau national et international.

A cette fin, elle enregistre toutes les données scientifiques et technologiques relatives à l'environnement et tien un recueil à jour de la législation et réglementation nationales et 
des instruments juridiques internationaux en matière d'environnement auxquels le Cameroun est partie.

ARTICLE 16.- (1) L'Administration chargée de l'environnement établit un rapport biannuel sur l'état de l'environnement au Cameroun et le soumet à l'approbation du Comité Inter- ministériel de l'Environnement.

(2) Ce rapport est publié et largement diffusé.

\section{CHAPITRE II}

\section{DES ETUDES D'IMPACT ENVIRONNEMENTAL}

ARTICLE 17.- (1) Le promoteur ou le maître d'ouvrage de tout projet d'aménagement, d'ouvrage, d'équipement ou d'installation qui risque, en raison de sa dimension, de sa nature ou des incidences des activités qui y sont exercées sur le milieu naturel, de porter atteinte à l'environnement est tenu de réaliser, selon les prescriptions du cahier des charges, une études d'impact permettant d'évaluer les incidences directes ou indirectes dudit projet sur l'équilibre écologique de la zone d'implantation ou de toute autre région, le cadre et la qualité de vie des populations et des incidences sur l'environnement en général.

Toutefois, lorsque ledit projet est entrepris pour le compte des services de la défense ou de la sécurité nationale, le ministre chargé de la défense ou, selon le cas, de la sécurité nationale assure la publicité de l'étude d'impact dans des conditions compatibles avec les secrets de la défense ou de la sécurité nationale.

(2) L'étude d'impact est insérée dans les dossiers soumis à enquête publique, lorsqu'une telle procédure est prévue.

(3) L'étude d'impact est à la charge du promoteur.

(4) Les modalités d'application des dispositions du présent article sont fixées par un décret d'application de la présente loi.

ARTICLE 18.- Toute étude d'impact non conforme aux prescriptions du cahier des charges est nulle et de nul effet.

ARTICLE 19.- (1) La liste des différentes catégories d'opérations dont la réalisation est soumise à une étude d'impact, ainsi que les conditions dans lesquelles l'étude d'impact est rendue publique sont fixées par un décret d'application de la présente loi.

suivantes :

(2) L'étude d'impact doit comporter obligatoirement les indications

- l'analyse de l'état initial du site et de l'environnement ;

- les raisons du choix du site ; 
- l'évaluation des conséquences prévisibles de la mise en œuvre du projet sur le site et son environnement naturel et humain ;

- l'énoncé des mesures envisagées par le promoteur ou maître d'ouvrage pour supprimer, réduire et, si possible, compenser les conséquences dommageables du projet sur l'environnement et l'estimation des dépenses correspondantes ;

- la présentation des autres solutions possibles et des raisons pour lesquelles, du point de vue de la protection de l'environnement, le projet présenté a été retenu.

ARTICLE 20.- (1) Toute étude d'impact donne lieu à une décision motivée de l'Administration compétente, après avis préalable du Comité Interministériel prévu par la présente loi, sous peine de nullité absolue de cette décision.

La décision de l'Administration compétente doit être prise dans un délai maximum de quatre (4) mois à compter de la date de notification de l'étude d'impact.

Passé ce délai, et en cas de silence de l'Administration, le promoteur peut démarrer ses activités.

(2) Lorsque l'étude d'impact a été méconnue ou la procédure d'étude d'impact non respectée en tout ou en partie, l'Administration compétente ou, en cas de besoin, l'Administration chargée de l'environnement requiert la mise en œuvre des procédures d'urgence appropriées permettant de suspendre l'exécution des travaux envisagés ou déjà entamés. Ces procédures d'urgence sont engagées sans préjudice des sanctions pénales prévues par la présente loi.

\section{CHAPITRE III}

\section{DE LA PROTECTION DES MILIEUX RECEPTEURS}

\section{SECTION I}

\section{DE LA PROTECTION DE L'ATMOSPHERE}

ARTICLE 21.- Il est interdit :

- de porter atteinte à la qualité de l'air ou de provoquer toute forme de modification de ses caractéristiques susceptibles d'entraîner un effet nuisible pour la santé publique ou les biens ;

- d'émettre dans l'air toute substance polluante notamment les fumées, poussières ou gaz toxiques corrosifs ou radioactifs, au-delà des limites fixées par les textes d'application de la présente loi ou, selon le cas, par des textes particuliers; d'émettre des odeurs qui, par leur concentration ou leur nature, s'avèrent particulièrement incommodantes pour l'homme.

ARTICLE 22.- (1) Afin d'éviter la pollution atmosphérique, les immeubles, les établissements agricoles, industriels, commerciaux ou artisanaux, les véhicules ou autres objets mobiliers possédés, exploités ou détenus par toute personne physique ou morale doivent être construits, exploités ou utilisés de manière à satisfaire aux normes techniques en vigueur ou établies en application de la présente loi ou de textes particuliers. 
(2) Des zones de protection spéciale faisant l'objet de mesures particulières sont, en cas de nécessité, instituées par décret sur proposition du Préfet territorialement compétent lorsque le niveau de pollution observée se situe en-deça du seuil minimum de qualité fixé par la réglementation ou au regard de certaines circonstances propres à en aggraver la dégradation.

(3) En vue de limiter ou de prévenir un accroissement prévisible de la pollution atmosphérique à la suite notamment de développements industriels et humains, d'assurer une protection particulière de l'environnement, ainsi que de préserver la santé de l'homme, des zones sensibles peuvent être créées et délimitées sur proposition du Préfet territorialement compétent par arrêté conjoint des Ministres chargés de l'environnement, de la santé publique, de d'administration territoriale et des mines.

(4) Le Préfet peut instituer des procédures d'alerte à la pollution atmosphérique, après avis des services techniques locaux compétents.

ARTICLE 23.- (1) Lorsque les personnes responsables d'émissions polluantes dans l'atmosphère, au-delà des normes fixées par l'Administration, n'ont pas pris de dispositions pour être en conformité avec la réglementation, l'Administration compétente leur adresse une mise en demeure de cette fin.

(2) Dans le cas où cette mise en demeure reste dans effet ou n'a pas produit les effets escomptés dans le délais imparti ou d'office, en cas d'urgence, l'Administration compétente doit, en concertation avec l'Administration chargée de l'environnement et les autres concernées, suspendre le fonctionnement de l'installation en cause ou faire exécuter les mesures nécessaires, aux frais du propriétaire ou en recouvrer le montant du coût auprès de ce dernier.

ARTICLE 24.- Aux fins de la protection de l'atmosphère, les Administrations compétentes, en collaboration avec l'Administration chargée de l'environnement et le secteur privé, sont chargées de prendre les mesures tendant à :

- appliquer le Protocole de Montréal et ses amendements ;

- développer les énergies renouvelables ;

- $\quad$ préserver la fonction régulatrice des forêts sur l'atmosphère.

\section{SECTION II}

DE LA PROTECTION DES EAUX CONTINENTALES ET DES PLAINES D'INONDATION

ARTICLE 25.- Les eaux continentales constituent un bien du domaine public dont l'utilisation, la gestion et la protection sont soumises à la présente loi ainsi qu'à celles de la législation et de la réglementation en vigueur. .

ARTICLE 26 .- L'Administration chargée de la gestion des ressources en eau dresse un inventaire établissant le degré de pollution des eaux continentales, en fonction des critères physiques, chimiques, biologiques et bactériologiques. Cet inventaire est révisé périodiquement ou chaque fois qu'une pollution exceptionnelle affecte l'état de ces eaux. 
ARTICLE 27.- Les plaines d'inondation font l'objet d'une protection particulière. Cette protection tient compte de leur rôle et de leur importance dans la conservation de la diversité biologique.

ARTICLE 28.- Le régime de protection des eaux continentales fait l'objet d'une loi particulière.

ARTICLE 29.- Sont interdits, sous réserve des dispositions de l'article 30 ci-dessous, les déversements, écoulements, rejets, dépôts, directs ou indirects de toute nature et, plus généralement, tout fait susceptible de provoquer la dégradation des eaux superficielles ou souterraines en modifiant leurs caractéristiques physiques, chimiques, biologiques ou bactériologiques.

ARTICLE 30.- (1) Un décret d'application de la présente loi fixe la liste des substances nocives ou dangereuse produites au Cameroun, dont le rejet, le déversement, le dépôt, l'immersion ou l'introduction de manière directe ou indirecte dans les eaux continentales camerounaises sont soit interdits, soit soumis à autorisation préalable.

(2) Les déversements d'eaux résiduaires dans le réseau d'assainissement public ne doit nuire ni à la conservation des ouvrages, ni à la gestion des réseaux.

(3) Les installations rejetant des eaux résiduaires dans les eaux continentales camerounaises établies antérieurement à la date de promulgation de la présente loi doivent se conformer à la réglementation dans un délai fixé par un décret d'application de ladite loi.

Les installations établies postérieurement à la date de promulgation de la présente loi doivent, dès leur mise en fonctionnement, être conformes aux normes de rejet fixées par la réglementation en vigueur.

\section{SECTION III}

\section{DE LA PROTECTION DU LITTORAL ET DES EAUX MARITIMES}

ARTICLE 31.- (1) Sans préjudicie des dispositions pertinentes des conventions internationales relatives à la protection de l'environnement marin, dûment ratifiées par la République du Cameroun, sont interdits le déversement, l'immersion et l'incinération dans les eaux maritimes sous juridiction camerounaise, de substances de toute nature susceptibles :

- de porter atteinte à la santé de l'homme et aux ressources biologiques maritimes; de nuire aux activités maritimes, y compris la navigation, l'aquaculture et la pêche ;

- d'altérer la qualité des eaux maritimes du point de vue de leur utilisation ;

- de dégrader les valeurs d'agrément et le potentiel touristique de la mer et du littoral.

(2) La liste des substances visées au (1) ci-dessus est précisée par un décret d'application de la présente loi. 
ARTICLE 32.- (1) Dans le cas d'avaries ou d'accidents survenus dans les eaux maritimes sous juridiction camerounaise à tout navire, aéronef, engin ou plate-forme transportant ou ayant à son bord des hydrocarbures ou des substances nocives ou dangereuses et pouvant créer un danger grave et imminent au milieu marin et à ses ressources, le propriétaire dudit navire, aéronef, engin ou plate-forme est mis en demeure par les autorités maritimes compétentes de remettre en l'état le site contaminé en application de la réglementation en vigueur.

(2) Dans le cas où cette mise en demeure reste sans effet ou n'a pas produit les effets attendus dans le délai imparti, les mesures nécessaires aux frais de l'armateur, de l'exploitant ou du propriétaire et en recouvrent le montant du coût auprès de ce dernier.

ARTICLE 33.- (1) Le capitaine ou le responsable de tout navire aéronef, engin, transportant ou ayant à son bord des hydrocarbures ou des substances nocives ou dangereuses et se trouvant dans les eaux maritimes sous juridiction camerounaise, est tenu de signaler par tout moyen, aux autorités compétentes tout événement de mer survenu à son bord et qui est ou pourrait être de nature à constituer une menace pour le milieu marin et des intérêts connexes.

(2) Les dispositions nécessaires pour prévenir et combattre toute pollution marine en provenance des navires et des installations sises en mer et/ou sur terre sont fixées par un décret d'application de la présente loi.

ARTICLE 34.- (1) L’Administration chargée des domaines peut accorder, sur demande, une autorisation d'occupation du domaine public. L'occupation effectuée en vertu de cette autorisation ne doit entraver ni le libre accès aux domaines publics maritime et fluvial, ni la libre circulation sur la grève, ni être source d'érosion ou de dégradation du site.

(2) Seules sont autorisées sur le domaine public maritime et fluvial, à titre d'occupation privative temporaire, les installations légères et démontables à l'exclusion de toute construction en dur ou à usage d'habitation.

ARTICLE 35.- Il est délimité le long des côtés maritimes, des berges fluviales et lacustres une zone non aedificandi dont le régime est fixé par la législation domaniale.

\section{SECTION IV}

DE LA PROTECTION DES SOLS ET DU SOUS-SOL

ARTICLE 36.- (1) Le sol, le sous-sol et les richesses qu'ils contiennent, en tant que ressources limitées, renouvelables ou non sont protégés contre toutes formes de dégradation et gérées conjointement et de manière rationnelle par les Administrations compétentes.

(2) Un décret d'application de la présente loi, pris sur rapport conjoint des Administrations concernées, fixe : 
- les conditions particulières de protection destinées à lutter contre la désertification, l'érosion, les pertes de terres arables et la pollution du sol et de ses ressources par les produits chimiques, les pesticides et les engrais ;

- la liste des engrais, des pesticides et autres substances chimiques dont l'utilisation est autorisée ou favorisée dans les travaux agricoles ;

- les quantités autorisées et les modalités d'utilisation afin que les substances ne portent pas atteinte à la qualité du sol ou des autres milieux récepteurs.

ARTICLE 37.- (1) Les titulaires de tires miniers ou de titres de carrières sont tenus à l'obligation de remettre en l'état les sites exploités.

(2) Toutefois, les titulaires de titres miniers ou de titres de carrières peuvent choisir de payer le coût financier des opérations de remise en état exécutées par l'Administration compétente.

Le montant et les modalités sont réservées au Fonds prévu par la présente loi et ne peuvent recevoir aucune autre affectation.

ARTICLE 38.- (1) Sont soumis à l'autorisation préalable de chaque Administration concernée et après avis obligatoire de l'Administration chargée de l'environnement, l'affectation et l'aménagement des sols à des fins agricoles, industrielles, urbanistiques ou autres, ainsi que les travaux de recherche ou d'exploitation des ressources du sous-sol susceptibles de porter atteinte à l'environnement.

(2) Un décret d'application de la présente loi fixe les conditions de délivrance de l'autorisation prévue au (1) et les activités ou usages qui, en raison des dangers qu'ils présentent pour le sol, le sous-sol ou leurs ressources, doivent être interdits ou soumis à des sujétions particulières.

\section{SECTION $V$}

\section{DE LA PROTECTION DES ETABLISSEMENTS HUMAINS}

ARTICLE 39.- (1) La protection, la conservation et la valorisation du patrimoine culturel et architectural sont d'intérêt national.

(2) Elles sont parties intégrantes de la politique nationale de protection et de mise en valeur de l'environnement.

ARTICLE 40.- (1) Les plans d'urbanisme et les plans de lotissement publics ou privés prennent en compte les impératifs de protection de l'environnement dans le choix des emplacements prévus pour les zones d'activités économiques, résidentielles et de loisirs. Ces plans doivent, préalablement à leur application recueillir l'avis obligatoire de l'Administration chargée de l'environnement.

(2) Les agglomérations urbaines doivent comporter des terrains à usage récréatif et des zones d'espace vert, selon une proportion harmonieuse fixée par les documents 
d'urbanisme et la loi forestière, compte tenu notamment des superficies disponibles, du coefficient d'occupation du sol et de la population résidentielle.

ARTICLE 41.- Les permis de construire sont délivrés en tenant dûment compte de la présence des établissements classés et de leur impact sur l'environnement, et peuvent être refusés ou soumis à des prescriptions spéciales élaborées conjointement par les Administrations chargées de l'environnement et de l'urbanisme, si les constructions envisagées sont de nature à avoir des conséquences dommageables pour l'environnement.

\section{CHAPITRE IV}

DES INSTALLATIONS CLASSEES DANGEREUSES, INSALUBRES OU INCOMMODES ET DES ACTIVITES POLLUANTES

\section{SECTION I DES DECHETS}

ARTICLE 42.- Les déchets doivent être traités de manière écologiquement rationnelle afin d'éliminer ou de réduire leurs effets nocifs sur la santé de l'homme, les ressources naturelles, la faune et la flore, et sur la qualité de l'environnement en général.

ARTICLE 43.- (1) Toute personne qui produit ou détient des déchets doit en assurer elle- même l'élimination ou le recyclage, ou les faire éliminer ou recycler auprès des installations agréées par l'Administration chargée des établissements classés après avis obligatoire de l'Administration chargée de l'environnement.

Elle est, en outre, tenue d'assurer l'information du public sur les effets sur l'environnement et la santé publique des opérations de production, de détention, d'élimination ou de recyclage des déchets, sous réserve des règles de confidentialité, ainsi que sur les mesures destinées à en prévenir ou à en compenser les effets préjudiciables.

(2) Un décret d'application de la présente loi fixe les conditions dans lesquelles doivent être effectuées les opérations de collecte, de tri, de stockage, de transport, de récupération, de recyclage ou de toute autre forme de traitement, ainsi que l'élimination finale des déchets pour éviter la surproduction de ceux-ci, le gaspillage de déchets récupérables et la pollution de l'environnement en général.

ARTICLE 44.- Sont formellement interdits, compte dûment tenu des engagements internationaux du Cameroun, l'introduction, le déversement, le stockage ou le transit sur le territoire national des déchets produits hors du Cameroun.

ARTICLE 45.- La fabrication, l'importation, la détention en vue de la vente, la mise à la disposition du consommateur de produits ou matériaux générateurs de déchets font l'objet d'une réglementation fixée par arrêtés conjoints des Administrations compétentes, en vue de faciliter l'élimination desdits déchets ou, le cas échéant, d'interdire ces activités. 
ARTICLE 46.- (1) Les collectivités territoriales décentralisées assurent l'élimination des déchets produits par les ménages, éventuellement en liaison avec les services compétents de l'Etat, conformément à la réglementation en vigueur.

(2) En outre, elles :

- $\quad$ veillent à ce que tous les dépôts sauvages soient enrayés ;

- assurent l'élimination, si nécessaire avec le concours des services compétents de l'Etat ou des entreprises agréées, des dépôts abandonnés, lorsque le propriétaire ou l'auteur du dépôt n'est pas connu ou identifié.

ARTICLE 47.- (1) L'élimination des déchets par la personne qui les produit ou les traite doit être faite sur autorisation et sous la surveillance conjointe des Administrations chargées respectivement de l'environnement et des mines, selon les prescriptions fixées par un décret d'application de la présente loi ;

(2) Le dépôt des déchets en décharge doit se faire dans des décharges faisant l'objet de contrôles périodiques et respectant les normes techniques minima d'aménagement des décharges.

(3) Les déchets industriels spéciaux qui, en raison de leurs propriétés, sont dangereux, ne peuvent pas être déposés dans des installations de stockage recevant d'autres catégories de déchets.

ARTICLE 48.- (1) Lorsque les déchets sont abandonnés, déposés ou traités contrairement aux prescriptions de la présente loi et des règlements pris pour son application, l'autorité investie du pouvoir de police doit, après mise en demeure notifiée au producteur, assurer d'office l'élimination desdits déchets aux frais dudit producteur.

(2) L'Administration doit obliger le producteur à consigner entre les mains d'un comptable public, une somme correspondant au montant des travaux à réaliser. Le comptable public compétent est désigné par arrêté du Ministre chargé des finances.

ARTICLE 49.- L'immersion, l'incinération ou l'élimination par quelque procédé que ce soit, des déchets dans les eaux continentales et/ou maritimes sous juridiction camerounaises sont strictement interdites, compte dûment tenu des engagements internationaux du Cameroun.

ARTICLE 50.- (1) L'obligation générale d'entretien à laquelle sont soumis les concessionnaires du domaine public comporte celle d'éliminer, de faire éliminer ou de recycler les déchets qui s'y trouvent.

(2) Est strictement interdit le dépôt des déchets sur le domaine public, y compris le domaine public maritime tel que défini par la législation en vigueur. 
ARTICLE 51.- (1) L'enfouissement des déchets dans le sous-sol ne peut être opéré qu'après autorisation conjointe des Administrations compétentes qui fixent les prescriptions techniques et les règles particulières à observer.

(2) L'enfouissement des déchets sans l'autorisation prévue à l'alinéa (1) du présent article donne lieu à un désenfouissement opéré par le responsable de l'enfouissement ou, après mise en demeure de l'Administration compétente, en collaboration avec les autres Administrations concernées.

ARTICLE 52.- (1) Les sites endommagés par les travaux réalisés sans autorisation ou sans respect des prescriptions et les sites contaminés par des décharges sauvages ou des enfouissement non autorisés font l'objet d'une remise en l'état par les responsables ou d'une restauration la plus proche possible de leur état originel.

(2) En cas de mise en demeure de l'Administration compétente restée sans suite pendant un an, la remise en l'état ou la restauration du site est effectuée par celle-ci, en collaboration avec les autres Administrations concernées, aux frais de l'auteur du dommage, de la décharge sauvage ou de l'enfouissement.

ARTICLE 53.- Le rejet dans l'air, l'eau ou le sol d'un polluant est soumis à une autorisation dont les conditions de délivrance sont fixées par un décret d'application de la présente loi.

\section{SECTION II}

\section{DES ETABLISSEMENTS CLASSES}

ARTICLE 54.- Sont soumises aux dispositions de la législation et de la réglementation en vigueur sur les établissements classés, les usines, ateliers, dépôts, chantiers et, d'une manière générale, les installations industrielles, artisanales ou commerciales exploitées ou détenues par toute personne physique ou morale, publique ou privée, qui présentent ou peuvent présenter soit des dangers pour la santé, la sécurité, la salubrité publique, l'agriculture, la nature et l'environnement en général, soit des inconvénients pour commodité du voisinage.

ARTICLE 55.- (1) Afin de prévenir et de contrôler les accidents dans les établissements classés, le responsable de l'établissement industriel ou commercial classé est tenu de procéder à l'ouverture dudit établissement, à une étude des dangers.

(2) L'étude des dangers prévus à l'alinéa (1) ci-dessus doit comporter les indications suivantes :

- le recensement et la description des dangers suivant leur origine interne ou externe ;

- les risques pour l'environnement et le voisinage ;

- la justification des techniques et des procédés envisagés pour prévenir les risques, en limiter ou en compenser les effets ;

- la conception des installations ;

- les consignes d'exploitation ;

- les moyens de détection et d'intervention en cas de sinistre. 
ARTICLE 56.- (1) L'exploitant de tout établissement de première ou de deuxième classe, tel que défini par la législation sur les établissements classés, est tenu d'établir un plan d'urgence propre à assurer l'alerte des autorités compétentes et des populations avoisinantes en cas de sinistre ou de menace de sinistre, l'évacuation du personnel et les moyens pour circonscrire les causes du sinistre.

(2) Le plan d'urgence doit être agréé par les Administrations compétentes qui s'assurent périodiquement du bon état et de la fiabilité des matériels prévus pour la mise en œuvre du plan.

\section{SECTION III}

\section{DES SUBSTANCES CHIMQIES NOCIVES ET/OU DANGEREUSES}

ARTICLE 57.- (1) Les substances chimiques nocives et/ou dangereuses qui, en raison de leur toxicité, ou de leur concentration dans les chaînes biologiques, présentent ou sont susceptibles de présenter un danger pour la santé humaine, le milieu naturel et l'environnement en général, lorsqu'elles sont produites, importées sur le territoire national ou évacuées dans le milieu, sont soumises au contrôle et à la surveillance des Administrations techniques compétentes, en relation avec l'Administration chargée de l'environnement.

(2) Les substances radioactives sont régies par une loi particulière.

ARTICLE 58.- Un décret d'application de la présente loi, pris sur rapport conjoint des Administrations compétentes, réglemente et fixe :

- les obligations des fabricants et importateurs de substances chimiques destinées à la commercialisation, à la composition des préparations mises sur le marché, le volume à commercialiser ;

- la liste des substances dont la production, l'importation, le transit et la circulation sur le territoire national sont interdits ou soumis à autorisation préalable des Administrations chargées du contrôle et de la surveillance des substances chimiques, nocives et dangereuses ;

- les conditions, le mode, l'itinéraire et le calendrier de transport, de même que toutes prescriptions relatives au conditionnement et à la commercialisation des substances sus-visées ;

- les conditions de délivrance de l'autorisation préalable ;

- la liste des substances dont la production, l'importation, le transit et la circulation sur le territoire national sont autorisés.

ARTICLE 59.- (1) Les substances chimiques, nocives et dangereuses fabriquées, importées ou mises en vente en infraction aux dispositions de la présente loi sont saisies par les agents habiletés en matière de répression des fraudes, ou ceux assermentés des administrations compétentes.

(2) Lorsque les substances visées au (1) présentent un danger réel et imminent, elles doivent être détruites ou neutralisées dans les meilleurs délais par les soins des Administrations visées à l'alinéa (1) ci-dessus, aux frais de l'auteur de l'infraction. 


\section{SECTION IV}

\section{DES NUISANCES SONORES ET OLFACTIVES}

ARTICLE 60.- (1) Sont interdites les émissions de bruits et d'odeurs susceptibles de nuire à la santé de l'homme, de constituer une gêne excessive pour le voisinage ou de porter atteinte à l'environnement.

(2) Les personnes à l'origine de ces émissions doivent prendre toutes les dispositions nécessaires pour les supprimer, les prévenir ou en limiter la propagation sans nécessité ou par manque de précaution.

(3) Lorsque l'urgence le justifie, les communes doivent prendre toutes mesures exécutoires destinées, d'office, à faire cesser le trouble. En cas de nécessité, elles peuvent requérir le concours de la force publique.

ARTICLE 61.- Un décret d'application de la présente loi, pris sur rapport conjoint des Administrations compétentes détermine :

- le cas et les conditions dans lesquelles sont interdits ou réglementés les bruits causés sans nécessité absolue ou dus à un défaut de précaution ;

- les conditions dans lesquelles les immeubles, les établissements industriels, commerciaux, artisanaux ou agricoles, les véhicules ou autres objets mobiliers possédés, exploités ou détenus par toute personne physique ou morale, doivent être exploités, construits ou utilisés de manière à satisfaire aux dispositions de la présente loi et de ses textes d'application;

- les conditions dans lesquelles toutes mesures exécutoires doivent être prises par les communes et destinées, d'office, à faire cesser le trouble, sans préjudices des condamnations pénales éventuelles ;

- les délais dans lesquels il doit être satisfait aux dispositions de la présente loi à la date de publication de chaque règlement pris pour son application.

\section{CHAPITRE V}

DE LA GESTION DES RESSOURCES NATURELLES ET DE LA CONSERVATION DE LA DIVERSITE BIOLOGIQUE

ARTICLE 62.- La protection de la nature, la préservation des espèces animales et végétales et de leurs habitats, le maintien des équilibres biologiques et des écosystèmes, et la conservation de la diversité biologique et génétique contre toutes les causes de dégradation et les menaces d'extinction sont d'intérêt national. Il est du devoir des pouvoirs publics et de chaque citoyen de veiller à la sauvegarde du patrimoine naturel.

ARTICLE 63.- Les ressources naturelles doivent être gérées rationnellement de façon à satisfaire les besoins des générations actuelles sans compromettre la satisfaction de ceux des générations futures.

ARTICLE 64.- (1) L'utilisation durable de la diversité biologique du Cameroun se fait notamment à travers :

- $\quad$ un inventaire des espèces existantes, en particulier celles menacées d'extinction ; 
- des plans de gestion des espèces et de préservation de leur habitat ;

- $\quad$ un système de contrôle d'accès aux ressources génétiques.

(2) La conservation de la diversité biologique à travers la protection de la faune et de la flore, la création et la gestion des réserves naturelles et des parcs nationaux sont régies par la législation et la réglementation en vigueur.

(3) L'Etat peut ériger toute partie du territoire national en une aire écologiquement protégée. Une telle aire fait l'objet d'un plan de gestion environnemental.

ARTICLE 65.- (1) L'exploitation scientifique et l'exploitation des ressources biologiques et génétiques du Cameroun doivent être faites dans des conditions de transparence et de collaboration étroite avec les institutions nationales de recherche, les communautés locales et de manière profitable au Cameroun dans les conditions prévues par les conventions internationales en la matière dûment ratifiées par le Cameroun, notamment la Convention de Rion de 1992 sur la diversité biologique.

(2) Un décret d'application de la présente loi détermine les sites historiques, archéologiques et scientifiques, ainsi que les sites constituant une beauté panoramique particulière et organise leur protection et les conditions de leur gestion.

ARTICLE 67.- (1) L'exploration et l'exploitation des ressources minières et des carrières doivent se faire d'une façon écologiquement rationnelle prenant en compte les considérations environnementales.

\section{TITRE IV}

DE LA MISE EN CEUVRE ETU DU SUIVI DES PROGRAMMES

\section{CHAPITRE UNIQUE}

\section{DE LA PARTICIPATION DES POPULATIONS}

ARTICLE 72.- La participation des populations à la gestion de l'environnement doit être encouragée, notamment à travers :

- le libre accès à l'information environnementale, sous réserve des impératifs de la défense nationale et de la sécurité de l'Etat ;

- des mécanismes consultatifs permettant de recueillir l'opinion et l'apport des populations ;

- la représentation des populations au sein des organes consultatifs en matière d'environnement ;

- la production de l'information environnementale ;

- la sensibilisation, la formation, la recherche, l'éducation environnementale.

ARTICLE 73.- L'enseignement de l'environnement doit être introduit dans les programmes d'enseignement des cycles primaire et secondaire, ainsi que des établissements d'enseignement supérieur. 
ARTICLE 74.- Afin de renforcer la prise de conscience environnementale dans la société ainsi que la sensibilisation et la participation des populations aux questions environnementales, les Administrations chargées de l'environnement, de la communication et les autres Administrations et organismes publics concernés organisent des campagnes d'information et de sensibilisation à travers les média et tous autres moyens de communication.

A cet égard, ils mettent à contribution les moyens traditionnels de communication ainsi que les autorités traditionnelles et les associations oeuvrant dans le domaine de l'environnement et du développement.

\section{TITRE V}

\section{DES MESURES INCITATIVES}

ARTICLE 75.- Toute opération contribuant à enrayer l'érosion, à combattre efficacement la désertification, ou toute opération de boisement ou de reboisement, toute opération contribuant à promouvoir l'utilisation rationnelle des ressources renouvelables notamment dans les zones de savane et la partie septentrionale du pays bénéficie d'un appui du Fonds prévu par la présente loi.

ARTICLE 76.- (1) Les entreprises industrielles qui importent des équipements leur permettant d'éliminer dans leur processus de fabrication ou dans leurs produits les gaz à effet de serre notamment le gaz carbonique, le chloro-fluoro-carbone, ou de réduire toute forme de pollution bénéficient d'une réduction du tarif douanier sur ces équipements dans les proportions et une durée déterminées, en tant que de besoins, par la loi de Finances.

(2) Les personnes physiques ou morales qui entreprennent des actions de promotion de l'environnement bénéficient d'une déduction sur le bénéfice imposable suivant des modalités fixées par la loi des Finances.

\section{TITRE VI}

\section{DE LA RESPONSABILITE ET DES SANCTIONS}

\section{CHAPITRE I}

\section{DE LA RESPONSABILITE}

ARTICLE 77.- (1) Sans préjudice des peines applicables sur le plan de la responsabilité pénale, est responsable civilement, sans qu'il soit besoin de prouver une faute, toute personne qui, transportant ou utilisant des hydrocarbures ou des substances chimiques, nocives et dangereuses, ou exploitant un établissement classé, a causé un dommage corporel ou matériel se rattachant directement ou indirectement à l'exercice des activités susmentionnées.

(2) La réparation du préjudice visé à l'alinéa (1) du présent article est partagée lorsque l'auteur du préjudice prouve que le préjudice corporel ou matériel résulte de la faute de la victime. Elle est exonérée en cas de force majeure. 
ARTICLE 78.- Lorsque les éléments constitutifs de l'infraction proviennent d'un établissement industriel, commercial, artisanal ou agricole, le propriétaire, l'exploitant, le directeur, ou selon le cas, le gérant peut être déclaré responsable du paiement des amendes et frais de justice dus par les auteurs de l'infraction, et civilement responsable de la remise en l'état des sites.

\section{CHAPITRE II}

\section{DES SANCTIONS PENALES}

ARTICLE 79.- Est punie d'une amende de deux millions (2.000.000) à cinq millions (5.000.000) de FCFA et d'une peine d'emprisonnement de six (6) mois à deux (2) ans ou de l'une de ces deux peines seulement, toute personne ayant:

- réalisé, sans étude d'impact, un projet nécessitant une étude d'impact ;

- réalisé un projet non conforme aux critères, normes et mesures énoncés pour l'étude d'impact ;

- empêché l'accomplissement des contrôles et analyses prévus par la présente loi et/ou par ses textes d'application.

ARTICLE 80.- Est punie d'une amende de cinquante millions (50.000.000) à cinq cent millions (500.000.000) de FCFA et d'une peine d'emprisonnement à perpétuité, toute personne qui introduit des déchets toxiques et/ou dangereux sur le territoire camerounais.

ARTICLE 81.- (1) Est punie d'une amende de dix (10) millions à cinquante (50) millions de FCFA et d'une peine d'emprisonnement de deux (2) à cinq (5) ans ou de l'une de ces deux peines seulement, toute personne qui importe, produit, détient et/ou utilise contrairement à la réglementation, des substances nocives ou dangereuses.

(2) En cas de récidive, le montant maximal des peines est doublé.

ARTICLE 82.- (1) Est punie d'une amende d'un million (1.000.000) à cinq millions (5.000.000) de FCFA et d'une peine d'emprisonnement de six (6) mois à un (1) an ou de l'une de ces deux peines seulement, toute personne qui pollue, dégrade les sols et soussols, altère la qualité de l'air ou des eaux, en infraction aux dispositions de la présente loi.

(2) En cas de récidive, le montant maximal des peines est doublé.

ARTICLE 83.- (1) Est puni d'une amende de dix millions (10.000.000) à cinquante millions.

(50.000.000) de FCFA et d'une peine d'emprisonnement de six (6) mois à un (1) an ou de l'une de ces deux peines seulement, tout capitaine de navire qui se rend coupable d'un rejet dans les eaux maritimes sous juridiction camerounaise d'hydrocarbures ou d'autres substances liquides nocives pour le milieu marin, en infraction aux dispositions de la présente loi et de ses testes d'application ou des conventions internationales relatives à la prévention de la pollution marine auxquelles le Cameroun est partie. 
(2) Lorsque le navire en infraction est un navire autre qu'un navire-citerne et de jauge brute inférieure à quatre cents (400) tonneaux, les peines prévues à l'alinéa précédent du présent article sont réduites, sans que le minimum de l'amende puisse être inférieur à un million (1.000.000) de FCFA.

(3) En cas de récidive, le montant maximal des peines est doublé.

(4) Les pénalités prévues par le présent article ne s'appliquent pas aux rejets effectués par un navire pour assurer sa propre sécurité ou celle d'autres navire, ou pour sauver des vies humaines, ni aux déversements résultant de dommages subis par le navire sans qu'une faute ne puisse être établie à l'encontre de son capitaine ou de son équipage.

ARTICLE 84.- (1) Est punie d'une amende de cinq cent mille (500.000) à deux millions (2.000.000) de FCFA et d'une peine d'emprisonnement de six (6) mois à un (1) an ou de l'une de ces deux peines seulement, toute personne qui fait fonctionner une installation ou utilise un objet mobilier en infraction aux dispositions de la présente loi.

(2) En cas de récidive, le montant maximal des peines est doublé.

ARTICLE 85.- Les sanctions prévues par la présente loi sont complétées par celles contenues dans le Code pénal ainsi que dans différentes législations particulières applicables à la protection de l'environnement.

ARTICLE 86.- La sanction est doublée lorsque les infractions suscitées sont commises par un agent relevant des Administrations chargées de la gestion de l'environnement, ou avec sa complicité.

ARTICLE 87.- Les dispositions des articles 54 et 90 du Code Pénal relatives au sursis et aux circonstances atténuantes ne sont pas applicables aux sanctions prévues par la présente loi.

\section{CHAPITRE III}

\section{DE LA CONSTATATION DES INFRACTIONS}

ARTICLE 88.- (1) Sans préjudice des prérogatives reconnues au ministère public, aux officiers de police judiciaire à compétence générale, les agents assermentés de l'Administration chargée de l'environnement ou des autres Administrations concernées, notamment ceux des domaines, du cadastre, de l'urbanisme, des travaux publics, des forêts, de la marine marchande, des mines, de l'industrie, du travail et du tourisme sont chargés de la recherche, de la constatation et des poursuites en répression des infractions aux dispositions de la présente loi et de ses textes d'application.

(2) Les agents mentionnés à l'alinéa (1) ci-dessus prêtent serment devant le tribunal compétent, à la requête de l'Administration intéressée, suivant des modalités par un décret d'application de la présente loi. 
(3) Dans l'exercice de leurs fonctions, les agents assermentés sont tenus de se munir de leur carte professionnelle.

ARTICLE 89.- Toute infraction constatée fait l'objet d'un procès-verbal régulier. La recherche et la constatation des infractions sont effectuées par deux (2) agents qui cosignent le procès-verbal. Ce procès-verbal fait foi jusqu'à l'inscription en faux.

ARTICLE 90.- (1) Tout procès-verbal de constatation d'infraction doit être transmis immédiatement à l'Administration compétente qui le fait notifier au contrevenant. Celui-ci dispose d'un délai de vingt (20) jours à compter de cette notification pour contester le procès-verbal. Passé ce délai, toute contestation devient irrecevable.

(2) En cas de contestation dans les délais prévus à l'alinéa (1) du présent article, la réclamation est examinée par l'Administration compétente.

Si la contestation est fondée, le procès-verbal est classé sans suite.

Dans le cas contraire, et à défaut de transaction ou d'arbitrage définitifs, l'Administration compétente procède à des poursuites judiciaires conformément à la législation en vigueur.

\section{CHAPITRE IV}

\section{DE LA TRANSACTION ET DE L'ARBITRAGE}

ARTICLE 91.- (1) Les Administrations chargées de la gestion de l'environnement ont plein pouvoir pour transiger. Elles doivent, pour ce faire, être dûment saisies par l'auteur de l'infraction.

(2) Le montant de la transaction est fixé en concertation avec l'Administration chargée des finances. Ce montant ne peut être inférieur au minimum de l'amende pénale correspondante.

(3) La procédure de transaction doit être antérieure à toute procédure judiciaire éventuelle, sous peine de nullité.

(4) Le produit de la transaction est intégralement versé au Fonds prévu par la présente loi.

ARTICLE 92.- Les parties à un différend relatif à l'environnement peuvent le régler d'un commun accord par voie d'arbitrage.

ARTICLE 93.- (1) Les autorités traditionnelles ont compétence pour régler des litiges liés à l'utilisation de certaines ressources naturelles, notamment l'eau et le pâturage sur la base des us et coutumes locaux, sans préjudice du droit des parties au litige d'en saisir les tribunaux compétents. 
(2) Il est dressé un procès-verbal du règlement du litige. La copie de ce procès-verbal dûment signé par l'autorité traditionnelle et les parties au litige ou leurs représentants est déposée auprès de l'autorité administrative dans le ressort territorial de laquelle est située la communauté villageoise où a eu lieu le litige.

\section{TITRE VII}

\section{DES DISPOSITIONS DIVERSES ET FINALES}

ARTICLE 94.- Les écosystèmes de mangroves font l'objet d'une protection particulière qui tient compte de leur rôle et de leur importance dans la conservation de la diversité biologique marine et le maintien des équilibres écologiques côtiers.

ARTICLE 95.- L'Etat assure la conservation "in situ » et « ex situ » des ressources génétiques suivant des modalités fixées par des lois particulières.

ARTICLE 96.- (1) Toute décision prise ou autorisation donnée au titre de la présente loi sans l'avis préalable de l'Administration chargée de l'environnement requis par ladite loi, est nulle et de nul effet.

(2) Toute personne ayant intérêt à agir peut en invoquer la nullité.

(3) Des décrets d'application de la présente loi fixent, suivant le cas, les modalités suivant lesquelles est donné l'avis préalable de l'Administration chargée de l'environnement.

ARTICLE 97.- Des décrets d'application de la présente loi en précisent, en tant que de besoin, les modalités.

ARTICLE 98.- (1) La présente loi s'applique sans préjudice des dispositions non contraires des lois particulières en vigueur en matière de gestion de l'environnement.

(2) Toutefois, sont abrogées les dispositions de l'article 4(1) premier tirer de la loi n89/27 du 29 décembre 1989 portant sur les déchets toxiques et dangereux.

ARTICLE 99.- La présente loi sera enregistrée, publiée suivant la procédure d'urgence, puis insérée au Journal Officiel en français et en anglais. 


\section{LES MODALITES DE DELEGATION DES SERVICES DE L'EAU POTABLE ET DE L'ASSAINISSEMENT LIQUIDE EN MILIEU URBAIN ET PERIURBAIN}

Décret $\mathrm{N}^{\circ}$ 2005/493/ du 31 décembre 2005

\section{Le Président de la République décrète :}

\section{Titre I - Dispositions Générales}

Art I : Le présent décret fixe les modalités de délégation des services publics de l'eau potable et de l'assainissement liquide en milieu urbain et périurbain.

Art II : Au sens du présent décret :

- Constituent des activités de service public d'alimentation en eau potable: les activités de production, de transport, de stockage, de traitement et de distribution publique d'eau potable

- Constituent des activités de service public d'assainissement : les activités de collecte, de transport, et d'épuration des eaux usées, réalisées au moyen d'infrastructures et d'installations publiques.

Art III : Le service public de l'eau potable est confié par l'Etat, dans le cadre des conventions de délégation de la gestion de service public à :

- Une société à capital public : société de patrimoine, responsable de la gestion des biens et droits affectés au service de l'eau potable en milieu urbain et périurbain, et qui est chargée de la constitution, de la maintenance et de la gestion des infrastructures de captage, de production, de stockage et de transport de l'eau potable

- Une ou plusieurs sociétés chargées de la production et de la distribution de l'eau potable en milieu urbain et périurbain, ainsi que de l'entretien des infrastructures et du traitement de l'eau, et des activités liées à la fonction commerciale, notamment la relève, la facturation et l'encaissement des recettes.

Art IV : (1) Le service public d'assainissement des eaux usées en milieu urbain et périurbain peut être confié à des sociétés d'économie mixte ou à des sociétés privées chargées du service de distribution de l'eau potable, sur la base d'une ou plusieurs conventions particulières qui en définissent les conditions et modalités.

(2) Ces conventions sont approuvées par décret, lorsque l'autorité concédante est l'Etat, et par délibération du conseil pour les activités territoriales décentralisées

Titre II - Des modalités de délégation du service public de la production en milieu urbain et périurbain

Art V : (1) Dans le périmètre de la SNEC tel qu'il existe à la signature du présent décret et dans des éventuelles extensions, le service public de production et de distribution de l'eau potable en milieu urbain et périurbain est confié par l'Etat, dans le cadre d'un contrat d'affermage et d'un cahier des charges et pour une période initiale de dix (10) ans, à une société anonyme dont le capital est détenu en totalité ou au minimum aux deux tiers par des personnes physiques ou morales de droit privé. 
3. Il peut également lui être confié l'assainissement liquide dans les conditions prévues à l'alinéa (1) ci-dessus.

4. Le contrat d'affermage et le cahier des charges y afférent liant l'Etat, le concessionnaire et la société d'exploitation, précisent les conditions et modalités dans lesquelles certains biens, certains droits et certaines obligations de la SNEC seront transférés à la société d'exploitation.

5. A l'expiration de la période initiale de dix (10) ans indiquée ci-dessus, l'Etat et les collectivités territoriales décentralisées pourront, conformément à la législation et à la réglementation en vigueur, désigner d'autres délégataires de service public de la distribution de l'eau potable en milieu urbain et périurbain.

Art VI : (1) Le capital social de la société fermière du service public de production et de distribution de l'eau potable en milieu urbain et périurbain, retenu pour la période initiale indiquée à l'article 5 ci-dessus, est détenu à hauteur de deux tiers au moins par des actionnaires privés dont $51 \%$ au moins par un actionnaire de référence, et $24 \%$ au moins par les actionnaires camerounais.

(2) L'actionnaire de référence visé à l'alinéa (1) ci-dessus doit être un professionnel du secteur, recruté par appel à concurrence, conformément à la règle applicable en matière de privatisation des entreprises d'un secteur public et parapublic.

Art VII : La société d'exploitation, le concessionnaire et l'autorité délégante sont liés par des contrats d'objectifs et de performance dont les dispositions seront définies par les études approuvées par des instances compétentes.

\section{Titre III - De l'assainissement liquide}

Art VIII : (1) Le service public de l'assainissement liquide peut être confié à terme, par voie conventionnelle, dans les zones urbaines du Cameroun, aux sociétés délégataires de service public de la distribution de l'eau potable en milieu urbain et périurbain.

Dans ce cas, elles assurent le recouvrement de la taxe d'assainissement à reverser dans un compte d'affectation spéciale ouvert à cet effet.

(2) Les modalités de fonctionnement dudit compte sont fixées par arrêté conjoint du ministre chargé de l'Eau et du ministre chargé des Finances.

\section{Titre IV - Dispositions diverses transitoires et finales}

Art IX : L'entrée en vigueur de la convention de concession et du contrat d'affermage entraine de plein droit la résiliation des conventions de concession accordées à la Société Nationale des Eaux du Cameroun (SNEC).

Art X : (1) Le personnel nécessaire au démarrage des activités du concessionnaire et de la société bénéficiaire du contrat d'affermage est choisi en priorité parmi le personnel de la SNEC. 
(2) Le transfert du personnel visé à l'alinéa (1) ci-dessus est effectif à compter de la date d'entrée en vigueur de la convention de concession ou du contrat d'affermage.

Art XI : (1) Une commission procédera à l'inventaire et au transfert des actifs de la SNEC nécessaires à l'exploitation de la société de patrimoine.

3. La composition et les modalités de fonctionnement de la commission visée à l'alinéa (1) ci-dessus, sont déterminées par un texte particulier du Premier Ministre.

4. Les opérations de transfert des actifs de la SNEC à la société de patrimoine devront être achevées avant le démarrage des activités de celle-ci.

5. Les actifs résiduels de la SNEC seront transférés au ministre chargé de la gestion de l'Etat.

Art XII : Le ministre chargé de l'Eau et ministre chargé des Finances sont, chacun en ce qui le concerne, chargés de l'exécution du présent décret qui sera enregistré, publié selon la procédure d'urgence puis inséré au journal officiel en français et en anglais.

Yaoundé, le 31 Décembre 2009

Le Président de la République 


\section{REFERENCES BIBLIOGRAPHIQUES}

\section{OUVRAGES}

\section{I.1. OUVRAGES GENRAUX}

ADOUKI (D.E), Droit international public, Tome 1, Paris, l'Harmattan, 2002, 336p.

BEAU (M.), L'art de la thèse, Paris, La découverte, 2003, 196p.

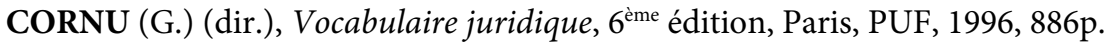

GOUNELLE (M.), Relations internationales, Dalloz, Collection "Mémentos ", $6^{\mathrm{e}}$ éd., 2004, p.57.

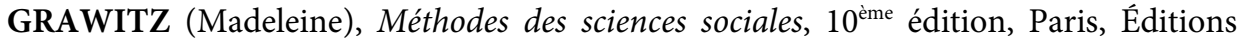
Dalloz, 1996, 400p.

GRAWITZ (M.), Méthodes des sciences sociales, éd Dalloz, $11^{\mathrm{e}}$ éd., France, 2001, 1019p.

GUILLIEN (Raymond) et VINCENT (Jean), Lexique des termes juridiques, $12^{\text {ème }}$ édition, Paris, Dalloz, 1999, 561p.

\section{I.2. OUVRAGES SPECIALISES}

BOISSON de CHAZOURNES (L.), DESGANE (R.), ROMANO (C.), Protection internationale de l'environnement, Recueil d'instruments juridiques, Paris, éd. Pédone, 1998, 1117p.

BOSCO (H.), TANAWA (E.) et NGNIKAM (E.), L'eau potable au Cameroun. Approvisionnement en eau potable, Tome I, Yaoundé, PUY, 2001, 359p.

BROWN-WEISS (E.), In Fairness to future Generations: International Law, Common Patrimony and Intergenerational Equity, New York, Transnational Publishers, 1998.

COHRE, AAAS, DDC et UN-HABITAT, Manuel de droit à l'eau et l'assainissement, un outil pour aider les décideurs et praticiens à développer des stratégies de mise en ouvre du droit de l'homme à l'eau et l'assainissement, Genève, 2008, 302p.

CONAC (G.) et (F.), Dir, La terre, l'eau et le droit en Afrique, à Madagascar et à L'île Maurice, Bruylant/AUPELF-UREF, Belgique, 1998, 759p.

DUBOIS (M.J.M.), La rédaction scientifique, éd.Estem, Belgique, 2005, 117p.

DUPUY(P.M.), La responsabilité internationale des Etats pour dommages d'origine technologique et industrielle, paris, Pedone, 1976, 309p.

FAURE (M.), L'analyse économique du droit de l'environnement, Bruxelles, éd.Bruylant, 2007, 362p.

FAURE (M.), SONG (Y.), China and international environmental liability, legals Remedies for Transboundary Pollution, New Horizons in environmental law, 2008, 360p. GUILLIEN (R), Dir, Lexique des termes juridiques, Dalloz, 12 éd., 1999, 561p.

KAMTO, (M.,) Droit de l'environnement en Afrique, EDICEF-AUPELF, France, 1996, $416 \mathrm{p}$.

KISS (A.) et (J.P.) BEURIER, Droit international de l'environnement, Collections Etudes Internationales, Paris, Éd. Pedone, 2000, 424p.

La Tullaye (de) (L. et G.), Hydrotour. 6 milliards d'acteurs pour sauver l'eau, éditions Biglo, 2006, 156p. 
LAVIEILLE (J.M.), Droit international de l'environnement, France, éd. Ellipses, 1998, 191p.

NGNIKAM (E.) et '(E.) TANAWA, Les villes d'Afrique face à leurs déchets, Utbm, décembre 2006, 281p.

PNUD, Rapport mondial sur le développement humain 2006, Au-delà de la pénurie: Pouvoir, pauvreté et crise mondiale de l'eau, 552p.

PRIEUR (M.) et (S.) DOUMBE-BILLE, Recueil francophone des traités et textes internationaux en Droit de l'environnement, Belgique, éd. Bruylant, 1998, 719p.

PRIEUR (M.), Droit de l'environnement, $4^{\text {ème }}$ édition, Paris, Dalloz, 2001, 944p.

PRIEUR (M.), Dir, Réunion mondiale des juristes et associations de droit de l'environnement, Vers un nouveau droit de l'environnement ?, CIDCE, 2003, 736p.

PRIEUR (M.), Dir, La mise en cuvre du droit international de l'environnement dans les pays francophones, PULIM, 2003, 579p.

SADELEER (N.), Les principes du pollueur-payeur, de prévention et de précaution, Essai sur la genèse et la portée juridique de quelques principes du droit de l'environnement, édition Bruylant, Belgique, 1999, 347p.

\section{ARTICLES DE DOCTRINE}

A.F.D., «Le droit à l'eau, un droit pour tous les citoyens », Académie de l'eau, Brochure, voir www.academie-eau.org, 2006, 4p.

AUBRIOT (J.), «Le droit à l'eau : émergence, définition, situation actuelle et position des acteurs ", Service ACF-France, août, 2007, 94p.

ANDELA (J.J.), "Les implications juridiques du mouvement constitutionnel du 18 janvier 1996 en matière d'environnement au Cameroun", in Revue juridique de l'environnement, décembre 2009, 12p.

ALISSOUTIN (R.L.), "La négation du savoir local dans les politiques de l'eau en Afrique ", in www.inter-reseaux.org/IMG/pdf/allissoutin_eau.pdf, consulté le 05 janvier 2009.

AMIN (S.), "L'eau, bien commun des peuples », in L'eau, patrimoine commun de l'humanité, p33-40.

AMOUGOU (T.J.P.), «L'eau, bien public, bien privé : l'Etat, les communautés locales et les multinationales ", in L'eau, patrimoine commun de l'humanité, pp.147-170.

ATANGANA (A.J.L.), "Les 20 ans de la Charte africaine des Droits de l'homme et des Peuples (Bilan jurisprudentiel)» in Droits de l'Homme en Afrique, Contributions interdisciplinaires, 2001-2004, pp.50-64.

CASTILLO (A.A.), "L'eau, source de vie et de conflits dans les communautés andines d'Equateur ", in L'eau, patrimoine commun de l'humanité, pp.119-1140.

CAUDAL (S.), "Les conditions juridiques de gestion intégrée de l'environnement », Université Jean Moulin 3, 16p.

CEDE, «Le droit à l'eau potable et à l'assainissement», Académie de l'eau, www.academie-eau.org, juin 2005, 8p.

CHARRIER (B.), Green Cross International, Rencontres internationales pour le droit d'accès à l'eau, Marseille, 23-24 novembre 2006, " Principes fondamentaux pour une 
Convention-cadre sur le droit à l'eau», consulté dans le site www.greencross.fr, le 26 mai 2008.

DUPUY(P.M.), «La responsabilité internationale des Etats pour dommages d'origine technologique et industrielle », Paris, Pedone, 1976.

FAVIER (C.), Préface, in Petrella (R.) (Sous la direction de), "L'eau. Res publica ou marchandise?", Éditions, La Dispute, 2003.

CLAPAROLS (A.M.), "La crise de l'eau aux philippines», in L'eau, patrimoine commun de l'humanité, pp.41-44.

GENE (C.), " Rapport sur la proposition de loi sur la coopération internationale des collectivités territoriales et des agences de l'eau dans les domaines de l'alimentation en eau et de l'assainissement ", Sénat, $\mathrm{n}^{\circ} 347,16$ juin 2004, p.5.

GUERARD (S.), "La gestion démocratique de l'eau, un enjeu général d'intérêt mondial », consultable dans www.cidegef.refer.org/douala/Guerard.doc, 46p.

GOURDREAU (F.) et RANCOURT (M.E.), «Le droit à l'eau face à la pratique des Etats », Université du Québec, Montréal, février 2004, 31p.

GWP, «Partager la connaissance sur la Gestion Intégrée des Ressources en Eau», Toolbox, 2007, 130p.

HENRAD (C.), "Introduction: the justiciability of ESC rights and the interdepen-dence of al fundamental rights", in http://www.erasmuslawreview.nl/, pp.377-378.

KISS (A.), "Chronique de Droit International de l'Environnement", in Annuaire Française de droit international.

KISS (A.), "Le droit à la conservation de l'environnement », in Revue universelle des droits de l'homme, Vol. 2, 1990, n 12, p.445.

LAUNEY (J.), « Moderniser la gestion de l'eau », Rapport d'information, AN, $\mathrm{N}^{\circ} 1170$, 03 novembre 2003, p.20.

MORIARTY(P.), et suivant, «La gestion intégrée des ressources en eau, le sous secteur de l'approvisionnement en eau et l'assainissement domestique», extrait de cahier thématique 9-F, WHO collaborating centre since 1968.

MWANZA WA MWANZA, "L'accès à l'eau dans les villes africaines", in L'eau, patrimoine commun de l'humanité, pp.105-110.

NZATI M. M. (D.M.), «Quel bilan dresser de l'effectivité et de la justiciabilité des droits économiques, sociaux et culturels en République démocratique du Congo au regard de la Déclaration universelle des droits de l'homme et de la Charte africaine des droits de l'homme et des Peuples », avril 2009, 8p.

OMS-UNICEF, «Evaluation mondiale 2000 de l'approvisionnement en eau et l'assainissement ", note 16, p.2.

PAQUEROT (S.), «Les droits d'accès à l'eau : aspects politiques et juridiques au plan international », 22 mai 2002, Créteil, 9p.

PAQUEROT (S.), «Ressources en eau: les différentes facettes des conflits internationaux ", lex electronica, Vol $12 \mathrm{~N}^{\circ}$ 2, 2007, consulté dans le site www.lexelectronica.org/articles/v12-2/paquerot.pdf.

POYDENOT (A.), "Le droit international de l'eau, état des lieux ", in Les notes d'analyse du CIHEAM, $\mathrm{N}^{\circ}$ 29-février 2008, pp.1-32., www.ciheam.org, consulté le 10 mai 2008. 
SOW (M.), "L'accès à l'eau au Sahel à l'ère de la privatisation ", in L'eau, patrimoine commun de l'humanité, pp.171-182.

SMETS (H.), «Le droit à l'eau ", CEDE-AESN, Académie de l'eau, www.academieeau.org, 2002, 166p.

SMETS (H.), «Pour un droit effectif à l'eau potable », Académie de l'eau, avril 2005, 142 p.

SMETS (H.), «Le droit à l'eau dans les législations nationales », Académie de l'eau, octobre 2005, 78p.

SMETS (H.), "Une aide pour faciliter l'accès à l'eau des plus démunis en France ", Académie de l'eau, août 2006, 18p.

SMETS (H.), "Comment mettre en œuvre le droit à l'eau en France? », Académie de l'eau, octobre 2006, 18p.

SMETS (H.), «La reconnaissance officielle du droit à l'eau en France et à l'international », Académie de l'eau, Nanterre, décembre 2006, 114p.

SMETS (H.), «L'accès à l'eau potable et le droit international », Académie de l'eau, 2007, 50p.

SMETS (H.), "Le droit d'accès à l'eau potable dans le contexte méditerranéen », Académie de l'eau, mars 2007, 49p.

SMETS (H.), «Le rôle des municipalités et des collectivités territoriales dans la mise en œuvre du droit à l'eau ", Académie de l'eau, mars 2007, 20p.

SMETS (H.), "Implementing the right to water in France », French Water Academy, april 2007, 10p.

SMETS (H.), "La prise en compte des dettes d'eau des usagers démunis en France », Académie de l'eau, avril 2008, 222p.

SMETS (H.), «De l'eau à un prix abordable, la pratique des Etats », Académie de l'eau, 2008, 254p.

SMETS (H.), Dir., "Le droit à l'assainissement dans les législations nationales », Académie de l'eau, Paris, 2009, 454p.

SMETS (H.), «La mise en œuvre du droit à l'eau, les solutions à Paris », Académie de l'eau, Paris, août 2010, 140p.

TAMAYO (G.E.), «Les barrages hydroélectriques. La fin justifie-t-elle les moyens? in L'eau, patrimoine commun de l'humanité, pp.203-208.

UNESCO, «Propositions pour les nouvelles règles juridiques dans le domaine de l'eau et de l'assainissement ", Académie de l'eau, www.academie-eau.org, octobre 2002, 22p.

UNESCO, «Les aspects juridiques des services de l'eau», Académie de l'eau, www.academie-eau.org, octobre 2002.

ZELMYS (M.D.C.) ; "L'eau, ressource vitale et source de conflits à l'aube du nouveau millénaire » ; in L'eau, patrimoine commun de l'humanité, p.22.

\section{MEMOIRES ET THESES}

ASSEMBONI (N.A.) Epse OGUNJIMI, «Le droit de l'environnement marin et côtier en Afrique occidentale : cas de cinq pays francophones », thèse de doctorat, Université de Limoges, septembre 2006, 577p. 
ATONTSA (M.J.C), «L'apport du droit international de l'environnement pour l'accès à l'eau potable en Afrique centrale », Mémoire de Master, Université de Limoges, août 2007, 71p.

BENABDALLAH (J.), "Le règlement pacifique des différents internationaux », Mémoire de DESA, MOHAMED Bedhri (Dir.), Université Mohamed $1^{\text {er }}$ Oudja, 2007, consultable sur www.memoireonline.com.

BONNEL (G.), «Le principe juridique écrit et le droit de l'environnement », thèse de doctorat (nouveau régime), Université de Limoges, 511p.

ERWANN (L.C.), «La prise en compte de l'environnement par les règles locales d'urbanisme », thèse de doctorat, Université de Paris I, janvier 1997, 714p.

KAMDOUM (T.P.B.), « La contribution du droit international de l'environnement dans la lutte contre les pollutions non industrielles en Afrique centrale : cas du Cameroun », Mémoire de Master, Université de Limoges, août 2008, 70p.

KRISTIN (B.), L'antagonisme "commerce et environnement» ou le principe de développement durable comme fil conducteur pour la réconciliation des intérêts commer-ciaux et environnementaux sous l'article XX du GATT, thèse de doctorat, Université de Laval, 2007.

NGWAINMBI (F.G.), Mémoire de Master D.I.C.E., «Femme et environnement pour un développement durable dans la sous région de l'Afrique centrale au regard du droit international de l'environnement », Université de Limoges, août 2006. 71p.

PAQUEROT (S.), «Le statut de l'eau douce en droit international: penser la res publica " universelle, thèse de doctorat, octobre 2003, 545p.

SOUMY (I.), "L'accès des organisations non gouvernementales aux juridictions internationales ", thèse de doctorat, Université de Limoges, septembre 2005, 628p.

TIEBLEY (Y.D.), "La côte d'ivoire et la gestion durable des ressources naturelles marines ", thèse de doctorat, Université de Maastricht, mai 2010, 369p.

TIETZMANN E SILVA (J.A.), "Vers un droit pour les établissements humains durables ", thèse de doctorat (nouveau régime), Université de Limoges, décembre 2007, $633 p$.

\section{LES TEXTES INTERNATIONAUX}

\section{Les accords à caractère universel}

a. Les textes explicites de reconnaissance du droit à l'eau potable

- L'action 21 (1992) N.U. Doc. A/CONF.151/26 et annexes.

- La Déclaration de Dublin sur l'eau dans un objectif de développement de 1992

- La Déclaration de Genève (1949) et ses deux Protocoles additionnels (1977).

- La Convention sur le droit relatif aux utilisations des cours d'eau à des fins autres que la navigation, AG/New York, 21/05/1997.

- La Convention sur l'élimination de toutes sortes de discriminations à l'égard des femmes de 1979.

- La Convention sur les droits de l'enfant de 1989.

- L'Observation Générale $N^{\circ} 15$, Le droit à l'eau (2002) U.N. Doc. E/C.12/2002/11, disponible sur www.ohchr.org.

- Le Pacte d'Istanbul sur l'eau pour les autorités locales et régionales, $5^{\text {ème }}$ Forum mondial de l'eau, Turquie, 2009. 
- La Résolution A/Res/64/292 du 28 juillet 2010 sur le droit à l'eau et l'assainissement.

- La Résolution A/64/L.63/Rev.1 du 30 septembre 2010 sur le droit à l'eau potable et l'assainissement.

\section{b. Les textes implicites de reconnaissance du droit à l'eau potable}

- CDESC, La nature des obligations des Etats parties, (1990) Observation Générale n³, 14 décembre, $5^{\mathrm{e}}$ session, U.N. Doc. E/1991/23.

- La Charte mondiale de la nature, $28 / 10 / 1982$.

- La Charte mondiale des sols, 26/11/1981

- CESCR, Droits économiques, sociaux et culturels des personnes âgées, (1995) Observation Générale ${ }^{\circ}$ 6, 8 décembre, $13^{\mathrm{e}}$ session : E/1996/22.

- CCPR, Le droit à la vie, (1982) Observation Générale n 6, 30 avril, $16^{e}$ session.

- Commission des droits de l'homme, Droits économiques, sociaux et culturels : le droit à l'alimentation (2001) Rapport établi par M. Jean ZIEGLER, rapporteur spécial sur le droit à l'alimentation, conformément à la résolution 2000/10 de la Commission des droits de l'homme, 7 février 2000, $57^{\mathrm{e}}$ session E/CN.4/2001/53, para. 39.

- La Convention de Ramsar sur les Zones humides de 1971.

- La Convention internationale sur l'élimination de toutes formes de discriminations raciales de 1965.

- La Convention sur la lutte contre la désertification, Paris, 17/06/1994.

- La Convention sur la diversité Biologique, Rio, 5/06/1992.

- La Convention sur le droit de la mer, Montégo Bay, 10/12/1982.

- La Convention sur les changements climatiques, 1992.

- La Déclaration de la Conférence, les églises pour l'eau en Afrique, Entebbe Mai 2007.

- La Déclaration de la conférence des Nations Unies sur l'environnement humain (Déclaration de Stockholm) (1972) Doc. N.U. A/CONF.48/14/Rev.1 ; I.L.M. 1416, 1420.

- La Déclaration sur les forêts, Rio, juin 1992.

- La Déclaration du millénaire des Nations Unies, (2000) $55^{\mathrm{e}}$ session, 13 septembre, A/RES/55/2, disponible sur http://www.un.org/millénuim.

- La Déclaration universelle des droits de l'homme de 1948, document des Nations Unies A/810 p.71.

- La Déclaration universelle pour l'élimination définitive de la faim et de la malnutrition (1974) Rés. 3348 (XXIX) 17 décembre.

- L’Accord Général sur les Tarifs et le Commerce (GATT), 30/10/1947.

- Le droit à l'éducation, (1999) Observation Générale $\mathrm{n}^{\circ} 13,21^{\mathrm{e}}$ session, E/C.12/1999/10.

- Le droit à un logement suffisant, (1991) Observation Générale $n^{\circ} 4,13$ décembre, $6^{\mathrm{e}}$ session, E/1992/23.

- Le droit à une nourriture suffisante, (1999) Observation Générale n 12, 12 mai 1999, $20^{\mathrm{e}}$ session, E/C.12/1999/5.

- Le droit au meilleur état de santé susceptible d'être atteint, (2000), Observation Générale $n^{\circ} 14,11$ août 2000, 22 $2^{\mathrm{e}}$ session, E/C.12/2000/4.

- Le Protocole de Kyoto de 1997 (relatif à la Convention-cadre des Nations Unies sur les changements climatiques de 1992).

- Le Pacte international relatif aux droits civils et politiques, 1966. 
- Le Pacte international relatif aux droits économiques sociaux et culturels, 1966.

- Le Recueil des traités multilatéraux relatifs à la protection de l'environnement, PNUE, Nairobi, 1982.

- Relationship between the enjoyment of economic, social and cultural rights and the promotion of the realization of the right to drinking water supply and sanitation, 25 juin 2002, $44^{\mathrm{e}}$ session, E/CN.4/Sub.2/2002/10.

- The right to food, 10 janvier 2003, 59e session, E/CN.4/2003/54.

\section{Les accords à caractère régional}

\section{a. Les accords régionaux africains}

- La Charte africaine des droits de l'homme et des peuples de 1981.

- La Charte africaine des droits et du bien être de l'enfant 1990.

- La Charte des Eaux du Fleuve Sénégal de 2002.

- La Convention africaine sur la conservation de la nature et des ressources naturelles, Alger, 15/09/1968.

- La Convention de Maputo ou encore la Convention africaine pour la conservation de la nature et des ressources naturelles de 2003.

- La Convention sur l'interdiction d'importer en Afrique des déchets dangereux et sur le contrôle des mouvements transfrontières et la gestion des déchets dangereux produits en Afrique, Bamako, 29/01/1991.

- La Convention sur le contrôle des mouvements transfrontières de déchets dangereux et de leur élimination, Bâle, (1989) et son protocole (1999).

- La Déclaration de Kampala sur le développement durable en Afrique, Ouganda, $16 / 06 / 19891^{1 \text { ère }}$ conférence régionale africaine sur l'environnement.

- Le Protocole à la Charte africaine des droits de l'homme et des peuples relatif aux droits des femmes de 2003.

- Le Protocole d'accord de Khartoum, Afrique centrale, 24/01/1982.

- Le Protocole d'accord de Nairobi sur les zones protégées ainsi que la faune et la flore sauvage.

\section{b. Les accords régionaux non africains}

- La Charte européenne de l'eau, 6/05/1968.

- La Convention relative à la protection du patrimoine mondial, Paris, 23/11/1972.

- La Convention relative à la responsabilité civile des dommages résultant des activités dangereuses pour l'environnement, Lugano, 10/03/1993.

- La Convention de New York sur le droit relatif à l'utilisation des cours d'eaux à des fins autres que la navigation de 1997.

- La Convention relative aux accidents industriels: effets transfrontières, Helsinki, 1992.

- La Convention sur le droit à l'information, Aarhus, 1998.

- La Convention sur la protection de l'environnement par le droit pénal, Strasbourg, $10 / 11 / 1998$.

- La Convention sur la protection et l'utilisation des cours d'eau transfrontières et des lacs internationaux, Helsinki, 17/03/1992.

- La Convention sur l'évaluation de l'impact sur l'environnement dans un contexte transfrontière, Espoo, 1991. 
- L'Accord de Montréal sur l'élimination des substances chimiques appauvrissant la couche d'ozone de 2007.

- La Convention de Stockhlom sur les Polluants Organiques Persistants de 2001.

- La Convention des Nations Unies sur les droits des peuples autochtones de 2007.

- Le Protocole de Londres sur l'eau et la santé de 1999 (relatif à la Convention sur la protection et l'utilisation des cours d'eaux transfrontières et des lacs internationaux de 1992).

- Le Protocole de Kyoto sur les climats, 11/12/ 1997.

- Le Protocole de Montréal et ses amendements (relatifs à des substances qui appauvrissent la couche d'ozone), 16/09/1987.

- Le Protocole de San Salvador de 1988 relatif à la Convention américaine sur les droits de l'Homme dans le domaine des Droits Economiques, Sociaux et Culturels.

- Le Protocole sur l'eau et la santé, Londres, du 17 juin 1999.

- Les sept protocoles de la Convention sur les pluies acides.

\section{LES CODES ET TEXTES DE LOIS INTERNES}

\section{Les codes}

- Le Code de l'environnement camerounais.

- Le Code de l'environnement français.

\section{Les Lois et décrets}

- La Constitution camerounaise : 1961, 1972, 1996 et 2008.

- Le Contrat d'affermage du service public de l'alimentation en eau potable des centres urbains et périurbains du Cameroun.

- Le Décret N²001/ 61/PM du 08 mai 2001 fixant les attributions, l'organisation et le fonctionnement du Comité national de l'eau au Cameroun.

- Le Décret $N^{\circ}$ 2001/62/PM du 08 mai 2001 fixant les modalités de désignation des agents assermentés pour la surveillance et le contrôle de la qualité des eaux.

- Le Décret $\mathrm{N}^{\circ}$ 2001/6 3/PM du 08 mai 2001 réglementant les périmètres de protection autour des points de captages, de traitement et de stockage des eaux potabilisables.

- Le Décret N²001/64/PM du 08 mai 2001 précisant les modalités et conditions de prélèvement des eaux de surface ou des eaux souterraines à destins industriels ou commerciaux.

- Le Décret $\mathrm{N}^{\circ}$ 2001/65/PM du 08 mai 2001 précisant les modalités de protection des eaux de surfaces et des eaux souterraines contre la pollution.

- Le Décret $\mathrm{N}^{\circ}$ 2002/1721/PM du 8 octobre 2002 précisant les règles d'assiette, de contrôle et de recouvrement dans le cadre du Programme de sécurisation des recettes des mines, de l'eau et de l'énergie.

- Le Décret $N^{\circ} 2003 / 1397$ du 10 juillet 2003 modifiant et complétant les articles $1^{\text {er }}, 2$ et 4 du Décret $\mathrm{N}^{\circ}$ 2002/1721/PM du 8 octobre 2002 précisant les règles d'assiette, de contrôle et de recouvrement dans le cadre du Programme de sécurisation des recettes des mines, de l'eau et de l'énergie.

- Le Décret $\mathrm{N}^{\circ}$ 2005/087 du 29 mars 2005 portant organisation du Ministère de l'Energie et de l'Eau. 
- Le Décret $\mathrm{N}^{\circ}$ 2005/3089/PM du 29 mai 2005 précisant les règles d'assiette, de contrôle et de recouvrement de la taxe d'assainissement et de redevance et de prélèvement des eaux.

- L'annexe de la déclaration de la redevance Nº 2005/3089/PM du 29 mai 2005.

- Le Décret N ${ }^{\circ}$ 2005/494 du 31 décembre 2005 portant création de la Cameroon Water Utilities Corporation.

- Le Décret $\mathrm{N}^{\circ}$ 2006/117 du 29 mars 2006 portant approbation des statuts de la Cameroon Water Utilities Corporation.

- La loi $\mathrm{N}^{\circ}$ 96/12 du 05 août 1996 portant loi-cadre relative à la gestion de l'environnement.

- La loi N 98/005 du 14 avril 1998 portant régime de l'eau au Cameroun.

- La loi $\mathrm{N}^{\circ} 001$ du 16 Avril 2001 portant code minier.

- La loi $\mathrm{N}^{\circ} 2004 / 018$ du 22 juillet 2004 fixant les règles applicables aux communes.

- La loi $\mathrm{N}^{\circ}$ 2004/019 du 22 juillet 2004 fixant les règles applicables aux régions.

\section{SUPPORTS VIDEOS ET CD ROM}

- AUPEL-UREF, Le droit international de l'environnement, cours sur cassette vidéo, Vidéo scope, Université de Nancy 2, 1998.

- AUPEL-AREF, Recueil francophone des textes internationaux en droit de l'environnement, $\mathrm{CD}$ Rom, Universités francophones, nouveaux supports, DOCMEF.

\section{MELANGES ET AUTRES DOCUMENTS IMPORTANTS}

- Assessing climate change impacts, CICERO/UNEP, septembre 1996.

- CAMWATER, «Investir dans le secteur de l'eau potable au Cameroun, juin 2000.

- $\mathrm{CDH}$., « Les droits de l'homme et l'accès à l'eau », Décision 2/104, 27 novembre 2006.

- Document de la Banque Africaine de Développement : « Politique de gestion intégrée des ressources en eau », OCOD, avril 2000, 94p.

- Document de réflexion et plan d'action, «Pour la mise en œuvre du droit à l'eau en tant que droit humain, une plate forme pour organiser la mobilisation », Atelier $\mathrm{N}^{\circ} 1$ du FAME, Genève, 18 mars 2005, 11p.

- Document fiche d'information des droits de l'homme $\mathrm{N}^{\circ} 33$, "Questions fréquemment posées concernant les droits économiques, sociaux et culturels », UN Genève, mars 2009, 69p.

- Document, stratégie nationale de gestion des déchets, Draft II, Yaoundé, 2007.

- Décision $\mathrm{N}^{\circ}$ 2004-04 du 04 février 2004 de la Commission nationale du débat public relative au projet d'extension des capacités de Fos-conteneurs «FOS 2XL", JORF (Journal officiel de la République française), 18 février 2004, (texte consultable sur : www.legigrance.gouv.fr.

- Dirk et Heiko W, brochure, ATS PROVILLAGE, octobre 2005.

- Document d'orientation, Processus d'Elaboration du Plan d'Action de la GIRE du Cameroun, octobre 2005.

- Etudes et document du conseil d'Etat, TIBERGHIEN (F.) et suivant, «L'eau et son droit », février 2010, 582p. 
- Information Eau, $N^{\circ} 592$ : juillet, août, septembre 2009: «La synthèse de l'OIE : la GIRE dans les pays en développement : quelles clés pour sa réussite ? ", Consultée dans www.oieau.org, le 04 mars 2010.

- Inforesources, la «Gestion Intégrée des Ressources en Eau, la voie du développement durable », focus N1/03.

- La monographie sur la gestion des ressources en eau du Cameroun élaborée en février 2005.

- Legal protection of the Environment in Developping Countries, Colloque de l'Association internationale des sciences juridiques, Mexico, 25-28 août 1974, Universidad Nacional Autonoma de Mexico.

- Les Notes d'analyses du CIHEAM, $\mathrm{N}^{\circ} 29$, «Le droit international de l'eau, état des lieux », p.26, février 2008.

- Manuel du droit à l'eau et l'assainissement, résumé exécutif : un outil pour aider les décideurs et praticiens à développer les stratégies de mise en œuvre des stratégies du droit de l'homme à l'eau et l'assainissement.

- Message de Mme Irina Bokova (Directrice générale de l'UNESCO) à l'occasion de la journée mondiale de l'eau tenue le 22 mars 2010 sous le thème « De l'eau propre pour un monde sain ».

- Plan national de gestion de l'environnement, Cameroun, 1996.

- Principes islamiques relatifs à la conservation de l'environnement, UICN, Gland, 1980.

- Programme du Cameroun pour la mise en application du Protocole de Montréal relatif à l'élimination des SAO, 1993.

- Rapport d'activité de la commission du bassin du lac Tchad, 1995.

- Rapport de pré-planification des activités de l'initiative néerlandaise de l'eau au Cameroun (tenu à Kribi du 20 au 23 décembre 2004).

- Rapport d'activité du Bureau National de l'Ozone, Décembre 1996.

- Rapport de la célébration de la journée internationale de lutte contre la désertification, 1 ère éd., juin 1995.

- Rapport de la conférence des Nations Unies sur l'eau, Mar del Plata, Argentine, 1977.

- Rapport du Haut commissariat des Nations Unies aux droits de l'homme sur la portée et la teneur des obligations pertinentes en rapport avec les droits de l'homme qui concernent l'accès équitable à l'eau potable et l'assainissement contractées au titre des instruments internationaux relatifs au droit de l'homme, AG, 16 août 2007, 32p.

- Rapport du progrès de l'exécution du projet national sur les changements climatiques, février 1997.

- Rapport sommaire, séminaire organisé conjointement par l'Association canadienne pour les Nations Unies et la Direction Générale de la sécurité humaine et des droits de la personne, Ministère des Affaires étrangères et du Commerce international du Canada, 29 et 30 mars 2007, "Un droit humain à l'eau », 19p.

- Rapport sur l'eau insalubre, première cause de mortalité dans le monde, consulté le 03 mai 2008, in www.solidarités.org.

- Registre des traités sur l'environnement.

- Treaty Body Database, Documents par pays, disponible sur http://www.unhchr.ch/tbs/doc.nsf. 
- UNESCO, Environnement et droits de l'homme, ouvrage collectif, Pascale Kromarek (Dir), Paris, 1987. 